\title{
MOLTEN-CAUSTIC-LEACHING (MCL OR GRAVIMELT) SYSTEM INTEGRATION PROJECT
}

DOE/PC/91257--T14

TOPICAL REPORT FOR TEST

DE93 005216

CIRCUIT OPERATION

CONTRACT NUMBER DE-AC22-86-PC91,257

NOVEMBER 1990

\author{
PREPARED BY APPLIED TECHNOLOGY DIVISION \\ TRW SPACE AND TECHNOLOGY GROUP \\ ONE SPACE PARK \\ REDONDO BEACH, CA 90278
}

\author{
PREPARED FOR \\ U.S. DEPARTMENT OF ENERGY \\ PITTSBURGH ENERGY TECHNOLOGY CENTER \\ P.0. BOX 10940 - MS/922-206 \\ PITTSBURGH, PA 15236
}


Page

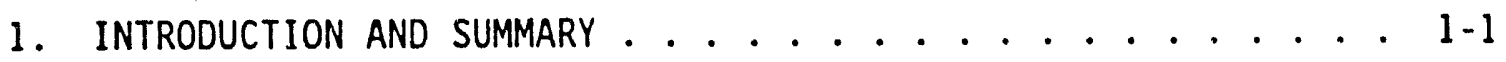

1.1 PROCESS DESCRIPTION .............. 1-2

1.2 TEST COALS. . . . . . . . . . . . . . . . . .

1.3 OPERATIONS TESTS RESULTS. ...............11

1.4 REPORT OUTLINE. . . . . . . . . . . . . . 1-14

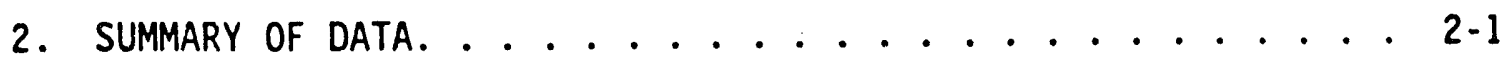

2.1 TEST MATRIX AND RUN CONDITION SUMMARY ....... 2-1

2.2 SULFUR AND ASH REMOVAL. . . . . . . . . . 2-2

2.3 volatiles AND HEAT CONTENT. . . . . . . . . 2-2

2.4 PRODUCT COAL. . . . . . . . . . . . . 2-2

3. OPERATIONS TEST RESUltS. . . . . . . . . . . . . . . .

3.1 COAL PRODUCT QUALITY. . . . . . . . . . 3-2

3.1 .1 Sulfur Removal . . . . . . . . . 3-3

3.1.1.1 Pittsburgh No. 8;50:50 KOH/NaOH. . . 3-3

3.1.1.2 Pittsburgh No. 8; NaOH Only..... 3-11

3.1.1.3 Kentucky No.9. .......... 3-16

3.1.2 Ash Removal. . . . . . . . . . . 3-19

3.1.2.1 Pittsburgh No. 8; 50:50 KOH/NaOH. . . 3- 3-19

3.1.2.2 Pittsburgh No. 8; NaOH Only..... 3-25

3.1.2.3 Kentucky No.9. ......... 3-30

3.1 .3 Heating Value. . . . . . . . . 3-32

3.1 .4 Volatile content ........... 3-33

3.1 .5 Moisture Content ........... 3-33

3.1 .6 Trace Element Anaiysis . . . . . . 3-35

3.2 SULFUR FORMS ANALYSIS ............... 3-36

3.3 KILN GAS. . . . . . . . . . . . . . . . $3-42$

3.4 HUMIC ACID AND PHENOLICS FORMATION. . . . . . . . 3.44 
3.5 CARbonate fORMATION ................. $3-47$

3.5.1 Effect of Caustic/Coal Ratio on Carbonate

3.5.2 Effect of kiln Temperature on carbona .... 3-53

3.5.3 Effect of Coal Type on

3.5.4 Effect of Caustic Type on Carbote Formation... 3-57

3.5.5 Kiln Discharge Versus Spent Caustic Formation. . 3 3-58

3.5.6 Suppression of Carbonatent Caustic Data . . . . 3-59

3.6 PARTICLE SIZE DISTRIBUTION.

3.7 PROCESS LIQUID ANALYSIS ............. . . . 3-66

3.7.1 Partition of Aluminum, Silicon and Iron. . . . . 3 3-66

3.7 .2 Regeneration of Caustic Solution ....... 3-... 3-69

3.7.3 Treatment of Acid Wash Water. . . . . .

3.8 WASH TRAIN PERfORMANCE. . . . . . . . . . $3-72$

3.9 MATERIAL BALANCE. . . . . . . . . . . 3-79

3.9 .1 Coal Material Balance. . . . . . . . . 3-79

3.9.2 Sulfur Material Balance. . . . . . . .

3.10 CORROSION/EROSION DATA. ................. $3-84$

4. EQUIPMENT EVALUATION ...................... 4-1

4.1 KILN. ...................... 4-1

4.2 DISSOLVER/QUENCH TANK SYSTEM. .......... 4-5

4.3 filtration. . . . . . . . . . . . . . 4-8

4.3.1 Filtration Background. . . . . . . . . 4. 4-8

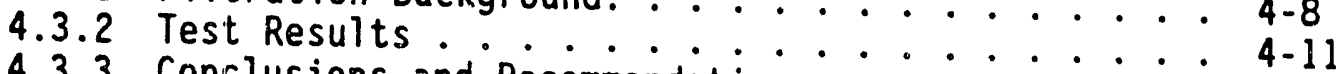

4.3.3 Conclusions and Recommendations. ............. 4-13

4.4 WATER AND ACID WASHING. ........... 4-. . 4

4.5 CAUSTIC REgeneration. ............ 4-. . . .

4.5.1 Equipment Deșcription and Operation. ..... 4-18 


\section{TABLE OF CONTENTS}

Page

4.5.2 Off-line Mineral Matter Recovery Experiments . . 4-22

4.5.2.1 Step 1 - Filtration of Feed Sample. . . 4-22

4.5.2.2 Step 2 - Evaporation to $50 \mathrm{wt} \% \mathrm{NaOH}$. . 4-26

4.5.2.3 Step 3 - High Temperature Treatment . . 4-28

4.5.2.4 Step 4 - Lime Treatment . . . . . . 4 4-31

4.5.2.5 Step 5 - Conclusions......... 4-31

4.6 EVAPORATOR AND FLAKER ................ . . 4-35

4.6.1 Equipment Description. ............. 4-39

4.6.2 Pretest Operations............... 4-40

4.6.3 Test Operations. .............. 4-41

4.6.4 Conclusions and Recommendations. . . . . . . 4-56

4.7 WASTE TREATMENT . . . . . . . . . . . . . . 4-58

4.8 DATA ACQUISITION AND CONTROL SYSTEM.......... 4-61

APPENDIX A. MCL RUN DATA SUMMARY. . . . . . . . . . . . . A-1

APPENDIX B. PRODUCT COAL ANALYSIS DATA. . . . . . . . . . . B-1

APPENDIX C. PRODUCT COAL DRYING . . . . . . . . . . . C C-1 


\section{LIST OF FIGURES}

Page

Figure 1-1. Block Diagram of the MCL Process. . . . . . . . 1-3

Figure 1-2. Schematic of the MCL Process............ 1-8

Figure 1-3. MCL Integrated Test Circuit Product Data for the Week of May 29, 1989 (Run 9)............ 1-13

Figure 2-1. Sulfur and Ash Data for Kiln and Product Coal as a Function of Coal Exit Time ........ 2-19

Figure 2-2. Volatiles, Sulfur and Heat Content Data for Product Coal as a Function of Coal Exit Time. . . . 2-31

Figure 3-1. Effect of Temperature and Caustic/Coal Ratio (R) on Sulfur Removal - Pittsburgh $\mathrm{No} .8 ; \mathrm{KOH} / \mathrm{NaOH}=1 . \cdot 3-8$

Figure 3-2. Comparison of Predicted and Experimental Values for Sulfur Content of $\mathrm{MCL}$ Coal Product - Pittsburgh No. $8 ; \mathrm{KOH} / \mathrm{NaOH}=1 . . . . . . . . .3-9$

Figure 3-3. Effect of Temperature and Caustic/Coal Ratio (R) on Sulfur Removal - Pittsburgh No. $8 ; \mathrm{KOH} / \mathrm{NaOH}=0.3-13$

Figure 3-4. Comparison of Predicted and Experimental Values for Sulfur Content of MCL Coal Product - Pittsburgh No. 8; $\mathrm{KOH} / \mathrm{NaOH}=0 . . . . . . . . . .3-14$

Figure 3-5. Effect of Temperature and Caustic Type on Sulfur Removal - Kentucky No. 9 Coal ......... 3-18

Figure 3-6. Effect of Temperature and Caustic/Coal Ratio (R) on Ash Removal - Pittsburgh No. 8; KOH/NaOH $=1$. . 3-21

Figure 3-7. Comparison of Predicted and Experimental Values for Ash Content of $\mathrm{MCL}$ Coal Product - Pittsburgh No. $8 ; \mathrm{KOH} / \mathrm{NaOH}=1 . . . . . . . . .3-22$

Figure 3-8. Correlation Between Pittsburgh No. 8 Coal Product Sulfur and Ash Content. . . . . . . . . . 3-24

Figure 3-9. Effect of Temperature and Caustic/Coal Ratio (R) on Ash Removal - Pittsburgh No. 8; KOH/NaOH $=0$. . . 3-27

Figure 3-10. Comparison of Predicted and Experimental Values for Ash Content of $\mathrm{MCL}$ Coal Product - Pittsburgh

No. $8 ; \mathrm{KOH} / \mathrm{NaOH}=0 . . . . . . . . .2 .3-28$ 
Figure 3-11. Effect of Temperature and Caustic Type on Ash

Removal - Kentucky No.9 Coal ......... 3-31

Figure 3-12. Coal Product Moisture vs. Ash Content - Pittsburgh No. 8 Coal. .............. 3-34

Figure 3-13. Comparison of Sulfate Sulfur in Kiln Discharge Coal and Washed Coal Product ........... . 3-40

Figure 3-14. Effect of Leaching Temperature on Conversion to Humics................. 3-46

Figure 3-15. Effect of Caustic/Coal Ratio on Carbonate Formation at $427^{\circ} \mathrm{C} \mathrm{Kiln} \mathrm{Wall} \mathrm{Temperature.} \mathrm{.} \mathrm{.} \mathrm{.} \mathrm{.} \mathrm{.} \mathrm{.} \mathrm{.} \mathrm{3-54}$

Figure 3-16. Effect of Kiln Temperature on Conversion of Coal to Carbonate at Caustic/Coal $\geq 2.0$....... 3-55

Figure 3-17. Effect of Kiln Temperature on Conversion of Caustic to Carbonate at Caustic/Coal $\geq 2.0$. . . . . . . 3-56

Figure 3-18. Comparison of Carbonate Formation in Kiln Discharge and Spent Caustic Samples.......... 3-60

Figure 3-19. Particle Size Distribution for Feed Coal and Kiln Discharge Coal.............. 3-63

Figure 3-20. Particle Size Distribution for Feed Coal and Washed Coal Product. .............. 3-64

Figure 4-1. Rotary Kiln Reaction System............ 4-2

Figure 4-2. Water Washing System. .............. 4-10

Figure 4-3. Acid Wa. ling System.............. 4-16

Figure 4-4. Caustic Regeneration System . . . . . . . . . 4-19

Figure 4-5. Laboratory Processing Scheme Outline. . . . . . . 4-23

Figure 4-6. Caustic Concentration System. . . . . . . . . 4-36

Figure 4-7. Vapor/Liquid Overhead Equilibrium ........ . 4-44

Figure 4-8. Water Treatment System. . . . . . . . . . . . 4-59 
Table 1-1. MCL Design Material Balance. . . . . . . . . . 1-5

Table 1-2. Coal Feeds to MCL Circuit.............. 1-10

Table 2-1. Test Matrix: Variable-by-Variable. . . . . . . 2-4

Table 2-2. Run Condition Summary. . . . . . . . . . 2-8

Table 2-3. Qualities and Characteristics of Coal Products

Collected from MCL Operations.......... 2-50

Table 2-4. MCL Product Coal Summary ............ 2-53

Table 3-1. Coal Product Quality for Tests with Pittsburgh No. 8 Coal and 50:50 KOH/NaOH. ............ 3-4

Table 3-2. Coal Product Quality for Tests with Pittsburgh No. 8

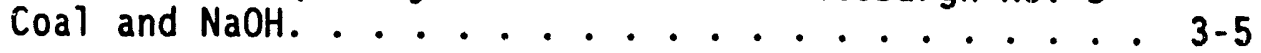

Table 3-3. Coal Product Quality for Tests with Kentucky No. 9 Coal ................... 3-6

Table 3-4. Quantitative Cation and Anion Analysis . . . . . 3-37

Table 3-5. Removal of Minor and Trace Elements From Coal Semi-quantitative Emission Spectrographic Analysis,

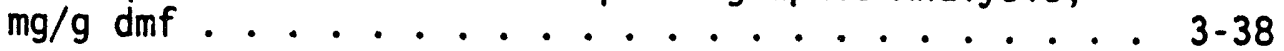

Table 3-6. Sulfur Forms Analysis Results. . . . . . . . 3-39

Table 3-7. Kiln Gas Analysis Results. . . . . . . . . . 3-43

Table 3-8. Formation of Humic Acid. . . . . . . . . . . 3-45

Table 3-9. Carbonate Formation. ............ 3-50

Table 3-10. Coal Particle Size Distribution. . . . . . . . 3-62

Table 3-11. Partition of Aluminum, Silicon and Iron. . . . . 3-67

Table 3-12. Concentration Levels of Aluminum, Silicon and Iron in Spent and Regererated Caustic ........ 3-71

Table 3-13. Concentration Levels of Aluminum, Silicon, Iron, Sodium and Potassium in Acid Wash Water. ...... 3-73

Table 3-14. Centrifuge Centrate pH Measurements. . . . . . . 3-75 


\section{LIST OF TABLES}

Page

Table 3-15. Coal Fines in C-201 Centrate........ 3-77

Table 3-16. Moisture Content of Centrifuge Cake. . . . . . . 3-78

Table 3-17. Coal Material Balance. . . . . . . . . . . 3-80

Table 3-18. Concentration Levels of Sulfur in Spent and Regenerated

Caustic............... 3-83

Table 3-19. Corrosion/Erosion Rates in MCL Test Loop . . . . 3-86

Table 3-20. Visual Inspection of Erosion Coupons . . . . . . 3-87

Table 4-1. Analysis of Regeneration Feed Solution . . . . . 4-25

Table 4-2. Solids and Liquids From Step 1. . . . . . . . . 4-27

Table 4-3. Mass Balance - Step 1. .. . . . . . . . . . 4-27

Table 4-4. Solids and Liquids From Step 2........... . 4-29

Table 4-5. Mass Balance - Step 2.............. . 4-29

Table 4-6. Solids and Liquids From Step 3.......... 4-30

Table 4-7. Mass Balance - Step 3.............. . 4-30

Table 4-8. Solids and Liquids From Step 4. . . . . . . . . 4-32

Table 4-9. Mass Balance - Step 4............... 4-32

Table 4-10. Analysis of Solids and Liquids From Steps 1 Through 4. 4-33

Table 4-11. Mineral Matter Recovery Summary - Laboratory

Scale Regeneration of Feed Solution VP2023 . . . . 4-34

Table 4-12. Evaporator Performance Summary . . . . . . . . 4-37

Table 4-13. Data Tabulation - Evaporator Operating Test No. 1. . 4-42

Table 4-14. Data Tabulation - Evaporator Operating Test No. 2. . 4-47

Table 4-15. Data Tabulation - Evaporator Operating Test No. 3. . 4-49

Table 4-16. Data Tabulation - Evaporator Operating Test No. 4. . 4-52

Table 4-17. Data Tabulation - Evaporator Operating Test No. 4A . 4-55 


\section{ABSTRACT}

The objectives of the task covered in this document are to operate an integrated MCL test circuit to demonstrate the technical capability of the process for producing a demineralized and desulfurized coal that meets New Source Performance Standards (NSPS), to test process conditions aimed at lower costs, and to deliver product coal. These objectives were met by the operation of the integrated test circuit during a 54-test process matrix that resulted in the production of 3,000 pounds of treated coal. Product MCL coal might be used to displace oil in some turbine and diesel engines and may be used in the retrofit of oil-fired boilers to coal-fired boilers. Two high sulfur, high ash coals representative of the Eastern United States coal production were processed: Pittsburgh No. 8 and Kentucky No. 9. Although mild kiln conditions $\left(325\right.$ to $415^{\circ} \mathrm{C}$ and 1 to 2.3 hours residence time) and low caustic to coal ratios (1:1 to $3: 1$ ) were used, the combination of continuous operation and rigorous exclusion of air from the system allowed the production of MCL coal that had product sulfur content well below NSPS standards, very low carbonate production, very little volatiles loss, and low alkali retention by the product $\mathrm{MCL}$ coal. Optimization testing resulted in a product coal containing 0.4 percent sulfur $\left(0.6\right.$ lbs $\mathrm{SO}_{2} /$ million Btu) and 0.15 percent ash with more than 90 percent organic sulfur removal, 95 percent $\mathrm{SO}_{2}$ reduction from run-of-mine coal, 91 percent $\mathrm{SO}_{2}$ reduction from precleaned process feed coal, and with heat content of about 14,000 Btu per pound. 


\section{INTRODUCTION AND SUMMARY}

This is a report of the results obtained from the operation of an integrated test circuit for the Molten-Caustic-Leaching (MCL or Gravimelt) process for the desulfurization and demineralization of coal. A detailed description of the test circuit and the shakedown test results are presented in a separate document entitled, "Topical Report for Test Circuit Procurement, Fabrication, Installation, Shakedown, and Test Plan Formulation". The project is sponsored by the Pittsburgh Energy Technology Center of the U.S. Department of Energy under Contract No. DE-AC22-86-PC91257.

The objectives of operational testing of the 20 pounds of coal per hour integrated $M C L$ test circuit are: 1) to demonstrate the technical capability of the process for producing a demineralized and desulfurized coal that meeis New Source Performance Standards (NSPS), 2) to determine the range of effective process operation, 3) to test process conditions aimed at significantly lower costs, and 4) to deliver product coal.

These objectives were met by the operation of the integrated MCL test circuit that produced coal with sulfur content well below the New Source Performance Standards and with equipment performance consistent with commercial design requirements. An assessment of the results indicate that the MCL circuit with modifications is capable of integrated, continuous, long-duration operational testing.

A 54-test process matrix was performed resulting in the production of 3,000 pounds of treated coal suitable for further testing and evaluation. Two coals representative of the Eastern United States coal production were processed: Pittsburgh No. 8 and Kentucky No. 9. Pittsburgh No. 8 coal was used for most of the testing. Optimization testing was perforined resulting in a product coal containing 0.4 percent sulfur 10.6 lbs $\mathrm{SO}_{2} /$ million $\mathrm{Btu}$ ) and 0.15 percent ash with more than 90 percent organic 
sulfur removal, 95 percent $\mathrm{SO}_{2}$ reduction from run-of-mine coal, and 91 percent $\mathrm{SO}_{2}$ reduction from precleaned process feed coal. The results indicate that Eastern coals can be treated to meet NSPS standards for sulfur oxides control while providing a product coal with heat content of about 14,000 Btu per pound and an ash content as low as a tenth of a percent.

The following sections of this Introduction and Summary contain a description of the integrated circuit, analyses and NSPS targets for the two project coals, a summary of the test results, conclusions, and a report outline.

\subsection{PROCESS DESCRIPTION}

The MCL process utilizes a melt of sodium hydroxide or mixtures of sodium and potassium hydroxides at reaction temperatures of 325 to $415^{\circ} \mathrm{C}$ to remove virtually all of the sulfur and mineral matter from coal. The process is a potential replacement for the costly flue gas desulfurization systems contemplated for smaller utilities and industrial boilers. The product coal might also displace oil in some turbine and diesel engines and may be used in the retrofit of oil-fired boilers to coai-fired boilers. Product MCL coal may also have an application as an inexpensive pre-activated or activated carbon for extraction of pollutants from waste water or to clean-up and concentrate radioactive or toxic waste.

The test circuit consists of six unit operations (Figure 1-1) which together provide a continuous system for leaching coal with caustic and regenerating the reactant. These units are:

- A kiln for reacting molten caustic with coal (Section 100)

- A seven stage water washing section for recovering caustic from the coal (Section 200)

- A three stage acid washing section for removing residual metals and alkali and providing an ultra-pure coal product (Section 300)

- A regeneration section to provide purified aqueous caustic (Section 400) 


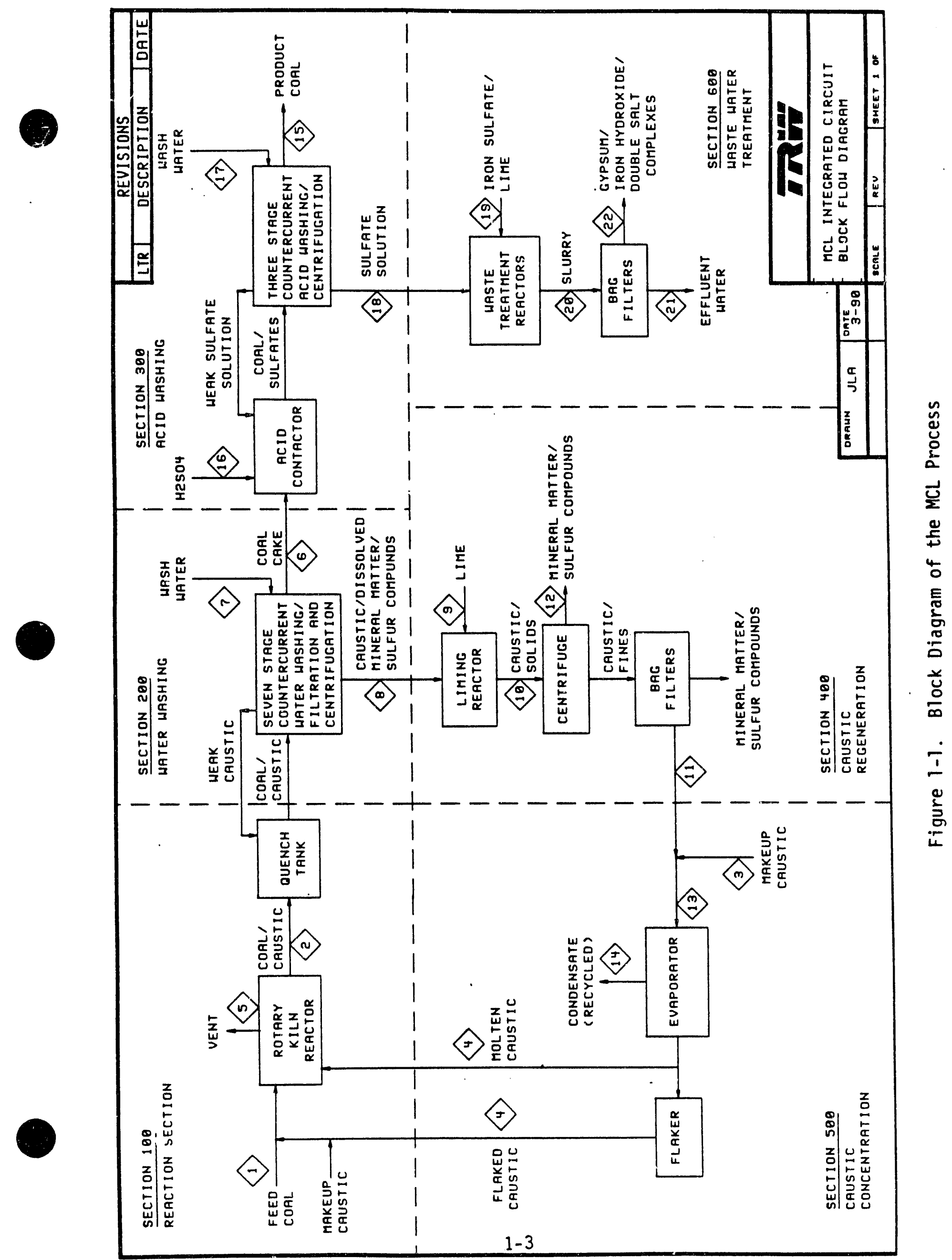


- An evaporator section to provide molten or flaked caustic for recycle to the kiln reactor (Section 500 )

- A water treatment section to provide either dischargeable.or recyclable water (Section 600).

The material balance used to design the integrated test circuit for a $20 \mathrm{lb} / \mathrm{hr}$ plant is presented in Table 1-1 along with design assumptions. The design was based on TRW's knowledge and experience acquired from the previous modular Gravime it program, as well as information provided by equipment vendors.

The integrated test circuit facility that was constructed at the TRW San Juan Capistrano test site in California contains about 150 pieces of commercial equipment including filters, centrifuges, tanks, reactors, feeders, a kiln, and a rising film evaporator. It occupies 3700 square feet and is fitted with more than 6000 feet of piping, 425 valves, 80 instruments and controls as well as a computer control room and a data acquisition and reduction system.

A schematic of the MCL process is shown in Figure 1-2. Feed coal is first combined with anhydrous sodium hydroxide, or mixed sodium and potassium hydroxides, in a rotary kiln reactor where the mixture is heated to reaction temperatures of 325 to $415^{\circ} \mathrm{C}$ causing the caustic to: 1 ) become sorbed in the coal matrix, 2) react with the coal sulfur and mineral matter, and 3 ) dissolve the reaction products containing sulfur and inorganic components.

The reaction mixture exits the rotary kiln in the form of pellets that are washed with water in a seven stage countercurrent separation system consisting of two filters and five centrifuges. As an example, four weights of wash water per weight of coal may be used resulting in a $50 \%$ aqueous reacted caustic solution exiting the first stage of filtration. Nearly all of the coal-derived iron and a small amount of sodium and/or potassium remain with the ${ }^{\circ}$ coal cake exiting this countercurrent washing system. 
○ ఝุ

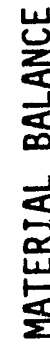

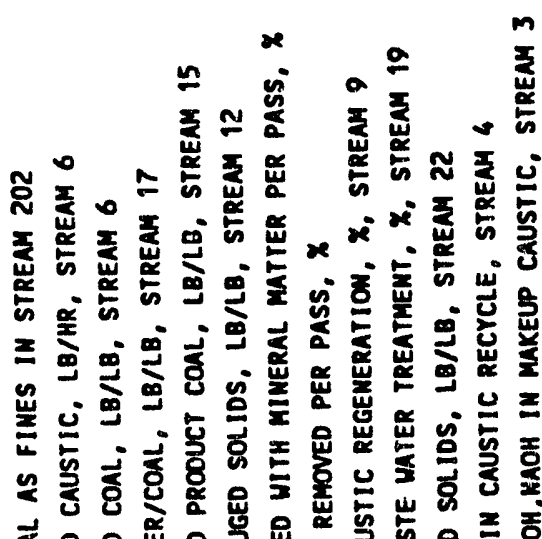

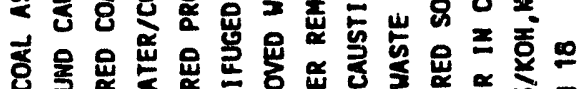

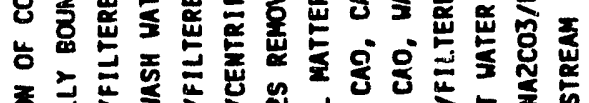

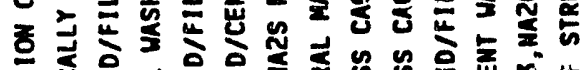

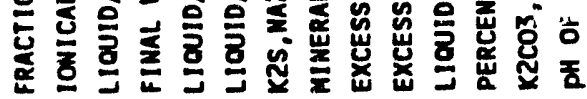

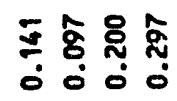

灾

岁

กิ

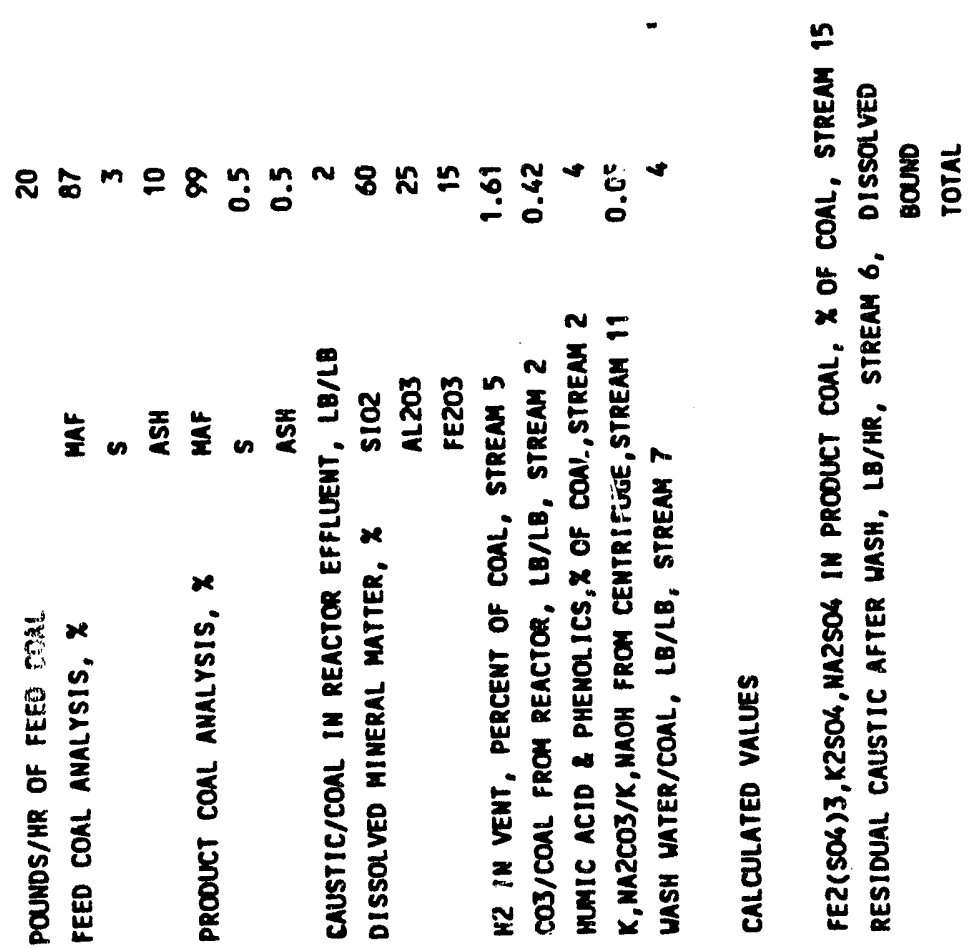

$\check{1}$

$\stackrel{w}{\rightleftarrows}$ 


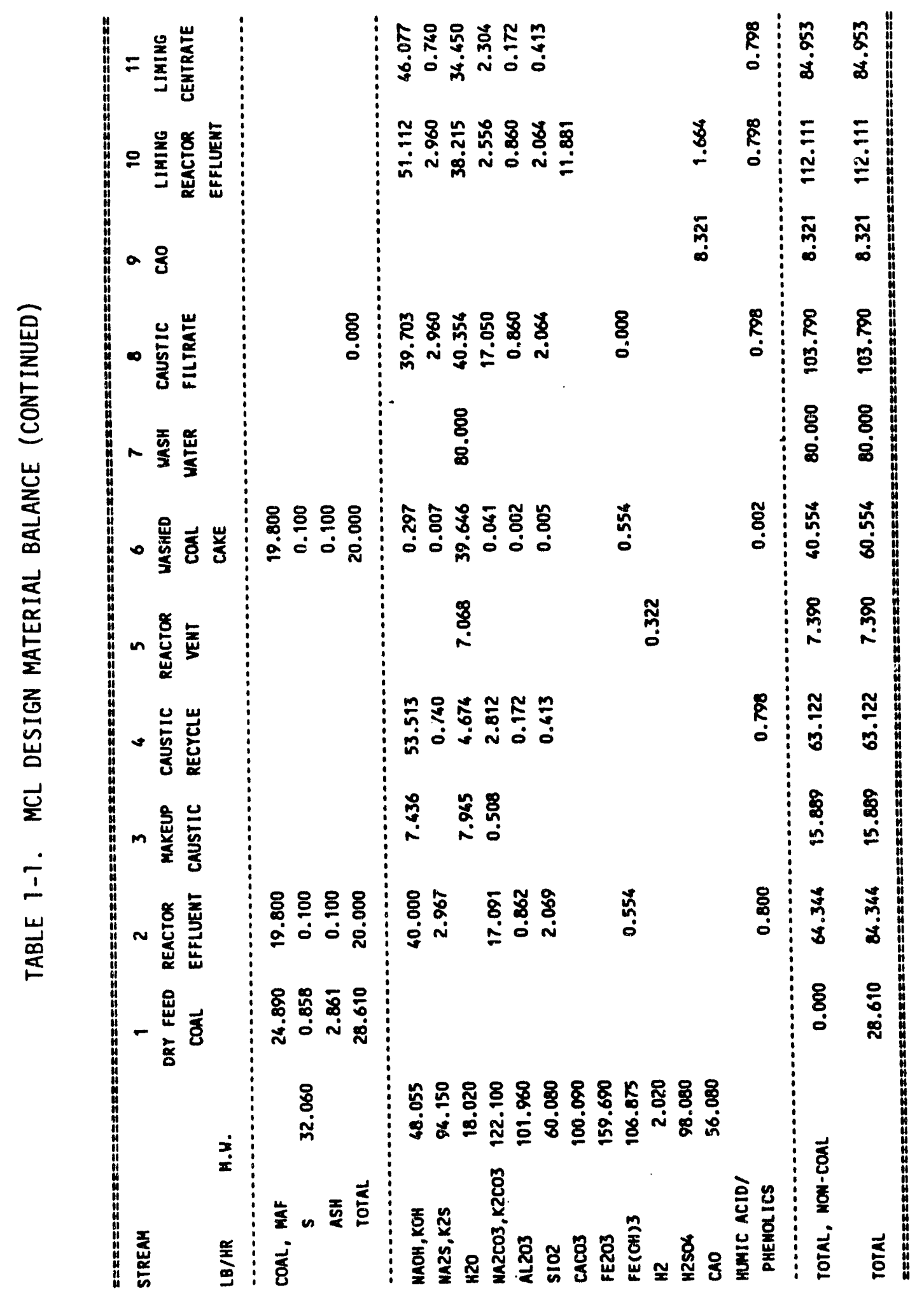




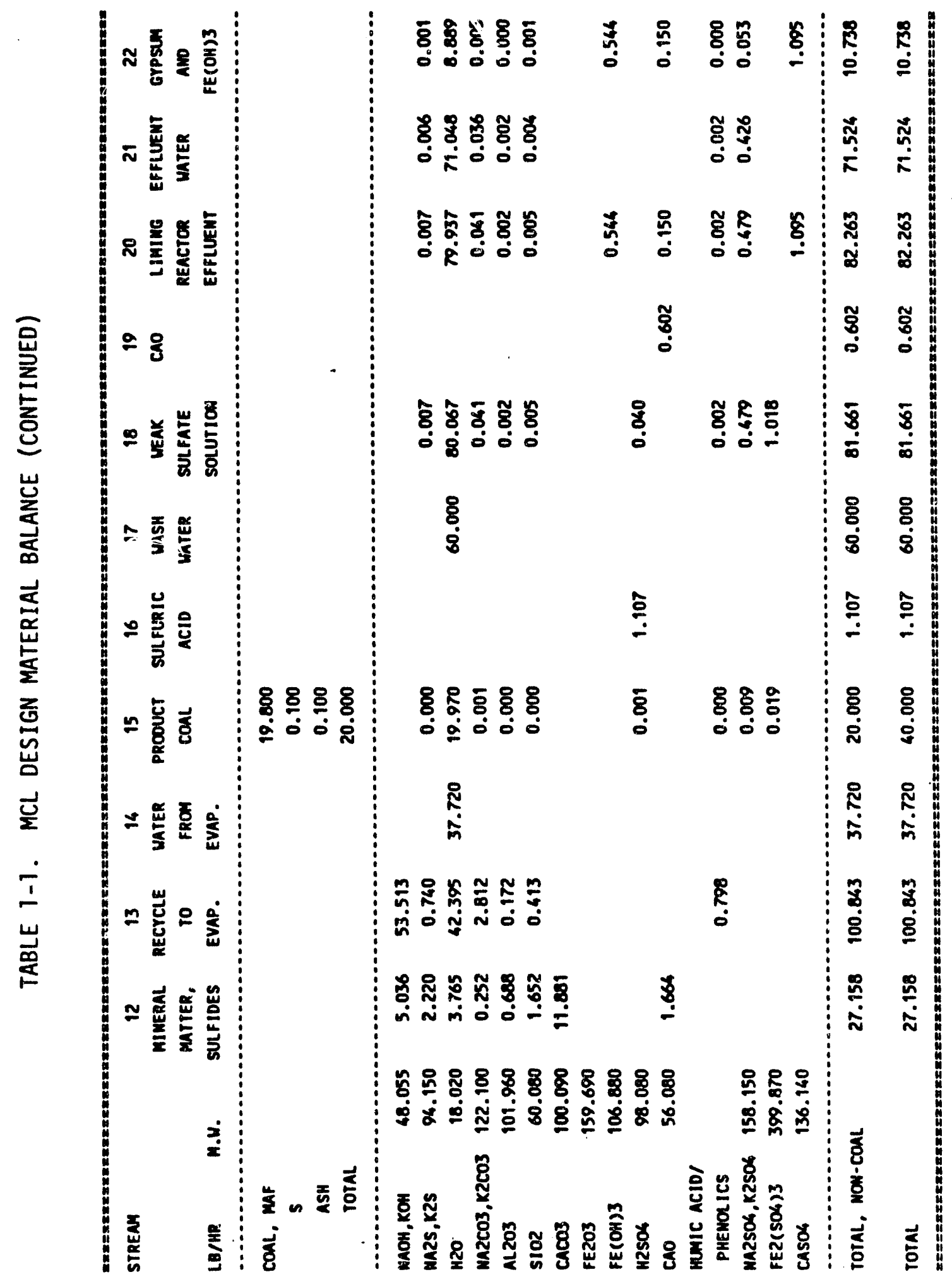




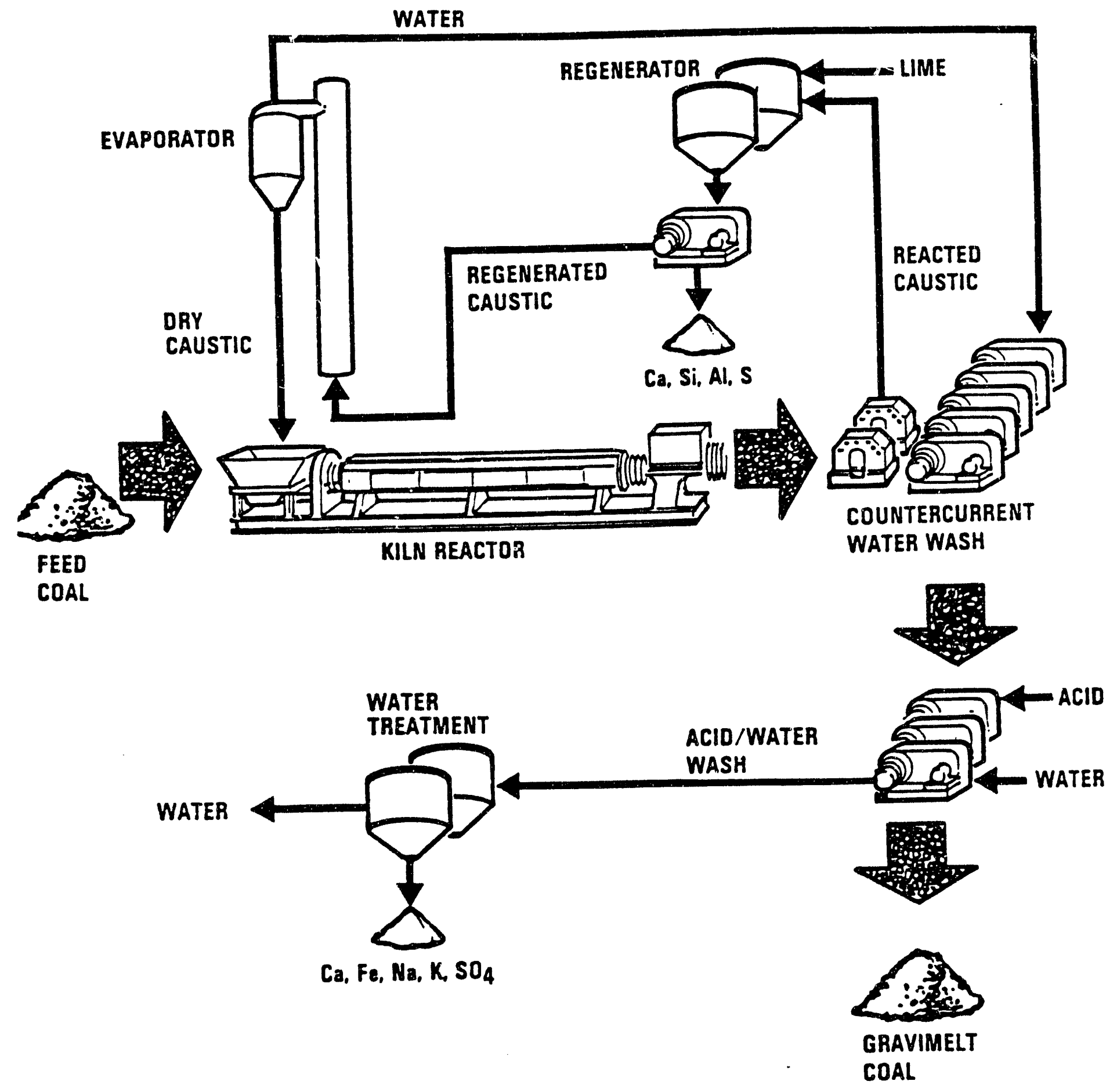

Figure 1-2. Schematic of the MCL Process 
The coal cake is next washed to remove the residual iron and caustic in a countercurrent three stage centrifuge system. Sulfuric acid is added to the first stage to produce a pH of 2 in order to dissolve the residual alkali and iron hydroxide. As an example, three weights of wash water per weight of coal may be used resulting in an acid extract leaving the first stage containing $2,000 \mathrm{ppm}$ of mixed sodium and potassium sulfates and $17,000 \mathrm{ppm}$ of iron sulfate. The product coal exiting this acid washing system contains one-half weight of sorbed water.

All of the iron sulfate and a major portion of the alkali sulfates can be removed by a sequence of heating and lime treatment to form insoluble minerals such as gypsum, and the water can be recycled. Under some (very carefully controlled) conditions, the precipitate formed can be a jarosite-like double salt which can be easily disposed of or land-filled.

The aqueous caustic recovered from the first countercurrent washing circuit is limed at 180 to $250^{\circ} \mathrm{F}$ to remove the coal-derived mineral matter, sulfur compounds, and carbonates. The mixture is allowed to stand to permit precipitation of the impurities before being centrifuged. The purified liquid is sent to a caustic evaporator where the water is recovered for recycle to the first wash train, while producing anhydrous caustic (as either a molten liquid or as flakes) for reuse in the initial leaching of the coal.

\subsection{TEST COALS}

A major goal of the integrated $M C L$ project is to demonstrate reduction in sulfur to meet New Source Performance Standards. These standards are based on the sulfur content per million Btu, which is expressed in the form of lbs $\mathrm{SO}_{2} / 10^{6} \mathrm{Btu}$. This removal applies to the run-of-mine (ROM) coal analysis. The two coals to be tested in this program (Table 1-2) contain $8-11$ lbs $\mathrm{SO}_{2} / 10^{6} \mathrm{Btu}$, which is the range that represents a majority of the coal mines east of the Mississippi, and falls within Category 3 of the New Source Performance Standards, which requires 90 percent reduction from $\mathrm{ROM}$ to 0.8 to 1.1 lbs $\mathrm{SO}_{2} / 10^{6} \mathrm{Btu}$. 
TABLE 1-2. COAL FEEDS TO MCL CIRCUIT

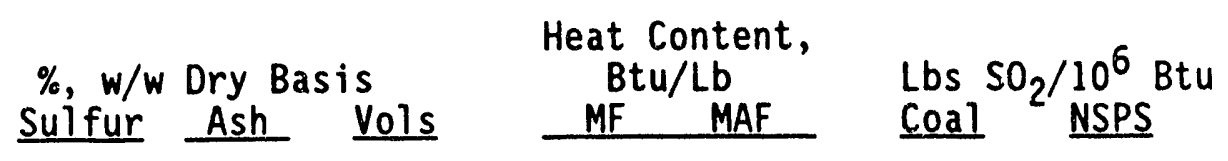

Coal

Pittsburgh No. $8^{a}$

Run of Mine

Cleaned

$5.08 \quad 34.90$

38.60

9144

14719

11.10

$4.27 \quad 11.57$

38.60

13016

6.55

1.11

Kentucky No. $9^{b}$

Run of Mine

Cleaned

$\begin{array}{rrrrr}4.70 & 17.00 & -- & 10525 & -- \\ 3.41 & 9.25 & 40.53 & 13259 & 14610\end{array}$

8.93

$5.14 \quad 0.89$ Powhatan No. 6 Mine (Powhatan Point, Ohio) Nacco Division, North
American Coai Company

b Pittsburgh \& Midway Coal Company 
The data within the table show that each coal is reduced in sulfur content per unit heat content by about 40-45 percent by physical cleaning at the mine, but the remaining sulfur content is about five times that required by the New Source Performance Standards. There are two options for meeting New Source Performance Standards, either post-combustion removal (flue gas desulfurization) or front-end cleaning as represented by the Gravimelt (MCL) process.

\subsection{OPERATIONS TESTS RESULTS}

The integrated MCL test circuit was operated on an around-the-clock basis for nine operating weeks resulting in 750 hours of matrix testing over the period of time from January through June of 1989. Analyses were obtained on process streams such as product coal,. slurries, filtrates, centrates, kiln gas, and various effluent solids. These data were assessed in detail. An operations summary is as follows:

1. A 54 test main parameter operational matrix has been performed with variation in average kiln wall temperature, 371 to $438^{\circ} \mathrm{C}$; kiln residence time, 1 to 2.3 hours; sodium hydroxide or mixtures of sodium and potassium hydroxides; caustic to coal ratios of $1: 1$ to $3: 1$; feed coal particle size of 14 mesh and 6 mesh $\times 0$; two coals (Pittsburgh No. 8 and Kentucky No. 9, with the Pittsburgh No. 8 seam being emphasized); fresh versus recycled caustic; and nitrogen flow direction in kiln (cocurrent versus countercurrent).

2. As a part of the above test matrix, the plant was operated to produce MCL coal with virtually no loss of heat content, small loss of volatiles, minimum carbonate formation, 1.1 to 2 weights of moisture per weight of coal in the caustic washing section, 0.88 to 1.46 weights of moisture to coal in the acid washing section (product coal), and which can utilize sodium hydroxide in place of mixed sodium and potassium hydroxides or 6 mesh $\times 0$ coal in place of 14 mesh $\times 0$ coal.

3. The plant produced 3,000 lbs (dry basis) of $\mathrm{MCL}$ coal varying in quality from 0.4 percent sulfur to 1.9 percent sulfur, 0.1 percent ash to 2.4 percent ash, $14,250 \mathrm{Btu} / 1 \mathrm{~b}$ to $12,600 \mathrm{Btu} / \mathrm{1b}$ and volatiles from 35 percent to 21 percent.

4. Organic sulfur removal ranged from 57 percent at moderate temperatures, where small loss of volatiles and heat content was observed, and maximized at over 90 percent removal where there was minimal heat content loss. 
5. Both Pittsburgh No. 8 and Kentucky No. 9 coals were reduced to NSPS compliance levels.

6. Optimization testing was performed on the Pittsburgh No. 8 coal with sodium hydroxide resulting in product coal containing 0.4 percent sulfur $\left(0.60\right.$ lbs $\left.\mathrm{SO}_{2} / \mathrm{million} \mathrm{Btu}\right)$ and 0.15 percent ash with more than 90 percent organic sulfur removal.

7. Best overall coal products (Pittsburgh No. 8) were prepared with $\mathrm{NaOH}$ resulting in 0.40 to 0.77 percent sulfur; 0.15 to 0.64 percent ash; 13,400 to 14,200 Btu/1b; 24 percent volatiles; 0.60 lbs $\mathrm{SO}_{2} /$ million Btu $\left(95\right.$ percent $\mathrm{SO}_{2}$ reduction from $\mathrm{ROM}$ and 91 percent from precleaned process feed) to 1.08 lbs $\mathrm{SO}_{2} / \mathrm{milli}$ ion Bt: (90 percent $\mathrm{SO}_{2}$ reduction from ROM and 84 percent from precleared process feed).

The following process conclusions were drawn from the test information: 1) the combination of continuous operation, rigorous exclusion of air from the system, and mild conditions allows the production of $\mathrm{MCL}$ coal, for the first time, which has very low carbonate production or volatiles loss and which does not have the propensity to form excessively wet cakes in countercurrent washing, 2) the low moisture content of the cakes can significantly lower processing costs through the elimination of a number of stages of washing and the sitilization of less wash water, 3) low alkali retention by $\mathrm{MCL}$ coal obtained from the water washing section indicates that alkali losses may be reduced to an insignificant level resulting in large cost savings to the process, 4) the use of one weight of caustic per weight of coal instead of 2 or 2-1/2 weights of caustic would result in additional savings of wash water and evaporation energy costs, and 5) carbonate formation may not be a problem in continuous test circuit operation, thereby saving lime costs and enhancing operation.

All of the product sulfur and ash data obtained in the final week of operation (Pittsburgh No. 8 coal) is presented in Figure 1-3. The run was made under a single set of conditions, varying only in the use of $\mathrm{NaOH}$ for the latter part of the week and mixed sodium and potassium hydroxides at the beginning of the week. Sulfur removal averaged 93 percent from ROM and 88 percent from mine cleaned coal. Ash reduction averaged 98 percent 


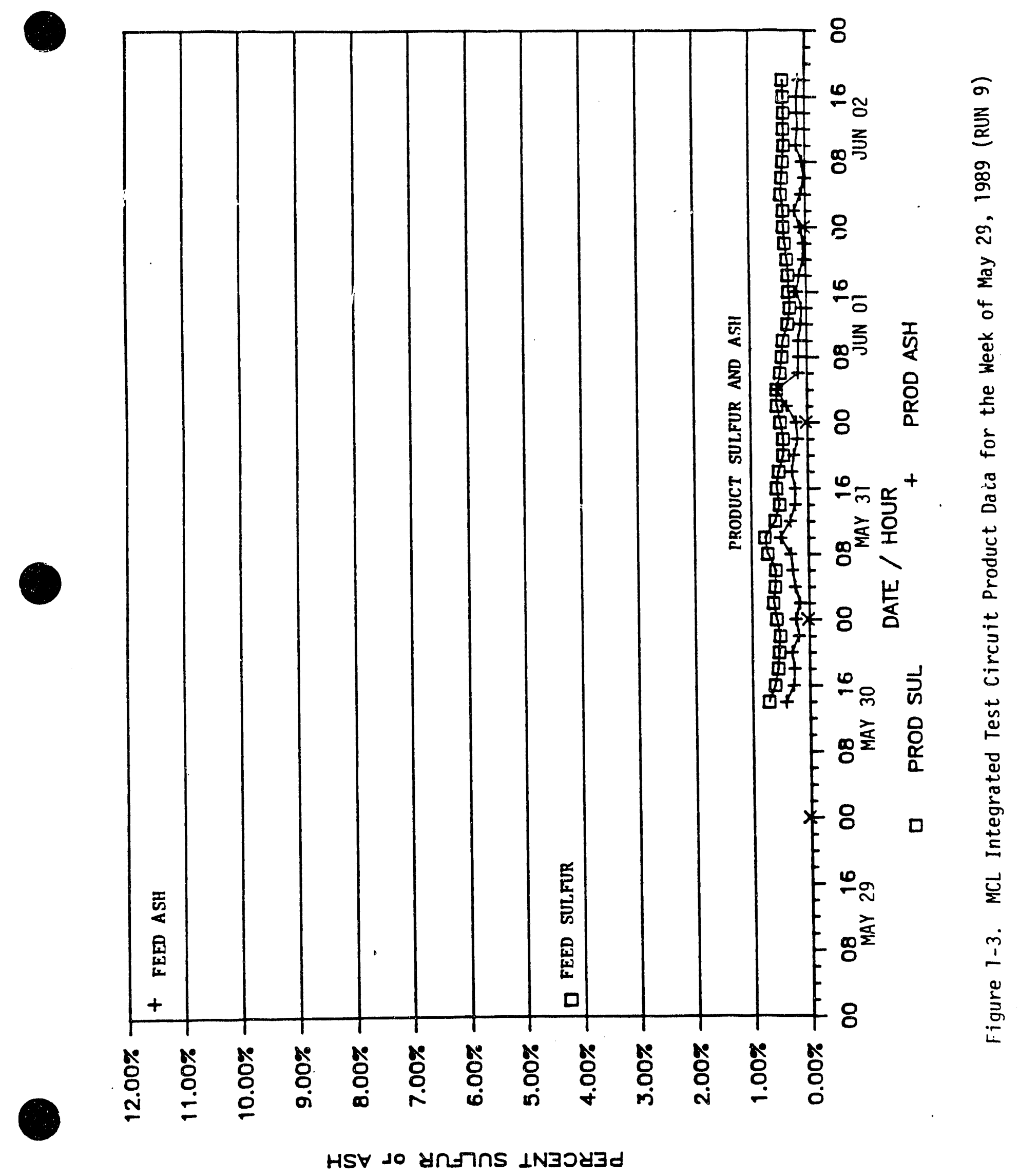


from the coal fed to the process. For several periods during the latter part of the week, the ash content was so low as to be essentially immeasurable $u$ y the standard ASTM technique.

\subsection{REPORT OUTLINE}

The following sections of this report contain a compilation of run conditions and product coal data, an engineering assessment of the operating test results, and an equipment evaluation. 


\section{SUMMARY OF DATA}

The MCL integrated test circuit was operated on an around-the-clock basis for nine operating weeks resulting in 750 hours of matrix testing over the period of time from January through June of 1989. The normal mode of operation during this time was to operate around-the-clock for a week (two 12-hour shifts for five days) followed by a week of scheduled downtime for maintenance and refurbishment (repair and modify equipment as necessary), data analycis, and future test planning. Each week of operation was designated as a "run" for a total of nine runs. Each run was then subdivided into imaller uni:s of time $(A, B, C, D)$ based on operational changes called for by the test matrix.

The following sections contain a compilation of the more critical test data including a test matrix summary, a run conditions summary, suifur and ash results by run, volatiles and heat content summaries by run, coal product data tabulation, and product ccal drying and shipping data. Analyses were cbtained on process streams such as product coal, slurries, filtrates, centrates, kiln gas, and various effluent solids.

\subsection{TEST MATRIX AND RUN CONDITION SUMMARY}

In order to provide sufficient data for evaluation, a fractional factorial test matrix was formulated such that the two coals and the process variables are tested against each other in a statistically relevant manner. Process variables tested include potassium-to-sodium ratio, caustic-to-coal ratio, kiln temperature, kiln residence time (RPM, auger speed, auger direction - forward vs. backward), fresh vs. recycled caustic, feed coal mesh size ( 14 vs. 6 mesh $\times 0)$, nitrogen flow direction in kiln (cocurrent vs. countercurrent). The test matrix was aimed at providing: 1) the highest grade compliance coal containing both ultra-low-sulfur and ultra-low-ash, and 2) evaluation of the most economic processing conditions as well as production of coal samples with the minimum by-product formation. 
The test matrix performed during the Task 6 integrated operation effort is presented in Table 2-1 on a variable-by-veriable basis. A run-by-run summary of operating conditions is presented in Table 2-2. A much more detailed run-by-run summary of operating conditions including product coal analyses and heat content is presented in Appendix A.

\subsection{SULFUR AND ASH REMOVAL}

The sulfur and ash content of the MCL integrated test circuit product coal is presented on an hour-by-hour basis in Figure 2-1. These data are line-connected for ease of inspection. Analyses of intermediate samples taken at the kiln exit are also shown. Approximately four hours should be added to the abscissa of these samples to align with the time of exit of the product coal collected at the final wash station. This is to correct for residence time in the water and acid washing sections.

As a point of reference it should be noted that the feed Pittsburgh No. 8 coal analyses are: $4.27 \%$ total sulfur; $2.54 \%$ organic sulfur; $11.57 \%$ ash; 13,016 MF Btu/lb, 14,719 MAF Btu/lb; and the feed Kentucky No. 9 analyses are: $3.41 \%$ total sulfur; $1.85 \%$ organic sulfur; $9.25 \%$ ash; 13,259 MF Btu/1b; 14,610 MAF Btu/1b.

\subsection{VOLATILES AND HEAT CONTENT}

Volatiles, sulfur, and heat content by run as a function of coal exit time are presented in Figure 2-2. A tabular listing of kiln exit coal and product coal sulfur and ash content along with product coal volatiles and heat content is included in Appendix B.

\subsection{PRODUCT COAL}

Table 2-3 contains a listing of all product coal samples fully processed in the integrated test circuit together with analyses to aid in the selection of samples for delivery to the. DOE at the end of the program. 
Selected sample bags of MCL product coal were placed in a $\mathrm{GN}_{2}$-purged coal drying oven (about eleven bags per load) for six hours, with the oven set at its minimum temperature of $140^{\circ} \mathrm{F}$. This removed about $15 \%$ of the moisture from the samples. The samples were repackaged in new plastic bags and relabeled with the new weight. The dried samples were place in nine 55-galion steel drums for shipment to DOE. Presented in Appendix $C$ is list of all coal samples that were dried and shipped to DOE. The total weight shipped to DOE is summarized in Table $2-4$.

Eight of the selected sample bags listed in Appendix $C$ for Pittsburgh No. 8 Run 4C1 3-7-89 12:45 through 19:15 were not dried because they could not be located in the storage drums. Samples from Kentucky No. 9 Run $7 \mathrm{~A}$ 5-1-89 20:15 through 22:15 and Pittsburgh No. 8 Run 9A 5-30-89 17:15 through 19:15 (about 10 pounds dry basis Kentucky No. 9 coal and 74 pounds dry basis Pittsburgh No. 8 coal) were dried and placed in an "MCL repository" for future use and analysis. 
TABLE 2-1. TEST MATRIX: VARIABLE-B.YY-VARIABLE

PITT 8

$\mathrm{KOH} / \mathrm{NaOH}=1$

Caustic/Cosl=1

$\begin{array}{lrrrrrr}\text { Run } & 1 A & 3 A 1 & 3 A 2 & 3 A 3 & 6 E 1 & 6 F 1 \\ \text { Temp, C } & 390 & 427 & 427 & 427 & 427 & 427 \\ \text { Res Time, hr } & 1.5 & 2.0 & 2.3 & 2.2 & 2.0 & 2.0 \\ \text { Kiln RPM } & 2 & 1 & 1 & 1 & 1 & 1 \\ \text { Auger Speed, X max } & 30 & 30 & 15 & 30 & 30 & 30 \\ \text { Auger sec F/sec B } & 20 / 10 & 20 / 10 & 20 / 10 & 17 / 13 & 20 / 10 & 20 / 10\end{array}$

PITT 8

KOH $/ \mathrm{NaOH}=1$

Caustic/Cost $=1.5$

$\begin{array}{lrrrr}\text { Run } & 18 & 1 C & 81 & 88 \\ \text { Temp, C } & 390 & 410 & 427 & 427 \\ \text { Res Time, hr } & 1.5 & 1.5 & 2.1 & 2.1 \\ \text { Kiln RPM } & 2 & 2 & 0.8 & 0.8 \\ \text { Auger Speed, X max } & 30 & 30 & 30 & 30 \\ \text { Auger sec F/sec B } & 20 / 10 & 20 / 10 & 20 / 10 & 20 / 10\end{array}$

"Witrogen flow was countercurrent to coal fezd in Runs $8 A$ and 8B. Also, 6 mesh coal was used in Run 8B.

PITT 8

$\mathrm{KOH} / \mathrm{NaOH}=1$

Caustic/Coal $=2$

$\begin{array}{lrrrrrrrrrr}\text { Run } & 10 & 2 A & 2 B & 2 C & 383 & 382 & 381 & 5 A 1 & 7 D & \text { TE } \\ \text { Temp, C } & 410 & 390 & 390 & 427 & 432 & 438 & 438 & 413 & 427 & 427 \\ \text { Res Time, hi } & 1.5 & 1.5-2.0 & 2.0 & 2.0 & 2.2 & 2.3 & 2.0 & 2.0 & 2.1 & 2.1 \\ \text { Kiln RPH } & 2 & 2 / 1.5 / 1 & 1 & 1 & 1 & 1 & 1 & 1 & 0.8 & 0.8 \\ \text { Auger Speed, X max } & 30 & 30 & 30 & 30 & 30 & 15 & 30 & 30 & 30 & 30 \\ \text { Augger sec F/sec B } & 20 / 10 & 20 / 10 & 20 / 10 & 20 / 10 & 17 / 13 & 20 / 10 & 20 / 10 & 20 / 10 & 20 / 10 & 20 / 10\end{array}$

* Witrogen flow was countercurrent $O$ coal feed $i, 1$ Runs $7 D$ and $7 E$. Also, recycled caustic was fed with coal in Run 70 .

PITT 8

$\mathrm{KOH} / \mathrm{NaOH}=1$

Caustic/Coal $=2.5$

$\begin{array}{lrrr}\text { Run } & 9 A & 9 A 1 & 98 \\ \text { Temp, C } & 427 & 438 & 438 \\ \text { Res Time, hr } & 2.1 & 2.1 & 2.1 \\ \text { Kiln RPM } & 0.8 & 0.8 & 0.8 \\ \text { Auger Speed, X max } & 30 & 30 & 30 \\ \text { Auger sec F/sec B } & 20 / 10 & 20 / 10 & 20 / 10\end{array}$

"Witrogen flow was countercureent to coal feed in Runs $9 A, 9 A 1$ and $9 B$. Also, recyeled caustic was fed with coal in Run $9 B$. 
TABLE 2-1. TEST MATRIX: VARIABLE-BY-VARIABLE (CONTINUED)

PITT 8

$\mathrm{KOH} / \mathrm{NaOH}=1$

Caustic/Coal $=3$

$\begin{array}{lrr}\text { Run } & 3 C 9 & 7 C \\ \text { Temp, C } & 438 & 427 \\ \text { Res Time, hr } & 2.0 & 2.1 \\ \text { Kiln RPM } & 1 & 0.8 \\ \text { Auger Speed, X max } & 30 & 30 \\ \text { Auger sec F/sec B } & 20 / 10 & 20 / 10\end{array}$

"Witrogen flow was countercurrent to 6 mesh coal feed in Rin 7C.

\section{PITT 8}

$\mathrm{KOH} / \mathrm{NaOH}=0$

Caustic/Coal $=0$

$\begin{array}{lr}\text { Run } & 4 \text { A } \\ \text { Temp, C } & 410 \\ \text { Res Time, hr } & 2.0 \\ \text { Kiln RPM } & 1 \\ \text { Auger Speed, \& max } & 30 \\ \text { Auger sec F/sec B } & 20 / 10\end{array}$

PITT 8

$\mathrm{KOH} / \mathrm{NaOH}=0$

Caustic/Coal $=1$

$\begin{array}{lrr}\text { Run } & 6 A 9 & 6 C 1 \\ \text { Temp, C } & 427 & 410 \\ \text { Res Time, hr } & 2.0 & 2.0 \\ \text { Kiln RPM } & 1 & 1 \\ \text { Auger Speed, \& max } & 30 & 30 \\ \text { Auger sec F/sec B } & 20 / 10 & 20 / 10\end{array}$

PITT 8

$\mathrm{KOH} / \mathrm{NaOH}=0$

Caustic/Coal $=1.5$

$\begin{array}{lrrrrr}\text { Run } & 6 B 1 & 601 & 8 C & 80 & 8 E \\ \text { Temp, C } & 427 & 410 & 427 & 442 & 412 \\ \text { Res Time, hr } & 2.0 & 2.0 & 2.1 & 2.1 & 2.1 \\ \text { Kiln RPM } & 1 & 1 & 0.8 & 0.8 & 0.8 \\ \text { Auger Speed, \% max } & 30 & 30 & 30 & 30 & 30 \\ \text { Auger sec F/sec B } & 20 ; 10 & 20 / 10 & 20 / 10 & 20 / 10 & 20 / 10\end{array}$

- $\mathrm{Nitrogen}$ flow was countercurrent to 6 mesh coal feed in Runs $8 \mathrm{C}, 80$ and $8 E$. 
TABLE 2-1. TEST MATRIX: VARIABLE-BY-VARIABLE (CONTINUED)

PITT 8

$\mathrm{KOH} / \mathrm{NaOH}=0$

Caustic/Coal $=2$

$\begin{array}{lrrrrrrr}\text { Run } & 4 C 1 & 4 C 2 & 4 C 3 & 4 C 4 & 4 C 5 & 4 C 6 & 4 C 7 \\ \text { Temp, C } & 413 & 416 & 420 & 423 & 430 & 435 & 449 \\ \text { Res Time, hr } & 2.0 & 2.0 & 2.0 & 1.5 * & 1.0 * & 1.0 * & 1.0 * \\ \text { Kiln RPM } & 1 & 1 & 1 & 1 & 1 & 1 & 1 \\ \text { Auger Speed, X max } & 30 & 30 & 30 & 30 & 30 & 30 & 30 \\ \text { Auger sec F/sec B } & 20 / 10 & 20 / 10 & 20 / 10 & 20 / 10 & 20 / 10 & 20 / 10 & 20 / 10\end{array}$

- Residence time based on heated zones only.

PITT 8

$\mathrm{KOH} / \mathrm{NaOH}=0$

Caustic/Coal $=2$

$\begin{array}{lrrrrrr}\text { Run } & 5 B 1 & 582 & 583 & 5 B 4 & 585 & 8 F \\ \text { Temp, C } & 413 & 420 & 423 & 430 & 427 & 412 \\ \text { Res Time, hr } & 2.0 & 2.0 & 1.5^{*} & 1.0 * & 2.0 & 2.1 \\ \text { Kiln RPM } & 1 & 1 & 1 & 1 & 1 & 0.8 \\ \text { Auger Speed, \% max } & 30 & 30 & 30 & 30 & 30 & 30 \\ \text { Auger sec F/sec B } & 20 / 10 & 20 / 10 & 20 / 10 & 20 / 10 & 20 / 10 & 20 / 10\end{array}$

- Residence time based on heated zones only.

Nitrogen flow was countercurrent to coal feed in Run BF.

PITT 8

$\mathrm{KOH} / \mathrm{NaOH}=\mathrm{O}$

Caustic/COal $=2.5$

$\begin{array}{lr}\text { Run } & 9 \mathrm{C} \\ \text { Temp, C } & 438 \\ \text { Res Time, hr } & 2.1 \\ \text { Kiln RPM } & 0.8 \\ \text { Auger Speed, X max } & 30 \\ \text { Auger sec F/sec B } & 20 / 10\end{array}$

- Mitrogen flow was countercurrent to coal feed in Run 9 .

KENT 9

$\mathrm{KOH} / \mathrm{NaOH}=1$

Caustic/Coal $=2$

$\begin{array}{lrr}\text { Run } & 20 & 2 E \\ \text { Temp, C } & 427 & 438 \\ \text { Res rime, hr } & 2.0 & 2.0 \\ \text { Kiln RPM } & 1 & 1 \\ \text { Auger Speed, X max } & 30 & 30 \\ \text { Auger sec F/sec B } & 20 / 10 & 20 / 10\end{array}$


TABLE 2-1. TEST MATRIX: VARIABLE-BY-VARIABLE (CONTINUED)

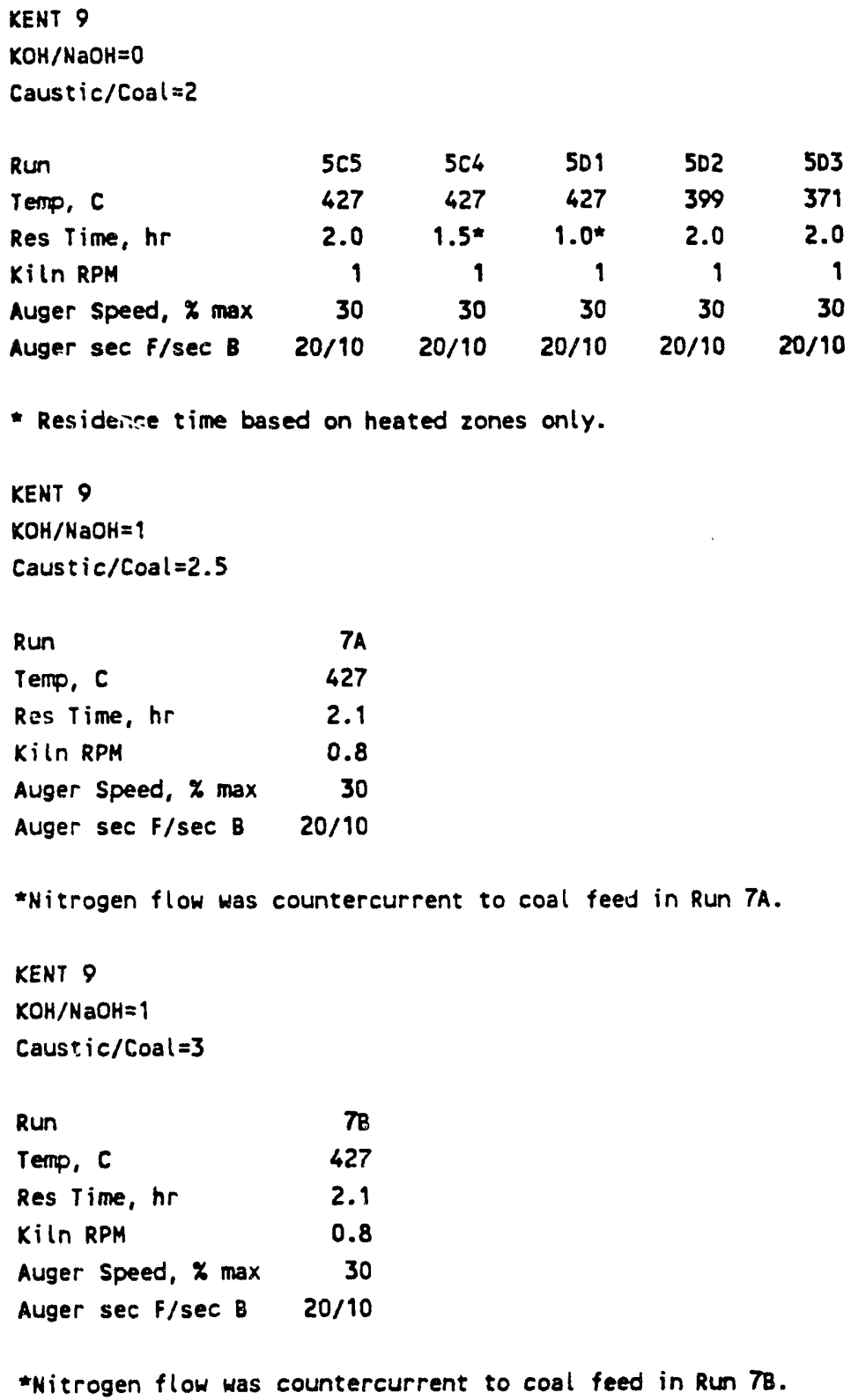




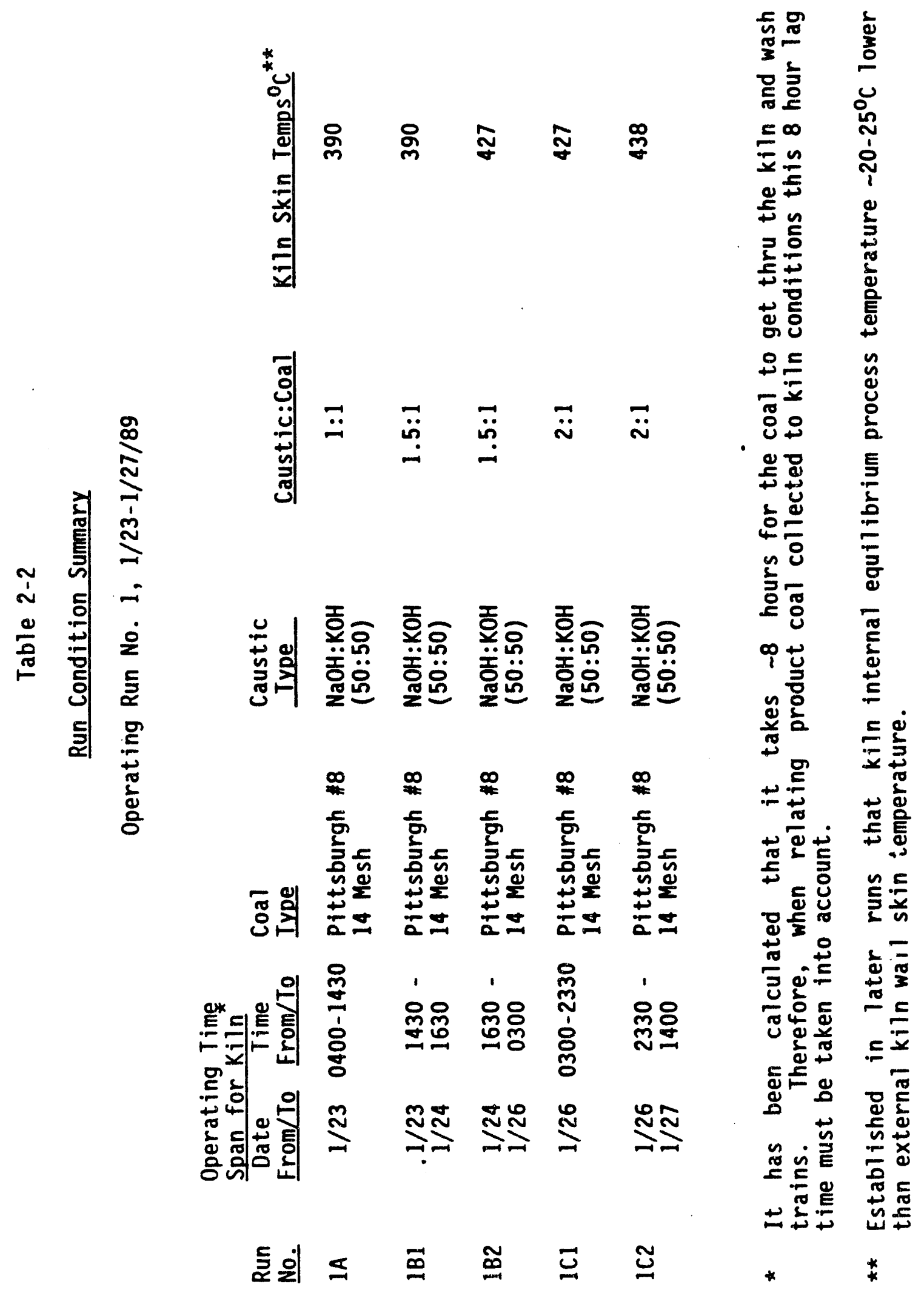




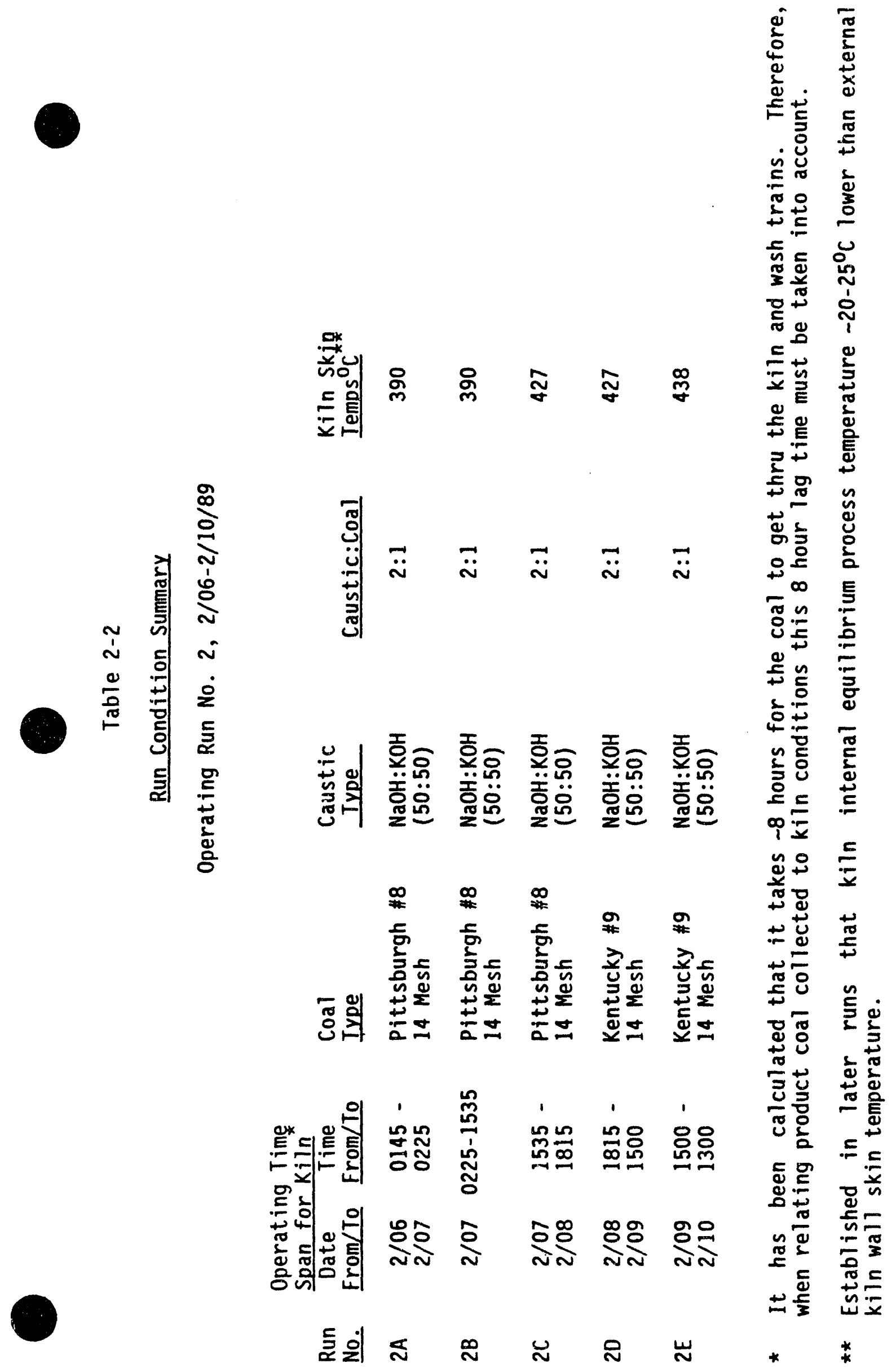




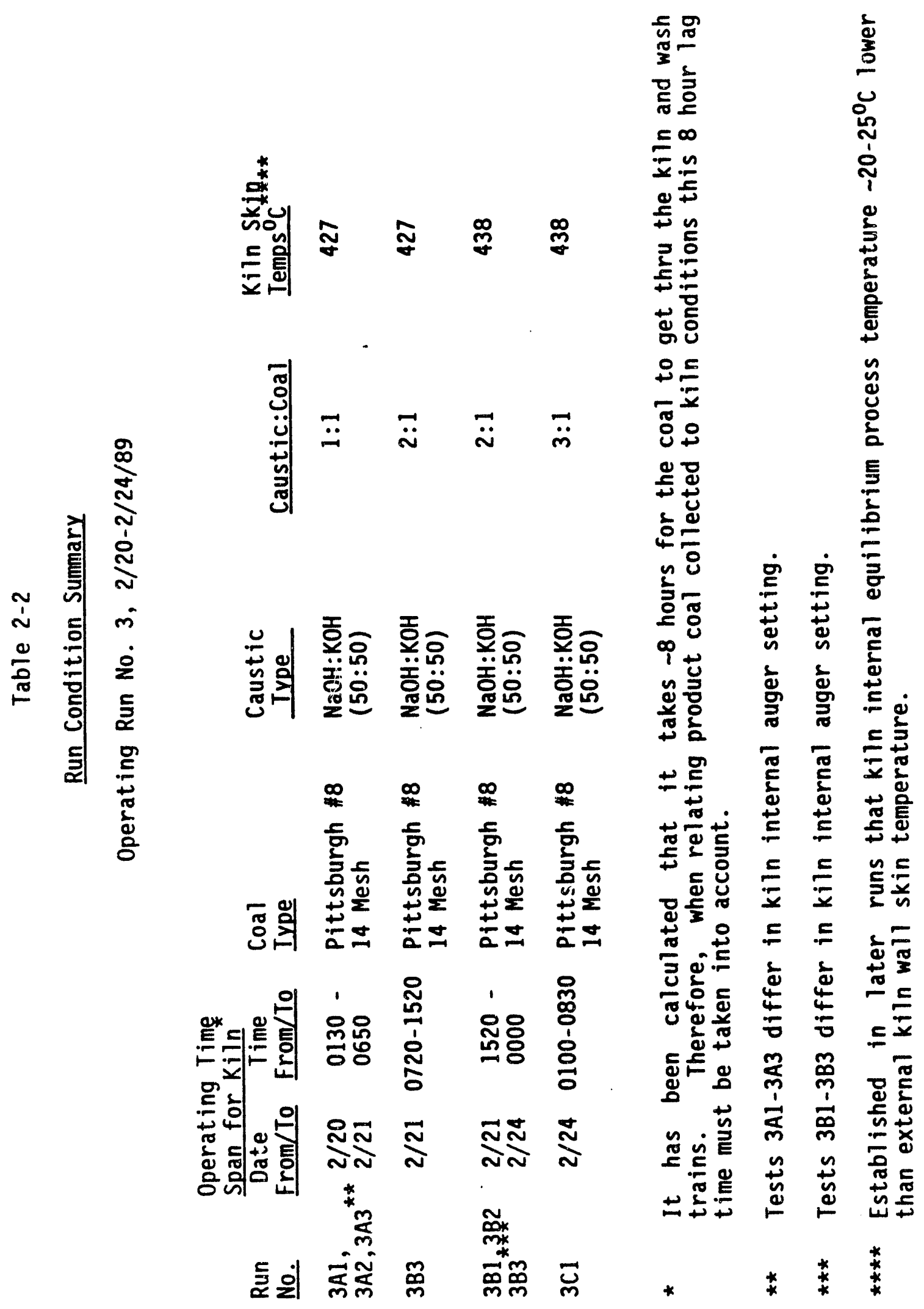




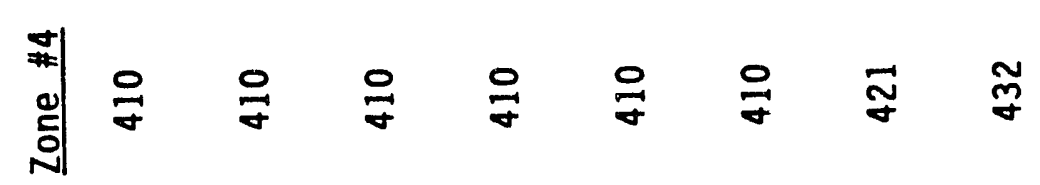

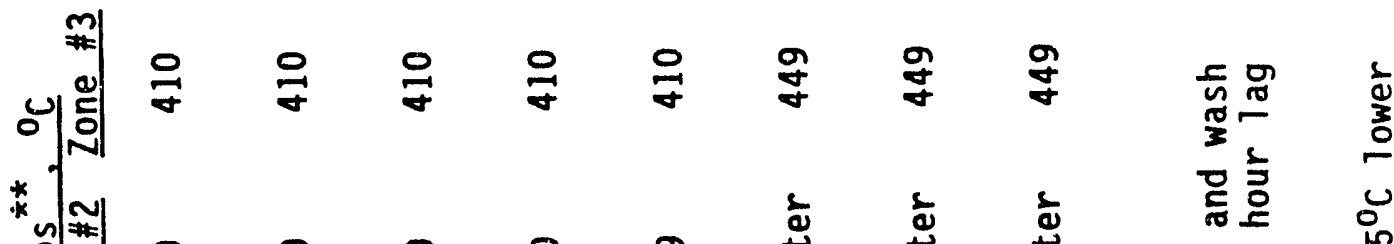

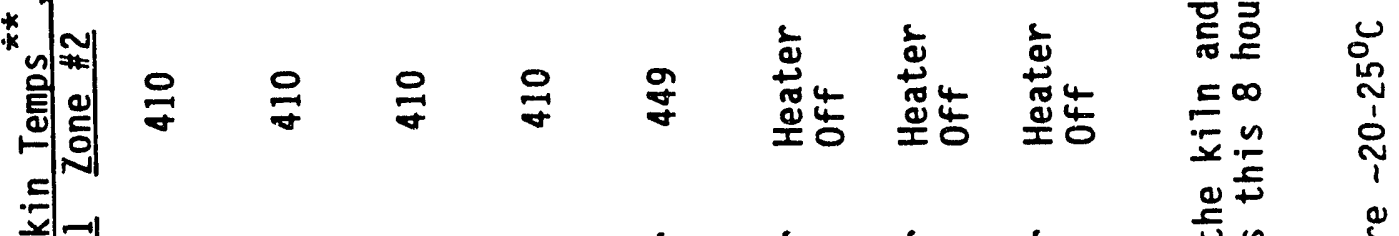

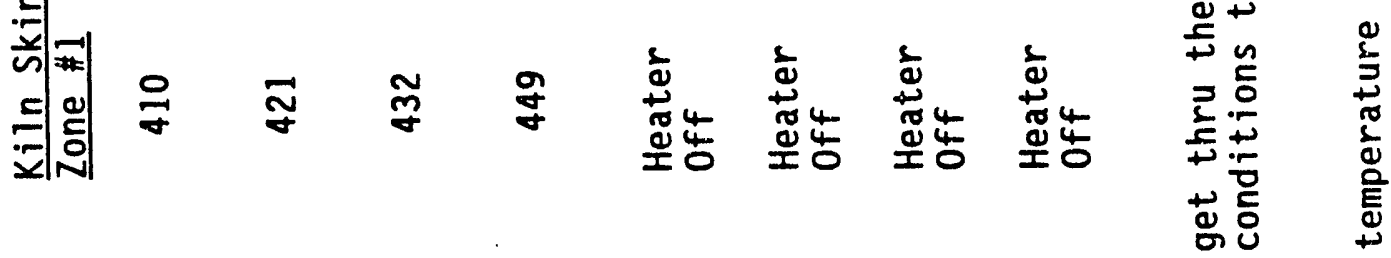
竞离

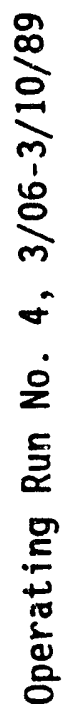

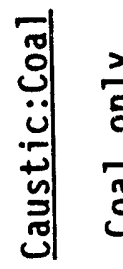

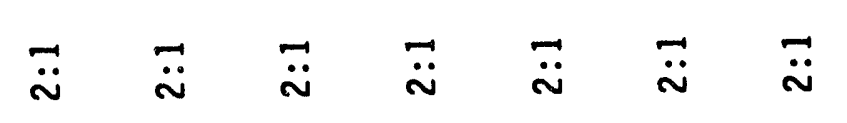
旅

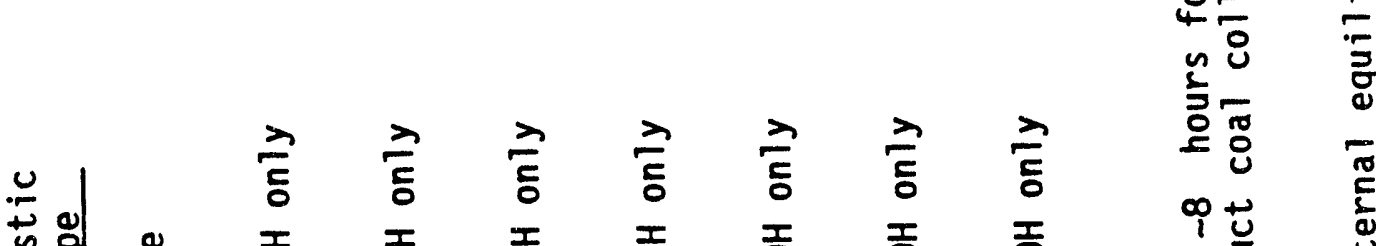

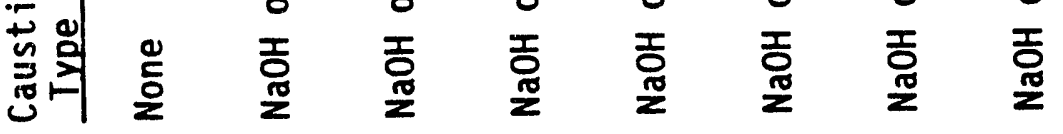

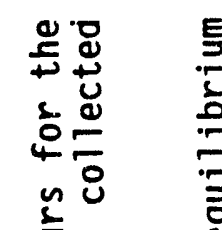

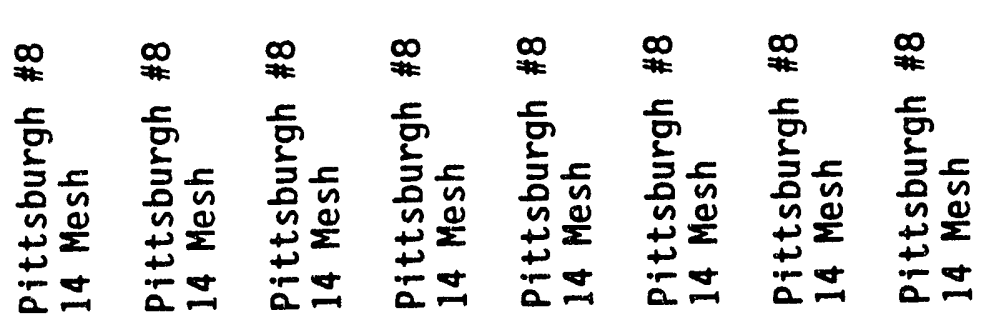

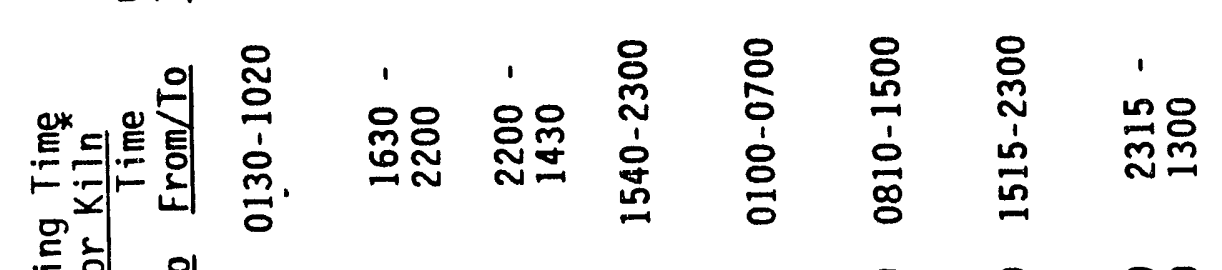

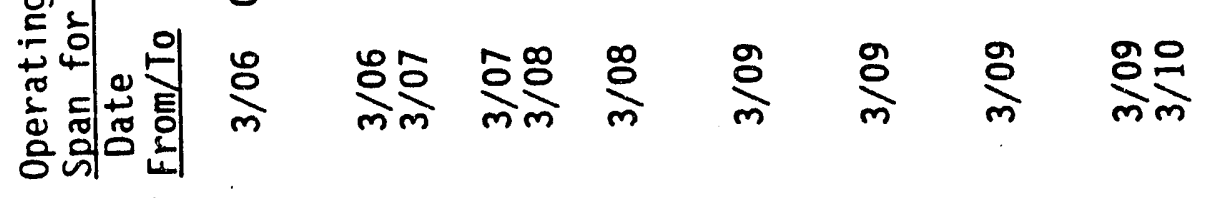

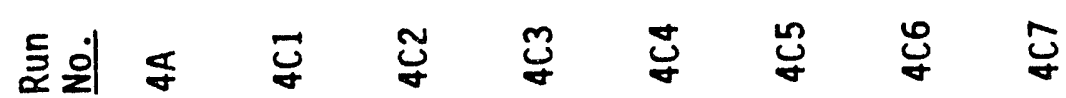




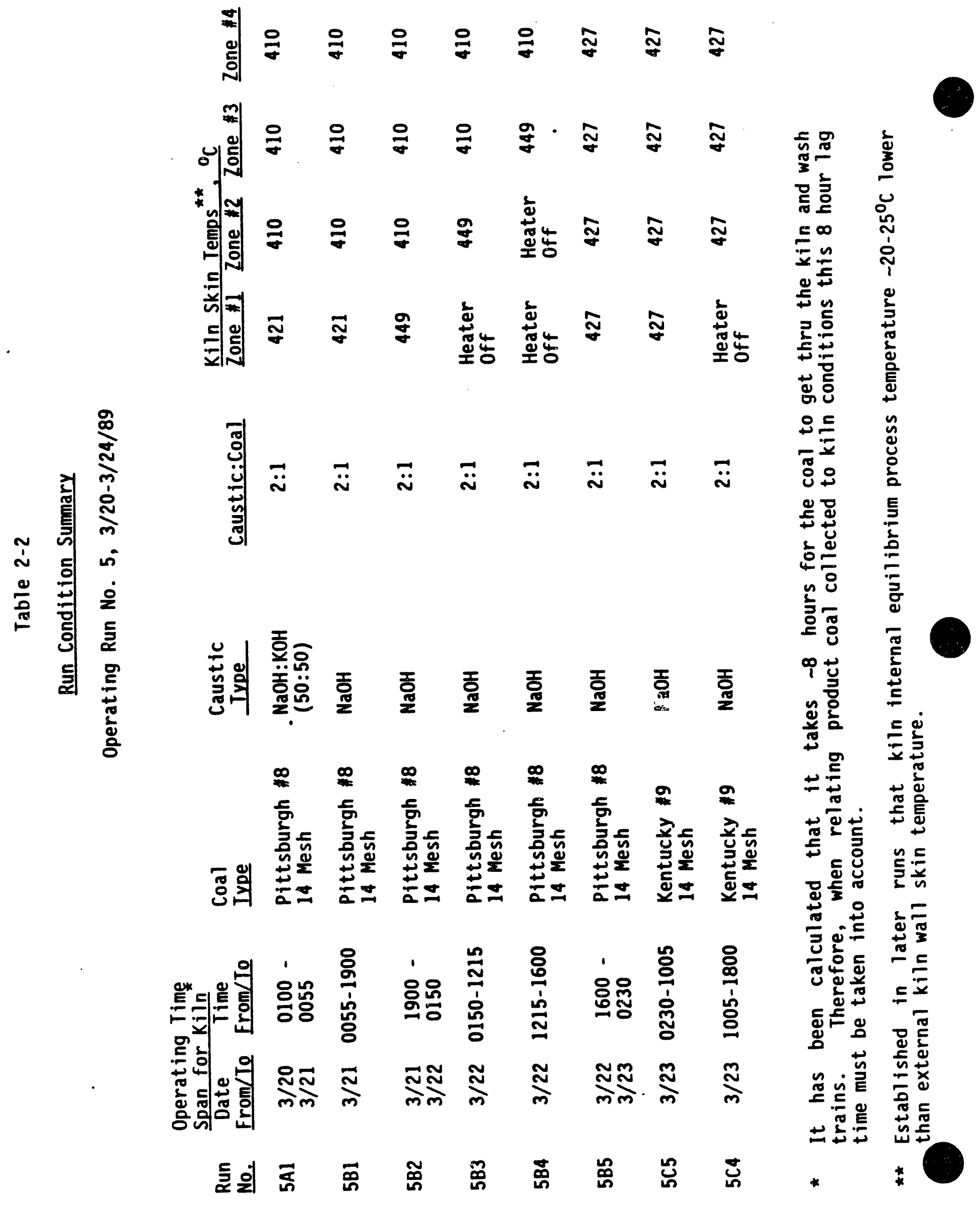




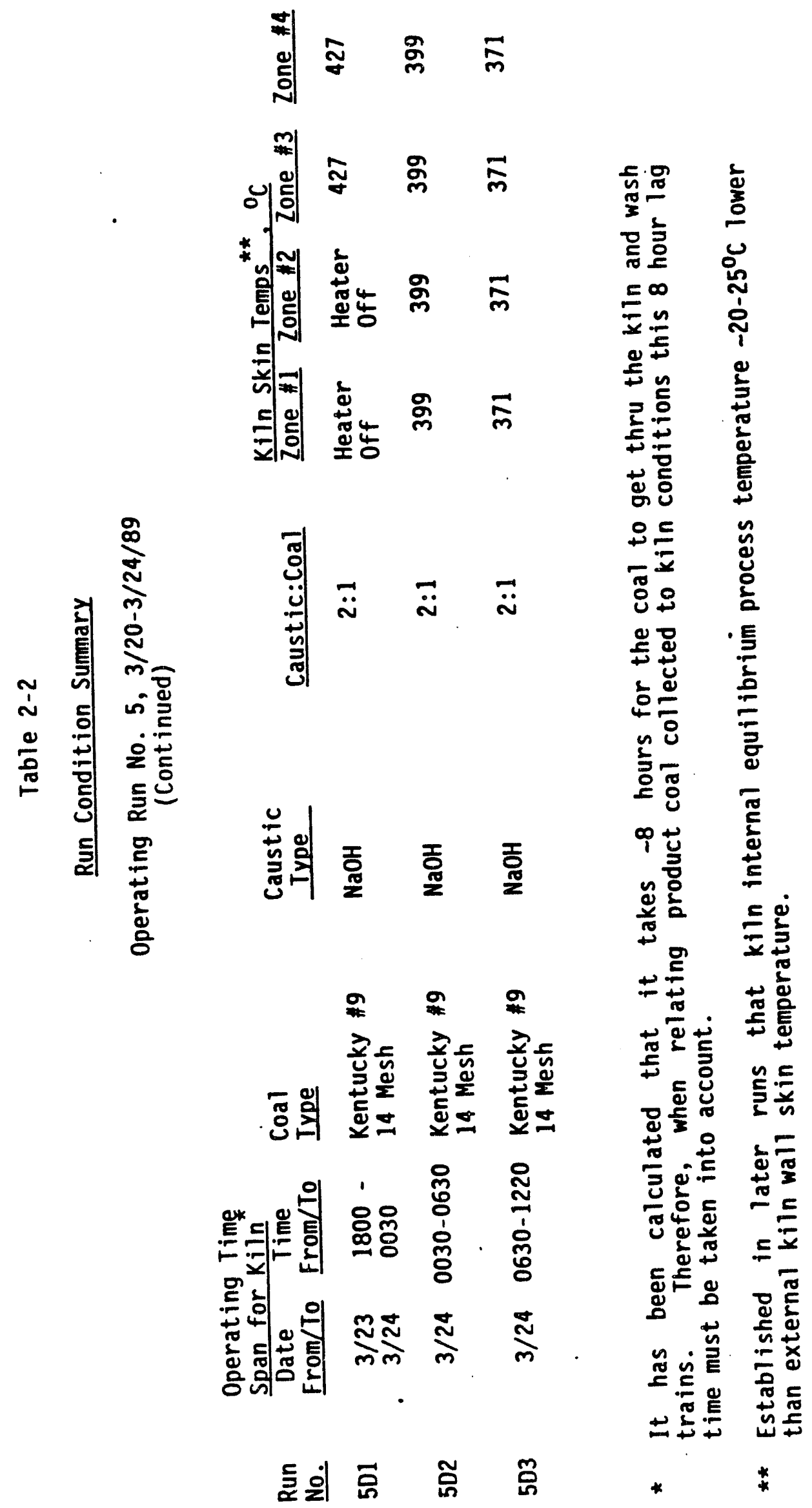




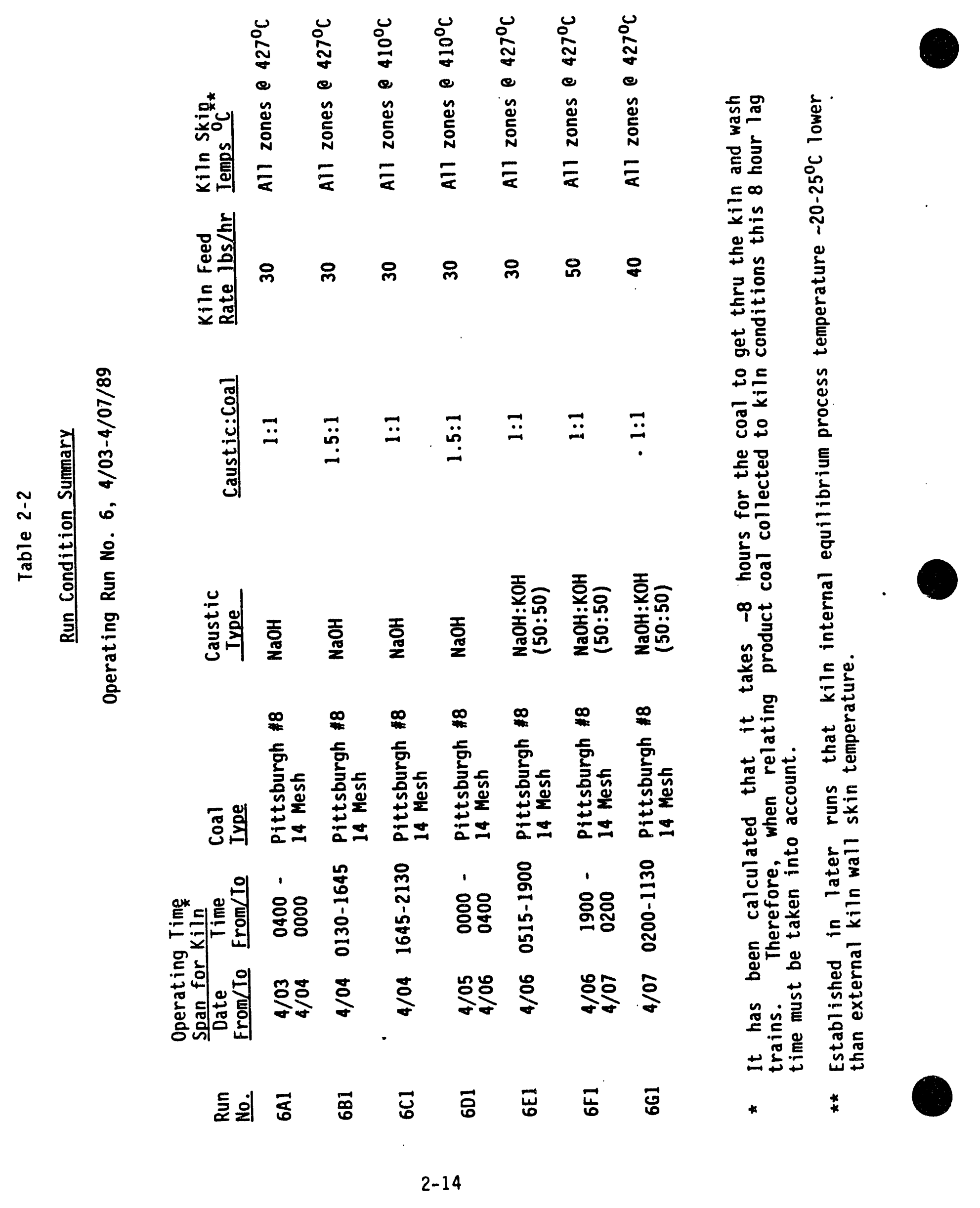



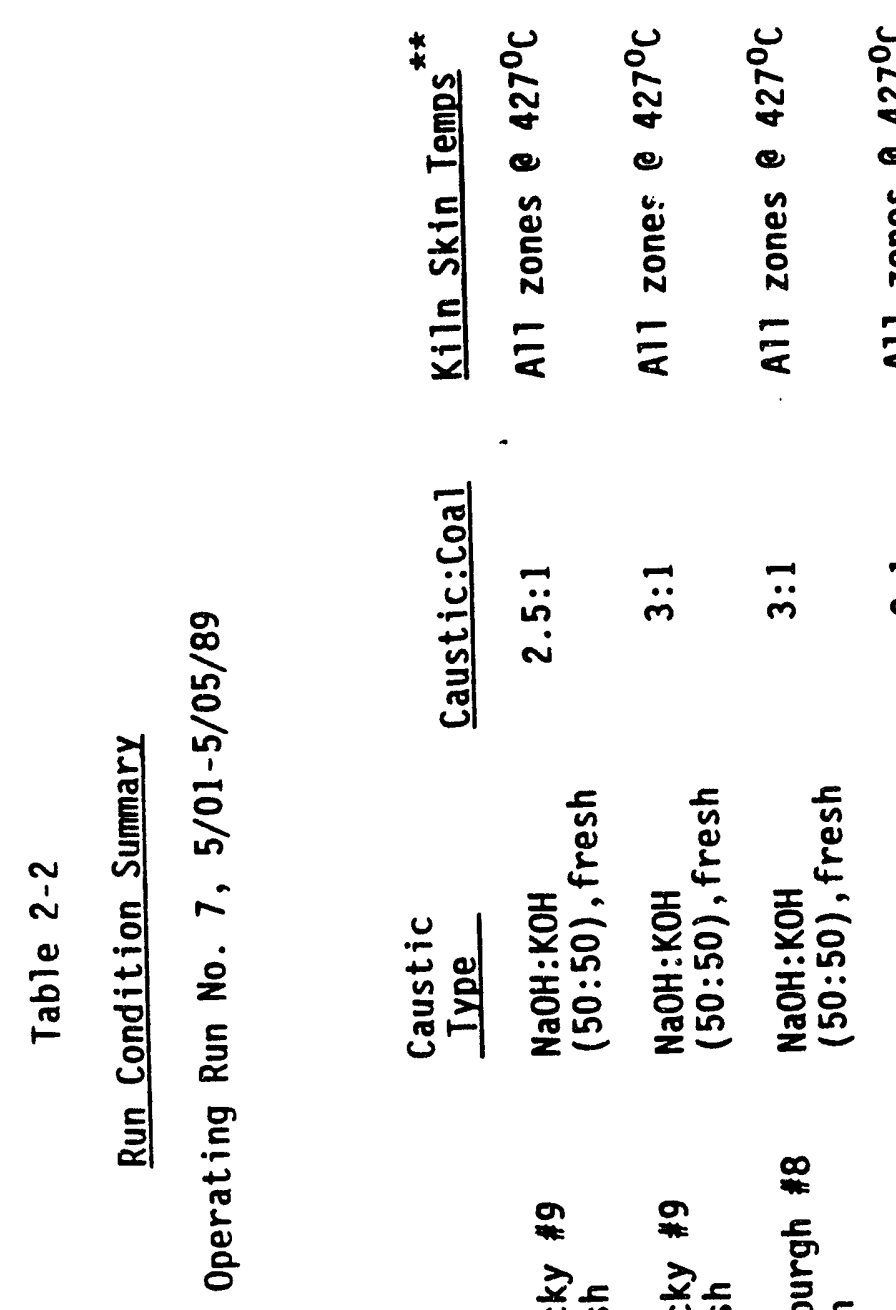

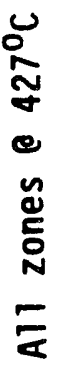

동

3

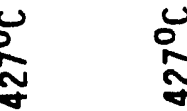

융 을

$=\infty$

$\frac{\pi}{\frac{1}{5}}$

$\geq 气$

$2 \pm$

岕 응

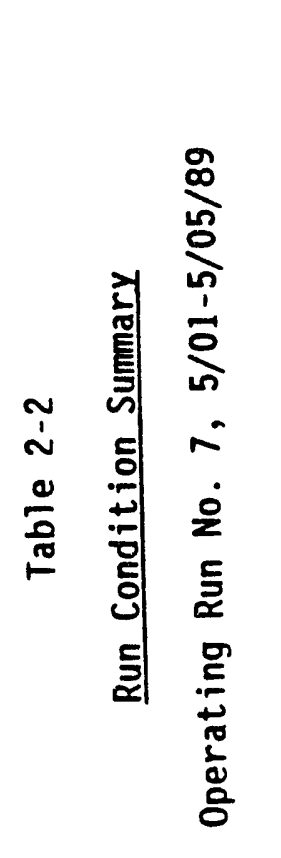

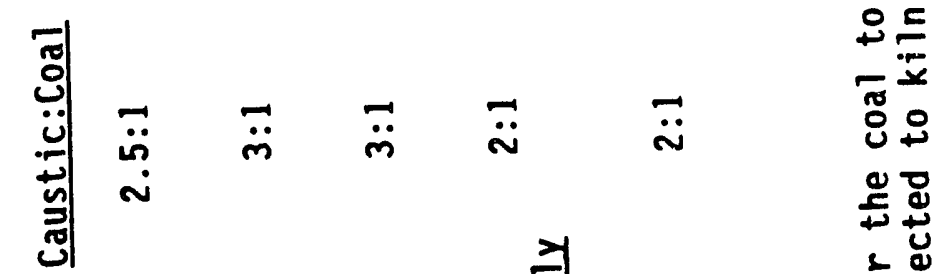

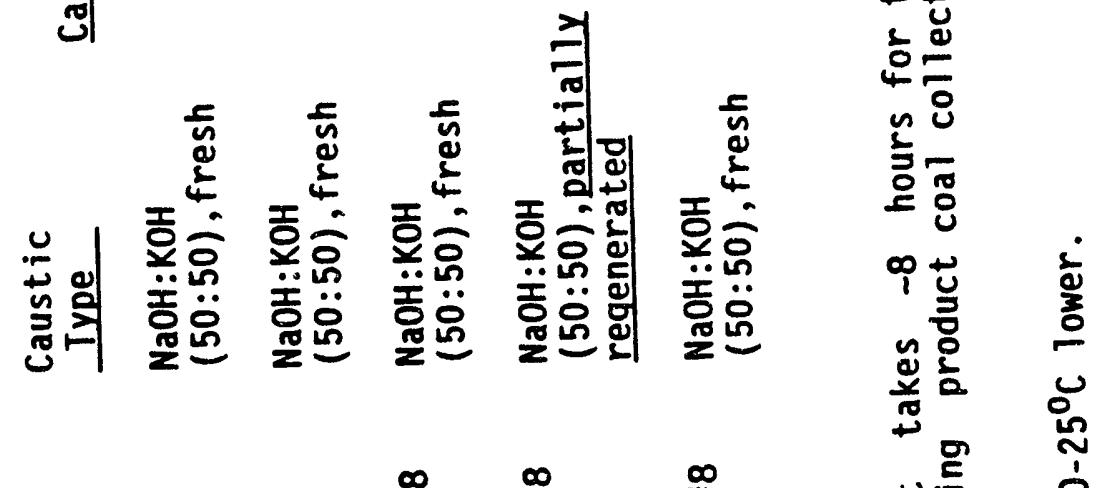

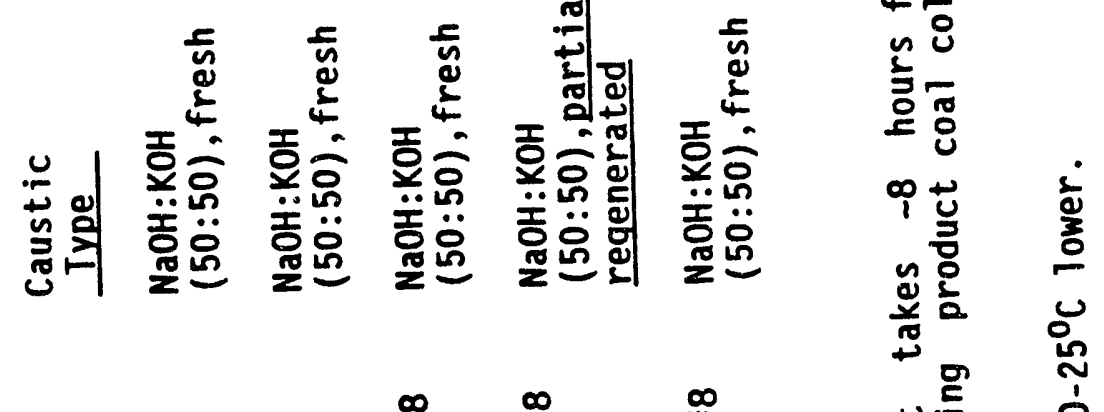

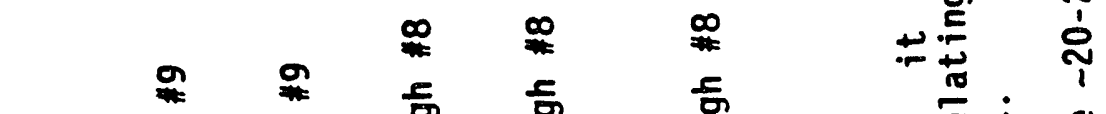

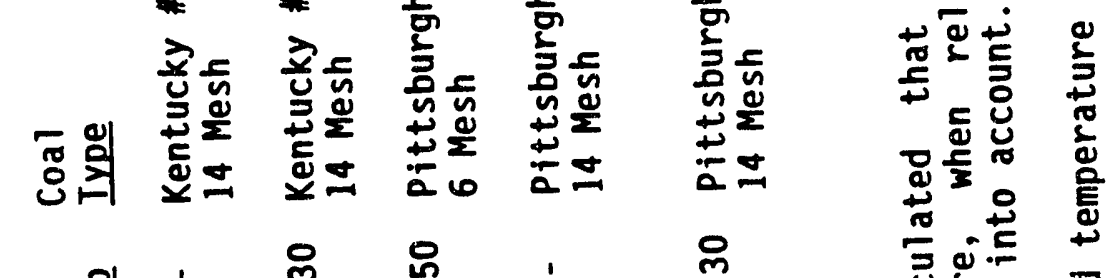

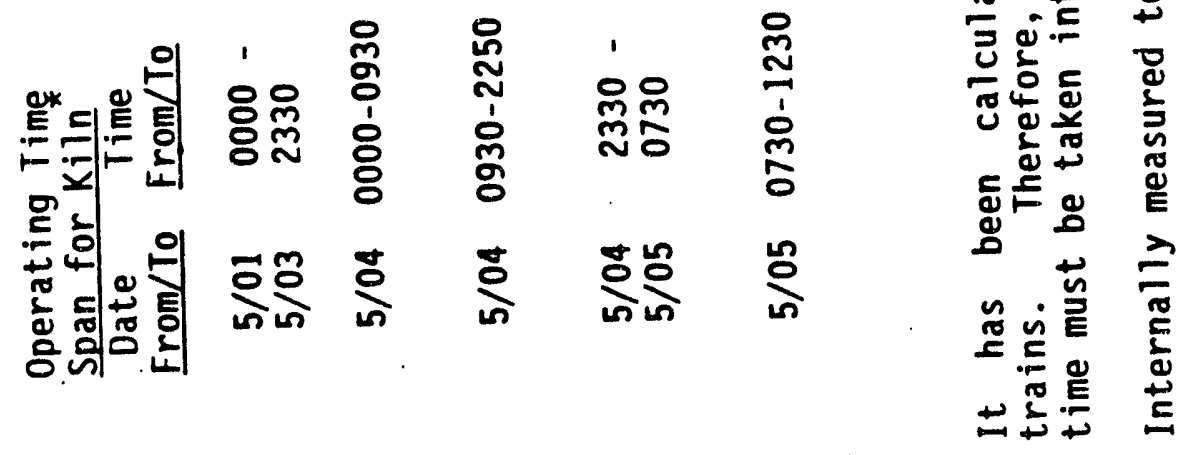

至这 

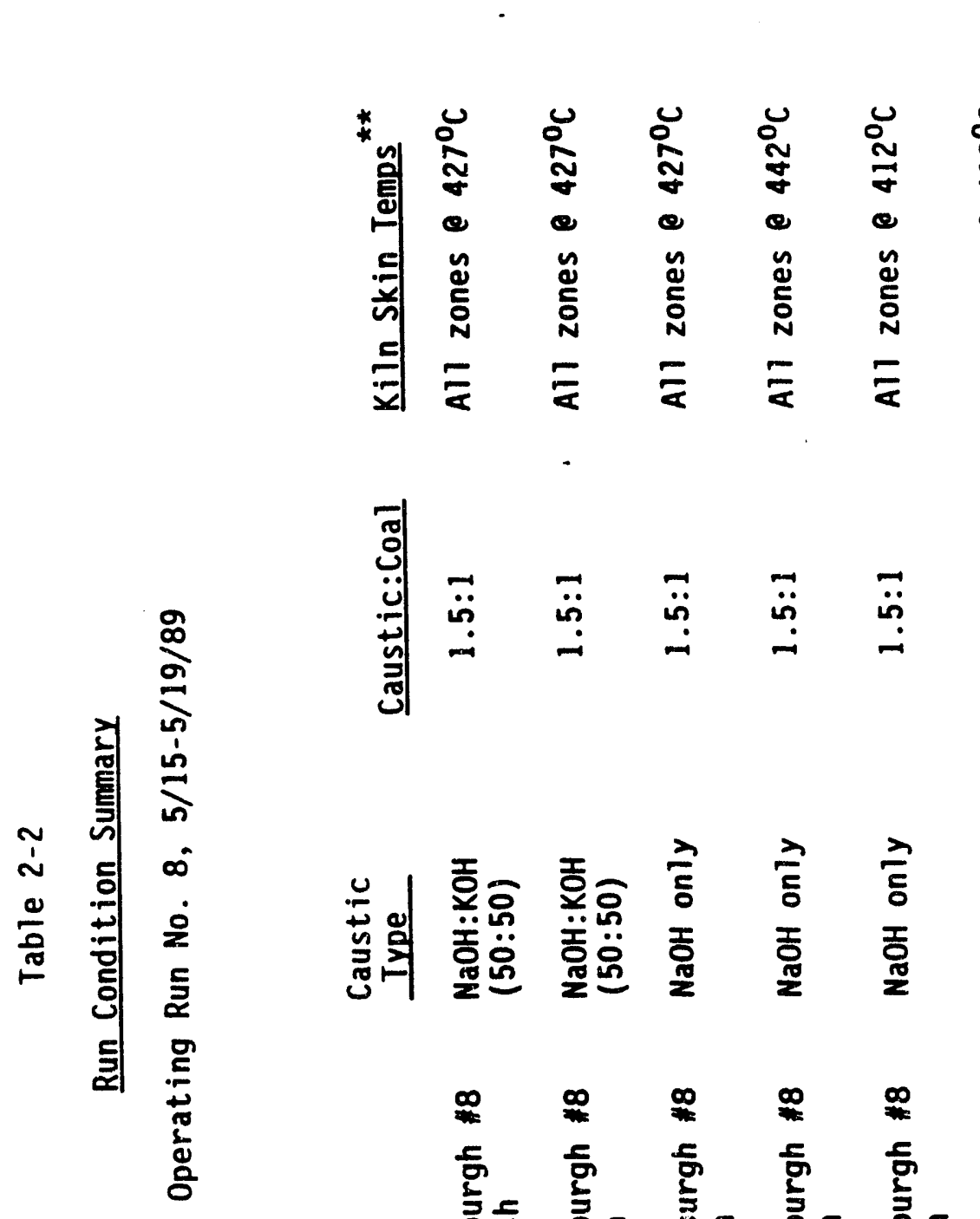

兵易

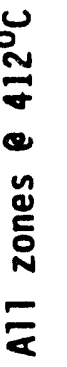

읂 올

$\leq \infty$

$=n$

흔

동

平

응

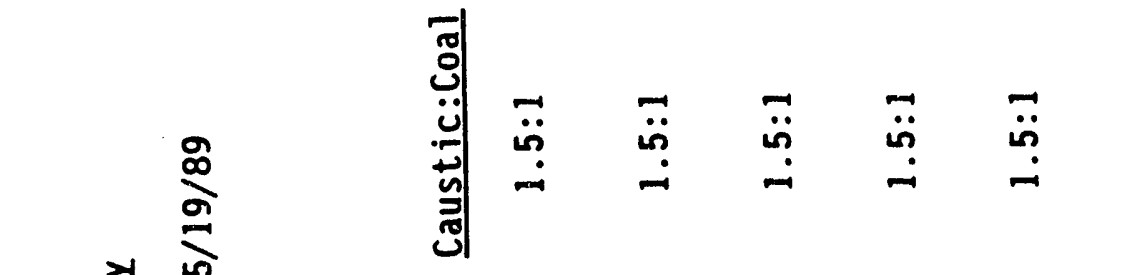

우드

훙요

옹

ț

文告

4 웅

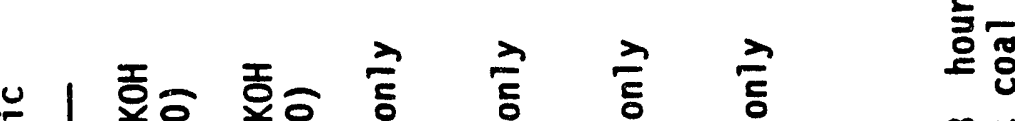

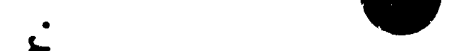

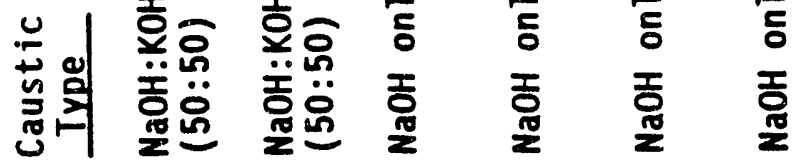

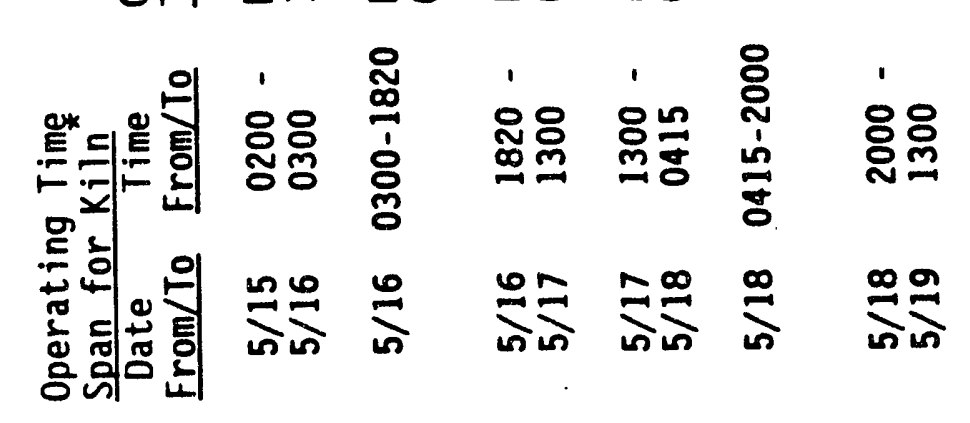

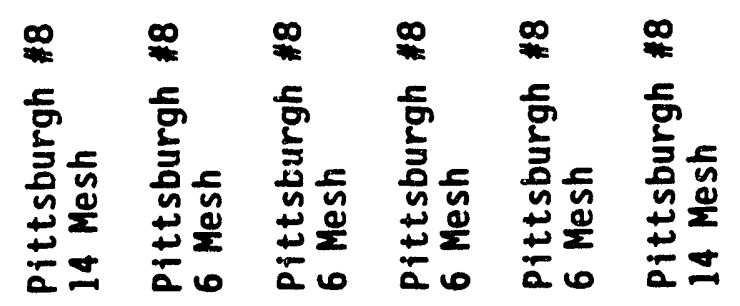

웅윰

范

$\frac{\dot{y}}{\underline{z}}$

눈

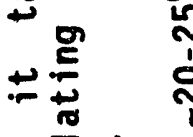

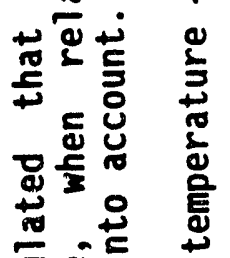

节

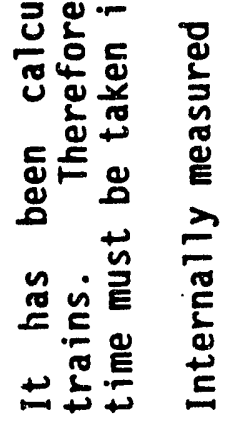

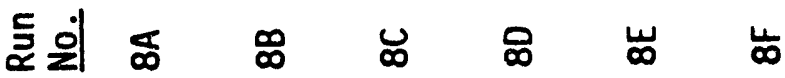




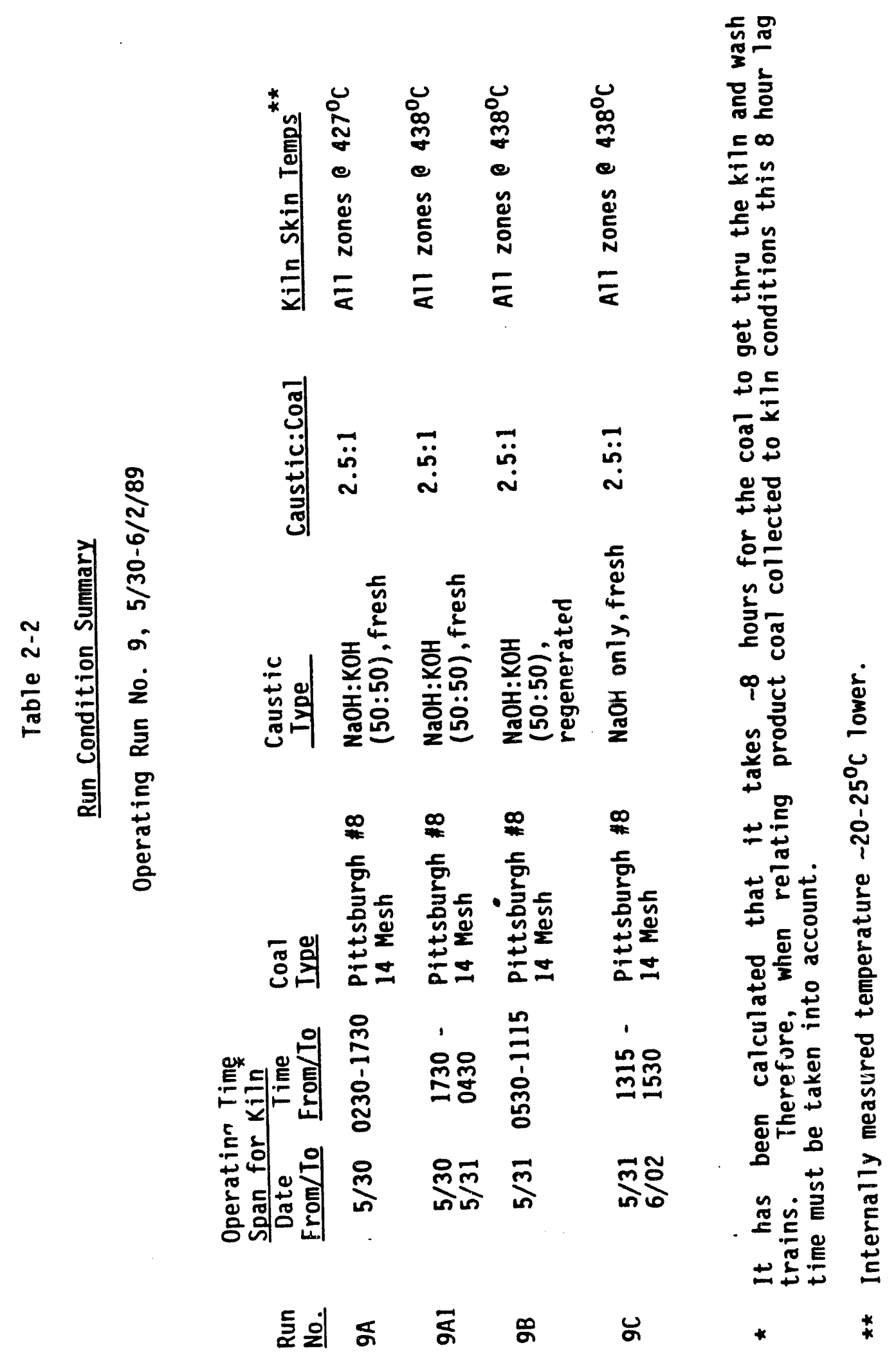


Figure 2-1. Sulfur and Ash Data for Kiln and Product Coal as a Function of Coal Exit Time 


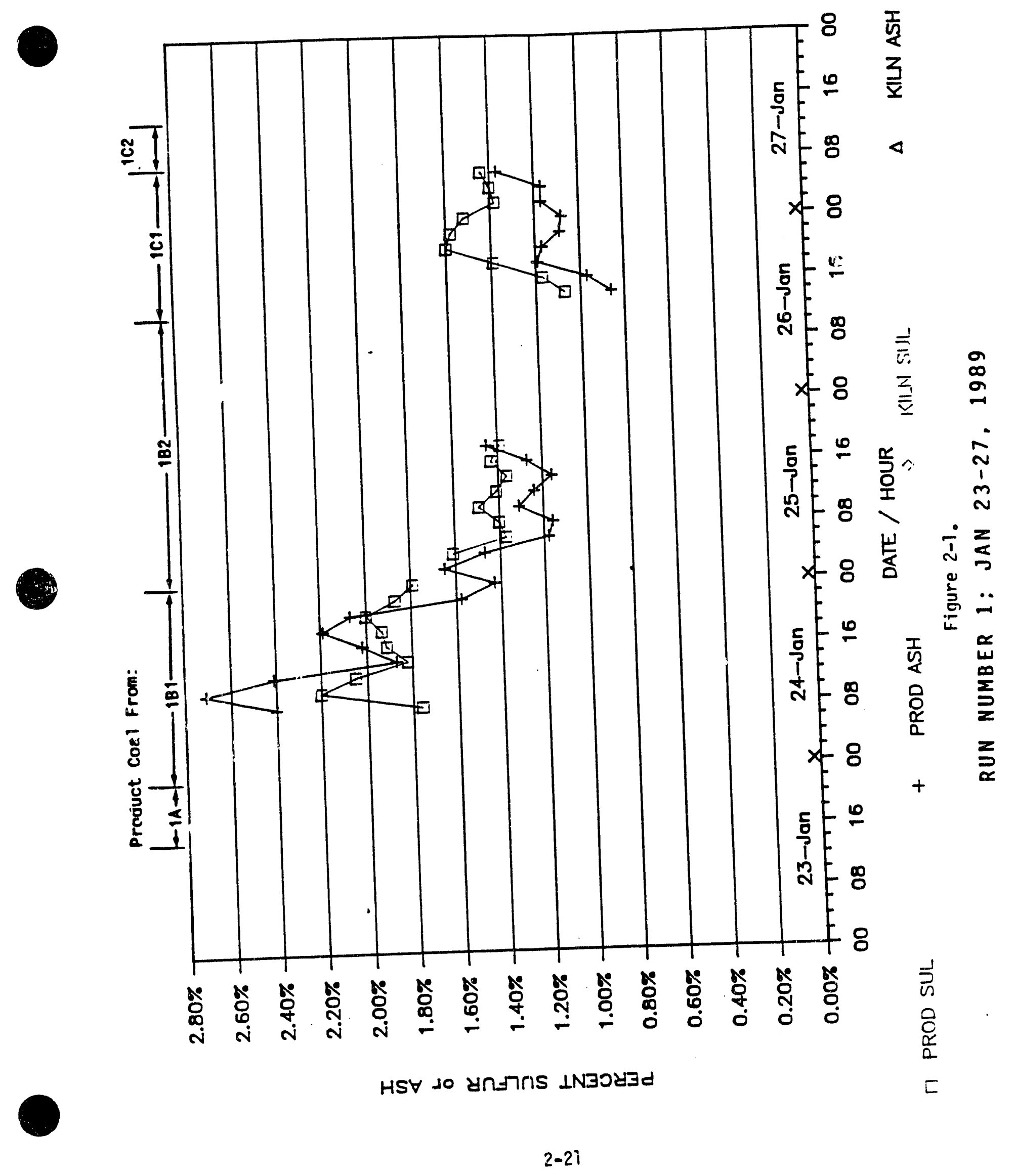




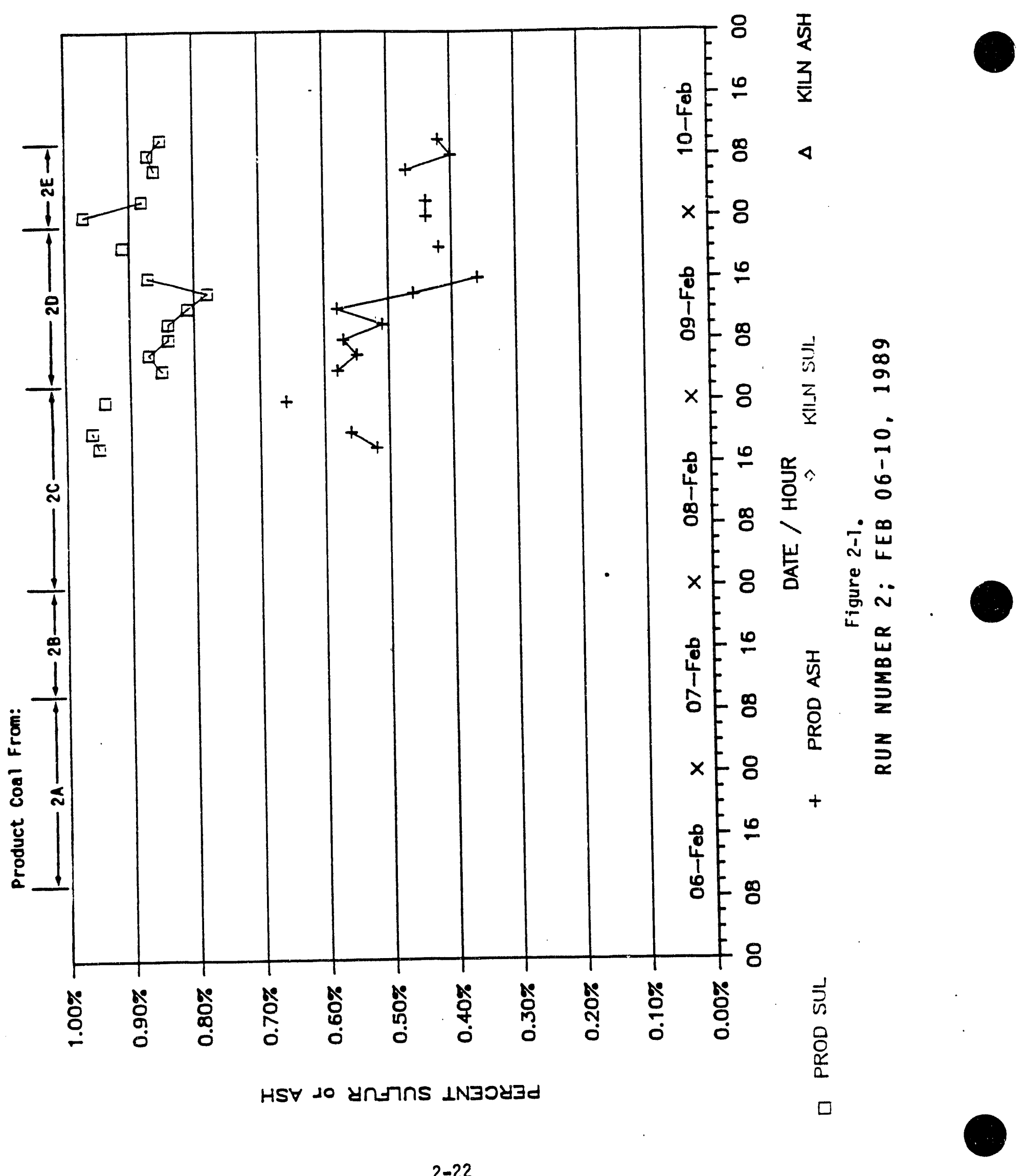




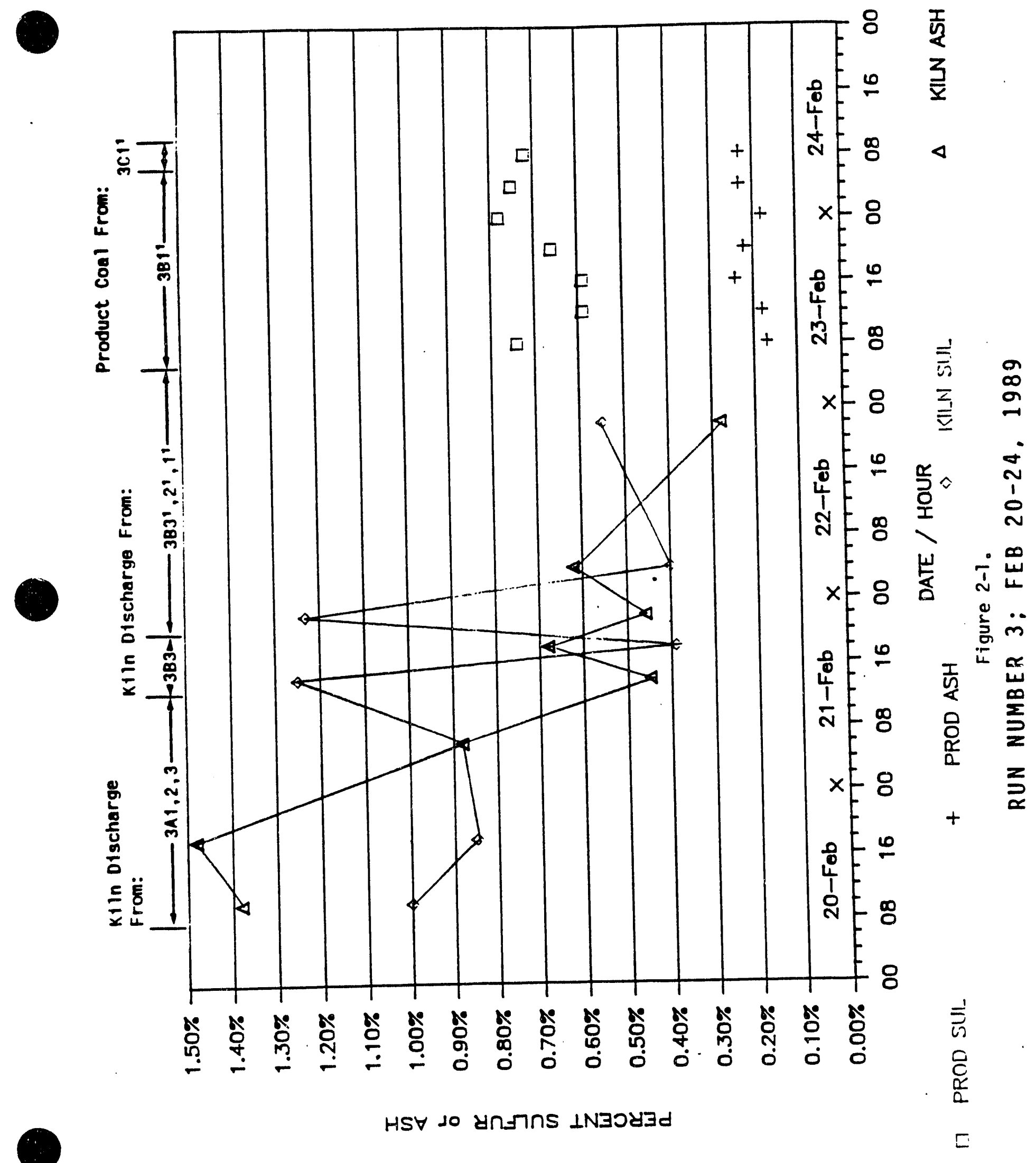




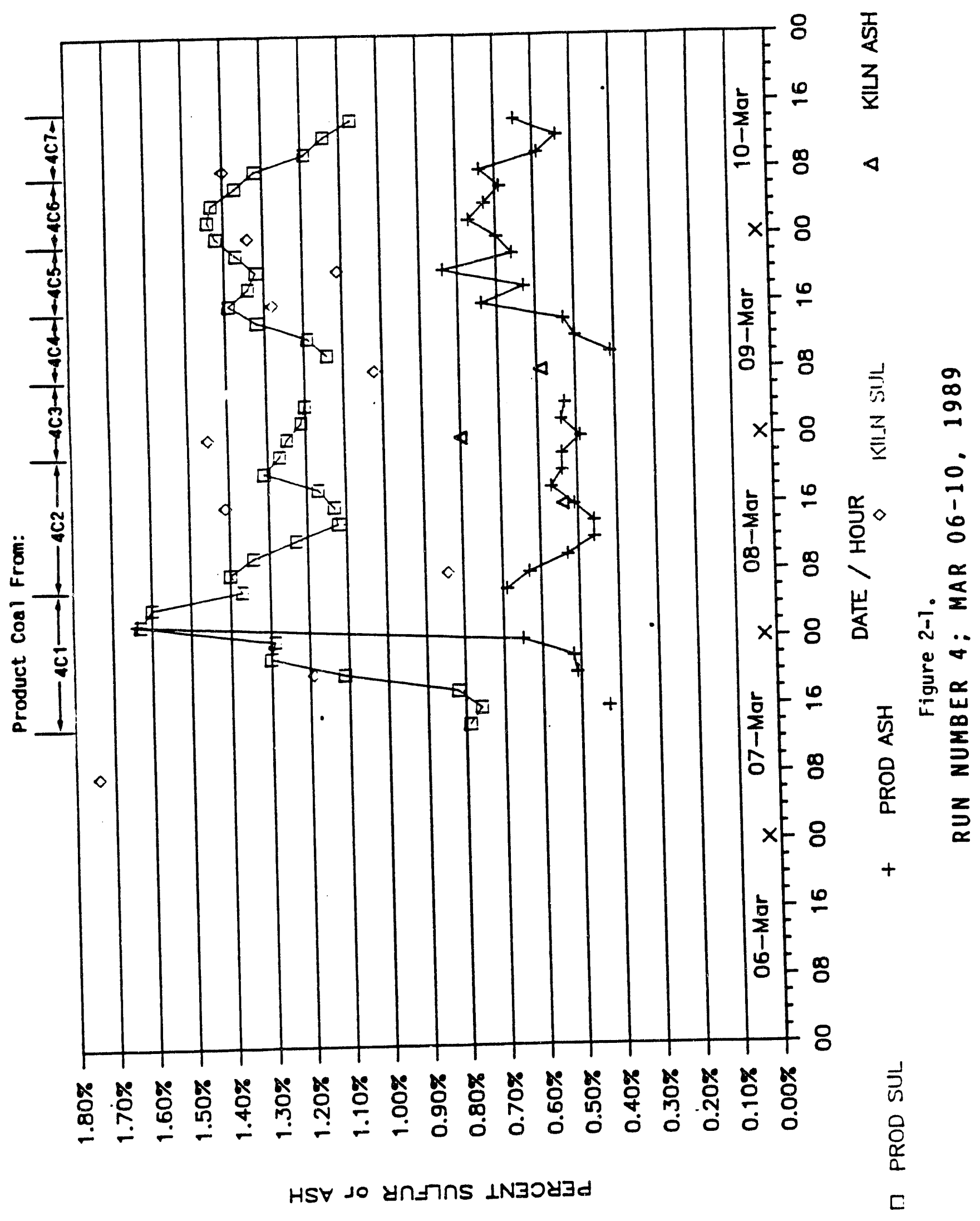




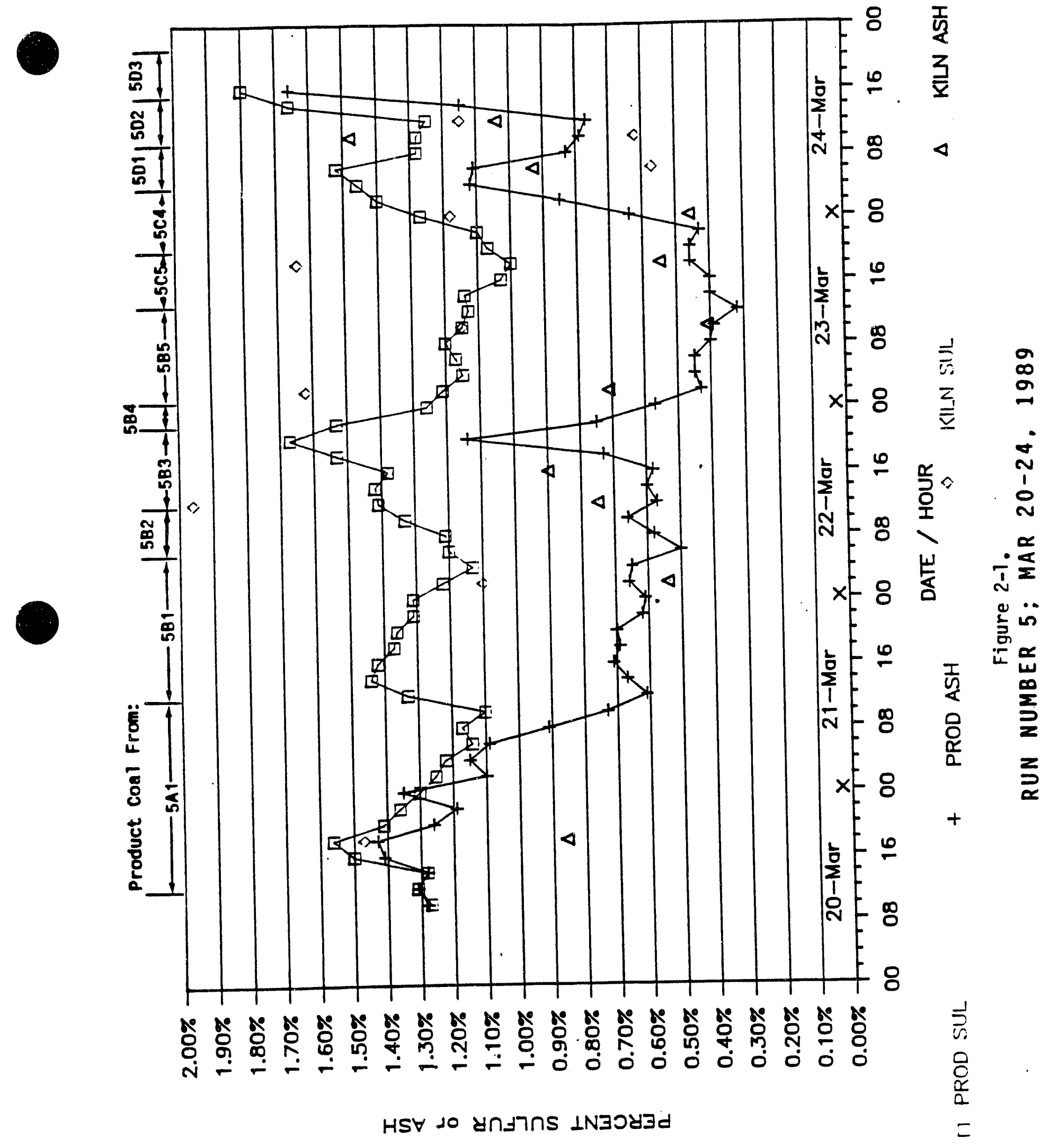




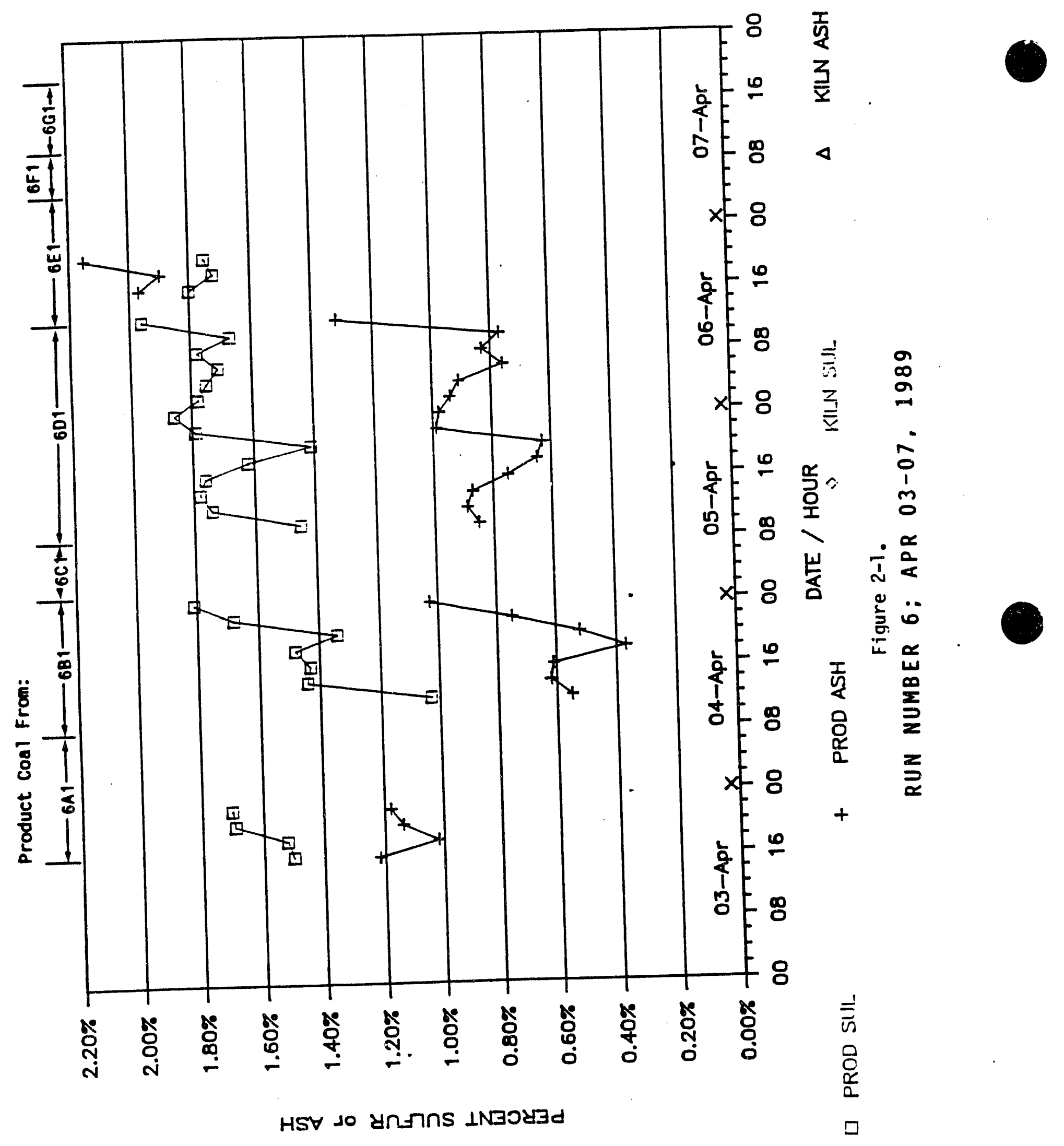




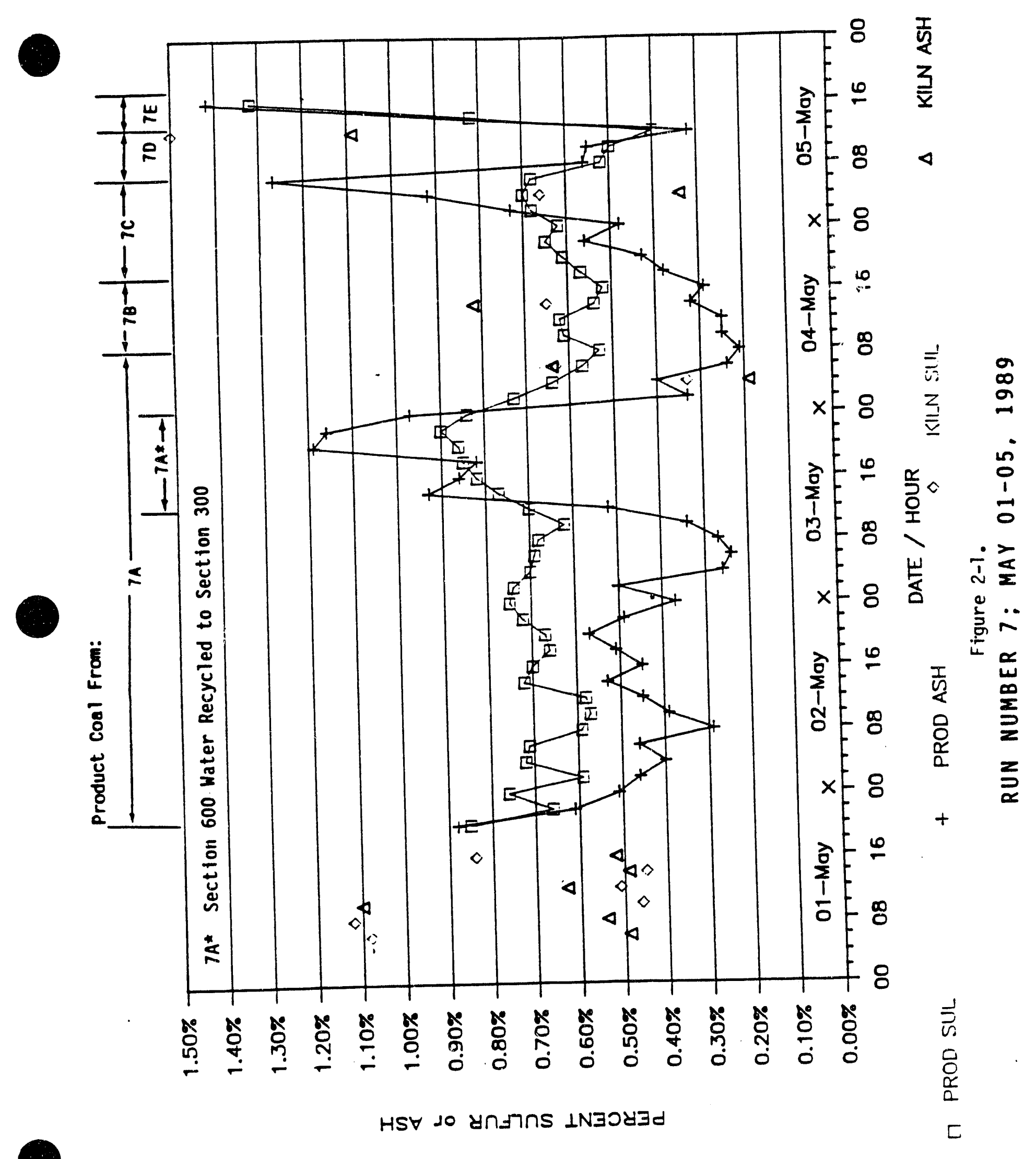




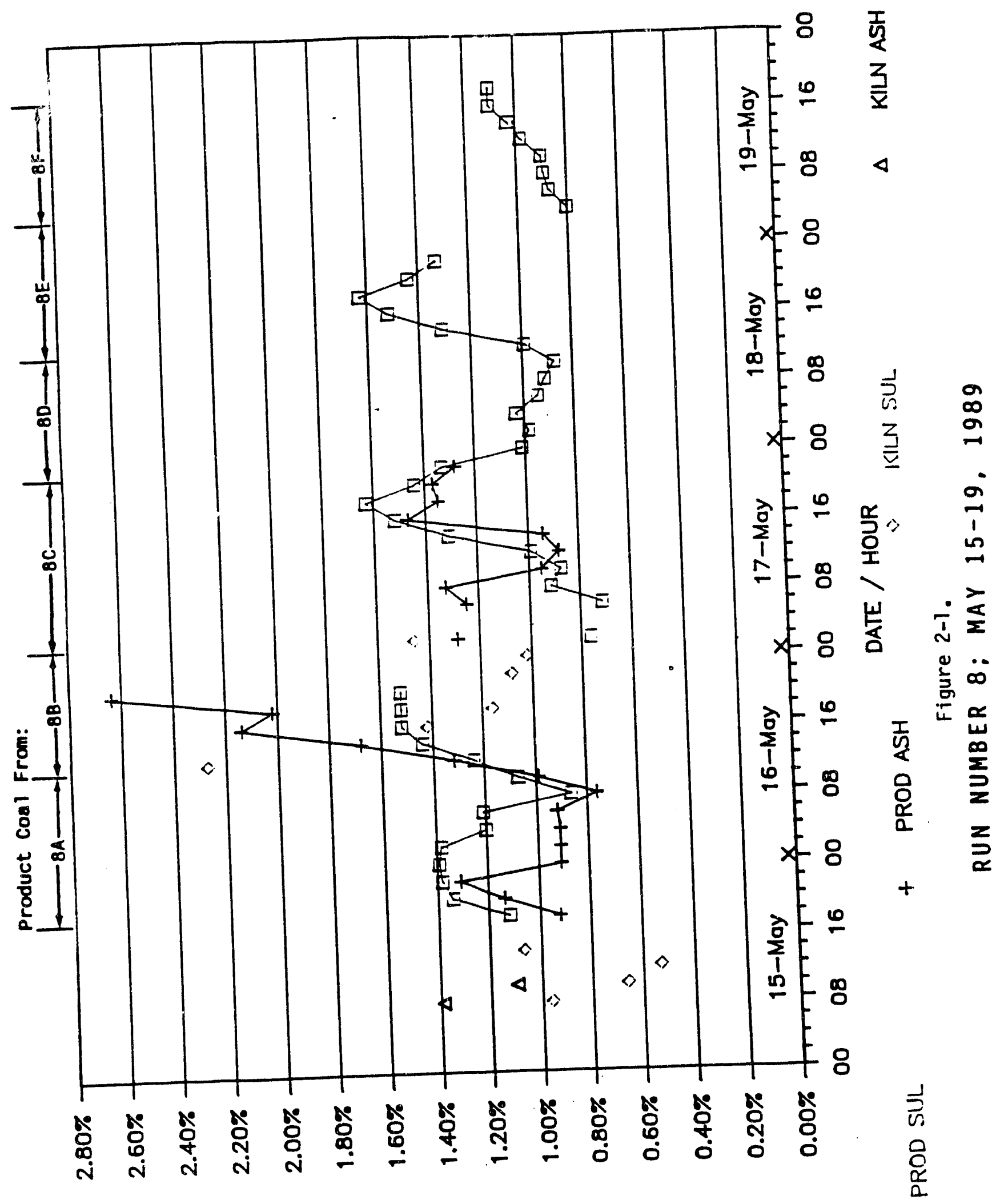

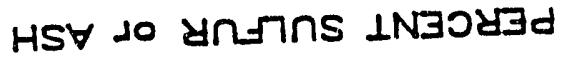




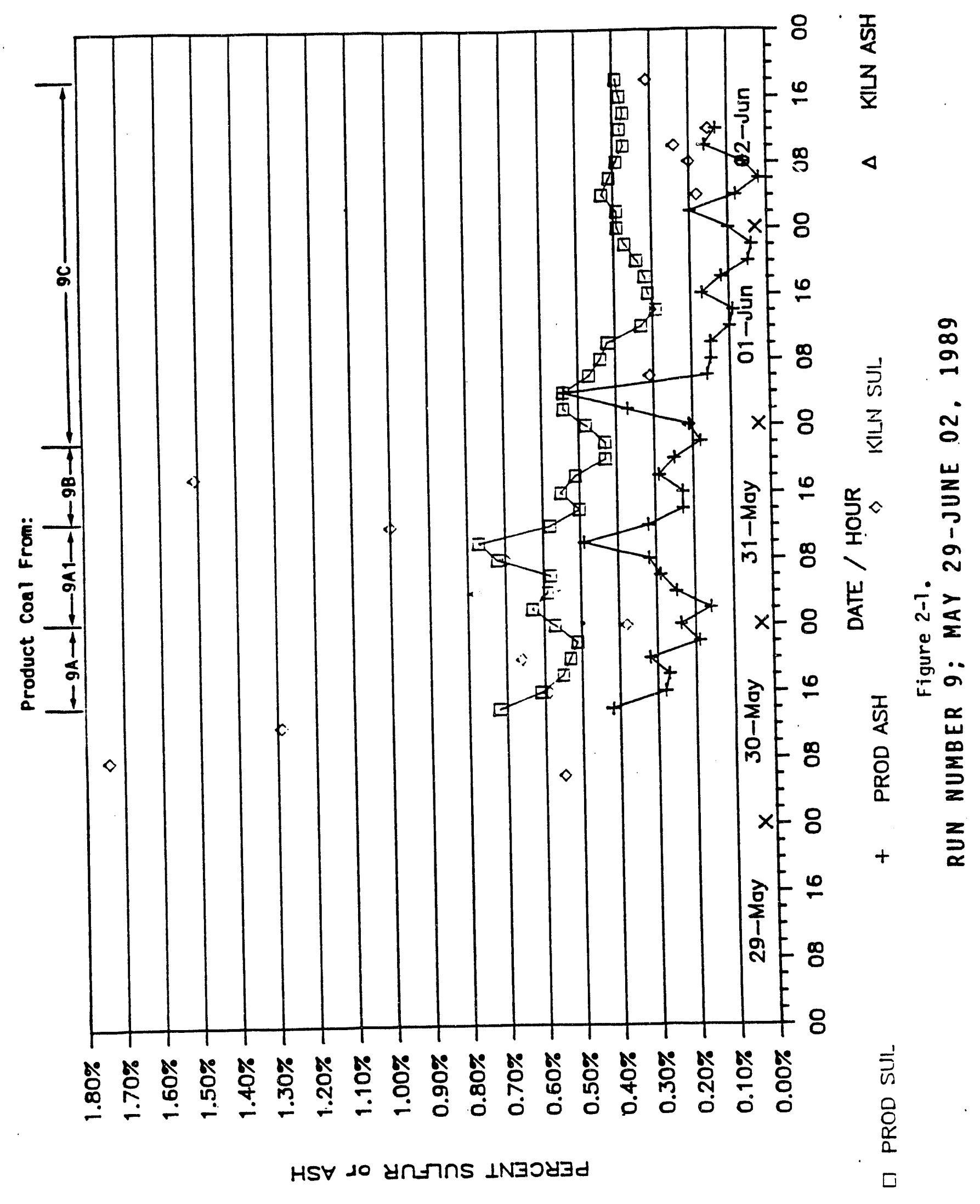


Figure 2-2. Volatiles, Sulfur and Heat Content Data for Product Coal as a Function of Coal Exit Time 


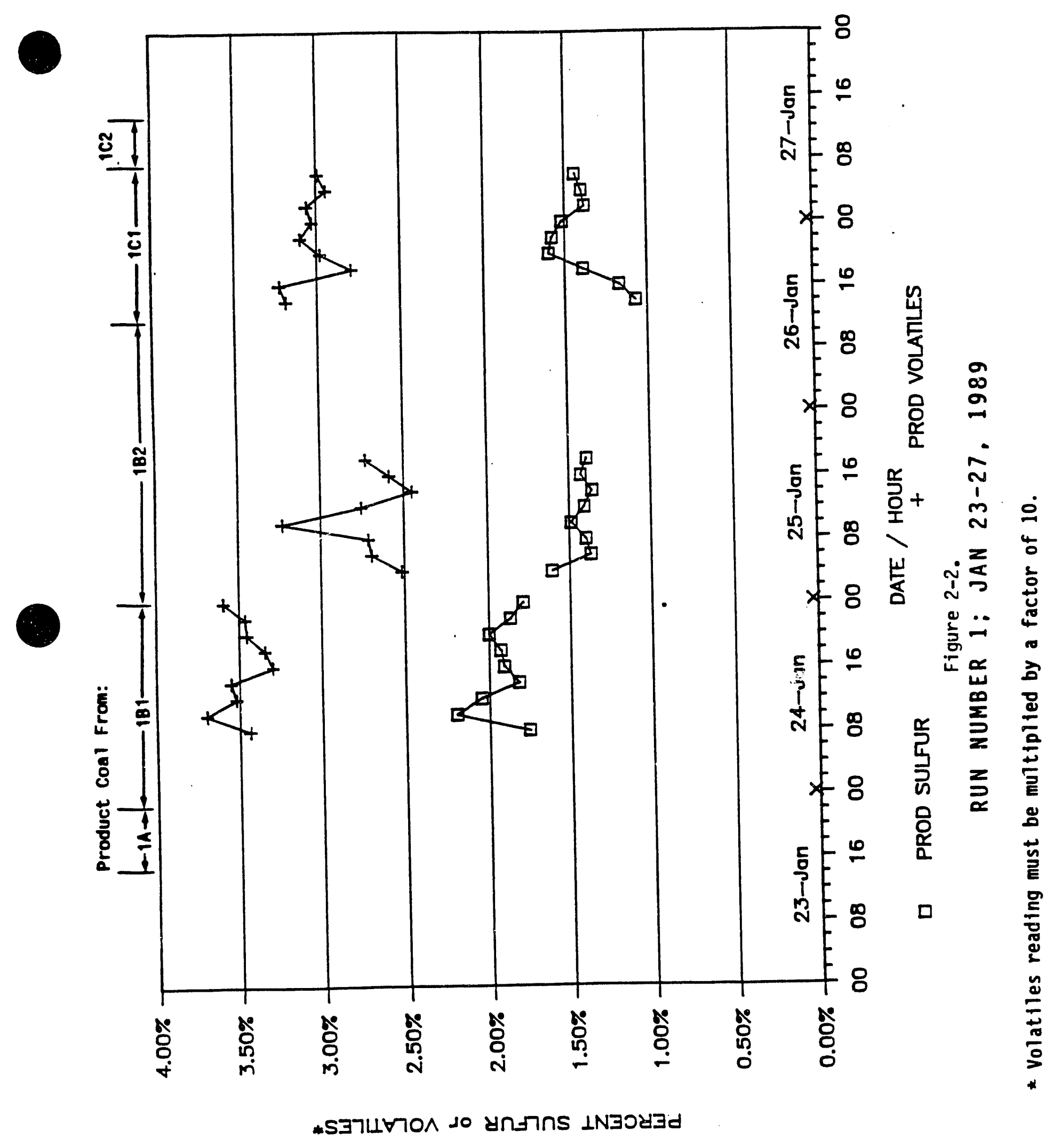




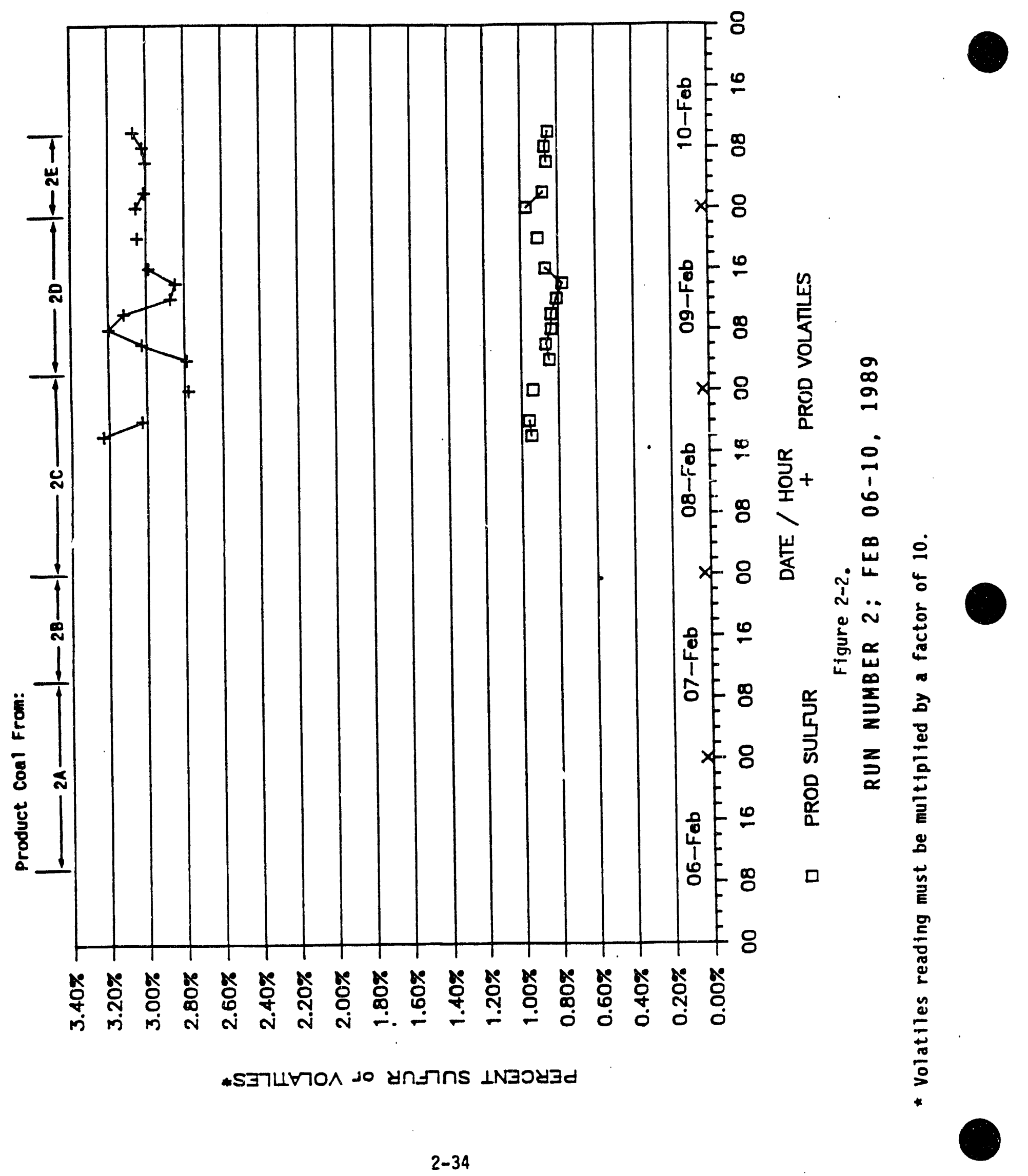




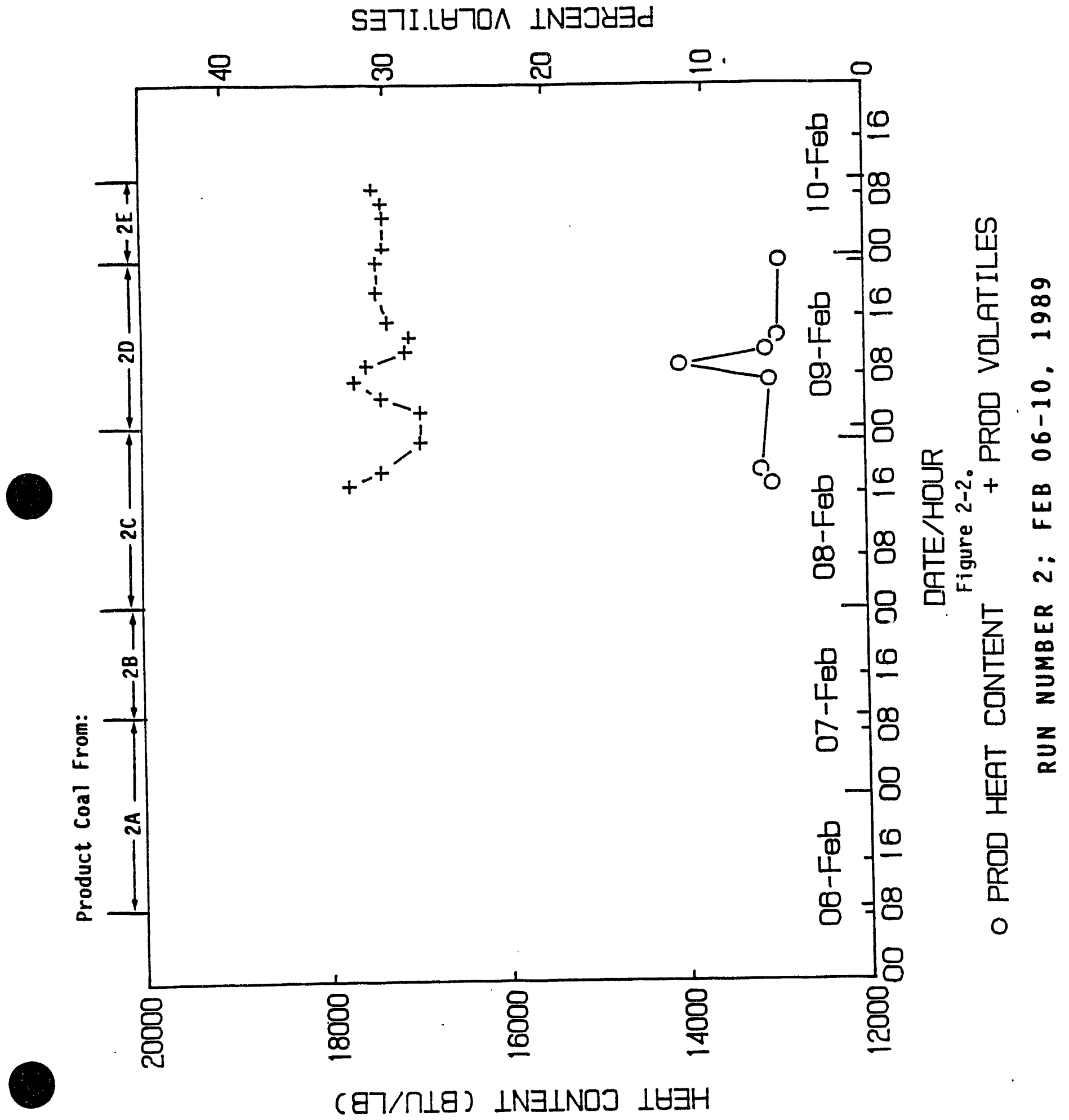




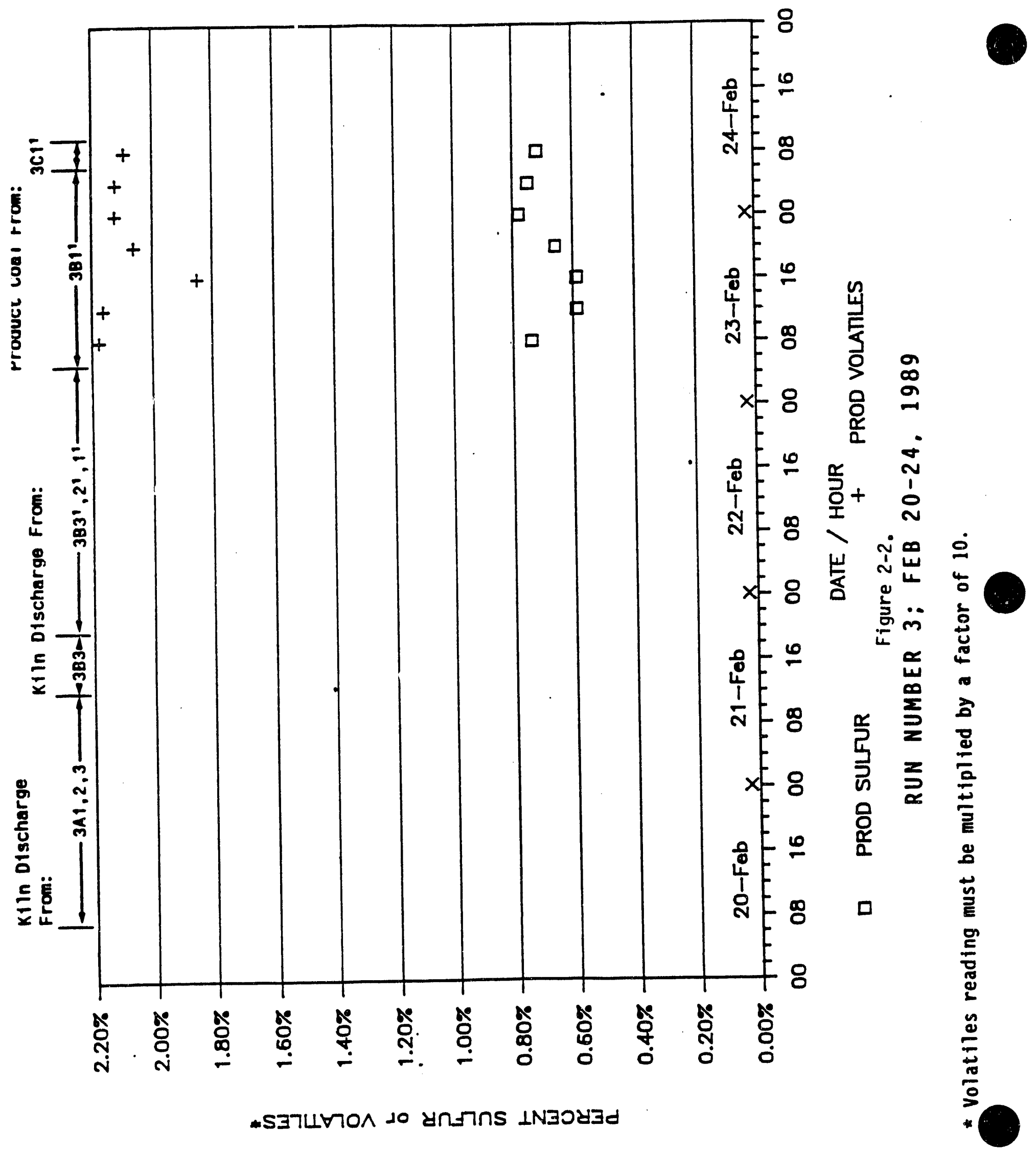




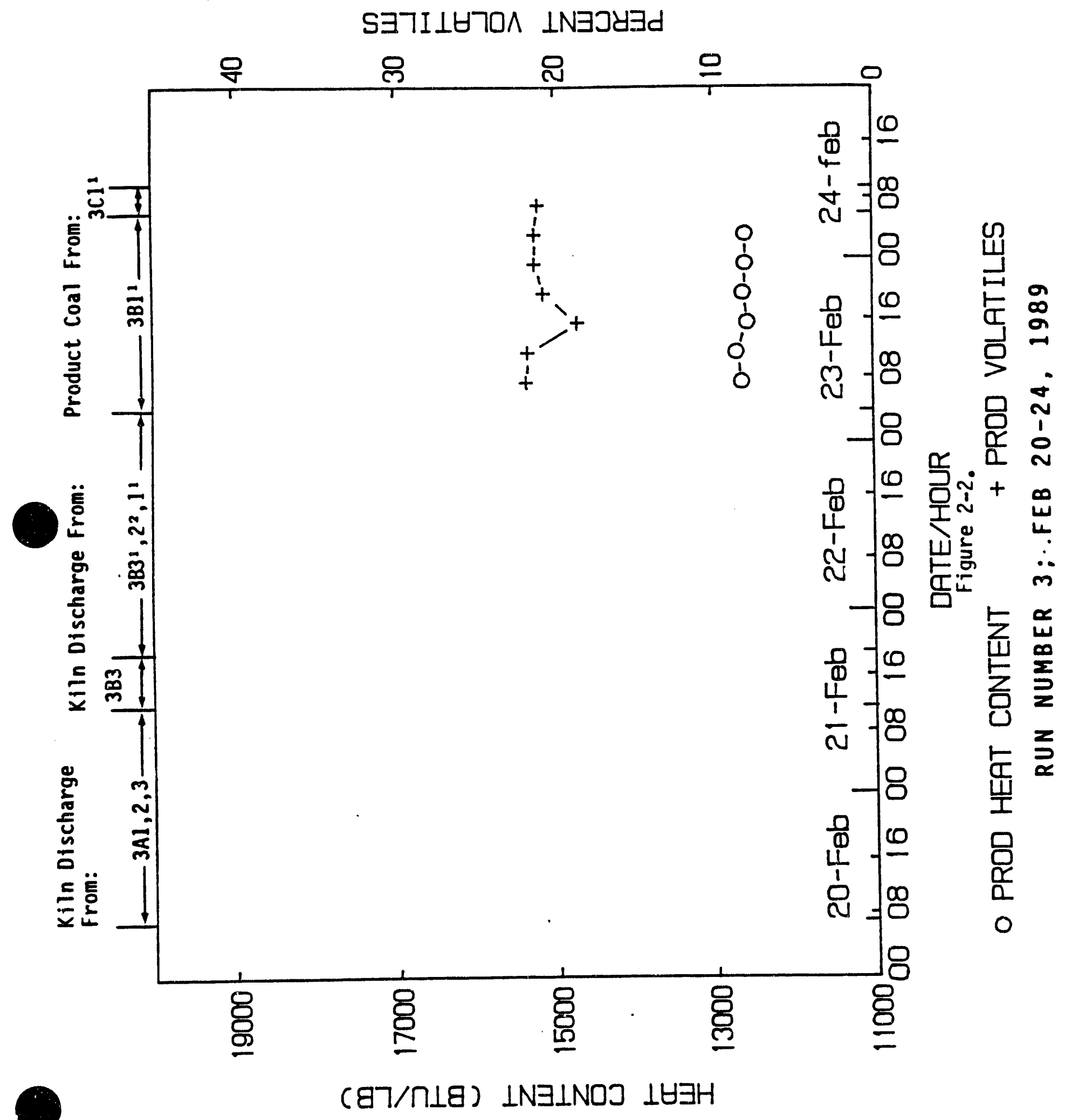




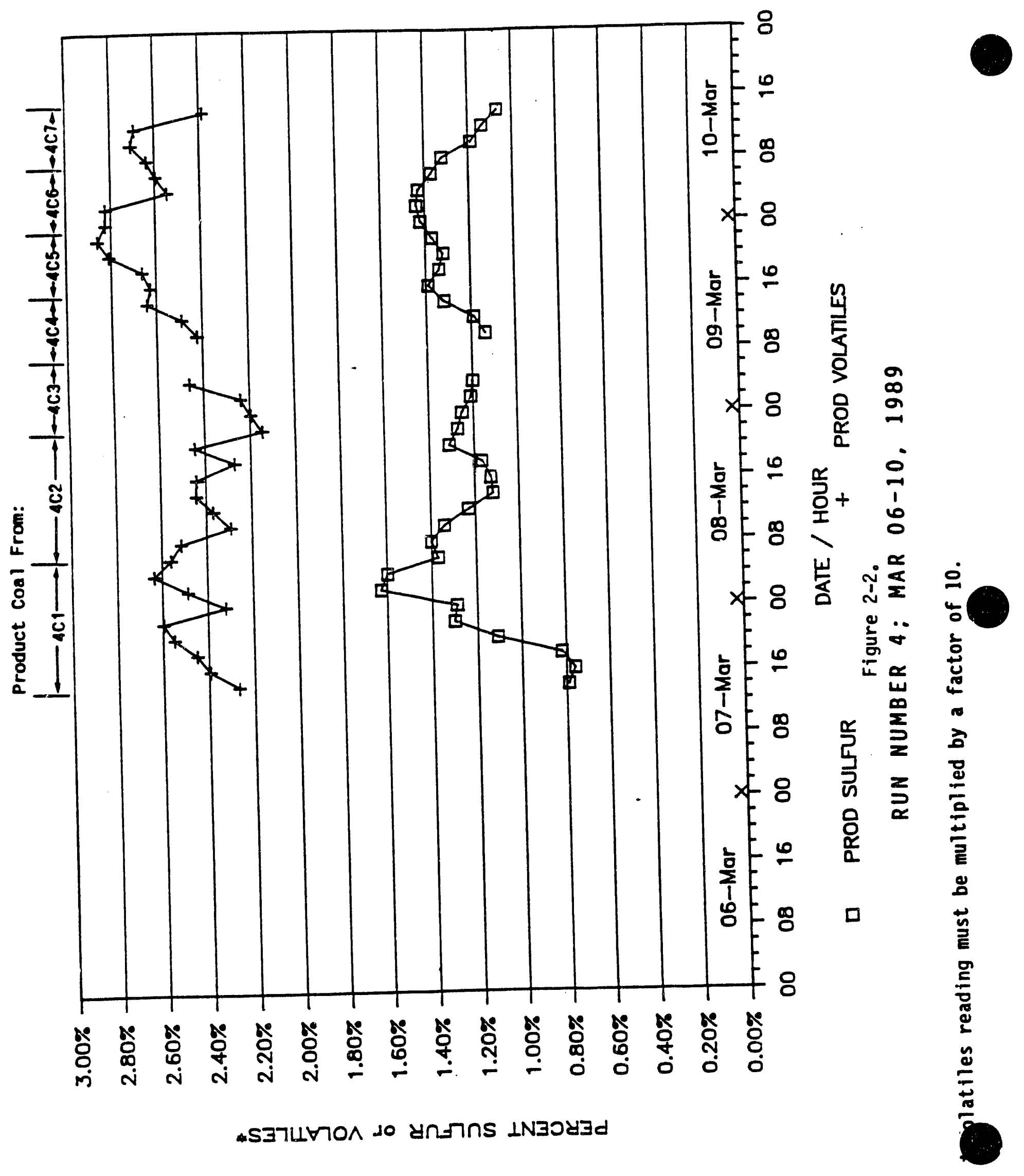




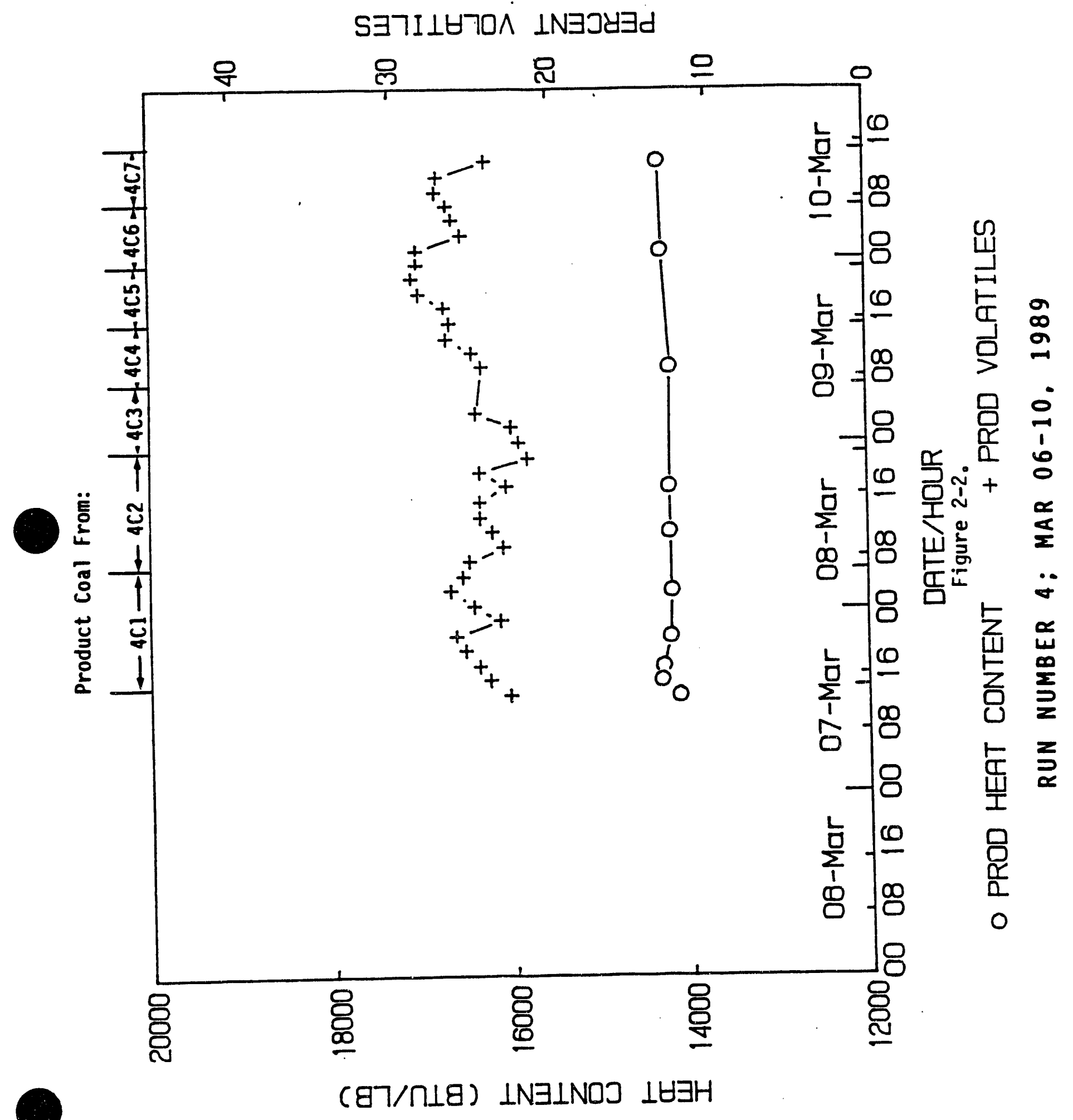




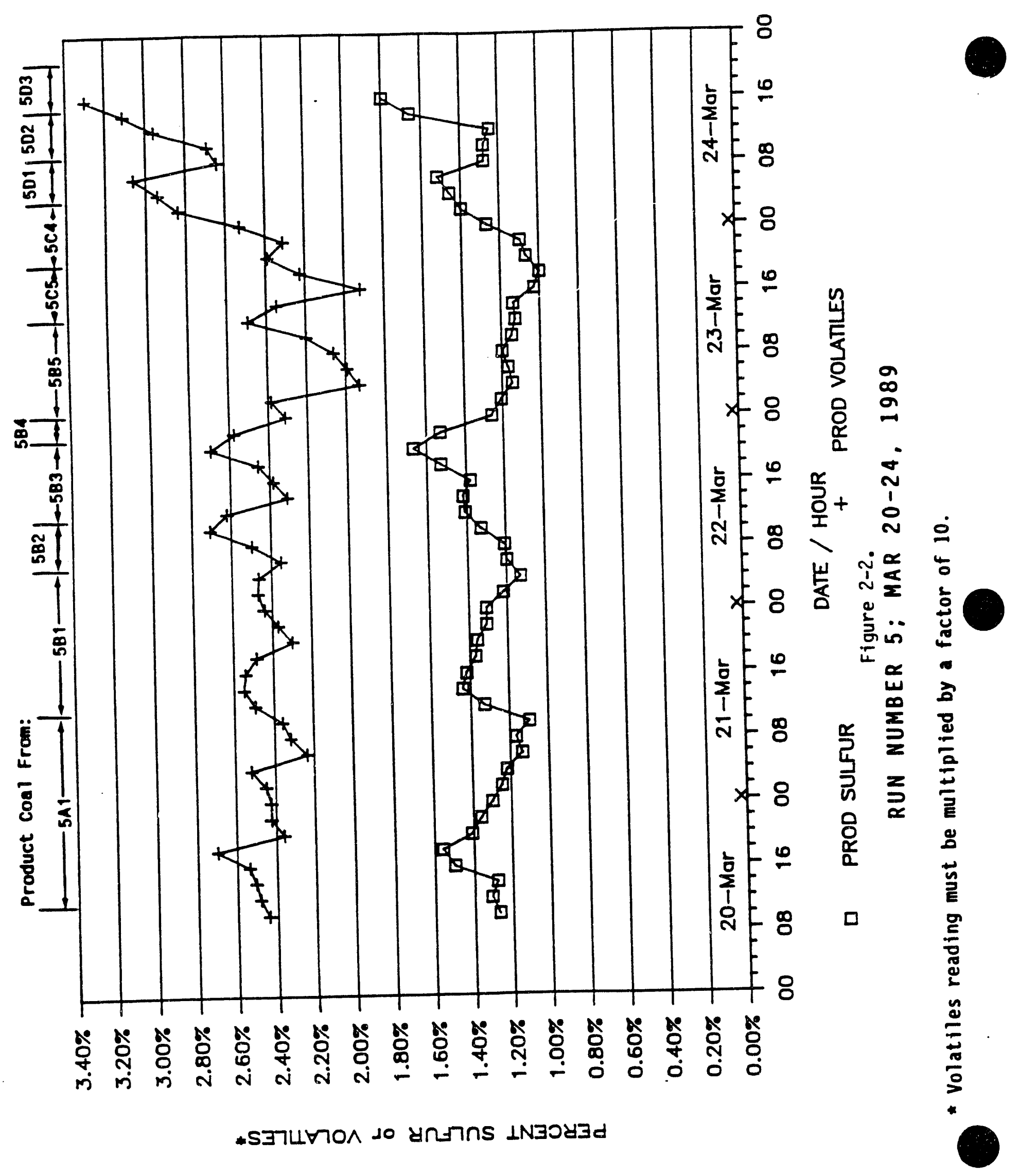




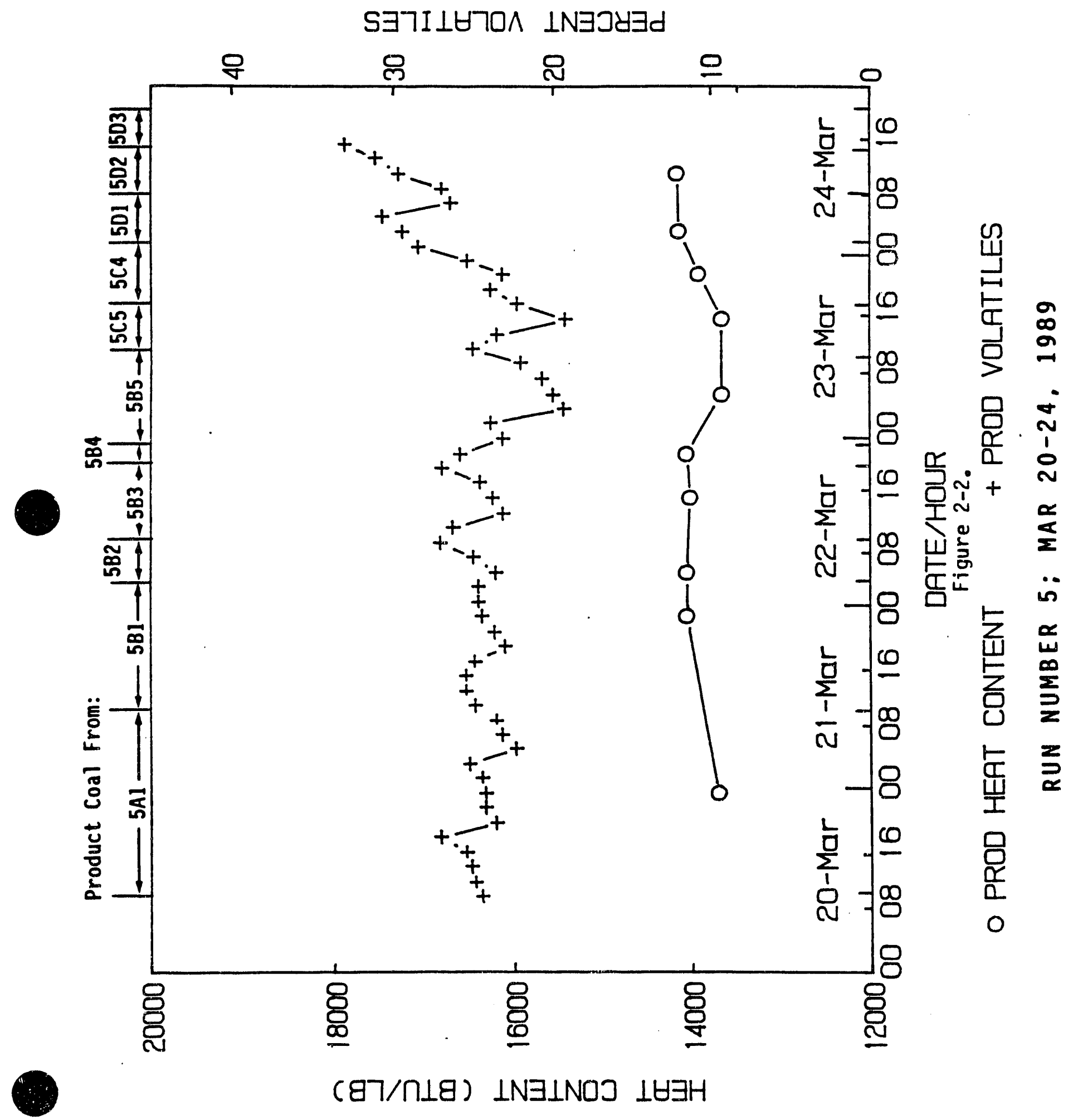




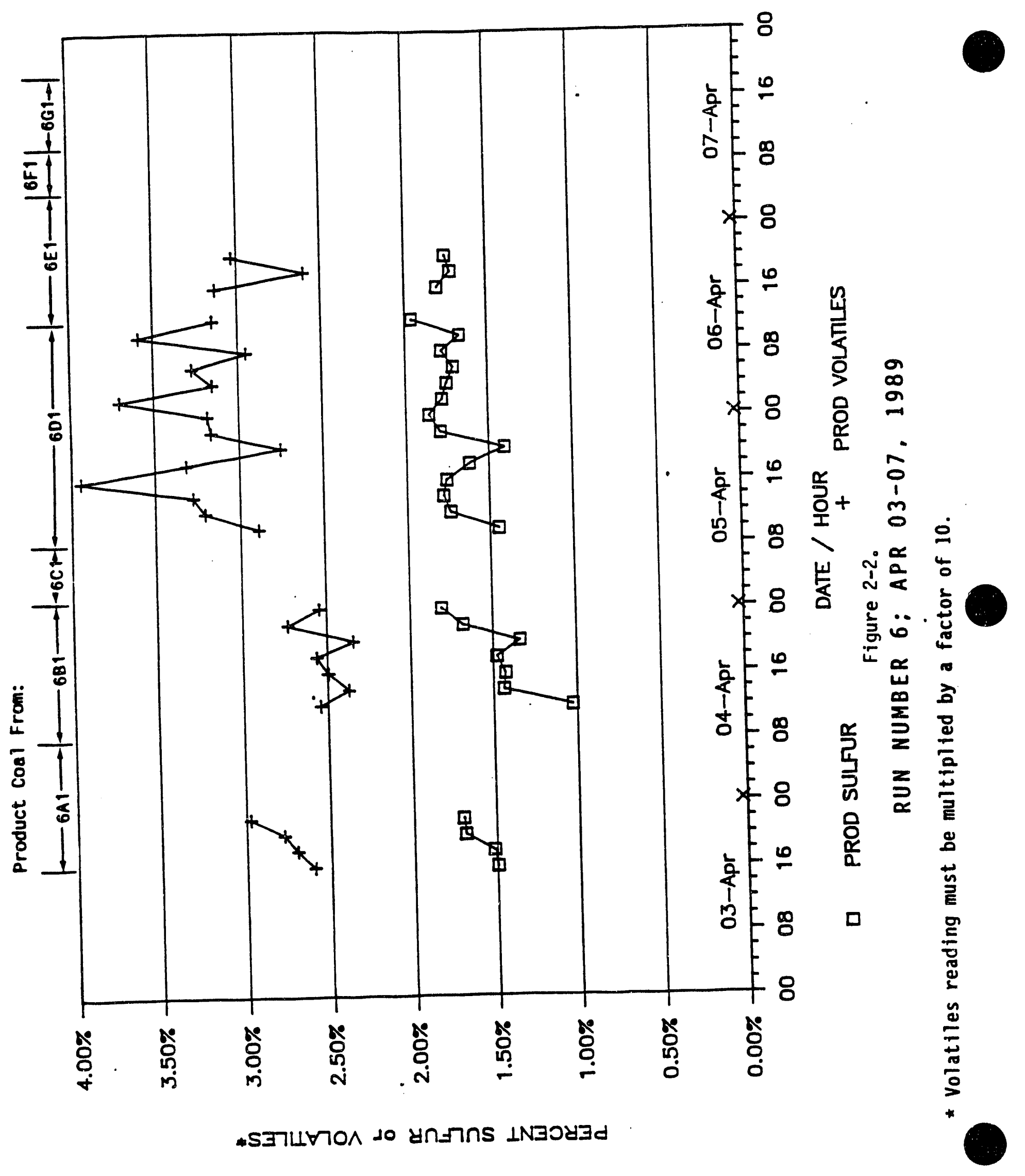




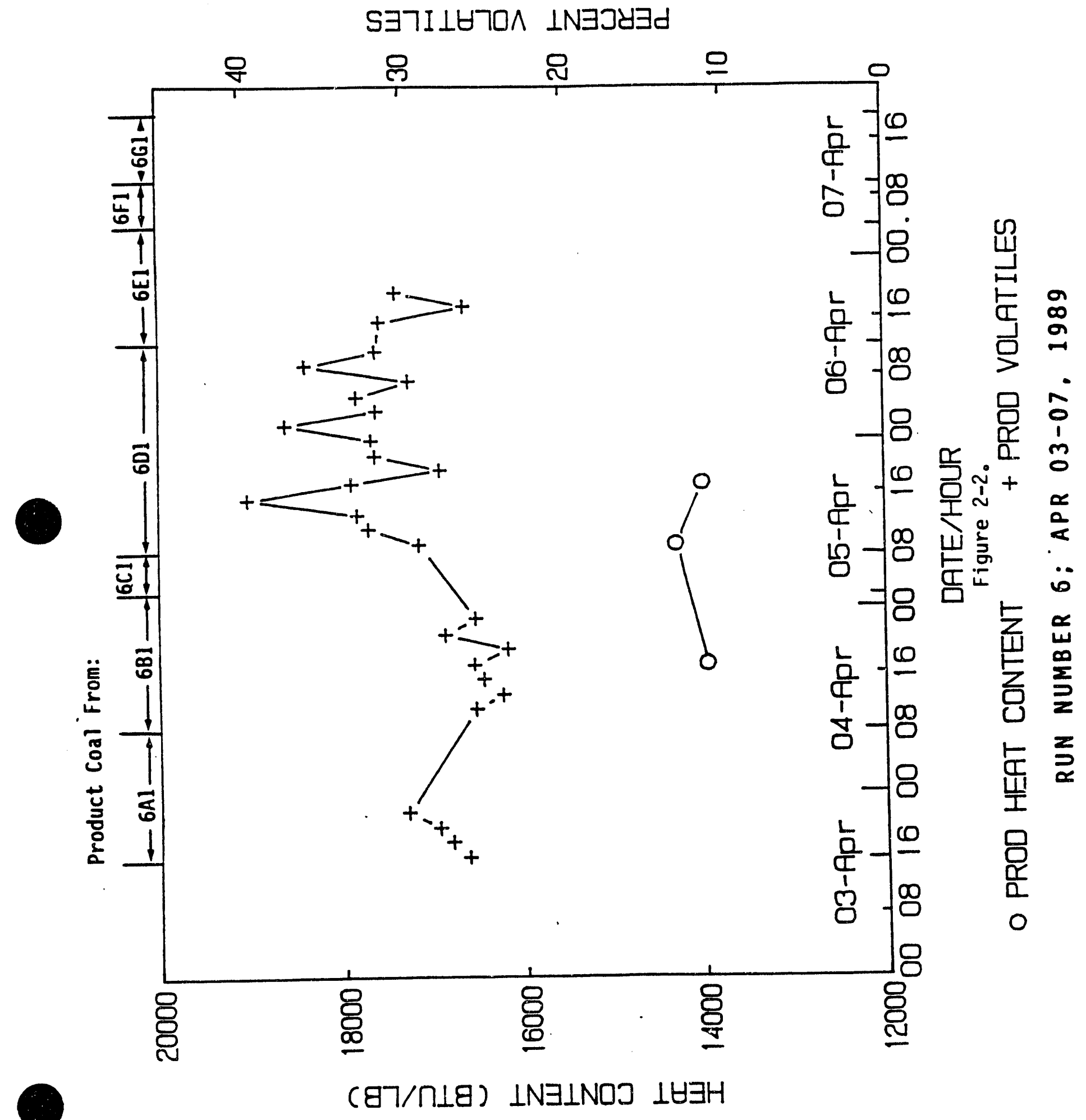




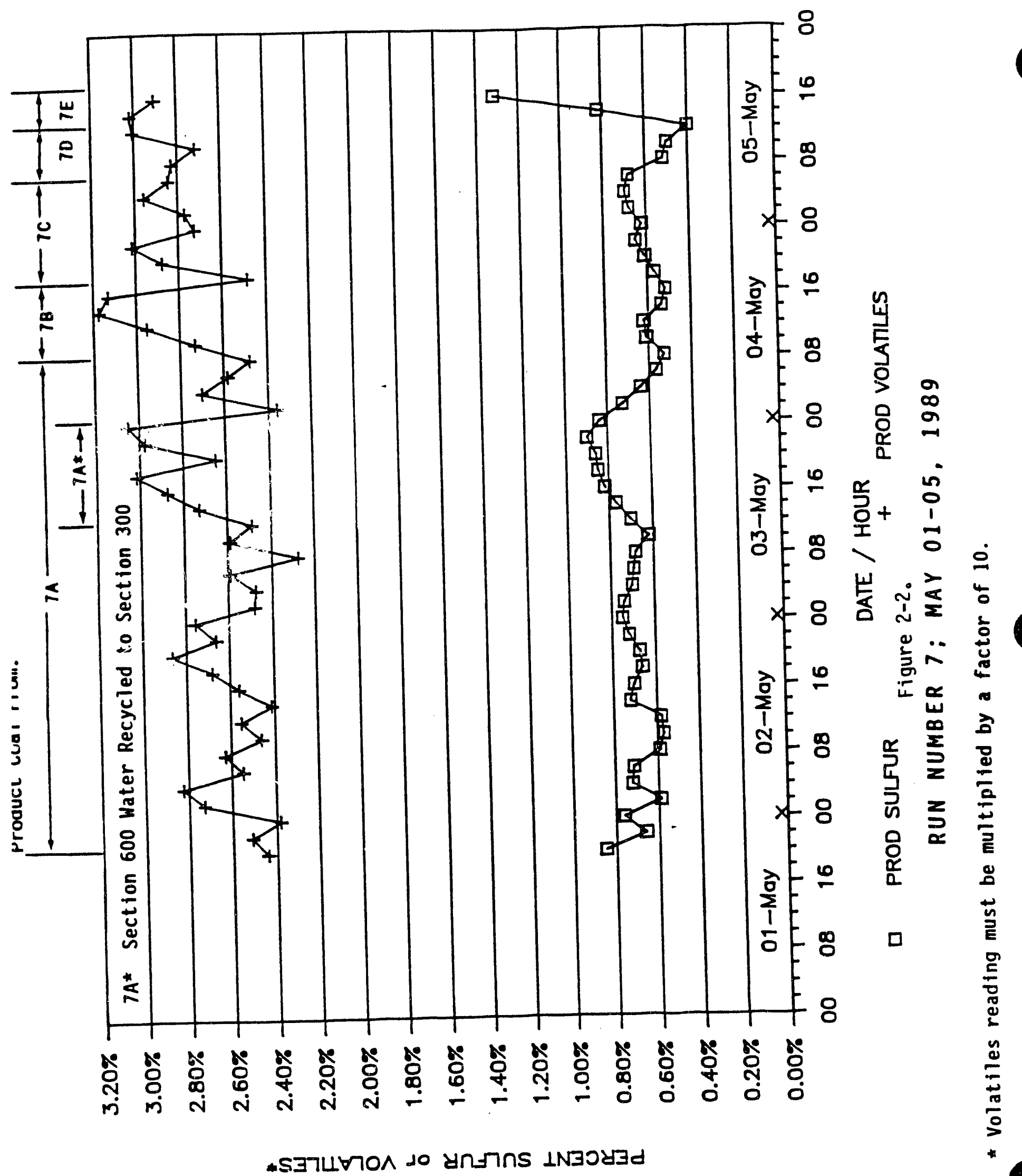


S $\exists า I \perp \forall า 0 \wedge \perp N \exists J y \exists d$

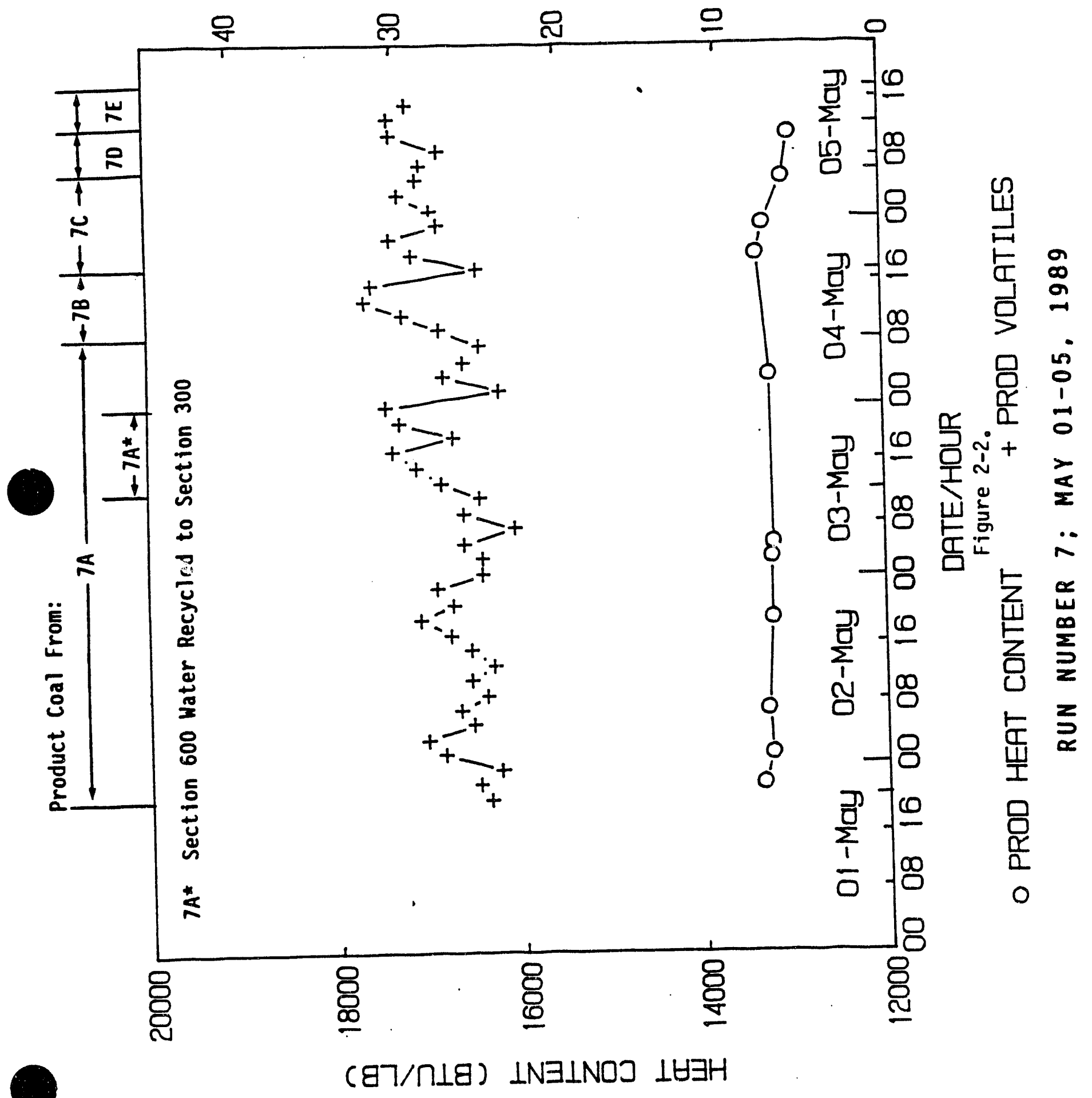




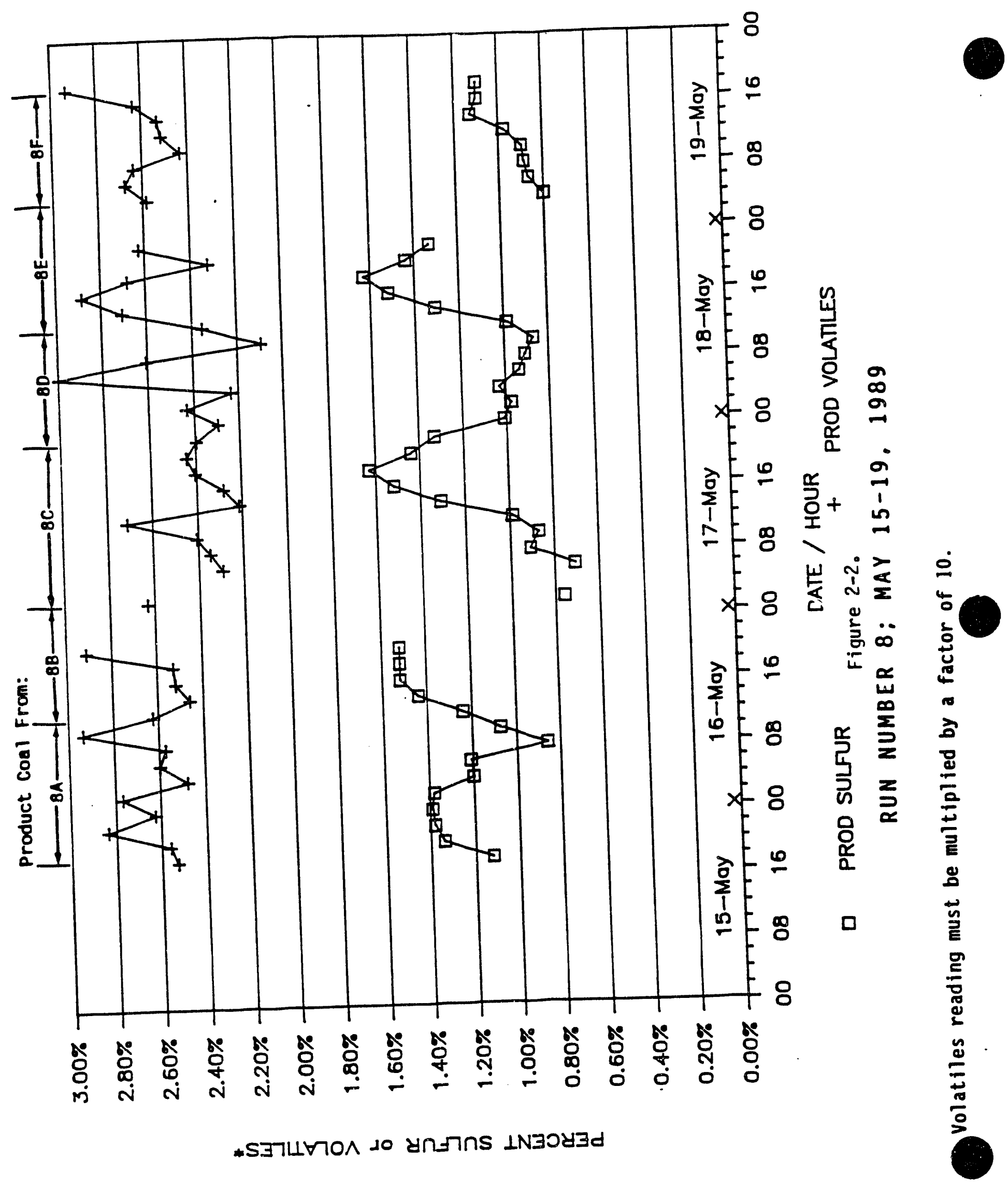




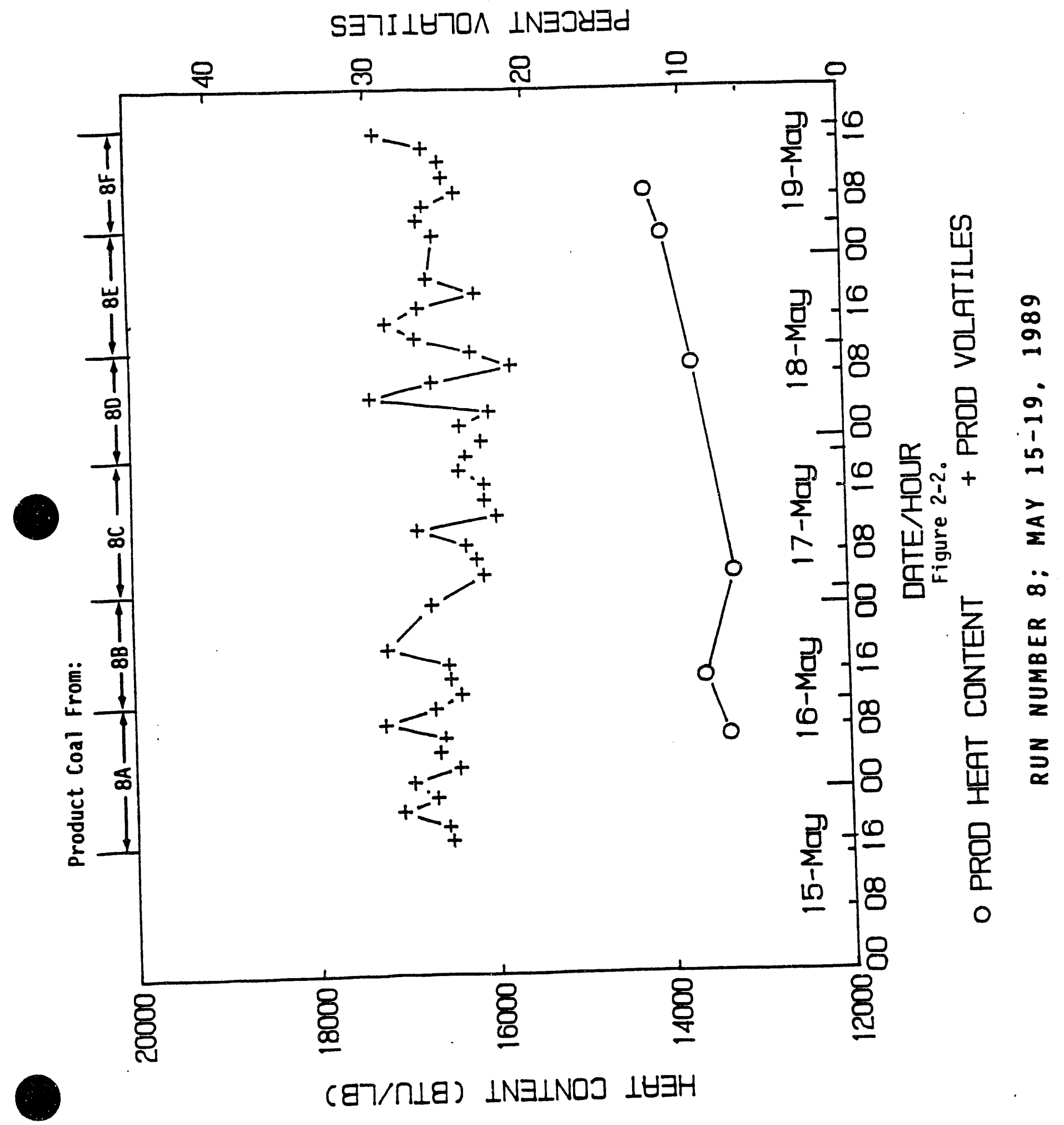




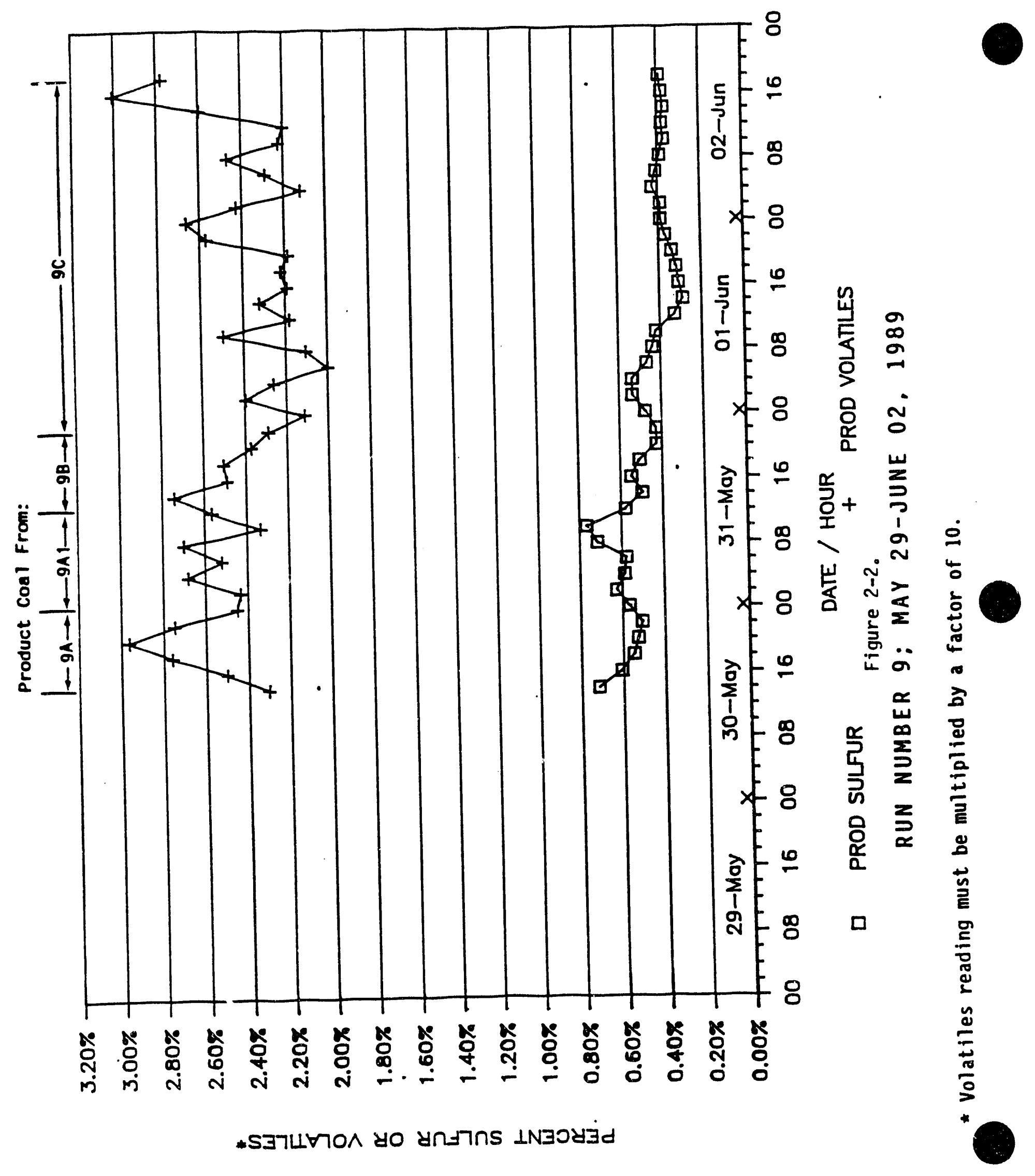




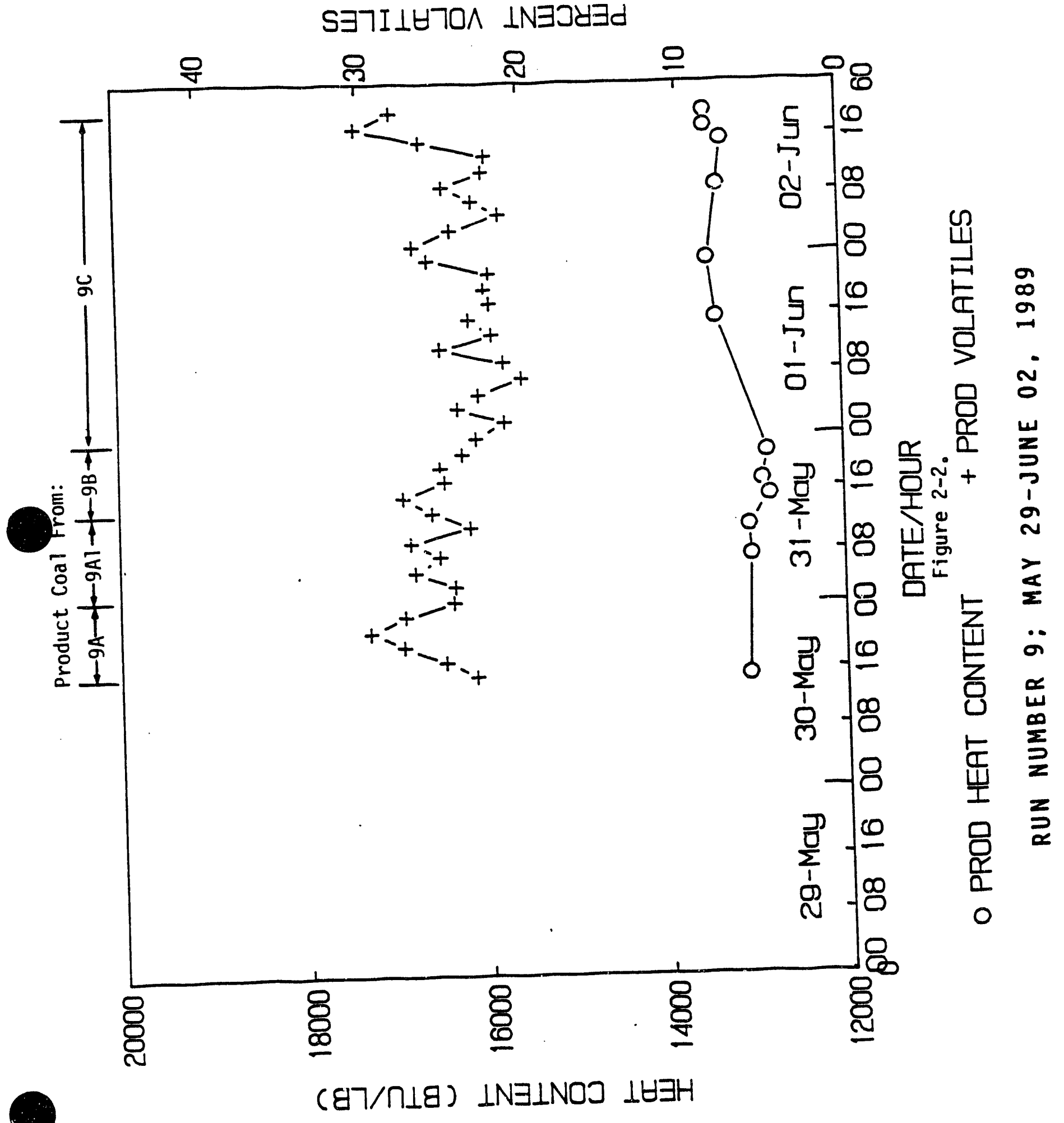


TABLE 2-3.

Quantities and Characteristics of Coal Products Collected from MCL Operations

\begin{tabular}{|c|c|c|c|c|c|c|c|c|}
\hline Run & $\begin{array}{l}\text { Coal } \\
\text { Type }\end{array}$ & $\begin{array}{l}\text { Coal } \\
\text { Product } \\
\text { As } \\
\text { Collected }\end{array}$ & $\begin{array}{l}\text { Dry } \\
\text { Coal } \\
\text { Product }\end{array}$ & $\begin{array}{l}\text { \% Sulfur } \\
\text { (Dry } \\
\text { Basis) }\end{array}$ & $\begin{array}{l}\text { \% Ash } \\
\text { (Dry } \\
\text { Basis) }\end{array}$ & $\begin{array}{l}\text { \% Vol } \\
\text { (Dry } \\
\text { Basis) }\end{array}$ & $\begin{array}{l}\text { Btu/7b } \\
\text { (Dry } \\
\text { Basis) }\end{array}$ & Mo isture \\
\hline
\end{tabular}

\begin{tabular}{|c|c|c|c|c|c|c|c|c|}
\hline $\begin{array}{l}\text { IA } \\
1 B \\
I C \\
1 D \\
I E\end{array}$ & $\begin{array}{l}\text { Pitt } 8 \\
\text { Pitt } 8 \\
\text { Pitt } 8 \\
\text { Pitt } 8 \\
\text { Pitt } 8\end{array}$ & 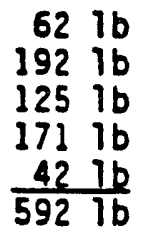 & $\begin{array}{r}301 \mathrm{~b} \\
931 \mathrm{~b} \\
561 \mathrm{~b} \\
771 \mathrm{~b} \\
201 \mathrm{~b} \\
2761 \mathrm{~b}\end{array}$ & $\begin{array}{l}1.93^{\star} \\
1.93 \\
1.43 \\
1.39 \\
1.93^{\star}\end{array}$ & $\begin{array}{l}2.32 \\
2.08 \\
1.32 \\
1.12 \\
2.43^{\star}\end{array}$ & $\begin{array}{l}32.77 \\
34.88 \\
27.40 \\
30.36 \\
30.68 \star\end{array}$ & $\begin{array}{l}13000^{\star} \\
13000^{\star} \\
13000^{\star} \\
13000^{\star} \\
13000^{\star}\end{array}$ & $\begin{array}{l}51.59 \\
51.59 \\
55.10 \\
55.17 \\
51.59\end{array}$ \\
\hline $\begin{array}{l}28 \\
2 C \\
2 D \\
2 E\end{array}$ & $\begin{array}{l}\text { Pitt } 8 \\
\text { Pitt } 8 \\
\text { Kent } 9 \\
\text { Kent } 9\end{array}$ & $\begin{array}{rr}84 & 1 \mathrm{~b} \\
216 & 1 \mathrm{~b} \\
189 & 1 \mathrm{~b} \\
192 & 1 \mathrm{~b} \\
681 & 1 \mathrm{~b}\end{array}$ & $\begin{array}{rr}44 & 1 b \\
89 & 1 b \\
841 b \\
89 \\
306 \quad 1 b\end{array}$ & $\begin{array}{l}1.93^{\star} \\
0.77 \\
0.78 \\
0.89\end{array}$ & $\begin{array}{l}2.43 \\
0.64 \\
0.47 \\
0.43\end{array}$ & $\begin{array}{l}30.68 \\
28.37 \\
29.94 \\
30.27\end{array}$ & $\begin{array}{l}13000 * \\
13092 \\
13226 \\
13000^{*}\end{array}$ & $\begin{array}{l}47.03 \\
58.83 \\
55.72 \\
53.89\end{array}$ \\
\hline $\begin{array}{l}381 \\
3 C 1\end{array}$ & $\begin{array}{l}\text { Pitt } 8 \\
\text { Pitt } 8\end{array}$ & $\begin{array}{r}1441 \mathrm{~b} \\
321 \mathrm{~b}\end{array}$ & $\begin{array}{l}641 b \\
141 b \\
781 b\end{array}$ & $\begin{array}{l}0.71 \\
0.72\end{array}$ & $\begin{array}{l}0.23 \\
0.23\end{array}$ & $\begin{array}{l}20.84 \\
20.93\end{array}$ & $\begin{array}{l}12617 \\
12617\end{array}$ & $\begin{array}{l}55.74 \\
56.35\end{array}$ \\
\hline $\begin{array}{l}4 C 1 \\
4 C 1^{+} \\
4 C 2 \\
4 C 3 \\
4 C 4 \\
4 C 5 \\
4 C 6 \\
4 C 7\end{array}$ & $\begin{array}{l}\text { Pitt } 8 \\
\text { Pitt } 8 \\
\text { Pitt } 8 \\
\text { Pitt } 8 \\
\text { Pitt } 8 \\
\text { Pitt } 8 \\
\text { Pitt } 8 \\
\text { Pitt } 8\end{array}$ & $\begin{array}{r}151 \mathrm{1b} \\
191 \mathrm{~b} \\
1541 \mathrm{~b} \\
851 \mathrm{~b} \\
651 \mathrm{~b} \\
581 \mathrm{~b} \\
761 \mathrm{~b} \\
691 \mathrm{~b} \\
6581 \mathrm{~b}\end{array}$ & $\begin{array}{rl}72 & 1 b \\
9 & 1 b \\
73 & 1 b \\
40 & 1 b \\
31 & 1 b \\
27 & 1 b \\
37 & 1 b \\
33 & 1 b \\
313 & 1 b\end{array}$ & $\begin{array}{l}1.14 \\
0.77 \\
1.25 \\
1.22 \\
1.17 \\
1.35 \\
1.42 \\
1.22\end{array}$ & $\begin{array}{l}0.68 \\
0.64 \\
0.54 \\
0.52 \\
0.46 \\
0.68 \\
0.72 \\
0.64\end{array}$ & $\begin{array}{l}24.65 \\
23.73 \\
23.91 \\
22.36 \\
24.59 \\
27.22 \\
27.65 \\
26.05\end{array}$ & $\begin{array}{l}14226 \\
14241 \\
14219 \\
14000^{\star} \\
14201 \\
14000^{\star} \\
14268 \\
14291\end{array}$ & $\begin{array}{l}52.45 \\
54.16 \\
52.38 \\
52.52 \\
52.89 \\
53.14 \\
51.31 \\
52.45\end{array}$ \\
\hline
\end{tabular}

\footnotetext{
*Estimated values

Quantities of coal products collected are subject to confirmation

$4 \mathrm{Cl}^{+}$represents coal product collected at 13:45, 16:00, 17:10 and 18:10 or 3/7/1989, or the first hours of Run $4 \mathrm{Cl}$. Compliance coal was produced during this poriod.
} 
TABLE 2-3.

Quantities and Characteristics of Coal Products Collected from MCL Operations (Continued)

\begin{tabular}{|c|c|c|c|c|c|c|c|c|}
\hline Run & $\begin{array}{l}\text { Coal } \\
\text { Type }\end{array}$ & $\begin{array}{l}\text { Coal } \\
\text { Product } \\
\text { As } \\
\text { Collected }\end{array}$ & $\begin{array}{l}\text { Dry } \\
\text { Coal } \\
\text { Product }\end{array}$ & $\begin{array}{l}\text { \% Sulfur } \\
\text { (Dry. } \\
\text { Basis) }\end{array}$ & $\begin{array}{l}\text { \% Ash } \\
\text { (Dry } \\
\text { Basis) }\end{array}$ & $\begin{array}{l}\text { \% Vol } \\
\text { (Dry } \\
\text { Basis) }\end{array}$ & $\begin{array}{l}\text { Btu/1b } \\
\text { (Dry } \\
\text { Basis) }\end{array}$ & $\begin{array}{c}\% \\
\text { Moisture }\end{array}$ \\
\hline $\begin{array}{l}5 A 1 \\
5 B 1 \\
5 B 2 \\
5 B 3 \\
5 B 4 \\
5 B 5 \\
5 C 5 \\
5 C 4 \\
5 D 1 \\
502\end{array}$ & $\begin{array}{l}\text { Pitt } 8 \\
\text { Pitt } 8 \\
\text { Pitt } 8 \\
\text { Pitt } 8 \\
\text { Pitt } 8 \\
\text { Pitt } 8 \\
\text { Kent } 9 \\
\text { Kent } 9 \\
\text { Kent } 9 \\
\text { Kent } 9\end{array}$ & $\begin{array}{r}2271 \mathrm{lb} \\
181 \text { ib } \\
701 \mathrm{~b} \\
911 \mathrm{~b} \\
421 \mathrm{~b} \\
1061 \mathrm{~b} \\
731 \mathrm{~b} \\
781 \mathrm{~b} \\
401 \mathrm{~b} \\
431 \mathrm{~b} \\
10011 \mathrm{~b}\end{array}$ & $\begin{array}{rl}124 & 1 \mathrm{~b} \\
81 & 1 \mathrm{~b} \\
30 & 1 \mathrm{~b} \\
41 & 1 \mathrm{~b} \\
191 \mathrm{i} \\
481 \mathrm{~b} \\
351 \mathrm{ib} \\
351 \mathrm{~b} \\
191 \mathrm{~b} \\
211 \mathrm{~b} \\
4531 \mathrm{~b}\end{array}$ & $\begin{array}{l}1.31 \\
1.32 \\
1.20 \\
1.46 \\
1.60 \\
1.19 \\
1.10 \\
1.11 \\
1.46 \\
1.27\end{array}$ & $\begin{array}{l}1.23 \\
0.67 \\
0.58 \\
0.63 \\
0.95 \\
0.45 \\
0.37 \\
0.50 \\
1.03 \\
0.80\end{array}$ & $\begin{array}{l}24.52 \\
24.47 \\
24.65 \\
24.69 \\
26.39 \\
21.49 \\
22.57 \\
23.66 \\
29.48 \\
27.64\end{array}$ & $\begin{array}{l}13686 \\
14052 \\
14059 \\
14023 \\
14047 \\
13656 \\
13651 \\
13918 \\
14130 \\
14152\end{array}$ & $\begin{array}{l}55.28 \\
55.16 \\
56.61 \\
54.40 \\
55.23 \\
54.81 \\
51.69 \\
55.73 \\
53.65 \\
52.05\end{array}$ \\
\hline $\begin{array}{l}6 \mathrm{AD} \\
6 \mathrm{BI} \\
6 \mathrm{Cl} \\
601 \\
6 \mathrm{EI}\end{array}$ & $\begin{array}{l}\text { Pitt } 8 \\
\text { Pitt } 8 \\
\text { Pitt } 8 \\
\text { Pitt } 8 \\
\text { Pitt } 8\end{array}$ & $\begin{array}{rl}91 & 1 b \\
160 & 16 \\
11 & 1 b \\
419 & 16 \\
140 & 1 b \\
82116\end{array}$ & $\begin{array}{rl}43 & 1 \mathrm{~b} \\
74 & \mathrm{lb} \\
5 & \mathrm{ib} \\
190 & 1 \mathrm{~b} \\
73 & 1 \mathrm{~b} \\
385 & 1 \mathrm{~b}\end{array}$ & $\begin{array}{l}1.60 \\
1.55 \\
1.74^{\star} \\
1.74 \\
1.72\end{array}$ & $\begin{array}{l}1.14 \\
0.64 \\
1.14^{\star} \\
0.87 \\
2.02\end{array}$ & $\begin{array}{l}27.65 \\
25.15 \\
32.56^{\star} \\
32.56 \\
30.84\end{array}$ & $\begin{array}{l}13948^{\star} \\
13948 \\
14000^{\star} \\
14150 \\
13000^{\star}\end{array}$ & $\begin{array}{l}52.24 \\
53.93 \\
52.24 \\
54.74 \\
47.73\end{array}$ \\
\hline $\begin{array}{l}7 A \\
7 A^{+} \\
7 B \\
7 C \\
7 D \\
7 E\end{array}$ & $\begin{array}{l}\text { Kent } 9 \\
\text { Kent } 9 \\
\text { Kent } 9 \\
\text { Pitt } 8 \\
\text { Pitt } 8 \\
\text { Pitt } 8\end{array}$ & $\begin{array}{rl}571 & 1 \mathrm{~b} \\
30 & 1 \mathrm{~b} \\
85 & 1 \mathrm{~b} \\
80 & 1 \mathrm{~b} \\
29 & 1 \mathrm{~b} \\
13 & 1 \mathrm{~b} \\
7781 \mathrm{~b}\end{array}$ & $\begin{array}{rl}238 & 1 \mathrm{~b} \\
12 & 1 \mathrm{~b} \\
35 & 1 \mathrm{~b} \\
33 & 1 \mathrm{~b} \\
13 & 1 \mathrm{~b} \\
6 & 1 \mathrm{~b} \\
325 & 1 \mathrm{~b}\end{array}$ & $\begin{array}{l}0.71 \\
0.58 \\
0.56 \\
0.64 \\
0.56 \\
1.32\end{array}$ & $\begin{array}{l}0.55 \\
0.38 \\
0.27 \\
0.68 \\
0.58 \\
1.42\end{array}$ & $\begin{array}{l}26.36 \\
25.49 \\
29.07 \\
28.13 \\
28.94 \\
29.15\end{array}$ & $\begin{array}{l}13262 \\
13262 \\
13285 \\
13349 \\
12976 \\
13349 \star\end{array}$ & $\begin{array}{l}58.26 \\
59.29 \\
59.37 \\
58.35 \\
55.86 \\
51.35\end{array}$ \\
\hline $\begin{array}{l}8 A \\
8 B \\
8 C \\
8 D \\
8 D \\
8 F\end{array}$ & $\begin{array}{l}\text { Pitt } 8 \\
\text { Pitt } 8 \\
\text { Pitt } 8 \\
\text { Pitt } 8 \\
\text { Pitt } 8 \\
\text { Pitt } 8\end{array}$ & $\begin{array}{rl}253 & 1 \mathrm{~b} \\
106 & \mathrm{lb} \\
169 & \mathrm{lb} \\
126 & \mathrm{ib} \\
99 & 1 \mathrm{~b} \\
112 & 1 \mathrm{~b} \\
865 & 1 \mathrm{~b}\end{array}$ & $\begin{array}{r}1131 \mathrm{lb} \\
501 \mathrm{~b} \\
821 \mathrm{~b} \\
601 \mathrm{~b} \\
481 \mathrm{~b} \\
521 \mathrm{~b} \\
4051 \mathrm{~b}\end{array}$ & $\begin{array}{l}1.22 \\
1.35 \\
1.18 \\
0.96 \\
1.46 \\
0.97\end{array}$ & $\begin{array}{l}1.01 \\
1.95 \\
1.20 \\
1.03 \\
1.18 \\
0.54\end{array}$ & $\begin{array}{l}26.54 \\
26.12 \\
23.91 \\
24.41 \\
26.45 \\
26.19\end{array}$ & $\begin{array}{l}13359 \\
13616 \\
13278 \\
13694 \\
14001 \\
14177\end{array}$ & $\begin{array}{l}55.14 \\
52.66 \\
51.58 \\
52.12 \\
51.34 \\
54.03\end{array}$ \\
\hline
\end{tabular}

*Estimated values
Quantities of coal products collected are subject to confirmation

$7 A^{+}$represents coal product collected at $8: 15,9: 15,10: 15$ and 1215 on 5/2/1989.

Compliance coal was produced during this period of $7 A$. 
TABLE 2-3.

Quantities and Characteristics of Coal Products Collected from MCL Operations (Continued)

\begin{tabular}{|c|c|c|c|c|c|c|c|c|}
\hline Run & $\begin{array}{l}\text { Coal } \\
\text { Type }\end{array}$ & $\begin{array}{l}\text { Coal } \\
\text { Product } \\
\text { As } \\
\text { Coliected }\end{array}$ & $\begin{array}{l}\text { Dry } \\
\text { Coal } \\
\text { Product }\end{array}$ & $\begin{array}{l}\text { \% Sulfur } \\
\text { (Dry } \\
\text { Basis) }\end{array}$ & $\begin{array}{l}\text { \% Ash } \\
\text { (Dry } \\
\text { Basis) }\end{array}$ & $\begin{array}{l}\text { \% Vol } \\
\text { (Ory } \\
\text { Basis) }\end{array}$ & $\begin{array}{l}\text { Btu/lo } \\
\text { (Ory } \\
\text { Basis) }\end{array}$ & $\begin{array}{c}\% \\
\text { Moisture }\end{array}$ \\
\hline $\begin{array}{l}9 A \\
9 A] \\
9 B \\
9 C\end{array}$ & $\begin{array}{l}\text { Pitt } 8 \\
\text { Pitt } 8 \\
\text { Pitt } 8 \\
\text { Pitt } 8\end{array}$ & $\begin{array}{rl}100 & 16 \\
82 & 16 \\
58 & 16 \\
345 & 16 \\
585 & 16\end{array}$ & $\begin{array}{rr}41 & 16 \\
35 & 16 \\
26 & 16 \\
150 & 16 \\
252 & 16\end{array}$ & $\begin{array}{l}0.59 \\
0.65 \\
0.49 \\
0.40\end{array}$ & $\begin{array}{l}0.27 \\
0.33 \\
0.24 \\
0.15\end{array}$ & $\begin{array}{l}25.97 \\
25.63 \\
24.84 \\
23.65\end{array}$ & $\begin{array}{l}13079 \\
13049 \\
12848 \\
13393\end{array}$ & $\begin{array}{l}58.83 \\
57.39 \\
56.11 \\
56.49\end{array}$ \\
\hline
\end{tabular}

* Volatile content of product coal approaches $30 \%$ near end of run 
TABLE 2-4. MCL PRODUCT COAL SUMMARY

\begin{tabular}{|c|c|c|}
\hline $\begin{array}{l}\text { Ship } \\
\text { Drum } \\
\text { No. }\end{array}$ & $\begin{array}{l}\text { Coal } \\
\text { Iype }\end{array}$ & $\begin{array}{l}\text { Net } \\
\text { Ship, } \\
\text { Wt. Lbs }\end{array}$ \\
\hline $\begin{array}{l}096 \\
098 \\
108 \\
109 \\
107 \\
112 \\
116 \\
119 \\
120\end{array}$ & $\begin{array}{ll}\text { Ky } & 9 \\
\text { Ky } & 9 \\
\text { Ky } & 9 \\
\text { Ky } & 9 \\
\text { Pitt } & 8 \\
\text { Pitt } & 8 \\
\text { Pitt } & 8 \\
\text { Pitt } & 8 \\
\text { Pitt } & 8\end{array}$ & $\begin{array}{l}176.5 \\
200.8 \\
218.1 \\
247.0 \\
173.9 \\
173.4 \\
214.7 \\
173.8 \\
244.9\end{array}$ \\
\hline $\begin{array}{l}\text { Total } \\
\text { Total }\end{array}$ & $\begin{array}{l}\text { Ship Wt. Ky } 9 \\
\text { Ship Wt. Pitt } 8\end{array}$ & $\begin{array}{l}842.4 \\
980.7\end{array}$ \\
\hline $\begin{array}{l}\text { Total } \\
\text { Total }\end{array}$ & $\begin{array}{l}\text { Dry Wt. Ky } 9 \\
\text { Dry Wt. Pitt } 8\end{array}$ & $\begin{array}{l}486.0 \\
631.0\end{array}$ \\
\hline
\end{tabular}




\section{OPERATION TEST RESULTS}

The objectives of operational testing of the 20 pounds of coal per hour integrated MCL test circuit were: 1) to demonstrate the technical capability of the MCL process for producing a demineralized and desulfurized coal that meets New Source Performance Standards (NSPS), 2) to determine the range of effective process operation, 3) to test process conditions aimed at significantly lower costs, and 4) to deliver product coal. The integrated test circuit produced coal with sulfur content well below the New Source Performance Standards and with equipment performance consistent with commercial design requirements. An assessment of the results indicates that the MCL circuit with modifications is capable of integrated, continuous, long-duration operational testing.

Nine series of operational tests covering a 54-test matrix were conducted during the January to June, 1989 time period, using either 50:50 $\mathrm{KOH} / \mathrm{NaOH}$ or only $\mathrm{NaOH}$ as the leaching agent. Over 750 hours of operational time were logged resulting in the production of 3,000 pounds of treated coal suitable for further testing and evaluation. Two feed coals representative of the Eastern United States coal production were processed: Pittsburgh No. 8 and Kentucky No. 9. Pittsburgh No. 8 coal was used for most of the testing. The feed coal size was 14 mesh in all but 5 of the tests, during which 6 mesh coal was fed to the kiln. The rotary kiln was operated with average wall temperatures of 371 to $438^{\circ} \mathrm{C}$. The residence time of the coal/caustic mixture in the heated zones of the rotaly $k i l n$ was approximately 2 hours for a majority of the runs. However, the heaters in the first, or the first and second, zones of the rotary kiln were shut off during selected runs to simulate the conditions of shorter residence time. Nitrogen gas was passed through the kiln to suppress carbonate formation and to assure that the hydrogen and hydrocarbon gases present in the kiln gas would be below the flammability limit. The flow of nitroger inside the kiln was cocurrent with the coal/caustic flow in the first sia series of tests, and countercurrent to the coal/caustic flow in the last three series of tests. 
The wash train during the operational tests included 5 centrifuge stages in the caustic washing section and 3 centrifuge stages in the acid washing section. The two rotary drum vacuum filters in the wash train were only tested during early plant operation, and one filter was used for short periods during some of the operational runs. (See Section 4.3 for more details.) These vacuum filters will be redesigned and included as part of the wash train in the next phase of the operational tests.

Regeneration of the caustic was conducted by the addition of lime to the spent caustic solution, typically at a temperature of $43^{\circ} \mathrm{C}$. The spent caustic solution sent to the regenerator contained less than $15 \%$ caustic as a result of the vacuum filters not being on-line (see Section 4.3.2). The caustic concentration will be increased to approximately $50 \%$ after the incorporation of the two vacuum filters in the wash train.

\subsection{COAL PRODUCT QUALITY}

Coal product samples were obtained either from the end of the wash train (CP samples) or from the kiln discharge (KD samples) for analysis. The KD samples were acquired for several reasons: to provide an early indication whether the kiln operating conditions were conducive to production of compliance coal; to determine the residence time of the coal/caustic mixture inside the kiln by collection of all discharge products; to perform material balances; and to evaluate the formation of carbonates and sulfates inside the rotary kiln. The CP samples, on the other hand, were more representative of the product obtained from an integrated $\mathrm{MCL}$ plant. There was also less variability in the $C P$ samples from the same run because of the mixing and reslurrying processes in the wash train. For most of the runs, analysis results for both $C P$ and $K D$ samples are available. In these cases, the $C P$ results were used as the basis for assessing the effects of operating parameters on coal product quality. The KD results were used wherever $C P$ results were unavailable. 
The complete analysis results for the sulfur content, ash content, volatile content, moisture content and heating value of the coal product samples are presented in Appendix $A$ of this report. These analysis results are summarized in Tables 3-1,3-2 and 3-3 for Pittsburgh No. 8 coal processed with mixed caustic (sodium and potassium hydrcxides), Pittsburgh No. 8 coal processed with only sodium hydroxide, and Kentucky No. 9 coal processed with either mixed caustic or sodium hydroxide, respectively.

\subsubsection{Sulfur Removal}

The sulfur content of the MCL coal product generally decreases with increasing caustic/coal ratio and increasing reaction temperature, but also depends on the type of coal and the type of caustic used, as well as the residence time of the coal/caustic mixture in the heated zones of the rotary kiln.

\subsubsection{Pittsburgh No. $8 ; 50: 50 \mathrm{KOH} / \mathrm{NaOH}$}

The analysis results presented in Table 3-1 show that the combination of high kiln wall temperature, long residence time and high caustic/coal ratio (R) will likely produce compliance coal. Approximately $90 \%$ sulfur dioxide removal (based on $1 \mathrm{~b} /$ million Btu removed from run-of-mine coal) was achieved with kiln wall temperature $\geq 427^{\circ} \mathrm{C}$, residence time of 2.0 hours, and caustic/coal $=2$, as indicated by the Run $2 \mathrm{C}$, Run $3 \mathrm{BI}$ and Run 70 test results at $89.5 \%, 89.8 \%$ and $92.3 \%$ sulfur dioxide removal, respectively. Further, sulfur dioxide removal of $90 \%$ or above was achieved with kiln wall temperature $\geq 427^{\circ} \mathrm{C}$, residence time of 2.0 hours, and caustic/coal $\geq 2.5$, as indicated by the Run $3 C 1$, Run $7 C$, Run $9 A$, Run $9 A 1$ and Run $9 B$ test results at $90.0 \%, 91.3 \%, 91.9 \%, 91.1 \%$ and 93.3\% sulfur dioxide removal, respectively.

The effects of caustic/coal ratio and reaction temperature on sulfur removal was also evaluated by regression analysis. The correlation between the suifur content of the coal product and the caustic/coal ratio (R) and the kiln wall temperature $\left(T\right.$ in $\left.{ }^{\circ} \mathrm{C}\right)$ is as follows: 


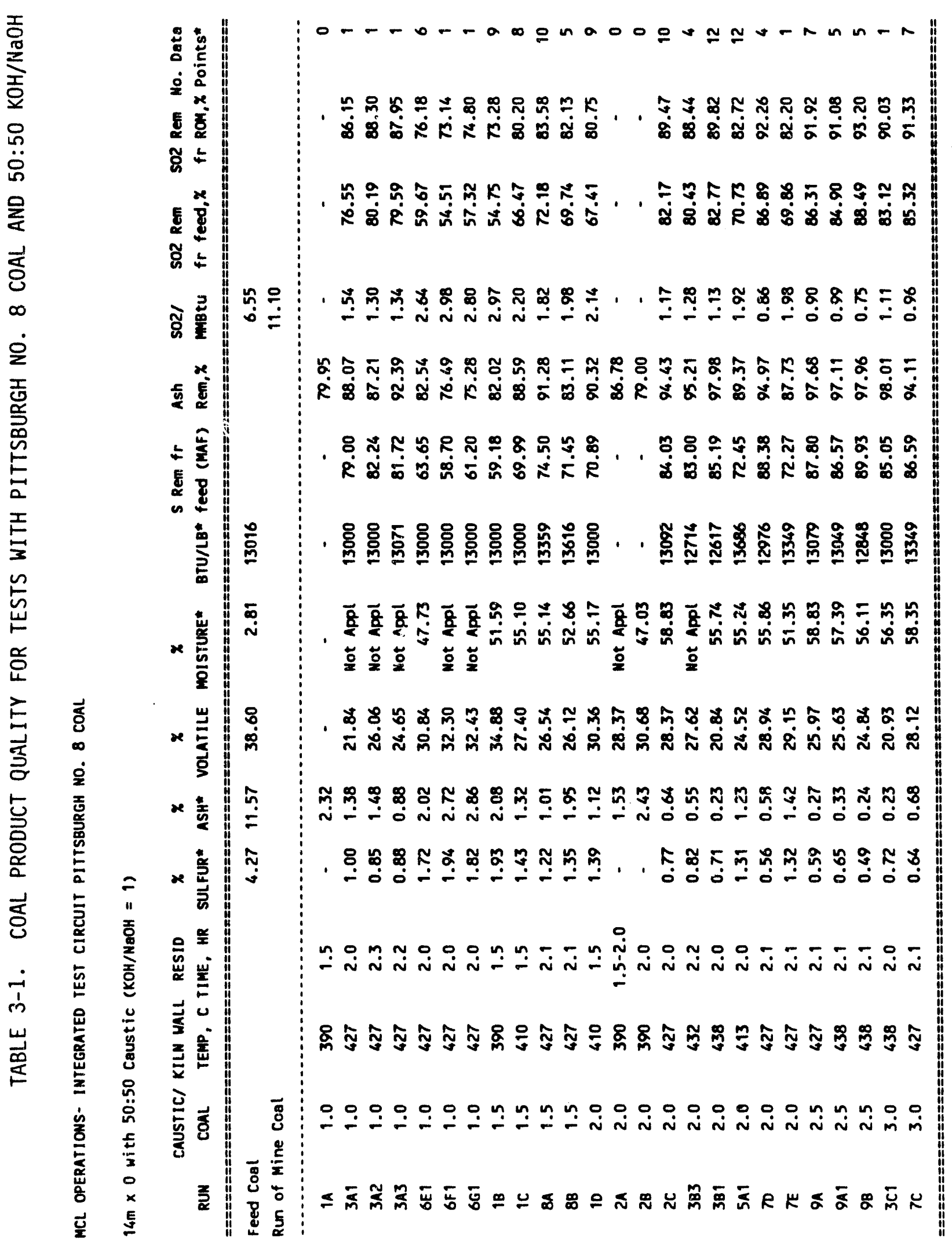

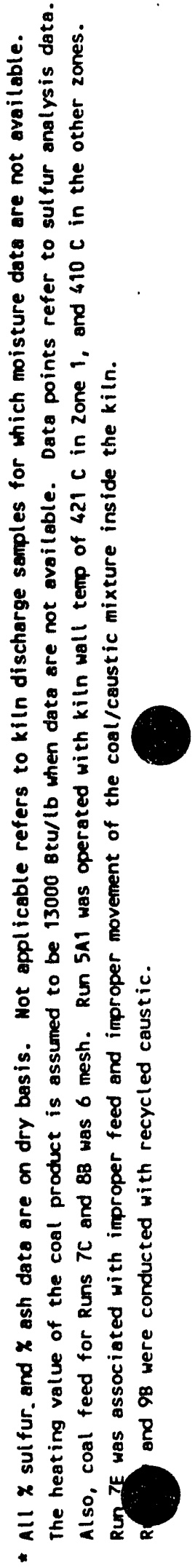




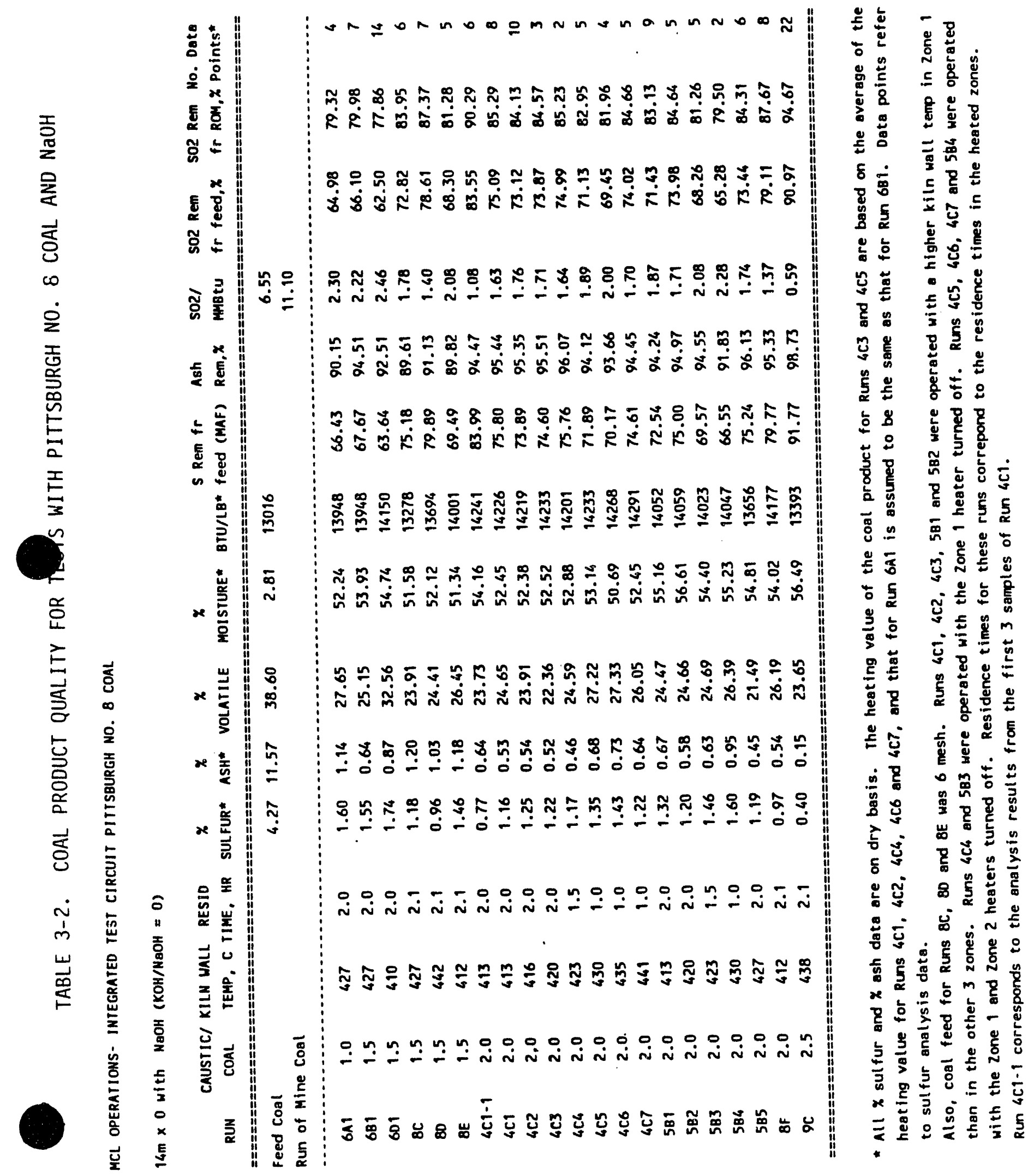




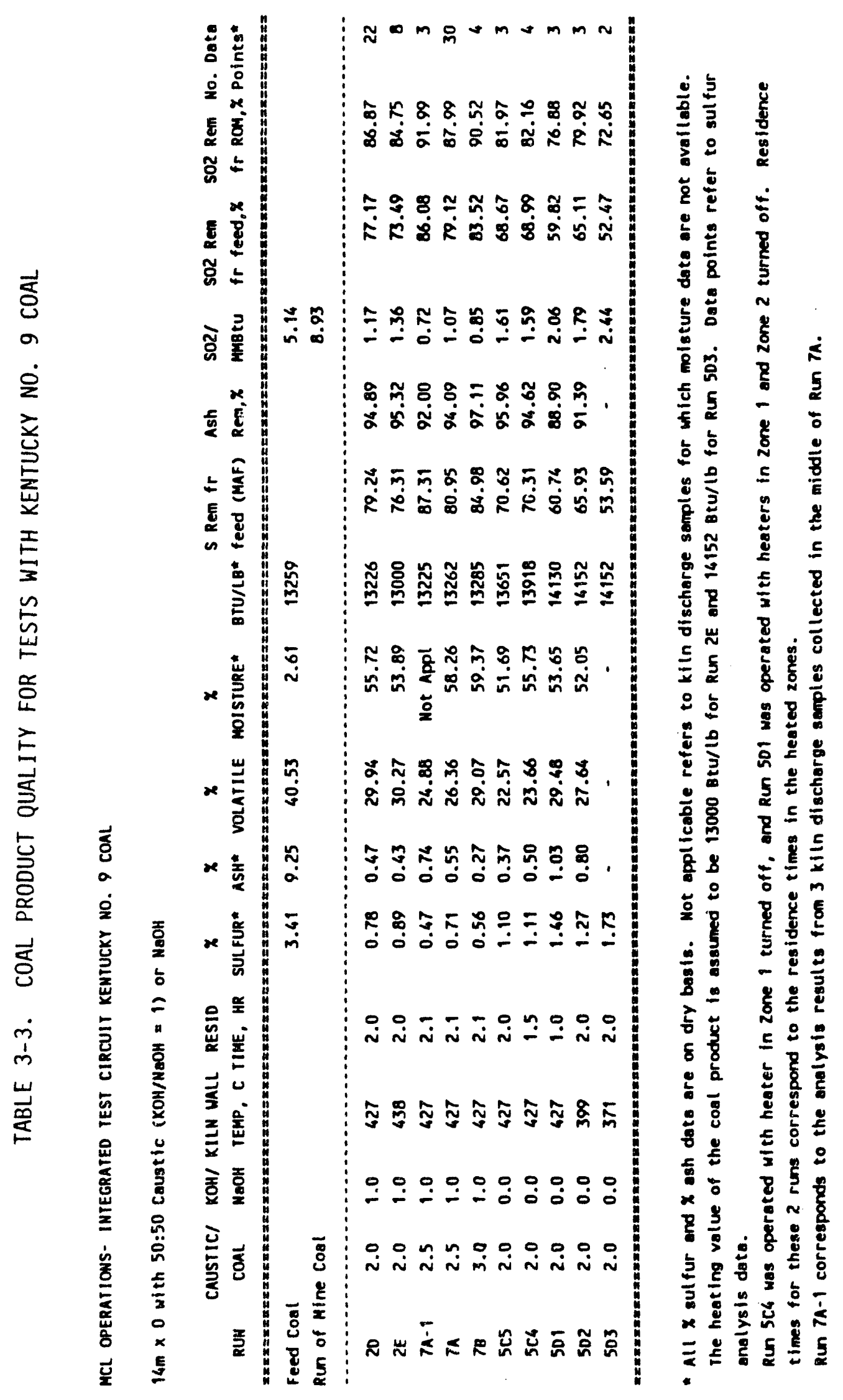




$$
\text { \% sulfur }=10.143-0.3697 R-0.01975 T
$$

with a correlation coefficient of 0.7848 . The correlation between the sulfur content of the coal product and the kiln wall temperature, if only runs with caustic/coal ratio $\geq 2$ are included in the regression analysis, is as follows:

$$
\% \text { sulfur }=11.393-0.02478 T
$$

with a correlation coefficient of -0.8209 . The negative regression coefficients in these correlations indicate that the sulfur content of the MCL coal product decreases with increasing caustic/coal ratio and increasing kiln wall temperature. These same effects are illustrated by plotting the sulfur analysis results in Figure 3-1. However, Figure 3-1 and Table 3-1 also show that based on the limited test results from Runs $3 A 1,3 A 2$ and $3 A 3$, it may be possible to achieve 86 to $88 \%$ sulfur dioxide removal with caustic/coal ratio of 1 and kiln wall temperature of $427^{\circ} \mathrm{C}$. At higher reaction temperatures, it is conceivable that $90 \%$ sulfur dioxide removal (corresponding to $0.7 \%$ sulfur in $\mathrm{MCL}$ coal) may be achieved even at a caustic/coal ratio of 1 . On the other hand, Figure 3-1 and Table 3-1 indicate that at kiln wall temperatures below or near $410^{\circ} \mathrm{C}$ and with nitrogen flow and coal feed in cocurrent direction, less than $81 \%$ sulfur removal can be obtained, as shown by the test results from Runs 1B, 1C, 1D and $5 \mathrm{Al}$.

In Figure 3-2, the sulfur content of the MCL coal product from analysis of the samples is compared with the predicted values according to the correlation represented by equation [1]. For 12 of the 21 runs, the predicted and experimental sulfur levels are in very good agreement. For Runs $2 C, 3 A 1,3 A 2,3 A 3$ and $7 D$, the predicted sulfur levels are higher than the experimental values. For Runs $3 C 1,6 E 1,6 F 1$ and $6 G 1$, the predicted sulfur levels are lower than the experimental values: Only one sample each from Runs $3 \mathrm{Al}, 3 \mathrm{~A} 2,3 \mathrm{~A} 3,3 \mathrm{Cl}, 6 \mathrm{Fl}$ and $6 \mathrm{Gl}$, however, was acquired and analyzed. Therefore, some of the disagreement between predicted and 


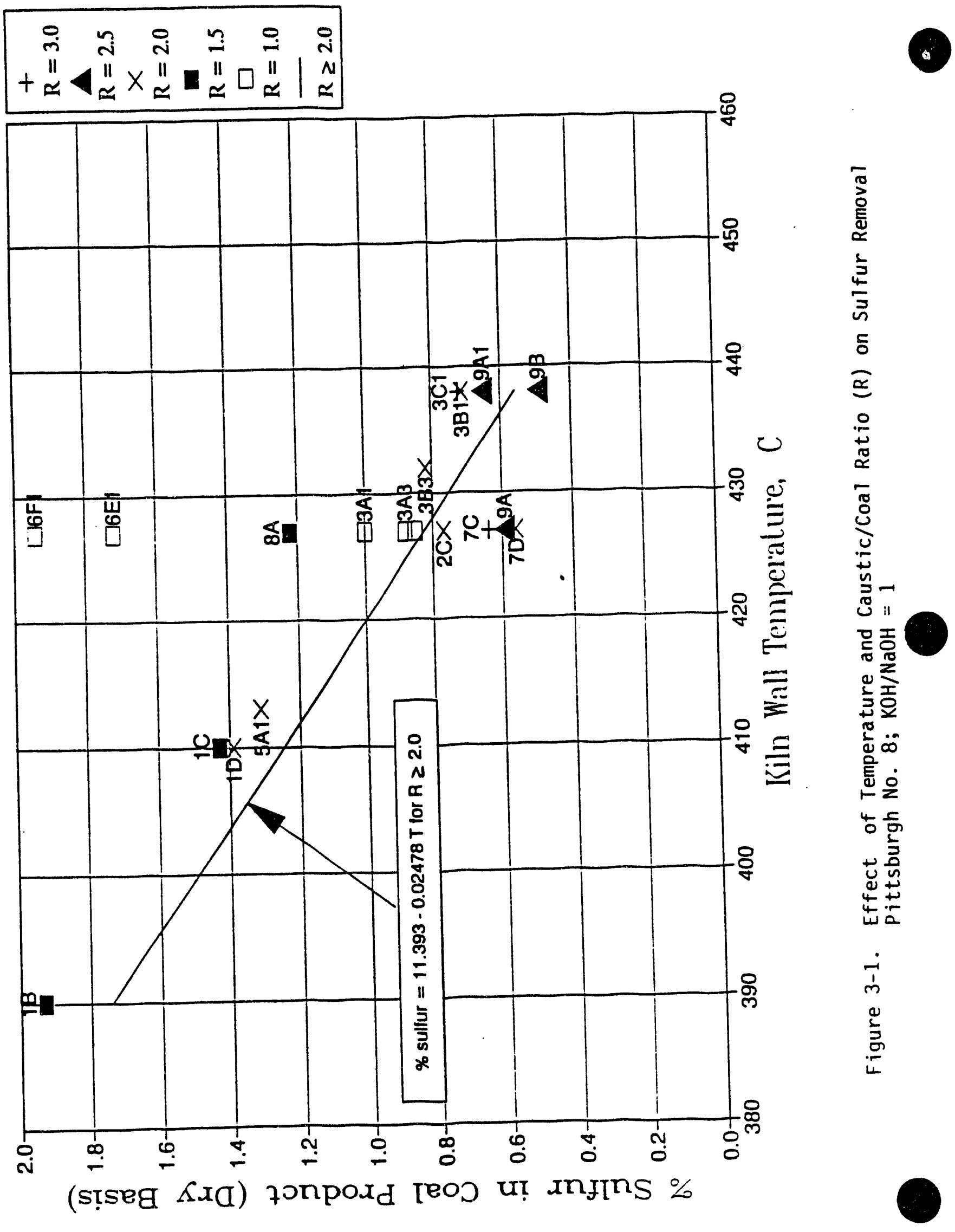




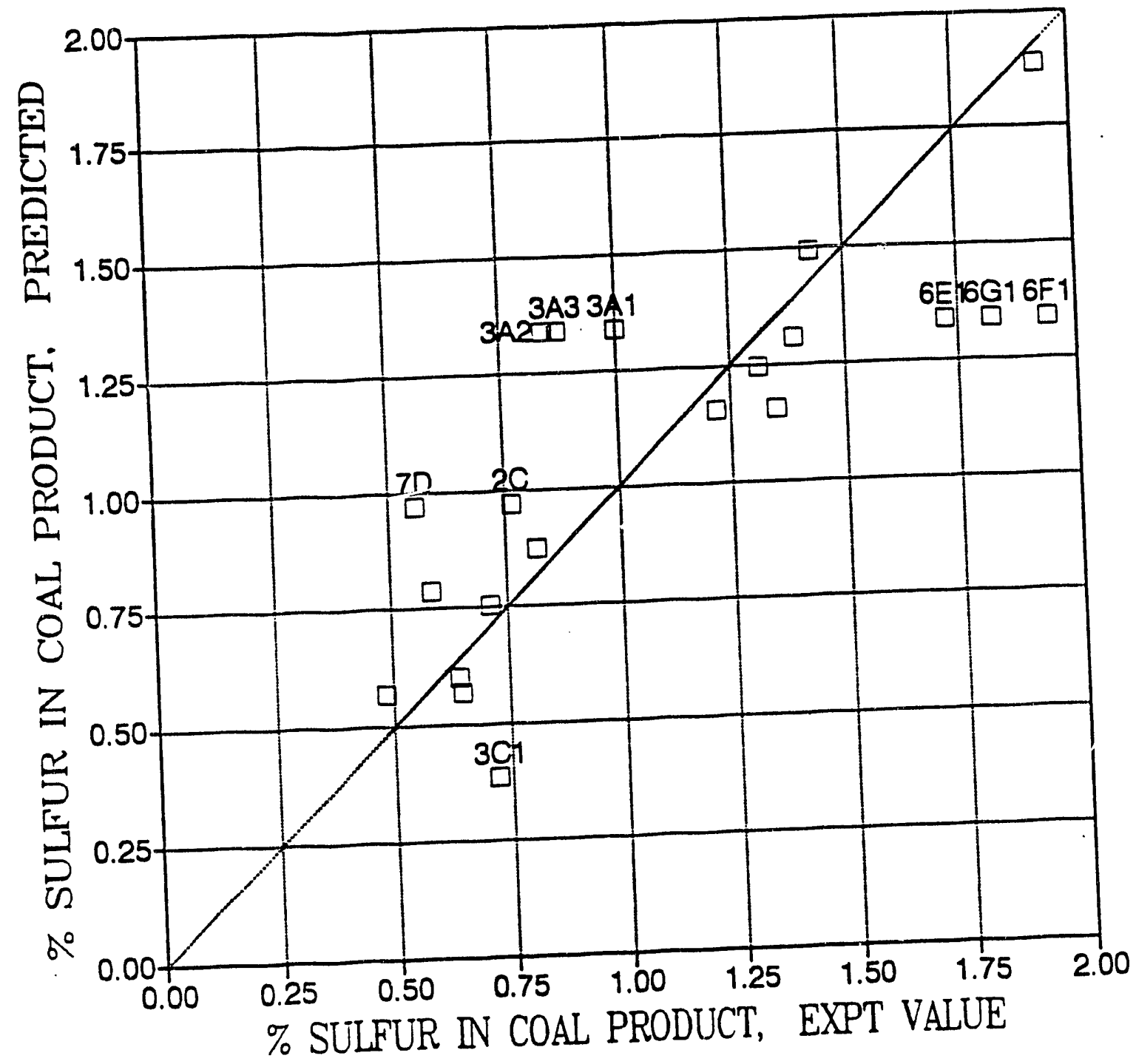

Figure 3-2. Comparison of Predicted and Experimental Values for Sulfur Content of $\mathrm{MCL}$ Coal Product - Pittsburgh No. $8 ; \mathrm{KOH} / \mathrm{NaOH}=1$ 
experimentally determined sulfur levels may be simply due to the small number of samples analyzed in these runs to provide a good estimate of the actual sulfur level.

The effects of countercurrent versus cocurrent nitrogen flow was evaluated by comparing sulfur removal from runs with otherwise similar operating conditions. Runs $7 C$ and $7 D$, with nitrogen flow in countercurrent direction to the coal/caustic flow, resulted in sulfur dioxide removal of 91.3\% and 92.3\%. By comparison, the corresponding Runs $2 \mathrm{C}$ and $3 \mathrm{Cl}$ with nitrogen and coal/caustic flow in cocurrent direction, resulted in lower sulfur dioxide removal of $89.5 \%$ and $90.0 \%$. In runs with cocurrent nitrogen and coal/causti: flow, the temperature of the coal/caustic mixture in the first heated zone was typically about $130^{\circ} \mathrm{C}$ below the kiln wall temperature. In runs with countercurrent nitrogen and coal/caustic flow, the temperature sensor for the coal/caustic mixture was moved downstream near the second heated zone. However, the sensor temperature in these runs was typically only $30^{\circ} \mathrm{C}$ below the kiln wall temperature. Therefore, the higher sulfur removal for the countercurrent nitrogen flow runs was due to longer residence time of the coal/caustic mixture at temperatures of near $400^{\circ} \mathrm{C}$. For Pittsburgh No. 8 coal processed with 50:50 $\mathrm{KOH} / \mathrm{NaOH}$, no tests were conducted with some of the kiln heaters shut off. Thus, no data are available to assess the effects of shorter residence time on sulfur removal due to shut off of the heated zones.

Runs $7 D$ and $9 B$ were conducted using caustic mixtures that contained regenerated caustic. In Run 7D, this caustic mixture was the evaporator flake product obtained from an evaporator feed consisting of $51 \%$ caustic $(50: 50 \mathrm{KOH} / \mathrm{NaOH})$, prepared by mixing regenerated $13 \%$ caustic $(50: 50$ $\mathrm{KOH} / \mathrm{NaOH})$ with purchased caustic solids $(50: 50 \mathrm{KOH} / \mathrm{NaOH})$. The concentration of regenerated caustic in the caustic feed to the kiln in Run 70 was $14 \%$. In Run 9B, the caustic feed was the evaporator flake product obtained totally from regenerated caustic. This evaporator produci contained $80.6 \%$ potassium and sodium hydroxide, $5.6 \%$ potassium and sodium carbonate, $0.4 \%$ potassium and sodium sulfide, and approximately 
13.4\% moisture. The Run $7 D$ and Run $9 B$ test results show sulfur dioxide removal of $92.3 \%$ and $93.2 \%$, respectively. These test results ciemonstrate that high sulfur removal can be achieved using regenerated caustic.

Runs $8 A$ and $8 B$ were conducted under simil. conditions except that 14 mesh coal feed was used in Run $8 A$ and 6 mesh coal feed in Run 8B. The average sulfur content of the MCL coal product was $1.22 \%$ for Run $8 A$ and $1.35 \%$ for Run $8 B$. Therefore, it appears that processing with a finer coal feed would result in higher sulfur removal.

\subsubsection{Pittsburgh No. 8; NaOH Only}

In the analysis results presented in Table $3-2,94.7 \%$ sulfur dioxide removal (based on $1 b /$ million Btu removed from run-of-mine coal) was obtained for Run $9 \mathrm{C}$, with kiln wall temperature of $438^{\circ} \mathrm{C}$, residence time of 2.1 hours, caustic/coal ratio of 2.5 , and nitrogen and coal/caustic flow in countercurrent direction. In addition, over $90 \%$ sulfur dioxide removal was obtained during the first 14 hours of operation for Run $4 C 1$ (shown as Run 4C1-1 in Table 3-2). However, the same level of sulfur removal was not achieved in latter parts of the same run. Sulfur dioxide removal for all other runs was less than $88 \%$. At caustic/coal of 1.5 or 1.0, and with nitrogen and coal/caustic flow in cocurrent direction, sulfur dioxide removal was less than $80 \%$, as shown by the test results from Runs $6 \mathrm{Al}, 6 \mathrm{BI}$ and $6 \mathrm{Dl}$.

The correlation between the sulfur content of the coal product and caustic/coal ratio $(R)$ and the kiln wall temperature $\left(T\right.$ in $\left.{ }^{\circ} \mathrm{C}\right)$ is:

$$
\text { \% sulfur }=9.785-0.6440 R-0.01756 T
$$

with a correlation coefficient of 0.8971 , if the regression analysis exclude data points for runs with shut off of one or two kiln heaters (Runs 4C4, 4C5, $456,4 C 7,5 B 3$ and 5B4). These excluded data points represent ruirs operated with shorter residence time in the heated zones, which is ar additional parameter not addressed in the above correlation. 
The correlation between the sulfur content of the coal product and the kiln wall temperature, if in addition only runs with caustic/coal ratio $\geq 2$ are included in the regression analysis, is as follows:

$$
\text { \% sulfur }=11.443-0.02466 \mathrm{~T}
$$

with a correlation coefficient of -0.7366 . The correlation represented by equation [4] is very similar to the correlation represented by equation [2], and gives only slightly higher sulfur content for the coal product. This implies that with caustic/coal $\geq 2, \mathrm{NaOH}$ is almost as effective as 50:50 $\mathrm{KOH} / \mathrm{NaOH}$ in removing sulfur from Pittsburgh No. 8 coal. By comparing the correlations represented by equations [1] and [3], it al so appears that sulfur removal is more sensitive to the caustic/coal ratio for $\mathrm{NaOH}$ than for $50: 50 \mathrm{KOH} / \mathrm{NaOH}$. At caustic/COal ratio of 1.0 or 1.5 , these correlations indicate that $50: 50 \mathrm{KOH} / \mathrm{NaOH}$ would be more effective than $\mathrm{NaOH}$ in removing sulfur from Pittsburgh No. 8 coal. The difference in sulfur removal could be partly attributed to the lower melting point of the $50: 50 \mathrm{KOH} / \mathrm{NaOH}$ (approximately $220^{\circ} \mathrm{C}$ ) versus $\mathrm{NaOH}\left(318^{\circ} \mathrm{C}\right.$ ), so that there is effectively longer residence time for the mixed caustic than for $\mathrm{NaOH}$ in molten form to penetrate the coal matrix. The intimate contact between molten caustic and the coal matrix is also apparently more important for low caustic/coal ratios, where less molten caustic is accessible to the coal matrix. However, these comparisons may no longer be applicable if molten caustic feed were to be used in the MCL process.

The effects of reaction temperature and caustic/coal ratio are also illustrated in Figure 3-3. It is shown that operation with high kiln wall temperaiure and caustic/coal ratio $\geq 2$ would result in low sulfur content in the coal product. Again, it is conceivable that with molten caustic feed, high sulfur removal can be achieved even at low caustic/coal ratios.

In Figure 3-4, the sulfur content of the $M C L$ coal product from analysis of the samples is compared with the predicted values according to the correlation represented by equation [3]. For all 14 runs with residence time of 2 hours, the predicted and experimental sulfur levels 


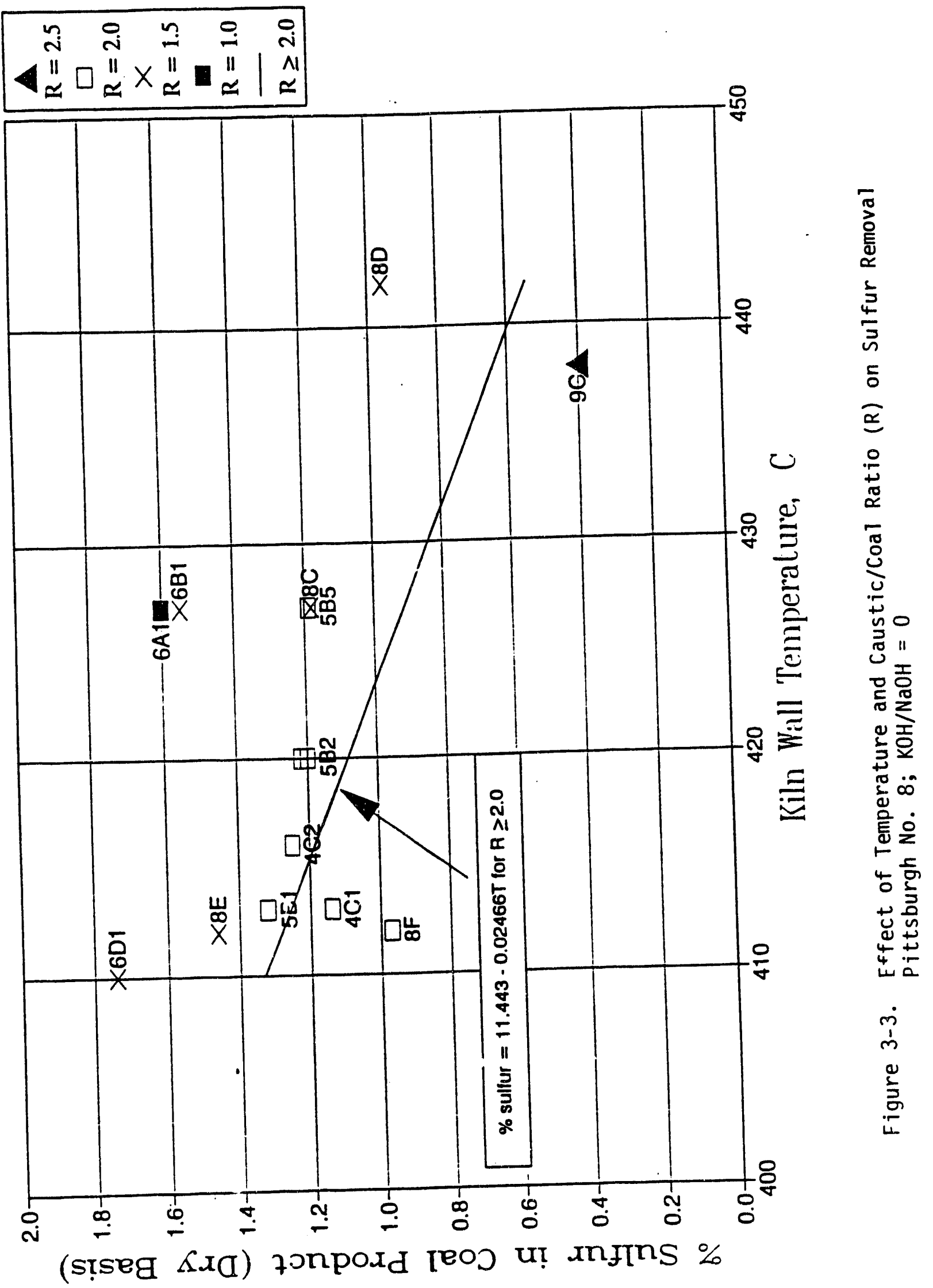




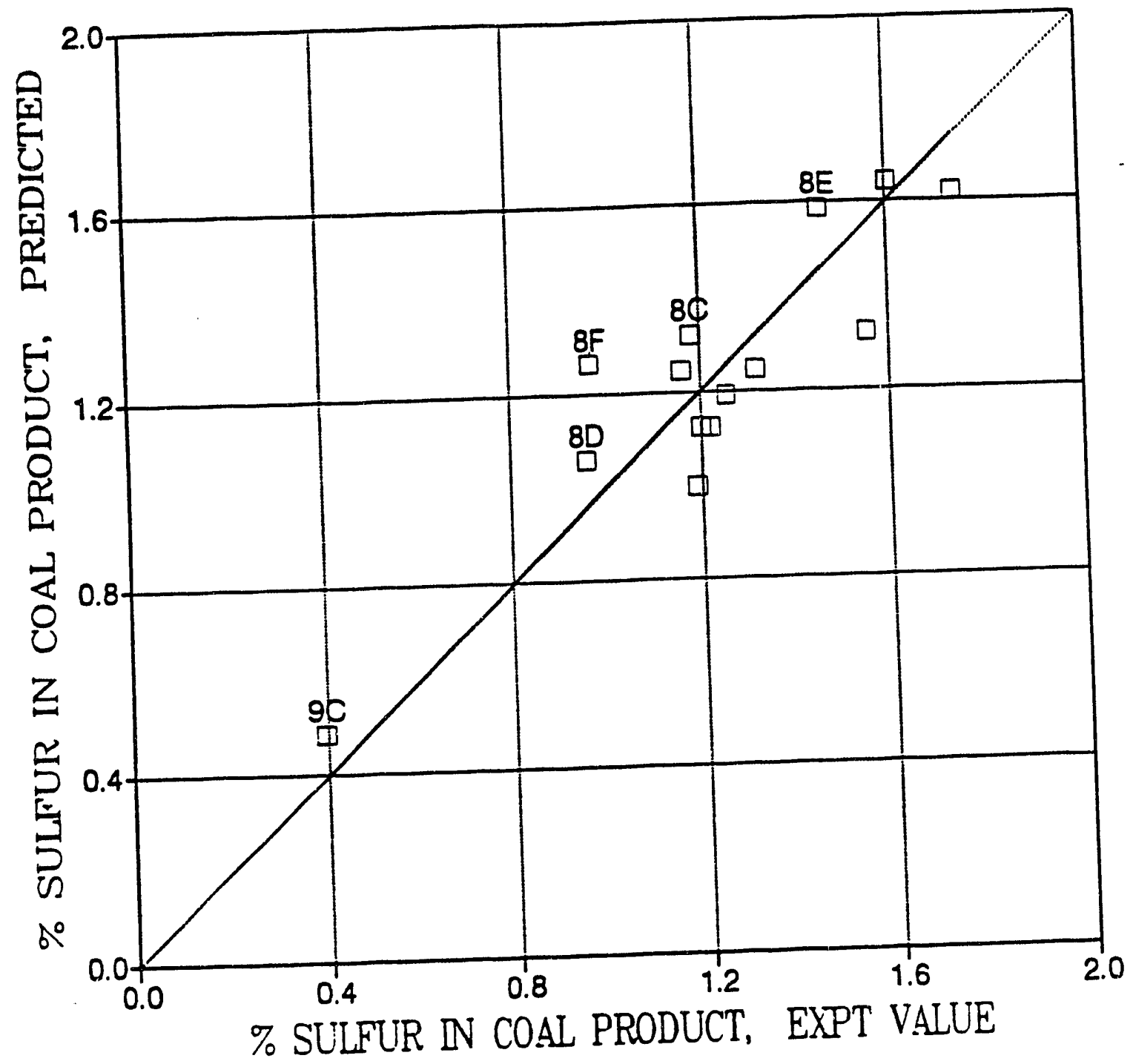

Figure 3-4. Comparison of Predicted and Experimental Values for Sulfur Content of $\mathrm{MCL}$ Coal Product.. Pittsburgh No. 8; $\mathrm{KOH} / \mathrm{NaOH}=0$ 
are in good agreement. The runs with shorter residence times are not represented in this figure. Examination of the data points, however, indicated that for all five runs (Runs $8 \mathrm{C}, 80,8 \mathrm{E}, 8 \mathrm{~F}$ and $9 \mathrm{C}$ ) conducted with nitrogen flow in countercurrent direction to the flow of the coal/caustic mixture, the predicted sulfur levels are higher than the experimental values. This suggests that the correlation equation [3] over predicts the sulfur levels in the case of countercurrent nitrogen fiow, which is more effective than cocurrent nitrogen flow in sulfur removal.

There is only one pair of runs to directly compare the effects of countercurrent versus cocurrent nitrogen flow on sulfur removal. Runs 6B1 and $8 \mathrm{C}$ were conducted under similar conditions except that nitrogen flow was in countercurrent direction to coal/caustic flow in the latter run, and that 6 mesh coal was fed to the kiln. Even with the coarser coal fed, the sulfur dioxide removal for Run $8 \mathrm{C}$, at $84.0 \%$, was higher than the $80.0 \%$ obtained for Run 6Bl. This again demonstrates that countercurrent nitrogen flow is more effective than cocurrent nitrogen flow in sulfur removal.

The effect of coal feed size on sulfur removal is less clear when only sodium hydroxide was used as the leaching agent. Runs $8 C, 8 D$ and $8 E$ were conducted with 6 mesh coal feed. However, these runs were also all conducted with a caustic/coal ratio of 1.5 and nitrogen and coal/caustic flow in countercurrent direction. There were no other runs conducted at similar operating conditions and with 14 mesh coal feed to provide direct comparison. Runs $8 E$ and $8 F$ ( 14 mesh coal feed) were both conducted with kiln wall temnerature of $412^{\circ} \mathrm{C}$, residence time of 2.1 hours and countercurreni nitrogen flow. With a caustic/coal ratio of 2.0 , the sulfur content of the coal product from Run $8 \mathrm{~F}$ was $0.97 \%$. Using the dependence of sulfur content on caustic/coal ratio as represented by equation [3], the projected sulfur content of the coal product would be $1.29 \%$ at a caustic/coal ratio of 1.5 with 14 mesh coal feed. The sulfur content of the coal product from Run $8 \mathrm{E}$ was $1.46 \%$. Thus, this indirect comparison shows that sulfur removal would be higher for 14 mesh than for 6 mesh coal feed. 
Runs $4 C 4$ and 5B3 were operated with the Zone 1 heater turned off. In addition, Runs 4C5, 4C6, 4C7 and 5B4 were operated with Zone 1 and Zone 2 heaters turned off. Turning the heaters off effectively reduced the residence times of the coal/caustic mixture in the heated zones to 1.5 hours (one heater turned off) or 1.0 hour ( 2 heaters turned off). The sulfur removal for these runs are compared with the sulfur removal for runs with all four kiln heaters operating (residence time of 2.0 hours):

$\underline{\text { Run }}$

$\begin{array}{llllllll}4 C 3 & 4 C 4 & 4 C 5 & 4 C 6 & 4 C 7 & 5 B 2 & 5 B 3 & 5 B 4\end{array}$

Kiln Wall Temp. ${ }^{\circ} \mathrm{C} \quad 420 \quad 423 \quad 430 \quad 435 \quad 441 \quad 420 \quad 423 \quad 430$

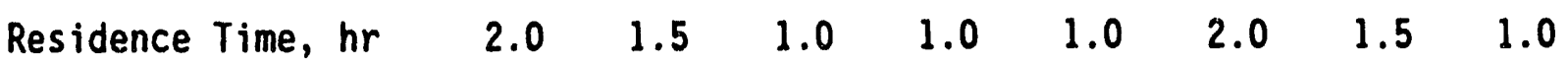

$\begin{array}{llllllllll}\text { \% Sulfur in Coal } & 1.22 & 1.17 & 1.35 & 1.43 & 1.22 & 1.20 & 1.46 & 1.60\end{array}$

The effects of residence time orl sulfur removal are difficult to assess by only comparing the test results from any two runs. However, it is clear from the Runs $4 C 5,4 C 6$ and $4 C 7$ test results that at a residence time of 1.0 hour, less sulfur was removed from the coal than in Runs 4 C 3 and $4 C 4$, which were operated for longer residence times at lower kiln wall temperatures. The Runs 5B2, 5B3 and 5B4 test results also show that as the residence time decreased from 2.0 hours to 1.5 hours and then to 1.0 hour, the sulfur content of the coal product increased from $1.20 \%$ to $1.46 \%$ and then to $1.60 \%$, notwithstanding the higher kiln wall temperatures for runs with the shorter residence times.

\subsubsection{Kentucky No. 9}

There were fewer number of tests conducted with Kentucky No. 9 than with Pittsburgh No. 8 coal feed. In the analysis results presented in Tab:e 3-3, four tests were conducted using 50:50 KOH/NaOH and five tests were conducted using only $\mathrm{NaOH}$. Specifically, the test results from Run $7 B$ show that with nitrogen flow in countercurrent direction to coal feed, $90.5 \%$ sulfur dioxide removal (from run-of-mine coal on $1 \mathrm{~b} / \mathrm{milli}$ ion Btu basis) was achieved using $50: 50 \mathrm{KOH} / \mathrm{NaOH}$, caustic/coal $=3$, kiln wall temperature of $427^{\circ} \mathrm{C}$, and residence time of 2.1 hours. For Run $7 \mathrm{~A}$ with 
caustic/coal $=2.5$ and same operating conditions as Run $7 B$, an average sulfur dioxide removal of $88.0 \%$ was obtained. There was a period in the middle of Run $7 \mathrm{~A}$ (designated as Run $7 \mathrm{~A}-1$ ), however, during which $92.0 \%$ sulfur dioxide removal was obtained. These test results demonstrate that under the appropriate operating conditions, compliance coal can be obtained using the MCL process and Kentucky No. 9 coal feed.

The sulfur dioxide removal for the Kentucky No. 9 tests conducted using $\mathrm{NaOH}$ was all under $83 \%$, but all these tests were at mild temperature conditions and caustic/coal ratio of 2.0. It may be possible to attain much higher sulfur dioxide removal with nitrogen flow in countercurrent direction to flow of the coal/caustic mixture, kiln wall temperature $\geq 427^{\circ} \mathrm{C}$, and using either a caustic/coal ratio $>2.0$ or caustic feed in molten form. (If caustic is fed to the kiln at temperature in molten form instead of as flakes at room temperature, the coal/caustic mixture would be at reaction temperature for a longer time.)

As shown in Figure 3-5, high kiln wall temperature and the use of 50:50 $\mathrm{KOH} / \mathrm{NaOH}$ instead of $\mathrm{NaOH}$ generally lead to high sulfur removal. There is an insufficient number of data points to obtain a two-parameter correlation between the sulfur content of the coal product and the caustic/coal ratio $(R)$ and the kiln wall temperature $\left(T\right.$ in $\left.{ }^{\circ} \mathrm{C}\right)$. However, for processing with $50: 50 \mathrm{KOH} / \mathrm{NaOH}$, there is good correlation between the sulfur content of the coal product and caustic/coal ratio, at a kiln wall temperature of $427^{\circ} \mathrm{C}$ :

$$
\% \text { sulfur }=1.217-0.2174 R
$$

with a correlation coefficient of -0.9748 . Also, for processing with $\mathrm{NaOH}$, there is good correlation between the sulfur content of the coal product and kiln wall temperature, at a caustic/coal ratio of 2.0 :

$$
\% \text { sulfur }=5.855-0.01125 \mathrm{~T}
$$




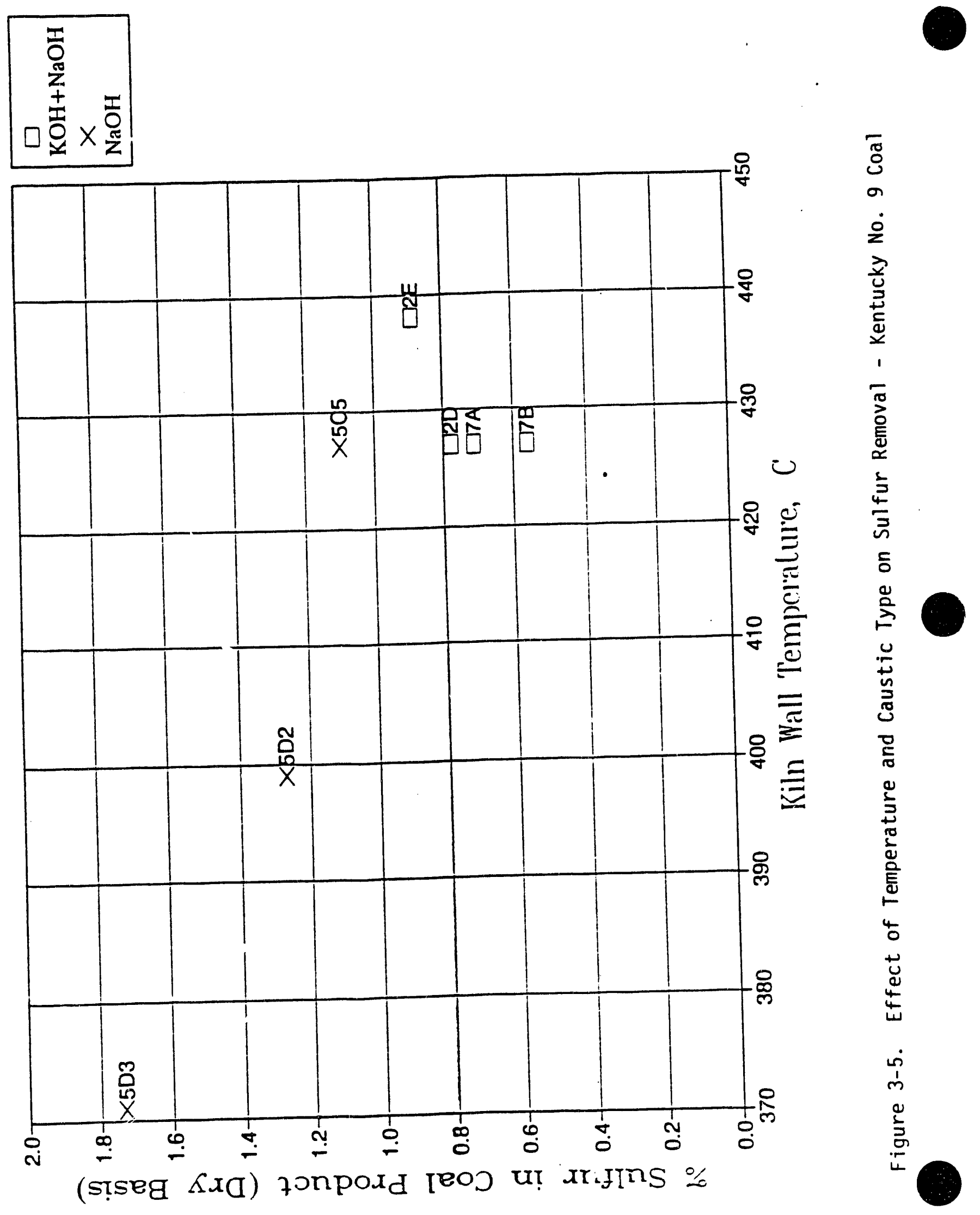


with a correlation coefficient of -0.9665 . Compared to the correlations [1] to [4] for Pittsburgh No. 8 coal, the smaller regression coefficients in the above correlations appear to indicate lesser dependence of sulfur removal on caustic/coal ratio and kiln wall temperature in the processing of Kentucky No. 9 coal.

There are four pairs of runs that can be used to compare sulfur removal for Kentucky No. 9 coal versus Pittsburgh No. 8 coal. Each pair represents operation at the same conditions except with a different coal feed. The sulfur contents of the Kentucky No. 9 and Pittsburgh No. 8 coal product for these runs were:

\begin{tabular}{|c|c|c|c|c|}
\hline Coal & 1st Pair & 2nd Pair & 3rd Pair & 4th Pair \\
\hline NT 9 & $0.56 \%$ (Run 7B) & $0.78 \%$ (Run 2D) & $0.47 \%$ (Run $7 A-1$ ) & $1.10 \%$ (Run $5 C 5$ ) \\
\hline PITT 8 & $0.64 \%$ (Run $7 C$ ) & $0.77 \%$ (Run $2 \mathrm{C}$ ) & $0.59 \%$ (Run 9A) & $1.19 \%$ (Run $5 B 5$ ) \\
\hline
\end{tabular}

Overall, the sulfur content of the coal product was approximately the same for the two coals under similar operating conditions. This also implies that more sulfur was removed from the Pittsburgh No. 8 coal, because the average sulfur content of this feed coal is $4.27 \%$ as compared to the $3.41 \%$ for Kentucky No. 9 coal.

\subsubsection{Ash Removal}

The ash content of the MCL coal product also decreases with increasing caustic/coal ratio and increasing reaction temperature, and depends on the type of coal and caustic used in processing, and the residence time of the coal/caustic mixture in the heated zones of the rotary kiln.

\subsubsection{Pittsburgh $\mathrm{No} \cdot 8 ; 50: 50 \mathrm{KOH} / \mathrm{NaOH}$}

As shown in Table 3-1, ash removal for Pittsburgh No. 8 coal is strongly dependent on reaction temperature. Thi: ash content of the coal product was above $1.1 \%$ for all runs with kiln wall temperature $\leq 410^{\circ} \mathrm{C}$. Kiln wall temperatures $\geq 427^{\circ} \mathrm{C}$ were generally needed to reduce the ash content of the coal product to below $0.5 \%$, as indicated by the test results from Runs $3 B 1,3 C 1,9 A, 9 A 1$ and $9 B$. 
The effect of caustic/coal ratio on ash removal appears to be more pronounced at low ratio levels. For example, the ash content of the coal product increased from $0.64 \%$ for Run $2 \mathrm{C}$ (caustic/coal $=2$ ) to $1.48 \%$ for Run $3 A 2$ (caustic/coal $=1$ ), at the same kiln wall temperature of $427^{\circ} \mathrm{C}$ and approximately the same residence time. On the other hand, the ash content of the coal product was $0.23 \%$ for both Run $3 B 1$ (caustic/coal = 2) and Run $3 \mathrm{Cl}$ (caustic/coal $=3$ ). These two runs were both operated at the kiln wall temperature of $438^{\circ} \mathrm{C}$ and residence time of 2.0 hours. Thus, it appears that a minimum caustic/coal ratio may be needed for efficient ash removal. It is possible, however, that a lower caustic/coal ratio would be effective if molten caustic were to be fed to the kiln, because of the greater accessibility of the caustic to the coal matrix.

Regression analysis of the test data shows that the correlation between the ash content of the coal product and the caustic/coal ratio ( $R$ ) and the kiln wall temperature $\left(T\right.$ in $\left.{ }^{\circ} \mathrm{C}\right)$ is:

$$
\text { \% ash }=11.870-0.7869 R-0.02191 \mathrm{~T}
$$

with a correlation coefficient of 0.8109 . There is a better correlation between the ash content of the coal product and the kiln wall temperature when only runs with caustic/coal ratio $\geq 2.0$ are included in the regression analysis:

$$
\text { \% ash }=15.941-0.03588 \mathrm{~T}
$$

with a correlation coefficient of -0.9407 . The effects of high caustic/coal ratio and high kiln wall temperature in reducing the ash content of the coal product are also illustrated in figure 3-6.

In Figure 3-7, the ash content of the MCL coal product from analysis of the samples is plotted against the predicted values represented by the correlation equation [7]. For 15 of the 24 runs, the predicted and experimental ash levels are in fairly good agreement. For Runs $1 C, 3 A 3$, 


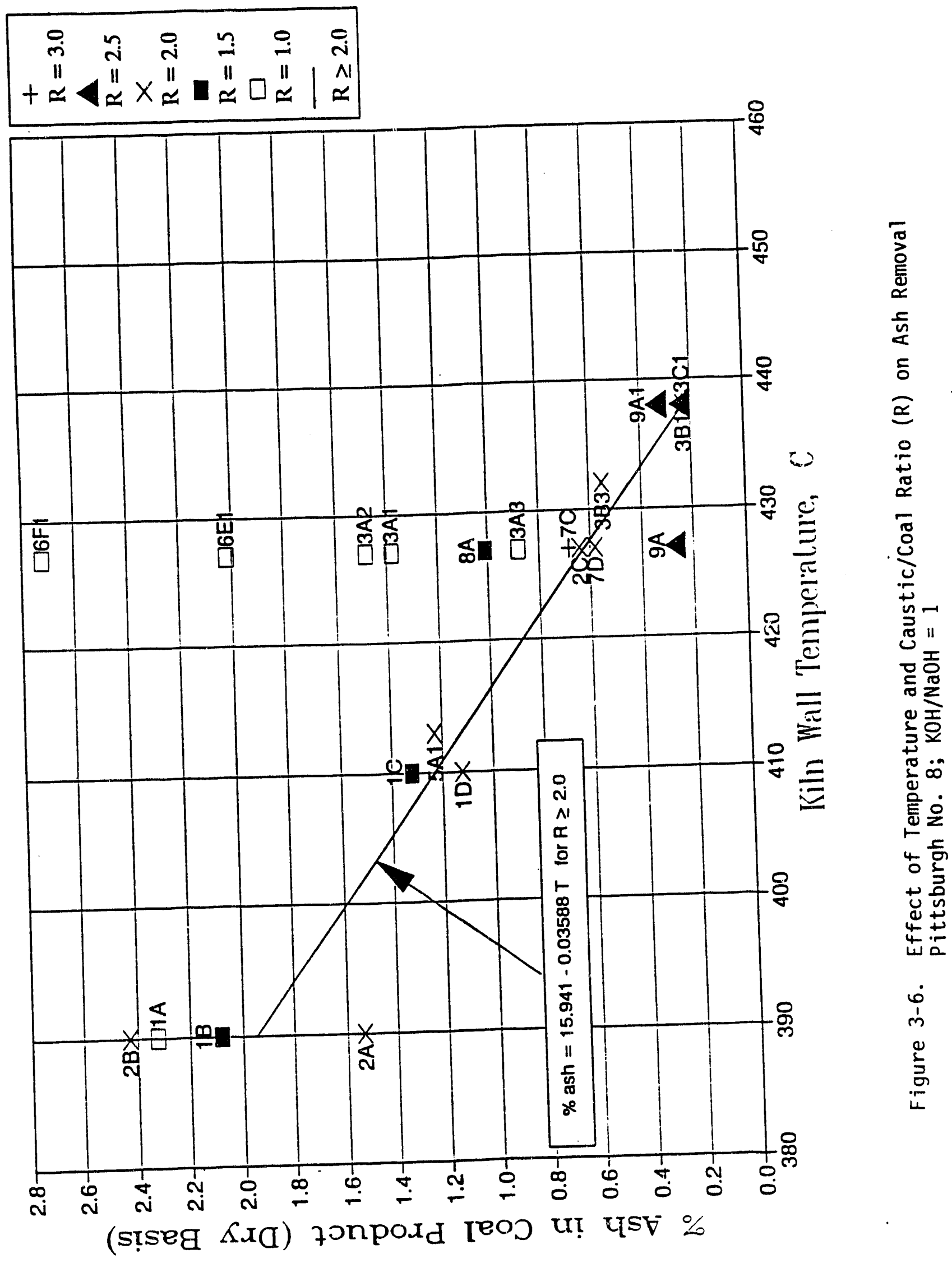




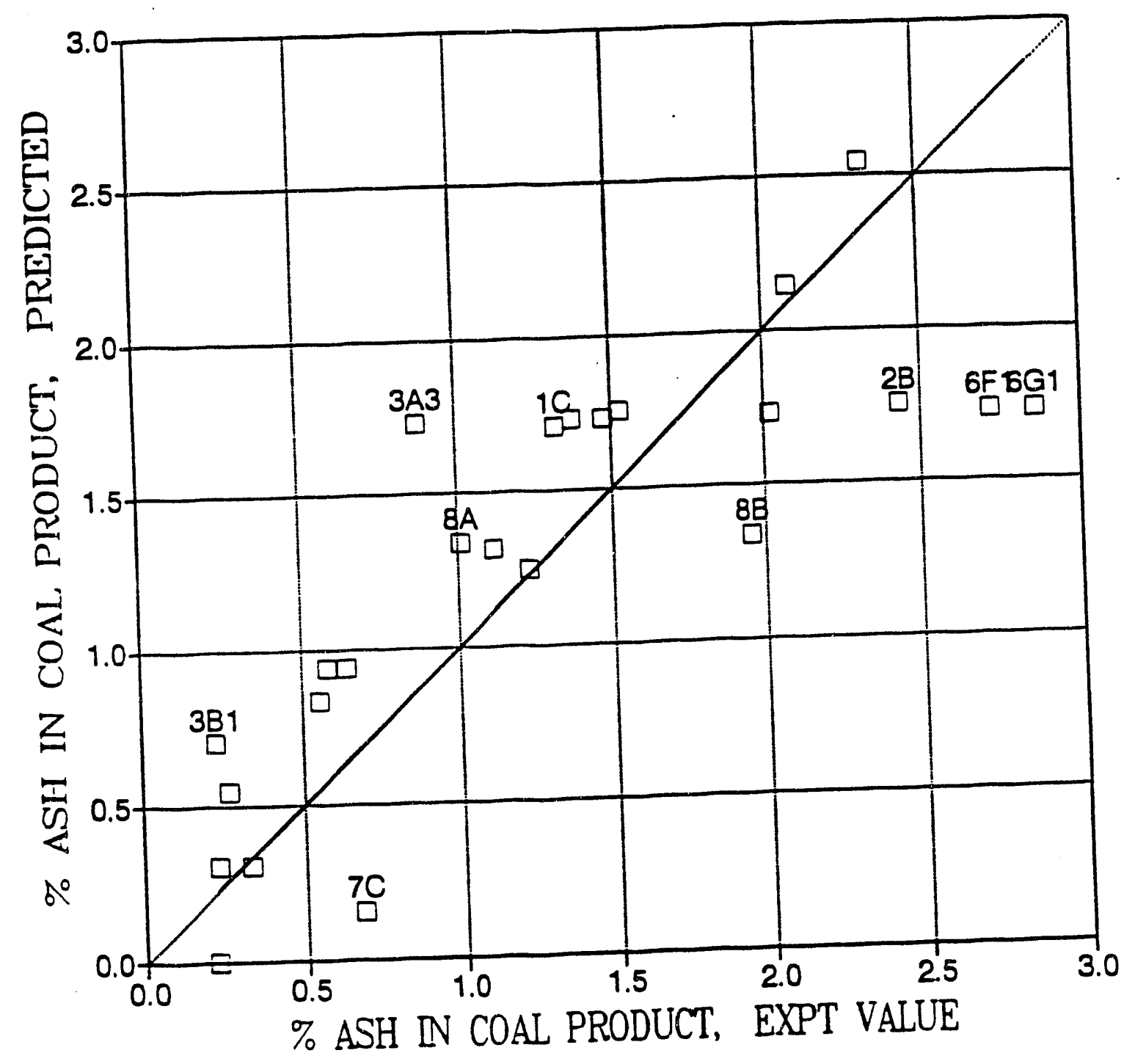

Figure 3-7. Comparison of Predicted and Experimental Values for Ash Content of $\mathrm{MCL}$ Coal Product - Pittsburgh No. $8 ; \mathrm{KOH} / \mathrm{NaOH}=1$ 
3B1 and 8A, the predicted ash levels are higher than the experimental values. For Runs $2 B, 6 F 1,6 G 1,7 C$ and $8 B$, the predicted ash levels are lower than the experimental values. The largest discrepancies between the predicted and experimental ash levels are associated with Runs 2B, 3A3, $6 F 1$ and 6G1. For these four runs, however, only one sample from each run was acquired and analyzed, and the disagreement may be due to the insufficient sample size to provide a good estimate of the actual ash level. The coal feed in Run $8 B$ was 6 mesh, which led to higher than predicted ash level in the coal product. In addition, Run 3BI was operated with a caustic/coal ratio of 2.0 and kiln wall temperature of $438^{\circ} \mathrm{C}$, whereas Run $7 \mathrm{C}$ was operated with a caustic/coal ratio of 3.0 and kiln wall temperature of $427^{\circ} \mathrm{C}$. The lower than predicted ash level for Run 3B1, along with the higher than predicted ash level for Run $7 C$, is an indication that the dominating factor for ash removal is kiln temperature when the caustic/coal ratio $\geq 2.0$. In fact, the predicted ash levels using correlation equation [8] are $0.23 \%$ for Run $3 B$ 1 and $0.62 \%$ for Run $7 C$, which agree very well with the corresponding experimental ash levels of $0.23 \%$ and $0.68 \%$.

The ash content of the coal product from Runs $7 D$ and $9 B$ was $0.58 \%$ and $0.24 \%$, respectively. Both runs were conducted using caustic mixtures containing regenerated caustic. These test results confirm that high ash removal can be readily achieved using regenerated caustic.

The effect of feed coal size on ash removal can be assessed by comparing the test results from Runs $8 \mathrm{~A}$ and $8 \mathrm{~B}$, which were conducted under otherwise similar conditions but with 14 mesh and 6 mesh coal feed, respectively. The average ash content of the coal product from Run $8 \mathrm{~A}$ was $1.01 \%$. By comparison, the average ash content of the coal product from Run $8 \mathrm{~B}$ was $1.95 \%$. Therefore, it appears that the use of a finer coal feed in the MCL process could effect higher ash removal, at least at a low caustic/coal ratio of 1.5 .

As shown in Figure 3-8, there is reasonably good correlation between the sulfur content and ash content of the coal product: 


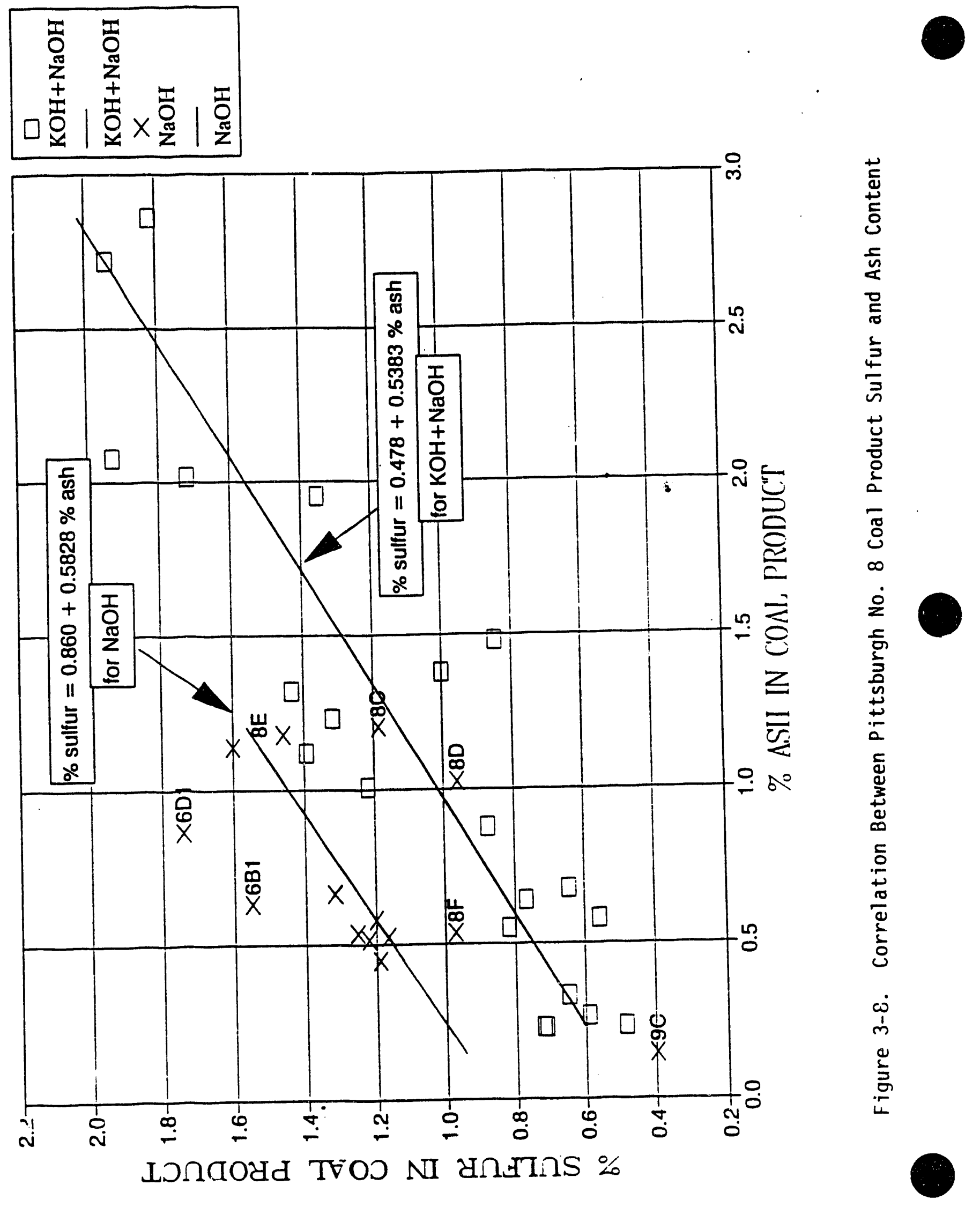




$$
\% \text { sulfur }=0.478+0.5383 \% \text { ash }
$$

with a correlation coefficient of 0.9075 , despite some scattering of data points on both sides of the correlation line. This implies that in general, the operating conditions that favor sulfur removal also facilitate ash removal.

\subsubsection{Pittsburgh No. 8; NaOH Only}

The analysis results presented in Table 3-2 show that $\mathrm{NaOH}$ is apparently more effective than $50: 50 \mathrm{KOH} / \mathrm{NaOH}$ in removing ash from coal. This is demonstrated by comparing the test results from three sets of runs, all conducted at a residence time of approximately 2.0 hours and under similar operating conditions within each set:

$\begin{array}{lcccc}\text { Run } & \text { Caustic/Coal } & \text { Nall Temp. }{ }^{\circ} \mathrm{C} & \text { KOH/NaOH } & \text { Ash Content of Coal Product } \\ \text { 2C } & 2.0 & 427 & 1 & 0.64 \% \\ 5 \mathrm{~B} 5 & 2.0 & 427 & 0 & 0.45 \% \\ & 2.0 & 413 & 1 & 1.23 \% \\ 5 \mathrm{Al} & 2.0 & 412 & 0 & 0.54 \% \\ 8 \mathrm{~F} & 2.5 & 438 & 1 & 0.24 \% \\ 9 \mathrm{~B} & 2.5 & 438 & 0 & 0.15 \%\end{array}$

In each of the three sets, the run using $\mathrm{NaOH}$ resulted in a coal product containing less ash than the coal product from the run using 50:50 $\mathrm{KOH} / \mathrm{NaOH}$. In particular, the average ash content of the coal product from Run $9 \mathrm{C}$ was only $0.15 \%$. This suggests that $\mathrm{NaOH}$ may be used for the production of ultra low-ash coal under appropriate operating conditions.

The ash content of the coal product can be correlated with the caustic/coal ratio $(R)$ and the kiln wall temperature $\left(T\right.$ in $\left.{ }^{\circ} \mathrm{C}\right)$, by regression analysis of the test data for runs with residence time of approximately 2.0. hours:

$$
\% \text { ash }=2.774-0.7416 R-0.00174 T
$$


with a correlation coefficient of 0.8836 . In addition, if only runs with caustic/coal ratio $\geq 2.0$ are considered, the correlation between the ash content of the coal product and kiln wall temperature is:

$$
\text { \% ash }=7.010-0.01551 \mathrm{~T}
$$

with a correlation coefficient of -0.8945 . In comparing the correlation equations [7] for 50:50 $\mathrm{KOH} / \mathrm{NaOH}$ and [10], the predicted ash content of the coal product would always be lower for processing with $\mathrm{NaOH}$ than for 50:50 $\mathrm{KOH} / \mathrm{NaOH}$, at any caustic/coal ratio and up to a kiln wall temperature of $444^{\circ} \mathrm{C}$.

In Figure 3-9, it is shown that high caustic/coal ratios and high kiln wall temperatures are necessary to reduce the ash content of the coal product to very low levels. In Figure 3-10, the ash contents of the coal product as predicted from the correlation equation [10] are compared with the corresponding experimental values. For 11 of the 14 runs, the predicted and experimental ash levels are in good agreement. The exceptions are Runs $6 \mathrm{Bl}, 8 \mathrm{C}$ and $8 \mathrm{E}$. However, both Runs $8 \mathrm{C}$ and $8 \mathrm{E}$ were conducted using 6 mesh coal feed, which resulted in higher ash levels than predicted by the correlation. In addition to these runs, Run $8 D$ was also conducted with 6 mesh coal feed. The average ash content of the coal product was $1.03 \%$, as compared t,o the predicted value of $0.89 \%$. Thus, for all three runs with 6 mesh coal feed, the ash contents of the coal product are higher than the predicted values. Because the predicted ash levels are based on a correlation based primarily on test data from runs with 14 mesh coal feed, the implication is that a finer coal feed would produce a $\mathrm{MCl}$ coal of lower ash content.

As in the case of sulfur removal, the effects of residence time on ash remuval can be assessed by examining the test results from the runs with one or two kiln heaters turned off, thereby reducing the residence time of the coal/caustic mixture in the heated zones: 


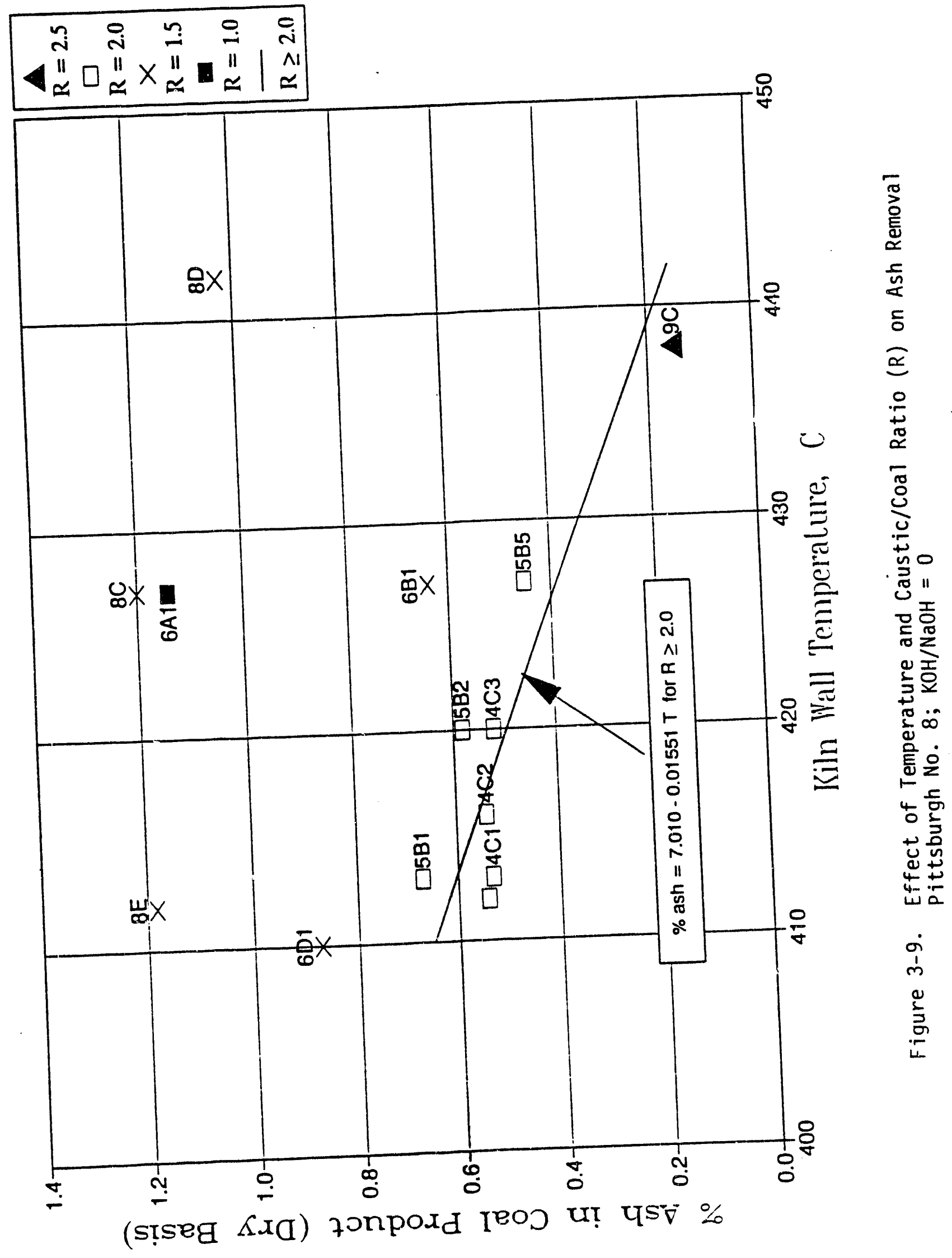




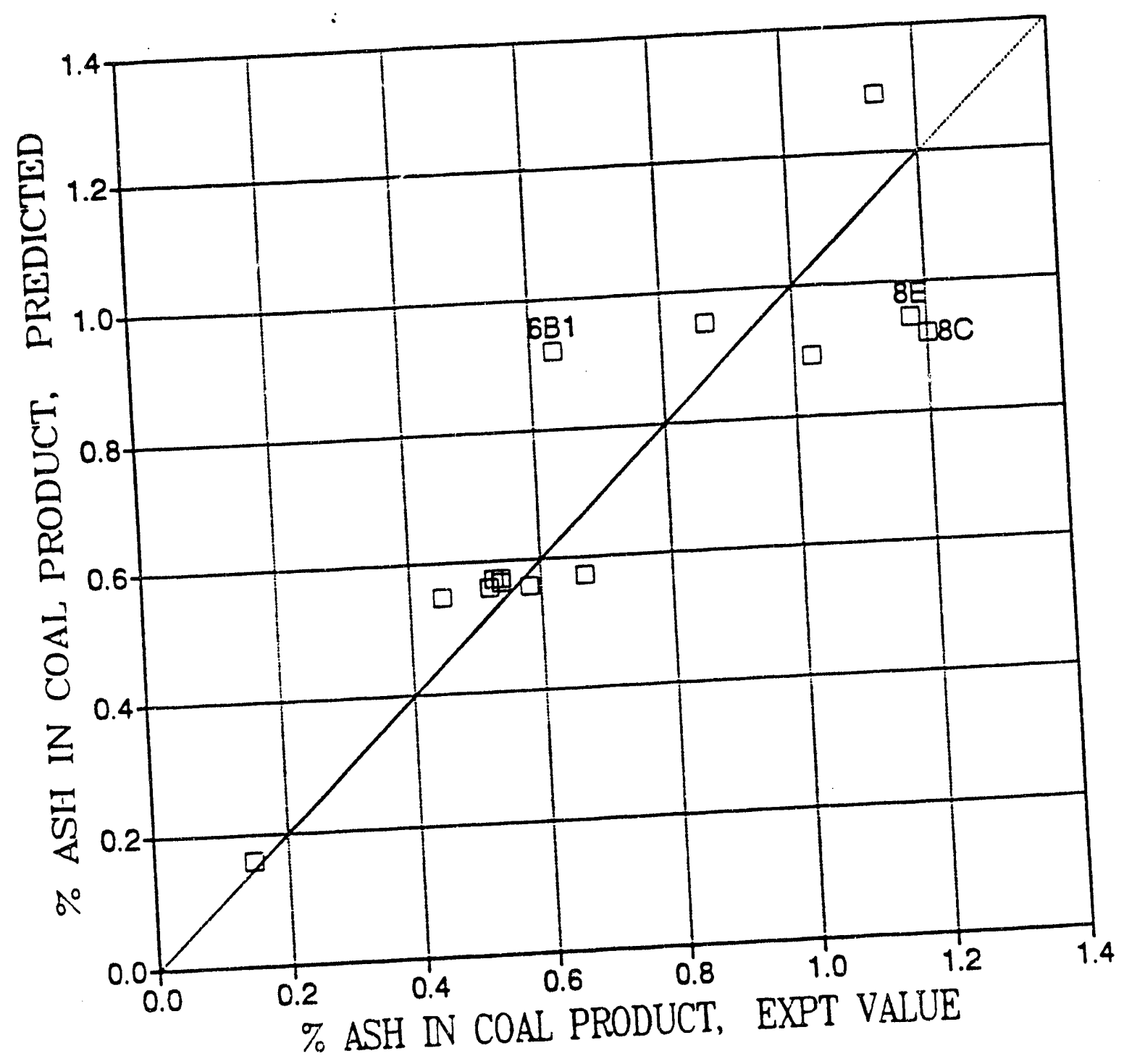

Figure 3-10. Comparison of Predicted and Experimental Values for Ash Content of $\mathrm{MCL} \mathrm{COal}$ Product - Pittsburgh No. $8 ; \mathrm{KOH} / \mathrm{NaOH}=0$ 


$\begin{array}{llllllll}4 C 3 & 4 C 4 & 4 C 5 & 4 C 6 & 4 C 7 & 5 B 2 & 5 B 3 & 5 B 4\end{array}$

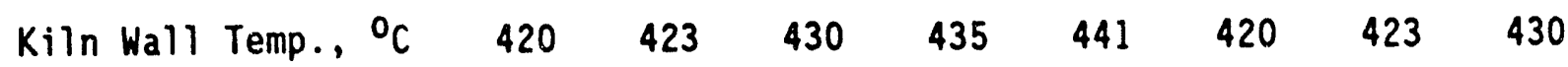

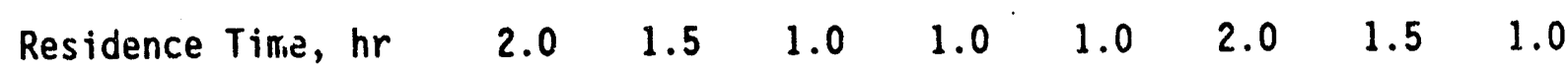

$\begin{array}{lllllllll}\text { \% Ash in Coal } & 0.52 & 0.46 & 0.68 & 0.73 & 0.64 & 0.58 & 0.63 & 0.95\end{array}$

Comparison of the test results from Runs $4 C 3$ versus $4 C 4$, and $5 B 2$ versus $5 B 3$ suggest that there is no significant impact on ash removal in reducing the residence time from 2.0 to 1.5 hours. At a residence time of 1.0 hour, however, it is evident from the Runs $4 C 5,4 C 6$ and $4 C 7$ test results that less ash was removed from the coal than in Runs $4 C 3$ and $4 C 4$. Similarly, less ash was removed from the coal in Run 5B4 than in Runs 5B2 and 5B3. For Pittsburgh No. 8 coal processed with $\mathrm{NaOH}$, it appears that a residence time of about 1.5 hours is needed for effective ash removal.

For processing with $\mathrm{NaOH}$, there is little correlation between the sulfur content and the ash content of the coal product:

$$
\% \text { sulfur }=0.860+0.5828 \% \text { ash }
$$

with a correlation coefficient of 0.5521 . As shown in Figure 3-8, there is considerable data scatter on both sides of the correlation line. Examination of the data scatter indicates that Runs 6B1 and 6D1, both operated with a caustic/coal ratio of 1.5 , resulted in coal products with higher sulfur content than predicted by the correlation. This is attributed to the higher than usual ash removal under the operating conditions for these two runs. On the other hand, Runs $8 C, 8 D, 8 E, 8 F$ and $9 \mathrm{C}$, all operated with nitrogen flow in countercurrent direction to flow of the coal/caustic mixture, resulted in coal products with lower sulfur content than predicted by the correlation. Therefore, it appears that in processing with $\mathrm{NaOH}$, countercurrent nitrogen flow is needed more for sulfur removal than for ash removal. This is probably because in countercurrent nitrogen flow, the temperature of the coal/caustic mixture in the first zone is considerably higher than that in concurrent nitrogen flow, and a longer residence time in the high temperature zones is needed for sulfur removal than for ash removal. 


\subsubsection{Kentucky No. 9}

As indicated in Table 3-3, high ash removal can be achieved with Kentucky No. 9 coal feed. Specifically, the test results from Runs 2D, 2E $5 \mathrm{C5}$ and $7 \mathrm{~B}$ demonstrate that coal products containing less than $0.5 \%$ ash can be obtained using either $50: 50 \mathrm{KOH} / \mathrm{NaOH}$ or $\mathrm{NaOH}$. Figure 3-11 shows that $\mathrm{kiln}$ wall temperatures $\geq 427^{\circ} \mathrm{C}$ are generally needed to produce $\mathrm{MCL}$ coal containing less than $0.5 \%$ ash.

There is an insufficient number of data points to obtain a correlation between the ash content of the coal product and the caustic/coal ratio or the kiln wall temperature. The effect of residence time on ash removal, however, can be assessed by comparing the test results from Runs 5C5, 5C4 and 5D1, all operated with $\mathrm{NaOH}$, caustic/coal ratio $=2.0$, and $\mathrm{kiln}$ wall temperature of $427^{\circ} \mathrm{C}$ for the heated zones, except that the Zone 1 heater was turned off in Run $5 \mathrm{C} 4$ and both the Zone 1 and Zone 2 heaters were turned off in Run 5D1. The ash content of the coal product was $0.37 \%$ for Run 5C5 (residence time of 2.0 hours), $0.50 \%$ for Run $5 C 4$ (residence time of 1.5 hours), and increased to $1.03 \%$ for Run 501 (residence time of 1.0 hour). As in the case of Pittsburgh coal, it appears that a residence time of 1.5 hours is needed to produce low ash MCL coal.

Both Runs $2 D$ and $5 C 5$ were conducted at a kiln wall temperature of $427^{\circ} \mathrm{C}$, residence time of 2.0 hours, and caustic/coal ratio $=2.0$. The average ash content of the coal product from Run 2D, processed with 50:50 $\mathrm{KOH} / \mathrm{NaOH}$, was $0.47 \%$. By comparison, Run $5 \mathrm{C5}$ was operated with $\mathrm{NaOH}$ and resulted in a coal product containing an average of $0.37 \%$ ash. This again demonstrates that $\mathrm{NaOH}$ may be more effective than $50: 50 \mathrm{KOH} / \mathrm{NaOH}$ in removing ash from coal.

There are four pairs of runs that can be used to compare ash removal for Kentucky No. 9 coal versus Pittsburgh No. 8 coal. Each pair represents operation at the same conditions except with a different coal feed. The ash contents of the Kentucky No. 9 and Pittsburgh No. 8 coal product for these runs were: 


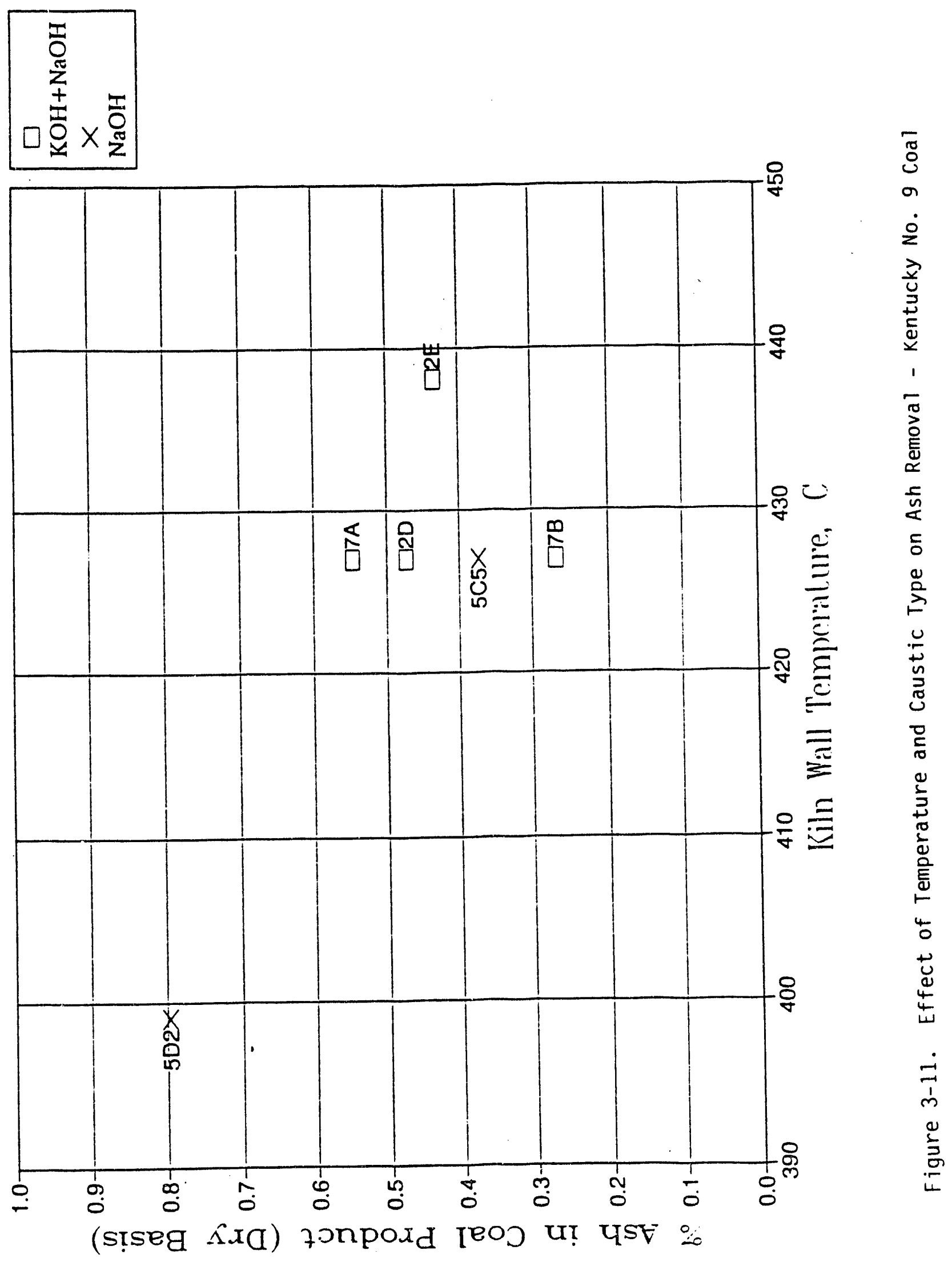




$\begin{array}{llllll}\text { Coal } & \text { 1st Pair } & \text { 2nd Pair } & \text { 3rd Pair } & \text { 4th Pair } \\ \text { KENT 9 } & 0.27 \% \text { (Run 7B) } & 0.47 \% \text { (Run 2D) } & 0.55 \% \text { (Run 7A) } & 0.37 \% \text { (Run 5C5) } \\ \text { PITT } 8 & 0.68 \% \text { (Run 7C) } & 0.64 \% \text { (Run 2C) } & 0.27 \% \text { (Run 9A) } & 0.45 \% \text { (Run 5B5) }\end{array}$

Even for Run $7 \mathrm{~A}$, the ash content for 5 of the 30 coal product samples collected and analyzed was between 0.24 to $0.29 \%$, or the same as that for Run 9A. Therefore, it appears that in most cases, a lower ash coal product could be obtained with Kentucky No. 9 than with Pittsburgh No. 8 coal feed. This could be partly due to the fact that the average ash content of the feed Kentucky No. 9 coal is $9.25 \%$ as compared to $11.57 \%$ for Pittsburgh No. 8 coal. Additional tests are needed to determine the specific processing conditions and mechanism that result in higher ash removal for Kentucky than for Pittsburgh coal.

\subsubsection{Heating Value}

As shown by the test results presented in Tables 3-1, 3-2 and 3-3, the heating value of the coal product depends on the type of caustic used for processing. With 50:50 $\mathrm{KOH} / \mathrm{NaOH}$, the average heating value of the coal product was approximately $13000 \mathrm{Btu} / \mathrm{lb}$. With $\mathrm{NaOH}$, the average heating value of the coal product increased to approach $14000 \mathrm{Btu} / \mathrm{lb}$. This was true with either Pittsburgh No. 8 or Kentucky No. 9 coal feed.

The heating value of the coal product also depends on the severity of the processing conditions. For runs conducted with Pittsburgh No. 8 coal feed and caustic/coal ratio $\geq 2.0$, the correlation between the heating value and the kiln wall temperature $\left(T\right.$ in ${ }^{\circ} \mathrm{C}$ ) for processing with 50:50 $\mathrm{KOH} / \mathrm{NaOH}$ is:

$$
\text { Btu } / 1 b=27483-33.603 T
$$

with a correlation coefficient of -0.8346 . For processing with $\mathrm{NaOH}$ :

$$
\text { Btu } / 1 b=27394-31.895 T
$$


with a correlation coefficient of -0.9094 . For Kentucky No. 9 coal feed, there were insufficient data to use regression analysis to obtain any meaningful correlation with the process parameters. Nevertheless, it is expected that high kiln wall temperature would also decrease the heating value of the coal product.

\subsubsection{Volatile Content}

The volatile content of the coal product ranged from $20.93 \%$ (run $3 \mathrm{Cl}$ ) to $34.88 \%$ (Run 1B) for Pittsburgh No. 8 coal feed, and from $22.57 \%$ (Run $5 C 5$ ) to $30.27 \%$ (Run 2E) for Kentucky No. 9 coal feed. In general, the volatile content decreases with increasing caustic/coal ratio $(R)$ and increasing kiln wall temperature $\left(T\right.$ in $\left.{ }^{\circ} \mathrm{C}\right)$. There is little correlation between the volatile content of the coal product and these two process parameters. For Pittsburgh No. 8 coal processed with $50: 50 \mathrm{KOH} / \mathrm{NaOH}$ :

$$
\% \text { volatile }=82.362-1.3507 R-0.1246 \mathrm{~T}
$$

with a correlation ccefficient of 0.5912 . For Pittsburgh No. 8 coal processed with $\mathrm{NaOH}$ :

$$
\% \text { volatile }=78.854-3.7421 R-0.1116 \mathrm{~T}
$$

with a correlation coefficient of 0.6657 . There is no clear indication whether processing with $50: 50 \mathrm{KOH} / \mathrm{NaOH}$ or $\mathrm{NaOH}$ would produce a coal product of higher volatile content. For Kentucky No. 9 coal feed, there were again insufficient data to perform meaningful regression analysis.

\subsubsection{Moisture Content}

The moisture content of the coal product ranged from $43.73 \%$ (Run 6El) to $58.35 \%$ (Run $7 C$ ) for Pittsburgh No. 8 coal feed, and from $51.69 \%$ (Run $5 C 5$ ) to $59.37 \%$ (Run 7B) for Kentucky No. 9 coal feed. Both the ki7n processing conditions and the wash train performance would effiect the moisture content. However, it appears that wash train performance was fairly uniform from run to run, and correlations could be obtained between 
the moisture content and the ash content of the coal product, as depicted in Figure 3-12. For Pittsburgh No. 8 coal processed with 50:50 KOH/NaOH:

$$
\% \text { moisture }=58.951-4.0373 \% \text { ash }
$$

with a correlation coefficient of -0.8668 . For Pittsburgh No. 8 coal processed with $\mathrm{NaOH}$ :

$$
\% \text { moisture }=56.223-3.6669 \% \text { ash }
$$

with a correlation coefficient of -0.6620 . These correlations indicate that the kiln operating conditions that lead to lower ash removal would result in lower coal porosity and surface area, and therefore also lower moisture content for the coal product. No equivalent correlations were obtained for Kentucky No. 9 coal feed because of an insufficient number of data points.

\subsubsection{Trace Elentent Analysis}

Assessment of trace elements in the feed and product coal for two runs (Run 7A with Kentucky No. 9 coal and Run 9C with Pittsburgh No. 8 coal) was performed. These two coals were subjected to a series of analysis as follows:

- Quantitative analysis for $\mathrm{Na}, \mathrm{K}, \mathrm{Cl}$ and $\mathrm{F}$

- Semi-quantitative analysis for any remaining cations.

The above analysis required different sample preparation techniques which were as follows:

- Quantitative $\mathrm{Na}$ and $\mathrm{K}$ analysis - used ASTM D2795 which is a muffle ash at $750^{\circ} \mathrm{C}$ followed by $\mathrm{a}_{2} \mathrm{SO}_{4}$ - $\mathrm{HF}$ digestion.

- Quantitative $\mathrm{Cl}$ analysis - used a Parr oxygen bomb combustion over standard anion eluent. Solutions were analyzed directly by ion chromatography.

- Semi-quantitative Emission Spectrographic Analysis (ES) - the coal ash sample, which was ultimately analyzed, was obtained from 

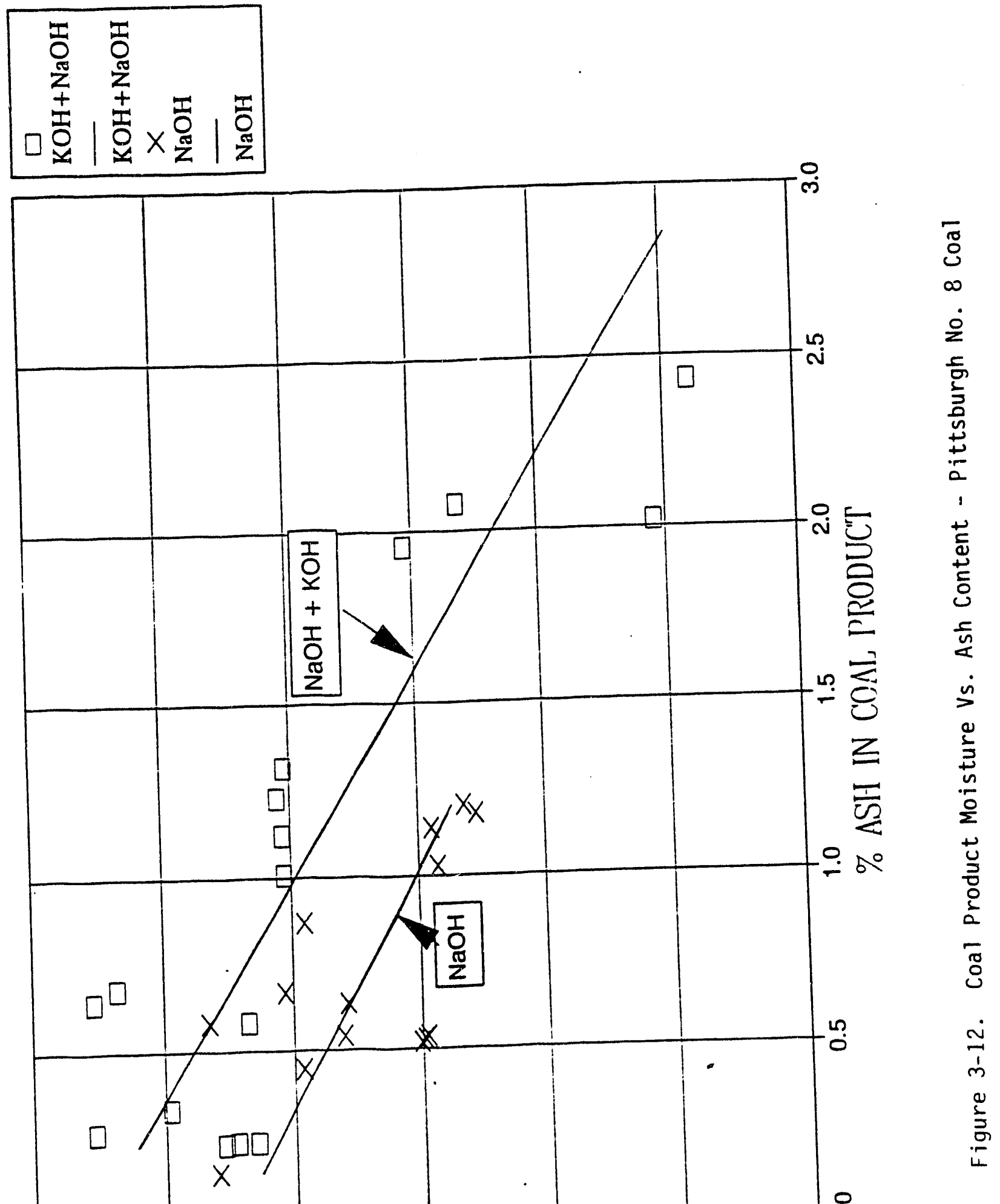
the parent coal using a low temperature $\left(<130^{\circ} \mathrm{C}\right)$ oxygen plasma procedure. The ash, after plasma ashing, was removed and submitted to Pacific Spectrochemical for ES analysis. (Note: low temperature ashing is used to retain elements normally lost using high temperature muffle ashing techniques).

The quantitative results obtained for $\mathrm{Na}, \mathrm{K}, \mathrm{Cl}$ and $\mathrm{F}$ are presented in Table 3-4. The ES results reduced $20 \mathrm{a} \mathrm{mg} / \mathrm{g}$ basis are summarized in Table 3-5 for 21 elements.

\subsection{SULFUR FORMS ANALYSIS}

Samples of kiln discharge coal and washed coal product from selected $M C L$ runs were analyzed to determine the forms of residual sulfur present in $\mathrm{MCL}$ coal. A secondary objective for this analysis was to resolve whether sulfate sulfur vas rormed in kiln processing, or as a result of subsequent washing by diluic suifuric acid. Therefore, some of the samples were only analyzed to determine sulfate sulfur and total sulfur. If sulfates were formed in kiln processing, it may be possible to delineate the operating conditions that suppress sulfate formation. If sulfates were formed by dilute sulfuric acid wash, then it may be necessary to consider alternate washing schemes in order to further reduce residual sulfur levels in $\mathrm{MCL}$ coal.

The sulfur form analysis results are presented in Table 3-6. As shown in this table, the amount of sulfate sulfur in MCL coal appears to remain invariant of coal type or processing conditions. The mean sulfate sulfur level for the MCL coal samples is $0.28 \%$, with a standard deviation of only $0.06 \%$.

Ten sets of sulfate sulfur data are compared in Figure 3-13, with each set representing kiln discharge (KD) coal versus washed coal product (CP) data from the same run. The comparisons show higher KD than CP sulfate sulfur levels in 6 data sets, same $K D$ and $C P$ sulfate sulfur level in 1 data set, and lower $K D$ than $C P$ sulfate levels in 3 data sets. In addition, the Pittsburgh No. 8 and the Kentucky No. 9 coal feed only contain $0.04 \%$ and $0.02-0.06 \%$ sulfate sulfur, respectively. This indicates that sulfate sulfur in MCL coal is formed in kiln processing, and not due 
TABLE 3-4. QUANTITATIVE CATION AND ANION ANALYSIS

\section{Coal Analysis, \% wt/wt Dry Coal Basis}

$\begin{array}{cllll}\text { Element } & \begin{array}{l}\text { Feed } \\ \text { Ky9 }\end{array} & \begin{array}{c}\text { Feed } \\ \text { Pitt 8 }\end{array} & \begin{array}{l}\text { Prod } \\ \text { Ky9 }\end{array} & \begin{array}{c}\text { Prod } \\ \text { Pitt 8 }\end{array} \\ \mathrm{Na} & 0.034 & 0.060 & 0.012 & 0.022 \\ \mathrm{~K} & 0.15 & 0.20 & 0.025 & 0.013 \\ \mathrm{Cl} & 0.16 & 0.11 & 0.0090 & 0.0105 \\ \mathrm{~F} & 0.0027 & 0.0050 & 0.0017 & 0.0044\end{array}$


TABLE 3-5. REMOVAL OF MINOR AND TRACE ELEMENTS FROM COAL SEMI-QUANTITATIVE EMISSION SPECTROGRAPHIC ANALYSIS, $\mathrm{mg} / \mathrm{g} \mathrm{dmf}$

\begin{tabular}{|c|c|c|c|c|c|c|}
\hline ELEMENT & $\begin{array}{l}\text { FEED } \\
\text { KYN } 9 \\
\end{array}$ & $\begin{array}{l}\text { FEED } \\
\text { PITTS } 8\end{array}$ & $\begin{array}{l}\text { PROD } \\
\text { KYN } 9 \\
\end{array}$ & $\begin{array}{l}\text { PROD } \\
\text { PITT } 8\end{array}$ & $\begin{array}{l}\text { \%REM } \\
\text { KYN } 9 \\
\end{array}$ & $\begin{array}{l}\text { \%REM } \\
\text { PITT } 8\end{array}$ \\
\hline $\begin{array}{l}\mathrm{Si} \\
\mathrm{Fe} \\
\mathrm{Al} \\
\mathrm{Mg} \\
\mathrm{Mn} \\
\mathrm{Ca} \\
\mathrm{K} \\
\mathrm{Ti} \\
\mathrm{Cr} \\
\mathrm{Ba} \\
\mathrm{B} \\
\mathrm{Pb} \\
\mathrm{Mo} \\
\mathrm{Sn} \\
\mathrm{V} \\
\mathrm{Cu} \\
\mathrm{Na} \\
\mathrm{Zr} \\
\mathrm{Co} \\
\mathrm{Sr}\end{array}$ & $\begin{array}{r}40 \\
8.8 \\
9.7 \\
0.5 \\
0.045 \\
0.57 \\
2 \\
0.63 \\
0.045 \\
0.2 \\
0.026 \\
0.02 \\
0.004 \\
0.004 \\
0.008 \\
0.007 \\
0.44 \\
0.023 \\
0.002 \\
0.025\end{array}$ & $\begin{array}{r}55 \\
16 \\
13 \\
0.63 \\
0.1 \\
3.4 \\
2 \\
0.43 \\
0.03 \\
0.2 \\
0.05 \\
0.02 \\
0.004 \\
0.004 \\
0.027 \\
0.023 \\
0.37 \\
0.055 \\
0.002 \\
0.069\end{array}$ & $\begin{array}{r}1.6 \\
0.24 \\
0.26 \\
0.024 \\
0.0037 \\
0.013 \\
0.24 \\
0.26 \\
0.014 \\
0.003 \\
0.0018 \\
0.0054 \\
0.0044 \\
5 E-05 \\
0.0018 \\
0.003 \\
0.1 \\
0.015 \\
0.00: 5 \\
0.0008\end{array}$ & $\begin{array}{r}1.1 \\
0.12 \\
0.09 \\
0.009 \\
0.003 \\
0.046 \\
0.0035 \\
0.19 \\
0.017 \\
0.0035 \\
0.001 \\
0.024 \\
0.003 \\
5 E-05 \\
0.002 \\
0.006 \\
0.15 \\
0.018 \\
0.001 \\
0.001\end{array}$ & $\begin{array}{r}96 \\
97 \\
97 \\
95 \\
92 \\
98 \\
88 \\
5 y \\
69 \\
99 \\
93 \\
73 \\
-10 \\
99 \\
78 \\
57 \\
77 \\
35 \\
25 \\
97\end{array}$ & $\begin{array}{r}98 \\
99 \\
99 \\
99 \\
97 \\
99 \\
100 \\
56 \\
43 \\
98 \\
98 \\
-20 \\
25 \\
99 \\
93 \\
74 \\
59 \\
67 \\
50 \\
99\end{array}$ \\
\hline $\mathrm{Cl}$ & 0.16 & 0.11 & 0.01 & 0.01 & 94 & 90 \\
\hline
\end{tabular}

ChToride analysis by Parr bomb ion chromatography. 
TABLE 3-6. SULFUR FORMS ANALYSIS RESULTS

\begin{tabular}{|c|c|c|c|c|c|c|c|c|}
\hline Run & $\begin{array}{l}\text { Coal } \\
\text { Iype }\end{array}$ & $\begin{array}{l}\text { Sample } \\
\text { Iype }\end{array}$ & $\begin{array}{r}\% \\
\text { Mean }\end{array}$ & $\begin{array}{l}\text { Ulfate Su } \\
\text { Std Dev. }\end{array}$ & $\begin{array}{l}\text { 1) fur } \\
\text { Data Pts }\end{array}$ & $\begin{array}{l}\text { \% Pyritic } \\
\text { Sulfur }\end{array}$ & $\begin{array}{l}\text { \% Organic } \\
\text { Sulfur }\end{array}$ & $\begin{array}{l}\text { \% Total } \\
\text { Sulfur }\end{array}$ \\
\hline $4 C 1$ & PITT 8 & $C P$ & 0.24 & 0.08 & 2 & 0.04 & 0.47 & 0.74 \\
\hline $\begin{array}{l}5 B 1 \\
5 D 1\end{array}$ & $\begin{array}{l}\text { PITT } 8 \\
\text { PITT } 8\end{array}$ & $\begin{array}{l}C P \\
C P\end{array}$ & $\begin{array}{l}0.29 \\
0 . ? 8\end{array}$ & $0 . \overline{01}$ & $\begin{array}{l}1 \\
2\end{array}$ & $\begin{array}{l}0.01 \\
0.02\end{array}$ & $\begin{array}{l}1.05 \\
1.05\end{array}$ & $\begin{array}{l}1.35 \\
1.38\end{array}$ \\
\hline $\begin{array}{l}7 A \\
7 A \\
7 B \\
7 B \\
7 C \\
7 C \\
7 D \\
7 D \\
7 E\end{array}$ & $\begin{array}{l}\text { KENT } 9 \\
\text { KENT } \\
\text { KENT } \\
\text { KENT } \\
\text { PITT } 8 \\
\text { PITT } 8 \\
\text { PITT } 8 \\
\text { PITT } 8 \\
\text { PITT } 8\end{array}$ & $\begin{array}{l}C P \\
K D \\
C P \\
K D \\
C P \\
K D \\
C P \\
K D \\
K D\end{array}$ & $\begin{array}{l}0.35 \\
0.29 \\
0.27 \\
0.35 \\
0.26 \\
0.26 \\
0.21 \\
0.36 \\
0.29\end{array}$ & $\begin{array}{c}0.08 \\
0.09 \\
- \\
- \\
- \\
- \\
0.04\end{array}$ & $\begin{array}{l}3 \\
3 \\
1 \\
1 \\
1 \\
1 \\
1 \\
1 \\
3\end{array}$ & $\begin{array}{c}0.01 \\
- \\
- \\
= \\
= \\
= \\
-\end{array}$ & $\begin{array}{c}0.22 \\
- \\
= \\
= \\
= \\
= \\
=\end{array}$ & $\begin{array}{l}0.59 \\
0.73 \\
0.56 \\
0.63 \\
0.54 \\
0 . \\
0.38 \\
0.66 \\
1.50\end{array}$ \\
\hline $\begin{array}{l}8 A \\
8 A \\
8 B \\
8 C \\
8 D \\
8 E \\
8 F \\
8 F\end{array}$ & $\begin{array}{l}\text { PITT } 8 \\
\text { PITT } 8 \\
\text { PITT } 8 \\
\text { PITT } 8 \\
\text { PITT } 8 \\
\text { PITT } 8 \\
\text { PITT } 8 \\
\text { PITT } 8\end{array}$ & $\begin{array}{l}C P \\
K D \\
C P \\
C P \\
C P \\
C P \\
C P \\
K D\end{array}$ & $\begin{array}{l}0.28 \\
0.34 \\
0.21 \\
0.13 \\
0.25 \\
0.23 \\
0.36 \\
0.35\end{array}$ & $\begin{array}{c}\overline{-} \\
0.03 \\
- \\
\overline{-} \\
0.07 \\
\overline{-} \\
0 . \overline{-}\end{array}$ & $\begin{array}{l}1 \\
4 \\
1 \\
1 \\
2 \\
1 \\
3 \\
1\end{array}$ & $\begin{array}{l}0.02 \\
- \\
0.07 \\
0.03 \\
0.03 \\
0.02 \\
0.01\end{array}$ & $\begin{array}{c}0.55 \\
- \\
1.00 \\
0.61 \\
0.56 \\
0.52 \\
0.63\end{array}$ & $\begin{array}{l}0.85 \\
0.80 \\
1.37 \\
0.77 \\
0.80 \\
0.76 \\
0.92 \\
1.01\end{array}$ \\
\hline $\begin{array}{l}9 A \\
9 A \\
9 A 1 \\
9 A 1 \\
9 R\end{array}$ & $\begin{array}{l}\text { PITT } 8 \\
\text { PITT } 8 \\
\text { PITT } 8 \\
\text { PITT } 8 \\
\text { PITT } 8 \\
\text { PITT } 8 \\
\text { PITT } 8 \\
\text { PITT } 8\end{array}$ & $\begin{array}{l}C P \\
K D \\
C P \\
K D \\
C P \\
K D \\
C P \\
K D\end{array}$ & $\begin{array}{l}0.27 \\
0.33 \\
0.30 \\
0.41 \\
0.26 \\
0.28 \\
0.30 \\
0.19\end{array}$ & $\begin{array}{c}0 . \\
0.03 \\
0.03 \\
0.03 \\
0.03 \\
0.02 \\
-\end{array}$ & $\begin{array}{l}1 \\
3 \\
2 \\
1 \\
3 \\
1 \\
6 \\
1\end{array}$ & $\begin{array}{c}0.01 \\
- \\
0.01 \\
- \\
0.003 \\
0.002 \\
-\end{array}$ & $\begin{array}{c}0.60 \\
0 . \overline{41} \\
0 . \overline{35} \\
0 . \overline{19} \\
-\end{array}$ & $\begin{array}{l}0.88 \\
0.97 \\
0.72 \\
0.79 \\
0.62 \\
1.25 \\
0.49 \\
0.23\end{array}$ \\
\hline
\end{tabular}

For pyritic and organic sulfur, a "-" indicates no data. 


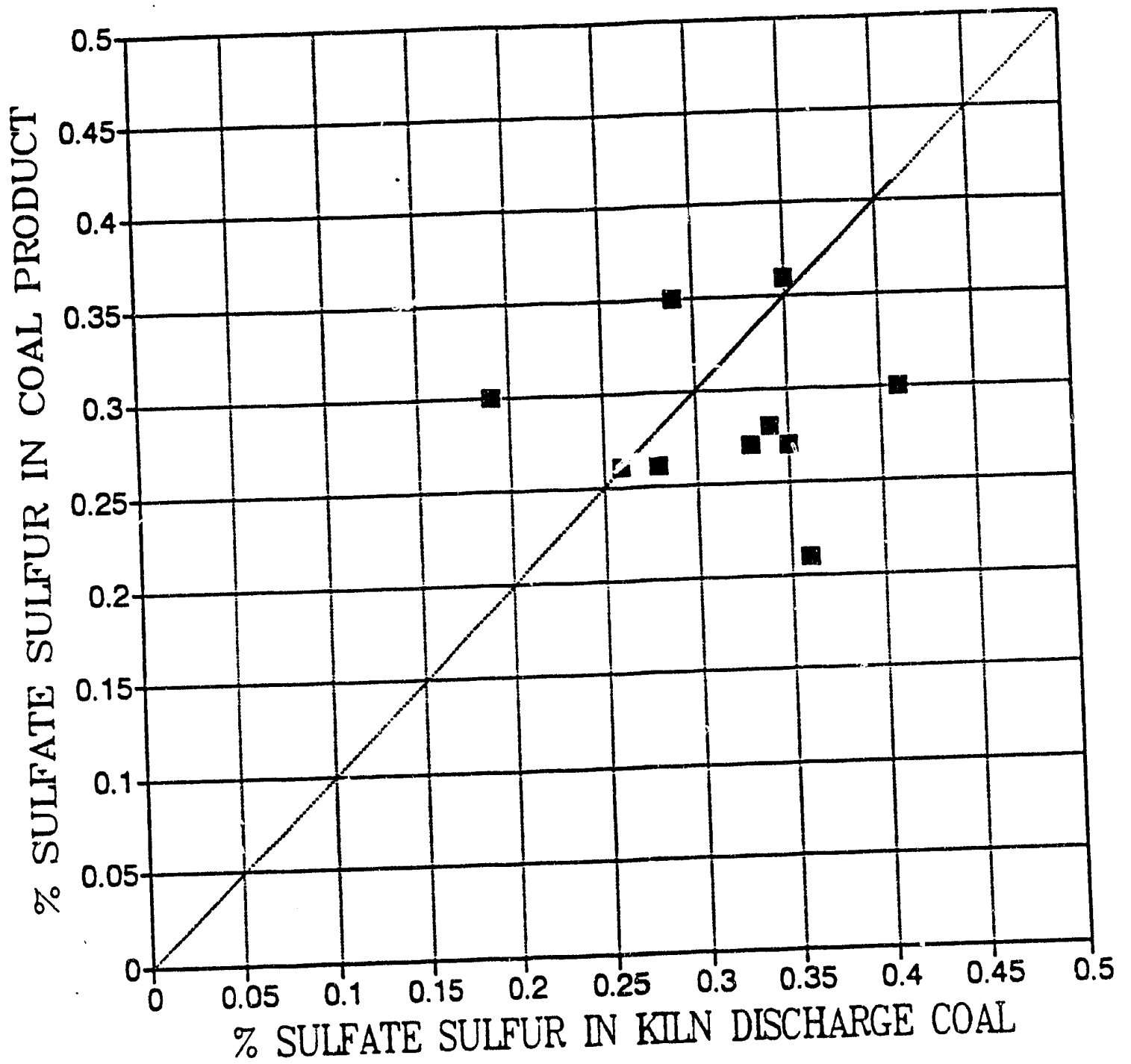

Figure 3-13. Comparison of Sulfate Sulfur in Kiln Discharge Coal and Washed Coal Product 
to washing by dilute sulfuric acid. It also appears that in at least some of the runs, downstream washing removes part of the sulfate sulfur initially formed. Thus, this sulfate level comparison provides evidence of the effectiveness of the countercurrent washing scheme in the integrated MCL plant.

The sulfate in MCL coal is probably present as iron sulfate, formed from the thiosulfate derived from the reaction of sodium or potassium hydroxide with coal pyritic sulfur:

$$
8 \mathrm{FeS}_{2}+30 \mathrm{NaOH}=34 \mathrm{Na}_{2} \mathrm{~S}+\mathrm{Na}_{2} \mathrm{~S}_{2} \mathrm{O}_{3}+4 \mathrm{Fe}_{2} \mathrm{O}_{3}+15 \mathrm{H}_{2} \mathrm{O}
$$

The above reaction indicates that $1 / 8$ of the pyritic sulfur could be converted to thiosulfate and subsequently to iron sulfate, which apparently cannot be readily removed from coal by washing with water or dilute sulfuric acid. For Pittsburgh No. $8 \mathrm{coal}$, the $1.69 \%$ pyritic sulfur and $0.04 \%$ sulfate sulfur in the coal feed could result in $0.25 \%$ sulfate sulfur in MCL coal. Similarly, the $1.84 \%$ pyritic sulfur and $0.02-0.06 \%$ sulfate sulfur in Kentucky No. 9 coal feed could result in $0.27 \%$ sulfate sulfur in MCL coal. These sulfate sulfur levels are approximately the same as the average $0.28 \%$ sulfate sulfate level determined from the MCL coal samples.

This retention of sulfate sulfur can therefore be reduced by utilizing low pyrite (highly cleaned) coals in the MCL process. For example, coal deeply cleaned to $0.5 \%$ pyritic sulfur, but containing any amount of organic sulfur should be reducible to $0.1 \%$ organic sulfur (one of the samples from Run $9 C$ ), $0.02 \%$ pyritic sulfur (Table $3-6$ ), and $0.07 \%$ sulfate sulfur (Table 3-6) for a total sulfur of $0.19 \%$.

The data presented in Table 3-6 also show that in almost every case, the pyritic sulfur in MCL coal has been reduced to extremely low levels. The mean residual pyritic sulfur level is $0.022 \%$ for Pittsburgh coal, and $0.01 \%$ for Kentucky coal. These represent $98.7 \%$ and $99.5 \%$ removal of the pyritic sulfur present in the Pittsburgh and Kentucky coals fed to the rotary kiln. 
The amount of residual organic sulfur in MCL coal is strongly dependent on processing conditions. The lowest organic sulfur level found is $0.08 \%$ from a Run $9 C$ coal product sample. The effects of processing conditions on sulfur removal are discussed in Section 3.1 .1 of this report.

\subsection{KILN GAS}

Kiln gas samples obtained from 5 MCL runs were analyzed to determine the gas composition, as well as the percentage of coal feed converted to kiln gas. The results of gas composition analysis and coal conversion calculations are presented in Table 3-7.

Except for Run 503, data from the other four runs provide consistent results. The Run 503 results appear to be out of place when compared with the results from the other runs. Run $5 D 3$ indicated much higher methane and $\mathrm{C}_{2}{ }^{+}$hydrocarbon content in the $k i$ in gas, and higher conversion of coal feed to kiln gas, despite mild kiln operating temperatures.

Comparison of the analytical results from Runs $1 C, 2 E, 5 C 4$ and $6 G 1$ shows that an average of $2.85 \%$ of the coal feed was converted to hydrogen and hydrocarbon gases. Operation at higher kiln temperatures (indicated by the Zone 1 sensor temperature) generally led to conversion of a higher percentage of the coal feed to kiln gas, when analysis results from Runs $2 E$ and $5 C 4$ (Kentucky No. 9) or Runs $1 C$ and 6G1 (Pittsburgh No. 8) are compared. Results from these runs also suggest conversion of a higher percentage of the Kentucky No. 9 than Pittsburgh No. 8 coal feed to kiln gas.

Analyses show the volatiles content of the feed coals to be $38.60 \%$ (Pittsburgh No. 8) and $40.53 \%$ (Kentucky No. 9) (see Table 1-2). The volatiles content of the product coal averages about 27\% (see Appendix A), for an overall decrease in volatiles of approximately $13 \%$. It is likely that 7 to $8 \%$ by weight of the volatiles loss is due to the desiccating conditions of dry molten caustic and temperatures around $390^{\circ} \mathrm{C}$ which would most likely remove the decomposition moisture of the organic 
TABLE 3-7. KILN GAS ANALYSIS RESULTS

\begin{tabular}{|c|c|c|c|c|c|}
\hline Run & $\underline{1 C}$ & $\underline{2 E}$ & $\underline{5 C 4}$ & $\underline{5 D 3}$ & $\underline{6 G 1}$ \\
\hline Coal Type & PITT 8 & KENT 9 & KENT 9 & KENT 9 & PITT 8 \\
\hline $\mathrm{KOH} / \mathrm{NaOH}$ & 1 & 1 & 0 & 0 & 1 \\
\hline Caustic/Coal & 1.5 & 2.0 & 2.0 & 1.0 & 1.0 \\
\hline $\begin{array}{l}\text { Kiln Wall } \\
\text { Temp, }{ }^{\circ} \mathrm{C}\end{array}$ & 410 & 438 & 427 & 371 & 427 \\
\hline Res Time, hr & 1.5 & 2.0 & 1.5 & 2.0 & 2.0 \\
\hline Sensor Temp, ${ }^{\circ} \mathrm{C}$ & $280 *$ & $308 *$ & 223 & 252 & 260 \\
\hline $\mathrm{H}_{2}, \mathrm{Vol} \%$ & 1.56 & 3.92 & 2.26 & 0.37 & 4.03 \\
\hline $\mathrm{CH}_{4}, \mathrm{~V}_{01 \%}$ & 0.192 & 0.263 & 0.26 & 0.94 & 0.26 \\
\hline $\mathrm{C}_{2}^{+}, \mathrm{V}_{01 \%}$ & 0.014 & 0.054 & 0.003 & 0.17 & 0.055 \\
\hline $\mathrm{CO}_{2}, \mathrm{Vol} \%$ & 0 & 0 & trace & 0 & 0.15 \\
\hline $\begin{array}{l}\text { Wt \% Coal Feed } \\
\text { to Kiln Gas }\end{array}$ & 2.00 & 4.78 & 2.84 & 5.94 & 1.78 \\
\hline
\end{tabular}

* Estimated, not actual measurement. 
consti:uents of coal as well as the water of hydration of the coal mineral matter. For example, Friedman, et al, " have shown that there is an $8 \%$ water component in the volatile matter of Pittsburgh seam coal when the coal is heated to $600^{\circ} \mathrm{C}$. It is possible that the MCL process conditions, while at a lower temperature, may be even more severe in desiccating action due to the presence of caustic. If this $8 \%$ moisture loss is added to the $2 \%$ loss to phenolics and the $3 \%$ loss to hydrogen/hydrocarbon gases, the $13 \%$ overall decrease in volatiles content is acccunted for.

\subsection{HUMIC ACID AND PHENOLICS FORMATION}

Soluble organic compounds present in the spent caustic solutions are classified as humic materials if they precipitate upon acidification, and as phenolic materials if they remain soluble upon acidification. Data on the conversion of coal feed to humics are presented in Table 3-8. Data on the conversion to phenolics are not reported because of analytical and sampling problems.

Data on the conversion of coal feed to humics are also plotted in Figure 3-14 as a function of the caustic/coal temperature in Zone 1 (Runs 1 to 5) or Zone 2 (Runs 8 and 9) of the rotary kiln. The nitrogen flow was concurrent with the coal/caustic flow in Runs 1 to 5 , and countercurrent to the coal/caustic flow in Runs 8 and 9 . The net result was that in Runs 1 to 5 , the temperature difference between the kiln wall and the coal/caustic mixture in Zone 1 was typically $131^{\circ} \mathrm{C}$. By comparison, the temperature difference between the kiln wall and the coal/caustic mixture in Zone 2 was only in the $19-32^{\circ} \mathrm{C}$ range in Runs 8 and 9. For Runs 1 to 5, the leaching temperature would increase in the subsequent zones of the rotary kiln and would be higher than the temperature indicated by the Zone 1 probe sensor. For Runs 8 and 9 , the leaching temperature in all four zones of the rotary kiln would be approximately the same as indicated by the Zone 2 probe sensor.

*Friedman, L. D., et al, Fuel, 47, 149 (1968). 
TABLE 3-8. FORMATION OF HUMIC ACID

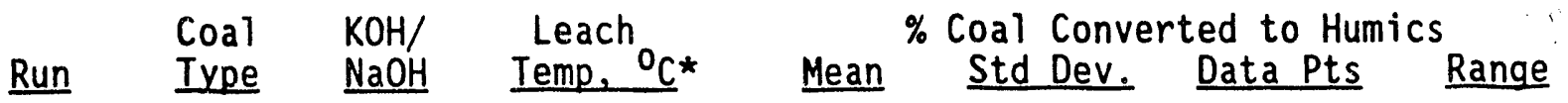

\begin{tabular}{|c|c|c|c|c|c|c|c|}
\hline $\begin{array}{l}1 B \\
1 C \\
1 D\end{array}$ & $\begin{array}{l}\text { PITT } 8 \\
\text { PITT } 8 \\
\text { PITT } 8\end{array}$ & $\begin{array}{l}1 \\
1 \\
1\end{array}$ & $\begin{array}{l}259 \\
279 \\
279\end{array}$ & $\begin{array}{l}0.533 \\
0.794 \\
1.231\end{array}$ & $\begin{array}{l}1 . \overline{041} \\
0.676\end{array}$ & $\begin{array}{l}1 \\
3 \\
4\end{array}$ & $\begin{array}{c}0.533 \\
0.105-1.992 \\
0.278-1.872\end{array}$ \\
\hline $\begin{array}{l}2 B \\
2 C \\
2 D \\
2 E\end{array}$ & $\begin{array}{l}\text { PITT } 8 \\
\text { PITT } 8 \\
\text { KENT } 9 \\
\text { KENT } 9\end{array}$ & $\begin{array}{l}1 \\
1 \\
1 \\
1\end{array}$ & $\begin{array}{l}259 \\
296 \\
296 \\
307\end{array}$ & $\begin{array}{l}0.249 \\
0.067 \\
0.236 \\
0.039\end{array}$ & $\begin{array}{c}0.148 \\
0.060 \\
- \\
-\end{array}$ & $\begin{array}{l}2 \\
3 \\
1 \\
1\end{array}$ & $\begin{array}{l}0.144-0.354 \\
0.027-0.136 \\
0.236 \\
0.039\end{array}$ \\
\hline $\begin{array}{l}3 \mathrm{~B} 1 \\
3 \mathrm{C} 1\end{array}$ & $\begin{array}{l}\text { PITT } 8 \\
\text { PITT } 8\end{array}$ & $\begin{array}{l}1 \\
1\end{array}$ & $\begin{array}{l}307 \\
307\end{array}$ & $\begin{array}{l}0.507 \\
0.217\end{array}$ & $\begin{array}{c}0.392 \\
-\end{array}$ & $\begin{array}{l}6 \\
1\end{array}$ & $\begin{array}{c}0.066-1.02 \\
0.217\end{array}$ \\
\hline $\begin{array}{l}4 C 1 \\
4 C 2 \\
4 C 3\end{array}$ & $\begin{array}{l}\text { PITT } 8 \\
\text { PITT } 8 \\
\text { PITT } 8\end{array}$ & $\begin{array}{l}0 \\
0 \\
0\end{array}$ & $\begin{array}{l}290 \\
302 \\
323\end{array}$ & $\begin{array}{l}3.97 \\
5.38 \\
1.74\end{array}$ & $\begin{array}{c}0 . \overline{4} 45 \\
-\end{array}$ & $\begin{array}{l}1 \\
2 \\
1\end{array}$ & $\begin{array}{l}3.97 \\
5.06-5.69 \\
1.74\end{array}$ \\
\hline $\begin{array}{l}5 B 1 \\
5 B 3 \\
5 C 5 \\
5 C 4 \\
5 D 3\end{array}$ & $\begin{array}{l}\text { PITT } 8 \\
\text { PITT } 8 \\
\text { KENT } 9 \\
\text { KENT } 9 \\
\text { KENT } 9\end{array}$ & $\begin{array}{l}0 \\
0 \\
0 \\
0 \\
0\end{array}$ & $\begin{array}{l}302 \\
237 \\
298 \\
223 \\
252\end{array}$ & $\begin{array}{c}3.17 \\
10.4 \\
1.67 \\
5.95 \\
2.49\end{array}$ & $\begin{array}{l}- \\
- \\
-\end{array}$ & $\begin{array}{l}1 \\
1 \\
1 \\
1 \\
1\end{array}$ & $\begin{array}{c}3.17 \\
10.4 \\
1.67 \\
5.95 \\
2.49\end{array}$ \\
\hline $\begin{array}{l}8 A \\
8 B \\
8 C \\
8 D \\
8 E \\
8 F\end{array}$ & $\begin{array}{l}\text { PITT } 8 \\
\text { PITT } 8 \\
\text { PITT } 8 \\
\text { PITT } 8 \\
\text { PITT } 8 \\
\text { PITT } 8\end{array}$ & $\begin{array}{l}1 \\
1 \\
0 \\
0 \\
0 \\
0\end{array}$ & $\begin{array}{l}395 \\
395 \\
403 \\
417 \\
389 \\
384\end{array}$ & $\begin{array}{l}1.94 \\
1.20 \\
0.744 \\
1.14 \\
1.27 \\
1.24\end{array}$ & $\begin{array}{c}- \\
- \\
0.276 \\
- \\
- \\
-\end{array}$ & $\begin{array}{l}1 \\
1 \\
2 \\
1 \\
1 \\
1\end{array}$ & $\begin{array}{c}1.94 \\
1.20 \\
0.548-0.939 \\
1.14 \\
1.27 \\
1.24\end{array}$ \\
\hline $\begin{array}{l}9 \mathrm{~A} 1 \\
9 \mathrm{~B} \\
9 \mathrm{C}\end{array}$ & $\begin{array}{l}\text { PITT } 8 \\
\text { PITT } 8 \\
\text { PITT } 8\end{array}$ & $\begin{array}{l}1 \\
1 \\
0\end{array}$ & $\begin{array}{l}407 \\
415 \\
419\end{array}$ & $\begin{array}{l}1.17 \\
0.209 \\
0.318\end{array}$ & $\begin{array}{c}- \\
0.319\end{array}$ & $\begin{array}{l}1 \\
1 \\
2\end{array}$ & $\begin{array}{c}1.17 \\
0.209 \\
0.093-0.524\end{array}$ \\
\hline
\end{tabular}

* Leaching temperature is based on temperatures measured by the thermocouple probe placed in either Zone 1 (Runs 4 and 5) or Zone 2 (Runs 8 and 9 ) of the rotary kiln. For Runs 1 to 3 , the leaching temperature is estimated by assuming a $131^{\circ} \mathrm{C}$ temperature difference between the Zone 1 kiln wall and the caustic/coal mixture. 

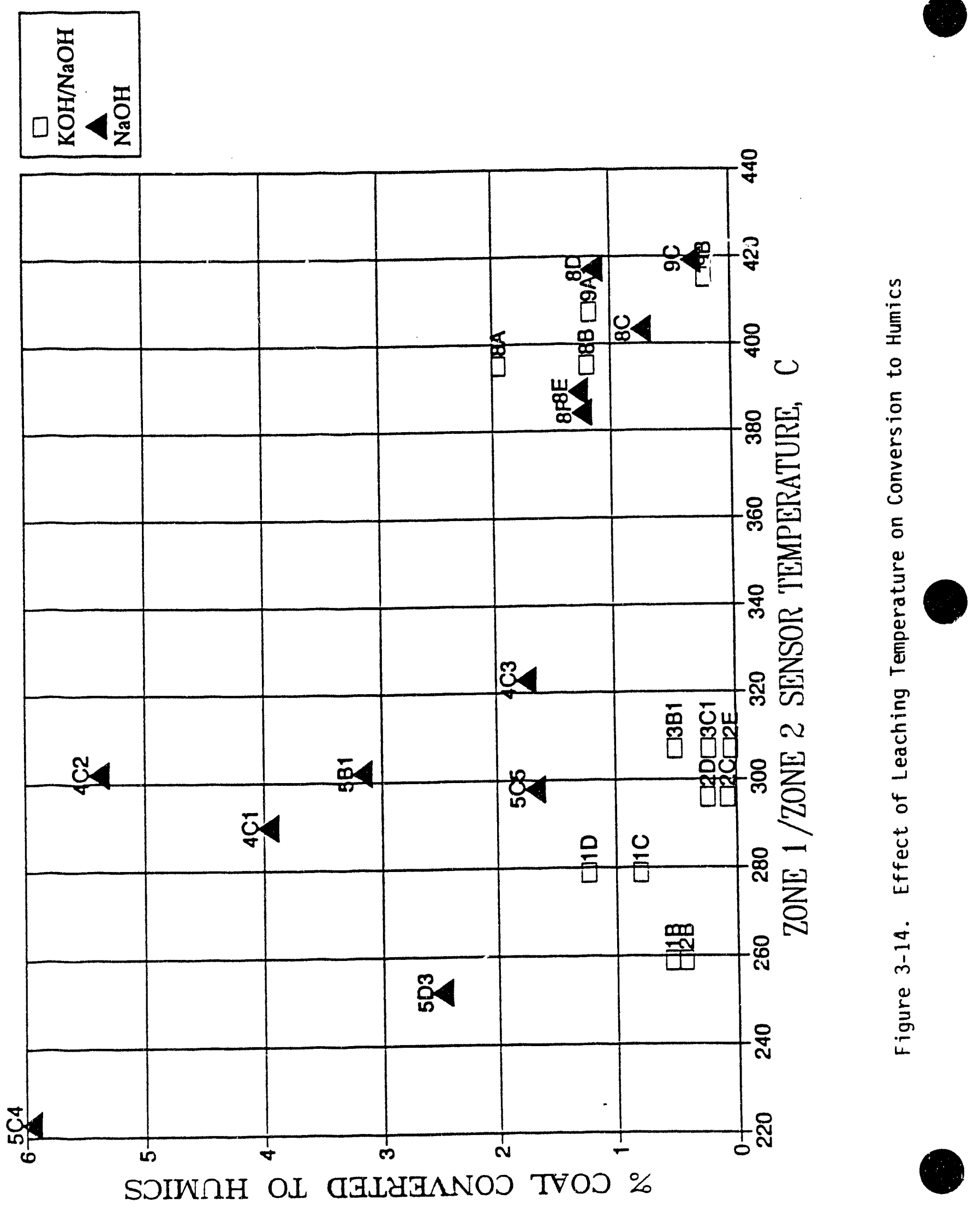
Based on the data from Runs $4 C 1,4 C 2,5 B 1,5 B 3,5 C 4$ and 5D3, formation of humics appears to be maximum when only sodium hydroxide was used and when Zone 1 leaching temperatures were near or below $300^{\circ} \mathrm{C}$. When mixed caustic was used for leaching, the maximum conversion of coal feed to humics was less than $2 \%$. However, at leaching temperatures higher than $384^{\circ} \mathrm{C}$, the conversion to humics was about the same whether sodium hydraxide or mixed caustic was used, and an average of $0.96 \%$ of the coal feed was converted to humics. At these temperatures, humics formation appears to decrease with leaching temperature. At leaching temperatures in excess of $415^{\circ} \mathrm{C}$ (Runs $9 \mathrm{~B}$ and $9 \mathrm{C}$ ), the data also show that low conversions of only 0.2 to $0.3 \%$ of the coal feed to humics are achievable.

At Zone 1 leaching temperatures near or below $300^{\circ} \mathrm{C}$, humics formation was also low when mixed caustic was used (Runs 1 to 3 ). Even though the average leaching temperature was higher than that for Zone 1 , these data suggest that it is possible to achieve low humics formation under mild leaching conditions.

\subsection{CARBONATE FORMATION}

Carbonate is formed by the reaction of molten caustic with coal carbon in the presence of carbon dioxide (air). The formation of carbonate results in both loss of carbon from coal as well as loss of caustic. Data from the $M C L$ integrated plant were evaluated to detel mine the effects of process parameters on carbonate formation, and to delineate the operating conditions that will minimize its formation.

During the operational runs, selected kiln discharge (KD) samples and spent caustic solution (VP2023 or VF2037) ${ }^{*}$ samples were collected and

\footnotetext{
* VP2023 and VF2037 refer to the locations where the samples were taken. VP2023 is the sample valve downstream of pump P-202 (and upstream of bag filters F-203). VF2037 is the sample valve downstream of bag filters $\mathrm{F}-203$ (on the filtrate to the regeneration section).
} 
analyzed for carbonate and caustic compositions. These composition data were used to compute the fraction of caustic converted to carbonate, as well as the fraction of coal or coal carbon converted to carbonate. The computations were based on the following equations:

$\mathrm{KOH}+\mathrm{NaOH}$ feed $=\mathrm{KOH}+\mathrm{NaOH}$ in product $+\mathrm{KOH}+\mathrm{NaOH}$ used for sulfur and ash removal $+\mathrm{KOH}+\mathrm{NaOH}$ converted to carbonate

Carbonate formed $=\mathrm{K}_{2} \mathrm{CO}_{3}+\mathrm{Na}_{2} \mathrm{CO}_{3}$ in product $-\mathrm{K}_{2} \mathrm{CO}_{3}+\mathrm{Na}_{2} \mathrm{CO}_{3}$ in caustic feed

Similar equations were used for $\mathrm{NaOH}$ feed. For $50: 50 \mathrm{KOH} / \mathrm{NaOH}$ feed, 1 pound of $\mathrm{KOH}+\mathrm{NaOH}$ converted to carbonate would result in 1.2783 pounds of potassium and sodium carbonate. Therefore:

$$
\% \text { of caustic converted to carbonate }=\frac{100 \times \text { carbonate formed }}{1.2783 \times \mathrm{KOH}+\mathrm{NaOH} \text { feed }}
$$

Similarly, for $100 \% \mathrm{NaOH}$ feed, I pound of $\mathrm{NaOH}$ converted to carbonate would result in 1.3250 pounds of sodium carbonate. In this case:

$$
\% \text { of caustic converted to carbonate }=\frac{100 \times \text { carbonate formed }}{1.3250 \times \mathrm{NaOH} \text { feed }}
$$

In reducing the data, the following composition for the commercial solid-caustic mixture was used: $92.42 \%$ sodium and potassium hydroxide, $3.37 \%$ sodium and potassium carbonate, and $4.21 \%$ water. This is the average composition of the mixed caustic fed to the rotary kiln, as determined from the analysis of nine samples. The same composition was used in reducing data for runs with sodium hydroxide feed, except substituting sodium for sodium/potassium. For Run 9B, recycled caustic from the evaporator was used as the feed, with the following composition: $80.61 \%$ sodium and potassium hydroxide, $5.59 \%$ sodium and potassium carbonate, $0.37 \%$ sodium and potassium sulfide, and $13.43 \%$ water. This is the composition used for reducing Run 98 data.

It was also assumed that the carbon in the carbonate formed was derived from the carbon in the coal feed. For 50:50 KOH/NaOH feed, 1 pound of $\mathrm{KOH}+\mathrm{NaOH}$ reacts with 0.12859 pounds of coal carbon (or 100 
pounds of caustic with 12.856 lbs of coal carbon) to form carbonate. Since the caustic feed contains only $92.42 \%$ sodium and potassium hydroxide and oniy part of this hydroxide is converted to carbonate, the percentage of coal feed converted to carbonate was calculated as follows:

$\%$ coal converted to carbonate $=\frac{0.12859 \times 92.42 \times \text { carbonate formed } \times r}{1.2783 \times \mathrm{KOH}+\mathrm{NaOH} \text { feed }}$ where $r$ is the caustic/coal feed ratio. For $100 \% \mathrm{NaOH}$ feed, 1 ib of $\mathrm{NaOH}$ reacts with 0.15015 ib of coal (or 100 pounds of $\mathrm{NaOH}$ with 15.015 lbs of coal), and the percentage of coal feed converted to carbonate was calculated as follows:

$\%$ coal converted to carbonate $=\frac{0.15015 \times 92.42 \times \text { carbonate formed } \times r}{1.3250 \times \mathrm{NaOH} \text { feed }}$

In Table 3-9, data on carbonate formation are presented on a run-by-run basis, in terms of fraction of caustic converted to carbonate. These data can also be readily translated to fraction of coal or coal carbon converted to carbonate, since the caustic/coal ratio for each run is known.

Based on the carbonate formation sata for the 46 runs presented in Table 3-9, the average conversion of caustic to carbenate is $17.57 \%$. (For those runs that had more than one carbonate formation data point, the data points were averaged for the run and this average run value was used in the calculation for the average conversion of caustic to carbonate for the 46 runs.) This corresponds to an average conversion of $4.18 \%$ of the feed coal to carbonate. In analyzing the carbonate formation data, the effects of four process parameters were investigated: caustic/coal ratio, kiln temperature, coal type, and caustic type. The effect of residence time on carbonate formation was not assessed because almost all the data were collected at a kiln residence time of 2 hours. Carbonates in the $\mathrm{MCL}$ product were measured either using the kiln discharge (KD) product, or by analysis of the carbonates and caustic in the spent caustic solution (VF2037 or VP2023). The kiln discharge carbonate data were compared 
TABLE 3-9. CARBONATE FORMATION

\begin{tabular}{|c|c|c|c|c|c|c|c|c|}
\hline Run & $\begin{array}{l}\text { Coal } \\
\text { Iype }\end{array}$ & $\begin{array}{l}\mathrm{KOH} / \\
\mathrm{N} \mathrm{OHOH}\end{array}$ & $\begin{array}{l}\text { Caustic/ } \\
\text { Coal }\end{array}$ & $\begin{array}{r}\text { Wall } \\
\text { Temp. }{ }^{\circ} \mathrm{C} \\
\end{array}$ & $\begin{array}{c}\text { Sample } \\
\text { Iype }\end{array}$ & $\begin{array}{l}\text { Frac of } \\
\text { Mean }\end{array}$ & $\begin{array}{l}\text { Caustic to } \\
\text { Std Dev. }\end{array}$ & $\begin{array}{r}\text { Carbonate } \\
\text { Data Pts }\end{array}$ \\
\hline IR & PIIT 8 & 1 & 1.0 & 390 & $\begin{array}{c}K D \\
V P 2023 \\
K D+V P\end{array}$ & $\begin{array}{l}0.0416 \\
0.197 \\
0.119\end{array}$ & $\begin{array}{l}0.0264 \\
0.0271 \\
0.0885\end{array}$ & $\begin{array}{l}3 \\
3 \\
6\end{array}$ \\
\hline $1 C$ & PITT 8 & 1 & 1.5 & 410 & $\begin{array}{c}K D \\
V P 2023 \\
K D+V P\end{array}$ & $\begin{array}{l}0.224 \\
0.216 \\
0.220\end{array}$ & $\begin{array}{c}. \\
0.0059 \\
0.000\end{array}$ & $\begin{array}{l}0 \\
1 \\
1 \\
2\end{array}$ \\
\hline 10 & PITT 8 & 1 & 2.0 & 410 & KD & 0.0943 & 0.0699 & 4 \\
\hline${ }_{B}^{A}$ & $\begin{array}{l}\text { PITT } 8 \\
\text { PITT } 8 \\
\text { PITT } 8 \\
\text { KENT } 9 \\
\text { KENT } 9\end{array}$ & $\begin{array}{l}1 \\
1 \\
1 \\
1 \\
1\end{array}$ & $\begin{array}{l}2.0 \\
2.0 \\
2.0 \\
2.0 \\
2.0\end{array}$ & $\begin{array}{l}390 \\
390 \\
427 \\
427 \\
438\end{array}$ & $\begin{array}{c}\text { KD } \\
\text { VF2037 } \\
\text { VF2037 } \\
\text { VF2037 } \\
\text { VF2037 }\end{array}$ & \begin{tabular}{l}
\multicolumn{1}{c}{0} \\
0.0844 \\
0.181 \\
0.203 \\
0.228
\end{tabular} & $\begin{array}{l}0.0257 \\
0.0274 \\
0.0183 \\
0.0146\end{array}$ & $\begin{array}{l}1 \\
2 \\
3 \\
2 \\
2\end{array}$ \\
\hline $\begin{array}{l}3 A 1 \\
3 A 2 \\
3 A 3 \\
3 B 3 \\
3 B 2 \\
3 B 1\end{array}$ & $\begin{array}{l}\text { PITT } 8 \\
\text { PITT } 8 \\
\text { PITT } 8 \\
\text { PITT } 8 \\
\text { PITT } 8 \\
\text { PITT } 8\end{array}$ & $\begin{array}{l}1 \\
1 \\
1 \\
1 \\
1 \\
1\end{array}$ & $\begin{array}{l}1.0 \\
1.0 \\
1.0 \\
2.0 \\
2.0 \\
2.0\end{array}$ & $\begin{array}{l}427 \\
427 \\
427 \\
432 \\
438 \\
438\end{array}$ & $\begin{array}{c}K D \\
K D \\
K D \\
K D \\
K D \\
K D \\
K D \\
\text { VF2037 } \\
\text { KD+VF } \\
\text { VF2037 }\end{array}$ & $\begin{array}{l}0.314 \\
0.279 \\
0.227 \\
0.267 \\
0.253 \\
0.342 \\
0.330 \\
0.332 \\
0.387\end{array}$ & $\begin{array}{c}- \\
- \\
- \\
0.0556 \\
- \\
0.0361 \\
0.0337 \\
-\end{array}$ & $\begin{array}{l}1 \\
1 \\
1 \\
3 \\
1 \\
1 \\
5 \\
6 \\
1\end{array}$ \\
\hline $4 C 1$ & PITT 8 & 0 & 2.0 & $421^{\star}$ & $\begin{array}{c}K D \\
\text { KF2037 } \\
\text { KD+VF }\end{array}$ & $\begin{array}{l}0.139 \\
0.206 \\
0.161\end{array}$ & $\begin{array}{l}0.0396 \\
0.0475\end{array}$ & $\begin{array}{l}2 \\
1 \\
3\end{array}$ \\
\hline $4 C 2$ & PITT 8 & 0 & 2.0 & $432 \star$ & $\begin{array}{l}K U+V F \\
K D \\
V F 2037 \\
K D+V F\end{array}$ & $\begin{array}{l}0.161 \\
0.136 \\
0.265 \\
0.201\end{array}$ & $\begin{array}{l}0.0384 \\
0.0384 \\
0.0316 \\
0.0802\end{array}$ & $\begin{array}{l}3 \\
2 \\
2 \\
4\end{array}$ \\
\hline $\begin{array}{l}4 C 3 \\
4 C 4\end{array}$ & $\begin{array}{l}\text { PITT } 8 \\
\text { PITT } 8\end{array}$ & $\begin{array}{l}0 \\
0\end{array}$ & $\begin{array}{l}2.0 \\
2.0\end{array}$ & $\begin{array}{l}449 * \\
336^{\star}\end{array}$ & $\begin{array}{c}K D \\
K D \\
V F 2037 \\
K D+V F\end{array}$ & $\begin{array}{l}0.167 \\
0.105 \\
0.419 \\
0.262\end{array}$ & $\begin{array}{c}- \\
\overline{-} \\
0.222\end{array}$ & $\begin{array}{l}1 \\
1 \\
1 \\
2\end{array}$ \\
\hline $\begin{array}{l}4 C 5 \\
4 C 6 \\
4 C 7\end{array}$ & $\begin{array}{l}\text { PITT } 8 \\
\text { PITT } 8 \\
\text { PITT } 8\end{array}$ & $\begin{array}{l}0 \\
0 \\
0\end{array}$ & $\begin{array}{l}2.0 \\
2.0 \\
2.0\end{array}$ & $\begin{array}{l}293^{*} \\
293^{*} \\
293^{*}\end{array}$ & $\begin{array}{l}\mathrm{KD} \\
\mathrm{KD} \\
\mathrm{KD}\end{array}$ & $\begin{array}{l}0.0898 \\
0.162 \\
0.102\end{array}$ & $=$ & $\begin{array}{l}1 \\
1 \\
1\end{array}$ \\
\hline
\end{tabular}

* These represent the wall temperatures in Zone 1 of the rotary kiln. For Runs $4 C 1,4 C 2$ and $4 C 3$, the $k i l n$ wall temperatures in Zones 2 to 4 were all $410^{\circ} \mathrm{C}$. For Runs $4 C 4,4 C 5,4 C 6$ and $4 C 7$, the $k i 1 n$ wall temperatures in the other 3 zones were: Zone $2-449^{\circ} \mathrm{C}(4 \mathrm{C} 4), 341^{\circ} \mathrm{C}(4 \mathrm{C} 5,4 \mathrm{C} 6,4 \mathrm{C} 7)$; Zone 3 $-410^{\circ} \mathrm{C}(4 \mathrm{C} 4), 449^{\circ} \mathrm{C}(4 \mathrm{C}, 4 \mathrm{C} 6,4 \mathrm{C} 7)$; Zone $4-410^{\circ} \mathrm{C}(4 \mathrm{C} 4), 410^{\circ} \mathrm{C}$ $(4 \mathrm{C}), 420^{\circ} \mathrm{C}(4 \mathrm{C} 6), 432^{\circ} \mathrm{C}(4 \mathrm{C} 7)$. 
TABLE 3-9. CARBONATE FORMATION (CONTINUED)

\begin{tabular}{|c|c|c|c|c|c|c|c|c|}
\hline Run & $\begin{array}{l}\text { Coal } \\
\text { Iype }\end{array}$ & $\begin{array}{l}\mathrm{KOH} / \\
\mathrm{NaOH}\end{array}$ & $\begin{array}{l}\text { Caustic/ } \\
\text { Coal }\end{array}$ & $\begin{array}{r}\text { Wall } \\
\text { Temp, }{ }^{\circ} \mathrm{C} \\
\end{array}$ & $\begin{array}{l}\text { Sample } \\
\text { Iype }\end{array}$ & $\begin{array}{l}\text { Frac of } \\
\text { Mean }\end{array}$ & $\begin{array}{l}\text { Caustic to } \\
\text { Std Dev. }\end{array}$ & $\begin{array}{r}\text { Carbonate } \\
\text { Data Pts }\end{array}$ \\
\hline $5 B 1$ & PITT 8 & 0 & 2.0 & $421^{*}$ & $\begin{array}{c}\text { KD } \\
\text { VP2023 }\end{array}$ & $\begin{array}{l}0.151 \\
0.149\end{array}$ & - & $\begin{array}{l}1 \\
1\end{array}$ \\
\hline 583 & PITT 8 & 0 & 2.0 & 339* & $\begin{array}{l}K D+V P \\
K D \\
V F 2037 \\
K D+V F\end{array}$ & $\begin{array}{l}0.150 \\
0.125 \\
0.191 \\
0.151\end{array}$ & $\begin{array}{l}0.0016 \\
0.0298 \\
0.0621 \\
0.0517\end{array}$ & $\begin{array}{l}2 \\
3 \\
2 \\
5\end{array}$ \\
\hline $5 B 5$ & PITT 8 & 0 & 2.0 & 427 & $\begin{array}{c}K D \\
V F 2037 \\
K D+V F\end{array}$ & $\begin{array}{l}0.0993 \\
0.169 \\
0.129\end{array}$ & 0.0139 & $\begin{array}{l}2 \\
1\end{array}$ \\
\hline $5 C 4$ & KENT 9 & 0 & 2.0 & $333^{*}$ & $\begin{array}{c}K D+V F \\
K D \\
V F 2037 \\
K D+V F\end{array}$ & $\begin{array}{l}0.122 \\
0.164 \\
0.208 \\
0.187\end{array}$ & $\begin{array}{l}0.0411 \\
0.0495 \\
0.141 \\
0.0900\end{array}$ & $\begin{array}{l}3 \\
2 \\
2 \\
4\end{array}$ \\
\hline $\begin{array}{l}501 \\
5 D 2\end{array}$ & $\begin{array}{l}\text { KENT } 9 \\
\text { KENT } 9\end{array}$ & $\begin{array}{l}0 \\
0\end{array}$ & $\begin{array}{l}2.0 \\
2.0\end{array}$ & $\begin{array}{l}281^{*} \\
399\end{array}$ & $\begin{array}{c}K D \\
K D \\
V F 2037 \\
K D+V F\end{array}$ & $\begin{array}{l}0.146 \\
0.0918 \\
0.113 \\
0.102\end{array}$ & $\begin{array}{c}- \\
0.0149\end{array}$ & $\begin{array}{l}1 \\
1 \\
1 \\
2\end{array}$ \\
\hline $\begin{array}{l}6 \mathrm{~B} 1 \\
6 \mathrm{DI} \\
6 \mathrm{El} \\
6 \mathrm{Fl}\end{array}$ & $\begin{array}{l}\text { PITT } 8 \\
\text { PITT } 8 \\
\text { PITT } 8 \\
\text { PITT } 8\end{array}$ & $\begin{array}{l}0 \\
0 \\
1 \\
1\end{array}$ & $\begin{array}{l}1.5 \\
1.5 \\
1.0 \\
1.0\end{array}$ & $\begin{array}{l}427 \\
410 \\
427 \\
427\end{array}$ & $\begin{array}{c}\text { VP2023 } \\
\text { KD } \\
\text { KD } \\
\text { KD }\end{array}$ & $\begin{array}{l}0.179 \\
0.0835 \\
0.139 \\
0.192\end{array}$ & $\begin{array}{c}0.0526 \\
- \\
0.0575 \\
-\end{array}$ & $\begin{array}{l}2 \\
1 \\
2 \\
1\end{array}$ \\
\hline $7 A$ & KENT 9 & 1 & 2.5 & 427 & $\begin{array}{c}K D \\
V F 2037 \\
K D+V F\end{array}$ & $\begin{array}{l}0.144 \\
0.0166 \\
0.126\end{array}$ & $\begin{array}{l}0.0907 \\
0.102\end{array}$ & $\begin{array}{l}6 \\
1 \\
7\end{array}$ \\
\hline $\begin{array}{l}7 C \\
7 D \\
7 E\end{array}$ & $\begin{array}{l}\text { PITT } 8 \\
\text { PITT } 8 \\
\text { PITT } 8\end{array}$ & $\begin{array}{l}1 \\
1 \\
?\end{array}$ & $\begin{array}{l}3.0 \\
2.0 \\
2.0\end{array}$ & $\begin{array}{l}427 \\
427 \\
427\end{array}$ & $\begin{array}{l}K D \\
K D \\
K D\end{array}$ & $\begin{array}{l}0.112 \\
0.289 \\
0.0067\end{array}$ & - & $\begin{array}{l}1 \\
1 \\
1\end{array}$ \\
\hline
\end{tabular}

*These represent the wall temperatures in Zone 1 of the rotary kiln. For Run $5 \mathrm{Bl}$, the kiln wall temperatures in Zones 2 to 4 were all $410^{\circ} \mathrm{C}$. For Run $5 \mathrm{~B} 3$, the $\mathrm{kiln}$ wall temperatures were: $449^{\circ} \mathrm{C}$ (Zone 2), $410^{\circ} \mathrm{C}$ (Zones 3 and 4 . For Run 5C4, the kiln wall temperatures in zones 2 to 4 were al1 $427^{\circ} \mathrm{C}$. For Run 501 , the kiln wall temperature: were: $331^{\circ} \mathrm{C}$ (Zone 2), $427^{\circ} \mathrm{C}$ (Zones 3 and 4 ). 
TABLE 3-9. CARBONATE FORMATION (CONTINUED)

Coal $\mathrm{KOH} /$ Caustic/ Wall
Run Type
NaOH Coal

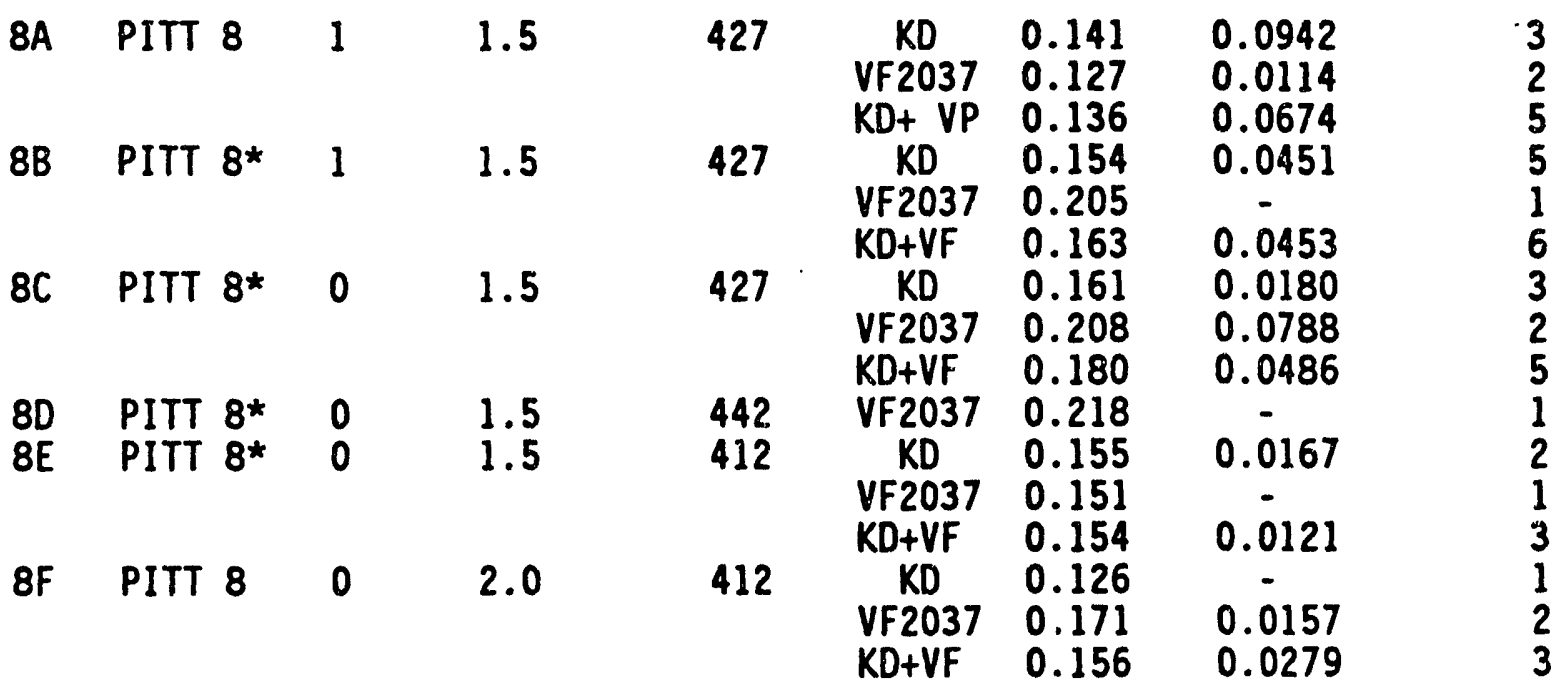

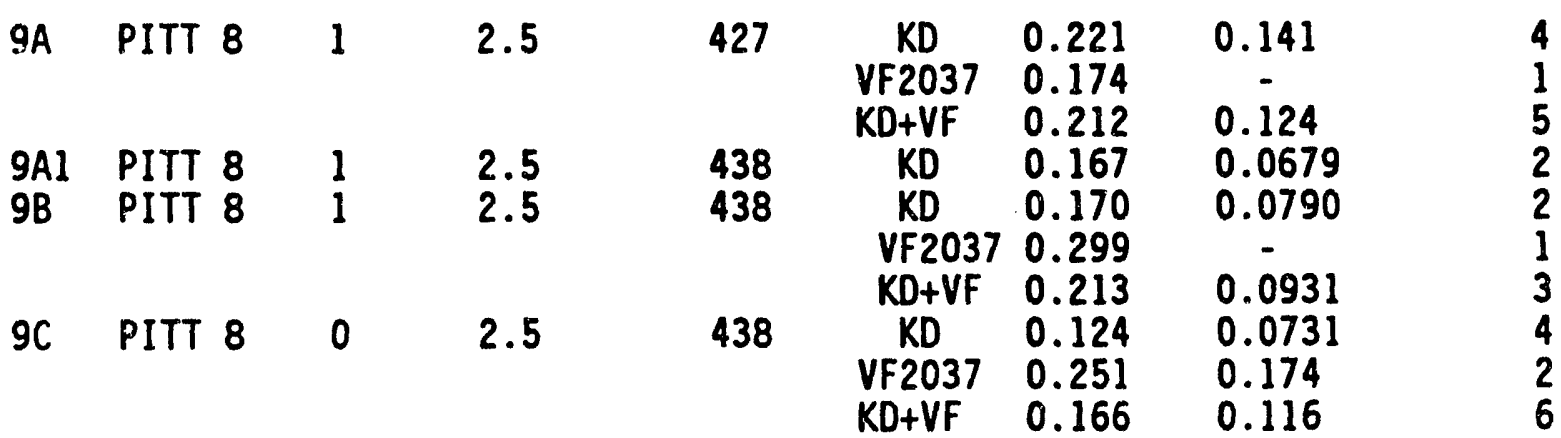

*For Runs $8 \mathrm{~B}, 8 \mathrm{C}, 8 \mathrm{D}$ and $8 \mathrm{E}, 6$ mesh coal was used in the coal feed to the rotary kiln. The coal feed for all the other runs was 14 mesh coal. Also, recycled caustic was used in Runs $7 D$ and $9 B$. 
with the spent caustic carbonate data to determine whether the two data sets are similar, or whether additional carbonate is generated in the wash section.

\subsubsection{Effect of Caustic/Coal Ratio on Carbonate Formation}

The effect of caustic/coal ratio on carbonate formation is evaluated by plotting the percentage of coal converted to carbonate at different caustic/coal ratios, at a kiln wall temperature of $427^{\circ} \mathrm{C}$. The fraction of coal feed converted to carbonate was computed as the ratio of the weight of carbonate carbon to the weight of coal feed. As shown in Figure 3-15, the general trend is that a higher percentage of the coal feed is converted to carbonate as the caustic/coal ratio increases. At a caustic/coal ratio of 1.0 , the conversion of coal feed to carbonate averages $2.73 \%$ and ranges from $1.65 \%$ to $3.73 \%$. By comparison, at a caustic/coal ratio of 2.0 or greater, the conversion of coal feed to carbonate averages $3.94 \%$ and exceeds $3.70 \%$ in 5 of the 7 runs. The slightly higher conversion of coal carbon to carbonates at the higher ratio of caustic/coal is probably due to the increased accessibility of coal surface to molten caustic.

\subsubsection{Effect of $\mathrm{Kiln}$ Temperature on Carbonate Formation}

The effect of operating temperature on carbonate formation was examined by plotting the percentage of coal and the percentage of caustic converted to carbonate versus the kiln wall temperature, at a caustic/coal ratio of 2.0 and greater. These plots, as presented in Figures 3-16 and 3-17, indicate a definite trend of increasing carbonate formation with increasing kiln operating temperature. At kiln wall temperatures of $410^{\circ} \mathrm{C}$ or below, carbonate formation is relatively low. For the four runs (Runs 1D, 2A, 2B and 5D2) at these temperatures, the average conversion of caustic to carbonate is $7.03 \%$. The corresponding average conversion of coal to carbonate is $1.78 \%$. 


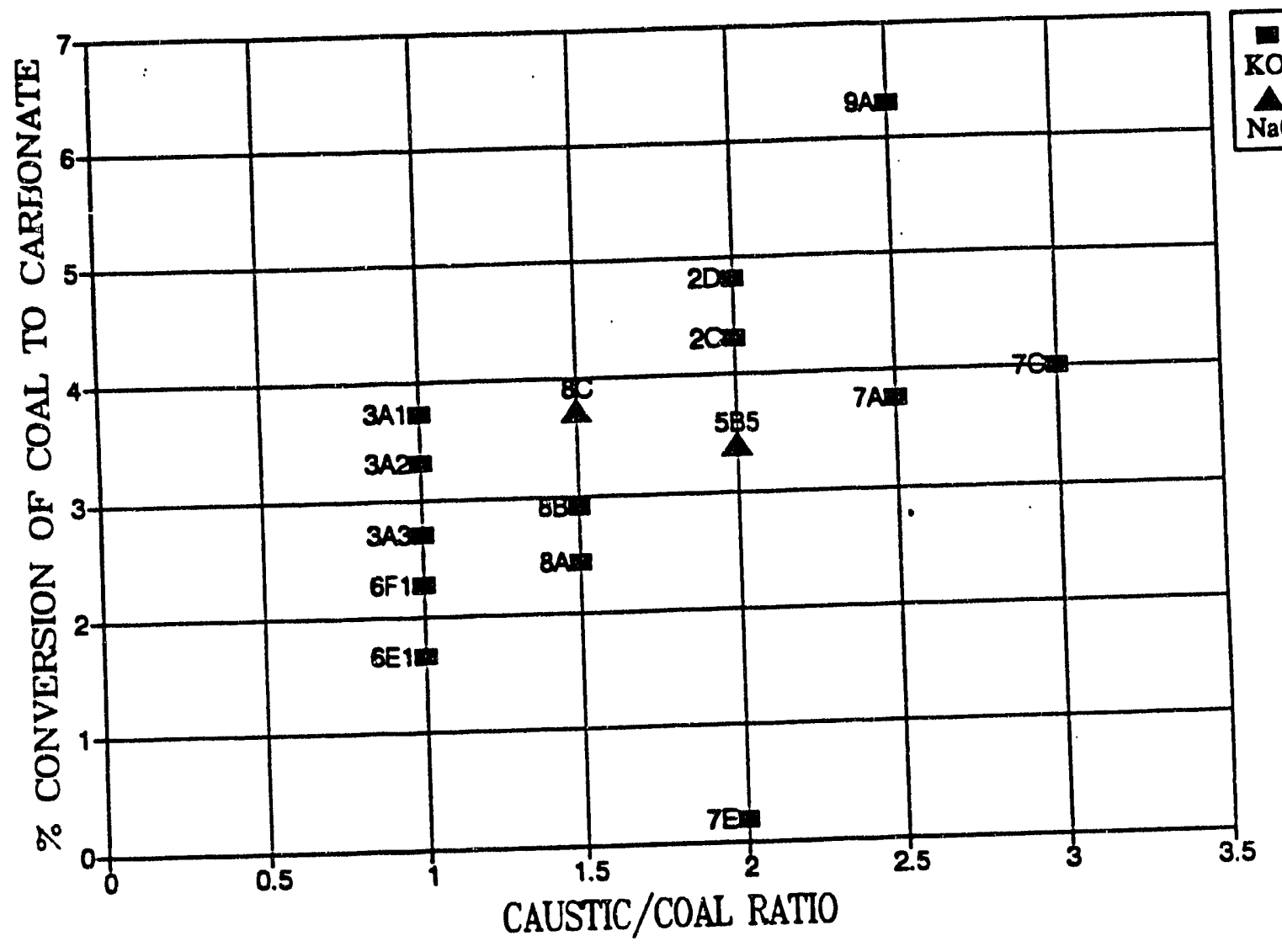

$\mathrm{KOH}+\mathrm{NaOH}$

$\mathrm{NaOH}$

Figure 3-15. Effect of Caustig/Coal Ratio on Carbonate

Formation at $42.7^{\circ} \mathrm{C} \mathrm{Kiln} \mathrm{Wall} \mathrm{Temperature}$ 


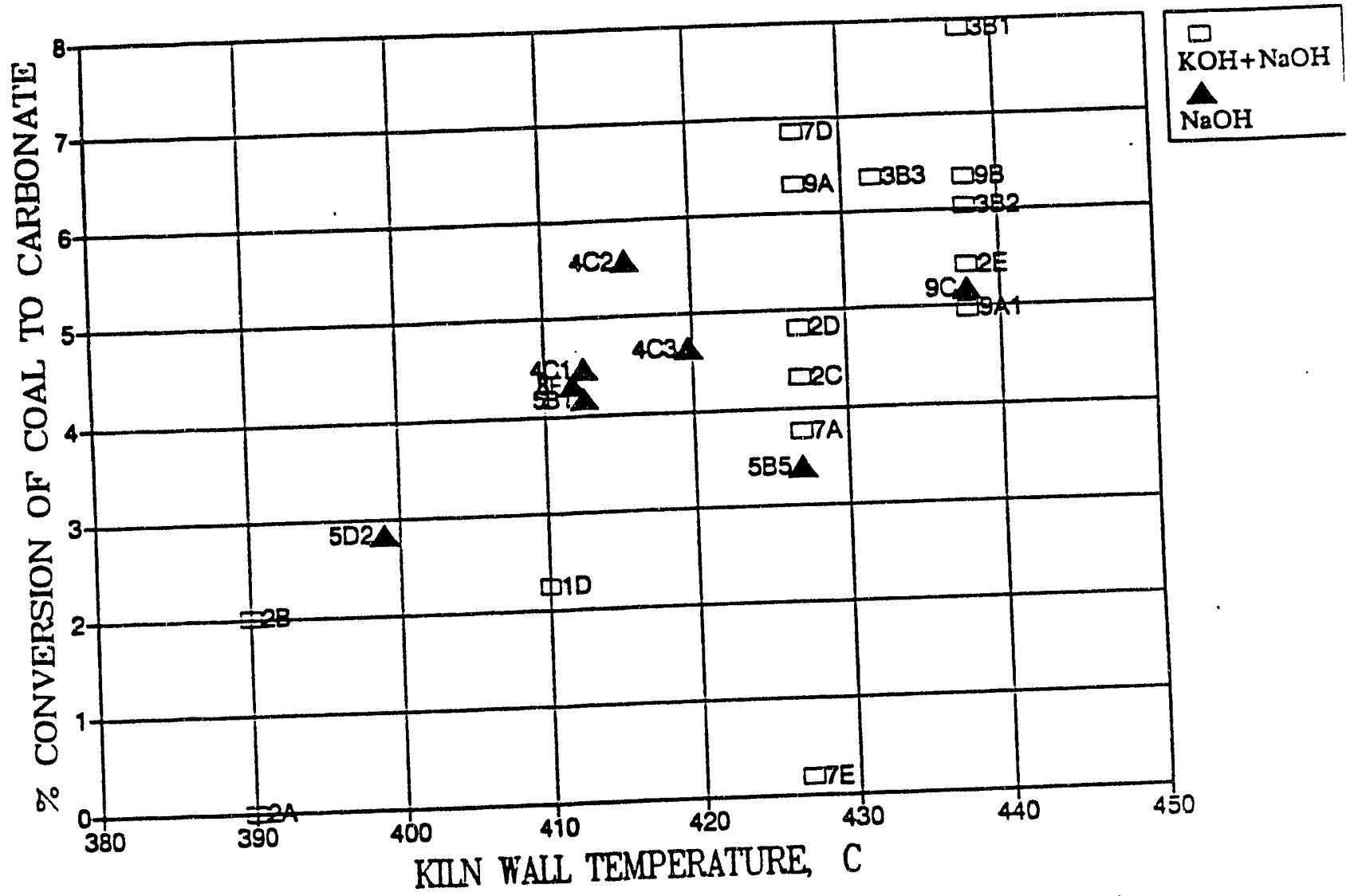

Figure 3-16. Effect of Kiln Temperature on Conversion of Coal to Carbonate at Caustic/Coal $\geq 2.0$ 


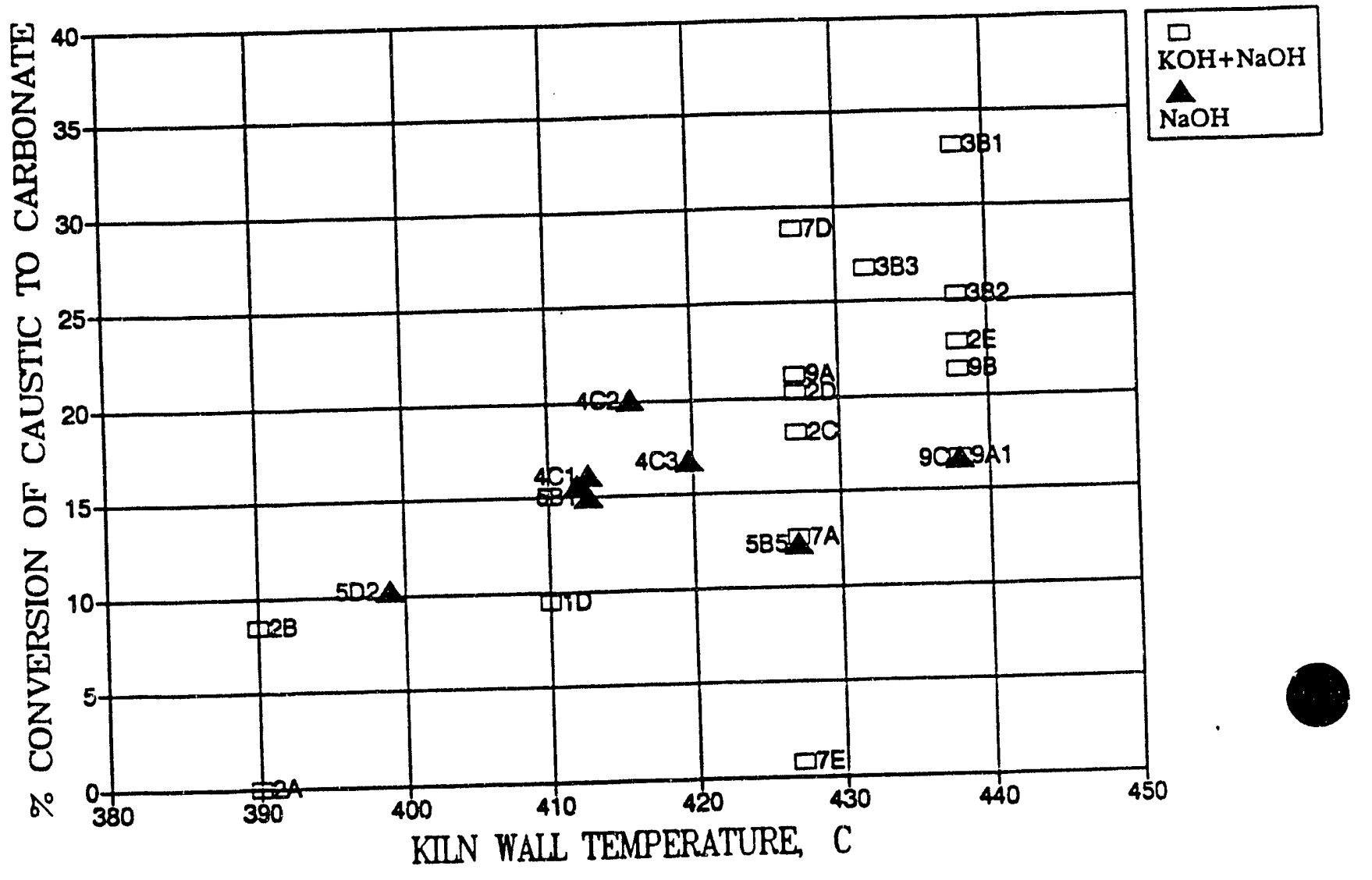
Figure 3-17. Effect of Kiln Temperature on Conversion of
Caustic to Carbonate at Caustic/Coal $\geq 2.0$ 
An important observation is that the temperature dependence of carbonate formation is much less pronounced when sodium hydroxide instead of mixed caustic was used. At kiln wall temperatures between $412^{\circ} \mathrm{C}$ and $438^{\circ} \mathrm{C}$, Figures $3-16$ and $3-17$ indicate that carbonate formation is not dependent on kiln wall temperature for sodium hydroxide.

\subsubsection{Effect of Coal Type on Carbonate Formation}

The data presented in Table 3-9 include those from 6 Kentucky No. 9 coal runs and 40 Pittsburgh No. 8 coal runs. The average conversion of Kentucky coal to carbonate is $4.35 \%$, with a standard deviation of $0.98 \%$. By comparison, the average conversion of Pittsburgh coal to carbonate is $4.16 \%$, with a standard deviation of $2.41 \%$. The difference between these average carbonate conversions for the two coal types is statistically insignificant.

The effect of coal type can also be evaluated by comparing carbonate formation in runs with similar operating conditions except coal type: Run $2 C$ versus Run 2D, and Run $3 B 1$ versus Run 2E. Data from these runs are summarized in the following table.

\begin{tabular}{|c|c|c|c|c|c|c|c|}
\hline Run & $\begin{array}{l}\text { Coal } \\
\text { Iype }\end{array}$ & $\begin{array}{l}\mathrm{KOH} / \\
\mathrm{NaOH} \\
\end{array}$ & $\begin{array}{c}\text { Caustic/ } \\
\text { Coal }\end{array}$ & $\begin{array}{l}\text { Wall } \\
\text { Temp, }{ }^{\circ} \mathrm{C}\end{array}$ & $\begin{array}{l}\text { Percent } \\
\text { Mean }\end{array}$ & $\begin{array}{l}\text { of Coal to } \\
\text { Std Dev. }\end{array}$ & $\begin{array}{l}\text { Carbonate } \\
\text { Data Pts }\end{array}$ \\
\hline $\begin{array}{l}2 C \\
2 D\end{array}$ & $\begin{array}{ll}\text { PITT } & 8 \\
\text { KENT } & 9\end{array}$ & $\begin{array}{l}1 \\
1\end{array}$ & $\begin{array}{l}2.0 \\
2.0\end{array}$ & $\begin{array}{l}427 \\
427\end{array}$ & $\begin{array}{l}4.31 \\
4.82\end{array}$ & $\begin{array}{l}0.652 \\
0.435\end{array}$ & $\begin{array}{l}3 \\
2\end{array}$ \\
\hline $\begin{array}{l}3 B 1 \\
2 E\end{array}$ & $\begin{array}{l}\text { PITT } 8 \\
\text { KENT } 9\end{array}$ & $\begin{array}{l}1 \\
1\end{array}$ & $\begin{array}{l}2.0 \\
2.0\end{array}$ & $\begin{array}{l}438 \\
438\end{array}$ & $\begin{array}{l}7.90 \\
5.43\end{array}$ & $\begin{array}{l}0.802 \\
0.347\end{array}$ & $\begin{array}{l}6 \\
2\end{array}$ \\
\hline
\end{tabular}

These data indicate that at $427^{\circ} \mathrm{C}$ kiln wall temperature, the average conversion to carbonate is essentially the same for Pittsburgh and Kentucky coals. At $438^{\circ} \mathrm{C}$ kiln' wall temperature, data for Runs $3 \mathrm{Bl}$ and $2 E$ show that the average conversion to carbonate may be lower for Kentucky coal than for Pittsburgh coal. However, there is only one data set to support this observation, and the overall data base still indicates small differences in carbonate formation between the Pittsburgh and Kentucky coals. 


\subsubsection{Effect of Caustic Type on Carbonate Formation}

The average coal conversion to carbonate is $4.22 \%$ for the 26 mixed caustic runs, with a standard deviation of $2.84 \%$. For the 20 sodium hydroxide runs, the average coal conversion to carbonate is $4.10 \%$, with a standard deviation of $1.22 \%$. The difference between these average conversions for the two caustic types is statistically insignificant. A more detailed analysis indicates that the effect of caustic type on carbonate formation appears to be temperature dependent. Examination of Figures 3-16 and 3-17 shows that at kiln wall temperatures of $420^{\circ} \mathrm{C}$ and below, the use of sodium hydroxide results in higher conversion to carbonate than the use of mixed caustic. However, at temperatures above $420^{\circ} \mathrm{C}$, lower conversion to carbonate is obtained with sodium hydroxide as compared to mixed caustic. This is due to the increased carbonate formation at high kiln temperatures for mixed caustic, and the relative insensitivity of carbonate formation to kiln temperatures for sodium hydroxide. Therefore, the use of sodium hydroxide instead of mixed caustic may result in lower carbonate formation at high kiln temperatures.

The effect of caustic type can also be assessed by comparing carbonate formation data from 4 pairs of runs: $1 C / 6 D 1,2 C / 5 B 5,8 B / 8 C$, and $9 A 1 / 9 C$. Each pair contains two runs with Pittsburgh No. 8 coal at the same caustic/coal ratio and kiln conditions, except one run used mixed caustic and the other run used sodium hydroxide. Data from these runs are summarized in the following table:

\begin{tabular}{|c|c|c|c|c|c|c|}
\hline Run & $\begin{array}{l}\mathrm{KOH} / \\
\mathrm{NaOH} \\
\end{array}$ & $\begin{array}{c}\text { Caustic/ } \\
\text { Coal }\end{array}$ & Wall & $\begin{array}{l}\text { Perc } \\
\text { Mean }\end{array}$ & $\begin{array}{l}\text { of Coal to } \\
\text { Std Dev. }\end{array}$ & $\begin{array}{l}\text { Carbonate } \\
\text { Data Pts }\end{array}$ \\
\hline $\begin{array}{l}1 C \\
6 D 1\end{array}$ & $\begin{array}{l}1 \\
0\end{array}$ & $\begin{array}{l}1.5 \\
1.5\end{array}$ & $\begin{array}{l}410 \\
410\end{array}$ & $\begin{array}{l}3.93 \\
1.74\end{array}$ & 0.105 & $\begin{array}{l}2 \\
1\end{array}$ \\
\hline $\begin{array}{l}2 \mathrm{C} \\
5 \mathrm{~B} 5\end{array}$ & $\begin{array}{l}1 \\
0\end{array}$ & $\begin{array}{l}2.0 \\
2.0\end{array}$ & $\begin{array}{l}427 \\
427\end{array}$ & $\begin{array}{l}4.31 \\
3.40\end{array}$ & $\begin{array}{l}0.652 \\
1.15\end{array}$ & $\begin{array}{l}3 \\
3\end{array}$ \\
\hline $\begin{array}{l}8 B \\
8 C\end{array}$ & $\begin{array}{l}1 \\
0\end{array}$ & $\begin{array}{l}1.5 \\
1.5\end{array}$ & $\begin{array}{l}427 \\
427\end{array}$ & $\begin{array}{l}2.90 \\
3.74\end{array}$ & $\begin{array}{l}0.806 \\
1.10\end{array}$ & $\begin{array}{l}6 \\
5\end{array}$ \\
\hline $\begin{array}{l}9 A 1 \\
9 C\end{array}$ & $\begin{array}{l}1 \\
0\end{array}$ & $\begin{array}{l}2.5 \\
2.5\end{array}$ & $\begin{array}{l}438 \\
438\end{array}$ & $\begin{array}{l}4.97 \\
5.18\end{array}$ & $\begin{array}{l}2.02 \\
3.62\end{array}$ & $\begin{array}{l}2 \\
6\end{array}$ \\
\hline
\end{tabular}


The data for Runs $2 \mathrm{C} / 5 \mathrm{~B} 5,8 \mathrm{~B} / 8 \mathrm{C}$ and $9 \mathrm{Al} / 9 \mathrm{C}$ show statistically the same coal conversions to carbonate for either type of caustic. Run 1C/6D1 data show lower coal conversions to carbonate for sodium hydroxide than for mixed caustic. Comparison of the Run IC and Run 6DI data, however, must take into account the limited number of data points. Run 1D, operated at the same conditions as Run $1 \mathrm{C}$ except with a caustic/coal ratio of 2.0 , resulted in an average conversion of $2.24 \%$ coal to carbonate, based on the analysis of $4 \mathrm{kiln}$ discharge samples. This is essentially the same average coal conversion to carbonate as in $6 \mathrm{Dl}$. Therefore, these comparisons show no significant difference in carbonate formation between the use of mixed caustic and sodium hydroxide.

\subsubsection{Kiln Discharge Versus Spent Caustic Data}

Twenty sets of carbonate conversion data are compared in Figure 3-18, with each set representing kiln discharge (KD) coal versus spent caustic data from the same run. The comparisons show that in 6 of the 20 runs, carbonate conversions are found to be approximately the same in the KD and spent caustic samples. In 12 of the 20 runs, higher carbonate conversions are obtained in the spent caustic than in the KD samples. There are only 2 runs for which carbonate conversions are higher in she KD samples than in the spent caustic samples. Therefore, it appears that at least in some of the runs, additional conversion of caustic to carbonate had taken place in the wash section of the integrated MCL circuit.

\subsubsection{Suppression of Carbonate Formation}

The discussion in the above sections show that carbonate formation can generally be suppressed by operating with low caustic/coal ratio, low kiln temperature, and possibly using sodium hydroxide instead of mixed caustic. Operation with low caustic/coal will usually result in unacceptably high residual sulfur and ash in the MCL coal. However, if molten caustic is injecied onto the coal inside the kiln, it may be possible to achieve high sulfur and ash removal with a relatively low caustic/coal ratio. Also, use of sodium hydroxide may result in fairly low carbonate formation even at high kiln temperatures. 


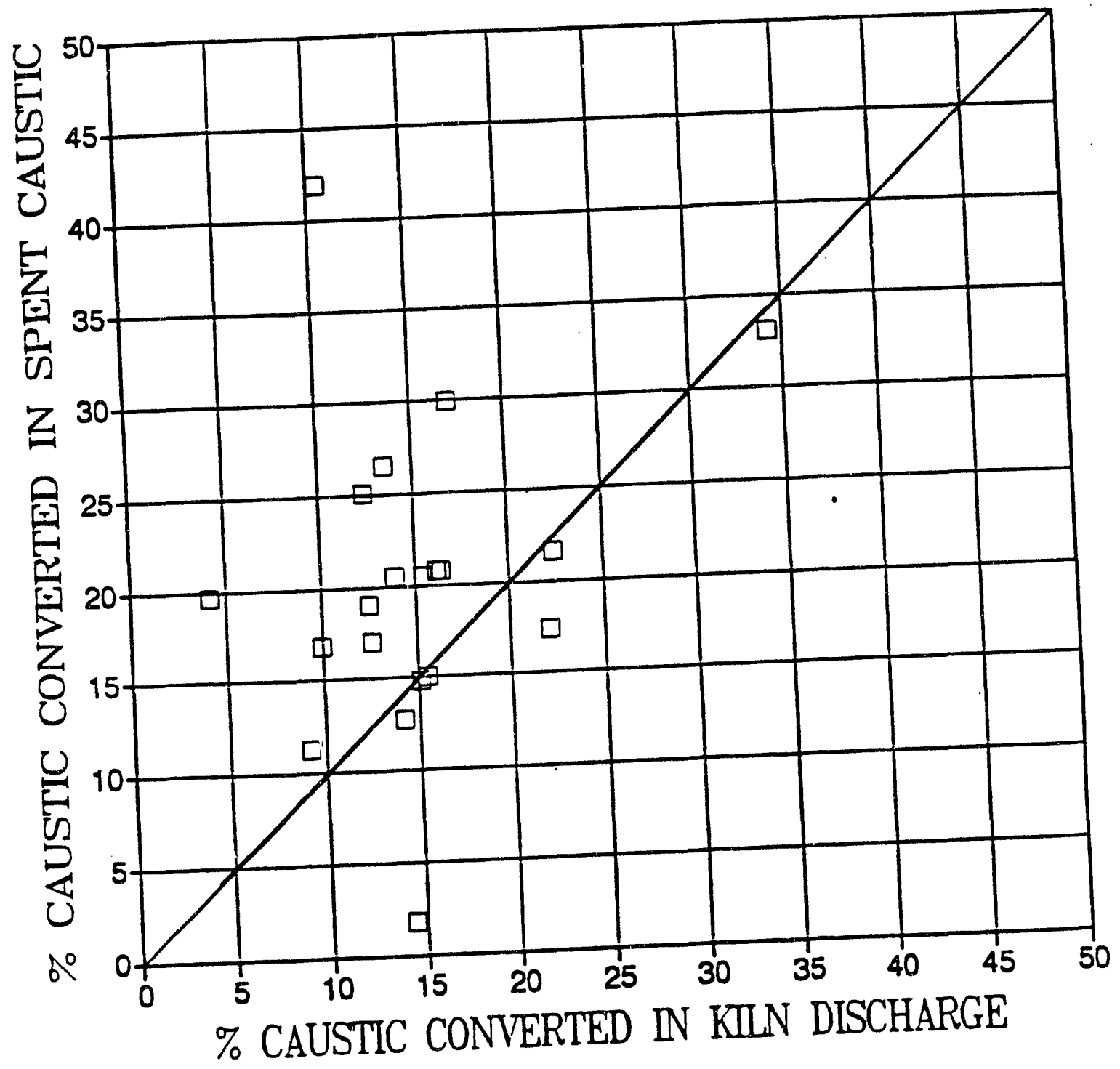

Figure 3-18. Comparison of Carbonate Formation in Kiln Discharge and Spent Caustic Samples 
Review of the carbonate formation data indicates in seven of the samples analyzed, the conversion of caustic to carbonate is at or below 3.3\%. These seven samples include one sample each from Runs 1B, 1D, 2A, $7 E$ and $8 A$, and two samples from Run $7 A$. In general, these runs are not associated with operating conditions that will specifically minimize carbonate formation. A possible explanation is that for these samples, the coal had been partially devolatilized in the heating process prior to reaction with caustic, such as in the case of poor mixing in the first heating zone.

As discussed previously, the average conversion of coal to carbonate is $4.22 \%$ for the 26 mixed caustic runs, and $4.10 \%$ for the 20 sodium hydroxide runs. The corresponding average caustic conversion to carbonate is $19.0 \%$ for mixed caustic, and $15.7 \%$ for sodium hydroxide. These results were achieved by exclusion of air in the rotary kiln with nitrogen flow. Research conducted at the Ames laboratory has demonstrated that carbonate formation can be further suppressed by the pretreatment devolatilization of coal prior to MCL. Thus, the optimum mode of operation for low carbonate formation may include using the first heated zone of the rotary kiln for coal devolatilization, followed by injection of molten caustic onto the partially devolatilized coal in the second heated zone.

\subsection{PARTICLE SIZE DISTRIBUTION}

Particle size distribution data for the feed coal and processed coal are presented in Table 3-10. Representative data from Table 3-10 are plotted in Figures $3-19$ and 3-20 to provide better illustration of the effects of $\mathrm{MCL}$ processing on coal particle size. The data plotted are derived from the experimental data, assuming that the coal particles follow a logarithmic-probability distribution of the form:

Cumulative $\%$ by Weight Undersize $=50\left[1+\operatorname{erf}\left(\log \left(X / X^{\prime}\right) / s\right)\right]$ 
TABLE 3-10. COAL PARTICLE SIZE DISTRIBUTION

\begin{tabular}{|c|c|c|c|c|c|c|c|}
\hline $\begin{array}{r}\text { Run/ } \\
\text { Sample }\end{array}$ & Date/Time & $\begin{array}{l}40 \text { mesh } \\
0.425 \mathrm{~mm}\end{array}$ & $\begin{array}{l}\text { Cumulat } \\
60 \text { mesh } \\
0.250 \mathrm{~mm}\end{array}$ & $\begin{array}{l}\text { ve } \% \text { Retai } \\
80 \text { mesh } \\
0.180 \mathrm{~mm}\end{array}$ & $\begin{array}{l}\text { ned on Sc } \\
100 \mathrm{mesh} \\
0.150 \mathrm{~mm}\end{array}$ & $\begin{array}{l}\text { en }^{*} \\
200 \mathrm{mesh} \\
0.075 \mathrm{~mm}\end{array}$ & $\begin{array}{c}\text { Pan } \\
0 \\
\end{array}$ \\
\hline Feed & 1212 & 47.0 & 64.0 & 71.4 & 75.2 & 85.3 & 100 \\
\hline $\begin{array}{l}1 B / C P \\
1 B / C P \\
1 B / C P \\
1 C / C P \\
1 C / C P\end{array}$ & $\begin{array}{l}0123 / 2230 \\
0124 / 0600 \\
0124 / 0830 \\
0124 / 2230 \\
0125 / 0630\end{array}$ & $\begin{array}{l}0.83 \\
0.79 \\
0.33 \\
0.24 \\
0.18\end{array}$ & $\begin{array}{l}3.03 \\
4.72 \\
1.42 \\
1.29 \\
0.74\end{array}$ & $\begin{array}{l}6.22 \\
9.57 \\
3.14 \\
3.65 \\
2.42\end{array}$ & $\begin{array}{c}9.1 \\
13.17 \\
4.96 \\
7.4 \\
4.93\end{array}$ & $\begin{array}{l}28.6 \\
32.29 \\
19.3 \\
35.58 \\
22.72\end{array}$ & $\begin{array}{l}100 \\
100 \\
100 \\
100 \\
100\end{array}$ \\
\hline $\begin{array}{l}2 B / K D \\
2 C / K D \\
2 C / K D\end{array}$ & $\begin{array}{l}0207 / 1430 \\
0208 / 0330 \\
0208 / 1100\end{array}$ & $\begin{array}{r}3.9 \\
46.2 \\
8.5\end{array}$ & $\begin{array}{l}16.1 \\
60.2 \\
31.0\end{array}$ & $\begin{array}{l}27.3 \\
66.2 \\
44.1\end{array}$ & $\begin{array}{l}34.6 \\
69.4 \\
50.9\end{array}$ & $\begin{array}{l}56.2 \\
78.2 \\
68.4\end{array}$ & $\begin{array}{l}100 \\
100 \\
100\end{array}$ \\
\hline $\begin{array}{l}3 B 1 / C P \\
3 B 1 / C P \\
3 C 1 / C P \\
3 C 1 / C P\end{array}$ & $\begin{array}{l}0223 / 0815 \\
0224 / 0415 \\
0224 / 0815 \\
0224 / 1215\end{array}$ & $\begin{array}{l}0.6 \\
0.3 \\
0.5 \\
0.5\end{array}$ & $\begin{array}{l}3.2 \\
1.7 \\
2.9 \\
2.8\end{array}$ & $\begin{array}{r}10.4 \\
6.4 \\
10.3 \\
9.5\end{array}$ & $\begin{array}{l}16.7 \\
11.4 \\
17.1 \\
15.7\end{array}$ & $\begin{array}{l}37.5 \\
35.0 \\
41.0 \\
38.4\end{array}$ & $\begin{array}{l}100 \\
100 \\
100 \\
100\end{array}$ \\
\hline $\begin{array}{l}\text { 6D1/KD } \\
6 \mathrm{DI} / \mathrm{KD} \\
6 \mathrm{Gl} / \mathrm{KD}\end{array}$ & $\begin{array}{l}0406 / 1435 \\
0406 / 0130 \\
0407 / 0655\end{array}$ & $\begin{array}{l}41.1 \\
28.3 \\
16.8\end{array}$ & $\begin{array}{l}59.0 \\
46.9 \\
39.4\end{array}$ & $\begin{array}{l}67.9 \\
58.0 \\
53.1\end{array}$ & $\begin{array}{l}72.6 \\
64.9 \\
60.8\end{array}$ & $\begin{array}{l}86.5 \\
83.8 \\
82.0\end{array}$ & $\begin{array}{l}100 \\
100 \\
100\end{array}$ \\
\hline
\end{tabular}

* The screen sizes are given in both mesh size (40 mesh to pan) and in the size of the corresponding screen opening $(0.425 \mathrm{~mm}$ to zero). CP is washed coal product and $K D$ is coal obtained from kiln discharge. 


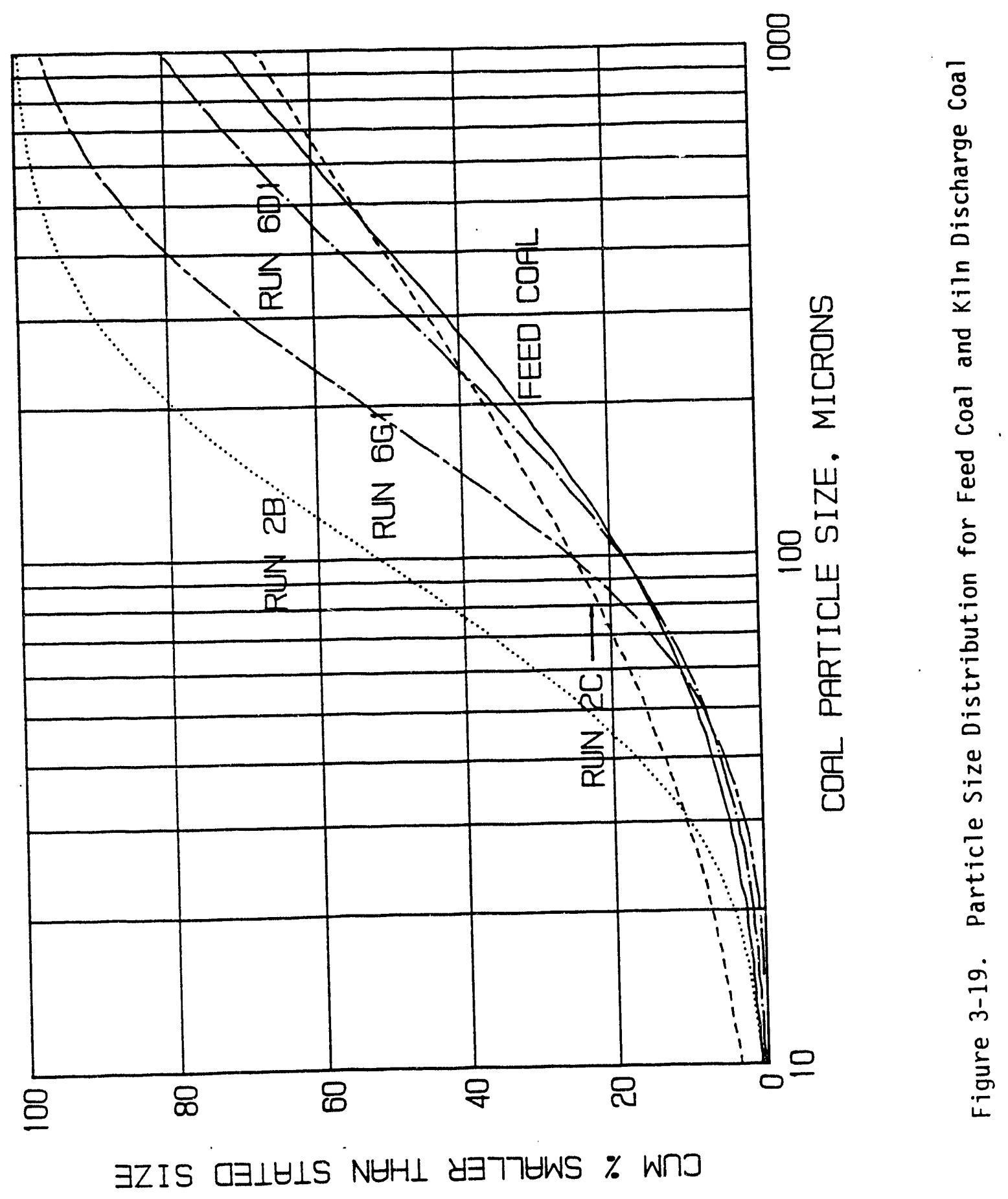




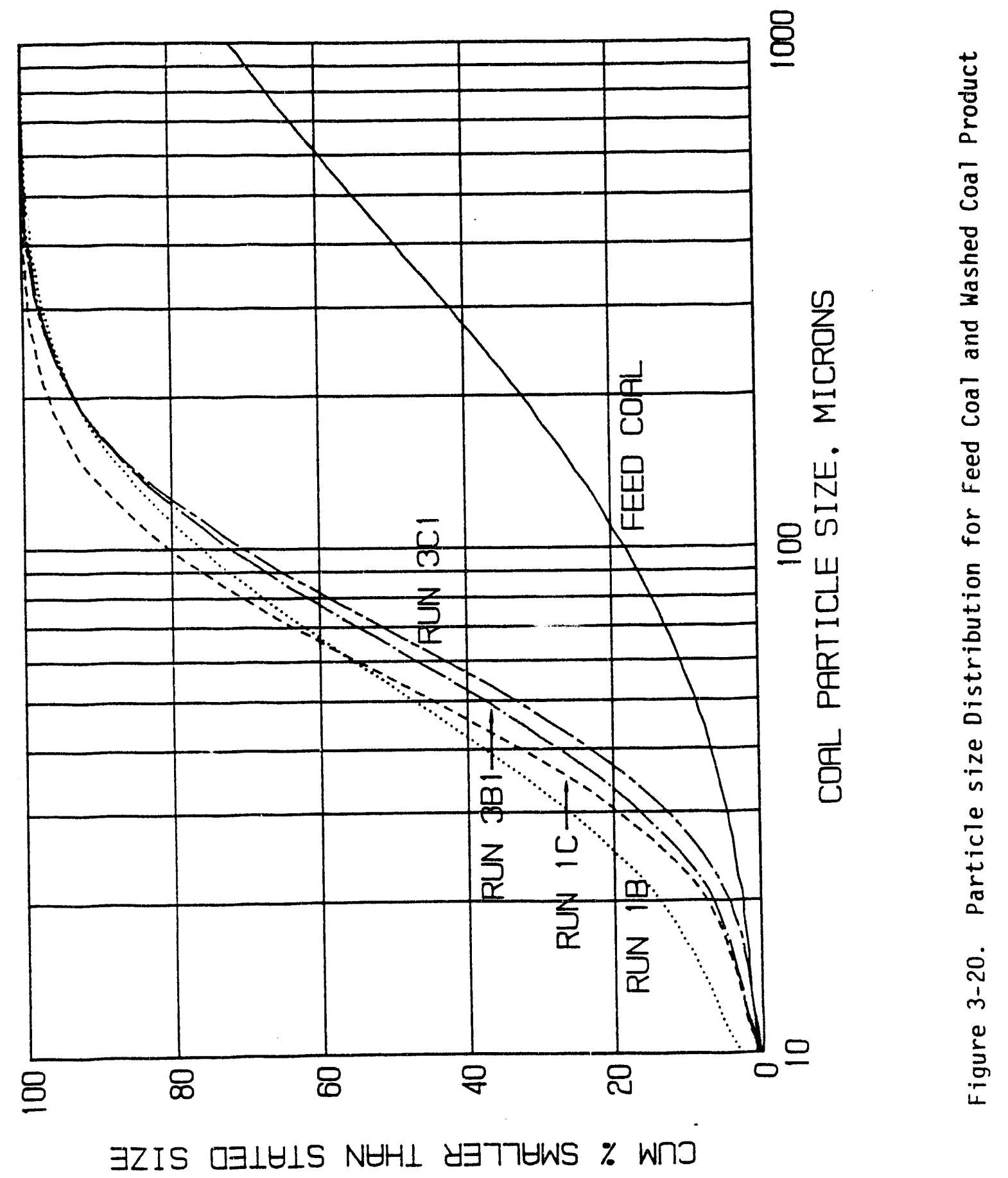


where $X=$ particle size, $X^{\prime}=$ parameter with dimension of size, $s=$ standard deviation parameter, and erf = normal probability function or error function. The parameters $x^{\prime}$ and $s$ were determined from linear regression of the experimental data. In all cases, it was found that the experimental data can be well represented by the logarithmic-probability function. This indicates that the logarithm of the coal particle size is normally distributed.

As shown in Figure 3-19, the effect of rotary kiln operation on cod particle size reduction is not totally clear. Data from Run 2C (0208/033C; and Run 6D1 (0406/1435) show that there was little or no size reduction for the coal particles after processing in the rotary kiln, based on examination of the kiln discharge (KD) coal particle size data illustrated in Figure 3-19. Data from Run $2 B$ and Run 6Gl, however, indicate that there was size reduction for at least the large coal paricicles. For example, approximately $48 \%$ of the coal particles in feed coal were greater than 400 microns ( 40 rash) in size. In Run 28 , only $7 \%$ of the KD coal particles were greater than this size. In Run $6 G 1,20 \%$ of the KD coal particles were greater than 400 microns ( 40 mssh). Thus, there appears to be some coal particle size reduction due to kiln processing, although the effects were not as significant as dissolver pump around and downstream processing by washing/centrifuge.

The data presented in Table 3-10 and the plot in Figure 3-20 show that there is significant reduction in coal particle size due to dissolver pump around and subsequent washing/centrifuging, as illustrated by the coal product $(C P)$ data from Runs $1 B, 1 C, 3 B 1$ and $3 C 1$. In the feed coal, approximately $69 \%$ of the coal particles were greater than 200 microns (65 mesh) in size. By comparison, only 2.8 to $8 \%$ of the coal particles are greater than 200 microns $(65$ mesh) in size in the washed coal product.

With the additional operation of the two vacuum filters to remove most of the spent causti - from $\mathrm{MCL}$ coal before centrifuge separation, it may be possible to lessen coal particle size reduction by reducing the number of centrifuge stages, or by reducing centrifuge speed and minimizinis shear generated in pump around loops and stirring of the coal slurry. 


\subsection{PROCESS LIQUID ANALYSIS}

Selected liquid samples were collected during the operational runs and analyzed to determine the partition of aluminum, silicon and iron in the wash sections, the effectiveness of caustic regeneration, and the effectiveness of acid wash water treatment. The analysis results are discussed in the following sections.

\subsubsection{Partition of Aluminum, Silicon and Iron}

The liquid samples collected for analysis included VP2023 (spent caustic solution upstream of the bag filter), VF2037 (caustic regenerator inlet), and VP304l (centrate from the first centrifuge, C-301, in the acid wash section to water treatment). The concentration levels of aluminum, silicon and iron in these samples are presented in Table 3-11. Also presented in this table are the computed concentration levels of aluminum, silicon and iron for a liquid stream entering the wash sections, based on the coal product generation rate and assuming that all mineral matter from coal is in solution. These computed concentration levels can be compared with the sum of the concentration levels of aluminum, silicon and iron in the VP2023+VP304: samples, because these samples represent the only exit stieams for mineral matter from the wash sections. In cases where data for the 1,2023 samples are unavailable, the computed concentration levels can be compared with the sum of the concentration levels in the VF2037 and VP3041 samples. This latter comparison does not take into account the amount of aluminum, silicon and iron that could be trapped by the wash section bag filters.

The data presented in Table 3-11 show that essentially all the aluminum and silicon in the coal feed were found in the caustic regeneration feed (VP2023 and VF2037), whereas most of the iron in the coal feed was found in the acid wash section (VP3041). The expected aluminum and silicon concentrations are in fairly good agreement with the measured values. On the average, approximately 107\% of the aluminum and $125 \%$ of the silicon in the coal feed could be found in the exit streams 
TABLE 3-11. PARTITION OF ALUMINUM, SILICON AND IRON

\begin{tabular}{|c|c|c|c|c|}
\hline Run & Sample & Al $(\mathrm{mg} / \mathrm{L})$ & $\underline{S i}(\mathrm{mg} / \mathrm{L})$ & $\mathrm{Fe}(\mathrm{mg} / \mathrm{L})$ \\
\hline $\begin{array}{l}2 B \\
2 B \\
2 B \\
2 B \\
2 B\end{array}$ & $\begin{array}{c}\text { VP2023 } \\
\text { VF2037 } \\
\text { VP3041 } \\
\text { VP2023+VP3041 } \\
\text { Computed }\end{array}$ & $\begin{array}{r}470 \\
500 \\
7 \\
477 \\
557\end{array}$ & $\begin{array}{r}950 \\
1100 \\
7 \\
957 \\
993\end{array}$ & $\begin{array}{l}3.9 \\
11 \\
220 \\
224 \\
971\end{array}$ \\
\hline $\begin{array}{l}2 C \\
2 C \\
2 C \\
2 C\end{array}$ & $\begin{array}{c}\text { VF2037 } \\
\text { VP3041 } \\
\text { VF2037+VP3041 } \\
\text { Computed }\end{array}$ & $\begin{array}{r}540 \\
10 \\
550 \\
451\end{array}$ & $\begin{array}{r}1120 \\
8 \\
1128 \\
805\end{array}$ & $\begin{array}{r}36 \\
355 \\
391 \\
787\end{array}$ \\
\hline $\begin{array}{l}2 D \\
2 D \\
2 D \\
2 D \\
2 D\end{array}$ & $\begin{array}{c}\text { VP2023 } \\
\text { VF2037 } \\
\text { VP3041 } \\
\text { VP2023+VP3041 } \\
\text { Computed }\end{array}$ & $\begin{array}{r}630 \\
568 \\
10 \\
640 \\
534\end{array}$ & $\begin{array}{r}1500 \\
1250 \\
8 \\
1508 \\
802\end{array}$ & $\begin{array}{r}26 \\
6 \\
370 \\
396 \\
729\end{array}$ \\
\hline $\begin{array}{l}3 B 1 \\
3 B 1 \\
3 B 1 \\
3 B 1 \\
3 B 1\end{array}$ & $\begin{array}{c}\text { VP2023 } \\
\text { VF2037 } \\
\text { VP3041 } \\
\text { VP2023+VP3041 } \\
\text { Computed }\end{array}$ & $\begin{array}{r}385 \\
453 \\
47 \\
432 \\
380\end{array}$ & $\begin{array}{l}748 \\
888 \\
147 \\
895 \\
678\end{array}$ & $\begin{array}{l}140 \\
105 \\
363 \\
503 \\
663\end{array}$ \\
\hline $\begin{array}{l}4 C 2 \\
4 C 2 \\
4 C 2 \\
4 C 2\end{array}$ & $\begin{array}{c}\text { VF2037 } \\
\text { VP3041 } \\
\text { VF2037+VP3041 } \\
\text { Computed }\end{array}$ & $\begin{array}{r}737 \\
12 \\
745 \\
551\end{array}$ & $\begin{array}{c}1482 \\
7.7 \\
1490 \\
983\end{array}$ & $\begin{array}{r}29 \\
500 \\
529 \\
961\end{array}$ \\
\hline $\begin{array}{l}4 C 3 \\
4 C 3 \\
4 C 3 \\
4 C 3\end{array}$ & $\begin{array}{c}\text { VF2037 } \\
\text { VP3041 } \\
\text { VF2037+VP3041 } \\
\text { Computed }\end{array}$ & $\begin{array}{l}349 \\
7.6 \\
357 \\
519\end{array}$ & $\begin{array}{l}806 \\
3.8 \\
810 \\
926\end{array}$ & $\begin{array}{r}13 \\
340 \\
353 \\
906\end{array}$ \\
\hline $\begin{array}{l}4 C 6 \\
4 C 6 \\
4 C 6 \\
4 C 6\end{array}$ & $\begin{array}{c}\text { VF2037 } \\
\text { VP3041 } \\
\text { VF2037+VP3041 } \\
\text { Computed }\end{array}$ & $\begin{array}{c}454 \\
8.1 \\
462 \\
529\end{array}$ & $\begin{array}{c}1040 \\
5.0 \\
1045 \\
943\end{array}$ & $\begin{array}{r}11 \\
400 \\
411 \\
922\end{array}$ \\
\hline $\begin{array}{l}5 B \\
5 B \\
5 B\end{array}$ & $\begin{array}{c}\text { VF2037 } \\
\text { VP3041 } \\
\text { VF2037+VP3041 } \\
\text { Computed }\end{array}$ & $\begin{array}{r}482 \\
47 \\
529 \\
574\end{array}$ & $\begin{array}{r}989 \\
44 \\
1033 \\
1024\end{array}$ & $\begin{array}{r}65 \\
550 \\
615 \\
1002\end{array}$ \\
\hline
\end{tabular}


TABLE 3-11. PARTITION OF ALUMINUM, SILICON AND IRON (CONTINUED)

\begin{tabular}{|c|c|c|c|c|}
\hline Run & Sample & Al $(m q / L)$ & $\underline{\mathrm{si}(\mathrm{mg} / \mathrm{L})}$ & $\mathrm{Fe}(\mathrm{mg} / \mathrm{L})$ \\
\hline $\begin{array}{l}5 C / 5 D \\
5 C / 5 D \\
5 C / 5 D \\
5 C / 5 D\end{array}$ & $\begin{array}{c}\text { VF2037 } \\
\text { VP3041 } \\
\text { VF2037+VP3041 } \\
\text { Computed }\end{array}$ & $\begin{array}{r}404 \\
12 \\
416 \\
435\end{array}$ & $\begin{array}{r}913 \\
9 \\
922 \\
654\end{array}$ & $\begin{array}{l}243 \\
495 \\
738 \\
594\end{array}$ \\
\hline $\begin{array}{l}7 A \\
7 A \\
7 A \\
7 A \\
7 A\end{array}$ & $\begin{array}{c}\text { VP2023 } \\
\text { VF2037 } \\
\text { VP3041 } \\
\text { VP2023+VP3041 } \\
\text { Computed }\end{array}$ & $\begin{array}{l}378 \\
302 \\
<0.5 \\
378 \\
521\end{array}$ & $\begin{array}{l}864 \\
756 \\
<0.5 \\
864 \\
783\end{array}$ & $\begin{array}{r}378 \\
30 \\
420 \\
798 \\
711\end{array}$ \\
\hline $\begin{array}{l}8 A \\
8 A \\
8 A \\
8 A \\
8 A\end{array}$ & $\begin{array}{c}\text { VP2023 } \\
\text { VF2037 } \\
\text { VP3041 } \\
\text { VP2023+VP3041 } \\
\text { Computed }\end{array}$ & $\begin{array}{r}1049 \\
860 \\
29 \\
1078 \\
918\end{array}$ & $\begin{array}{r}2105 \\
1873 \\
62 \\
2167 \\
1637\end{array}$ & $\begin{array}{r}525 \\
483 \\
540 \\
965 \\
1601\end{array}$ \\
\hline $\begin{array}{l}8 C \\
8 C \\
8 C \\
8 C \\
8 C\end{array}$ & $\begin{array}{c}\text { VP2023 } \\
\text { VF2037 } \\
\text { VP3041 } \\
\text { VP2023+VP3041 } \\
\text { Computed }\end{array}$ & $\begin{array}{r}526 \\
482 \\
13 \\
539 \\
518\end{array}$ & $\begin{array}{r}972 \\
959 \\
13 \\
985 \\
924\end{array}$ & $\begin{array}{l}137 \\
120 \\
299 \\
436 \\
903\end{array}$ \\
\hline $\begin{array}{l}8 \mathrm{E} \\
8 \mathrm{E} \\
8 \mathrm{E} \\
8 \mathrm{E} \\
8 \mathrm{E}\end{array}$ & $\begin{array}{c}\text { VP2023 } \\
\text { VF2037 } \\
\text { VP3041 } \\
\text { VP2023+VP3041 } \\
\text { Computed }\end{array}$ & $\begin{array}{r}311 \\
250 \\
10 \\
321 \\
427\end{array}$ & $\begin{array}{r}642 \\
531 \\
11 \\
653 \\
761\end{array}$ & $\begin{array}{r}88 \\
89 \\
313 \\
401 \\
744\end{array}$ \\
\hline $\begin{array}{l}9 A \\
9 A \\
9 A \\
9 A \\
9 A\end{array}$ & $\begin{array}{c}\text { VP2023 } \\
\text { VF2037 } \\
\text { VP3041 } \\
\text { VP2023+VP3041 } \\
\text { Computed }\end{array}$ & $\begin{array}{l}666 \\
710 \\
5.6 \\
722 \\
443\end{array}$ & $\begin{array}{r}1332 \\
1332 \\
<2 \\
1332 \\
789\end{array}$ & $\begin{array}{l}233 \\
178 \\
230 \\
463 \\
772\end{array}$ \\
\hline $\begin{array}{l}9 C \\
9 C \\
9 C \\
9 C \\
9 C\end{array}$ & $\begin{array}{c}\text { VP2023 } \\
\text { VF2037 } \\
\text { VP3041 } \\
\text { VP2023+VP3041 } \\
\text { Computed }\end{array}$ & $\begin{array}{r}400 \\
475 \\
4 \\
404 \\
419\end{array}$ & $\begin{array}{r}950 \\
1147 \\
<2 \\
950 \\
747\end{array}$ & $\begin{array}{l}140 \\
300 \\
195 \\
335 \\
730\end{array}$ \\
\hline
\end{tabular}


from the wash sections. These are good mass balance closures considering the fluctuations in concentration values during the course of each run. However, only about an average of $64 \%$ of the iron present in the coal feed could be found in the same exit streams (the iron mass balance was not as good as the aluminum and silicon mass balances).

For Runs $7 A, 8 A$, and $8 E$, some silicon and aluminum in the caustic regeneration feed were precipitated in the bag filter, as indicated by comparing the UP2023 and VF2037 concentration levels for these elements. Also, for Runs $7 A, 8 A$ and $9 A$, some of the iron present in the caustic regeneration feed were precipitated in the bag filter. The amount precipitated was likely a function of the residence time of the solution in the filter tank prior to being pumped to the caustic regenerator. Precipitation may also depend on the temperature and $\mathrm{pH}$ of the solution.

For Runs $7 A, 8 A, 9 A$ and $9 C$, the iron removed from the coal feed was almost equally partitioned between the caustic regeneration feed (before filtration) and the acid wash water. All four runs were conducted with caustic/coal feed ratios of 2.5 or 3.0 , which resulted in relatively high caustic concentrations. Thus, the amount of iron in the caustic regenerator feed appears to increase with high caustic concentrations.

\subsubsection{Regeneration of Caustic Solution}

Although the caustic solution obtained from the MCL operation contained less than $15 \%$ caustic, analysis results of the regenerator inlet (VF2037) and outlet (VF4024) samples indicate significant removal of silicon and aluminum compounds. Regeneration was conducted by the addition of lime to the caustic solution, typically at a temperature of $110^{\circ} \mathrm{F}\left(43^{\circ} \mathrm{C}\right)$. The VF4024 samples were acquired after the regenerated solution was centrifuged for solids removal, followed by passing the centrate through a bag filter. The spent caustic solution was also passed through a bag filter prior to entering the regenerator. During selected runs, samples (VP2023) of the spent caustic solution were collected upstream of the bag filter. As discussed in the previous section, 
comparison of the VF2037 and VP2023 data would provide an indication whether some of the mineral matter were removed in the bag filter even before entering the regenerator unit.

The concentration levels of aluminum, silicon and iron in the VF2037, VF4024 and VP2023 samples are presented in Table 3-12, including some of the data already contained in Table 3-11. Again presented in this table are the computed concentration levels for a liquid stream entering the wash sections, based on the coal product generation rate and assuming that all mineral matter from the coal is in solution. These computed concentration levels can be compared with the concentration levels of aluminum, silicon and iron in the VF2037 and VP2023 samples.

The data presented in Table 3-12 show that essentially all calculated aluminum and silicon in the coal feed were found in the caustic regenerator feed (VP2023 and VF2037), as pointed out in the previous discussion on partition of these elements.

The aluminum concentration levels in VF2037 were sometimes lower than those in the corresponding VF4024 samples. This is because the sample concentration levels represent instantaneous values which fluctuated during the course of the run. In the regeneration process, the calculated removal efficiency for aluminum ranged from 0 to $66.2 \%$ and averaged 21.9\%. Removal efficiency for silicon ranged from 31.1 to $87.3 \%$ and averaged $67.2 \%$. Removal efficiency is expected to improve once the vacuum filters are put on-line. The iron concentration in the spent caustic solution was typically fairly low, as most of the iron in the coal feed is partitioned to the acid wash water. Regardless of the the iron concentration in the spent caustic solution, the regenerated caustic contained 5 to $46 \mathrm{mg} / \mathrm{L}$ iron. In a concentrated caustic solution, the removal efficiencies for both silicon and aluminum compounds are expected to be even higher. 
TABLE 3-12. CONCENTRATION LEVELS OF ALUMINUM, SILICON AND IRON IN SPENT AND REGENERATED CAUSTIC

\begin{tabular}{|c|c|c|c|c|}
\hline Run & Sample & Al $(\mathrm{mg} / \mathrm{L})$ & $\underline{\mathrm{Si}(\mathrm{mg} / \mathrm{L})}$ & $\mathrm{Fe}(\mathrm{mg} / \mathrm{L})$ \\
\hline $\begin{array}{l}2 C \\
2 C \\
2 C\end{array}$ & $\begin{array}{l}\text { VF2037 } \\
\text { VF4024 } \\
\text { Computed }\end{array}$ & $\begin{array}{l}540 \\
374 \\
451\end{array}$ & $\begin{array}{r}1120 \\
142 \\
805\end{array}$ & $\begin{array}{r}36 \\
44 \\
787\end{array}$ \\
\hline $\begin{array}{l}3 \mathrm{~B} 1 \\
3 \mathrm{~B} 1 \\
3 \mathrm{~B} 1 \\
3 \mathrm{~B} 1\end{array}$ & $\begin{array}{l}\text { VP2023 } \\
\text { VF2037 } \\
\text { VF4024 } \\
\text { Computed }\end{array}$ & $\begin{array}{l}385 \\
453 \\
353 \\
380\end{array}$ & $\begin{array}{l}748 \\
888 \\
612 \\
678\end{array}$ & $\begin{array}{r}140 \\
105 \\
31 \\
663\end{array}$ \\
\hline $\begin{array}{l}3 C 1 \\
3 C 1 \\
3 C 1 \\
3 C 1\end{array}$ & $\begin{array}{l}\text { VP2023 } \\
\text { VF2037 } \\
\text { VF4024 } \\
\text { Computed }\end{array}$ & $\begin{array}{l}540 \\
515 \\
400 \\
418\end{array}$ & $\begin{array}{r}1300 \\
1170 \\
650 \\
746\end{array}$ & $\begin{array}{r}140 \\
140 \\
30 \\
729\end{array}$ \\
\hline $\begin{array}{l}5 B \\
5 B \\
5 B\end{array}$ & $\begin{array}{l}\text { VF2037 } \\
\text { VF4024 } \\
\text { Computed }\end{array}$ & $\begin{array}{l}482 \\
664 \\
574\end{array}$ & $\begin{array}{r}989 \\
411 \\
1024\end{array}$ & $\begin{array}{r}65 \\
31 \\
1002\end{array}$ \\
\hline $\begin{array}{l}5 C / 5 D \\
5 C / 5 D \\
5 C / 5 D\end{array}$ & $\begin{array}{l}\text { VF2037 } \\
\text { VF4024 } \\
\text { Computed }\end{array}$ & $\begin{array}{l}404 \\
702 \\
435\end{array}$ & $\begin{array}{r}913 \\
1253 \\
654\end{array}$ & $\begin{array}{r}243 \\
46 \\
594\end{array}$ \\
\hline $\begin{array}{l}7 A \\
7 A \\
7 A \\
7 A\end{array}$ & $\begin{array}{l}\text { VP2023 } \\
\text { VF2037 } \\
\text { VF4024 } \\
\text { Computed }\end{array}$ & $\begin{array}{l}378 \\
302 \\
352 \\
521\end{array}$ & $\begin{array}{l}864 \\
756 \\
264 \\
783\end{array}$ & $\begin{array}{r}378 \\
30 \\
44 \\
711\end{array}$ \\
\hline $\begin{array}{l}8 A \\
8 A \\
8 A \\
8 A\end{array}$ & $\begin{array}{l}\text { VP2023 } \\
\text { VF2037 } \\
\text { VF4024 } \\
\text { Computed }\end{array}$ & $\begin{array}{r}1049 \\
860 \\
659 \\
918\end{array}$ & $\begin{array}{r}2105 \\
1873 \\
395 \\
1637\end{array}$ & $\begin{array}{r}525 \\
483 \\
28 \\
1601\end{array}$ \\
\hline $\begin{array}{l}8 C \\
8 C \\
8 C \\
8 C\end{array}$ & $\begin{array}{l}\text { VP2023 } \\
\text { VF2037 } \\
\text { VF4024 } \\
\text { Computed }\end{array}$ & $\begin{array}{l}526 \\
482 \\
163 \\
518\end{array}$ & $\begin{array}{l}972 \\
959 \\
178 \\
924\end{array}$ & $\begin{array}{r}137 \\
120 \\
5 \\
903\end{array}$ \\
\hline $\begin{array}{l}8 \mathrm{E} \\
8 \mathrm{E} \\
8 \mathrm{E} \\
8 \mathrm{E}\end{array}$ & $\begin{array}{l}\text { VP2023 } \\
\text { VF2037 } \\
\text { VF4024 } \\
\text { Computed }\end{array}$ & $\begin{array}{l}311 \\
250 \\
379 \\
427\end{array}$ & $\begin{array}{l}642 \\
531 \\
139 \\
761\end{array}$ & $\begin{array}{r}88 \\
89 \\
11 \\
744\end{array}$ \\
\hline $\begin{array}{l}8 F \\
8 F \\
8 F \\
8 F\end{array}$ & $\begin{array}{l}\text { VP2023 } \\
\text { VF2037 } \\
\text { VF } 4024 \\
\text { Computed }\end{array}$ & $\begin{array}{l}774 \\
512 \\
348 \\
542\end{array}$ & $\begin{array}{r}1473 \\
1050 \\
165 \\
966\end{array}$ & $\begin{array}{r}225 \\
152 \\
11 \\
945\end{array}$ \\
\hline
\end{tabular}




\subsubsection{Ireatment of Acid Wash Water}

The liquid samples collected to determine the effectiveness of acid wash water treatment included VP3041 (centrate from the first centrifuge in the acid wash section, C-301, to water treatment), and VF6027 (the effluent from the lime contactor T-602). The concentration levels of aluminum, silicon, iron, sodium and potassium in these samples are presented in Table 3-13.

In almost all cases, the aluminum and iron levels in the treated water was less than $1 \mathrm{mg} / \mathrm{L}$, and the silicon level was less than $5 \mathrm{mg} / \mathrm{l}$. The single exception is the Run $8 \mathrm{E}$ data, which indicate higher levels of aluminum and silicon in the treated water as compared to the untreated acid wash water, and a relatively high iron concentration of $142 \mathrm{mg} / \mathrm{L}$ in the treated water. It appears that $8 E /$ VF6027 was, not a representative sample of the treated acid wash water. Overall, the test results show that lime addition is effective for removing iron from acid wash water.

For Runs $1 B, 2 C, 4 C 1$ and $8 C$, sodium removal ranged from 38 to $61 \%$ and averaged $47 \%$. For Runs $\mathrm{IB}$ and $2 \mathrm{C}$, potassium removal was $48 \%$ and $36 \%$, respectively. For the other runs for which data are available, sodium or potassium removal was insignificant. The reason for the low rates of sodium and potassium removal was that ferric oxide was not added to precipitate the double salts of sodium and potassium.

\subsection{WASH TRAIN PERFORMANCE}

The wash train during the operational runs included five centrifuge stages in the water washing section and three centrifuge stages in the acid washing section, except for short periods during which one of the vacuum filters was on-line. The performance of the centrifuges can be evaluated from measurements of coal particles in the centrates and cake moisture in the coal product. The effectiveness of the wash train can be determined from $\mathrm{pH}$ measurements as the washing progressed downstream.

The $\mathrm{pH}$ of the centrifuge centrates from selected runs was measured and is presented in Table 3-14. As expected, the $\mathrm{pH}$ in the centrate for all 
TABLE 3-13. CONCENTRATION LEVELS OF ALUMINUM, SILICON IRON, SODIUM AND POTASSIUM IN ACID WASH WATER

\begin{tabular}{|c|c|c|c|c|c|c|}
\hline Run & $\underline{\text { Sample }}$ & $\mathrm{Al}(\mathrm{mg} / \mathrm{L})$ & $\underline{\mathrm{Si}(\mathrm{mg} / \mathrm{L})}$ & $\mathrm{Fe}(\mathrm{mg} / \mathrm{L})$ & $\underline{\mathrm{Na}(\mathrm{mg} / \mathrm{L})}$ & $\underline{K(m g / L)}$ \\
\hline $\begin{array}{l}1 B \\
1 B\end{array}$ & $\begin{array}{l}\text { VP3041 } \\
\text { VF6027 }\end{array}$ & $\begin{array}{l}83 \\
<1\end{array}$ & $\begin{array}{l}87 \\
<1\end{array}$ & $\begin{array}{r}506 \\
<1\end{array}$ & $\begin{array}{l}200 \\
118\end{array}$ & $\begin{array}{r}187 \\
97\end{array}$ \\
\hline $\begin{array}{l}1 \mathrm{C} \\
1 \mathrm{C}\end{array}$ & $\begin{array}{l}\text { VP3041 } \\
\text { VF6027 }\end{array}$ & $\begin{array}{l}41 \\
<1\end{array}$ & $\begin{array}{r}27 \\
3\end{array}$ & $\begin{array}{r}260 \\
<1\end{array}$ & $4 \overline{425}$ & 505 \\
\hline $\begin{array}{l}10 \\
10\end{array}$ & $\begin{array}{l}\text { VP3041 } \\
\text { VF6027 }\end{array}$ & $\begin{array}{r}5 \\
<1\end{array}$ & $\begin{array}{l}6 \\
2\end{array}$ & $\begin{array}{r}578 \\
<1\end{array}$ & $2 \overline{131}$ & 315 \\
\hline $\begin{array}{l}2 C \\
2 C\end{array}$ & $\begin{array}{l}\text { VP3041 } \\
\text { VF6027 }\end{array}$ & $\begin{array}{l}10 \\
<1\end{array}$ & $\begin{array}{l}8 \\
2\end{array}$ & $\begin{array}{c}355 \\
0.1\end{array}$ & $\begin{array}{l}631 \\
388\end{array}$ & $\begin{array}{l}985 \\
632\end{array}$ \\
\hline $\begin{array}{l}2 E \\
2 E\end{array}$ & $\begin{array}{l}\text { VP3041 } \\
\text { VF6027 }\end{array}$ & $\begin{array}{r}9 \\
<1\end{array}$ & $\begin{array}{r}8 \\
<5\end{array}$ & $\begin{array}{l}390 \\
<0.5\end{array}$ & $\begin{array}{l}1538 \\
1400\end{array}$ & $\begin{array}{l}2188 \\
2092\end{array}$ \\
\hline $\begin{array}{l}3 B 1 \\
3 B 1\end{array}$ & $\begin{array}{l}\text { VP3041 } \\
\text { VF6027 }\end{array}$ & $\begin{array}{l}47 \\
<1\end{array}$ & $\begin{array}{r}147 \\
<5\end{array}$ & $\begin{array}{l}363 \\
<0.5\end{array}$ & - & - \\
\hline $\begin{array}{l}4 C 1 \\
4 C 1\end{array}$ & $\begin{array}{l}\text { VP3041 } \\
\text { VF6027 }\end{array}$ & $\begin{array}{l}15 \\
<1\end{array}$ & $\begin{array}{r}11 \\
2\end{array}$ & $\begin{array}{l}500 \\
<0.5\end{array}$ & $\begin{array}{r}225 \\
88\end{array}$ & - \\
\hline $\begin{array}{l}4 C 2 \\
4 C 2\end{array}$ & $\begin{array}{l}\text { VP3041 } \\
\text { VF6027 }\end{array}$ & $\begin{array}{l}12 \\
<1\end{array}$ & $<1$ & $\begin{array}{l}500 \\
<0.5\end{array}$ & $\begin{array}{l}769 \\
950\end{array}$ & - \\
\hline $\begin{array}{l}4 C 5 \\
4 C 5\end{array}$ & $\begin{array}{l}\text { VP3041 } \\
\text { VF6027 }\end{array}$ & $<1$ & $<^{4.8}$ & $\begin{array}{r}320 \\
<1\end{array}$ & $\begin{array}{l}353 \\
370\end{array}$ & - \\
\hline $\begin{array}{l}5 B \\
5 B\end{array}$ & $\begin{array}{l}\text { VP3041 } \\
\text { VF6027 }\end{array}$ & $\begin{array}{l}47 \\
2.5\end{array}$ & $\begin{array}{l}44 \\
<1\end{array}$ & $\begin{array}{l}550 \\
<0.5\end{array}$ & $\begin{array}{r}1248 \\
993\end{array}$ & - \\
\hline $\begin{array}{l}5 C \\
5 C\end{array}$ & $\begin{array}{l}\text { VP3041 } \\
\text { VF6027 }\end{array}$ & $\begin{array}{r}11 \\
4\end{array}$ & $\begin{array}{l}14 \\
<1\end{array}$ & $\begin{array}{l}470 \\
<0.5\end{array}$ & $\begin{array}{r}950 \\
1085\end{array}$ & - \\
\hline $\begin{array}{l}50 \\
5 D\end{array}$ & $\begin{array}{l}\text { VP3041 } \\
\text { VF6027 }\end{array}$ & $\begin{array}{r}7 \\
24\end{array}$ & $\begin{array}{r}10 \\
7\end{array}$ & $\begin{array}{l}520 \\
<0.5\end{array}$ & 1085 & - \\
\hline
\end{tabular}


TABLE 3-13. CONCENTRATION LEVELS OF ALUMINUM, SILICON, IRON SODIUM AND POTASSIUM IN ACID WASH WATER (CONTINUED)

$\begin{array}{lcccccc}\text { Run } & \text { Sample } & \text { AI (mg/L) } & \underline{S i(m g / L)} & \text { Fe(mg/L) } & \mathrm{Na}(\mathrm{mg} / \mathrm{L}) & \mathrm{K}(\mathrm{mg} / \mathrm{L}) \\ \text { 7A } & \text { VP3041 } & <0.5 & <0.5 & 420 & - & - \\ 7 A & \text { VF6027 } & <0.5 & <0.5 & <0.1 & - & - \\ 8 A & \text { VP3041 } & 29 & 62 & 540 & - & - \\ 8 A & \text { VF6027 } & 1.4 & 3 & <1 & - & - \\ 8 B & \text { VP3041 } & 7.7 & 110 & 885 & - & - \\ 8 B & \text { VF6027 } & <1 & 3 & 2 & - & - \\ 8 C & \text { VP3041 } & 13 & 13 & 299 & 1075 & - \\ 8 C & \text { VF6027 } & 2 & 5 & 6 & 550 & - \\ 8 E & \text { VP3041 } & 10 & 11 & 313 & 580 & - \\ 8 E & \text { VF6027 } & 20 & 84 & 142 & - & - \\ 9 A & \text { VP3041 } & 5.6 & <2 & 230 & - & - \\ 9 A & \text { VF6027 } & <1 & <2 & <0.2 & - & - \\ 9 C & \text { VP3041 } & 3.8 & <2 & 195 & - & - \\ 9 C & \text { VF6027 } & <1 & <2 & 1.3 & - & -\end{array}$

"-" indicates either no data or not applicable. 
TABLE 3-14. CENTRIFUGE CENTRATE PH MEASUREMENTS

$\begin{array}{lcccccc}\text { Sample } & \text { Run 2B } & \text { Run 2C } & \text { Run 2C } & \text { Run 2D } & \text { Run 2D } & \text { Run 2E } \\ \text { C-202 } & 13.5 & 13.8 & 13.9 & 13.9 & 13.9 & 14.0 \\ \text { C-203 } & 12.7 & 13.0 & 13.1 & 13.2 & 13.2 & 13.4 \\ \text { C-204 } & 12.0 & 12.4 & 11.2 & 12.7 & 12.7 & 12.9 \\ \text { C-205 } & 11.5 & 11.9 & 10.8 & 12.1 & 12.1 & 12.4 \\ \text { C-301 } & 1.2 & 1.0 & 0.6 & 1.0 & \text { ND } & \text { ND } \\ \text { C-302 } & 1.8 & 1.7 & 1.3 & 1.5 & 1.6 & 1.6 \\ \text { C-303 } & 2.4 & 2.2 & 1.9 & 2.0 & 2.1 & 2.0\end{array}$

* ND indicates no data. For Runs $2 C$ and $2 D$, the two samples from each run were obtained 12 hours apart. 
the runs decreased from $\mathrm{C}-202$ to $\mathrm{C}-205$, as washing progressed in the water washing section. In the acid washing section, the $\mathrm{pH}$ in the centrate increased from C-301 (where sulfuric acid solution was separated to be sent to waste water treatment) to $\mathrm{C}-303$ (where wash water was added), again as expected. These $\mathrm{pH}$ values suggest the effectiveness of the wash stations in removing caustic from coal in the water washing section, and in removing acid from coal in the acid washing section.

The percent of coal fines in the centrate from $\mathrm{C}-201$ is presented in Table 3-15. The concentrations of these coal fines ranged from: $0.01 \%$ to as much as $2.37 \%$. The average coal fines concentration in the $\mathrm{C}-201$ centrate was $0.26 \%$, with a standard deviation of $0.50 \%$. The differences in coal fines concentrations were probably caused by the differences in kiln coal product size distributions, as well as fluctuations in the caustic concentrations, both from run to run and within the same run. Also, separation in the first stage was not as good as in the later stages because of the smaller density difference between the concentrated caustic solution and the coal product in the first stage. During shakedown, the coal fines concentrations in the centrates from the other centrifuges were measured. The average concentration of coal particles was only $0.038 \%$ in the C-202 to C-205 centrate (water wash section), and $0.035 \%$ in the C-301 to C-303 centrate (acid wash section). These shakedown data show that the centrifuges performed extremely well with good separation.

As shown in Table 3-16, the moisture content of the centrifuge cake generally decreased from the 60-75\% range in the water wash section to $51-57 \%$ in the acid wash section. Good liquid removal was attained even for C-201, where the two data points indicated cake moisture contents of $65.8 \%$ and $65.0 \%$ In general, cake moisture should decrease as washing progresses downstream, as the density difference between the coal particles and the wash solution becomes greater. This is illustrated by the Run 4 C2 data, but not totally supported by the Run $9 \mathrm{C}$ data. 
TABLE 3-15. COAL FINES IN C-201 CENTRATE

\begin{tabular}{|c|c|c|}
\hline Run & Sample Date/Time & \% Coal Fines \\
\hline $\begin{array}{l}1 A \\
1 B \\
1 B \\
1 C \\
1 C \\
1 C \\
1 C \\
1 D \\
1 D \\
1 D \\
1 D\end{array}$ & $\begin{array}{l}0123 / 2000 \\
0124 / 0900 \\
0124 / 2100 \\
0125 / 0300 \\
0125 / 0900 \\
0125 / 1500 \\
0125 / 2030 \\
0126 / 1200 \\
0126 / 1800 \\
0127 / 0600 \\
0127 / 1200\end{array}$ & $\begin{array}{l}2.37 \\
0.05 \\
0.36 \\
0.02 \\
0.04 \\
0.01 \\
0.10 \\
0.02 \\
0.58 \\
0.47 \\
0.77\end{array}$ \\
\hline $\begin{array}{l}2 B \\
2 C \\
2 C \\
2 C \\
2 C \\
2 D\end{array}$ & $\begin{array}{l}0207 / 1130 \\
0207 / 2130 \\
0208 / 0330 \\
0208 / 0930 \\
0208 / 1530 \\
0209 / 0330\end{array}$ & $\begin{array}{l}0.04 \\
0.42 \\
0.02 \\
0.02 \\
0.04 \\
0.19\end{array}$ \\
\hline $\begin{array}{l}3 \mathrm{~B} 1 \\
3 \mathrm{~B} 1 \\
3 \mathrm{~B} 1 \\
3 \mathrm{~B} 1 \\
3 \mathrm{~B} 1 \\
3 \mathrm{Cl}\end{array}$ & $\begin{array}{l}0223 / 0044 \\
0223 / 1215 \\
0223 / 1815 \\
0224 / 0015 \\
0224 / 0615 \\
0224 / 1215\end{array}$ & $\begin{array}{l}0.18 \\
0.03 \\
0.03 \\
0.02 \\
0.02 \\
0.06\end{array}$ \\
\hline $9 C$ & $0601 / 1200$ & 0.28 \\
\hline
\end{tabular}


TABLE 3-16. MOISTURE CONTENT OF CENTRIFUGE CAKE

\begin{tabular}{|c|c|c|c|}
\hline Run & Sample Date/Time & Sample Location & \% Cake Moisture \\
\hline $\begin{array}{l}2 E \\
2 E\end{array}$ & $\begin{array}{l}0210 / 1450 \\
0210 / 1505\end{array}$ & $\begin{array}{l}C-205 \\
C-205\end{array}$ & $\begin{array}{l}65.79 \\
66.05\end{array}$ \\
\hline $\begin{array}{l}4 C 2 \\
4 C 2 \\
4 C 2 \\
4 C 2 \\
4 C 2 \\
4 C 2\end{array}$ & $\begin{array}{l}0308 / 1700 \\
0308 / 1700 \\
0308 / 1700 \\
0308 / 1700 \\
0308 / 1700 \\
0308 / 1700\end{array}$ & $\begin{array}{l}C-201 \\
C-202 \\
C-203 \\
C-204 \\
C-205 \\
C-302\end{array}$ & $\begin{array}{l}65.81 \\
61.03 \\
57.13 \\
53.19 \\
54.08 \\
51.53\end{array}$ \\
\hline $\begin{array}{l}9 C \\
9 C \\
9 C \\
9 C \\
9 C \\
9 C \\
9 C\end{array}$ & $\begin{array}{l}0601 / 1030 \\
0601 / 1030 \\
0601 / 1030 \\
0601 / 1030 \\
0601 / 1030 \\
0601 / 1030 \\
0601 / 1030\end{array}$ & $\begin{array}{l}C-201 \\
C-202 \\
C-203 \\
C-204 \\
C-205 \\
C-301 \\
C-302\end{array}$ & $\begin{array}{l}65.02 \\
76.72 \\
72.96 \\
75.89 \\
56.47 \\
55.78 \\
57.39\end{array}$ \\
\hline
\end{tabular}


As discussed in Section 3.1 .5 of this report, the moisture content of the final coal product ranged from $43.7 \%$ to $58.4 \%$ for Pittsburgh No. 8 coal feed, and from $51.7 \%$ to $59.4 \%$ for Kentucky No. 9 coal feed. This is an indication of the good performance of the centrifuges in removing liquid from the coal product. The moisture content is effected by both the centrifuge train performance and by kiln processing conditions, which determine the porosity of the coal product. It is shown in Section 3.1.5 that fairly good correlations could be obtained between the moisture content and the ash content of the coal product and that the centrifuge train performance was fairly uniform from run to run.

\subsection{MATERIAL BALANCE}

Three types of material balances were performed using the analysis resilts obtained for the operational runs. The overall material balances for coal on MAF basis and for sulfur are discussed in this section. The material balances for aluminum, silicon and iron have been discussed in Section 3.7.1, by comparing concentration levels of these elements in the exit streams from the wash sections with calculated concentration levels based on coal feed.

\subsubsection{Coal Material Balance}

The coal material balances for all nine MCL runs are shown in Table 3-17. These material balances are based on the coal feed to the rotary kiln, and the washed coal product and kiln discharge coal product collected, all obtained from the operation $10 \mathrm{~g}$ book and corrected to MAF coal, using feed coal and product coal analysis data. In addition, data from the MCL operations show that an average of $2.85 \%$ of the feed coal was converted to volatiles (mainly methane and hydrogen) in the kiln gas, and approximately $2 \%$ to humics and phenolics. These were used as the basis for estimating the amount of volatiles and humics and phenolics in each run.

As discussed in Section 3.5, analysis of the kiln discharge product and the spent caustic show that an average of $17.57 \%$ of the caustic feed 


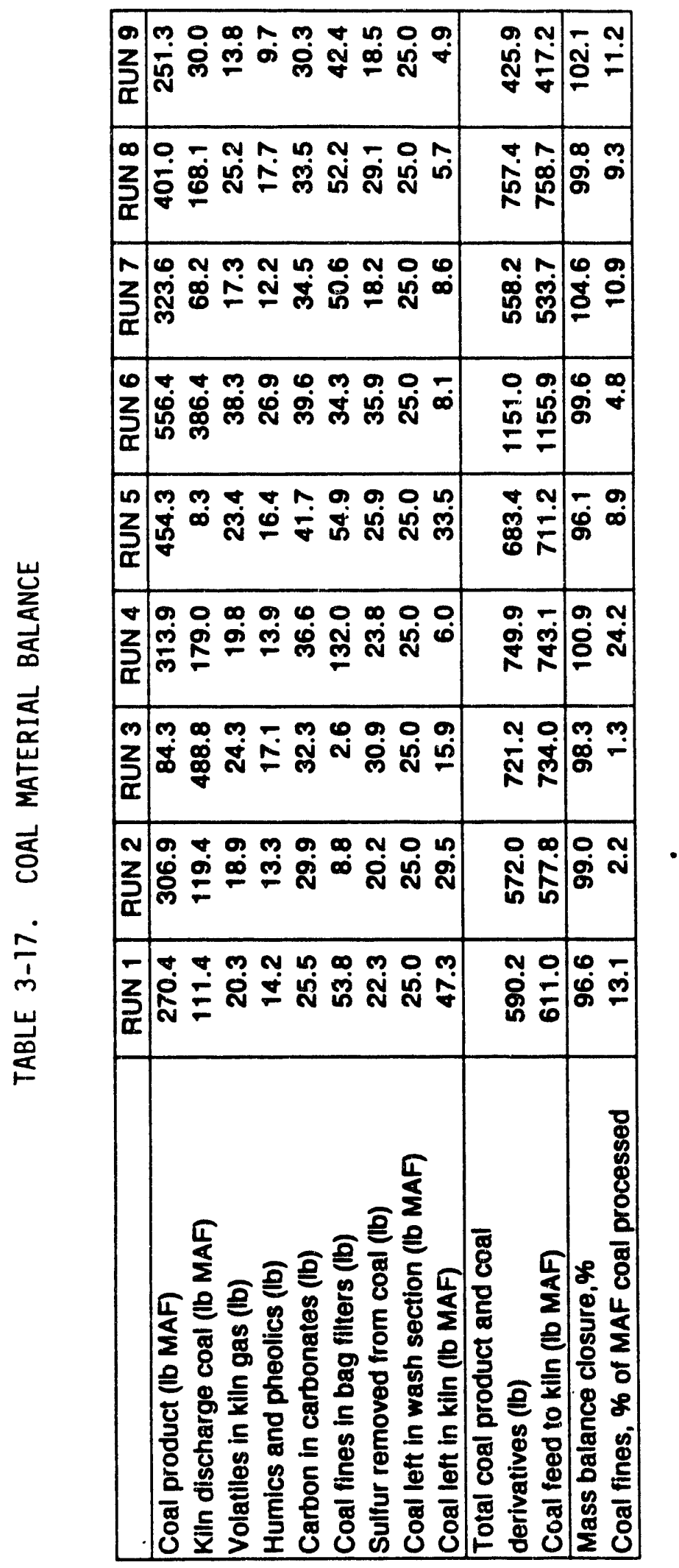


was converted to carbonates. The amount of coal carbon in carbonates was computed using the $17.57 \%$ caustic feed conversion rate, the caustic/coal feed ratio, and the percentage of carbon in carbonates. The sulfur removed from coal was computed from the difference of sulfur content of the feed coal and the sulfur contents of the washed coal product and kiln discharge coal product.

The amount of coal fines collected was estimated using the 120 1b per hour caustic solution flowrate, the total hours of operation of the caustic wash section in each run, and the concentration of coal fines in the caustic solution sent to the bag filters (where coal fines were collected). Except for Runs 2, 3 and 4, the amount of coal fines was based on a $0.435 \%$ coal fines concontration in the caustic wash solution. This $0.435 \%$ coal fines concentration in caustic solution was obtained from the average of Run 1 data. For Runs 2 and 3, coal fines concentrations of $0.122 \%$ and $0.057 \%$ from the analysis of the caustic wash solution were . used. For Run 4, the amount of coal fines was the sum of the coal fines collected on the bag filters (46.60 $\mathrm{lb}$ on dry basis) and the residual coal fines that passed through these bag filters $(85.43 \mathrm{lb})$. The amount of residual coal fines was exceptionally high for Run 4 , because an average of $\mathbf{0 . 8 5 \%} \mathrm{coal}$ fines concentration was found in the filtered caustic wash solution, probably due to the use of filter media of incorrect mesh size during the operation of the vacuum filter. The amount of coal fines in caustic solution fluctuated during the operation of each run, and would be significantly reduced if the two vacuum filters were in operation and with the proper filter media.

The amount of coal left in the wash section at the end of each run was estimated to be $25 \mathrm{lb}$. This was derived by first estimating that the amount of process solutions left in the wash tanks at the end of the run would be 514 lb ( 8 tanks $\times 14$ gallons per tank $\times 50 \%$ full $\times 8.34$ lb/gallon $x 1.1$ specific gravity), and then using an average $3.8 \%$ coal concentration in the solution (obtained from Run 1 data). The amount of coal left in the wash tanks is, therefore, $19.5 \mathrm{lb}$. The $25 \mathrm{lb}$ estimate includes allowance for some additional coal left in centrifuges and process 
piping. The amount of coal left in the rotary kiln at the end of each run was estimated from review of the operation $\log$ book data. For five of the nine runs, the equivalent of one hour of feed material was left inside the rotary kiln at the end of each run. For Runs 1, 2, 3 and 5, however, it appears that large quantities of feed material were still left inside the kiln, because the kiln was shut off shortly after the transfer of additional coal/caustic to the feed hopper.

As shown in Table 3-17, excellent mass balance closure is obtained for each of the nine runs, ranging from $96.1 \%$ for Run 5 to $105.0 \%$ for Run 9. For the nines runs combined, the total coal product and coal derivatives amounted to $6,230 \mathrm{lb}$, and the total coal feed to the rotary kiln was 6,243 1b. The resulting combined mass balance closure is $99.8 \%$.

\subsubsection{Sulfur Material Balance}

Only limited amount of analysis were performed to determine the sulfur levels in process liquids. The sulfur analysis data presented in Table 3-18 include those for the caustic regenerator inlet (VP2023 or VF2037) and the caustic regenerator outlet (VF4024). The spent caustic solution was passed through a bag filter prior to entering the regenerator, and the VP2023 and VF2037 samples represent samples collected upstream and downstream of the bag filter, respectively. Since sulfur in the form of sodium or potassium sulfide is not expected to be collected in the bag filter, the VP2023 and VF2037 samples should both provide information on the amount of sulfur extracted from processed coal.

Also presented in Table 3-18 are the computed sulfur levels in the spent caustic, based on the coal product generation rate and the difference in sulfur levels between the coal feed and the coal product. These computed sulfur levels can be compared with the corresponding sulfur levels in VP2023/VF2037 samples to determine the closeness of the sulfur balance.

As shown in Table 3-18, the sulfur levels in the VP2023/VF2037 samples for Runs 2D, $3 \mathrm{Bl}$ and $3 \mathrm{Cl}$ exceed the computed values, whereas those for 
TABLE 3-18. CONCENTRATION LEVELS. OF SULFUR IN SPENT AND REGENERATED CAUSTIC

\begin{tabular}{|c|c|c|c|c|c|}
\hline \multirow{2}{*}{ Run } & \multicolumn{2}{|c|}{$\begin{array}{l}\text { Sulfur Conc. in } \\
\text { VP2023/VF2037 (mg/L) }\end{array}$} & \multicolumn{2}{|c|}{$\begin{array}{l}\text { Sulfur Conc. in } \\
\text { VF4024 (mg/L) }\end{array}$} & \multirow[t]{2}{*}{$\begin{array}{l}\text { Computed Sulfur } \\
\text { Conc. (mg/L) }\end{array}$} \\
\hline & Mean & Range & Mean & Range & \\
\hline 20 & 1840 & 1840 & No Data & - & 1145 \\
\hline $3 B 1$ & 1430 & $880-1980$ & No Data & - & 838 \\
\hline $3 \mathrm{Cl}$ & 1980 & 1980 & No Data & - & 1240 \\
\hline $5 B$ & 1003 & $695-1350$ & 1403 & $1275-1500$ & 1465 \\
\hline $5 C / 5 D$ & 746 & $550-860$ & 1355 & $1320-1390$ & 865 \\
\hline $8 A$ & 1100 & $790-1300$ & 2307 & $2200-2480$ & 2407 \\
\hline $8 B$ & No Data & - & 1780 & 1780 & 1370 \\
\hline $8 C$ & 630 & $570-690$ & 1355 & $1280-1430$ & 1828 \\
\hline $8 D$ & 670 & 670 & 1730 & $1330-2130$ & 1049 \\
\hline $8 E$ & 340 & 340 & 1700 & 1700 & 1515 \\
\hline $8 \mathrm{~F}$ & 680 & $590-770$ & 1825 & $1680-1970$ & 2163 \\
\hline
\end{tabular}


Runs 5B, 5C/5D, 8A, 8C, 8D, $8 E$ and $8 F$ are well below the computed values. The experimentally determined sulfur levels range from $22 \%$ to $170 \%$ of the computed values. This relatively poor sulfur balance closure could be due to fluctuations in sulfur levels during the course of the run. For example, the sulfur levels in the six VF2037 samples for Run 5B range from 695 to $1350 \mathrm{mg} / \mathrm{L}$. Other possibilities are non-representative sampling or analysis error. For Runs $8 C, 8 D, 8 E$ and $8 F$, only sodium hydroxide was present in the caustic feed. The sodium levels in the VF2037 samples for these runs range from 11600 to $24500 \mathrm{mg} / \mathrm{L}$, whereas those in the corresponding VP2023 samples range from 33400 to $75200 \mathrm{mg} / \mathrm{L}$. The sodium levels in the VP2023 and VF2037 samples should be approximately the same, unless a significant fraction of the sodium compounds (sodium hydroxide, sodium carbonate and sodium sulfide) was collected in the bag filter as a result of precipitation. Since the sulfur levels for Run 8 were determined using the VF2037 samples, it is possible that these sulfur levels should be corrected by a factor of 2 to 4 , or the ratio of the sodium levels in the corresponding VP2023 and VF2037 samples.

The sulfur levels in the VF4024 samples, however, are in fairly good agreement with the computed sulfur levels in the spent caustic. This good agreement is probably due to the mixing of caustic solution in the regenerator, so that fluctuations in sulfur levels in the VF4024 samples are less pronounced, as noted in the range of VF4024 sulfur values presented in Table 3-18. The good agreement between the VF4024 and computed sulfur levels also suggests that: 1) the Run 8 VF2037 sulfur values are in error as a result of non-representative sampling or incorrect analysis, because low sulfur levels in the caustic regenerator inlet cannot lead to high and predicted sulfur levels in the caustic regerierator outlet; and 2) sulfur was not removed from the spent caustic solution in the caustic regenerator.

\subsection{CORROSION/EROSION DATA}

Two types of techniques were used to evaluate corrosion, rosion in the MCL integrated test facility: 1) placement of erosion coupons at selected locations; and 2) placement of electronic monitoring devices (Rohrback 
corrosometer probes) at selected locations. For the test coupons, the rates of corrosion/erosion were determined by weight and dimensional losses. The corrosometer probes measure corrosion/erosion by monitoring an electric potential across electrodes.

A total of 17 erosion coupons were installed in the MCL test 10op. At the conclusion of the $M C L$ tests, these coupons were removed from the system. A visual inspection of each coupon was performed, and the coupons were weighed, measured and photographed. These coupons were then placed in an ultrasonic cleaner with Alkanox soap and DI water for one hour and dried, reweighed and measured. The locations and materials of construction for these coupons, as well as the calculated corrosion/erosion rates from weight losses in thousandths of an inch per year (mpy) are presented in Table 3-19. The visual changes noted for the coupons are summarized in Table 3-20.

Based on the results presented in these tables, it is apparent that corrosion/erosion caused by the $\mathrm{MCL}$ solution on Inconel 600 and 316 stainless steel is practically negligible. Also, corrosion/erosion rates for Carpenter Alloy 20 were $13.2 \mathrm{mpy}$ at the inlet to the first acid wash centrifuge $(C-301)$, and 4.4 mpy at the inlet to the second acid wash centrifuge $(C-302)$. These rates are comparable to that caused by water corrosion of carbon steel at $10 \mathrm{mpy}$. Therefore, all the coupon materials tested should be suitable as materials of construction at the specific test locations of the MCL plant.

Four Rohrback corrosometer probes were installed in the MCL test loop. However, one of the probes (CC-203) was installed in the first vacuum filter slurry tank (T-203), which was not put into service. Another probe (CC-603) was installed in the acid waste treatment iron addition tank (T-601), which was also not put into service. Probe CC-102 (Inconel 600) was originally located in the bottom head of the T-102 dissolver tank, but had to be relocated to the top head (dry coal/caustic zone) to allow the tank pump around loop to return to the bottom head. As a result, the measured corrosion/erosion rate was effectively zero. 
TABLE 3-19. CORROSION/EROSION RATES IN MCL TEST LOOP

\begin{tabular}{|c|c|c|c|}
\hline Coupon ID & Location & Material & Corrosion/Erosion Rate, mpy \\
\hline $\begin{array}{l}C C-101 \\
C C-204 \\
C C-205 \\
C C-206 \\
C C-207 \\
C C-208 \\
C C-209 \\
C C-301 \\
C C-302 \\
C C-303 \\
C C-401 \\
C C-402 \\
C C-403 \\
C C-404 \\
C C-406 \\
C C-601 \\
C C-602\end{array}$ & $\begin{array}{l}\text { P-101 outlet } \\
\text { F-202 inlet } \\
C-201 \text { inlet } \\
C-202 \text { inlet } \\
C-203 \text { inlet } \\
C-204 \text { inlet } \\
C-205 \text { inlet } \\
C-301 \text { inlet } \\
C-302 \text { inlet } \\
C-303 \text { inlet } \\
T-401 \text { inlet } \\
T-402 \text { inlet } \\
C-401 \text { inlet } \\
\text { F401/402 inlet } \\
\text { F430/404 inlet } \\
F-601 \text { inlet } \\
F-602 \text { inlet }\end{array}$ & $\begin{array}{c}\text { Inconel } 600 \\
316 \text { SS } \\
316 \text { SS } \\
316 \text { SS } \\
316 \text { SS } \\
316 \text { SS } \\
316 \text { SS } \\
\text { CARP } 20 \\
\text { CARP } 20 \\
316 \text { SS } \\
316 \text { SS } \\
316 \text { SS } \\
316 \text { SS } \\
316 \text { SS } \\
316 \text { SS } \\
\text { CARP } 20 \\
316 \text { SS }\end{array}$ & $\begin{array}{l}0.23 \\
0.025 \\
0 \\
0 \\
0 \\
0 \\
0 \\
13.2 \\
4.4 \\
0.024 \\
0.072 \\
0.11 \\
0.057 \\
0.039 \\
0.59 \\
0.024 \\
0.017\end{array}$ \\
\hline
\end{tabular}


TABLE 3-20. VISUAL INSPECTION OF EROSION COUPONS

Coupon ID

CC -101

CC- -204

CC -205

CC-206

CC -207

CC -208

CC -209

CC -301

CC -302

$\mathrm{CC}-303$

CC -401

CC -402

CC -403

CC -404

CC. .06

$5 C-601$

CC -602
Visual Changes

Grey in color, edges appear to be rounded Slight discoloring, no other visual change Very black surface color, no other visual change Slight brownish gold coloring, slight rounding of edges Bronze in color, no other visual change Bronze in color, no other visual change Gold in color, some of the coloring is chipped from surface Dull grey color and surface appears to be etched Dull grey color, no other visual change Bright clean surface, looks new Brownish color, no other visual change Bright clean surface, no other visual change Black in color, no other visual change Light grey color, no other visual change Duil dark grey surface, looks burnt Bright light grey surface, no other visual change Deposit adhered to surface, one side only. Other side bright and clean 
Probe CC-604 (316 stainless steel) was located in the T-602 waste water treatment lime tank. The calculated corrosion/erosion rate based on probe readings was $0.27 \mathrm{mpy}$. This suggests very low corrosion/erosion rates for 316 stainless steel in the limed T-602 waste water environment. 


\section{EQUIPMENT EVALUATION}

The MCL integrated test circuit, in its current configuration, has demonstrated that it can be successfully operated on a short-term integrated basis at a total kiln solids feed rate (coal plus caustic) of up to $50 \mathrm{lbs} / \mathrm{hr}$. Most of the equipment operated as designed. The equipment problems discussed in this section in most cases are a function of equipment size and would not be a problem at commercial scale. For example, the flow rate in many of the lines is only $0.1 \mathrm{gpm}$. The piping used for these lines ( $1 / 2$ inch) is greatly oversized for this flow rate because any smaller piping would easily become plugged with coal particles. Thus, the flows in these lines are very low. Although the pumps, centrifuges, and vacuum filters purchased were the smallest available, they are in most cases oversized for this application. The problems experienced with this equipment would probably not occur at higher flowrates or at commercial scale. The concerns raised in the following sections need to be addressed and some modifications made to the plant in order to operate the MCL integrated test circuit on a long-term continuous basis.

\subsection{KILN}

The rotary kiln reactor was purchased from C.E. Raymond on the previous Gravimelt program. The kiln consists of a feed section, a 12 foot long furnace section, a cooling zone and a discharge area (Figure 4-1). The overall length of the kiln is about 32 feet. The main part of the kiln contains a 14-inch diameter tube which is 26 feet long. The tube is constructed of Inconel 601 which has high corrosion resistance to caustic at elevated temperatures. Part of the tube is enclosed in the 12 foot long furnace section which is electrically heated in four separate zones. The wall temperature of each zone is measured and controlled separately. The kiln was operated in the temperature range of $325^{\circ}$ to $415^{\circ} \mathrm{C}$ during the current integrated test operations. 


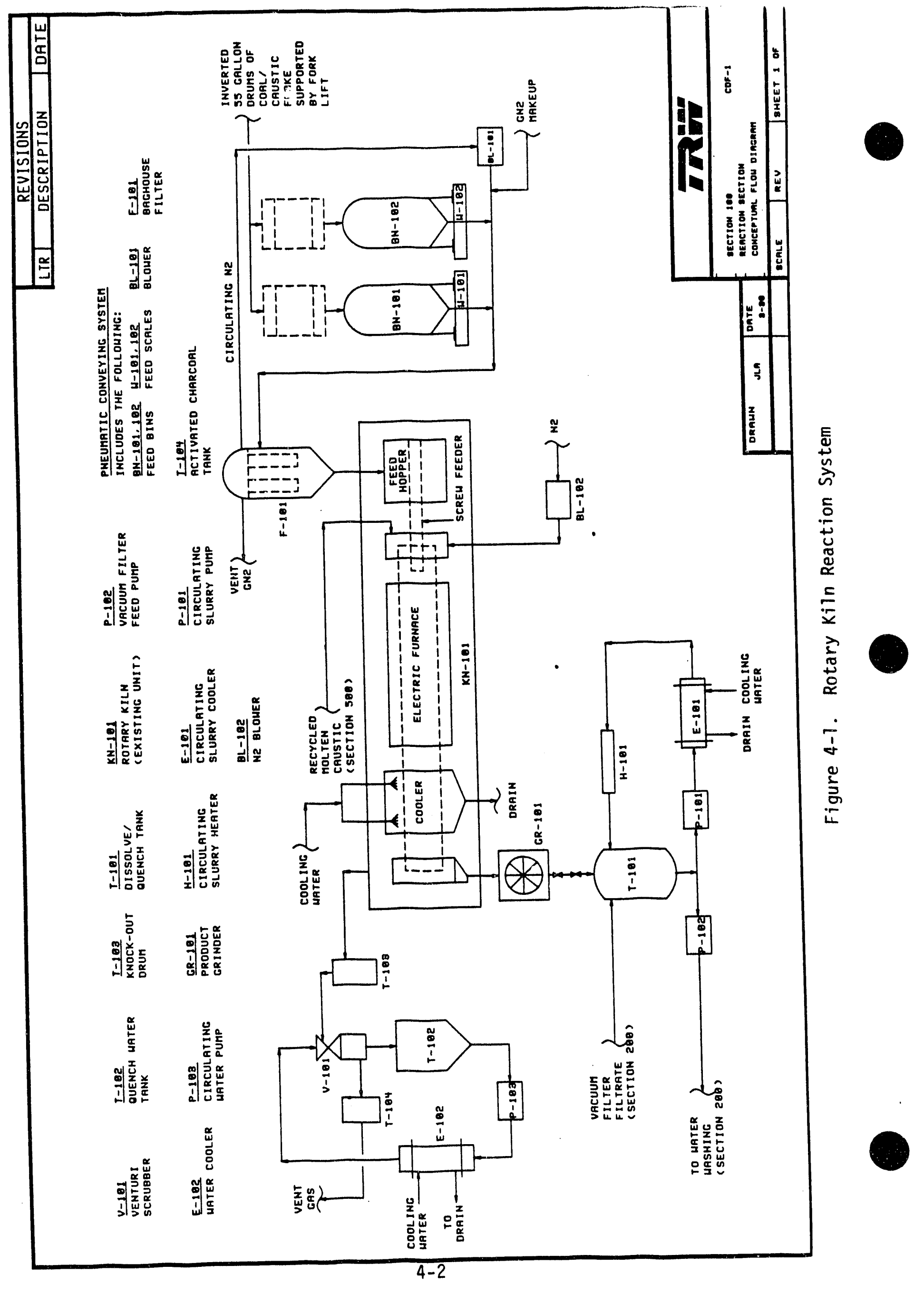


The coal-caustic mixture resides in the heated zone of the kiln for one to two hours. The residence time is controlled by setting the rotational speed of the $k i l n$, the angle of inclination, the feed rate, and the rotational settings of the wall scraper.

The kiln has been modified for this program to have the capability of operating with either an all solid feed stream consisting of coal and caustic flake or with separate feed streams consisting of coal and recycled molten caustic. The kiln throughput was probably limited by the large opening that had to be created in the end plate at the feed end of the kiln tube to accommodate the installation of the molten caustic injection line. At feed rates higher than $50 \mathrm{lb} / \mathrm{hr}$ of coal plus caustic, unacceptably large amounts of kiln solids backed up through this opening in the end plate and fell into the feed breech. This was demonstrated during coal feed kiln tests conducted prior to MCL shakedown operations. Removal of the molten feed caustic line (to debottleneck the kiln) was not done during test operations as molten caustic injection had not been demonstrated. Recycled molten caustic feed was not used during this test program due to vacuum filter and evaporator problems (see Sections 4.3 and 4.6).

The kiln was equipped for this program with a rotating auger/scraper to facilitate mixing of the coal and caustic and to keep the internal walls of the kiln tube free of sticky solid deposits. The wall scrapper is an auger-like device, six inches in diameter, that runs the length of the kiln tube and is in contact with the tube wall 15 degrees offset from the kiln bottom. It has a variable rotary speed driver and is rotated in an variable automatically timed sequence in alternate clockwise and counterclockwise directions.

Duriny this test program, when the kiln was charged with a high caustic to coal ratio such as $3: 1$, the auger/scraper worked very well. However, at lower, more economic caustic to coal ratios, a sticky mass apparentiy hardened on the kiln wall which the auger reduced to a thickness of perhaps a half-inch. The auger then rode over this thickness, leaving a coating on the kiln wall. The coating acted as an 
insulator, and the caustic/coal fed subsequently was not heated to the desired reaction temperature. It appears that $1: 1$ sodium hydroxide to coal, which otherwise might be a preferred mixture, is particularly prone to form this harden mass. If the auger were just a scraper and not used to mix the reactants, it might do a better job of cleaning the walls. TRW has looked at a cold model of the kiln and there is some indication that the auger, if mounted against the downward-wall of the kiln rather than the upward-wall, would more effectively scrape the wall clean.

At present, there is no way to know whether the walls are clean or coated. There is one internal temperature probe in the kiln, usually located at the same distance down the kiln that the zone 2 temperature control thermocouple is positioned. With good operation it has shown a temperature of abo'lt $54^{\circ} \mathrm{F}\left(30^{\circ} \mathrm{C}\right)$ lower than the Zone 2 thermocouple. During poor operation (such as when there was higher than expected sulfur in the product), the temperature differential was as much as $80^{\circ} \mathrm{F}$ $\left(44^{\circ} \mathrm{C}\right)$.

The kiln should be equipped with internal thermocouples in each heated zone and at the inlet and outlet of the heated section. This temperature data might not be needed in a commercial operation but is needed for process development and as a diagnostic device to determine if the walls remain clean. There is no other good way to determine whether the walls of the kiln are clean during operation.

The venturi gas scrubber system appears to run at a lower efficiency than desired. Installation of a new pump and venturi throat should solve this problem.

TRW recommends the following changes to be made to the kiln and its feed and discharge systems for any future testing:

\section{$\underline{\mathrm{Kiln}}$}

- Connect and insulate molten caustic feed line to kiln.

- Remount auger/scraper against downward-wall of kiln (or reverse kiln rotation). 
- Install new timer to automatically cycle auger/scraper speed and duration.

- Provide for higher auger speeds.

- Install six internal thermocouples, one in each of the four heated zone of the reactor and at the inlet and outlet of the kiln heated section to measure coal/caustic temperatures.

- Install additional data acquisition and control (DAC) capabilities to existing Yokogawa DAC system to accommodate additional temperature inputs.

\section{Gas Scrubber System}

- Remove and replace gas scrubber nozzle.

- Remove and replace scrubber pump.

- Install additinnal sample valves at various points in the kiln vent system.

- Build a gas sparger/extractor to prevent condensatic:- at the feed end of the kiln.

\section{Pneumatic Feed System}

- Fix pinhole leaks in bins and tanks.

- Consider continuous in-line mixer for blending coal/caustic.

- Find/install self-cleaning tank bottom valves.

- Provide divert valve at gas/solid separator tank to off-load the tank to drums.

- Replace/repair drum cones for coal/caustic mix handling.

\subsection{DISSOLVER/QUENCH TANK SYSTEM}

Following the kiln cooling zone where the coal/caustic mixture is cooled to about 100 to $150^{\circ} \mathrm{F}$, the solids exit the kiln through a bellows sell breaching arrangement. The bellows seal is capable of maintaining $r$ sures up to \pm 2 inches W.C. in the kiln tube without leakage. The ied solids from the kiln drop into a grinder/delumper for size reduction. The grinder/delumper is a new piece of equipment installed to break up the occasional large size coal/caustic balls which sometimes 
exited the kiln on the previous Gravimelt program. A constant, small particle size insures a constant, fast rate of caustic dissolution in the dissolver/quench tank.

From the grinder, the solids flow through a series of two knife gate valves which are operated sequentially by a timer, such that one of the valves is always closed. This "lock hoppering" protects the kiln from any in-leakage of steam from the downstream quench tank.

The 40-70 pounds per hour of solids (at design conditions) exiting the second gate valve, drop into a stirred 12 gallon Inconel quench tank, $T-101$, where they are dissolved in an aqueous caustic filtrate that flows into this tank from the downstream vacuum filter system (Figure 4-1). The quench tank is sized for a nominal residence time of 30 minutes $(1 / 2$ ful1). The solid caustic (as well as sulfur compounds and ash leached from the coal) dissolve in the filtrate to produce an approximately 50 percent caustic solution (at the design conditions). Due to the propensity of this solution to precipitate dissolved mineral matter and sulfur compounds on standing for extended periods of time, quench tank T-101 was designed to keep the residence time at a minimum.

The temperature of the resulting slurry is controlled at the desired value $\left(180^{\circ} \mathrm{F}\right.$ maximum) by adding or removing heat using a slurry heater, $\mathrm{H}-101$, or a water cooled slurry cooler, E-101, located in a pump-around loop external to the quench tank (see Figure 4-1). The caustic solution produced in $T-101$ is pumped to the first vacuum filter in the water washing system. Excess filter feed spills back to T-101.

When the kiln product is uniformly small in size (1 to 2 inch in diameter), as it is most often, the grinder/delumper worked fine; however, the kiln occasionally discharged very large (6 inch diameter) chunks of material which choked the feec chute to the delumper. In addition, the solids were discharged from the kiln in an intermittent manner upsetting the operation of the dissolver/quench tank. Both of these situations could potentially shut down a continuously operating plant. 
These problems were more likely to occur with coarser coal (i.e., 6 mesh $\times 0)$ and with higher concentrations of coal-to-caustic. When high coal-to-caustic ratios were used, a layer of material would harden on the kiln walls beneath the auger (see discussion in Section 4.1). Large chunks of this material would then flake off of the kiln walls, upsetting operations.

The delumper at the kiln outlet may need assistance since occasional large chunks of kiln product can block the chute to the delumper. In order to avoid this problem in the future, TRW is investigating installing a gross grinding device (perhaps a breaker bar) in the kiln discharge chute ahead of the delumper to reduce chunks to a size more easily handled by the del umper.

Even with the addition of a breaker bar, there still remains the problem of the intermittent discharge of solids from the kiln (the nature of the kiln process). Such intermittent discharge of solids upsets the operation of the dissolver/quench tank. This tank was designed to be only 12 gallons in size in order to minimize both the residence time and the precipitation of solids. With the intermittent discharge of solids to this tank, problems have developed with high solids loading leading to the discharge pump rupture disks blowing, disrupting operation. TRW has not even approached the higher concentrations of coal in the dissolver tank that will be handled when the vacuum filters are put on-line and the system runs at design conditions to give 40 to 50 percent caustic-in-water filtrate for regeneration. Part of the problem is that the dissolver tank outlet pump was controlled in an on-and-off mode rather than high-and-low operation due to problems both with the vacuum filters (see discussion of filtration in Section 4.3) and with sporadic kiln solids discharge. If the on-cycle is delayed too long and the slurry starts to settle, restarting the pump blows a rupture disk. This will likely become more critical at higher coal loadings in the slurry, although there is some off-set in that the higher concentration of caustic in the slurry will give higher viscosity to the aqueous phase with slower separation and floating of coal. 
In order to avoid the problem of the intermittent discharge of kiln solids upsetting quench tank operation, TRW is investigating installing an intermediate storage tank (15 to 30 minutes residence time) and an on- 1 ine discharge/weighing device ahead of the quench tank to collect the solids discharged from the kiln and to meter the ground solids into the dissolve tank at a controlled, steady rate.

TRW recommends the following changes to be made to the kiln outlet system for any future testing:

- Install a grinding device such as a breaker bar in the kiln discharge chute.

- Add an intermediate solids storage tank (surge volume) ahead of the quench tank.

- Install an on-line discharge weigh mechanism (such as a weigh belt feeder) to measure the kiln product discharge and provide a smooth constant feed to the dissolver tank.

- Remove, repair and replace knife gate valves at the kiln solids outlet.

\subsection{FILTRATION}

\subsubsection{Filtration Background}

Prior to the start of the current contract, TRW performed several laboratory-scale leaf filter tests and a series of off-line filter tests on a rental rotary drum vacuum filter to determine the conditions and equipment necessary for operation of the anticipated $\mathrm{MCL}$ integrated plant. Separation of the coal/solids from the water wash solution/slurry in the first separation unit downstream of the kiln was idenified as the most difficult separation to achieve since the density of 40 to $50 \%$ caustic solution at the design conditions is equal to or higher than the density of the caustic coal particles. In addition, the increased viscosity of such a solution, the large number of dissolved solids present, and the beginning of precipitation of some of the dissolved solids make this filtration step extremely difficult. 
Experience with the rental rotary drum vacuum filter was marginal but encouraging in that good results were obtained with freshly made slurries; however, filtration became nearly impossible as the slurries aged only 30 to 60 minutes. Laboratory leaf filter tests showed that fresh slurries filtered very well using 30-mesh square weave polypropylene filter media. Since the starting coal is nominally 14 -mesh $\times 0$ size, there was a concern about the amount of coal fines that would pass through the medium. The 30-mesh cloth provided the best overall performance of filtration speed vs. fines passage $(10-15 \%)$.

On the basis of these preliminary tests, two rotary drum vacuum filters of approximately 1 square foot surface area each were purchased and installed as the first two separation units in the integrated $\mathrm{MCL}$ plant. Two vacuum filtration stages are used prior to the five centrifuge stages because at caustic concentrations of greater than $15 \%$, the aqueous caustic solution has a greater specific gravity than the coal cake and thus the liquor cannot be separated from the cake using centrifuges. Only after two vacuum filtration stages is the liquor dilute enough for separation from the cake using centrifuges.

A block flow diagram of the multistage countercurrent water washing system is depicted in Figure 4-2. The coal/caustic slurry is sequentially washed and dewatered in two vacuum filters, five centrifuges, and six interstage slurry tanks in a countercurrent manner producing a washed coal virtually free of dissolved caustic and a concentrated aqueous caustic filtrate stream requiring regeneration. As the wash streams move in a countercurrent direction with respect to the solids flow, they become more concentrated in caustic and salts while the residual liquid on the solids becomes more dilute in caustic and salts.

The plant was designed for a wash water to coal ratio of about four to one. At this ratio, the filtrate from the first vacuum filter is an approximately $50 \%$ aqueous caustic solution containing most of the dissolved sulfur compounds anc silica and alumina mineral matter leached from the coal. This filtrate stream is filtered in a polishing bag 


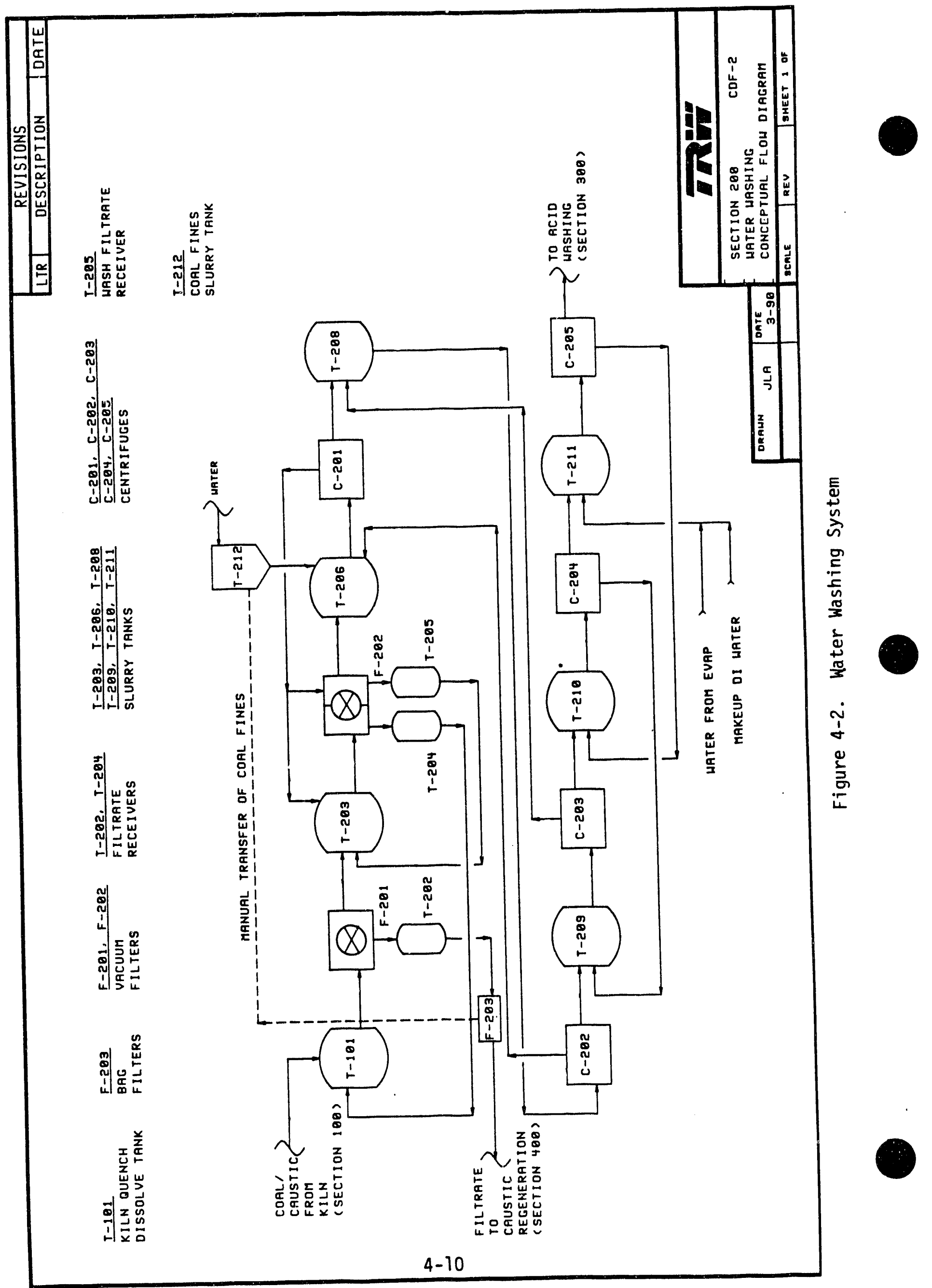


filter, F-203, to remove any remaining coal fines before being sent to the caustic regeneration system. The recovered coal fines are manualiy transferred downstream, reslurried with water, and reintroduced into the water washing system ahead of the first centrifuge (Figure 4-2).

The temperatures in the two vacuum filters will never be higher than $180^{\circ} \mathrm{F}$ to avoid boiling in the filters when a vacuum is drawn. 'The temperature of the feed to the first vacuum filter is established by the dissolver/quench tank pump-around loop containing a slurry heater and cooler. Slurry tanks are located next to and slightly below the two vacuum filters in order that the cakes produced by the filters can drop by gravity directly into the repulping tanks, eliminating the need for manually or mechanically transferring the cakes to the tanks. Progressive cavity pumps are used throughout the water wash system to provide a steady feed stream to the filters and centrifuges.

\subsubsection{Test Results}

Following installation of the two rotary drum vacuum filters but prior to start-up of the integrated plant, and numerous times during early plant operation, one rotary drum filter was put into service. At no time was the operation of the filter acceptable. Three or four different filter cloth meshes were tried along with several different slurry concentrations. In one series of tests, one half of the drum was blinded off to slow down the rate at which liquid was being removed from the filter pan by the vacuum.

Filter cakes were either lumpy or more often very thin (1/32 inch thick), were carly impermeable and resembled "fish skin". In nearly all cases, a large quantity of solids built up in the filter pan under the filter drum, eventually leading to binding of the drum against the solids. After numerous attempts to make the filter work, it was determined that two major problems were occurring.

First, the suspension of the coal solids in the liquid is facilitated. by liquid velocity; the slurry velocity in the $1 / 2$-inch delivery pipe was 
sufficient to maintain the solids in suspension. However, as the slurry entered the large filter pan, settling occurred as evidenced by the solids building up in the bottom of the filter pan rather than on the drum. As the solids settled, the liquid was very rapidly removed through the filter medium forcing the liquid level in the filter pan down. Then the liquid level became low enough that the liquid vacuum seal was broken (allowing air into the vacuum system); a complete loss of vacuum resulted.

Second, in order to control the level of liquid in the dissolver tank (where the dry, solid coal/caustic from the kiln is first contacted with water), the tank liquid level control was tied to the pump which emptied the dissolver tank to the filter pan. Coal/caustic solids were delivered from the kiln outlet into the dissolver tank in clumps rather than in an even manner (the nature of the kiln process, see earlier discussion in Section 4.2). As a results, for some short period, the liquid level in the dissolver tank would remain nearly constant, the liquid level control would be satisfied and the pump would stop. Conversely, a clump of solids would fall into the tank, the level control would sense an increased level and the pump would run as fast as required to bring the level down to the set point. The recipient of this start/stop pump activity was the filter pan which would alternately overflow and then starve the filter. In addition, each time the pump stopped, the solids separation problem in the filter pan became worse.

Unfortunately the offending pump was too small to allow the filter pan to overflow continuously (thus preventing both starvation and settling). In addition, the filter pan overflow pipe was not capable of handling the small, alternating overflow provided by the small pump, leading to hard packing of coal solids in the pipe, requiring by clean-up maneuvers by the operating crew.

After it was discovered that the two above problems were at the root of the filter non-performance, corrective actions were taken to bypass the two filters and utilize the remaining equipment on-hand. Instead of the design wash water to caustic ratio of four to one which would yield a 
caustic solution of about $50 \%$ from the first separation unit (first vacuum filter), the wash water to caustic ratio was greatly increased to about ten to one, yielding a caustic solution of about $15 \%$ from the first separation unit (which is now the first centrifuge). This centrate concentration was maintained at about $15 \%$ caustic because at any higher concentration, the density of the solution would be equal to or higher than the density of the coal particles and thus the liquor cannot be separated from the coal cake using centrifuges. Because of the filter problems and because the evaporator was not on-stream until late in the program, the coordination of filters using high caustic concentrations and evaporation to produce recyclable caustic was not attempted.

\subsubsection{Conclusions and Recommendations}

The two rotary drum vacuum filters need to be operated for an extended period of time to determine whether these units will or will not be a bottleneck for the plant at up to a $50 \mathrm{lb} / \mathrm{hr}$ coal-caustic kiln feed rate. The appropriate mesh size for the filter cloth needs to be determined and the filter feed system needs to be modified to prevent the filter pan and spill-back line from plugging and interrupting operations. Another option, suggested by Bird, the filter manufacturer, would be to convert the filters to a top-feeding mode. In any case, additional batch testing to know how to operate the filters is necessary. TRW recommends that a filter test program be conducted to determine a workable flow configuration for the filters. As these tests could result in the need to procure new equipment, this test program should be scheduled well in advance of recommencement of plant operations.

The problems with the filter feed system, described above, lead to several conclusions and recommendations:

- The vacuum filter feed philosophy needs to be completely revised (constant feed and spill-back, larger feed pump, uniform solids feed rate from kiln, isolation of vacuum pump seal water).

- In order to deliver kiln solids to the dissolver tank in a continuous fashion, it may be necessary to allow for a hold-up of kiln solids followed by a continuous feeder of some type to the dissolver tank. (See earlier discussion in Section 4.2.) 
- The control theory and system for liquid level control for the dissolver tank is not compatible with the required continuous feed to the filter. It may be possible to combine the current liquid level sensor with a larger pump allowing for constant overflow in the filter pan at some velocity which will prevent solids settling. It is possible that this constant pump-around overflow loop would be mostly insensitive to clump delivery of solids into the dissolver tank, thus making any recommendations for a solids holdup tank and feeder unnecessary. Tests must be run to determine this need.

- The filter pan overflow line appears to need more than the present slightly sloped gravity return design. A pump may be needed on the spill-back line.

\section{Additional Recommendations:}

- Rework the level control system in the vacuum filtrate tanks.

- Add a second set of bag filters to the existing bag filters, F-203. There was a fines-blinding problem. It was labor intensive to change the bags frequently. The bag filters would be in series, with a 25 micron cloth in the first set and a five micron cloth in the second set of bag filters.

- Revise filtrate centrifugal pump control system.

- Install pump-around loop for vacuum filters.

- Remove and replace slurry feed pump with larger pump.

- Reinsulate slurry lines.

There is a good probability for operation at the design conditions if the filter feed system is reworked. It is highly recommended that this work be commenced at an early date to allow for procurement of the proper supporting equipment before plant operations are resumed.

\subsection{WATER AND ACID WASHING}

After the two vacuum filters, the integrated MCL plant was designed to further water wash the coal cake in five centrifuges with interstage slurry tanks to remove any remaining caustic, sulfur forms, and dissolved silica and alumina mineral matter (Figure 4-2). This countercurrent 
washing produces a washed coal cake virtually free of dissolved caustic. Iron hydroxide does not dissolve in the aqueous caustic but remains on the coal cake until the later acid wash.

There were a number of advantages in using centrifuges wherever possible in place of filters in the integrated $20 \mathrm{lb} / \mathrm{hr}$ MCL plant. First and foremost, modular equipment testing on the previous Gravimelt Program had shown that cake moisture levels for dewatering Gravimelt coal are considerably lower for centrifuge operation than for filters. Other advantages are the relative simplicity of operation and control in a multistage system and a lower power requirement for centrifuges due to elimination of the vacuum pump subsystems.

In the acid'washing system, the coal cake from the final water washing centrifuge, c-205, is treated with sulfuric acid, at a pH of about two, to neutralize and to remove the iron hydroxides and the residual bound and dissolved caustic which form sulfate salts. The resulting slurry is then centrifuged and washed to remove the sulfate salts and excess acid producing the final coal product. A block flow diagram of the acid washing system is depicted in Figure 4-3. Three stages of centrifuges are used along with interstage slurry tanks to remove the sulfate salts and excess acid, producing the final coal product which is low in sulfur, ash, and sulfate salts. The centrate from the first centrifuge C-301, containing the excess acid and the sulfate salts, is sent to the waste water treatment system. The countercurrent acid washing arrangement is very similar to that used in the water washing system. About ten parts wash water per part coal were used (instead of the design three parts wash water) to increase the flow rates through the acid washing system.

Progressive cavity pumps are used throughout the water and acid washing system to provide a steady slurry feed stream to the centrifuges. Diaphragm pumps are used to recirculate the centrate streams to the repulping tanks. Tanks are located next to and sightly below the centrifuges in order that the cake produced by the centrifuges can drop by gravity directly into the repulping tanks. All tanks are 12 gallons in 


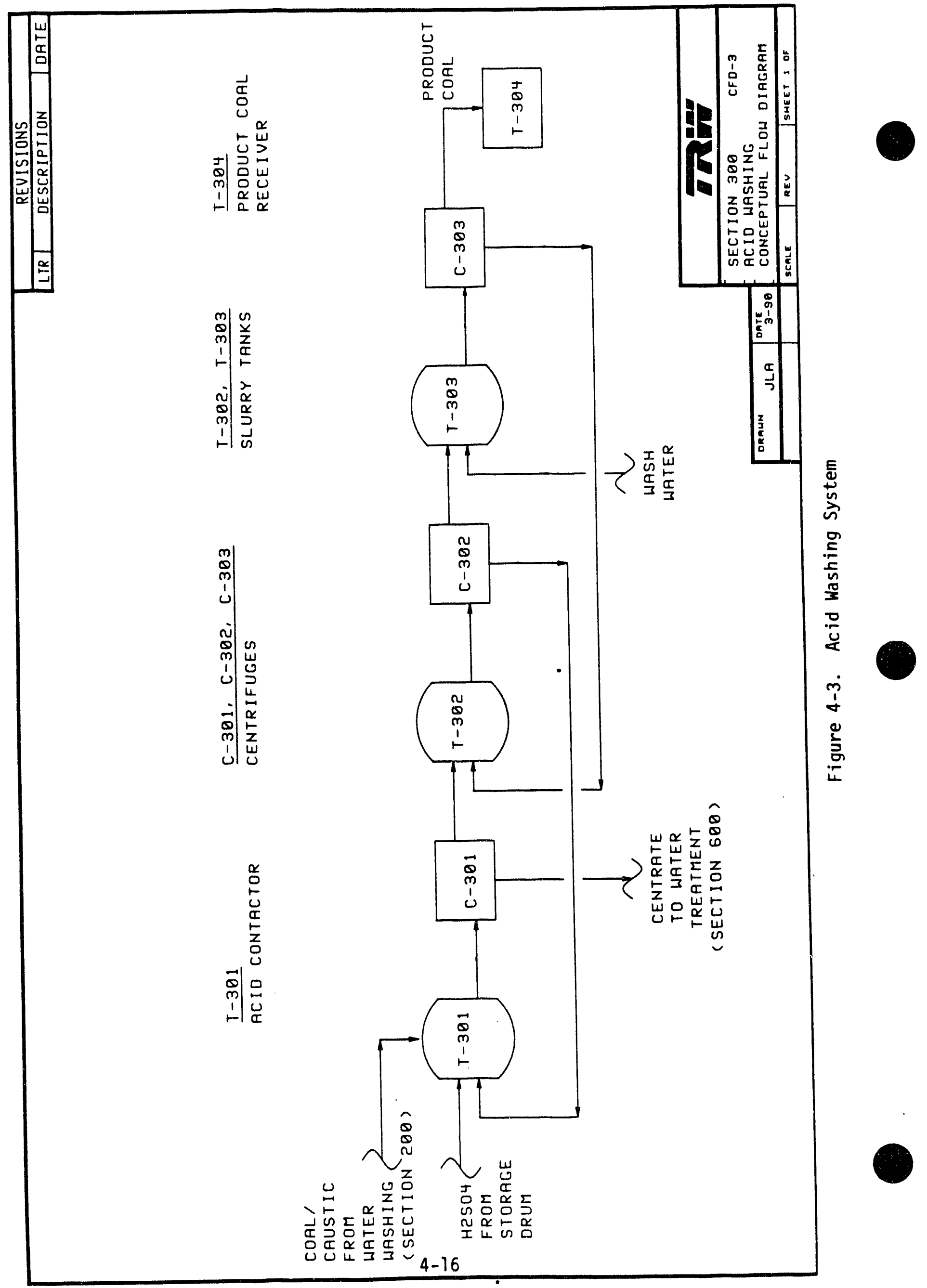


order to provide a nominal 30 minutes of residence time each. All tanks are provided with mixers to aid the repulping operations and with electric band heaters to maintain the slurries at temperatures up to $150^{\circ} \mathrm{F}$ to facilitate the liquid-solids separation in the centrifuges. All centrifuges are six inches in diameter.

The present slurry pumping capacity in the wash trains is just sufficient to not bottleneck the plant at a $50 \mathrm{lb} / \mathrm{hr}$ coal-caustic kiln feed rate. There was a noticeable decline in the performance of the progressive cavity slurry pumps in both the water and acid washing systems as testing progressed. Since this historically observed performance degradation is likely to continue, these pumps will very soon become a problem to continuous $\mathrm{plant}$ operations. TRW is considering refurbishing or replacing these pumps prior to recommencement of $\mathrm{plant}$ operations.

It has yet to be demonstrated that the water and acid wash trains can be operated at high solids loading without plugging occurring in the mix tanks and the slurry transport lines. The intermittent nature of the flow in the wash trains makes this a particular problem in the slurry transport lines. To date, the plant has operated successfully at about five percent slurry solids loading. At a $50 \mathrm{lb} / \mathrm{hr}$ coal-caustic kiln feed ratio, a $1: 1$ caustic:coal ratio, and a $50 \%$ caustic solution to regeneration, a slurry with a solids loading as high as $20 \%$ will have to be pumped. TRW recommends conducting slurry transport experiments in the plant (perhaps as part of a filter test program) prior to recommencement of operations, to determine the practical limits of slurry solids loading in the integrated facility.

Foaming was observed both in the dissolver tank and in the repulping tanks during operations. An antifoam solution was purchased and allowed to drip by gravity slowly into four of the tanks. The antifoam was very effective in reducing foaming. TRW is considering providing individual antifoam feed pumps for - each tank to eliminate clogging seen in the gravity flow feed system. 
The tank heaters and insulation appear to be inadequate. There was poor contact between the band heaters and the tanks. Also poor mixing was observed in the tanks. The mixer propellers were undersized (3 inch propeller type). TRW recommends improving the tank heaters, replacing all insulation, and changing all mixer propellers to larger impellers.

TRW recommends the following changes to be made to the water and acid washing systems for any future testing:

- Review antifoam/defoaming materiais and methods.

- Provide individual antifoam injection pumps for each tank.

- Change all mixer propellers to larger impellers.

- Install automatic $\mathrm{GN}_{2}$ purge of tank bubbler level indicators such that valves can be opened and closed by the control system.

- Install level controllers and surge systems for stabilizing flow through magnetic flow meters.

- Remove and replace electrical heaters on wash tanks (more wattage, more contact between heaters and tanks).

- Remove and replace insulation on wash tanks.

- Review all pump performances, replace or refurbish pumps (new stators rotors, motors, speed controllers). It is unlikely pumps in their present condition can handle design flows and concentrations.

- Install heater on wash water feed line to provide a higher temperature water supply.

- Inspect and refurbish centrifuge rotating parts as necessary.

\subsection{CAUSTIC REGENERATION}

\subsubsection{Equipment Description and Operation}

The caustic regeneration system has been designed to remove the dissolved coal mineral matter and sulfur compounds from the caustic before the caustic is sent to the evaporator and recycled to the kiln. The feed to the caustic regeneration section is the filtrate from the first vacuum filter in the water washing section (Figure 4-4). The system was designed 


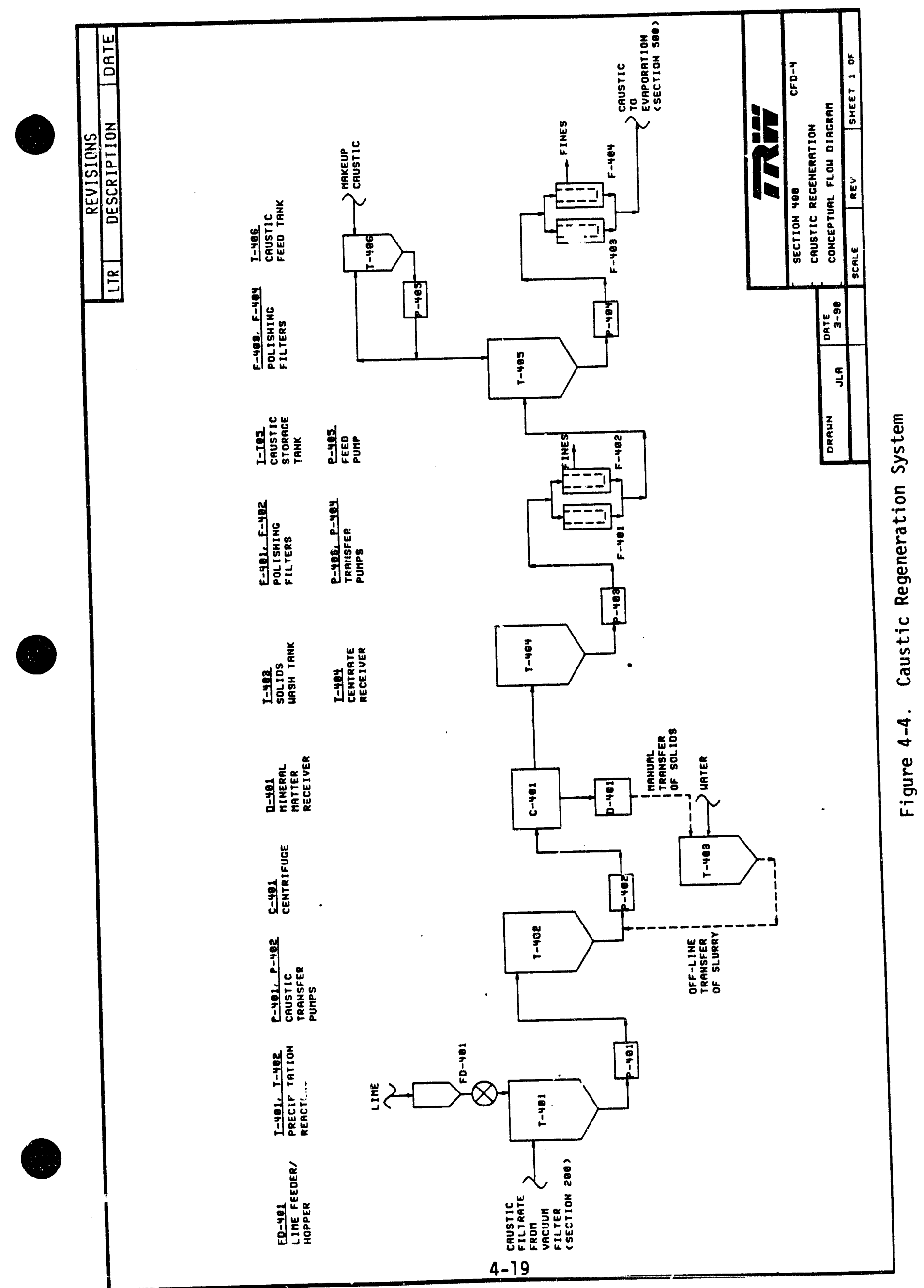


to process a filtrate containing approximately $50 \%$ caustic and $50 \%$ water, with associated dissolved mineral matter and sulfur compounds. However, due to problems with the vacuum filters (see Section 4.3), the feed to the caustic regeneration system was very dilute, only containing about $15 \%$ caustic.

The dissolved mineral matter and sulfur compounds are precipitated in the caustic regeneration system by the addition of lime. The precipitated solids are then mechanically separated from the caustic in a centrifuge and bag filters (Figure 4-4). The water is later removed from the mineral matter-free and sulfur-free caustic in the caustic concentration system by evaporation.

The feed to the caustic regeneration system is continuously pumped to an insulated 100 gallon precipitation tank, T-401, which provides a residence time of four to eight hours. The tank is provided with band heaters to heat and mainiain the caustic solution at reaction temperatures between $180^{\circ}$ and $250^{\circ} \mathrm{F}$.

Lime, $\mathrm{CaO}$, is added continuously by a solids feeder to tank T-401. The lime forms insoluble complexes with the mineral matter and also causes the precipitation of carbonates and sulfur compounds present. The caustic with the precipitated solids and excess lime is continuously transferred to a second heated 100 gallon precipitation tank, T-402, which can provide up to an additional eight hours of residence time to facilitate the further precipitation of mineral matter, carbonates, and sulfur-containing solids if needed. Such relatively long residence times may be required as the precipitation reactions involve potentially slow crystallizations. The tanks are provided with mixers to prevent the solids from settling in the tanks and plugging the tank outlet lines.

The caustic along with the precipitated solids and excess lime is transferred to centrifuge $€-401$ where most of the precipitated solids and excess lime are removed from the caustic. The remaining solids are removed downstream in bag filters F-401 through F-404. 
The centrifuge cake is collected in 55 gallon drums. These cake solids are wet with caustic solution and can be reslurried (washed with water) and recentrifuged off-line at a later time to make the solids more environmentally suitable for disposal.

The centrate is pumped through polishing bag filters, F-401 and F-402, to remove the remaining precipitated solids and excess lime not removed by centrifuge. The filtrate from the bag filters is collected in a 100 gallon storage tank, T-405, which also serves as the evaporator feed tank. Tank T-405 can hold up to 8 hours of caustic and provides a surge volume for caustic storage in case of a temporary shutdown of the evaporator system. The caustic is pumped from tank T-405 through polishing bag filters F-403 and F-404, and on to the evaporator where the remaining water is removed to produce an anhydrous caustic for recycle to the kiln. Polishing filters, F-403 and F-404, are present to protect the evaporation system from plugs caused by additional solids precipitation in tank $T-405$.

The caustic regeneration section operated well, but has not been tested under the high concentrations of caustic it was designed for due to problems with the vacuum filters. TRW recommends the following changes to be made to the caustic regeneration system to insure even better operation for any future testing:

- Install flow indicator in the lime feeder. The lime has a tendency to bridge in the feed hopper and the operators need a way to insur: that the lime feeder is actually feeding.

- Change all mixer propellers to impellers and replace the variable speed motors with the existiny faster single speed mixer motors
from the previous Gravimelt program. Poor mixing and solids settling were observed.

- The centrifuge feed pump ran too high/low because of batch discharge from the vacuum filtrate tanks. There is a need to smooth out the flow. A quench tank/filter fix would solve this problem (see earlier discussion in Sections 4.2 and 4.3 ). 


\subsubsection{Off-line Mineral Matter Recovery Experiments}

Due to problems with the vacuum filters, the feed to the caustic regeneration system was very dilute, usually containing less than $15 \%$ caustic. During Run $7 A(5 / 3 / 89$ at $22: 45)$, a sample (VP2023) of the spent caustic solution was collected upstream of the bag filter at the entrance to the regeneration system. An approximately one liter sample of this solution was processed off-line at conditions simulating those being used in the caustic regeneration section of the integrated MCL plant. An outline of the four steps in the laboratory processing scheme is shown in Figure 4-5. Analyses were performed on the feed solution, the filtrates, the wash solutions, and the solids at each off-line processing step.

The ashed solids were analyzed by X-ray diffraction for compound identification and for elemental composition by $D C$ arc emission spectroscopy. The filtrates and wash solutions were analyzed for Si, Al, and $\mathrm{Fe}$ by atomic absorption. The levels of hydroxide and carbonate ions were determined by $\mathrm{pH}$ titration. Total sulfur in the liquids was analyzed by ion chromatograph as sulfate ions. For this, a known amount $(0.5$ to 1 g) of the liquid was heated with about $1 \mathrm{mi} \mathrm{H}_{2} \mathrm{O}_{2}$ at about 80 to $90^{\circ} \mathrm{C}$ to oxidize any other forms of sulfur to sulfate. The solution was neutralized to $\mathrm{pH} 7$ before its analysis by ion chromatograph.

Table 4-1 summarizes the analysis results of the regeneration feed solution (VP2023) for the constituents of interest prior to treatment in Steps 1 through 4 which simulate various regeneration mineral recovery steps.

\subsubsection{Step 1 - Filtraticii of Feed Sample}

In Step 1 , the solids in the feed sample were separated by vacuum filtration and the filter cake ashed. The purpose of this step, which simulates filtration by the bag filters $(F-203)$ at the entrance to the regeneration system, is to remove any solids that may have precipitated on standing. Polypropylene felt material (style 7401) received from the integrated $\mathrm{MCL}$ test plant was used for the filtration. This is the same 
Figure 4-5. Laboratory Processing Scheme Outline

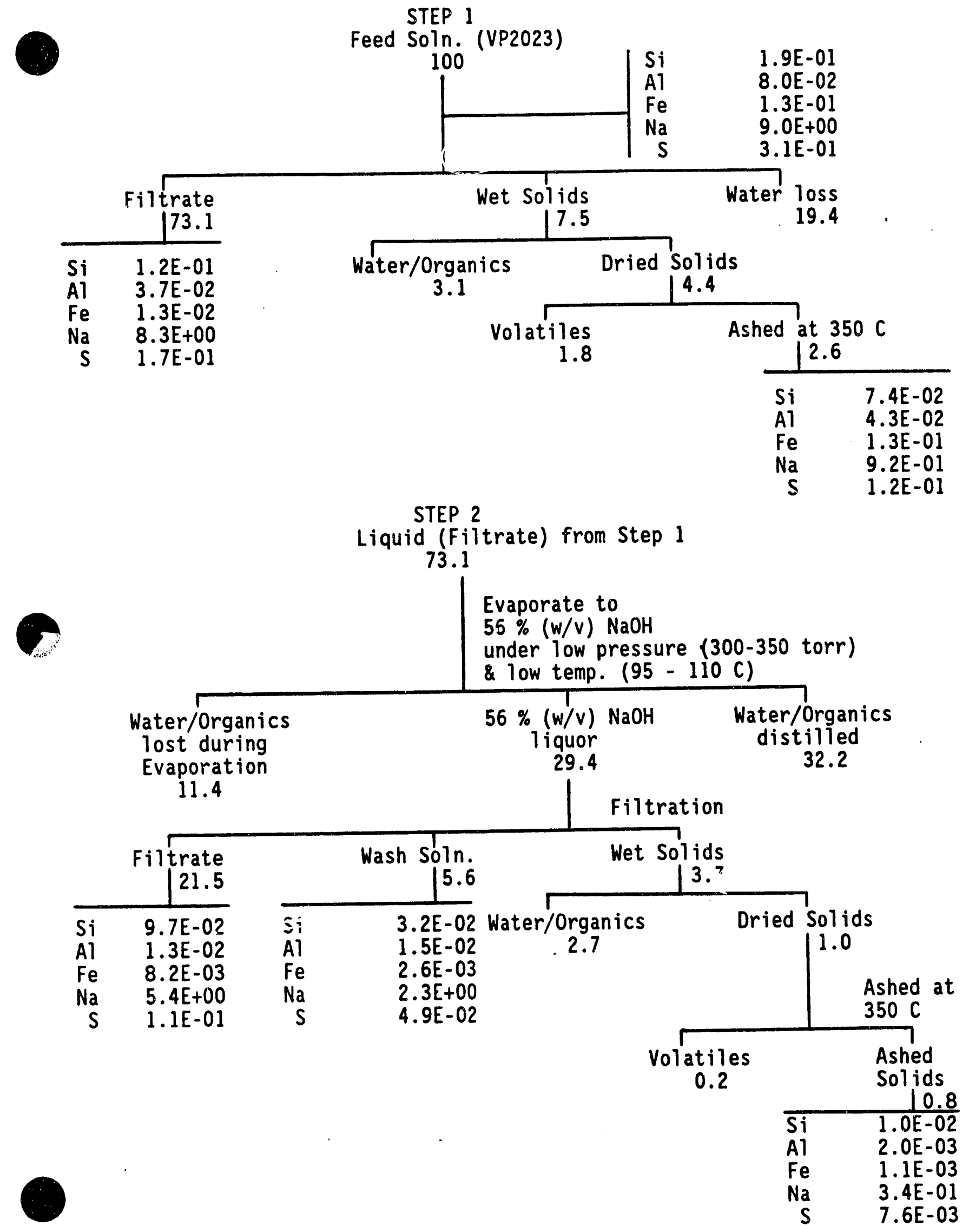


Figure 4-5. Laboratory Processing Scheme Outline (Continued)

STEP 3

Liquid (Filtrate) from Step 2

21.5

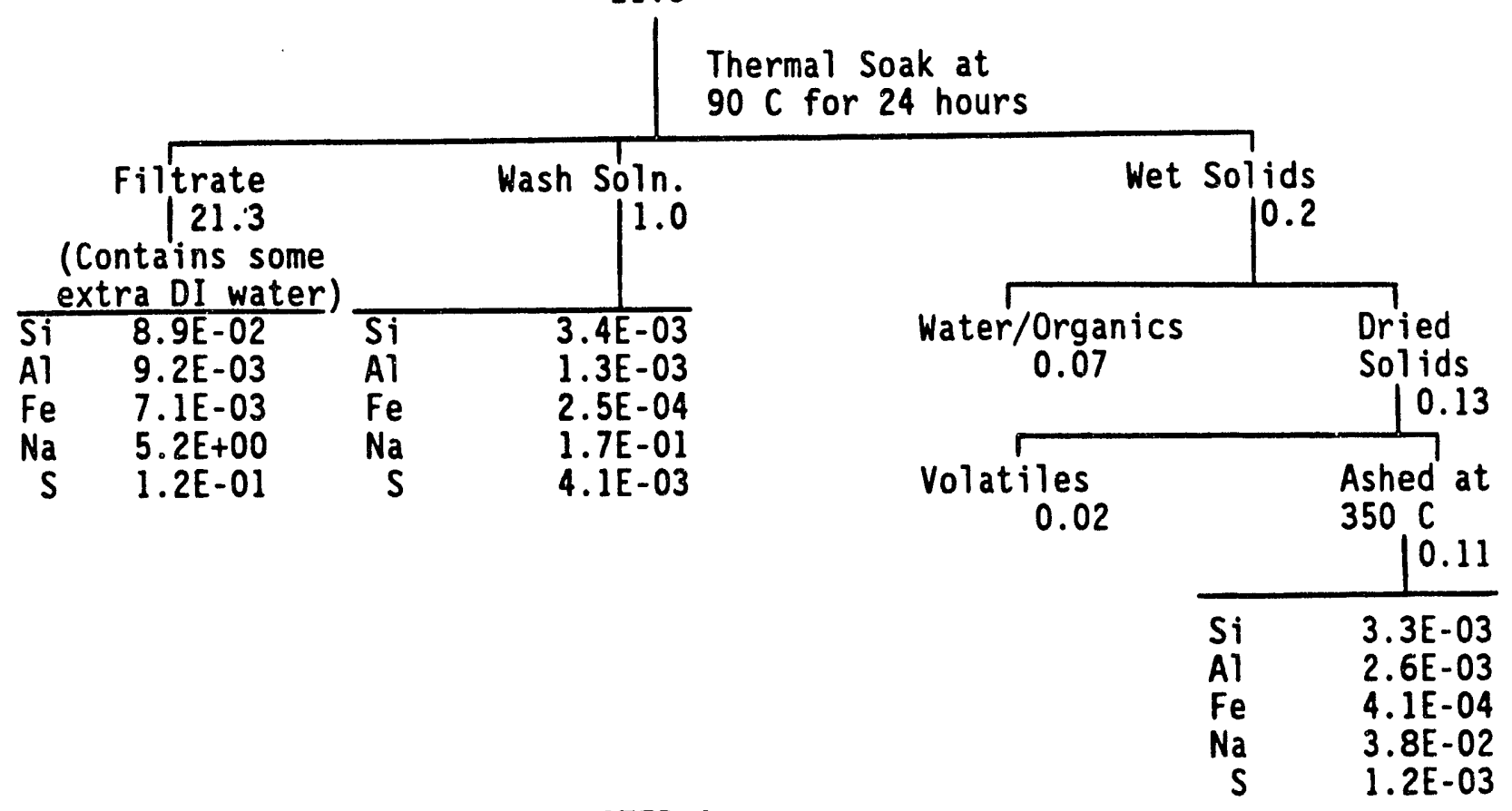

STEP 4

Liquid (Filtrate) from Step 3.

21.3

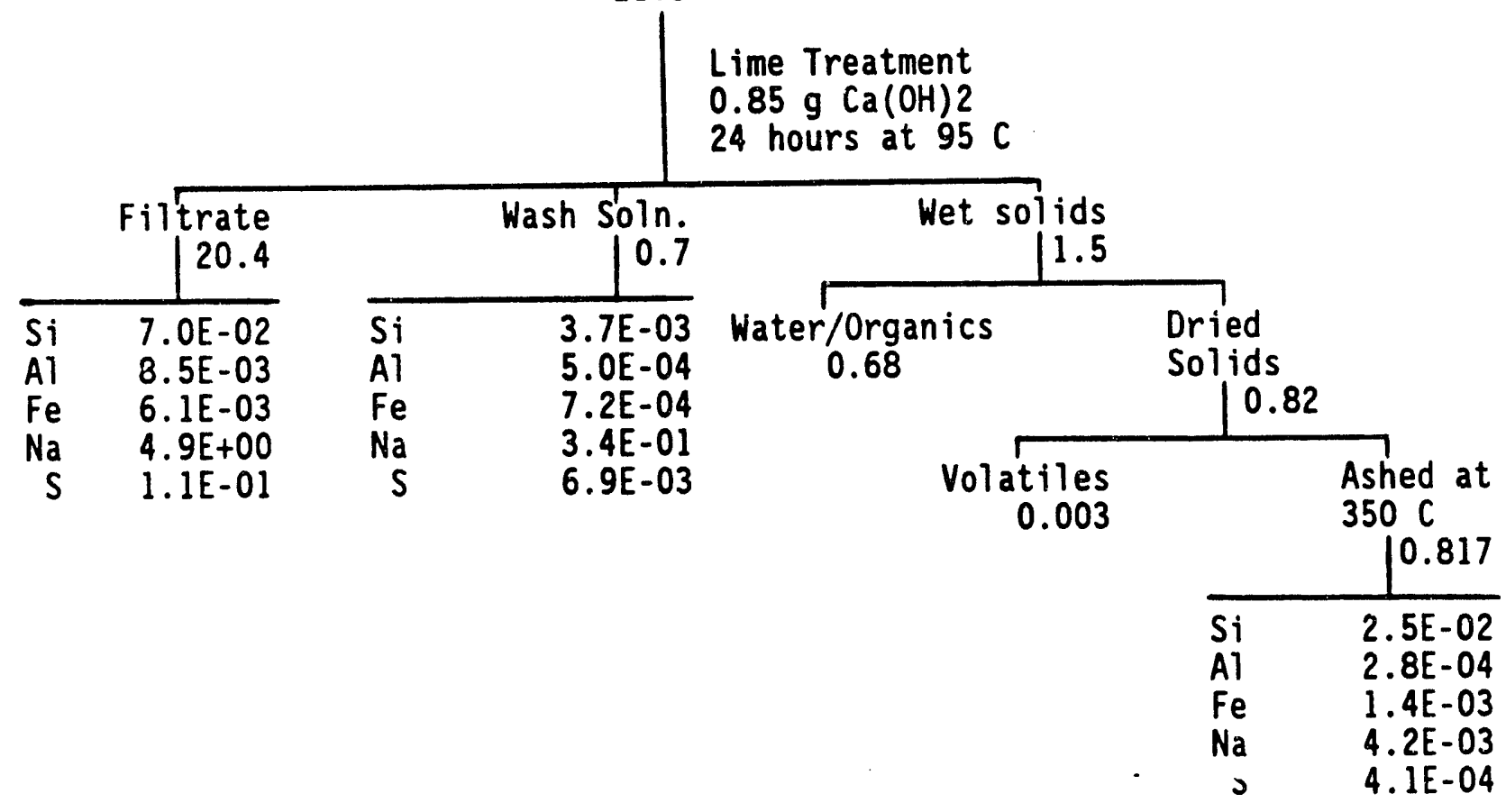


TABLE 4-1. ANALYSIS OF REGENERATION FEED SOLUTION

\begin{tabular}{|c|c|}
\hline $\begin{array}{l}\text { Density }\left(\mathrm{g} / \mathrm{cm}^{3}\right) \\
\mathrm{Si}(\mathrm{ug} / \mathrm{g}) \\
\text { Al }(\mathrm{ug} / \mathrm{g}) \\
\mathrm{Fe}(\mathrm{ug} / \mathrm{g}) \\
\mathrm{Na}(\mathrm{w} / \mathrm{w} \%)\end{array}$ & $\begin{array}{c}1.19 \\
1938 \\
796 \\
1348 \\
9.04\end{array}$ \\
\hline $\mathrm{OH}^{-1}$ as $\begin{aligned} \mathrm{NaOH} \\
(\mathrm{w} / \mathrm{v} \%) \\
(\mathrm{w} / \mathrm{w} \%)\end{aligned}$ & $\begin{array}{l}14.5 \\
12.2\end{array}$ \\
\hline $\begin{array}{r}\mathrm{CO}_{3}^{-2} \text { as } \mathrm{Na}_{2} \mathrm{CO}_{3} \\
(\mathrm{w} / \mathrm{v} \%) \\
(\mathrm{w} / \mathrm{w} \%)\end{array}$ & $\begin{array}{l}3.21 \\
2.69\end{array}$ \\
\hline $\begin{array}{l}\text { Total Sulfur }(\mathrm{ug} / \mathrm{g}) \\
\text { Sulfur present as Sulfate }(\mathrm{ug} / \mathrm{g})\end{array}$ & $\begin{array}{r}3130 \\
270\end{array}$ \\
\hline
\end{tabular}


filter media used in the bag filters in the MCL test plant. Secondary electron image on the felt material showed openings as big as 150 to 200 microns.

The wet filter cake was dried in an oven at $95^{\circ} \mathrm{C}$ for 4 to 5 hours prior to ashing at $350^{\circ} \mathrm{C}$. Analyses were performed on the the filtrate and the ashed solids. Results would indicate what proportion of the solids precipitate on standing, before lime or heat addition. The ashed solids were analyzed by $X$-ray diffraction for compound identification, and for elemental composition by $D C$ arc emission spectroscopy. The filtrate was analyzed for $\mathrm{Si}, \mathrm{Al}, \mathrm{Fe}$ and levels of hydroxide, carbonate, and sulfate ions by atomic absorption, $\mathrm{pH}$ titration, and ion chromatograph as described above. The results of the Step 1 analyses are listed in Tables 4-2 and 4-3. The flow chart in Figure 4-5 also indicates the levels of elements removed at each process step with the results normalized to 100 as the starting weight of the regeneration feed.

The results suggest that the initial filtration of the regeneration feed is specifically effective for iron removal (greater than $90 \%$ removal). In addition, about 40 percent of the silica and sulfur and over 50 percent of the alumina were removed. It must be noted that processing of the sample began on $5 / 19 / 89$ or about two weeks after the sample was taken from the test plant. Usually, the regeneration feed solution would not have this long for solids precipitation.

$X$-ray diffraction on the ashed solids indicated $\mathrm{Na}_{2} \mathrm{CO}_{3}$ and $\mathrm{Na}_{2} \mathrm{SO}_{4}$ as present as major phases. The presence of carbonates and sulfates were further confirmed by separate spot tests.

\subsubsection{Step 2 - Evaporation to $50 \mathrm{wt} \% \mathrm{NaOH}$}

This step involved evaporaiting water from the liquid filtrate from Step 1 by distillation at low temperature $\left(95\right.$ to $\left.110^{\circ} \mathrm{C}\right)$ under vacuum conditions ( 300 to 3\%0 torr) to about 50 weight percent (Figure 4-5). The evaporation was performed to concentrate the solution to simulate actual design concentrations. (The regeneration system was designed to process a 
TABLE 4-2. SOLIDS AND LIQUIDS FROM STEP 1

\begin{tabular}{lr} 
Filtration: & 1026.9 \\
Weight of feed solution (g) & 750.3 \\
Filtrate (g) & 77.5 \\
Wet Solids (g) & 45.2 \\
Dried Solids at $92-95^{\circ} \mathrm{C}(\mathrm{g})$ & 26.7 \\
Weight of ashed solids at $350^{\circ} \mathrm{C}$ & 41.7 \\
Wt \% of water with wet solids & 199.1 \\
Weight of water lost during & 19.4 \\
filtration (g) & \\
Wt \% of water loss & 4.4 \\
\multicolumn{2}{|l}{ Weight \% dried solids } \\
Weight \% liquid phase
\end{tabular}

TABLE 4-3. MASS BALANCE -. STEP 1

\begin{tabular}{|c|c|c|c|c|c|c|c|}
\hline $\begin{array}{l}\text { Working } \\
\text { Sample }\end{array}$ & $\begin{array}{c}\text { Quantity } \\
(g)\end{array}$ & Elements & $\begin{array}{l}\text { Expected } \\
\text { Levels (g) }\end{array}$ & Obse & ved & Total & $\begin{array}{c}\% \\
\text { Diff. }\end{array}$ \\
\hline Feed Soln. & 1026.9 & $\begin{array}{l}\mathrm{Si} \\
\mathrm{Al} \\
\mathrm{Fe} \\
\mathrm{Na} \\
\mathrm{S}\end{array}$ & $\begin{array}{r}1.990 \\
0.817 \\
1.384 \\
92.832 \\
3.214\end{array}$ & $\begin{array}{r}1.252 \\
0.383 \\
0.137 \\
84.784 \\
1.782\end{array}$ & $\begin{array}{l}0.774 \\
0.454 \\
1.388 \\
9.612 \\
1.252\end{array}$ & $\begin{array}{r}2.027 \\
0.837 \\
1.525 \\
94.396 \\
3.034\end{array}$ & $\begin{array}{r}1.8 \\
2.3 \\
10.2 \\
1.7 \\
-5.6\end{array}$ \\
\hline
\end{tabular}


feed solution containing approximately $50 \%$ aqueous caustic solution.) Due to problems with the vacuum filters (see Section 4.3), the two vacuum filters in the water washing section were bypassed and about ten parts of wash water per part coal were used to wash the coal instead of the design 3 parts of wash water per part coal. Thus, the regeneration feed sample collected during Run $7 \mathrm{~A}$ for this off-line processing was very dilute, containing only about $12 \%$ caustic by weight (Table 4-1).

The concentrated caustic solution from the Step 2 evaporation was filtered, and the solids cake was washed with D.I. water separately from the mother liquor, dried in an oven, and ashed (Figure 4-5). Analysis were performed on the filtrate, the wash solution, and the ashed solids. Results of analyses from Step 2 are listed in Tables 4-4 and 4-5 and in Figure 4-5. Very little additional precipitation of silica, alumina, iron, or sulfur (less than $10 \%$ ) occurred as a result of concentration to $50 \%$. X-ray diffraction on the ashed solids showed the presence of $\mathrm{Na}_{2} \mathrm{CO}_{3}$. The fact that there was so much sodium present in the wash solution indicates that sodium carbonate precipitated during concentration to $50 \%$ caustic but redissolved during the washing step.

\subsubsection{Step 3 - High Temperature Treatment}

The liquid filtrate from Step 2 was subjected to a $90^{\circ} \mathrm{C}$, thermal soak for 24 hours in a teflon vessel fitted with a teflon reflux condenser. No significant change in liquor volume was noticed after the thermal soak. The thermal soak was performed to facilitate the precipitation of alumina, silica, iron, and sulfur. The solution was then filtered, and the solids cake was washed with hot D.I. water separately from the mother liquor, dried in an oven, and ashed (Figure 4-5). The solids and liquids were analyzed as in Steps 1 and 2 (see Tables 4-6 and 4-7 and Figure 4-5 for results).

Very little additional precipitation of silica, iron, or sulfur (less than $5 \%$ ) occurred as a result of the addition of heat. However, about $22 \%$ of the remaining alumina precipitated. X-ray diffraction or the ashed solids showed the presence of $3 \mathrm{NaAlSiO}_{4} \cdot \mathrm{Na}_{2} \mathrm{CO}_{3}$. 
TABLE 4-4. SOLIDS AND LIQUIDS FROM STEP 2

$\begin{array}{lr}\text { Weight of filtrate from Step l (g) } & 511.5 \\ \text { Weight of filtrate after } & 205.9 \\ \text { concentration to - 50 wt \% NaOH (g) } & \\ \text { Weight of wet solids (g) } & 26.1 \\ \text { Weight of wash solution (g) } & 316.0 \\ \text { Weight of dried solids (g) } & 7.3 \\ \text { Weight of ashed solids at } 350^{\circ} \mathrm{C} & 5.8 \\ & \\ & \\ \text { Weight \% dried solids } & 96.5 \\ \text { Weight \% liquid phase } & \end{array}$

TABLE 4-5. MASS BALANCE - STEP 2

\begin{tabular}{|c|c|c|c|c|c|c|c|c|}
\hline \multirow{2}{*}{$\begin{array}{l}\text { Working } \\
\text { Sample }\end{array}$} & \multirow{2}{*}{$\begin{array}{l}\text { Quantity } \\
(\mathrm{g})\end{array}$} & \multirow[t]{2}{*}{ Element } & \multirow{2}{*}{$\begin{array}{l}\text { Expected } \\
\text { Levels (g) }\end{array}$} & \multicolumn{4}{|c|}{ Observed } & \multirow{2}{*}{$\begin{array}{l}\% \\
\text { Diff. }\end{array}$} \\
\hline & & & & Wash & Filtrate & Solids & Total & \\
\hline $\begin{array}{l}\text { Liquid } \\
\text { sample from } \\
\text { step } 1\end{array}$ & 511.5 & $\begin{array}{r}\mathrm{Si} \\
\mathrm{Al} \\
\mathrm{Fe} \\
\mathrm{Na} \\
\mathrm{S}\end{array}$ & $\begin{array}{r}0.854 \\
0.261 \\
0.093 \\
57.800 \\
1.215\end{array}$ & $\begin{array}{r}0.221 \\
0.105 \\
0.018 \\
15.800 \\
0.343\end{array}$ & $\begin{array}{r}0.681 \\
0.094 \\
0.057 \\
38.027 \\
0.763\end{array}$ & $\begin{array}{l}0.076 \\
0.015 \\
0.008 \\
2.453 \\
0.055\end{array}$ & $\begin{array}{r}0.978 \\
0.213 \\
0.084 \\
56.280 \\
1.161\end{array}$ & $\begin{array}{r}14.6 \\
-18.2 \\
-9.9 \\
-2.6 \\
-4.4\end{array}$ \\
\hline
\end{tabular}


TABLE 4-6. SOLIDS AND LIQUIDS FROM STEP 3

$\begin{array}{lr}\text { Weight of filtrate from Step 2 (g) } & 112.7 \\ \text { Weight of filtrate after } & 111.5 \\ \text { thermal soak for } 24 \text { hrs at } 90^{\circ} \mathrm{C}(\mathrm{g}) & \\ \text { Weight of Wet solids (g) } & 1.2 \\ \text { Weight of wash solution (g) } & 57.3 \\ \text { Weight of dried solids (g) } & 0.8 \\ \text { Weight of ashed solids at } 350^{\circ} \mathrm{C} \text { (g) } & 0.7 \\ & \\ \text { Weight \% dried solids } & 0.7 \\ \text { Weight \% liquid phase } & 99.3\end{array}$

TABLE 4-7. MASS BALANCE - STEP 3

\begin{tabular}{|c|c|c|c|c|c|c|c|c|}
\hline \multirow{2}{*}{$\begin{array}{l}\text { Working Q } \\
\text { Sample }\end{array}$} & \multirow{2}{*}{$\begin{array}{l}\text { Quantity } \\
\text { (g) }\end{array}$} & \multirow[t]{2}{*}{ Element } & \multirow{2}{*}{$\begin{array}{l}\text { Expected } \\
\text { Levels (g) }\end{array}$} & \multicolumn{4}{|c|}{ Observed } & \multirow{2}{*}{$\begin{array}{c}\% \\
\text { Diff. }\end{array}$} \\
\hline & & & & Wash & Filtrate & Solids & Total & \\
\hline $\begin{array}{l}\text { Liquid } \\
\text { sample from } \\
\text { step } 2\end{array}$ & 112.7 & $\begin{array}{r}\mathrm{Si} \\
\mathrm{Al} \\
\mathrm{Fe} \\
\mathrm{Na} \\
\mathrm{S}\end{array}$ & $\begin{array}{r}0.509 \\
0.070 \\
0.043 \\
28.400 \\
0.570\end{array}$ & $\begin{array}{l}0.019 \\
0.007 \\
0.001 \\
0.917 \\
0.022\end{array}$ & $\begin{array}{r}0.468 \\
0.048 \\
0.037 \\
27.206 \\
0.624\end{array}$ & $\begin{array}{l}0.020 \\
0.016 \\
0.002 \\
0.235 \\
0.007\end{array}$ & $\begin{array}{r}0.507 \\
0.071 \\
0.041 \\
28.357 \\
0.653\end{array}$ & $\begin{array}{r}-0.3 \\
1.6 \\
-3.5 \\
-0.2 \\
14.6\end{array}$ \\
\hline
\end{tabular}




\subsubsection{Step 4 - Lime Treatment}

The mother liquor (filtrate) from Step 3 was placed in the same high temperature treatment vessel as was used for the thermal soak in step 3. The sample was heat treated with a known amount of $\mathrm{Ca}(\mathrm{OH})_{2}$ for 24 hours at $95^{\circ} \mathrm{C}$. The amount of lime used $(0.85 \mathrm{~g})$ was calculated based on a stoichiometric reaction with the total sulfur present. Step 4 simulates the lime added step in the MCL regeneration system. The slurry was next filtered, and the solids cake was washed with D.I. water separately from the mother liquor, dried in an oven, and ashed (Figure 4-5). The solids and liquids were analyzed as described in Steps 1 through 3 (see Tables 4-8 and 4-9 and Figure 4-5 for results).

Very little additional precipitation of alumina or sulfur (less than $3 \%$ ) occurred as a result of the addition of lime. However, about $20 \%$ of the remaining silica and iron precipitated. $X$-ray diffraction indicated the presence of $\mathrm{Ca}(\mathrm{OH})_{2}$ and $\mathrm{CaCO}_{3}$ as major phases in the ashed solids.

Table 4-10 summarizes the analysis results performed on the solid and liquid samples collected from each of the four treatment steps. The mineral matter recovery results are summarized in Table 4-11.

\subsubsection{Conclusions}

The major conclusions from the off -1 ine mineral matter recovery steps are as follows:

1. The mineral matter recovery results (Table 4-11) suggest that the initial filtration of the regeneration feed is specifically effective for iron removal (greater tnan 90\% removal). In addition, about 40 percent of the silica and sulfur and over 50 percent of the alumina were removed by the initial filtration (before any heat or lime was added).

2. Most of the carbonate precipitated out during concentration of the feed to 50 percent $(w / w) \mathrm{NaOH}$.

4. Thermal soak treatment is not effective for mineral matter removal. 
TABLE 4-8. SOLIDS AND LIQUIDS FROM STEP 4

\begin{tabular}{lc} 
Weight of Filtrate from Step $3(\mathrm{~g})$ & 71.9 \\
Weight of $\mathrm{Ca}(\mathrm{OH}) 2$ for lime for & 2.88 \\
lime treatment (g) & 68.9 \\
Weight of filtrate & 4.9 \\
Weight of wet solids (g) & 35.4 \\
Weight of Wash solution (g) & 2.69 \\
Weight of dried solids (g) & 2.63 \\
Weight of ashed solids at $350^{\circ} \mathrm{C}$ & 3.7 \\
Weight \% dried solids & 96.3 \\
\hline
\end{tabular}

TABLE 4-9. MASS BALANCE - STEP 4

\begin{tabular}{|c|c|c|c|c|c|c|c|c|c|}
\hline \multirow{2}{*}{$\begin{array}{l}\text { Working } \\
\text { Sample }\end{array}$} & \multirow{2}{*}{\multicolumn{2}{|c|}{$\begin{array}{l}\text { Quantity } \\
\text { (g) }\end{array}$}} & \multirow[t]{2}{*}{ Element } & \multirow{2}{*}{$\begin{array}{l}\text { Expected } \\
\text { Levels }(g)\end{array}$} & \multicolumn{4}{|c|}{ Observed } & \multirow{2}{*}{$\begin{array}{c}\% \\
\text { Diff. }\end{array}$} \\
\hline & & & & & Wash & Filtrate & Solids & Total & \\
\hline $\begin{array}{l}\text { Liquid } \\
\text { sample } \\
\text { step } 3\end{array}$ & from & 71.3 & $\begin{array}{c}\mathrm{Si} \\
\mathrm{Al} \\
\mathrm{Fe} \\
\mathrm{Na} \\
\mathrm{S}\end{array}$ & $\begin{array}{r}0.302 \\
0.031 \\
0.024 \\
17.544 \\
0.402\end{array}$ & $\begin{array}{l}0.013 \\
0.002 \\
0.001 \\
1.204 \\
0.025\end{array}$ & $\begin{array}{r}0.235 \\
0.029 \\
0.021 \\
16.398 \\
0.385\end{array}$ & $\begin{array}{l}0.080 \\
0.001 \\
0.005 \\
0.014 \\
0.001\end{array}$ & $\begin{array}{r}0.328 \\
0.032 \\
0.026 \\
17.616 \\
0.411\end{array}$ & $\begin{array}{l}8.8 \\
1.2 \\
9.4 \\
0.4 \\
2.2\end{array}$ \\
\hline
\end{tabular}


TABLE 4-10. ANALYSIS OF SOLIDS AND LIQUIDS FROM STEPS 1 THROUGH 4

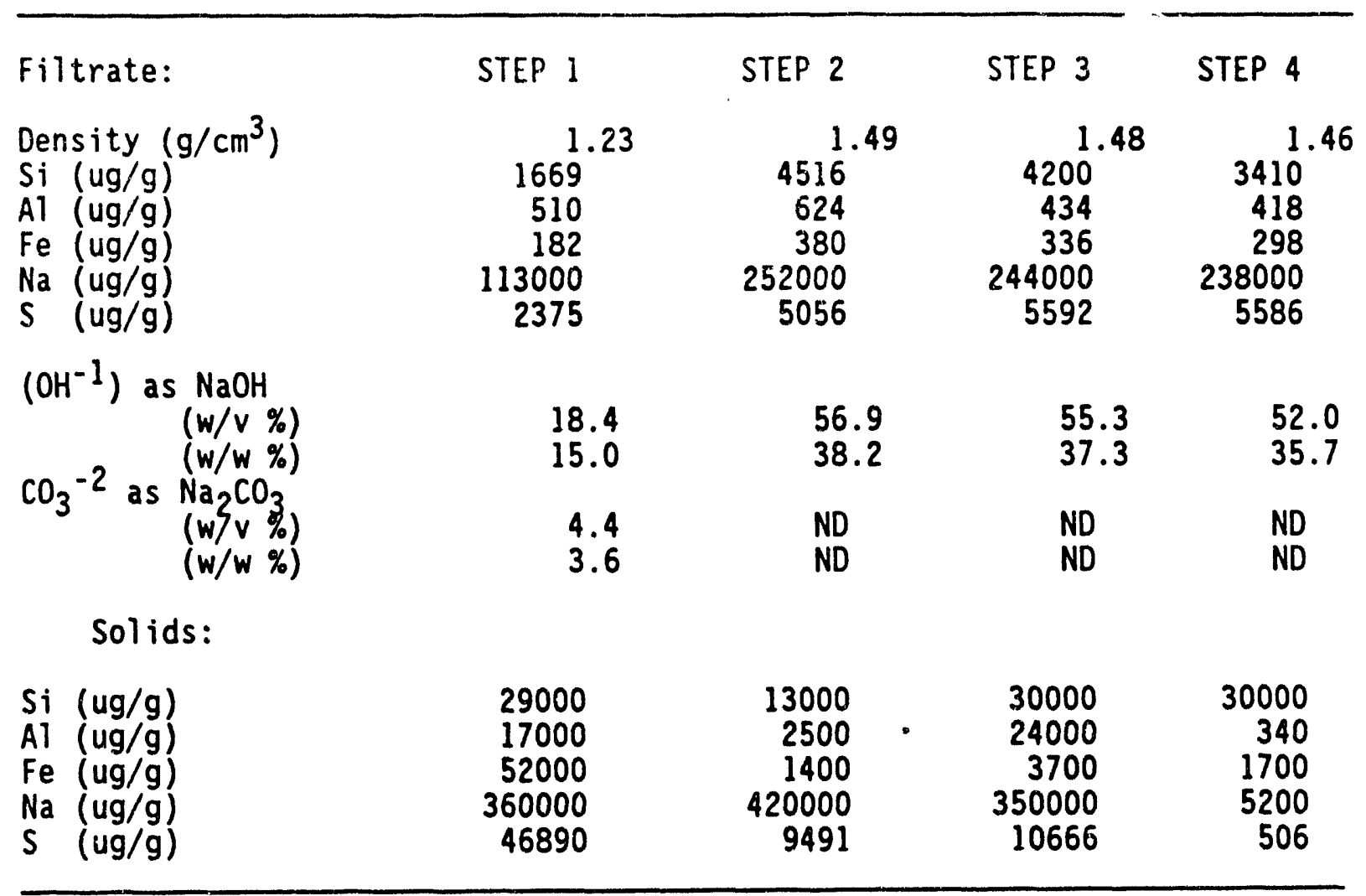


TABLE 4-11. MINERAL MATTER RECOVERY SUMMARY LABORATORY SCALE REGENERATION OF FEED SOLUTION VP2023

\begin{tabular}{|c|c|c|c|c|c|c|}
\hline STEP \# & $\begin{array}{c}\text { Initial } \\
\text { Conc. } \\
\text { (wt \%) }\end{array}$ & $\begin{array}{c}1 \\
\text { wt. } \% \text { rem }\end{array}$ & $\begin{array}{c}2 \\
\text { ed as sol }\end{array}$ & $\begin{array}{c}3 \\
\text { matter }\end{array}$ & 4 & $\begin{array}{l}\text { Total } \\
\text { Wt \% } \\
\text { Removed }\end{array}$ \\
\hline \multirow[t]{2}{*}{$\begin{array}{l}\mathrm{Si} \\
\mathrm{Al} \\
\mathrm{Fe} \\
\mathrm{Na} \\
\mathrm{S}\end{array}$} & $\begin{array}{l}1.9 E-01 \\
8.0 E-02 \\
1.3 E-01 \\
9.0 E+00 \\
3.1 E-01\end{array}$ & $\begin{array}{l}7.4 E-02 \\
4.3 E-02 \\
1.3 E-01 \\
9.2 E-01 \\
1.2 E-01\end{array}$ & $\begin{array}{l}1.0 E-02 \\
2.0 E-03 \\
1.1 E-03 \\
3.4 E-01 \\
7.6 E-03\end{array}$ & $\begin{array}{l}3.3 E-03 \\
2.6 E-03 \\
4.1 E-04 \\
3.8 E-02 \\
1.2 E-03\end{array}$ & $\begin{array}{l}2.5 E-02 \\
2.8 E-04 \\
1.4 E-03 \\
4.2 E-03 \\
4.1 E-04\end{array}$ & $\begin{array}{l}1.1 E-01 \\
4.8 E-02 \\
1.4 E-01 \\
1.3 E+00 \\
1.3 E-01\end{array}$ \\
\hline & & 1 & 2 & 3 & 4 & Total \\
\hline $\begin{array}{l}\mathrm{Si} \\
\mathrm{Al} \\
\mathrm{Fe} \\
\mathrm{Na} \\
\mathrm{S}\end{array}$ & & $\begin{array}{l}38.2 \\
54.5 \\
98.4 \\
10.2 \\
38.2\end{array}$ & $\begin{array}{l}5.4 \\
2.5 \\
0.8 \\
3.7 \\
2.4\end{array}$ & $\begin{array}{l}1.7 \\
3.3 \\
0.3 \\
0.4 \\
0.4\end{array}$ & $\begin{array}{r}12.6 \\
0.3 \\
1.0 \\
0.0 \\
0.1\end{array}$ & $\begin{array}{r}57.9 \\
60.7 \\
100.6 \\
14.4 \\
41.2\end{array}$ \\
\hline
\end{tabular}

EVALUATION OF MINERAL MATTER RECOVERY APPROACH

\begin{tabular}{|c|c|c|c|}
\hline Constituents & $\begin{array}{l}\% \text { Matter } \\
\text { Recovered } \\
\text { as Solids }\end{array}$ & $\begin{array}{l}\% \text { Matter } \\
\text { left over } \\
\text { in filtrate + wash }\end{array}$ & $\begin{array}{c}\% \\
\text { Error }\end{array}$ \\
\hline $\begin{array}{l}\mathrm{Si} \\
\mathrm{Al} \\
\mathrm{Fe} \\
\mathrm{Na} \\
\mathrm{S}\end{array}$ & $\begin{array}{r}57.9 \\
60.7 \\
100.6 \\
14.4 \\
41.2\end{array}$ & $\begin{array}{r}55.8 \\
31.7 \\
7.2 \\
84.2 \\
55.5\end{array}$ & $\begin{array}{r}13.7 \\
-7.6 \\
7.8 \\
-1.4 \\
-3.3\end{array}$ \\
\hline
\end{tabular}


5. Lime treatment is not effective for sulfur removal, but is effective silica and iron removal.

6. A material mass balance was performed for each treatment step and good agreement between expected and observed masses was obtained (Table 4-11).

The thermal soak and lime treatment may have been ineffective for mineral matter removal due to the fact that about two weeks elapsed between the time the sample was taken and the time laboratory processing began. During this time, a large percentage of the solids precipitated, leaving little solids left for removal by lime or heat audition. Additional experiments may be needed to confirm these results.

\subsection{EVAPORATOR AND FLAKER}

Several tests were conducted in the caustic evaporation/flaking system (Figure 4-6) during $\mathrm{MCL}$ system operation. Due to the problems with the . vacuum filters, aqueous caustic evaporator feed solutions were specially prepared for these tests. The results of these tests are summarized in Table 4-12. Based on the information in this table, the following results were obtained:

- Flaked product with a moisture content of 5-10\% was produced from $30-50 \%$ mixed caustic $(50: 50 \mathrm{NaOH}: \mathrm{KOH})$ feed solutions.

- Up to $130 \mathrm{lbs} / \mathrm{hr}$ of 50\% aqueous fresh mixed caustic (50:50 $\mathrm{NaOH}$ : $\mathrm{KOH})$ solution was processed for a short period by the evaporator/ flaker to produce a $10 \%$ moisture flake. This corresponds to one of the design cases for the Blaw Knox evaporator.

- A $50 \%$ aqueous mixed caustic $(50: 50 \mathrm{NaOH}: \mathrm{KOH})$ made from regenerated and fresh caustic (in the ratio 15:85, respectively) was processed by the evaporator/fiaker to produce an $8 \%$ moisture flake. This was at a feed rate of about $85 \%$ of the design rate for a $50 \%$ solution.

- A $50 \%$ aqueous mixed caustic $(50: 50 \mathrm{NaOH}: \mathrm{KOH})$ made from regenerated and fresh caustic (in the ratio $80: 20$, respectively) was processed by the evaporator/fiaker to produce a $10.5 \%$ moisture flake. However, this was at a feed rate of only $33 \%$ (15 1bs/hr of feed per evaporator tube) of the design rate for a $50 \%$ solution. The imited throughput that could be obtained, and the low overall heat transfer coefficient calculated for this particular test strongly indicate tube fouling/plugging. 


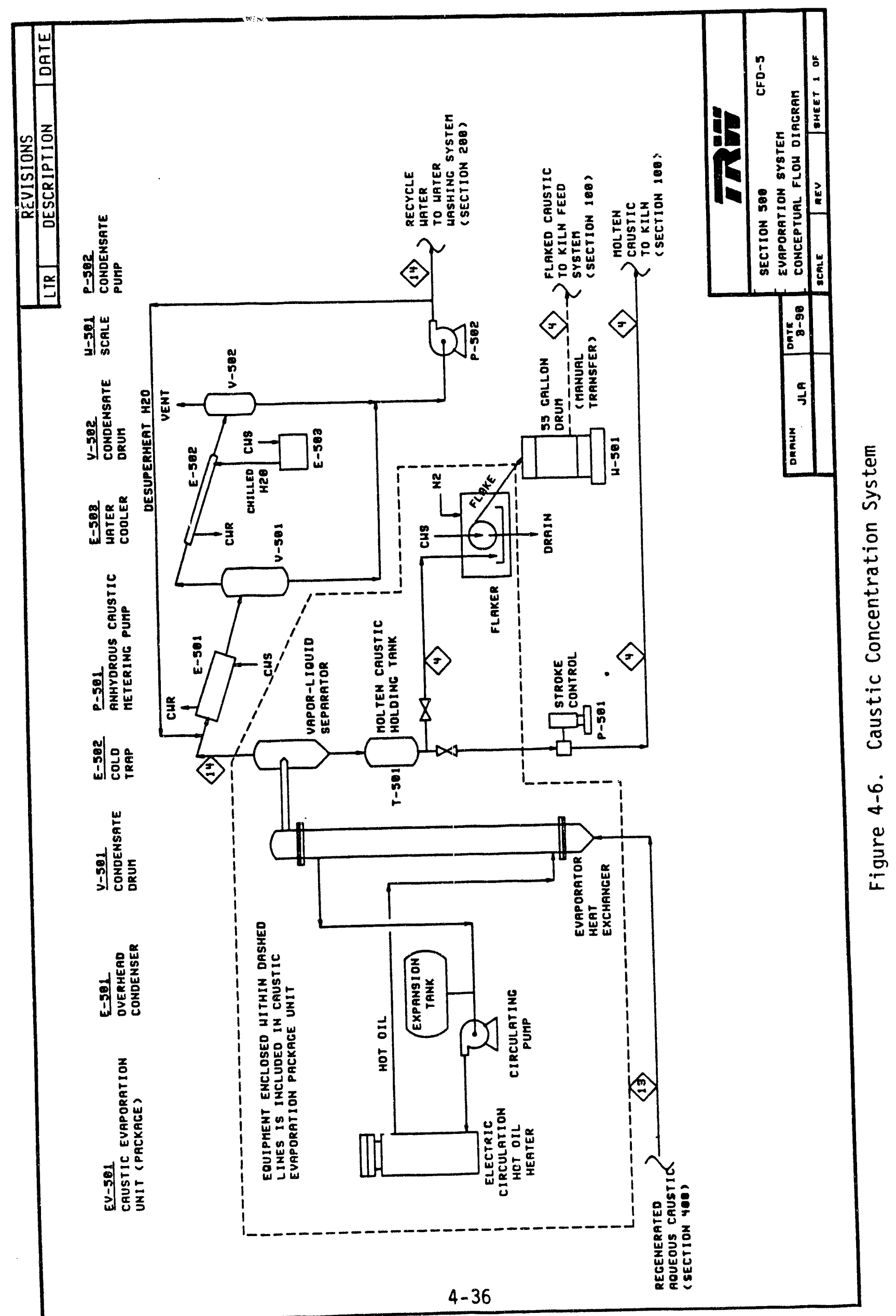




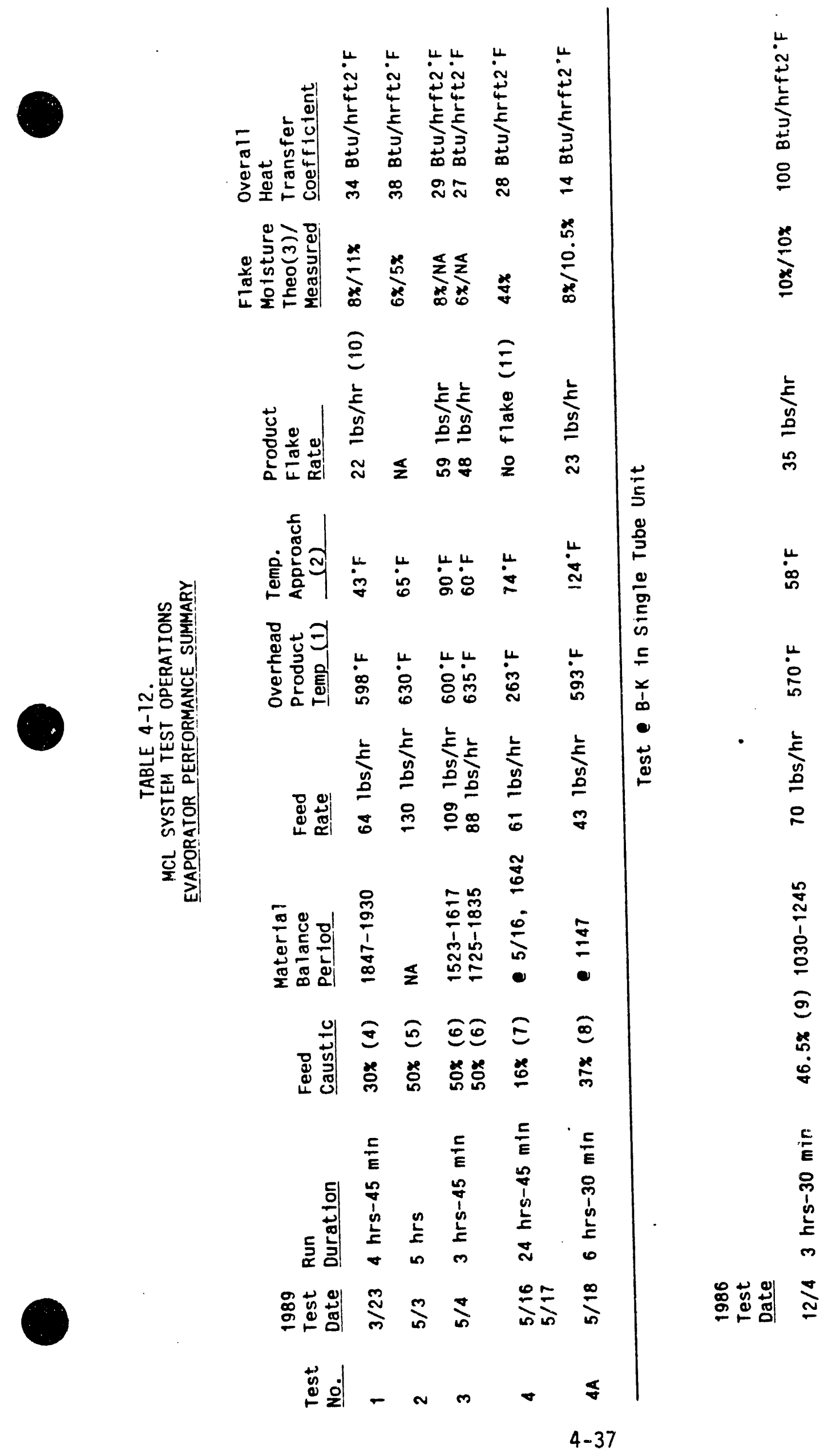




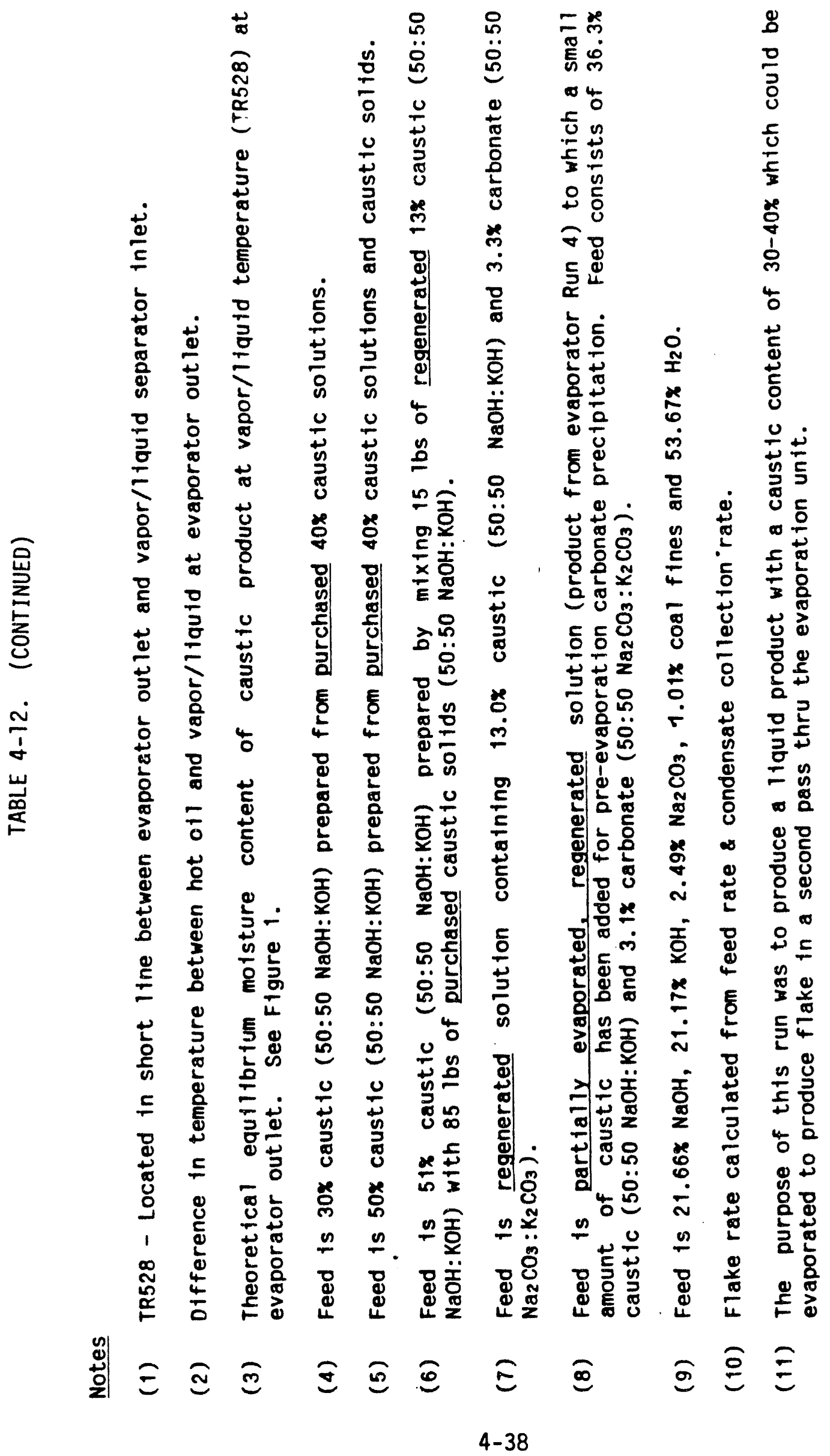


- None of the testing to date with $50 \%$ feed solutions has been able to duplicate the relatively high throughput ( $701 \mathrm{bs} / \mathrm{hr}$ per tube) and the overall heat transfer coefficient (about $100 \mathrm{Btu} / \mathrm{hr}-\mathrm{sf}^{\mathrm{O}} \mathrm{F}$ ) obtained when a similar solution was tested in a single tube evaporator at Blaw Knox's facility in Buffalo in 1986.

\subsubsection{Equipment Description}

The caustic evaporation unit was provided as a skid mounted package by Blaw Knox of Buffalo, New York. Aqueous caustic feed was stored and preheated in a 100 gallon storage tank provided by TRW. The hot caustic was pumped through 10 micron bag filters by a progressive cavity pump (provided by TRW) and into the Blaw Knox unit. This unit consists of a shell and tube exchanger in which hot oil circulates through the shell and the caustic flows through the tubes. The exchanger is vertical and the caustic is carried up the walls as a thin film by the evaporated steam. The hot oil and caustic flows are cocurrent. The exchanger has a total heat transfer surface of $11.65 \mathrm{ft}^{2}$ (provided by three, 15 feet long, one inch diameter Inconel tubes). The vapor/liquid exiting the top of the tubes is partitioned in a vapor-liquid separator vessel. The steam leaving the separator flows through a condensing system (provided by TRW). The molten caustic product leaving the separator drains by gravity through electrically traced piping into the pan of the flaking unit provided by Blaw Knox as part of their evaporator package. The flaker consists of a six inch diameter rotating drum (nine inches long) cooled internally with a water spray. The drum rotates through the pan collecting the molten caustic. Molten caustic picked up by the drum solidifies as it is cooled on the drum surface. The solid caustic is scraped off the drum as a thin flake by a knife and is collected in 55 galion drums.

Heat input to the evaporation unit is provided electrically by a Chromalox $60 \mathrm{~kW}$ hot oil unit supplied by Blaw Knox as part of their package. Syltherm 800 is heated in this unit and is circulated through the shell of the evaporating exchanger (and the jacket of the flaker pan) by a centrifugal pump. The oil exiting this equipment passes through an expansion tank, to allow for any necessary degassing, before returning to 
the heating unit. Syltherm 800 is a silicone type oil which is extremely stable at temperatures as high as $750^{\circ} \mathrm{F}$. All Syltherm containing lines are insulated and electrically traced.

The $\mathrm{Blaw}$ Knox unit was designed to process $180 \mathrm{lbs} / \mathrm{hr}$ of $30 \%$ aqueous caustic $(50: 50 \mathrm{NaOH}: \mathrm{KOH})$ or $130 \mathrm{Tbs} / \mathrm{hr}$ of $50 \%$ aqueous caustic $(50: 50$ $\mathrm{NaOH}: \mathrm{KOH}$ ) and dry these feeds to give a caustic product containing about $8 \%$ moisture. The overhead product temperature from the evaporator at this product moisture level is about $600^{\circ} \mathrm{F}$.

\subsubsection{Pretest Operations}

A number of deficiencies were noted in the Blaw Knox evaporator prior to start of actual test operations. The deficiencies which had an impact on the subsequent test operations were:

1) There was an unacceptably large heat leak to the atmosphere. The evaporator's hot oil system was started up and the hot oil was circulated through the evaporation unit at the expected normal operating temperature of about $700^{\circ} \mathrm{F}$. Electrical power flow to each of the three heating elements in the hot oil heating unit is indicated by a separate light for each element on the hot oil unit control panel. By tabulating the times the power indicating lights were on (over a reasonably long period of time), the power input io the circulating hot oil, without any caustic feed to the unit, was calculated. This power input represented the heat loss to the atmosphere by convection/radiation through the unit's insulation. At $700^{\circ} \mathrm{F}$ this heat loss was calculated at $35-40 \mathrm{~kW}$. This represented $58-67 \%$ of the $60 \mathrm{~kW}$ heat capacity of the hot 0 il system. Blaw Knox had only allowed for about seven $\mathrm{kW}$ of heat loss at the limiting design condition. This excessive heat loss severely limited the amount of feed that could be processed through the evaporator. A Blaw Knox consultant was on site for these heat loss tests and was in basic agreement with the findings. As a result of his recommendations, Blaw Knox agreed to provide, at their expense, an additional $60 \mathrm{~kW}$ of hot oil heating capacity. This new equipment was put in place late in the test operations program and was utilized for the first time during the test conducted on 5/3/89 (see Table 4-12).

2) The electrical tracing provided by Blaw Knox for the vapor-liquid separator and caustic product piping and fittings was inadequate to preheat this equipment to the elevated temperatures $\left(500-600^{\circ} \mathrm{F}\right)$ needed to avoid freezing of the product caustic at its design moisture level. The temperature measured at several points on the product caustic piping leveled out at $350-450^{\circ} \mathrm{F}$, more than 24 
hours after the electric tracing heating elements were turned on and in spite of the fact that the snap switches on these elements were set for $600^{\circ} \mathrm{F}$. The temperature reading at the caustic piping at the outlet of the vapor-liquid separator would not go above $165^{\circ} \mathrm{F}$. Several band heaters were added to the vapor-liquid separator and the flanges on the product caustic piping. This improved the situation considerably, especially in regards to reducing the time necessary to heat the caustic piping.

\subsubsection{Test Operations}

Test No. 1

Approximately 50 gallons of a $30 \%$ aqueous caustic (50:50 $\mathrm{NaOH}: \mathrm{KOH})$ solution was prepared (by dilution of fresh $40 \%$ caustic solutions) and stored in the evaporator feed tank. The tank heaters were used to preheat the stored solution to about $200^{\circ} \mathrm{F}$. The hot oil system was then turned on and the circulating $0 i 1$ heated to $650^{\circ} \mathrm{F}$.

The caustic was directed to the evaporator and the feed pumping rate was then adjusted until steady state conditions at the desired overhead product temperature (about $600^{\circ} \mathrm{F}$ ) with a hot oil temperature of about $650^{\circ} \mathrm{F}$ were achieved. The steady state feed. rate was about $0.1 \mathrm{GPM}$ (about $64 \mathrm{lbs} / \mathrm{r} . \mathrm{r}$ ). The raw data for Test No. 1 is presented in Table 4-13. The design flow for the unit is about 0.27 GPM with a $30 \%$ aqueous caustic feed. The low feed rate (about $40 \%$ of design) was attributed to the fact that $30-40 \mathrm{~kW}$ of the hot $0 i 1$ system's total available $60 \mathrm{~kW}$ of heat was being lost to the atmosphere through insulation convection/radiation 10sses. (At 0.27 GPM the required process heat load is 50-55 kW.) Flake was produced during the steady state period. For material balance purposes the time period 1847-1930 was selected. TRW was not able to get an accurate weight of flake collected during this period (due to windage losses - which were eliminated in later runs); however, based on the amount of feed pumped and condensaite collected, TRW was able to estimate the flake production rate at about $22 \mathrm{lbs} / \mathrm{hr}$. The moisture content 0 : the flake sampled during the steady state period was about $11 \%$. This compares to an equilibrium moisture content of about $8 \%$ which was calculated based on an evaporator overhead vapor/liquid temperature of $598^{\circ} \mathrm{F}$ (see Figure 4-7). An overall heat transfer coefficient of 34 Btu/hr-sf ${ }^{\circ} \mathrm{F}$ was calculated for the material balance time period. 

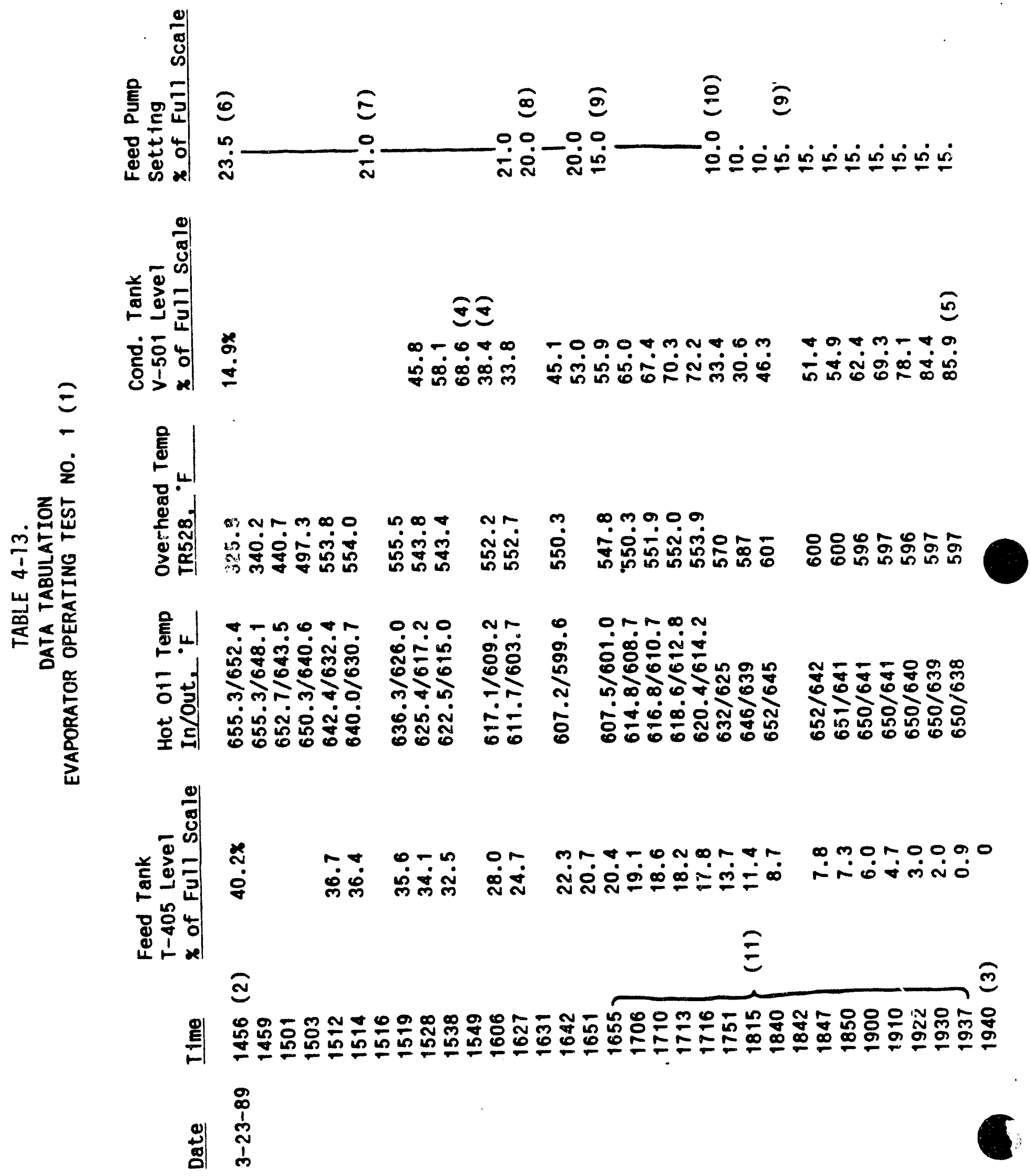


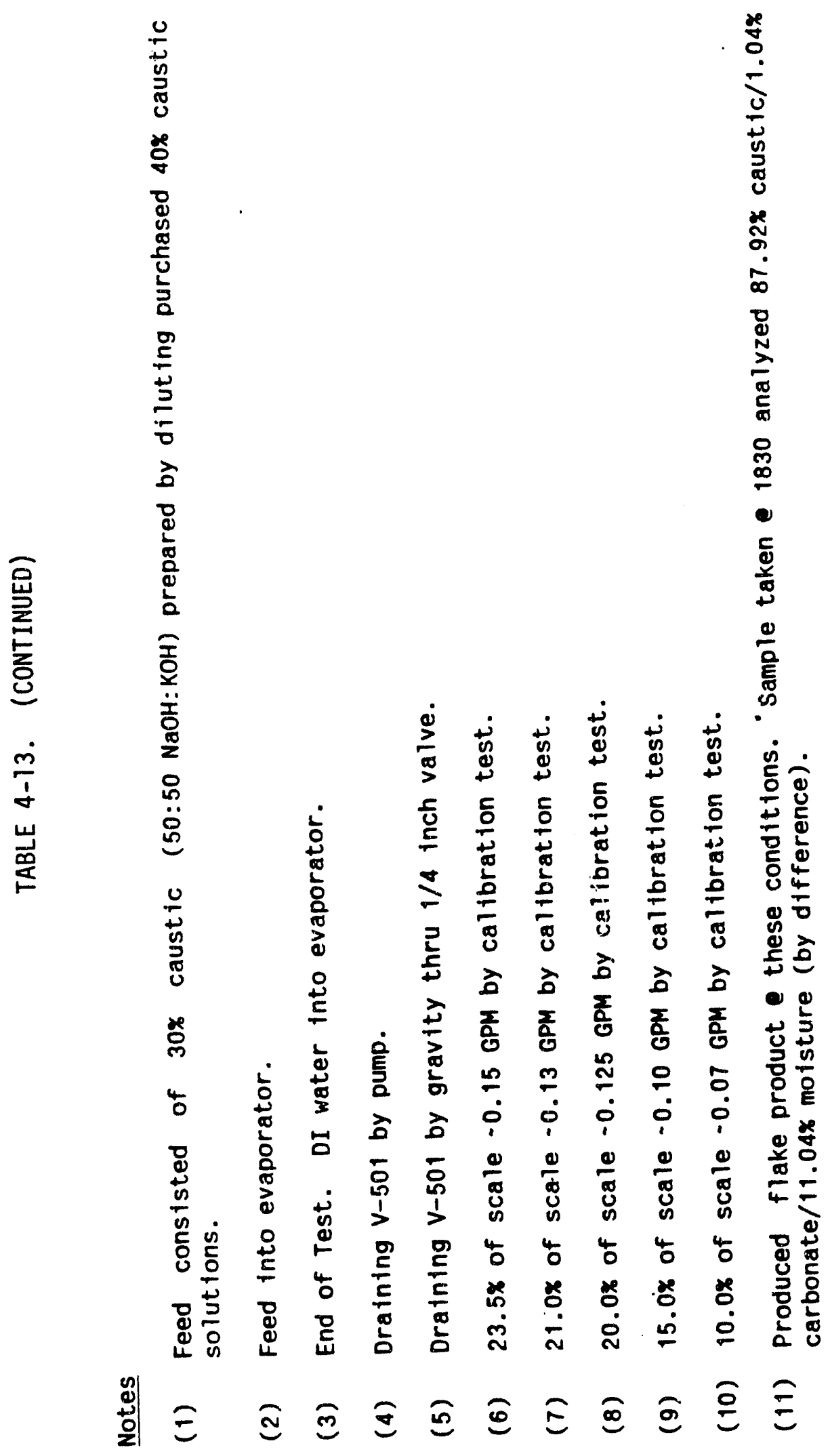




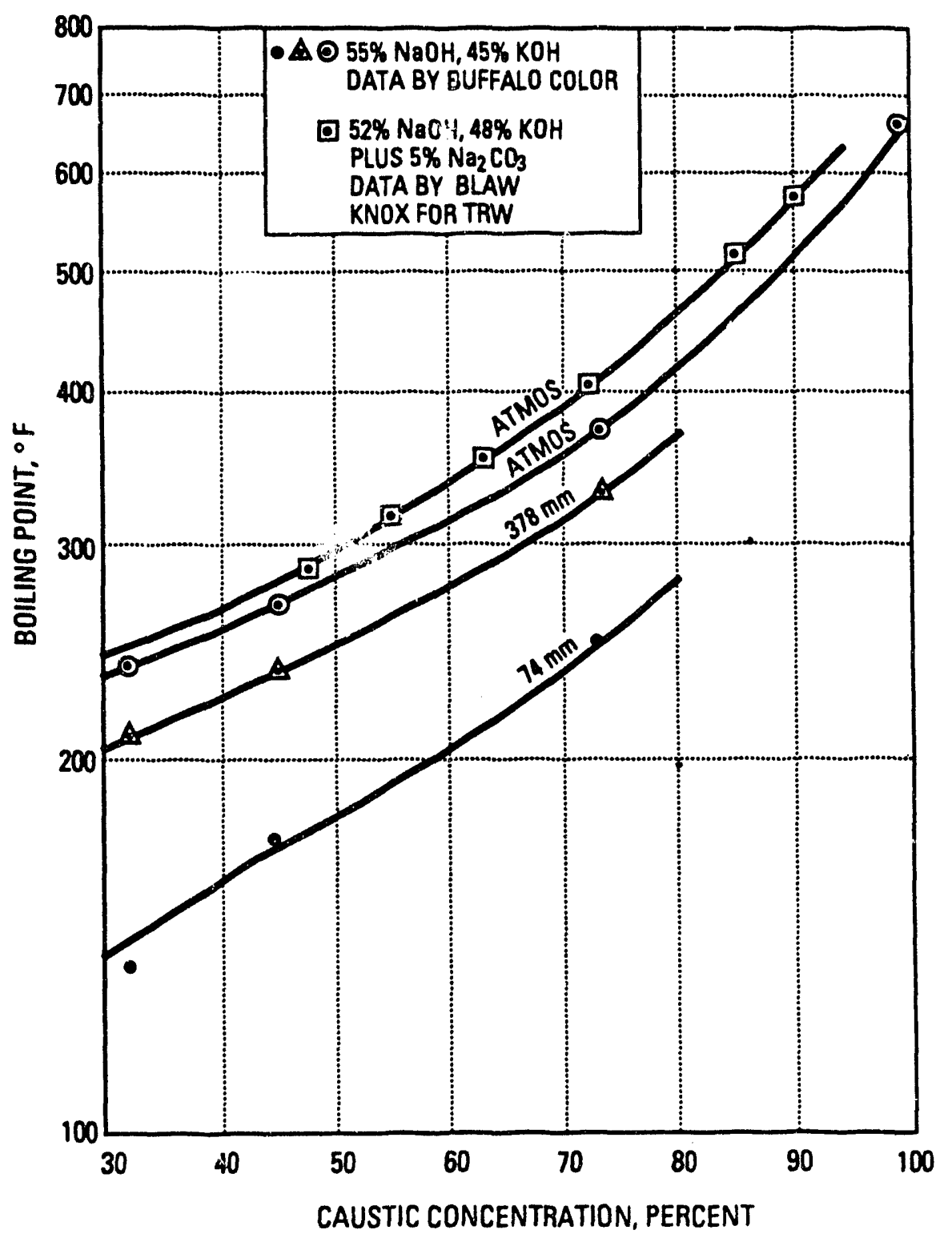

Figure 4-7. Vapor/Liquid Overhead Equilibrium 
A number of operating peculiarities were noted during this test run. Even though the feed was ing metered to the evaporator by the progressive cavity pump (set manually at a constant speed), the measured flow to the unit would cyclically surge high and then low. Surging was also noted in the product caustic flow into the flaker. In subsequent conversations with Blaw Knox, this was theorized to be caused by pressure surges in the evaporator resulting from the periodic collapse of the thin film of liquid moving up the tube walls. Due to the lack of available process heat, the unit was being operated at a feed rate that was a significant turn down from the design value. The resulting steam velocities in the tubes were not high enough to consistently drag the thin film of liquid up the tube walls. The liquid film occasionally collapsed causing pressure surges in the tubes and upsets in the feed flow due to slippage in the progressive cavity feed pump.

The system was also subject to disruptions whenever condensate was drained from the condensate drum, V-501 (Figure 4-6). Early in the run, condensate was pumped from the drum at a high rate. It was theorized that a vacuum was being created in the drum due to the rapid change of liquid volume in the drum. (Air could not be pulled back into the drum from the atmosphere due to the presence of a check valve in the vent line.) Later in the run, this situation was corrected by having condensate continuously drain by gravity at a low rate from the drum through a $1 / 4$ inch drain valve. The vent line from the drum was also cracked to allow air to flow back into the drum to keep up with the liquid volume losses.

Following Test No. 1, the overhead condensing system was disconnected from the evaporator. Uncondensed steam in future runs was vented directly to atmospheric pressure at the outlet of the separator into a 4 inch corrugated metal drain line. In reviewing the test operation, it was concluded that the pressure drop through the condensing system was too high and that this was probably contributing to the surging noted in the evaporator. It was decided that making this change would improve the operating characteristics of the evaporator. The negative side of this 
change is that the amount of water evaporated from the feed could no longer be monitored (as condensate), making material balance calculations more difficult.

Prior to commencing Test No. 2, the additional $60 \mathrm{~kW}$ of hot oil heating capacity was installed. in addition, an attempt was made to clean the evaporator tubes of any solid deposits by conducting a short duration soak of the tubes with dilute (5\%) acetic acid followed thorough flushing of the tubes with D.I. water.

Test No. 2

Approximately 50 gallons of a $50 \%$ aqueous caustis $5: 50 \mathrm{NaOH}: \mathrm{KOH}$ ) solution was prepared by strengthening fresh $40 \%$ aqueous caustic solution with the addition of fresh caustic solids. This solution was then stored and heated to about $200^{\circ} \mathrm{F}$ in the evaporator feed tank. The hot oil system was turned on and the circulating $0 i 1$ heated to about $700^{\circ} \mathrm{F}$.

The caustic was then pumped to the evaporator. The feed pumping rate was adjusted to achieve the desired overhead product temperature (about $600^{\circ} \mathrm{F}$ ) with a hot oil temperature of about $700^{\circ} \mathrm{F}$. The raw data for Test No. 2 is presented in Table 4-14. By the end of the run, the overhead product temperature had been successfully raised to about $630^{\circ} \mathrm{F}$ at a feed rate of $0.17 \mathrm{GPM}$ (about $130 \mathrm{lbs} / \mathrm{hr}$ ) and good flaked product was being produced.

A good material balance was not achieved for this run due to the fact that 1) flaked product was not produced until late in the run, and 2) condensate was not collected since the steam driven from the solution was vented directly to the atmosphere. However, a sample of flake taken at the end of the run (with the overhead temperature about $630^{\circ} \mathrm{F}$ ) had a moisture content of only five percent. The calculated equilibrium moisture content of six percent (see Figure 4-7) at a $630^{\circ} \mathrm{F}$ overhead temperature matched well with the measured analytical value. An overall heat transfer coefficient of $38 \mathrm{Btu} / \mathrm{hr}-\mathrm{sf}^{\circ} \mathrm{F}$ was calclilated at the 130 $\mathrm{lbs} / \mathrm{hr}$ feed rate to the evaporator. 

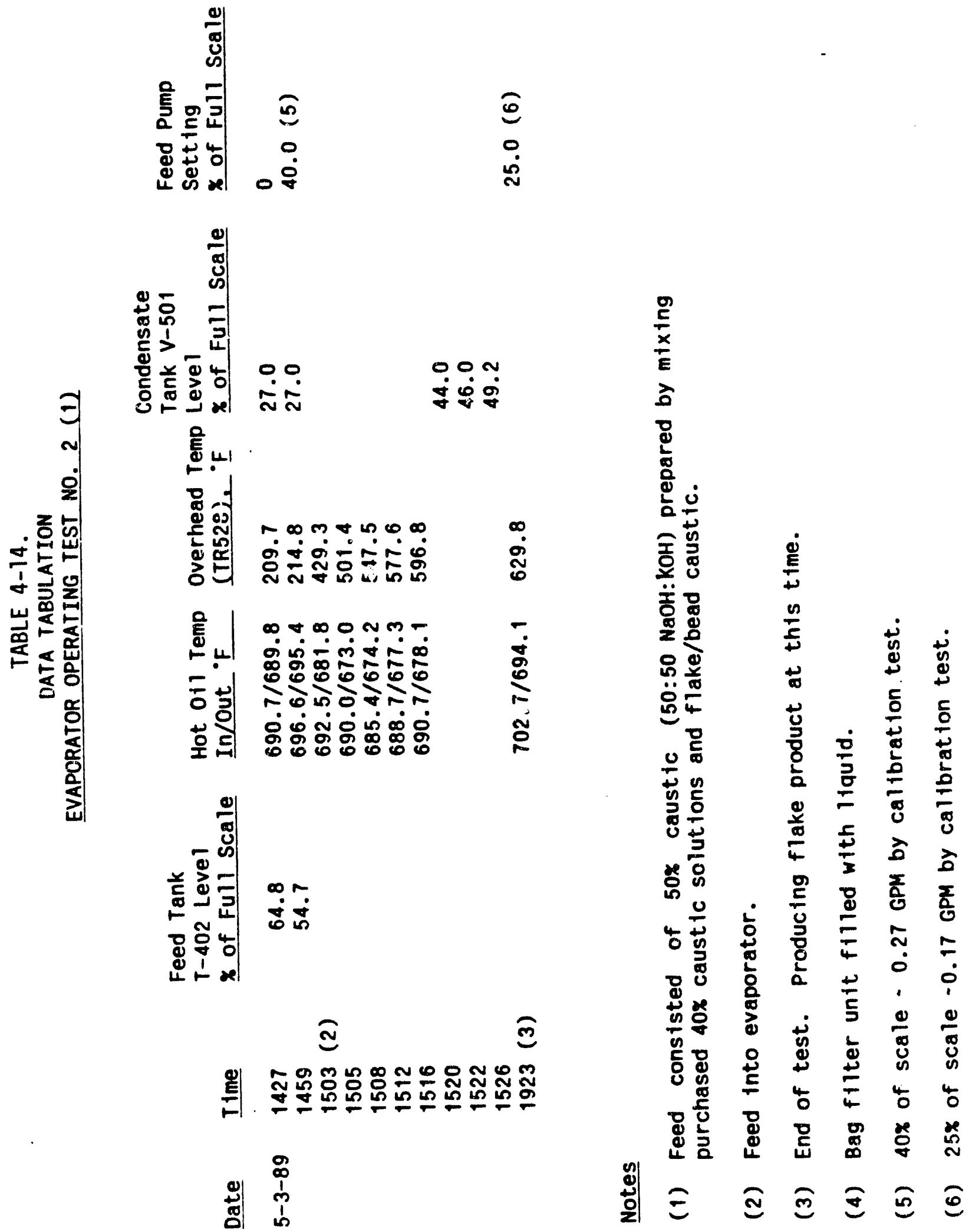
Test No. 3

Approximately 340 pounds of regenerated caustic solution (about $13 \%$ aqueous caustic, 50:50 $\mathrm{NaOH}: \mathrm{KOH}$ ) were accumulated in the regeneration system. Fresh solid $\mathrm{NaOH}$ (140 lbs) and fresh solid $\mathrm{KOH}$ (162 lbs) were slowly added to the solution to bring its strength up to $50 \%$ aqueous caustic $(50: 50 \mathrm{NaOH}: \mathrm{KOH})$. The mixture was mixed until the caustic solids had completely dissolved. Approximately $15 \%$ of the caustic in this mixture came from the regenerated solution and $85 \%$ of the caustic from the added fresh solids. The mixture was then pumped to a centrifuge (to separate precipitated carbonates and mineral matter as well as the lime added for regeneration). The centrate was stored and preheated in the evaporator feed tank. The hot oi? system was turned on and the circulating oil heated to about $700^{\circ} \mathrm{F}$.

The caustic was then directed into the evaporator. The feed pumping rate was adjusted to give the desired overhead product temperature (about $600^{\circ} \mathrm{F}$ ) with a hot $0 i 1$ temperature of about $700^{\circ} \mathrm{F}$. The raw data for Test No. 3 is presented in Table 4-15. For the time period 1523-1617 at a feed rate of about $0.145 \mathrm{GPM}$ ( $109 \mathrm{lbs} / \mathrm{hr}$ ) to the evaporator, an overhead product temperature of about $600^{\circ} \mathrm{F}$ (eight percent theoretical moisture in product) was achieved. Approximately 53.4 lbs of flake was collected in this period at an average product rate of $59.3 \mathrm{lbs} / \mathrm{hr}$. An overall heat transfer coefficient of $29 \mathrm{Btu} / \mathrm{hr}-\mathrm{sf}^{\circ} \mathrm{F}$ was calculated for this period. The feed rate to the evaporator was then reduced to about 0.12 GPM ( 88 lbs/hr). The overhead product temperature stabilized at about $635^{\circ} \mathrm{F}$ (six percent theoretical moisture in product) at this feed rate. Approximately 55.4 pounds of flake were collected at this feed rate at an average rate of $47.5 \mathrm{lbs} / \mathrm{hr}$. An overall heat transfer coefficient of 27 $\mathrm{Btu} / \mathrm{hr}-\mathrm{sf}^{\circ} \mathrm{F}$ was calculated for this steady state period.

Some feed surging was still noted during this test. However, venting the uncondensed steam directly to atmospheric pressure seems to have reduced the severity of this surging as compared to the first test run. 
TABLE 4-15.

DATA TABULATION

EVAPORATOR OPERATING TEST NO. 3 (1)

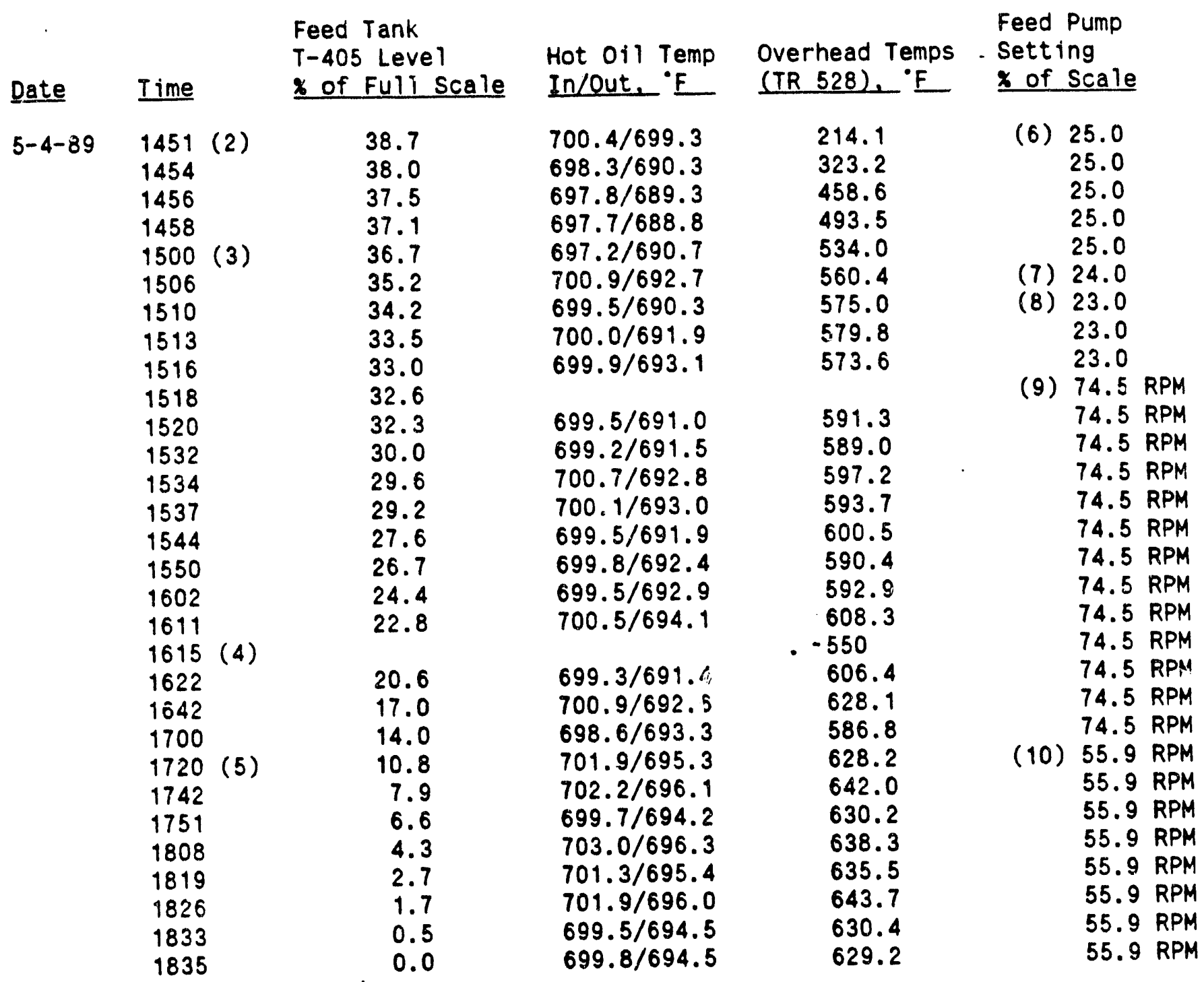

Flake Production:

Time Span:

1457 to 1523 collected 23.8 ibs or $54.9 \mathrm{lbs} / \mathrm{hr}$ flake

1523 to 1617 collected 53.4 lbs or $59.3 \mathrm{lbs} / \mathrm{hr}$ flake

1725 to 1835 collected 55.4 lbs or $47.5 \mathrm{lbs} / \mathrm{hr}$ flake 
TABLE 4-15. (CONTINUED)

NOTES

(1) Feed consisted of $51 x$ caustic (50:50 NaOH) prepared by mixing 15 lbs of regenerated $13 x$ caustic $(50: 50 \mathrm{NaOH}: \mathrm{KOH})$ with 85 los of purchased caustic solids (50:50 NaOH: $\mathrm{KOH})$.

(2) Feed into evaporator.

(3) Flake product begins.

(4) Unit upset.

(5) Readjusted knife on flaker drum. Knife had backed away from drum to allow cake to build to a thickness that precluded continued solidification of liquid.

(6) $25 \%$ of scale -0.17 GPM.

(7) $24 x$ of scale -0.16 GPM.

(8) $23 \%$ of scale $\cdot 0.15$ GPM.

(9) 74.5 RPM -0.145 GPM.

(10) 55.9 RPM -0.12 GPM. 
Test No. 4

The purpose of Test No. 4 (and the following Test 4A) was to operate the evaporator using a feed that was predominately regenerated solution. Equipment limitations (the vacuum filters were not on-line) in the water washing section of the MCL system limited the maximum caustic strength of regenerated solution to about $15 \%$ aqueous $(50: 50 \mathrm{NaOH}: \mathrm{KOH})$. The evaporator cannot concentrate this dilute of a solution to about $10 \%$ moisture product in a single pass. Therefore, the purpose of Test No. 4 was to concentrate the regenerated solution to a $30-40 \%$ aqueous caustic strength and then repump this solution through the evaporator (in test Run 4A) to produce a flake product.

The regenerated caustic solution was analyzed to contain $13 \%$ caustic (50:50 NaOH:KOH) and $3.3 \%$ carbonate $\left(50: 50 \quad \mathrm{Na}_{2} \mathrm{CO}_{3}: \mathrm{K}_{2} \mathrm{CO}_{3}\right)$. The solution was stored in the evaporator feed tank and preheated to about $200^{\circ} \mathrm{F}$.

The caustic was then directed into the evaporator. The feed rate and the hot oil temperature were adjusted to give an overhead temperature of about $240^{\circ} \mathrm{F}$. The raw data for Test No. 4 is presented in Table 4-16. Samples of the overhead liquid were periodically taken for specific gravity determination. The specific gravities obtained were 1.35-1.40 which was consistent with a $35-40 \%$ solution of mixed caustics.

Test No. 4 lasted slightly in excess of 24 hours (with a few interruptions to clear plugs which developed in the product caustic line). A total of 416 pounds of product solution were collected. This solution was analyzed to contain $32.3 \%$ caustic (50:50 $\mathrm{NaOH}: \mathrm{KOH})$ and $11.7 \%$ carbonate $\left(50: 50 \quad \mathrm{Na}_{2} \mathrm{CO}_{3}: \mathrm{K}_{2} \mathrm{CO}_{3}\right)$. An overall heat transfer coefficient of $28 \mathrm{Btu} / \mathrm{hr}-\mathrm{sf}^{0} \mathrm{~F}$ was calculated for the evaporator at time 1642 on $5 / 16 / 89$.

A small amount of fresh caustic solids (17 $1 \mathrm{bs}$ of $\mathrm{NaOH}$ and $201 \mathrm{bs}$ of $\mathrm{KOH})$ was added to the 416 lbs of liquid collected in Test 4 . This was done to simulate the original $\mathrm{MCL}$ system material balance in which $80 \%$ of 
TABLE 4-16.

DATA TABULATION

EVAPORATOR OPERATING TEST NO. 4 (1)

\begin{tabular}{|c|c|c|c|c|c|}
\hline Date & Time & $\begin{array}{l}\text { Feed Tank } \\
T-405 \text { Level } \\
\underline{x} \text { of Full Scale }\end{array}$ & $\begin{array}{l}\text { Hot oil Temp } \\
\text { In/Out, } \mathrm{F}\end{array}$ & $\begin{array}{l}\text { Overhead Temps } \\
\text { (TR 528) 'F }\end{array}$ & $\begin{array}{l}\text { Feed Pump } \\
\text { Setting } \\
\text { RPM } \\
\end{array}$ \\
\hline $5-16-89$ & $\begin{array}{l}1602(2) \\
1606 \\
1609 \\
1613 \\
1615(3) \\
1617 \\
1622(4) \\
1623 \\
1626 \\
1628 \\
1631 \\
1633 \\
1638 \\
1642 \\
1647 \\
1657 \\
1705 \\
1713\end{array}$ & $\begin{array}{l}66.6 \\
66.2 \\
65.9 \\
65.3 \\
64.9 \\
64.3 \\
63.0 \\
62.1 \\
61.2\end{array}$ & $\begin{array}{l}351.9 / 339.1 \\
355.6 / 334.3 \\
343.3 / 320.2 \\
346.0 / 316.6 \\
340.8 / 316.7 \\
348.6 / 318.5 \\
350.4 / \\
370.0 / 328.7 \\
368.5 / 332 . \\
367 . / 337.7 \\
370.9 / 332.8 \\
362.2 / 336.2 \\
359.4 / 336.7 \\
365.1 / 338 . \\
372.2 / 334.4 \\
367.1 / 338.3 \\
359.7 / 339.0\end{array}$ & $\begin{array}{l}162.2 \\
162.5 \\
188.9 \\
202.9 \\
207.5 \\
209.7 \\
214.7 \\
214.9 \\
216.8 \\
221.7 \\
227.1 \\
229.8 \\
233.3 \\
235.3 \\
237.0 \\
236.1 \\
235.3 \\
236.2\end{array}$ & $\begin{array}{l}75.4(5) \\
75.2 \\
75.2 \\
74.9 \\
58.8 \quad(6) \\
58.6 \\
58.7 \\
58.8 \\
58.5 \\
58.4 \\
58.3 \\
58.3 \\
58.3 \\
58.2 \\
58.2 \\
58.7 \\
58.5 \\
58.8\end{array}$ \\
\hline
\end{tabular}

Test continued until 5/17 1645

Overhead liquid Product Gravities (Net wt in $100 \mathrm{~mL}$ graduate):

Date Time

Gravity

$5 / 16$ e 1625 wt $=259.1$ gms $-136 \mathrm{gm}$ Tare $=123.1 \mathrm{gms} / 100 \mathrm{~mL}, \mathbf{s . g} .=1.23$

$1630 w t=268.5 \mathrm{gms}-136 \mathrm{gm}$ Tare $=132.5 \mathrm{gms} / 100 \mathrm{~mL}, \mathrm{~s} . \mathrm{g} .=1.325$

e $1638 w t=272$. gms $-136 \mathrm{gm} \mathrm{Tare}=136 \mathrm{gms} / 100 \mathrm{~mL}, \mathrm{s.g} .=1.36$

$1658 w t=272$. gms $-136 \mathrm{gm}$ Tare $=136 \mathrm{gms} / 100 \mathrm{~mL}, \mathbf{s . g} .=1.36$

e $1715 w t=274$. gms $-136 \mathrm{gm}$ Tare $=138 \mathrm{gms} / 100 \mathrm{~mL}, \mathrm{s.g} .=1.38$

- $1810 w t=278$. gms $-136 \mathrm{gm}$ Tare $=142 \mathrm{gms} / 100 \mathrm{~mL}, \mathrm{s.g} .=1.42$

$1910 w t=277$. gms $-136 \mathrm{gm} \cdot \mathrm{Tare}=141 \mathrm{gms} / 100 \mathrm{~mL}, \mathrm{s.g}=1.41$

- $2045 w t=276$. gms $-136 \mathrm{gm}$ Tare $=140 \mathrm{gms} / 100 \mathrm{~mL}$, s.g. $=1.40$

e $2145 w t=277$. gms $-136 \mathrm{gm}$ Tare $=141 \mathrm{gms} / 100 \mathrm{~mL}, \mathrm{s.g} .=1.41$

e $2245 w t=278$. gms $-136 \mathrm{gm}$ Tare $=142 \mathrm{gms} / 100 \mathrm{~mL}, \mathbf{s . g} .=1.42$

$5 / 170730 w t=274$. $\mathrm{gms}-136 \mathrm{gm} \mathrm{Tare}=138 \mathrm{gms} / 100 \mathrm{~mL}, \mathrm{s.g} .=1.38$ 


\section{Notes}

(1) Feed is regenerated solution containing $13.0 \%$ caustic $(50: 50$ $\mathrm{NaOH}: \mathrm{KOH})$ and $3.3 \%$ carbonate $\left(50: 50 \mathrm{Na}_{2} \mathrm{CO}_{3}: \mathrm{K}_{2} \mathrm{CO}_{3}\right)$.

(2) Feed into evaporator.

(3) Decreased feed pump speed.

(4) Increased oil temperature $20^{\circ} \mathrm{F}$.

(5) 75.4 RPM -0.145 GPM.

(6) 58.8 RPM -0.105 GPM. 
the caustic in the feed to the evaporator came from regenerated solution and $20 \%$ from fresh caustic added as makeup for plant caustic losses. The addition of fresh caustic also increased the solution caustic strength and caused a large percentage (about $70 \%$ ) of the carbonates in the solution to precipitate. This is important since a very high carbonate content in the solution could calse fouling in the evaporator tubes. After the fresh caustic addition, the solution was centrifuged to remove the precipitates. The centrate was stored in the evaporator feed tank for use in Test $4 \mathrm{~A}$. The solution in the tank was analyzed to contain $36.3 \%$ caustic $150: 50$ $\mathrm{NaOH}: \mathrm{KOH})$ and $3.1 \%$ carbonates $\left(50: 50 \mathrm{Na}_{2} \mathrm{CO}_{3}: \mathrm{K}_{2} \mathrm{CO}_{3}\right)$.

\section{Test $4 \mathrm{~A}$}

Solution from Test 4 (spiked with fresh caustic) was preheated to about $200^{\circ} \mathrm{F}$ in the evaporator feed tank. The hot 0 il system was turned on and the circulating oil heated to about $700^{\circ} \mathrm{F}$.

The caustic was then directed to the evaporator and the overhead temperature adjusted to give the desired oirerhead temperature of about $600^{\circ} \mathrm{F}$. The raw data for Test No. 4 is presented in Table 4-17.

TRW was able to approach an overhead temperature of $600^{\circ} \mathrm{F}$ only by decreasing the feed rate to a low value of about $0.07 \mathrm{GPM}(43 \mathrm{lbs} / \mathrm{hr}$ ) and by increasing the hot oil temperature to $720^{\circ} \mathrm{F}$. The evaporator performance gave indication of tube fouling (or perhaps plugging of one or two of the three tubes). In fact, a very low overall heat transfer coefficient of $14 \mathrm{Btu} / \mathrm{hr}-\mathrm{sf}^{0} \mathrm{~F}$ was calculated for this test. This is a significant decrease from the $30-40 \mathrm{Btu} / \mathrm{hr}-\mathrm{sf}^{\circ} \mathrm{F}$ values for the coefficients calculated for the ear? ier tests.

A total of 141 pounds of flake were collected during Test 4A. The first 14.2 pounds collected were rejected as being too wet for recycle to the kiln. The remaining 126.8 pounds were combined, well mixed in a drum roller and analyzed. This flake contained $84.3 \%$ caustic $(50: 50 \mathrm{NaOH}: \mathrm{KOH})$, $5.25 \%$ carbonate $\left(50: 50 \mathrm{Na}_{2} \mathrm{CO}_{3}: \mathrm{K}_{2} \mathrm{CO}_{3}\right)$ and $10.45 \%$ moisture. 
TABLE 4-17.

DATA TABULATION

EVAPORATOR OPERATING TEST NO. 4A (1)

\begin{tabular}{|c|c|c|c|c|c|}
\hline Date & Time & $\begin{array}{l}\text { Feed Tank } \\
T-405 \text { Leve } 1 \\
x \text { of Full Scale } \\
\end{array}$ & $\begin{array}{l}\text { Hot oil Temp } \\
\text { In/Out, E }\end{array}$ & $\begin{array}{l}\text { Overhead Temps } \\
\text { (TR 528). } \mathrm{F}\end{array}$ & $\begin{array}{l}\text { Feed Pump } \\
\text { Setting } \\
\text { RPM } \\
\end{array}$ \\
\hline $5 / 18 / 89$ & $\begin{array}{l}1025 \\
1028(2) \\
1030 \\
1033 \\
1036 \\
1037 \\
1039 \\
1040 \\
1043 \\
1046 \\
1047 \quad(3) \\
1054 \\
1058 \\
1104 \\
1112 \\
1119 \\
1135 \\
1147 \\
1329 \\
1425 \\
1426\end{array}$ & $\begin{array}{r}24.8 \\
\\
23.6 \\
22.9 \\
22.2 \\
21.6 \\
20.3 \\
19.3 \\
10.0 \\
5.3 \\
2.7\end{array}$ & $\begin{array}{l}700.2 / 698.5 \\
701.5 / 700.4 \\
698.7 / 692.9 \\
701.8 / 695.0 \\
699.5 / 693.9 \\
\\
701.6 / 697 . \\
712.8 / 707.1 \\
718 . / 713 . \\
722.6 / 717.6 \\
722.1 / 717.7 \\
722.5 / 718.6 \\
721.1 / 717.1 \\
721.2 / 716.8 \\
722.4 / 717.7 \\
720.6 / 716.8\end{array}$ & $\begin{array}{l}487.7 \\
511.8 \\
526.2 \\
541.8 \\
563.8 \\
592.0 \\
592.7 \\
581.6 \\
589.5 \\
566.2\end{array}$ & $\begin{array}{l}65.4 \text { RPM } \\
72.6(4) \\
71.7 \\
71.7 \\
62.4 \\
61.8 \\
55.7(5) \\
44.2 \\
43.9 \\
43.0 \\
39.2 \\
39.2 \\
38.6 \\
36.6 \\
35.8 \\
35.0(6) \\
35.3 \\
35.4 \\
34.9 \\
34.7\end{array}$ \\
\hline
\end{tabular}

Product Flake Collected:

Date Time

Lbs Flake

Flaking Rate

$5 / 18 / 89 \quad 1028-1106$

$1106-1136$

$1136-1215$

$1215-1300$

$1300-1400$

$1400-1445$

$1445-1530$

$1530-1645$

126.8 lbs $\left\{\begin{array}{l}14.2 \text { lbs (looks wet - kept separate) } \\ 10.6 \text { lbs looks dry } \\ 14.6 \text { lbs looks dry } \\ 17.4 \text { lbs looks dry } \\ 21.4 \text { lbs looks dry } \\ 21.4 \text { lbs looks dry } \\ 17.2 \text { lbs looks dry } \\ 24.2 \text { lbs looks dry } \\ 141.0 \text { lbs }\end{array}\right.$

$22.4 \mathrm{lbs} / \mathrm{hr}$

$21.2 \mathrm{lbs} / \mathrm{hr}$

$22.5 \mathrm{lbs} / \mathrm{hr}$

$23.2 \mathrm{lbs} / \mathrm{hr}$

$21.4 \mathrm{lbs} / \mathrm{hr}$

$28.5 \mathrm{lbs} / \mathrm{hr}$

$22.9 \mathrm{lbs} / \mathrm{hr}$

$19.4 \mathrm{lbs} / \mathrm{hr}$

Notes

(1) Feed consisted of $36.3 x$ caustic $(50: 50 \mathrm{NaOH}: \mathrm{KOH})$ and $3.1 x$ carbonates (50:50 $\left.\mathrm{Na}_{2} \mathrm{CO}_{3}: \mathrm{K}_{2} \mathrm{CO}_{3}\right)$.

(2) Feed into evaporator.

(3) Increased oil temperature $-20^{\circ} \mathrm{F}$.

(4) Feed rate -0.145 GPM.

(5) Feed rate -0.12 GPM.

(6) Feed rate -0.07 GPM. 


\subsubsection{Conclusions and Recommendations}

TRW was able to produce 5-10\% moisture flake from $30-50 \%$ mixed aqueous caustic $(50: 50 \mathrm{NaOH}: \mathrm{KOH})$ feed solutions to the evaporation unit. However, this was accomplished at feed rates lower than the design value for the unit. The low overall heat transfer coefficients calculated for the tests, particularly for the last test (Test 4A), pointed to fouling/ plugging of the evaporator tubes.

The caustic evaporator in its current fouled/plugged condition would definitely be a problem at a $50 \mathrm{lb} / \mathrm{hr}$ coal-caustic kiln feed rate. Problems that occur seem to be more related to plugging due to side products, such as carbonate. Visual inspection of the three evaporator tubes after the end of testing showed no plugging in any of the tubes. It was not possible to see thin film fouling if it was present.

It may well be that, if the evaporator could be charged with the 40-50 percent solution it was designed to handle, there will be no plugging and the unit will be relatively trouble free. A thorough inspection and cleaning of the evaporator should be undertaken prior to recommencement of plant operations. A modified overhead condensing system should al so be installed at this time. TRW recommends an evaporator test program (after the evaporator has been cleaned but prior to the start of plant operations) to verify that the unit can be operated without fouling and also to check out the operation of the unit with the new overhead condensing system in place.

The flaker has been used several times and it is able to keep up with the flow of concentrated caustic to it. If large amounts of caustic are to be made, isolating the atmosphere from the caustic flake by a nitrogen purge in a plastic shroud should be considered.

The molten caustic feed line was not used. There is considerable concern that the line might freeze if not heated adequately. The line cannot be tried until the evaporator can continuously produce molten caustic and that cannot be done until the filters are on-line. For 
testing the molten caustic feed line, the lowest melting eutectic mixture of sodium and potassium hydroxides should be employed. The advantage of direct injection of caustic into the kiln is that it would allow the maximum coal rate to the kiln. A second purpose is that a commercial unit would likely inject molten caustic rather than flaked caustic. An alternative would be to blend sodium and potassium hydroxides (50 percent aqueous) and evaporate this to 90 plus percent caustic which would then be pumped into the kiln to test the molten feed system. Regenerated caustic should not be used the first time molten caustic is injected into the kiln.

TRW recommends the following steps be taken to improve the evaporator performance during future operations:

- Inspect/clean the evaporator tubes (mechanically, if necessary).

- Redesign/replace the evaporator's overhead condensing system such that it does not cause a significant back pressure on the evaporator.

- Remove and replace evaporator condensate recycle system.

- larger condenser and evaporator outlet piping

- different pump, tank and level controller

- flowmeter

- Remove and replace electric trace heaters with larger heaters with temperature controllers (in order to process $\mathrm{NaOH}$ only feed). Also, improve the insulation in the molten caustic piping system to eliminate any cold spots which could result in caustic freezing.

- Remove and replace insulation on all evaporator outlet piping.

- Change out all type $J$ thermocouples with the $K$ thermocouples.

- Install a plastic shroud around flaker.

- Replumb outlet from molten caustic pump to increase head pressure on pump, and rework molten caustic pump circuit (buy check valves, insulate pump).

- Conduct a series of tests (after the improved overhead condensing system is installed) with a Blaw Knox consultant on hand to determine what is limiting the evaporator throughput and also what is causing the surging in the unit's feed and product flows. 


\subsection{WASTE TREATMENT}

The waste treatment system was designed to treat the acid containing centrate stream from the acid washing system to make this stream suitable for recycle or for disposal as waste water. This stream contains potassium sulfate, sodium sulfate, and ferric sulfate salts formed by the neutralization reactions between iron hydroxide, the residual caustic, and sulfuric acid. The sulfate salts and any residual acid in this centrate stream are contacted with ferric sulfate, $\left(\mathrm{Fe}_{2}\left[\mathrm{SO}_{3}\right)\right.$ and lime $(\mathrm{CaO})$ in the waste water treatment system to precipitate gypsum $\left(\mathrm{CaSO}_{4}\right)$, ferric hydroxide, $\mathrm{Fe}(\mathrm{OH})_{3}$, and complex double salts of sodium and iron.

The water treatment system contains two fiberglass 300 gallon tanks each followed by a bag filter system to remove the precipitated solids. A flow diagram of the water treatment section is depicted in Figure 4-8. The tanks were sized to provide about 24 hours residence time each since the reactions involve potentially slow crystallizations. The tanks are provided with immersion heaters, mixers, and screw feeders.

The system was designed to add ferric sulfate, $\mathrm{Fe}_{2}\left(\mathrm{SO}_{4}\right)_{3}$, to the firsi tank, T-601, in order to adjust the sodium to iron ratio to $1: 3$ to facilitate formation of complex double salts. If the sodium to iron ratio of the centrate stream from the acid washing section is found to be already near 1:3 due to exceptionally efficient washing in the water and acid washing systems, the centrate stream will be sent directly to the liming tank, T-602. In this configuration, the iron complex minerals are precipitated in tank $\mathrm{T}-602$ in the same step as the gypsum $\left(\mathrm{CaSO}_{4}\right)$ and other calcium salts and removed along with these solids from the waste water in bag filter F-602.

Lime is added to tank T-602 to neutralize the excess acid and precipitate gypsum, $\mathrm{CaSO}_{4}$, and ferric hydroxide, $\mathrm{Fe}(\mathrm{OH})_{3} \cdot \mathrm{A} \mathrm{pH}$ monitor/ controller is used to. control the speed of the lime screw feeder. The liming of alkali metal sulfates sometimes results in the 


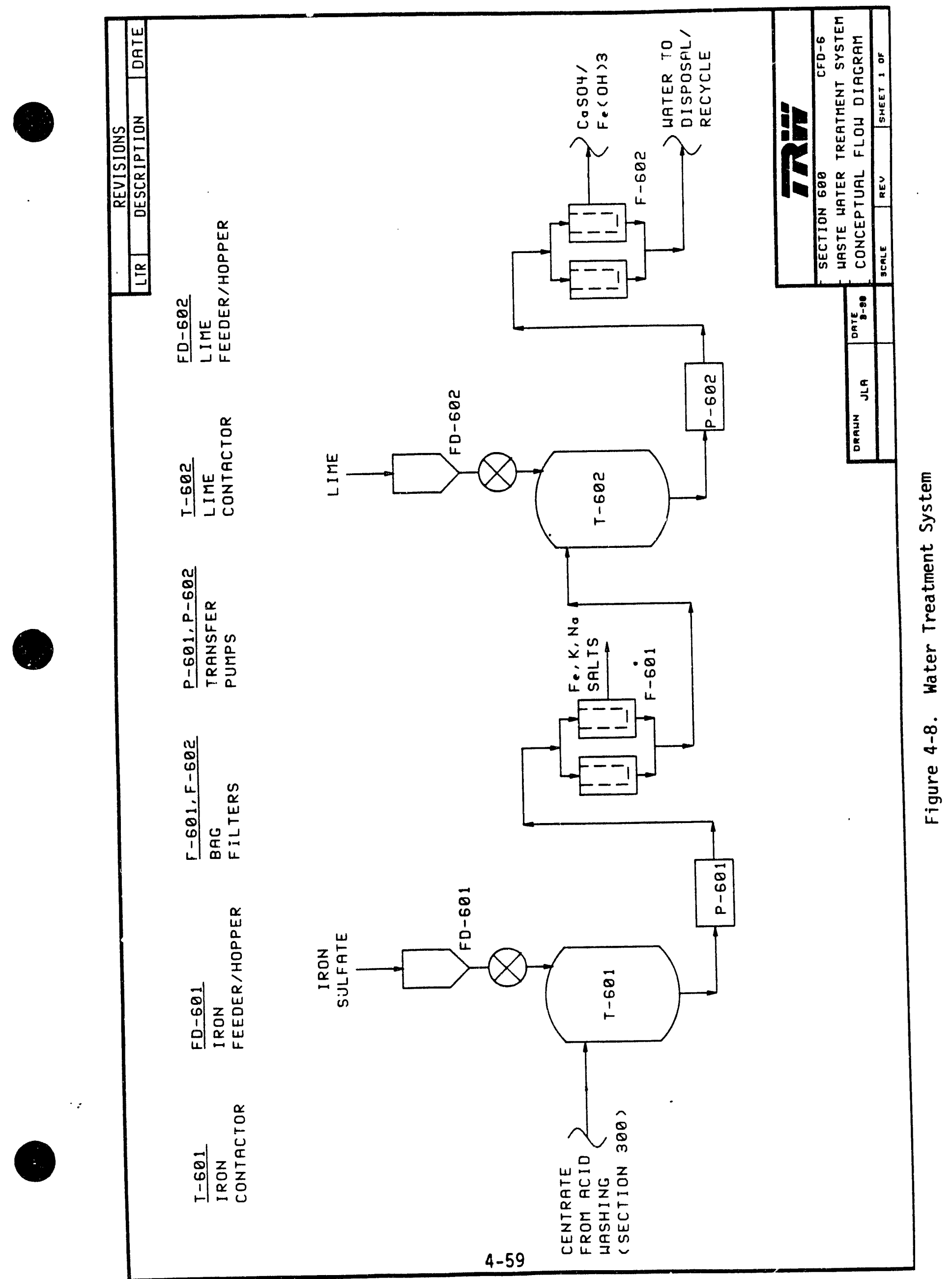


formation of highly insoluble syngenetic minerals which are intersalts of calcium and alkali metal sulfates. These salts are thus likely to be environmentally sound disposal products. The resulting sludge is removed in a bag filter, F-602, before the waste water is sent to disposal. If the dissolved solids (sodium, potassium, and calcium sulfates) are low enough, this stream will be recycled to the water washing section as wash water.

The water washing system produced much drier coal cakes than was expected $(0.25$ to 0.5 weights of water per weight of coal versus the design one to two weights of water per weight of coal), resulting in less caustic remaining on the coal sent to acid washing and a high iron to sodium ratio in the acid waste stream. As a result, there was no need to add iron sulfate to adjust the iron to sodium ratio in the waste treatment system. Thus tank T-601 was bypassed and the acid centrate was sent directly to T-602 for lime addition.

Since the sodium/potassium levels in the treated waste water were only $2000 \mathrm{ppm}$ versus the expect 5000 to $7000 \mathrm{ppm}$, the treated waste water was recycled as wash water to the water washing system during parts of Runs 6 and 7. However, whenever waste water was recycled, there was a noticeable increase in ash in the product coal. In order to avoid the problem of ash buildup in the product coal during future plant operation, TRW is investigating the addition of a demineralization unit on the recycle stream.

The method employed to date for separation, by decantation and bag filtration, of the gypsum and iron hydroxide precipitated from the limed waste effluent water requires constant operator attention. This would be a bottleneck in a long duration run. TRW recommends acquiring a centrifuge to replace the bag filters currently in use. A centrifuge would continuously remove the precipitate and would require little operator attention. 
TRW recommends the following changes to be made to the waste treatment system for any future testing:

- Review the need for tank T-601 (iron addition). This tank may not be needed.

- Replace fiberglass tank T-602 and bag filter F-602 with a clarifier and centrifuge.

- Install an improved breaker bar to prevent bridging in the lime feed hopper.

- Install a demineralization unit (i.e., ion exchange) on the recycled waste water.

\subsection{DATA ACQUISITION AND CONTROL SYSTEM}

The operation of the integrated $\mathrm{MCL}$ test circuit resulted in the generation of an extensive data base. Included in this data base are pressure (psig), vacuum (inches $\mathrm{H}_{2} \mathrm{O}$ or inches $\mathrm{Hg}$ ), differential pressure (inches $\mathrm{H}_{2} \mathrm{O}$ ), liquid flow (gpm), air or nitrogen flow (SCFM), temperature $\left({ }^{\circ} \mathrm{F}\right)$, and tank level (percent). This information, being voluminous, is most easily handled by a data acquisition and control system which collects and stores the process measurements in real time and utilize a portion of it for feedback control.

The microprocessor based data acquisition and control system installed at the test site is comprised of modular components as much as possible including process interface equipment, process control units and operator's display stations. The two operator's display stations incorporate CRT's displaying loop and alarm status and real time plant graphics. Keyboards allow configuration and control function adjustments to be entered into the system. The system was designed so that the failure of any single component will not disable the entire system.

The data acquisition and control system was designed to perform the following functions: 
- To measure and collect the data necessary to assess the technical performance of the process over the specified ranges of operating conditions.

- To evaluate the performance and reliability of selected instruments and controls in MCL service.

- To control and monitor the operation of the continuous MCL test plant over a wide range of operating conditions.

There are approximately 80 instruments and conirols in the integrated $\mathrm{MCL}$ plant.

Although the data acquisition and control system worked well, TRW still recommends the following changes to be made to insure continued operation of the system for any future testing:

- Find a better way to download Yokogawa data to Lotus spread sheets.

- Install speed indicators for all pumps currently without them.

- Expand the Yokogawa system to handle additional new inputs/outputs (such as temperature inputs); the current system is now full. 
APPENDIX A

MCL RUN DATA SUMMARY

A-1 
MCL RUN DATA SUMMARY ( $9 / 29 / 1989)$

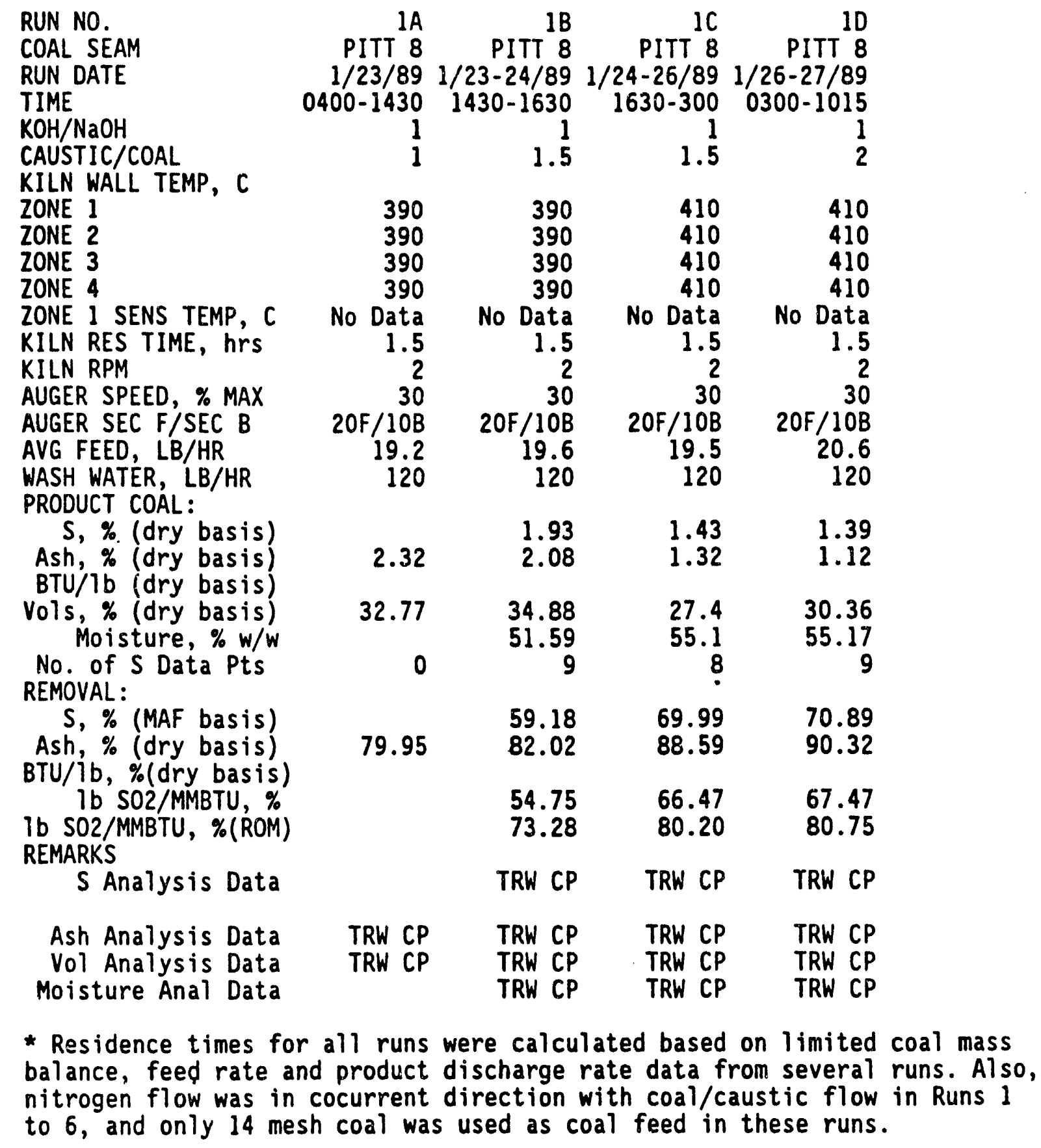


MCL RUN DATA SUMMARY

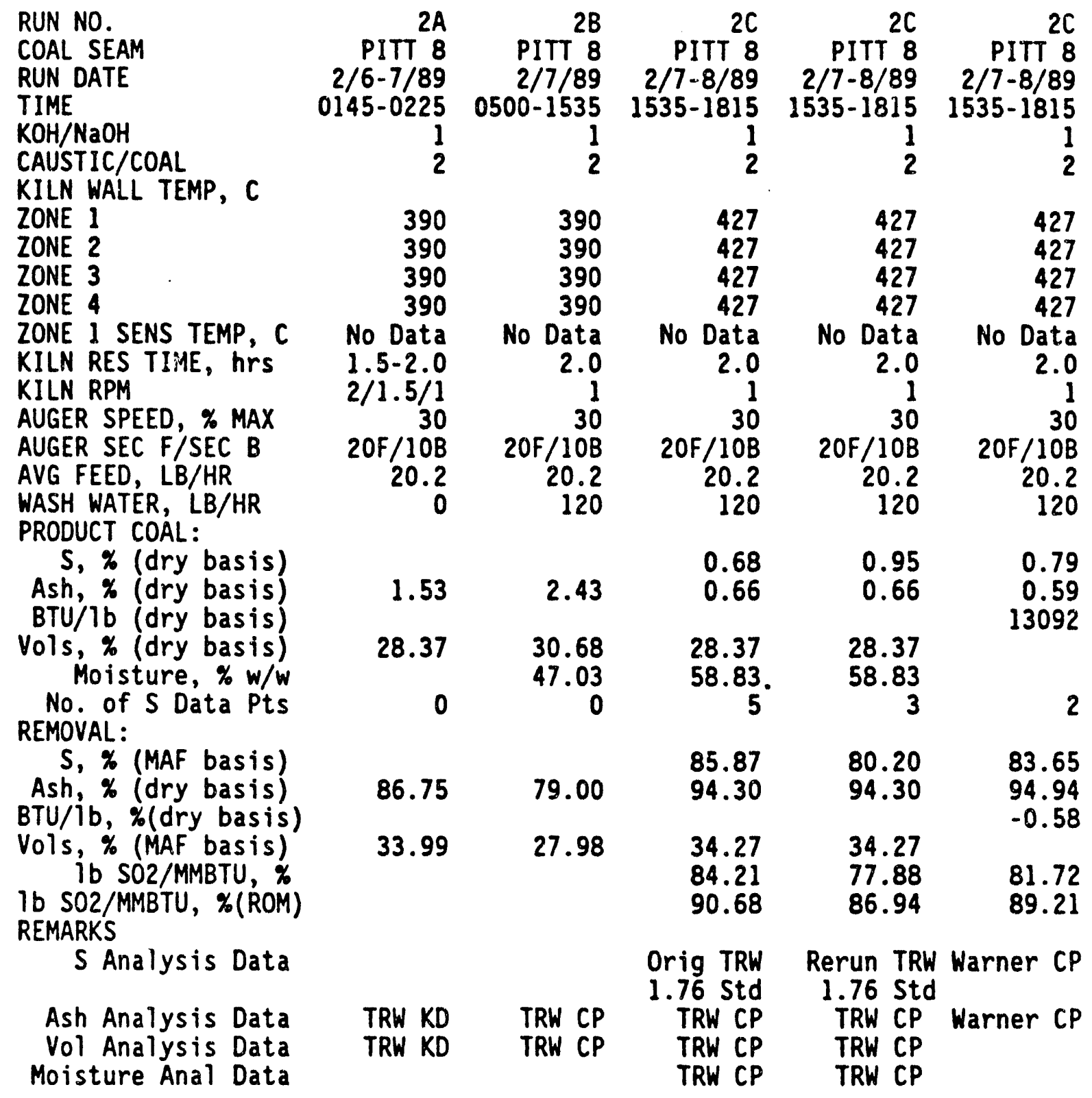


MCL RUN DATA SUMMARY

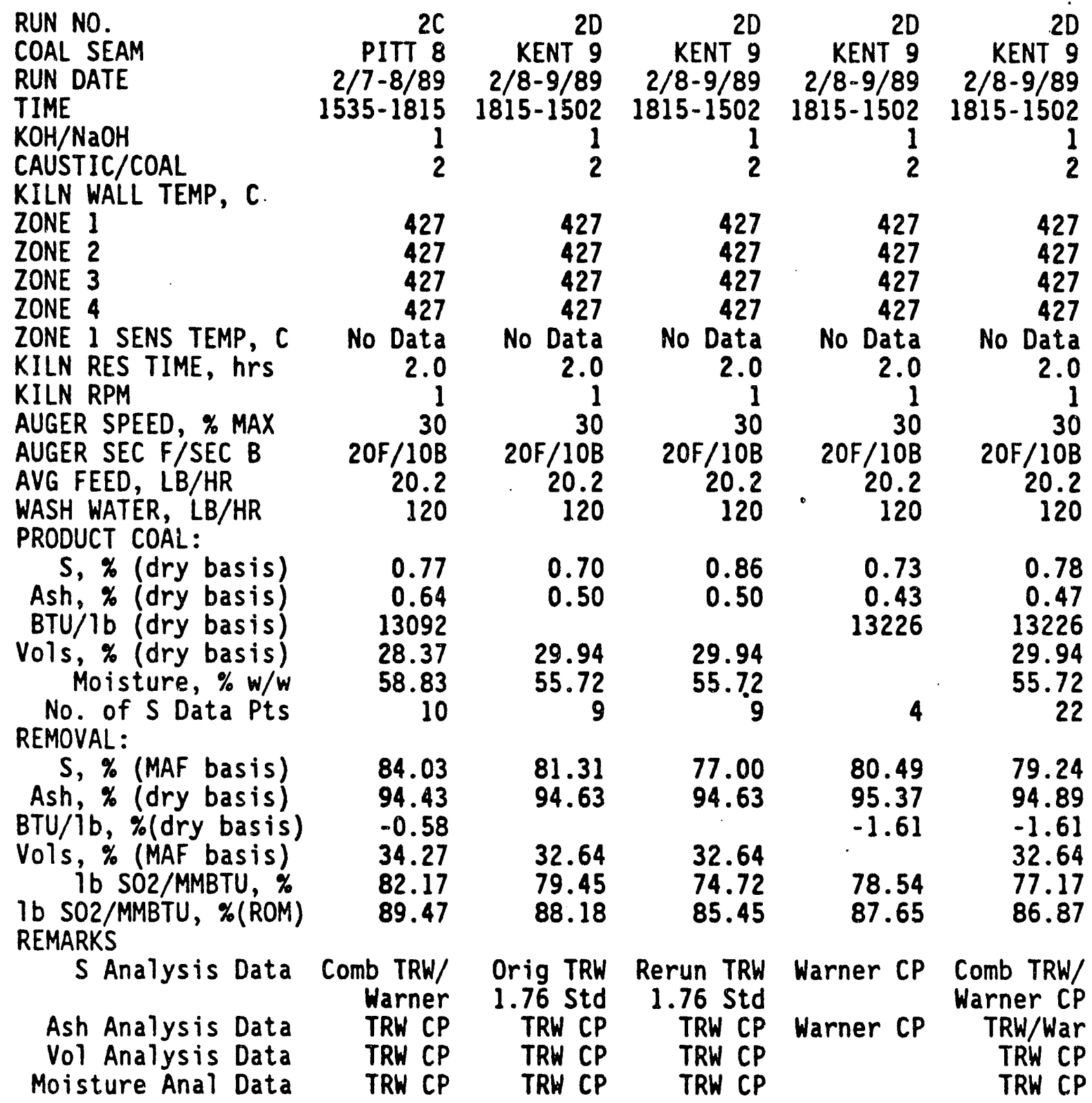


MCL RUN DATA SUMMARY

\begin{tabular}{|c|c|c|c|}
\hline $\begin{array}{l}\text { RUN NO. } \\
\text { COAL SEAM } \\
\text { RUN DATE } \\
\text { TIME } \\
\text { KOH/NaOH } \\
\text { CAUSTIC/COAL }\end{array}$ & $\begin{array}{r}2 E \\
\text { KENT } 9 \\
2 / 9-10 / 89 \\
1502-1450 \\
1 \\
2\end{array}$ & $\begin{array}{r}2 E \\
\text { KENT } 9 \\
2 / 9-10 / 89 \\
1502-1450 \\
1 \\
2\end{array}$ & $\begin{array}{r}2 E \\
\text { KENT } 9 \\
2 / 9-10 / 89 \\
1502-1450 \\
1 \\
2\end{array}$ \\
\hline $\begin{array}{l}\text { KILN WALL TEMP, } C \\
\text { ZONE } 1\end{array}$ & 438 & 438 & 438 \\
\hline $\begin{array}{l}\text { ZUNE } \\
\text { ZONE } 2 \\
\text { ZNNE } 3 \\
\text { ZONE } 4\end{array}$ & $\begin{array}{l}438 \\
438 \\
438 \\
438\end{array}$ & $\begin{array}{l}438 \\
438 \\
438 \\
438\end{array}$ & $\begin{array}{l}438 \\
438 \\
438\end{array}$ \\
\hline ZONE 1 SENS TEMP, $c$ & $\begin{array}{r}\text { No Data } \\
2.0\end{array}$ & $\begin{array}{r}\text { No Data } \\
2.0\end{array}$ & $\begin{array}{r}\text { No Data } \\
2.0\end{array}$ \\
\hline $\begin{array}{l}\text { KILN RPM } \\
\text { AUGER SPEED, \% MAX }\end{array}$ & & & \\
\hline $\begin{array}{l}\text { AUGER SEC F/SEC B } \\
\text { AVG FEED, LB/HR } \\
\text { WASH WATER, LB/HR }\end{array}$ & $\begin{array}{r}20 F / 10 B \\
20.2 \\
120\end{array}$ & $\begin{array}{r}20 F / 10 B \\
20.2 \\
120\end{array}$ & $\begin{array}{r}20 F / 10 B \\
20.2 \\
120\end{array}$ \\
\hline $\begin{array}{l}\text { PRODUCT COAL: } \\
\text { S, \% (dry basis) } \\
\text { Ash,\% (dry basis) } \\
\text { BTU/lb (dry basis) }\end{array}$ & $\begin{array}{l}0.91 \\
0.43\end{array}$ & $\begin{array}{l}0.87 \\
0.43\end{array}$ & $\begin{array}{l}0.89 \\
0.43\end{array}$ \\
\hline $\begin{array}{r}\text { Vols, \% (dry basis) } \\
\text { Moisture, \% w/w } \\
\text { No. of S Data Pts }\end{array}$ & $\begin{array}{r}30.27 \\
53.89 \\
4\end{array}$ & $\begin{array}{r}30.27 \\
53.89 \\
4\end{array}$ & $\begin{array}{r}30.27 \\
53.89 \\
8\end{array}$ \\
\hline $\begin{array}{l}\text { REMOVAL: } \\
\text { S, \% (MAF basis) } \\
\text { Ash, \% (dry basis) }\end{array}$ & $\begin{array}{l}75.74 \\
95.33\end{array}$ & $\begin{array}{l}76.88 \\
95.33\end{array}$ & $\begin{array}{l}76.31 \\
95.33\end{array}$ \\
\hline $\begin{array}{c}\text { BTU/Ib, \%(dry bas is) } \\
1 \mathrm{~b} \text { SO2/MMBTU, \% } \\
\text { lb SO2/MMBTU, } \% \text { (ROM) }\end{array}$ & $\begin{array}{l}72.86 \\
84.38\end{array}$ & $\begin{array}{l}74.13 \\
85.11\end{array}$ & $\begin{array}{l}73.49 \\
84.75\end{array}$ \\
\hline Analysis Data & $\begin{array}{l}\text { Orig TRW } \\
1.76 \text { Std }\end{array}$ & $\begin{array}{l}\text { Rerun TRW } \\
1.76 \text { Std }\end{array}$ & Comb TRW \\
\hline $\begin{array}{l}\text { Ash Analysis Data } \\
\text { Vol Analysis Data } \\
\text { Moisture Anal Data }\end{array}$ & $\begin{array}{l}\text { TRW CP } \\
\text { TRW CP } \\
\text { TRW CP }\end{array}$ & $\begin{array}{l}\text { TRW CP } \\
\text { TRW CP } \\
\text { TRW CP }\end{array}$ & $\begin{array}{l}\text { TRW CP } \\
\text { TRW CP } \\
\text { TRW CP }\end{array}$ \\
\hline
\end{tabular}


MCL RUN DATA SUMMARY

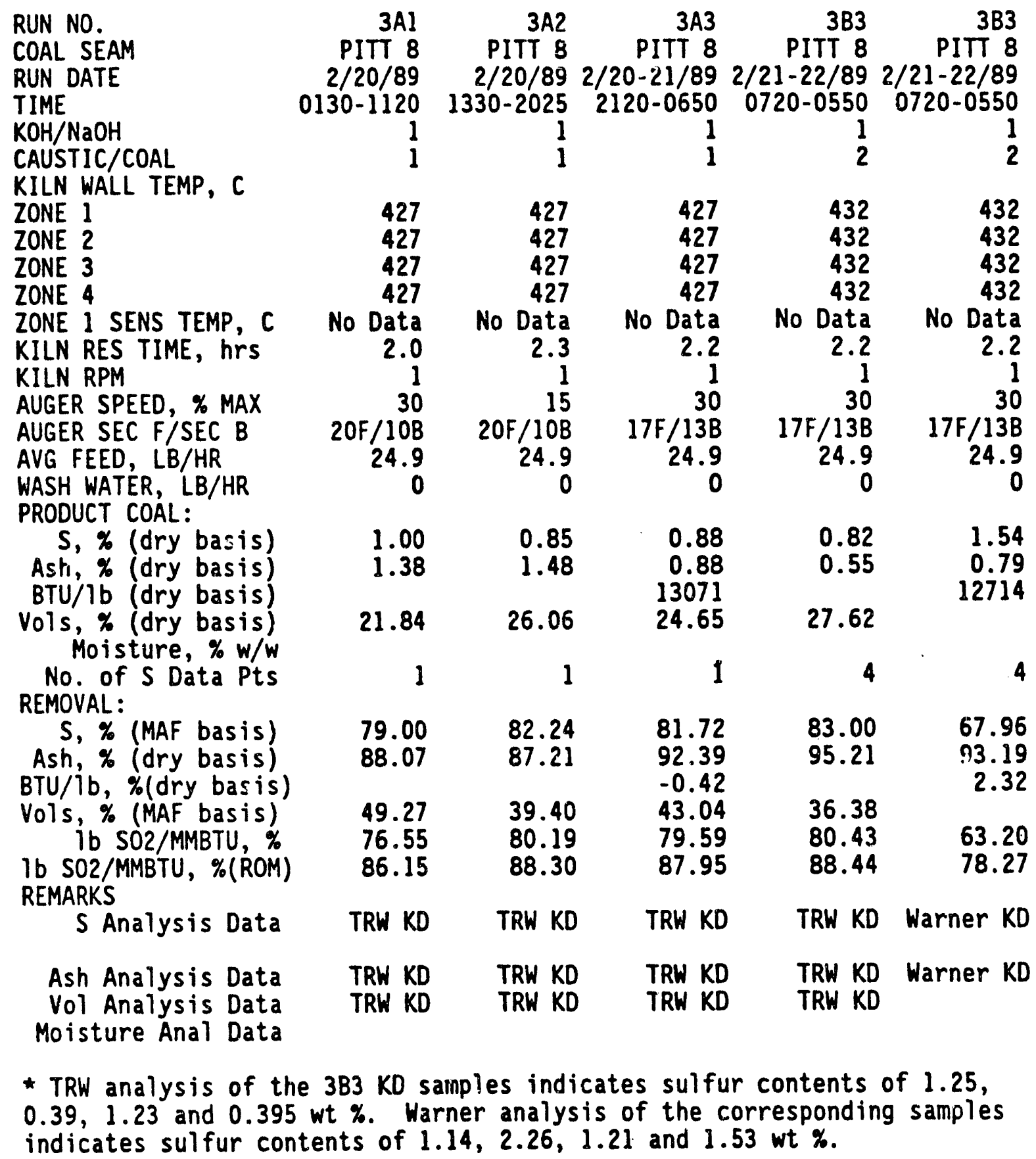


MCL RUN DATA SUMMARY

RUN NO.

COAL SEAM

RUN DATE

TIME

$\mathrm{KOH} / \mathrm{NaOH}$

CAUSTIC/COAL

KILN WALL TEMP, $C$

ZONE 1

ZONE 2

ZONE 3

ZONE 4

ZONE 1 SENS TEMP,

KILN RES TIME, hrS

KILN RPM

AUGER SPEED, \% MAX

AUGER SEC F/SEC B

AVG FEED, LB/HR

WASH WATER, LB/HR

PRODUCT COAL:

S, \% (dry basis)

Ash, \% (dry basis)

BTU/Ib (dry basis)

Vols, \% (dry basis)

Moisture, $\% w / w$

No. of S Data Pts

REMOVAL:

$S, \%$ (MAF basis)

Ash, \% (dry basis)

BTU/Ib, \%(dry basis)

Vols, \% (MAF basis)

ib SO2/MMBTU, \%

Ib S02/MMBTU, \%(ROM)

REMARKS

S Analysis Data No data TRW KD

Ash Analysis Data No data

Vol Analysis Data. No data

Moisture Anal Data No data
$3 B 2$

PITT 8

$0620-1150$

1

438

438

438

438

No Data

2.3

15

$20 F / 10 B$

0

120

0.55

0.28

23.53

0

88.58

97.58

45.94

87.10

92.38

TRW KD

TRW KD
$3 B 1$

PITT 8

$2 / 22-23 / 892 / 22-23 / 89$

$1530-24001530-24001530-2400$

2

1

438

438

438

438

No Data

2.0

1

$20 F / 10 B$

120

0.69

0.20

20.84

55.74

6

85.79

98.24

52.17

83.45

90.23

TRW

\section{Coal Prod}

TRW CP

TRW CP

TRW CP
PITT 8

1
2

0.74

0.26

12617

3B1

ITT 8

1

438

438

438

438

No Data No Data

2.0

120

120

0.71

0.23

12617

20.84

55.74

12

$\begin{array}{ll}84.59 & 85.19 \\ 97.72 & 97.98\end{array}$

$3.07 \quad 3.07$

82.07

89.41

82.77

89.82

Warner TRW/Warner Coal Prod Coal Prod Warner CP TRW/War CP

TRW CP

TRW CP
$20 F / 10 B$ 
MCL RUN DATA SUMMARY

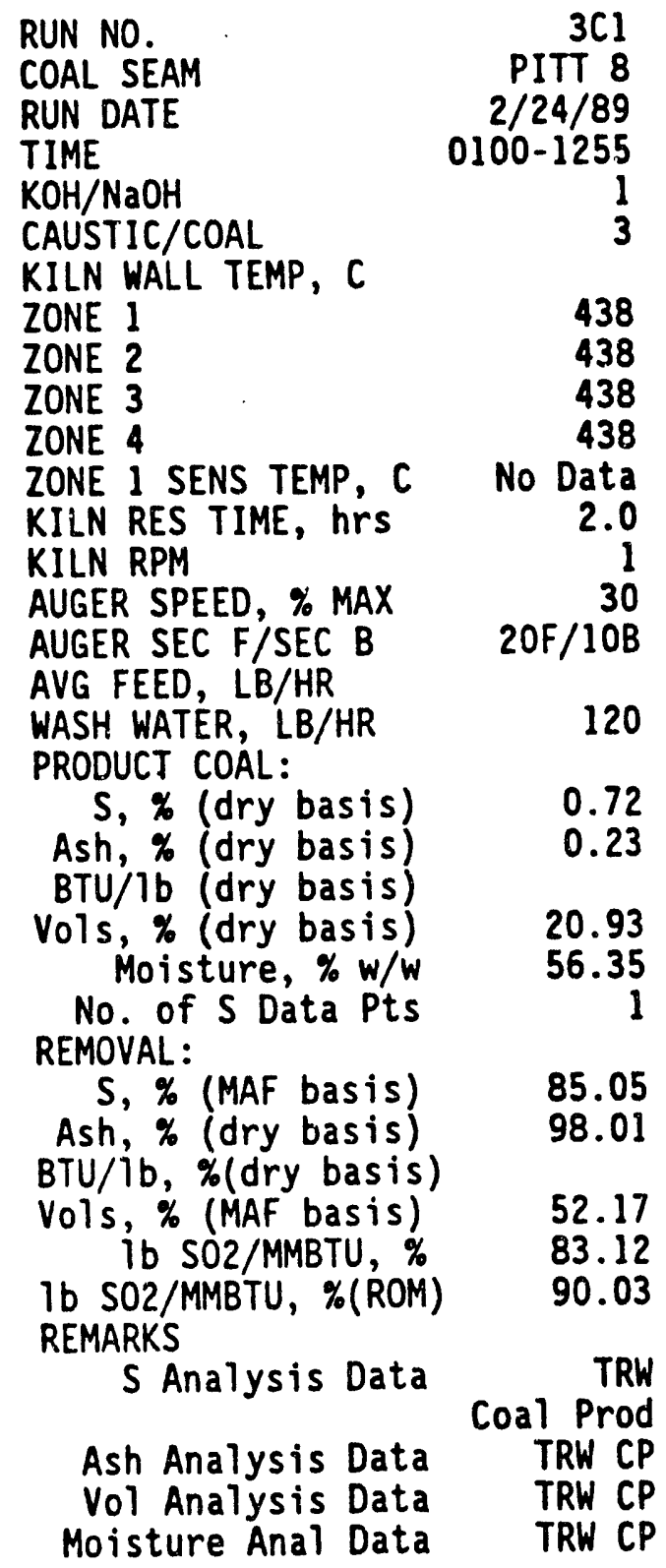


MCL RUN DATA SUMMARY

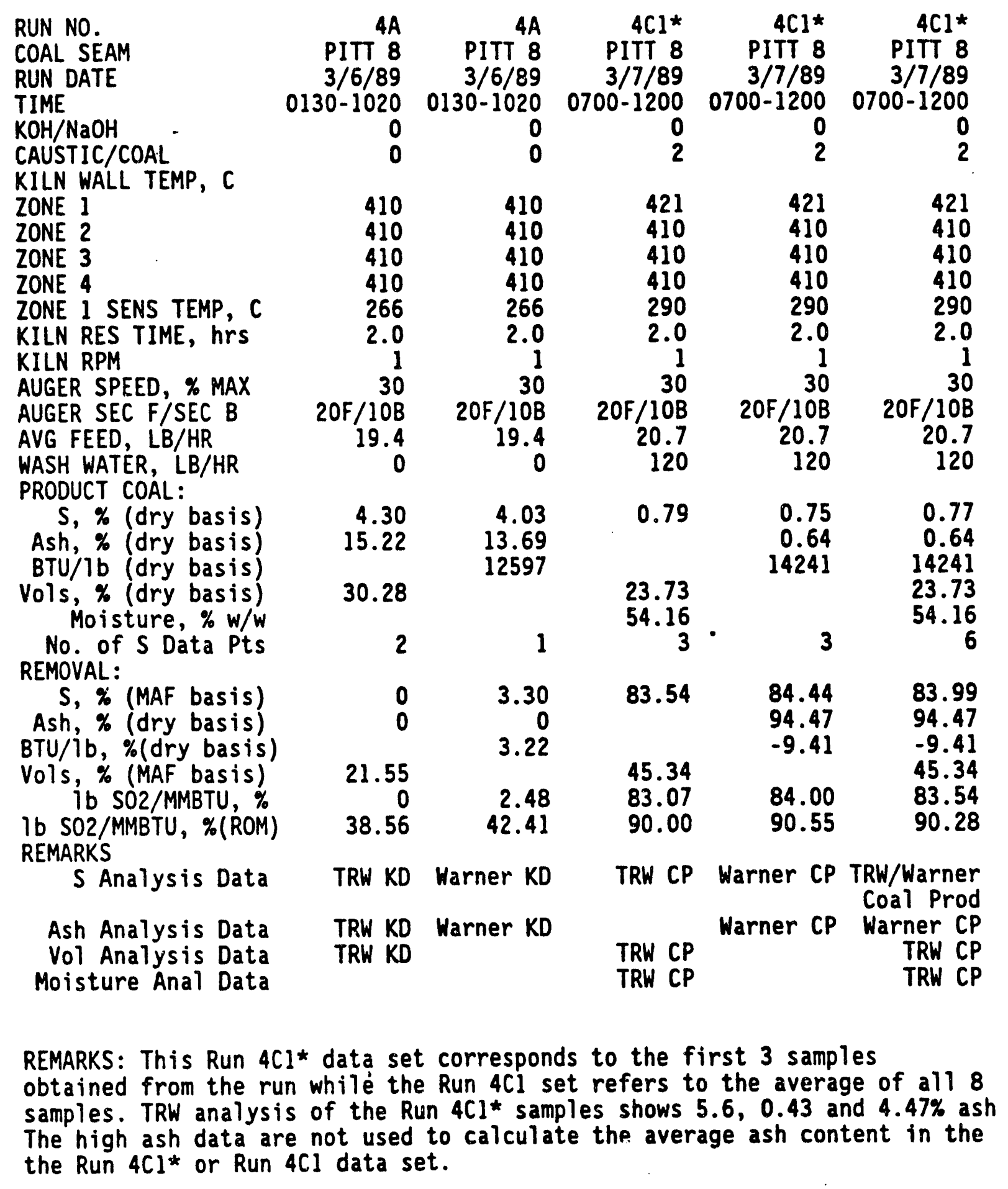


MCL RUN DATA SUMMMARY

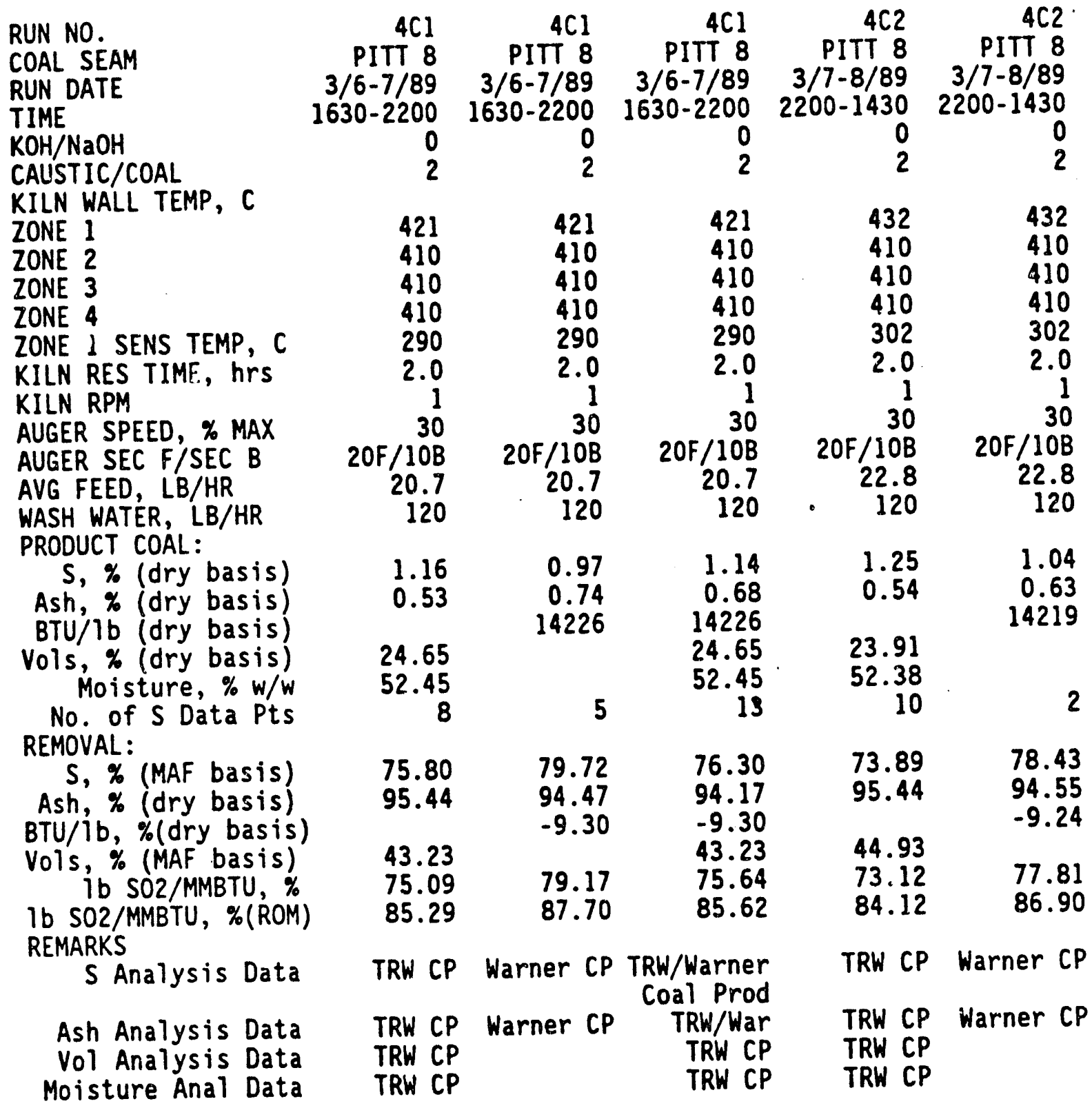


MCL RUN DATA SUMMARY

\begin{tabular}{|c|c|c|c|c|c|}
\hline $\begin{array}{l}\text { RUN NO. } \\
\text { COAL SEAM } \\
\text { RUN DATE } \\
\text { TIME } \\
\text { KOH/NaOH } \\
\text { CAUSTIC/COAL } \\
\text { KILN WALL TEMP.C }\end{array}$ & $\begin{array}{r}4 C 3 \\
\text { PITT } 8 \\
3 / 8 / 89 \\
1540-2300 \\
0 \\
2\end{array}$ & $\begin{array}{r}4 C 4 \\
\text { PITT } 8 \\
3 / 9 / 89 \\
0100-0700 \\
0 \\
2\end{array}$ & $\begin{array}{r}4 C 4 \\
\text { PITT } 8 \\
3 / 9 / 89 \\
0100-0700 \\
0 \\
2\end{array}$ & $\begin{array}{r}4 C 5 \\
\text { PITT } 8 \\
3 / 9 / 89 \\
0810-1500 \\
0 \\
2\end{array}$ & $\begin{array}{r}4 C 6 \\
\text { PITT } 8 \\
3 / 9 / 89 \\
1515-2300 \\
0 \\
2\end{array}$ \\
\hline $\begin{array}{l}\text { ZONE } 1 \\
\text { ZONE } 2 \\
\text { ZONE } 3 \\
\text { ZONE } 4 \\
\text { ZONE } 1 \text { SENS TEMP, C } \\
\text { KILN RES TIME, hrS* } \\
\text { KILN RPM } \\
\text { AUGER SPEED, \% MAX } \\
\text { AUGER SEC F/SEC B } \\
\text { AVG FEED, LB/HR } \\
\text { WASH WATER, LB/HR } \\
\text { PRODUCT COAL: }\end{array}$ & $\begin{array}{r}449 \\
410 \\
410 \\
410 \\
323 \\
2.0 \\
1 \\
30 \\
20 F / 10 B \\
22.8 \\
120\end{array}$ & $\begin{array}{r}336 \\
449 \\
410 \\
410 \\
232 \\
1.5 \\
1 \\
30 \\
20 F / 10 B \\
22.8 \\
120\end{array}$ & $\begin{array}{r}336 \\
449 \\
410 \\
410 \\
232 \\
1.5 \\
1 \\
30 \\
20 F / 10 B \\
22.8 \\
120\end{array}$ & $\begin{array}{r}293 \\
341 \\
449 \\
110 \\
170 \\
1.0 \\
1 \\
30 \\
20 F / 10 B \\
22.8 \\
120\end{array}$ & $\begin{array}{r}293 \\
341 \\
449 \\
421 \\
170 \\
1.0 \\
1 \\
30 \\
20 F / 10 \mathrm{~B} \\
22.8 \\
120\end{array}$ \\
\hline $\begin{array}{l}\text { S, \% (dry basis) } \\
\text { Ash, \% (dry basis) } \\
\text { BTU/lb (dry basis) }\end{array}$ & $\begin{array}{l}1.22 \\
0.52\end{array}$ & $\begin{array}{l}1.17 \\
0.46\end{array}$ & $\begin{array}{r}0.98 \\
0.62 \\
14201\end{array}$ & $\begin{array}{l}1.35 \\
0.68\end{array}$ & $\begin{array}{l}1.42 \\
0.72\end{array}$ \\
\hline $\begin{array}{l}\text { Vols, } \% \text { (dry basis) } \\
\text { Moisture, } \% \text { w/w } \\
\text { No. of } S \text { Data Pts } \\
\text { REMOVAL: }\end{array}$ & $\begin{array}{r}22.36 \\
52.52 \\
3\end{array}$ & $\begin{array}{r}24.59 \\
52.89 \\
2\end{array}$ & $1^{\circ}$ & $\begin{array}{l}27.22 \\
53.14 \\
5\end{array}$ & $\begin{array}{l}27.65 \\
51.31\end{array}$ \\
\hline $\begin{array}{c}\text { S, } \% \text { (MAF basis) } \\
\text { Ash, } \% \text { (dry basis) } \\
\text { BTU/ib. (dry basis) }\end{array}$ & $\begin{array}{l}74.60 \\
95.51\end{array}$ & $\begin{array}{l}75.76 \\
96.07\end{array}$ & $\begin{array}{r}9.58 \\
4.64\end{array}$ & $\begin{array}{l}71.89 \\
94.12\end{array}$ & $\begin{array}{l}70.17 \\
93.66\end{array}$ \\
\hline $\begin{array}{l}\text { Vols, } \% \text { (MAF basis) } \\
\text { ib SOL } 2 \text { MMBTU, } \% \\
\text { ib SO2/MMBTU, } \% \text { (ROM) }\end{array}$ & $\begin{array}{l}48.51 \\
73.87 \\
84.57\end{array}$ & $\begin{array}{l}43.82 \\
74.99 \\
85.23\end{array}$ & $\begin{array}{l}78.96 \\
87.58\end{array}$ & $\begin{array}{l}37.21 \\
71.13 \\
82.95\end{array}$ & $\begin{array}{l}36.93 \\
69.45 \\
81.96\end{array}$ \\
\hline S Analysis Data & TRW CP & TRW CP & Warner CP & TRW CP & TRW CP \\
\hline $\begin{array}{l}\text { Ash Analysis Data } \\
\text { Vol Analysis Data } \\
\text { Meisture Anal Data }\end{array}$ & $\begin{array}{l}\text { TRW } C P \\
\text { TRW CP } \\
\text { TRW CP }\end{array}$ & $\begin{array}{l}\text { TRW CP } \\
\text { TRW CP } \\
\text { TRW CP }\end{array}$ & War'ier CP & $\begin{array}{l}\text { TRW CP } \\
\text { TRW CP } \\
\text { TRW CP }\end{array}$ & $\begin{array}{l}\text { TRW CP } \\
\text { TRW CP } \\
\text { TRW CP }\end{array}$ \\
\hline
\end{tabular}


MCL RUN DATA SUMMARY

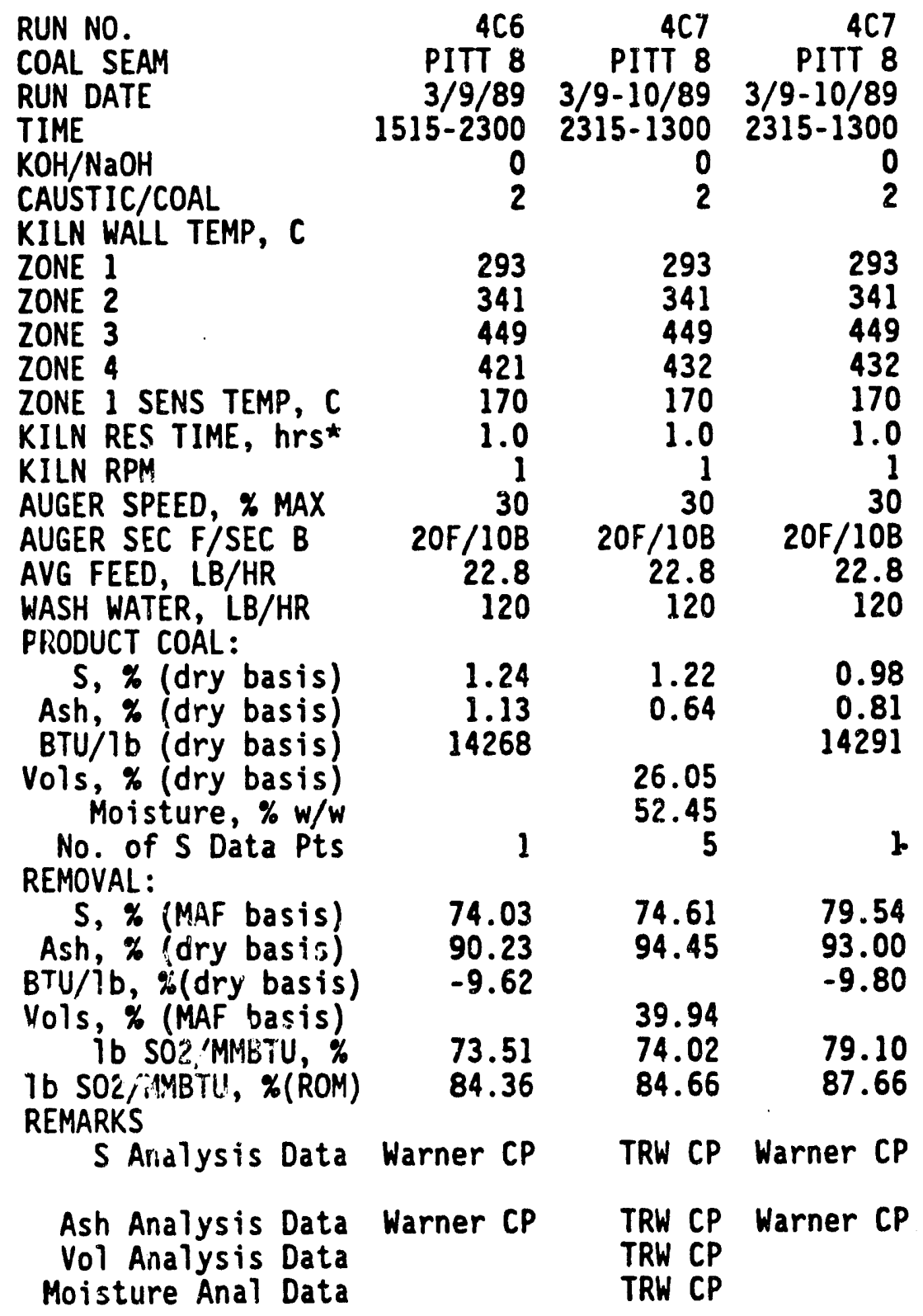

* Residence times for Runs $4 C 6$ and $4 C 7$, with 2 heated zones, were based on $1 / 2$ of that with 4 heated zones (Run $4(3)$ ). 
MCL RUN DATA SUMMARY

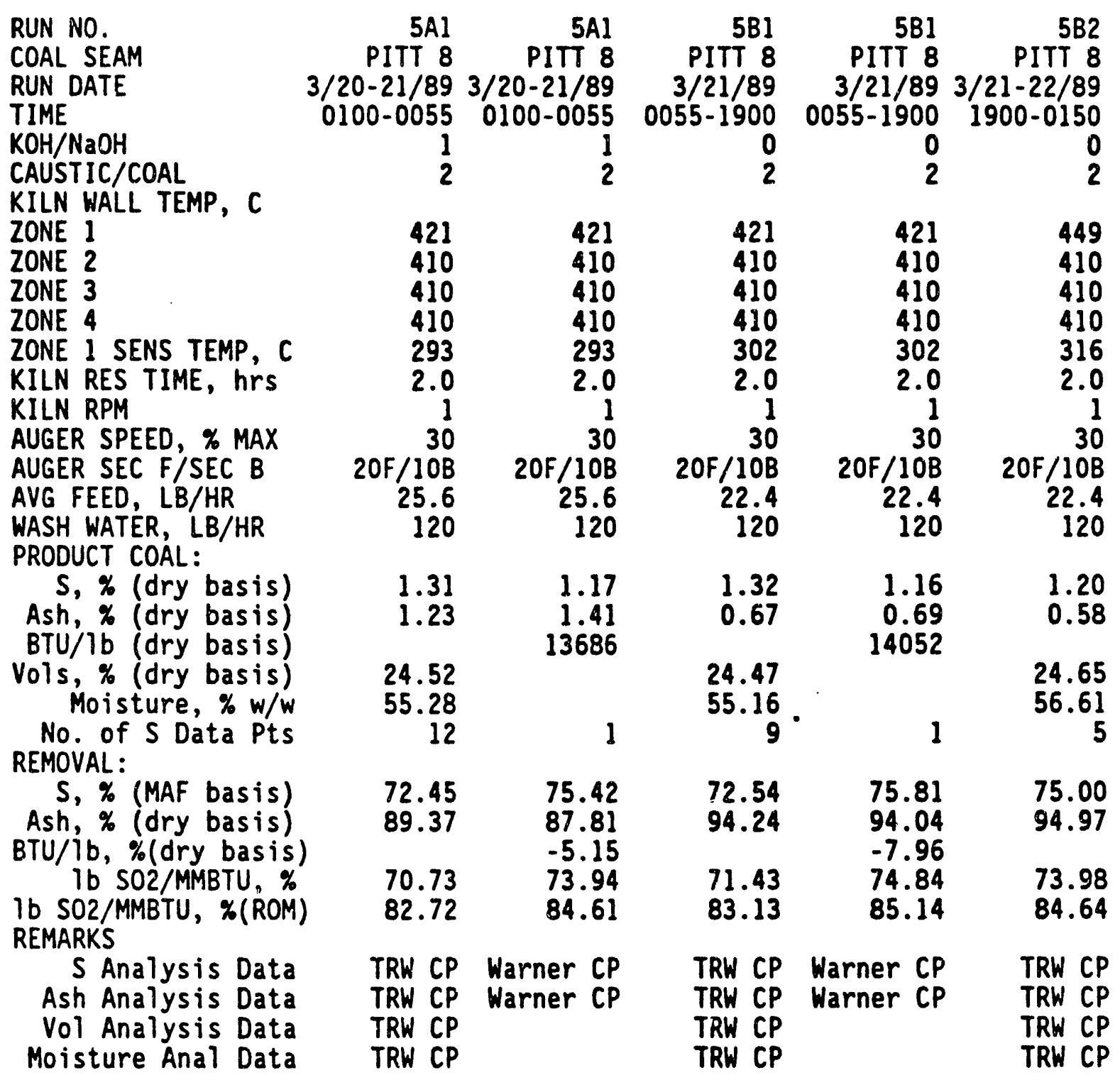


MCL RUN DATA SUMMARY

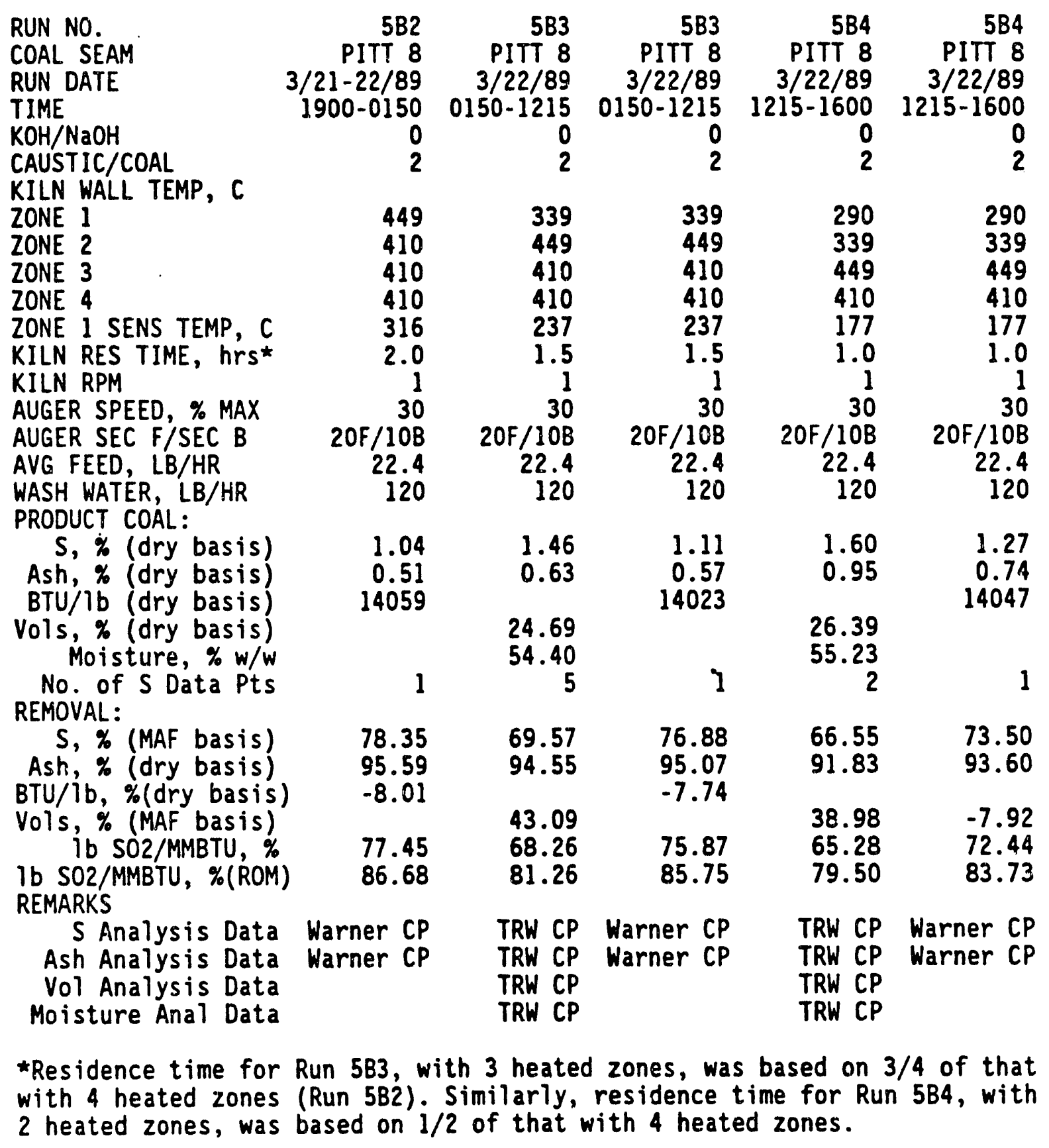


MCL RUN DATA SUMMARY

RUN NO.

COAL SEAM

RUN DATE

TIME

$\mathrm{KOH} / \mathrm{NaOH}$

CAUSTIC/COAL

KILN WALL TEMP, C

ZONE 1

ZONE 2

ZONE 3

ZONE 4

ZONE 1 SENS TEMP, C

KILN RES TIME, hrS

KILN RPM

AUGER SPEED, \% MAX

AUGER SEC F/SEC B

AVG FEED, LB/HR

WASH WATER, LB/HR

PRODUCT COAL:

S, \% (dry basis)

Ash, \% (dry basis)

BTU/1b (dry basis)

Vols, \% (dry basis) Moisture, $\% w / w$

No. of $S$ Data Pts

REMOVAL:

\section{S, $\%$ (MAF basis) \\ Ash, \% (dry basis) \\ BTU/ib, \%(dry basis) \\ Vols, \% (MAF basis) ib SO2/MMBTU, \% \\ Ib SO2/MMBTU, \%(ROM) REMARKS}

$S$ Analysis Data Ash Analysis Data Vol Analysis Data Moisture Anal Data
585

PITT 8

$3 / 22-23 / 893 / 22-23 / 89$

$1600-0230 \quad 1600-0230$

$\begin{array}{ll}0 & 0 \\ 2 & 2\end{array}$

$\begin{array}{rr}427 & 427 \\ 427 & 427 \\ 427 & 427 \\ 427 & 427 \\ 298 & 298 \\ 2.0 & 2.0 \\ 1 & 1 \\ 30 & 30 \\ 20 \mathrm{~F} / 10 \mathrm{~B} & 20 \mathrm{~F} / 10 \mathrm{~B} \\ 22.4 & 22.4 \\ 120 & 120\end{array}$

1.19

0.45

21.49

54.81

75.24

96.13

50.53

73.44

84.31

TRW CP Warner CP

TRW CP Warner CP

TRW CP

TRW CP

$$
\begin{array}{r}
0.95 \\
0.46 \\
13656
\end{array}
$$

80.23

96.02

$-4.92$

78.79

87.48
$5 \mathrm{C} 5$

KENT 9

$3 / 23 / 89$

$0230-1005$

0
2 $\begin{array}{rr}5 C 5 & 5 C 4 \\ \text { KENT } 9 & \text { KENT } 9 \\ 3 / 23 / 89 & 3 / 23 / 89 \\ 0230-1005 & 1005-1800 \\ 0 & 0 \\ 2 & 2\end{array}$

427
427
427
427
298
2.0
1
30
$20 \mathrm{~F} / 10 \mathrm{~B}$
22.6
120

333

427

427

427

223

1.5

1

$20 \mathrm{~F} / 10 \mathrm{~B}$

22.6

120

1.10

0.37

\subsection{7}

51.69

3

70.62

95.96

49.28

68.67

81.97

TRW CP

TRW CP

TRW CP

TRW CP
0.92

0.39

13651

1.11

0.50

23.66

55.73

70.31

94.62

95.78

$-2.96$

46.76

68.99

82.16

73.80
84.92

TRW CP

TRW CP

TRW CP

TRW CP 
MCL RUN DATA SUMMARY

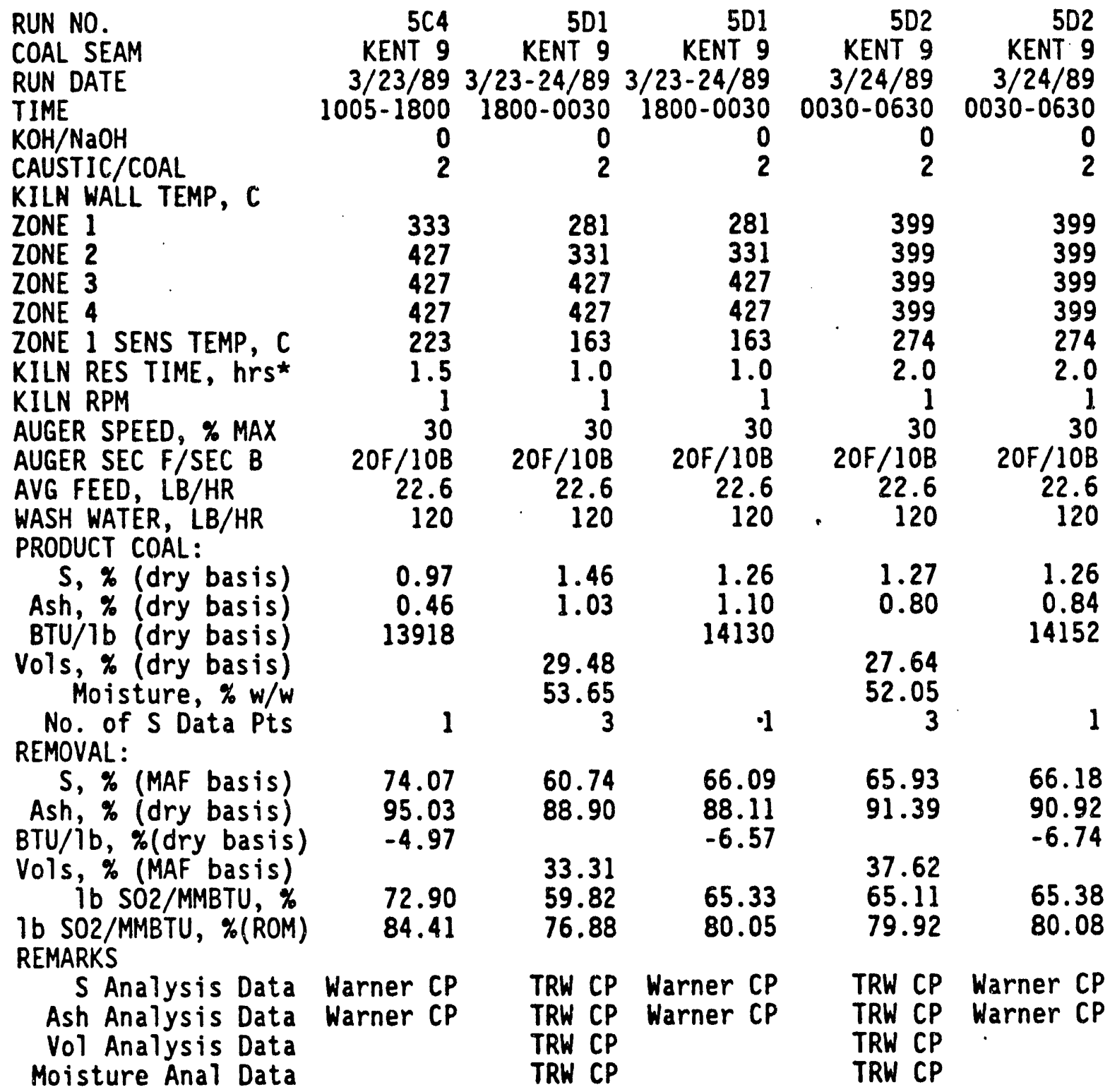

* Residence time for Run 5C4, with 3 heated zones, was based on $3 / 4$ of that with 4 heated zones (Run 5C5). Similarly, residence time for Run 5Dl, with 2 heated zones, was based on $1 / 2$ of that with 4 heated zones. 
MCL RUN DATA SUMMARY

RUN NO.

$5 D 3$

COAL SEAM

KENT 9

RUN DATE

TIME

$3 / 24 / 89$

$\mathrm{KOH} / \mathrm{NaOH}$

CAUSTIC/COAL

o

KILN WALL TEMP, C

ZONE 1

ZONE 2

371

371

ZONE 3

371

ZONE 4

371

ZONE I SENS TEMP, C

252

KILN RES TIME, hrS

KILN RPM

AUGER SPEED, \% MAX

AUGER SEC F/SEC B

AVG FEED, LB/HR

2.0

WASH WATER, LB/HR

22.6

120

PRODUCT COAL:

S, * (dry basis)

1.73

Ash, \% (dry basis)

BTU/1b (dry basis)

Vols, \% (dry basis) Moisture, $\% \mathrm{w} / \mathrm{w}$

No. of $S$ Data Pts

REMOVAL:

S, \% (MAF basis)

Ash, \% (dry basis)

BTU/Ib, \%(dry basis)

Vols, \% (MAF basis)

ib SO2/MMBTU, $\%$

Ib SO2/MMBTU, \%(ROM)

REMARKS

$S$ Analysis Data

Ash Analysis Data

Vol Analysis Data

Moisture Anal Data

TRW CP 
MCL RUN DATA SUMMARY

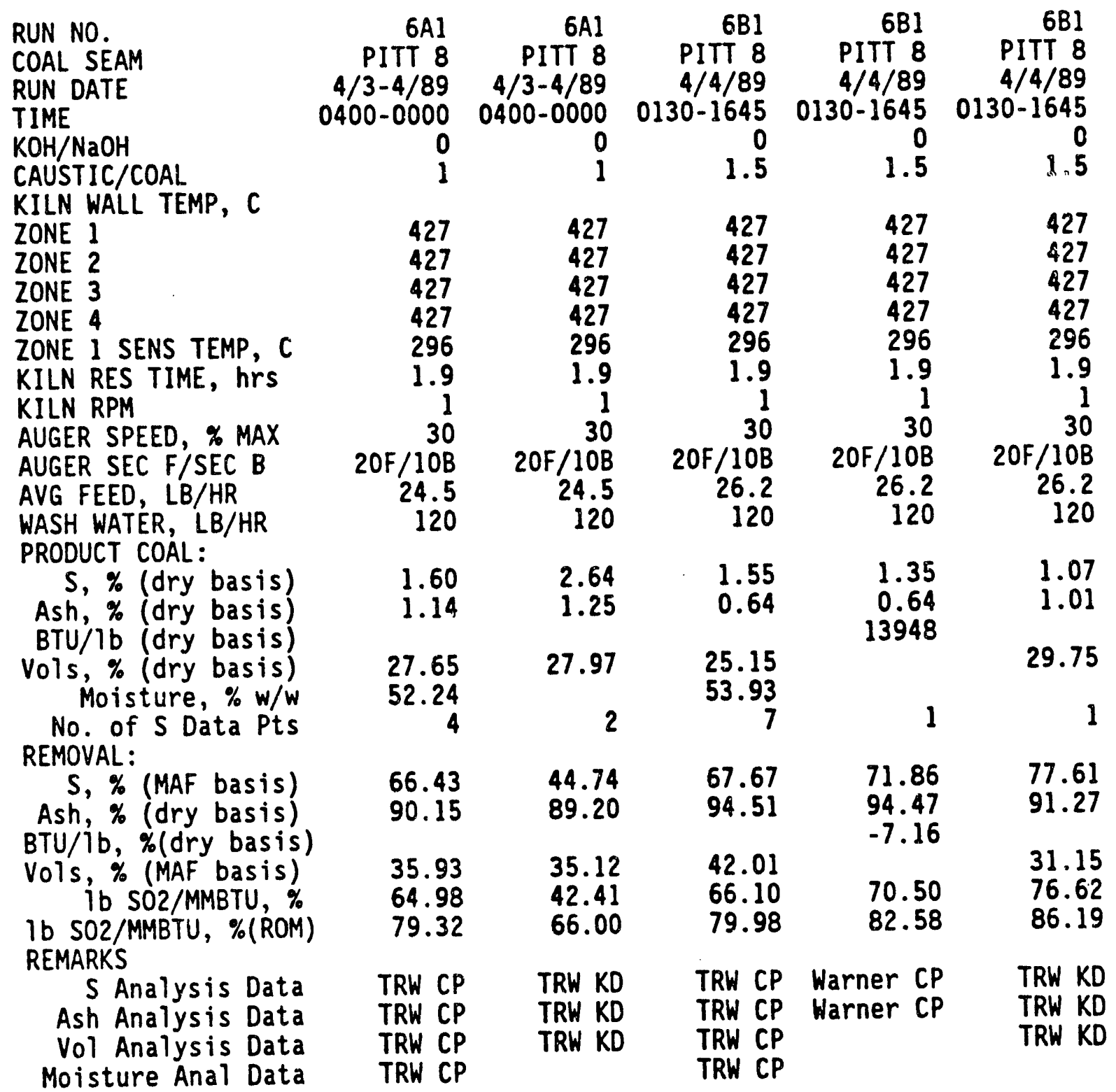


MCL RUN DATA SUMMARY

\begin{tabular}{|c|c|c|c|c|c|}
\hline $\begin{array}{l}\text { RUN NO. } \\
\text { COAL SEAM } \\
\text { RUN DATE } \\
\text { TIME } \\
\text { KOH/NaOH } \\
\text { CAUSTIC/COAL }\end{array}$ & $\begin{array}{r}6 D 1 \\
\text { PITT } 8 \\
4 / 5-6 / 89 \\
0000-0400 \\
0 \\
1.5\end{array}$ & $\begin{array}{r}6 D 1 \\
\text { PITT } 8 \\
4 / 5-6 / 89 \\
0000-0400 \\
0 \\
1.5\end{array}$ & $\begin{array}{r}6 D 1 \\
\text { PITT } 8 \\
4 / 5-6 / 89 \\
0000-0400 \\
0 \\
1.5\end{array}$ & $\begin{array}{r}6 E 1 \\
\text { PITT } 8 \\
4 / 6 / 89 \\
0515-1255 \\
1 \\
1\end{array}$ & $\begin{array}{r}6 E 1 \\
\text { PITT } 8 \\
4 / 6 / 89 \\
1255-1900 \\
1 \\
1\end{array}$ \\
\hline KILN WALL TEMP, C & & & & & \\
\hline 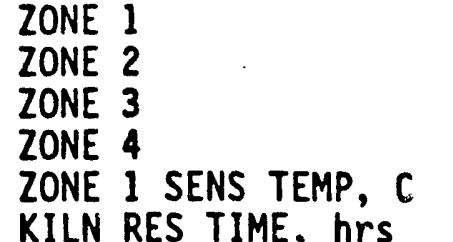 & $\begin{array}{l}410 \\
410 \\
410 \\
410 \\
281 \\
2.0\end{array}$ & $\begin{array}{l}410 \\
410 \\
410 \\
410 \\
281 \\
2.0\end{array}$ & $\begin{array}{l}410 \\
410 \\
410 \\
410 \\
281 \\
2.0\end{array}$ & $\begin{array}{l}427 \\
427 \\
427 \\
427 \\
296 \\
2.0\end{array}$ & $\begin{array}{l}427 \\
427 \\
427 \\
427 \\
296 \\
2.0\end{array}$ \\
\hline KILN RPM & 1 & & & 1 & 1 \\
\hline $\begin{array}{l}\text { AUGER SPEED, \% MAX } \\
\text { AUGER SEC F/SEC B } \\
\text { AVG FEED, LB/HR } \\
\text { WASH WATER, LB/HR } \\
\text { PRODUCT COAL: }\end{array}$ & $\begin{array}{r}30 \\
20 F / 10 B \\
27.8 \\
120\end{array}$ & $\begin{array}{r}30 \\
20 F / 10 \mathrm{~B} \\
27.8 \\
120\end{array}$ & $\begin{array}{r}30 \\
20 \mathrm{~F} / 10 \mathrm{~B} \\
27.8 \\
120\end{array}$ & $\begin{array}{r}30 \\
20 \mathrm{~F} / 10 \mathrm{~B} \\
31.7 \\
120\end{array}$ & $\begin{array}{r}30 \\
20 \mathrm{~F} / 10 \mathrm{~B} \\
31.7 \\
0\end{array}$ \\
\hline $\begin{array}{l}\text { S, \% (dry basis) } \\
\text { Ash, \% (dry basis) } \\
\text { BTU/1b (dry basis) }\end{array}$ & $\begin{array}{l}1.74 \\
0.87\end{array}$ & $\begin{array}{r}1.38 \\
0.75 \\
14150\end{array}$ & $\begin{array}{l}2.45 \\
2.35\end{array}$ & $\begin{array}{l}1.72 \\
2.02\end{array}$ & $\begin{array}{l}2.14 \\
2.81\end{array}$ \\
\hline $\begin{array}{l}\text { Vols, \% (dry basis) } \\
\text { Moisture, \% w/w }\end{array}$ & $\begin{array}{l}32.56 \\
54.74\end{array}$ & & 30.56 & $\begin{array}{l}30.84 \\
47.73\end{array}$ & 32.36 \\
\hline $\begin{array}{l}\text { No of of S Data Pts } \\
\text { REMOVAL: }\end{array}$ & & 2 & 1 & & \\
\hline $\begin{array}{c}\text { S, \% (MAF basis) } \\
\text { Ash, \% (dry basis) } \\
\text { BTU/ib, \%(dry basis) }\end{array}$ & 63.54 & $\begin{array}{l}71.31 \\
93.56 \\
-8.71\end{array}$ & $\begin{array}{l}48.04 \\
79.69\end{array}$ & $\begin{array}{l}63.65 \\
82.54\end{array}$ & $\begin{array}{l}54.40 \\
75.71\end{array}$ \\
\hline $\begin{array}{l}\text { Vols, \% (MAF basis) } \\
\text { ib SO2/MMBTU, \% } \\
\text { lo SO2/MMBTU, \%(ROM) } \\
\text { REMARKS }\end{array}$ & $\begin{array}{l}24.76 \\
62.50 \\
77.86\end{array}$ & $\begin{array}{l}24.86 \\
70.38 \\
82.51\end{array}$ & $\begin{array}{l}28.30 \\
47.22 \\
68.83\end{array}$ & & $\begin{array}{l}23.72 \\
49.82 \\
70.37\end{array}$ \\
\hline $\begin{array}{l}\text { S Analys is Data } \\
\text { Ash Analys is Data } \\
\text { Vol Analys is Data } \\
\text { Moisture Anal Data }\end{array}$ & $\begin{array}{l}\text { TRW CP } \\
\text { TRW CP } \\
\text { TRW CP } \\
\text { TRW CP }\end{array}$ & $\begin{array}{l}\text { Warner } C P \\
\text { Warner } C P\end{array}$ & $\begin{array}{l}\text { TRW } \\
\text { KD } \\
\text { TRW } \\
\text { TRD } \\
\text { TRD }\end{array}$ & $\begin{array}{l}\text { TRW } C P \\
\text { TRW CP } \\
\text { TRW CP } \\
\text { TRW CP }\end{array}$ & $\begin{array}{ll}\text { TRW } & \text { KD } \\
\text { TRW } & \text { KD } \\
\text { TRW } & \text { KD }\end{array}$ \\
\hline
\end{tabular}


MCL RUN DATA SUMMARY

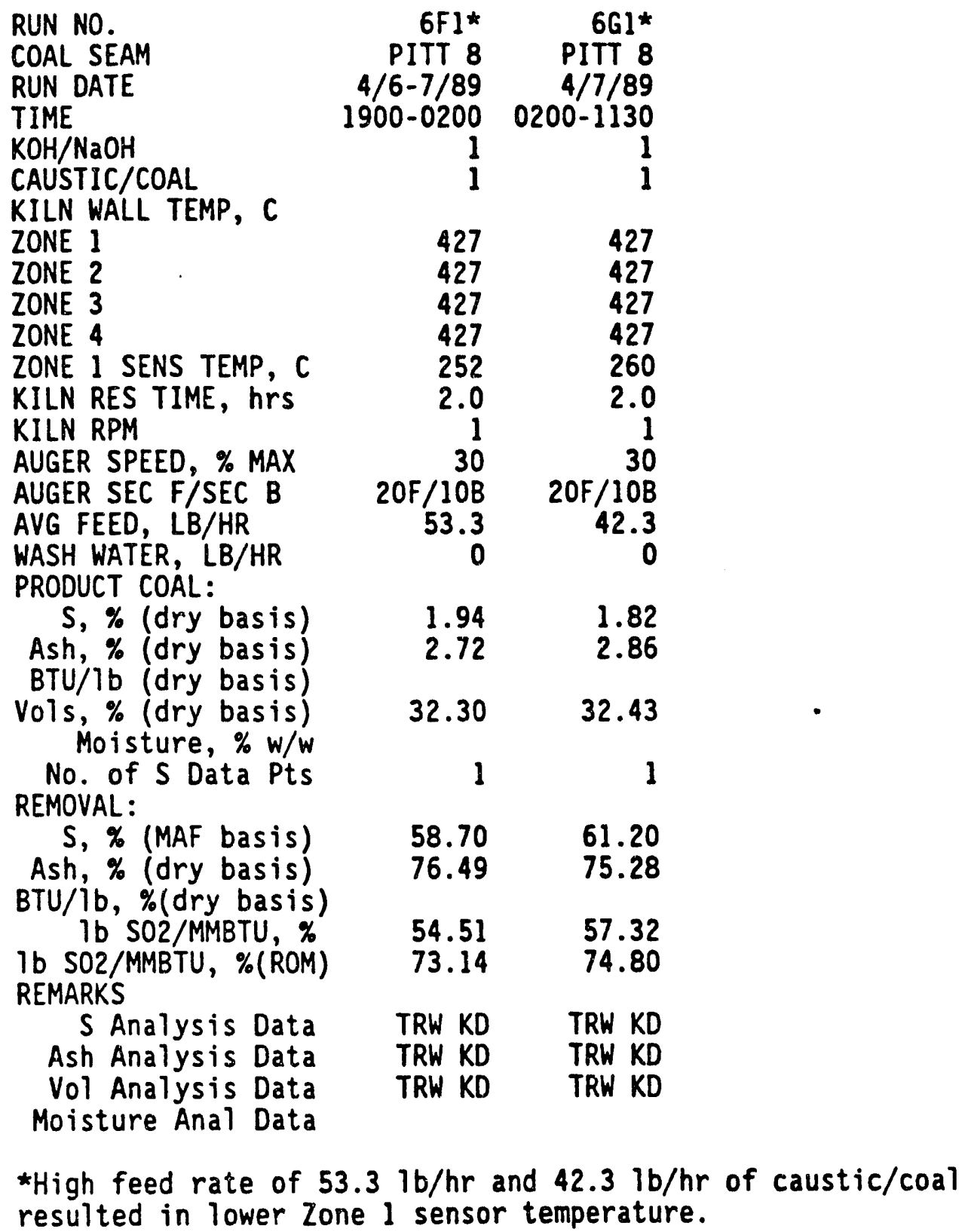


MCL RUN DATA SUMMARY

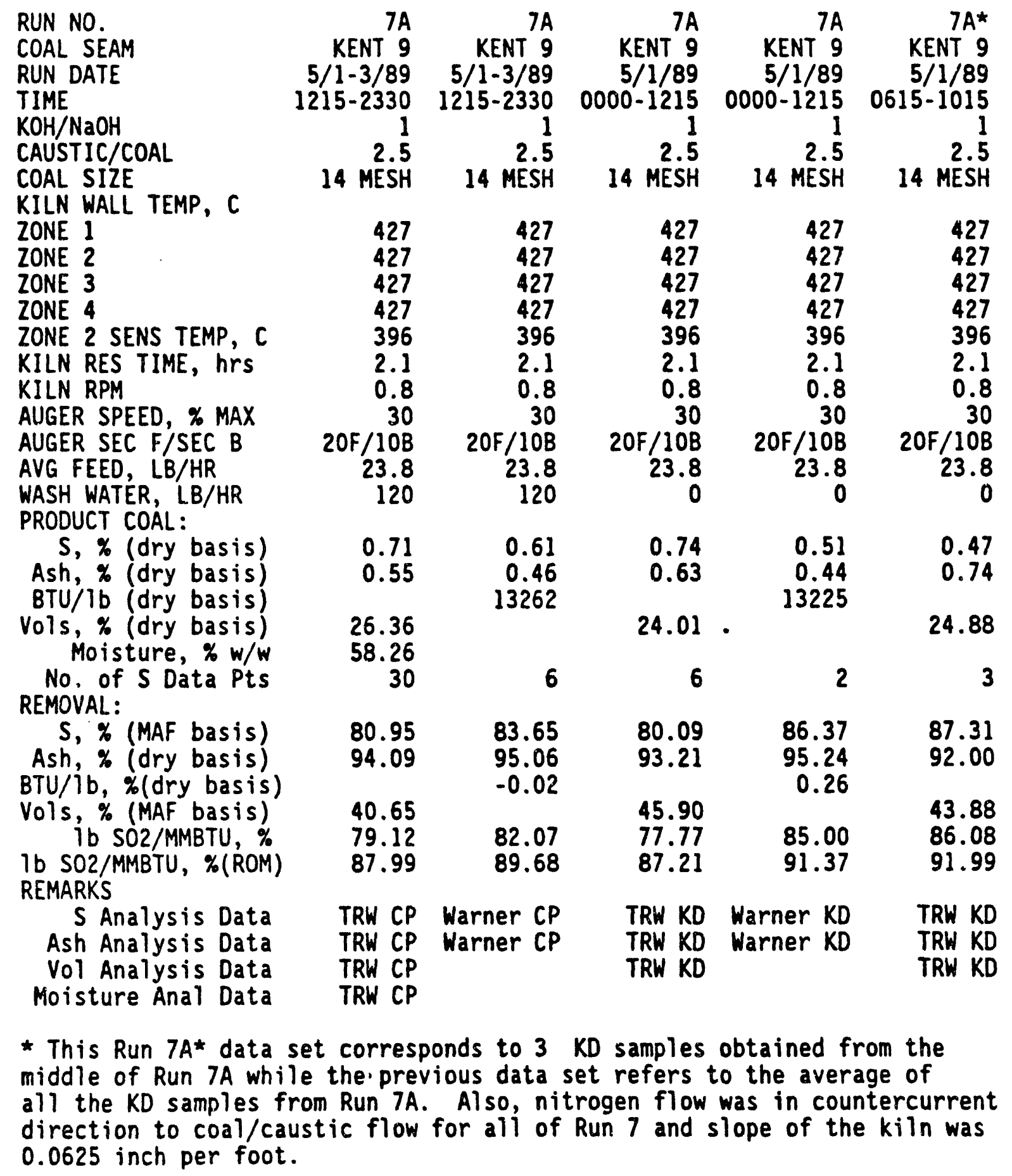


MCL RUN DATA SUMMARY

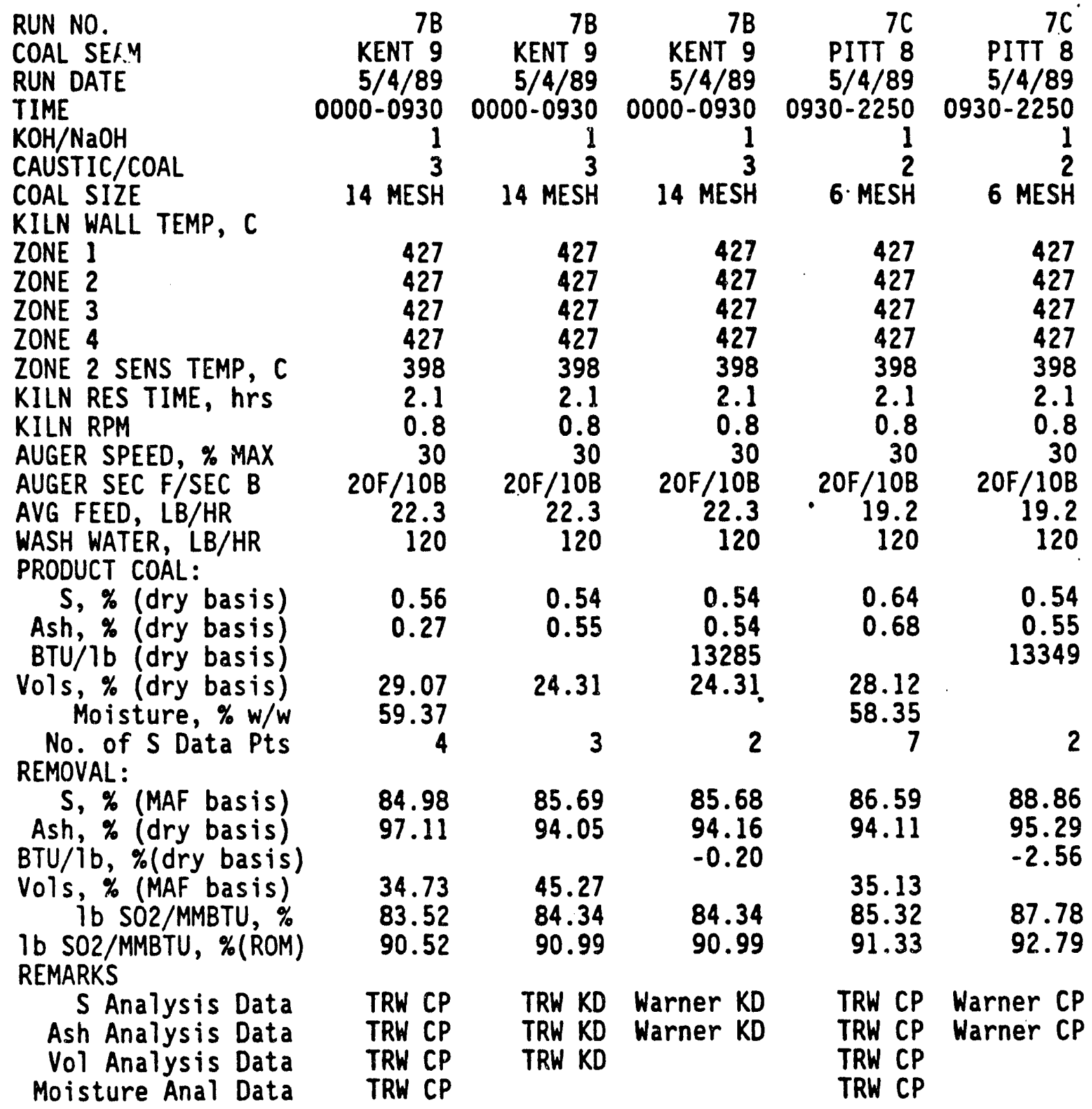


MCL RUN DATA SUMMARY

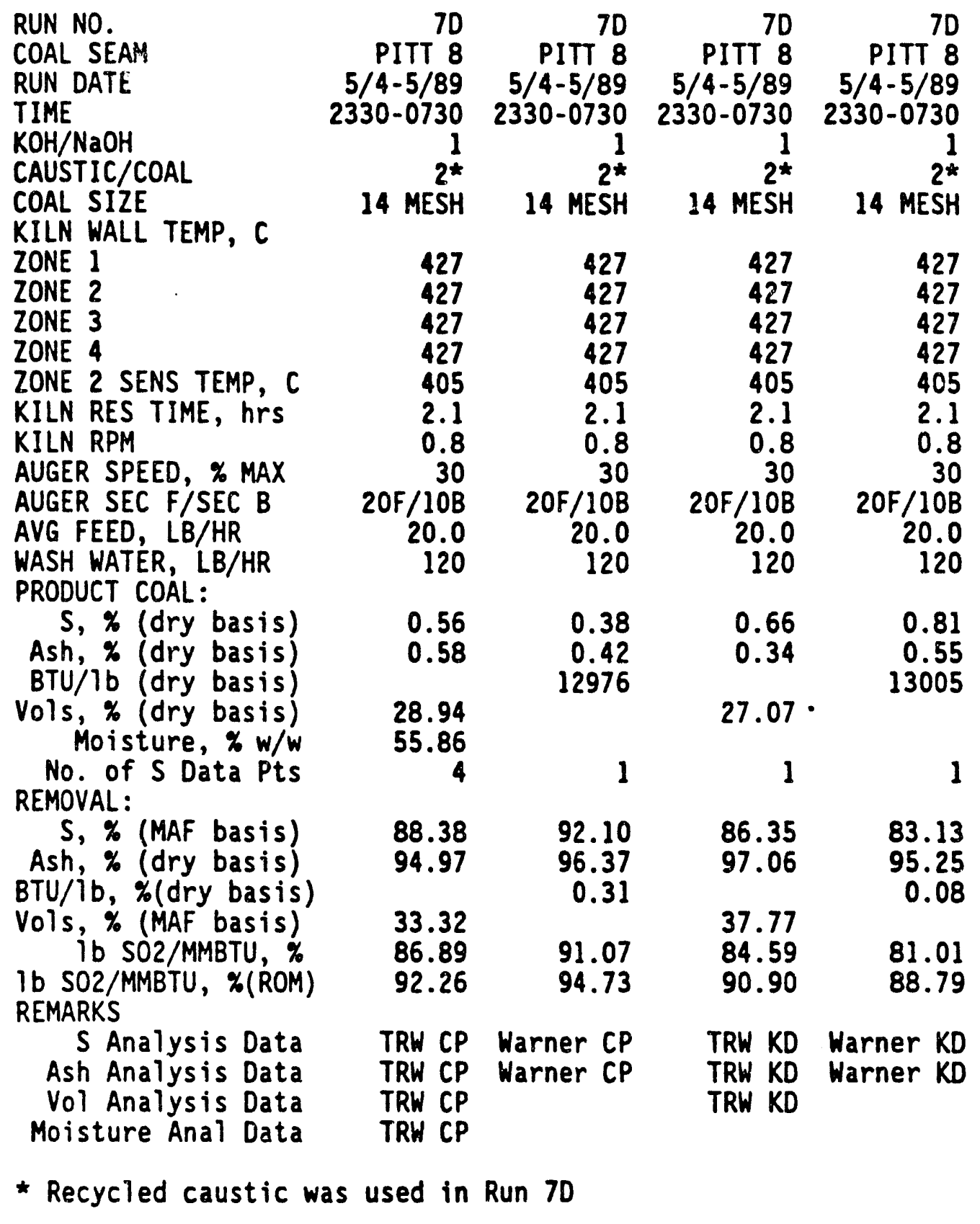


MCL RUN DATA SUMMARY

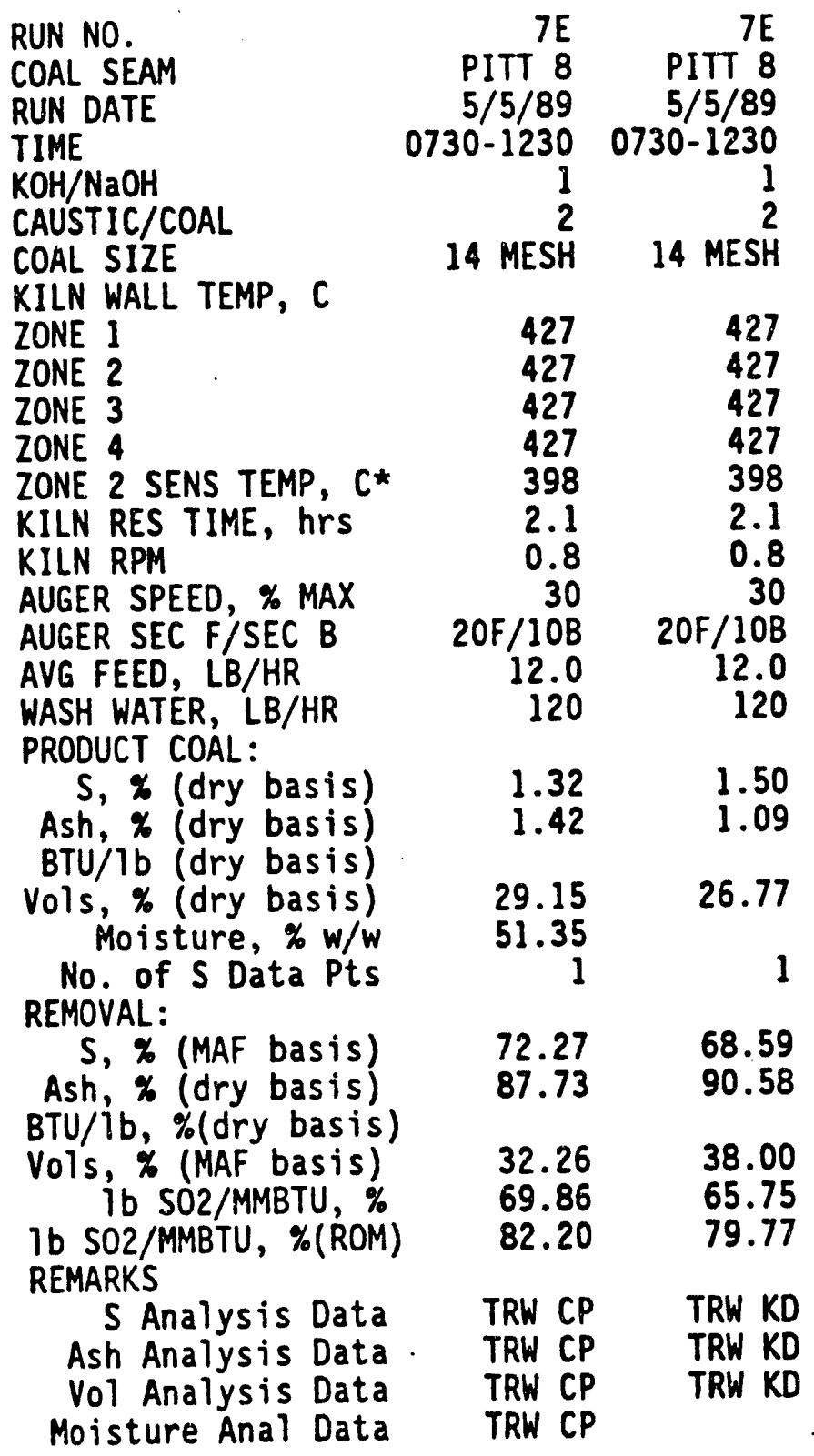

*After noticing large decrease in sensor temperature at the beginning of Run $7 E$, the auger was run fast forward for a short period during the middle of run, which brought the Zone 2 sensor temperature back to the normal level. However, the low initial sensor temperature also suggested improper feed conditions or improper movement of the coal/caustic mixture inside the kiln. 
MCL RUN DATA SUMMARY

\begin{tabular}{|c|c|c|c|c|c|}
\hline $\begin{array}{l}\text { RUN NO. } \\
\text { COAL SEAM } \\
\text { RUN DATE } \\
\text { TIME } \\
\text { KOH/NaOH } \\
\text { CAUSTIC/COAL } \\
\text { COAL SIZE } \\
\text { KILN WALL TEMP, C }\end{array}$ & $\begin{array}{r}8 A \\
\text { PITT } 8 \\
5 / 15-16 / 89 \\
0930-0300 \\
1 \\
1.5 \\
14 \text { MESH }\end{array}$ & $\begin{array}{r}8 A \\
\text { PITT } 8 \\
5 / 15 / 89 \\
0200-0930 \\
1 \\
1.5 \\
14 \text { MESH }\end{array}$ & $\begin{array}{r}8 A \\
P I T T 8 \\
5 / 15 / 89 \\
0200-0930 \\
1 \\
1.5 \\
14 \text { MESH }\end{array}$ & $\begin{array}{r}8 B \\
P I T T 8 \\
5 / 16 / 89 \\
0300-1820 \\
1 \\
1.5 \\
6 \text { MESH }\end{array}$ & $\begin{array}{r}8 B \\
\text { PITT } 8 \\
5 / 16 / 89 \\
0300-1820 \\
1 \\
1.5 \\
6 \text { MESH }\end{array}$ \\
\hline $\begin{array}{l}\text { ZONE } 1 \\
\text { ZONE } 2 \\
\text { ZONE } 3 \\
\text { ZNNE } 4 \\
\text { ZONN } 2 \text { SENS TEMP, C } \\
\text { KILN RES TIME, hrs } \\
\text { KI N RPM } \\
\text { AUGER SPEED, \% MAX } \\
\text { AUGER SEC F/SEC B } \\
\text { AVG FEED, LB/HR } \\
\text { WASH WATER, LB/HR } \\
\text { PRODUCT COAL: }\end{array}$ & $\begin{array}{r}427 \\
427 \\
427 \\
427 \\
395 \\
2.1 \\
0.8 \\
30 \\
20 F / 10 B \\
27.7 \\
120\end{array}$ & $\begin{array}{r}427 \\
427 \\
427 \\
427 \\
395 \\
2.1 \\
0.8 \\
30 \\
20 F / 10 B \\
27.7 \\
0\end{array}$ & $\begin{array}{r}427 \\
427 \\
427 \\
427 \\
395 \\
2.1 \\
0.8 \\
30 \\
20 F / 10 B \\
27.7 \\
0\end{array}$ & $\begin{array}{r}427 \\
427 \\
427 \\
427 \\
395 \\
2.1 \\
0.8 \\
30 \\
2.0 F / 10 B \\
20.3 \\
120\end{array}$ & $\begin{array}{r}427 \\
427 \\
427 \\
427 \\
395 \\
2.1 \\
0.8 \\
30 \\
20 \mathrm{~F} / 10 \mathrm{~B} \\
20.3 \\
120\end{array}$ \\
\hline $\begin{array}{l}\text { S, } \% \text { (dry basis) } \\
\text { Ash, } \% \text { (dry basis) } \\
\text { BTU/lo (dry basis) }\end{array}$ & $\begin{array}{l}1.22 \\
1.01\end{array}$ & $\begin{array}{l}0.80 \\
1.01\end{array}$ & $\begin{array}{r}0.85 \\
1.03 \\
13359\end{array}$ & $\begin{array}{l}1.35 \\
1.95\end{array}$ & $\begin{array}{l}1.40 \\
2.31\end{array}$ \\
\hline $\begin{array}{l}\text { Vols, \% (dry basis) } \\
\text { Moisture, } \% \text { w/w } \\
\text { No. of S Data Pts } \\
\text { REMOVAL: }\end{array}$ & $\begin{array}{r}26.54 \\
55.14 \\
10\end{array}$ & 4 & 1 & $\begin{array}{r}26.12 \\
52.66 \\
5\end{array}$ & 25.46 \\
\hline $\begin{array}{c}\text { S, \% (MAF basis) } \\
\text { Ash, \% (dry basis) } \\
\text { BTU/ib, \%(dry basis) }\end{array}$ & $\begin{array}{l}74.50 \\
91.28\end{array}$ & $\begin{array}{l}83.20 \\
91.28\end{array}$ & $\begin{array}{l}82.21 \\
91.10 \\
-2.64\end{array}$ & $\begin{array}{l}71.45 \\
83.11\end{array}$ & $\begin{array}{l}70.36 \\
80.03\end{array}$ \\
\hline $\begin{array}{l}\text { ib SO2/MMBTU, } \% \\
\text { Ib SO2/MMBTU, } \% \text { (ROM) } \\
\text { REMARKS }\end{array}$ & $\begin{array}{l}72.18 \\
83.58\end{array}$ & $\begin{array}{l}81.67 \\
89.18\end{array}$ & $\begin{array}{l}80.60 \\
88.55\end{array}$ & $\begin{array}{l}69.74 \\
82.13\end{array}$ & $\begin{array}{l}68.70 \\
81.52\end{array}$ \\
\hline $\begin{array}{l}\text { S Analysis Data } \\
\text { Ash Analysis Data } \\
\text { Vol Analysis Data } \\
\text { Moisture Anal Data }\end{array}$ & $\begin{array}{l}\text { TRW CP } \\
\text { TRW CP } \\
\text { TRW CP } \\
\text { TRW CP }\end{array}$ & $\begin{array}{l}\text { TRW KD } \\
\text { TRW KD }\end{array}$ & $\begin{array}{l}\text { WAR KD } \\
\text { WAR KD }\end{array}$ & $\begin{array}{l}\text { TRW CP } \\
\text { TRW CP } \\
\text { TRW CP } \\
\text { TRW CP }\end{array}$ & $\begin{array}{ll}T R W & K D \\
\text { TRW } & \text { KD } \\
\text { TRW } & \text { KD }\end{array}$ \\
\hline
\end{tabular}


MCL RUN DATA SUMMARY

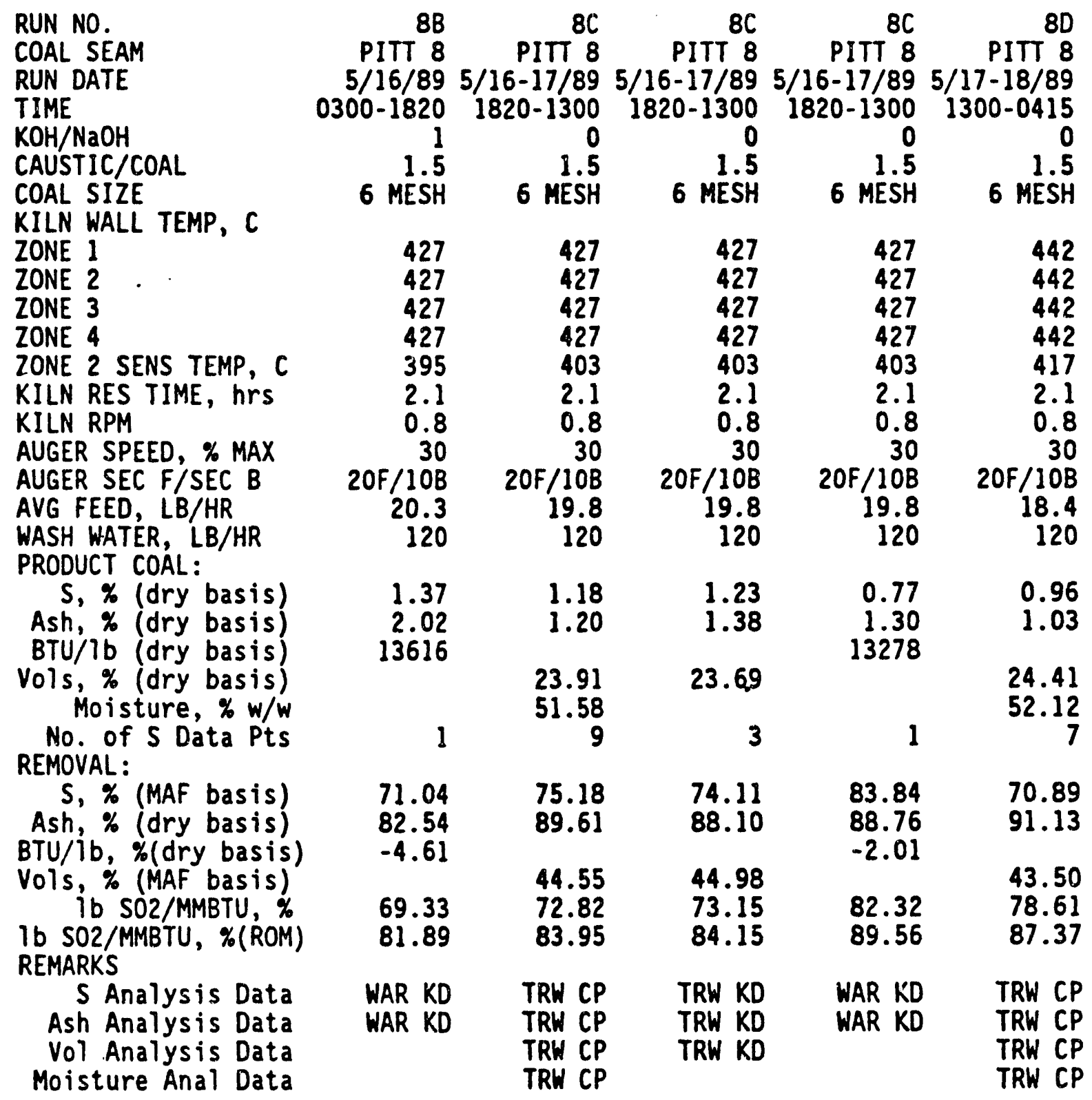


MCL RUN DATA SUMMARY

\begin{tabular}{|c|c|c|c|c|c|}
\hline $\begin{array}{l}\text { RUN NO. } \\
\text { COAL SEAM } \\
\text { RUN DATE } \\
\text { TIME } \\
\text { KOH/NaOH } \\
\text { CAUSTIC/COAL } \\
\text { COAL SIZE } \\
\text { KUN WAII TFMP }\end{array}$ & $\begin{array}{r}80 \\
\text { PITT } 8 \\
5 / 17-18 / 89 \\
1300-0415 \\
0 \\
1.5 \\
6 \text { MESH }\end{array}$ & $\begin{array}{r}8 E \\
\text { PITT } 8 \\
5 / 18 / 89 \\
0415-2000 \\
0 \\
1.5 \\
6 \text { MESH }\end{array}$ & $\begin{array}{r}8 E \\
\text { PITT } 8 \\
5 / 18 / 89 \\
0415-2000 \\
0 \\
1.5 \\
6 \text { MESH }\end{array}$ & $\begin{array}{r}8 E \\
\text { PITT } 8 \\
5 / 18 / 89 \\
0415-2000 \\
0 \\
1.5 \\
6 \text { MESH }\end{array}$ & $\begin{array}{r}8 F \\
\text { PITT } 8 \\
5 / 18-19 / 89 \\
2000-1300 \\
0 \\
2 \\
14 \text { MESH }\end{array}$ \\
\hline $\begin{array}{l}\text { ZONE } 1 \\
\text { ZONE } 2 \\
\text { ZONE } 3 \\
\text { ZONE } 4 \\
\text { ZONE } 2 \text { SENS TEMP, C } \\
\text { KILN RES TIME, hrS } \\
\text { KILN RPM } \\
\text { AUGER SPEED, \% MAX } \\
\text { AUGER SEC F/SEC B } \\
\text { AVG FEED, LB/HR } \\
\text { WASH WATER, LB/HR } \\
\text { PRODUCT COAL: }\end{array}$ & $\begin{array}{r}442 \\
442 \\
442 \\
442 \\
417 \\
2.1 \\
0.8 \\
30 \\
20 F / 10 B \\
18.4 \\
120\end{array}$ & $\begin{array}{r}412 \\
412 \\
412 \\
412 \\
389 \\
2.1 \\
0.8 \\
30 \\
20 F / 10 B \\
18.3 \\
120\end{array}$ & $\begin{array}{r}412 \\
412 \\
412 \\
412 \\
389 \\
2.1 \\
0.8 \\
30 \\
20 F / 10 B \\
18.3 \\
120\end{array}$ & $\begin{array}{r}412 \\
412 \\
412 \\
412 \\
389 \\
2.1 \\
0.8 \\
30 \\
20 F / 10 B \\
18.3 \\
120\end{array}$ & $\begin{array}{r}412 \\
412 \\
412 \\
412 \\
384 \\
2.1 \\
0.8 \\
30 \\
20 F / 10 B \\
17.7 \\
120\end{array}$ \\
\hline $\begin{array}{l}\text { S, \% (dry basis) } \\
\text { Ash, \% (dry basis) } \\
\text { BTU/lb (dry basis) }\end{array}$ & $\begin{array}{r}0.80 \\
1.00 \\
13694\end{array}$ & $\begin{array}{l}1.46 \\
1.18\end{array}$ & $\begin{array}{l}2.20 \\
1.47\end{array}$ & $\begin{array}{r}0.76 \\
0.73 \\
14001\end{array}$ & $\begin{array}{l}0.97 \\
0.54\end{array}$ \\
\hline $\begin{array}{l}\text { Vols, } \% \text { (dry basis) } \\
\text { Moisture, } \% w / w \\
\text { No. of } S \text { Data Pts } \\
\text { REMOVAL: }\end{array}$ & 1 & $\begin{array}{l}26.45 \\
51.34\end{array}$ & 25.21 & 1 & $\begin{array}{l}26.19 \\
54.03\end{array}$ \\
\hline $\begin{array}{l}\text { S, } \% \text { (MAF basis) } \\
\text { Ash, } \% \text { (dry basis) } \\
\text { BTU/ib, } \% \text { (dry basis) } \\
\text { Ib SO2/MMBTU, } \% \\
\text { Ib SO2/MMBTU, } \% \text { (ROM) } \\
\text { REMARKS }\end{array}$ & $\begin{array}{l}83.26 \\
91.36 \\
-5.21 \\
82.19 \\
89.48\end{array}$ & $\begin{array}{l}69.49 \\
89.82 \\
68.30 \\
81.28\end{array}$ & $\begin{array}{l}53.86 \\
87.29\end{array}$ & $\begin{array}{l}84.14 \\
93.69 \\
-7.57 \\
83.45 \\
90.23\end{array}$ & $\begin{array}{l}79.77 \\
95.33\end{array}$ \\
\hline $\begin{array}{l}\text { S Analysis Data } \\
\text { Ash Analysis Data } \\
\text { Vol Analysis Data } \\
\text { Moisture Anal Data }\end{array}$ & $\begin{array}{l}\text { WAR KD } \\
\text { WAR KD }\end{array}$ & $\begin{array}{l}\text { TRW CP } \\
\text { TRW CP } \\
\text { TRW CP } \\
\text { TRW CP }\end{array}$ & $\begin{array}{ll}\text { TRW } & K D \\
\text { TRW } & \text { KD } \\
\text { TRW } & \text { KD }\end{array}$ & $\begin{array}{l}\text { WAR KD } \\
\text { WAR KD }\end{array}$ & $\begin{array}{l}\text { TRW CP } \\
\text { TRW CP } \\
\text { TRW CP } \\
\text { TRW CP }\end{array}$ \\
\hline
\end{tabular}


MCL RUN DATA SUMMARY

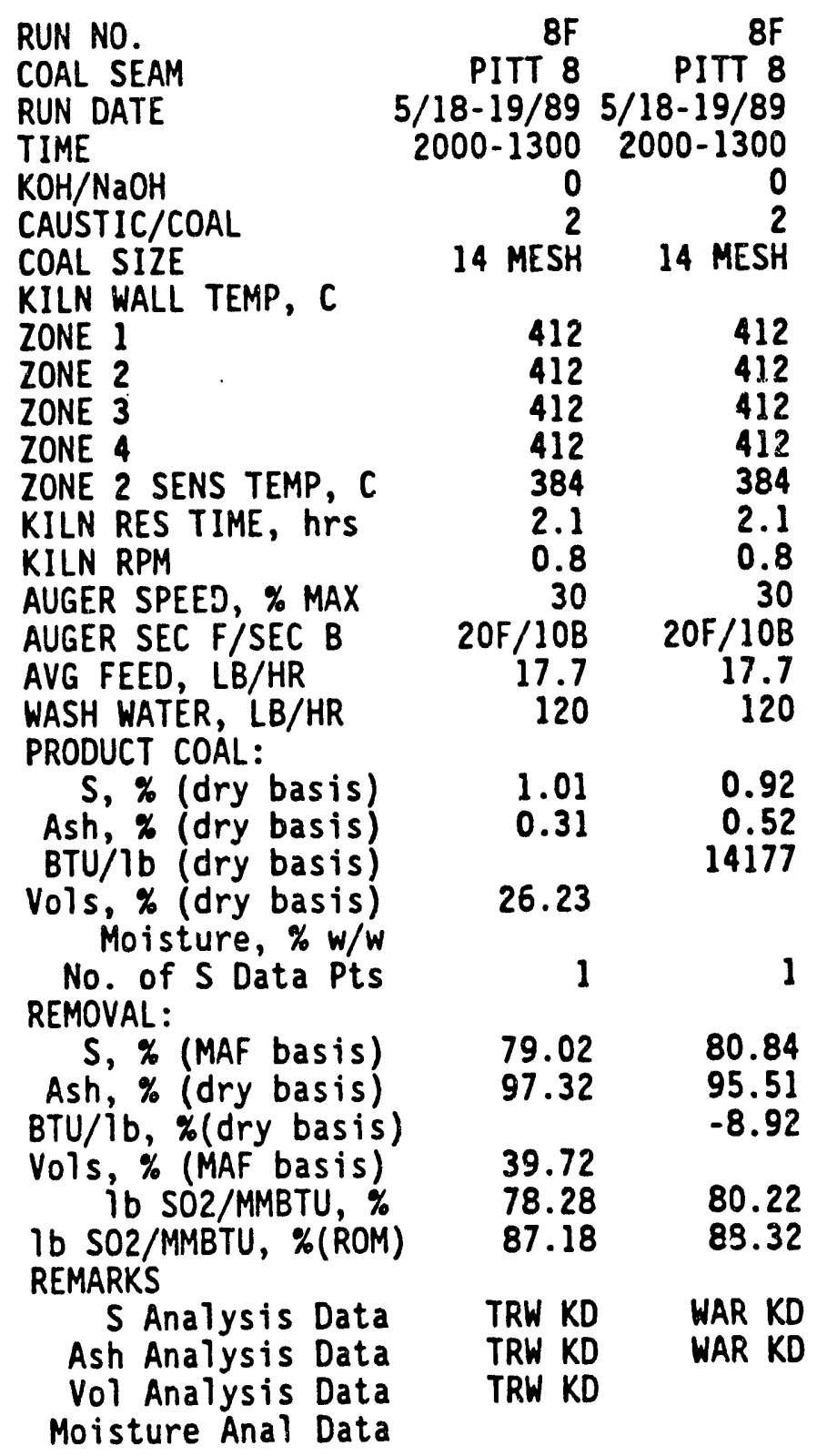


MCL RUN DATA SUMMARY

RUN NO.

COAL SEAM

RUN DATE

TIME

$\mathrm{KOH} / \mathrm{NaOH}$

CAUSTIC/COAL

COAL SIZE

KILN WALL TEMP, $C$

ZONE 1

ZONE 2

ZONE 3

ZONE 4

ZONE 2 SENS TEMP, $C$

KILN RES TIME, hrS

KILN RPM

AUGER SPEED, \% MAX

AUGER SEC F/SEC B

AVG FEED, LB/HR

WASH WATER, LB/HR

PRODUCT COAL:

S, $\%$ (dry basis)

Ash, \% (dry basis)

BTU/Ib (dry basis)

Vols, \% (dry basis) Moisture, \% w/w

No. of $S$ Data Pts REMOVAL:

$$
S, \% \text { (MAF basis) }
$$

Ash, \% (dry basis)

BTU/lb, \%(dry basis) Ib SO2/MMBTU, \%

Ib SO2/MMBTU, \%(ROM)

REMARKS

S Analysis Data

Ash Analysis Data

Vol Analysis Data

Moisture Anal Data

9A

PITT 8

$5 / 30 / 89$

0515-1730

2.5

14 MESH

\section{7}

427

427

427

395

2.1

0.8

30

$20 F / 10 B$

24.8

120

0.59

0.27

25.97

58.83

7

87.80

97.68

86. 31

91.92

TRW CP

TRW CP

TRW CP

TRW CP
$9 A$

PITT 8

$5 / 30 / 89$

0515-1730

2.5

$14 \mathrm{MESH}$

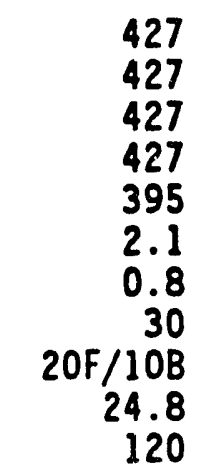

0.88

0.84

13079

22.60

1

81.62

92.74

$-0.48$

79.49

87.89

WAR CP

WAR CP

WAR CP $\begin{array}{rrr}9 A & 9 A 1 & 9 A 1 \\ \text { PITT } 8 & \text { PITT } 8 & \text { PITT } 8 \\ 5 / 30 / 89 & 5 / 30-31 / 89 & 5 / 30-31 / 89 \\ 0230-0515 & 1730-0430 & 1730-0430\end{array}$

2.5

14 MESH

2.5

14 MESH

427

427

427

427

395

2.1

0.8

30

2OF/10B

24.8

438

438

438

438

407

2.1

0.8

$20 F / 108$

17.2

120

0.97

0.74

0.65

0.33

0.72

0.66

13049

$26.84 \quad 25.63$

8

57.39

22.28

2

$\begin{array}{ll}79.67 & 86.57\end{array}$

97.11

84.99

93.65

84.90

94.34

77.29

91.08

$-0.25$

86.59

TRW KD

TRW KD

TRW KD

TRW CP

83.18

90.07

* Nitrogen flow was in countercurrent direction to coal/caustic flow for all of Run 9 . 
MCL RUN DATA SUMMARY

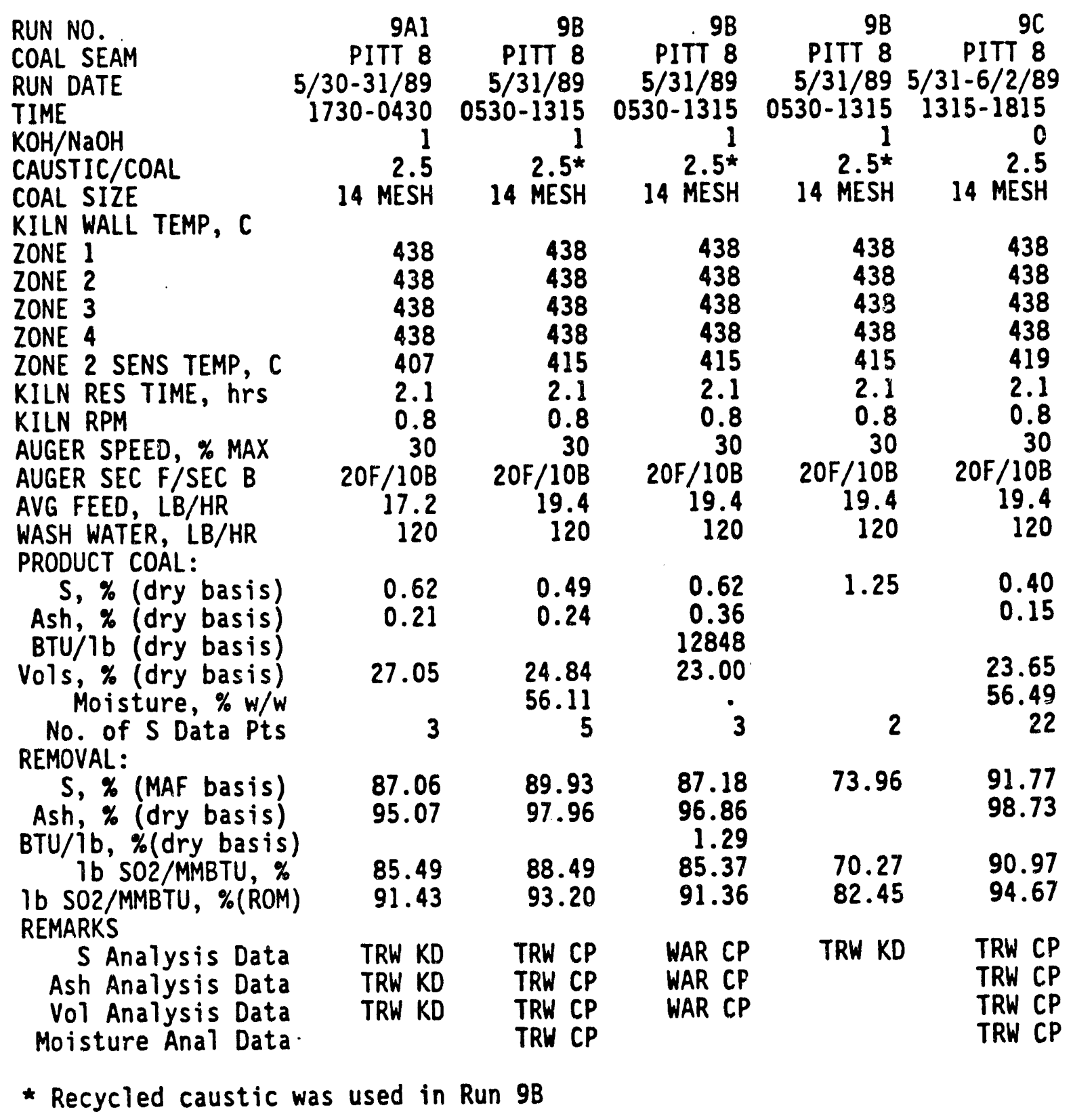


MCL RUN DATA SUMMARY

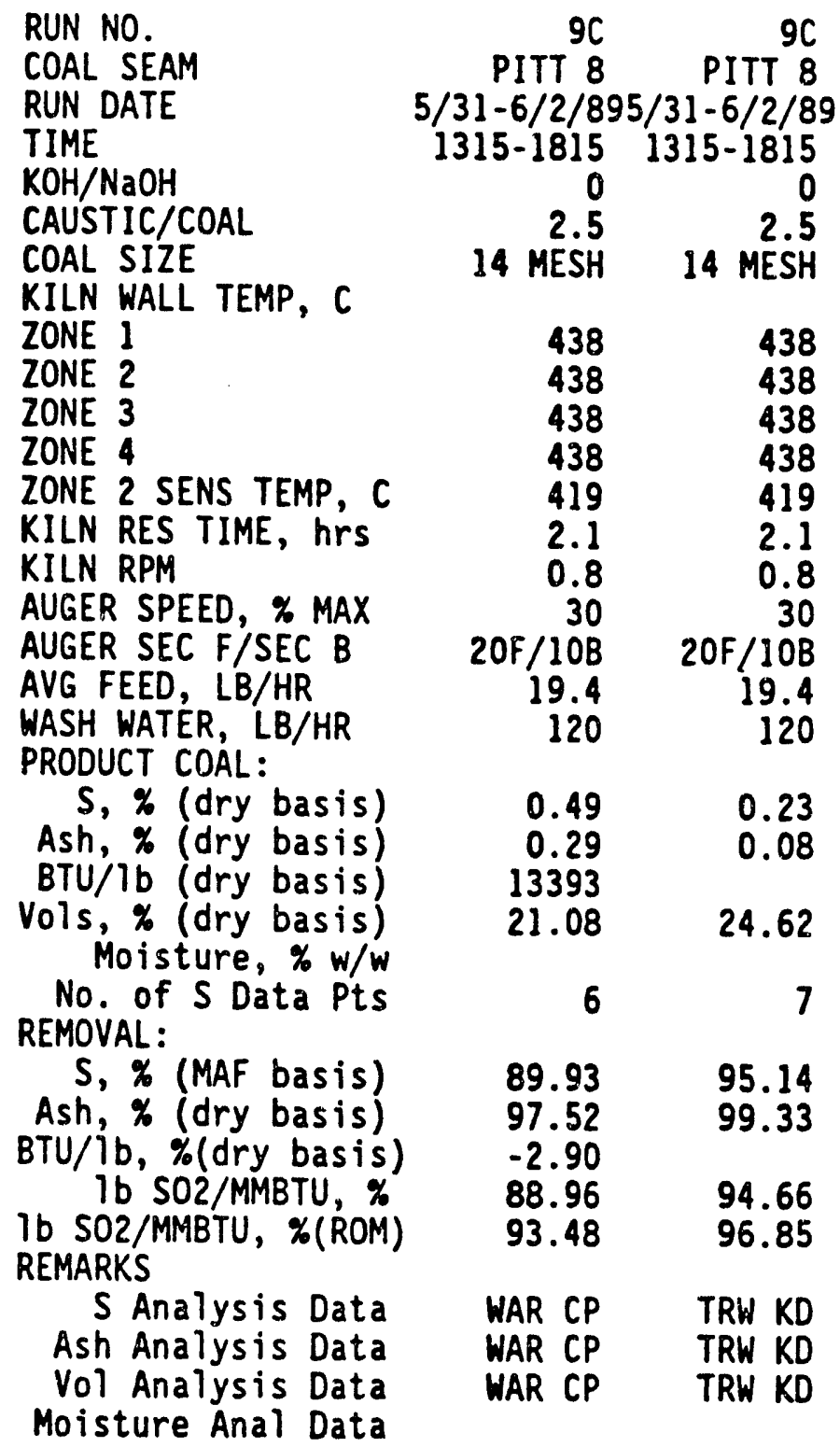


APPENDIX B

PRODUCT COAL ANALYSIS DATA

B-1 
COAL PRODUCT DATA TABULATION

RUN NO. $1 ; 1 / 23-1 / 27 / 89$

RUN NO. 1

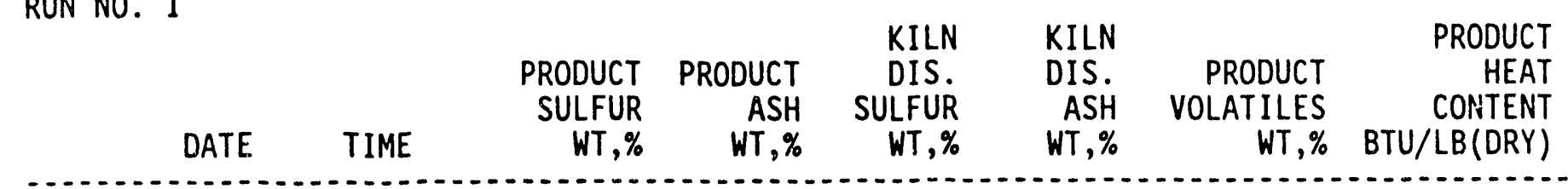

$\begin{array}{lll}1 & 23-J a n & 00 \\ 2 & 23-J a n & 02 \\ 3 & 23-J a n & 04 \\ 4 & 23-J a n & 06 \\ 5 & 23-J a n & 08 \\ 6 & 23-J a n & 10 \\ 7 & 23-J a n & 12 \\ 8 & 23-J a n & 14 \\ 9 & 23-J a n & 16 \\ 10 & 23-J a n & 18 \\ 11 & 23-J a n & 20 \\ 12 & 23-J a n & 22 \\ 13 & 24-J a n & 00 \\ 14 & 24-J a i n & 02 \\ 15 & 24-\text { Jan } & 04 \\ 16 & 34-J a n & 06\end{array}$

$16 \quad 24-$ Jan 06

$17 \quad 24-J a n \quad 08$

18 24-Jan 10

$1.76 \%$

$2.40 \%$

$34.41 \%$

$2.20 \% \quad 2.71 \%$

$37.02 \%$

$\begin{array}{lll}2.05 \% & 2.41 \% & -\end{array}$

24-Jan 12

$1.82 \% \quad 1.87 \%$

$35.54 \%$

$1.91 \% \quad 2.02 \%$

$32.99 \%$

$1.93 \% \quad 2.19 \%$

$33.49 \%$

$2.00 \% \quad 2.07 \%$

$34.57 \%$

$1.87 \% \quad 1.58 \%$

$34.67 \%$

$1.79 \% \quad 1.43 \%$

$35.98 \%$

25 25-Jan 00

$1.65 \%$

$25.16 \%$

$1.61 \% \quad 1.47 \%$

$26.95 \%$

$1.37 \% \quad 1.18 \%$

$27.15 \%$

$1.40 \% \quad 1.16 \%$

$32.31 \%$

$1.41 \% \quad 1.24 \%$

$27.55 \%$

$1.36 \% \quad 1.16 \%$

$24.53 \%$

$1.43 \% \quad 1.27 \%$

$25.88 \%$

$1.39 \% \quad 1.45 \%$

$27.29 \%$

35 25-Jan 20

$36 \quad 25-J a n \quad 22$

$37 \quad 26-J a n \quad 00$

38 26-Jan 02

39 26-Jan 04

40 26-Jan 06

41 26-Jan 08

42 26-Jan 10 
COAL PRODUCT DATA TABULATION

RUN NO. $1 ; 1 / 23-1 / 27 / 89$

RUN NO. 1

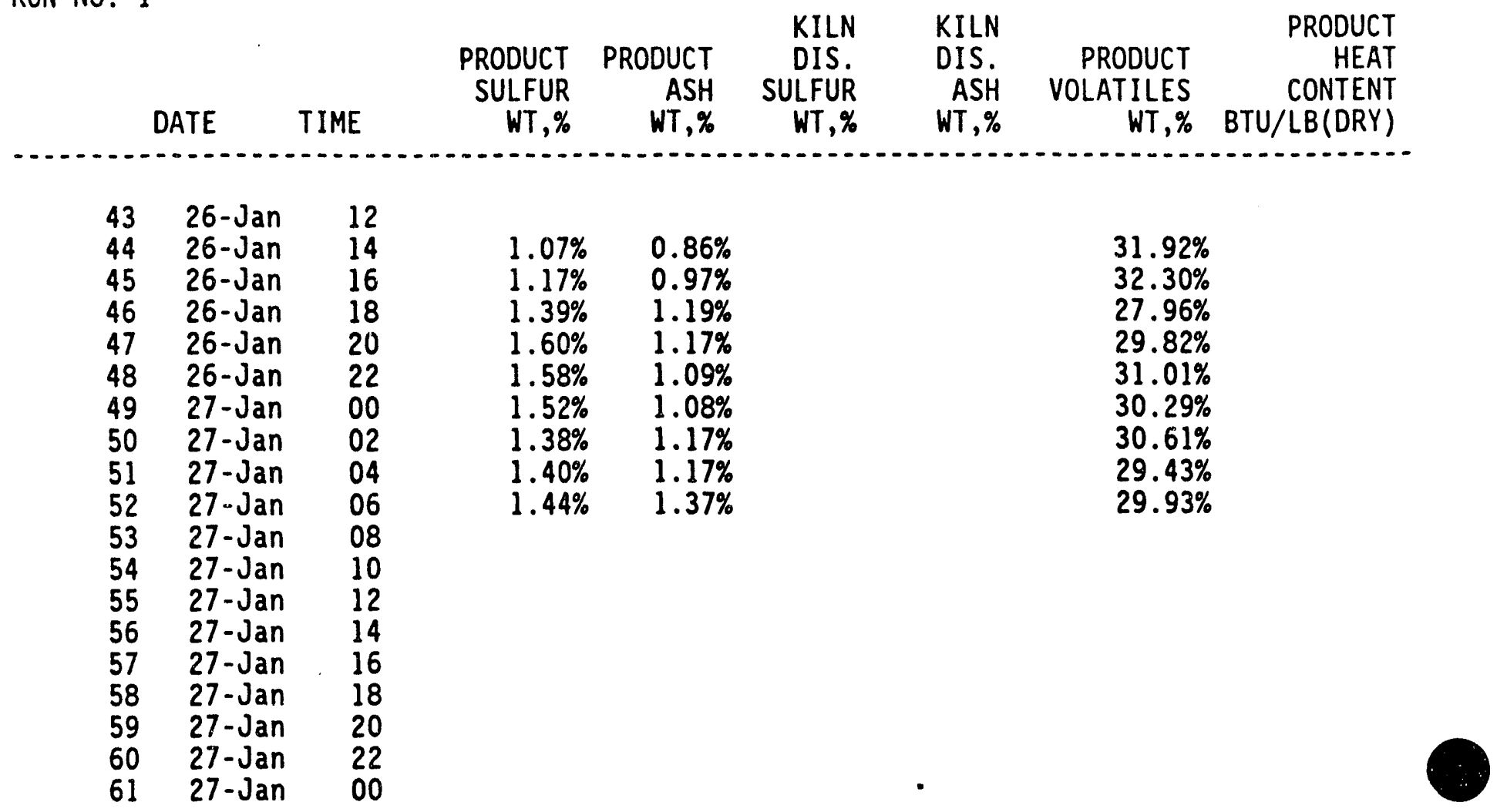


COAL PRODUCT DATA TABULATION

RUN NO. $2 ; 2 / 6-2 / 10 / 89$

RUN NO. 2

\begin{tabular}{|c|c|c|c|c|c|c|c|}
\hline & IME & $\begin{array}{r}\text { PRODUCT } \\
\text { SULFUR } \\
\text { WT } \%\end{array}$ & $\begin{array}{r}\text { PRODUCT } \\
\text { ASH } \\
\text { WT, \% }\end{array}$ & $\begin{array}{l}\text { KILN. } \\
\text { DIS. } \\
\text { SULFUR } \\
\text { WT, \% }\end{array}$ & $\begin{array}{l}\text { KILN } \\
\text { DIS. } \\
\text { ASH } \\
\text { WT, \% }\end{array}$ & $\begin{array}{r}\text { PRODUCT } \\
\text { VOLATILES } \\
\text { WT,\% }\end{array}$ & $\begin{array}{r}\text { PRODUCT } \\
\text { HEAT } \\
\text { CONTENT } \\
\text { BTU } / \mathrm{LB}(D R Y)\end{array}$ \\
\hline
\end{tabular}

\begin{tabular}{|c|}
\hline 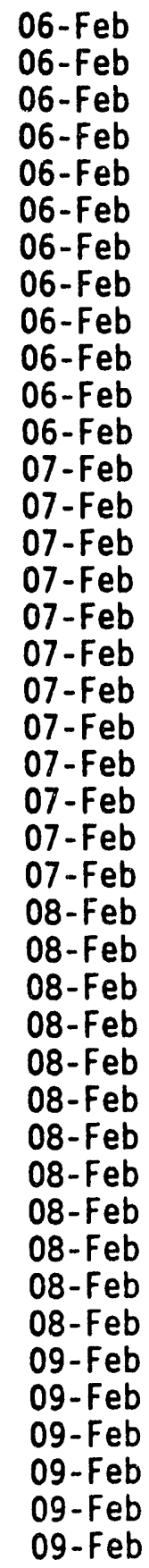 \\
\hline
\end{tabular}

$0.95 \% \quad 0.52 \%$

$0.96 \% \quad 0.56 \%$

$0.94 \% \quad 0.66 \%$

$0.85 \%$

$0.58 \%$

$0.87 \%$

$0.55 \%$

$0.84 \%$

$0.57 \%$

$0.84 \% \quad 0.51 \%$
$32.32 \%$

$30.27 \%$

13036

13148

$27.80 \%$

$27.88 \%$

$30.25 \%$

$32.00 \%$

$31.20 \%$ 
COAL PRODUCT DATA TABULATION

RUN NO. $2 ; 2 / 6-2 / 10 / 89$

RUN NO. 2

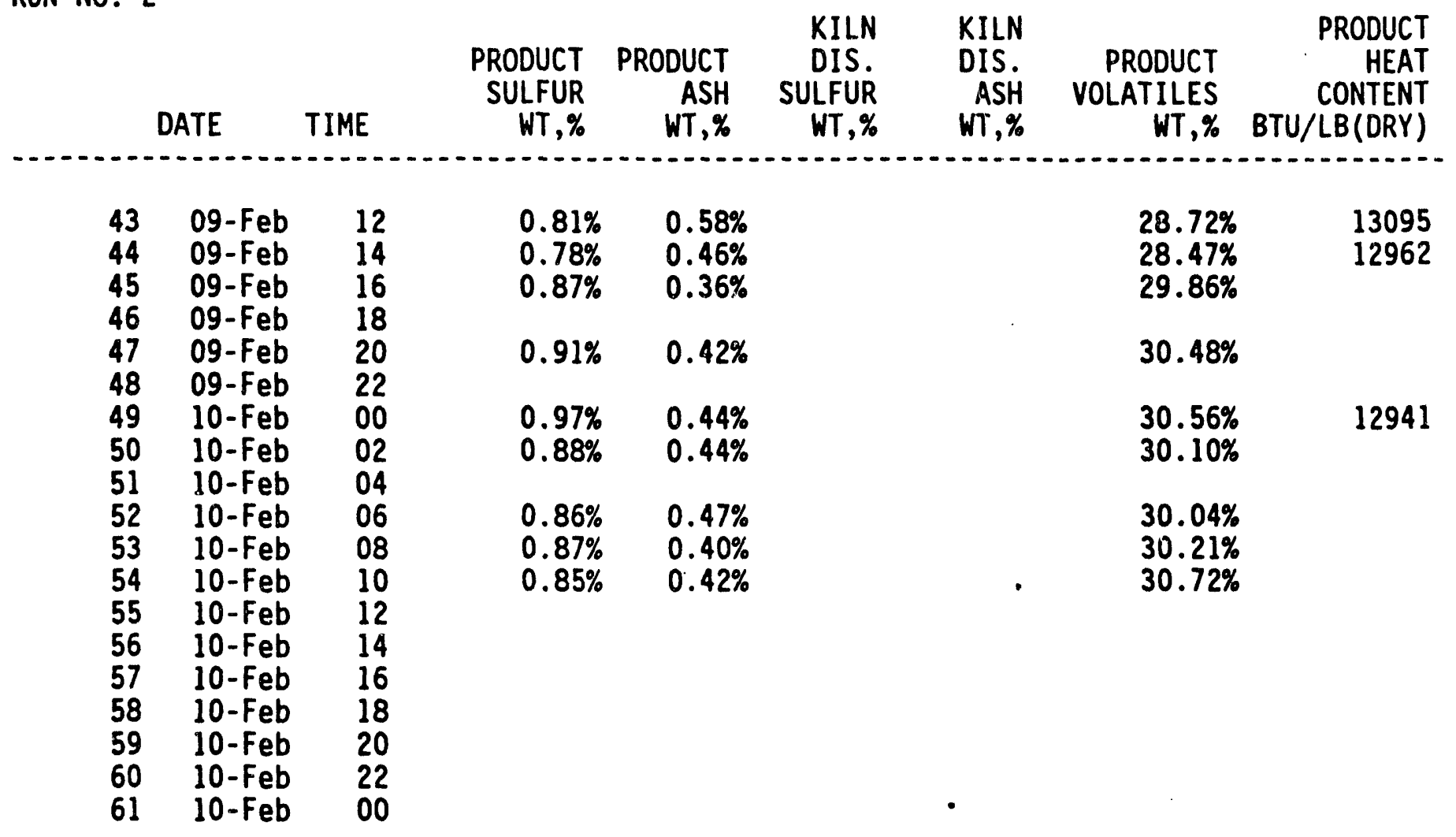


COAL PRODUCT DATA TABULATION

RUN NO. $3 ; 2 / 20-2 / 24 / 89$

RUN NO. 3

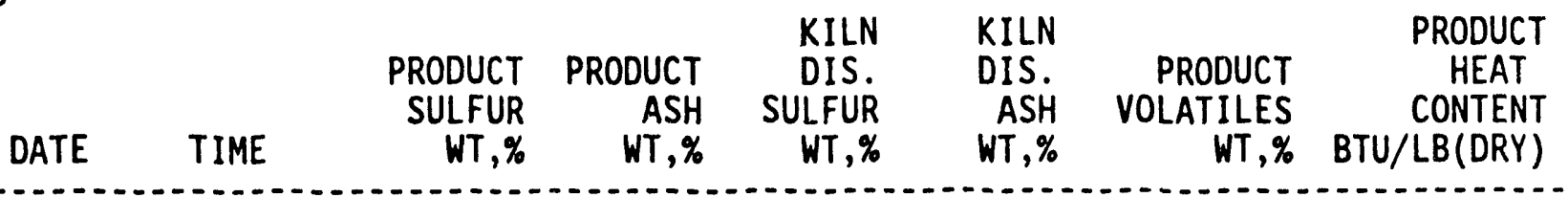

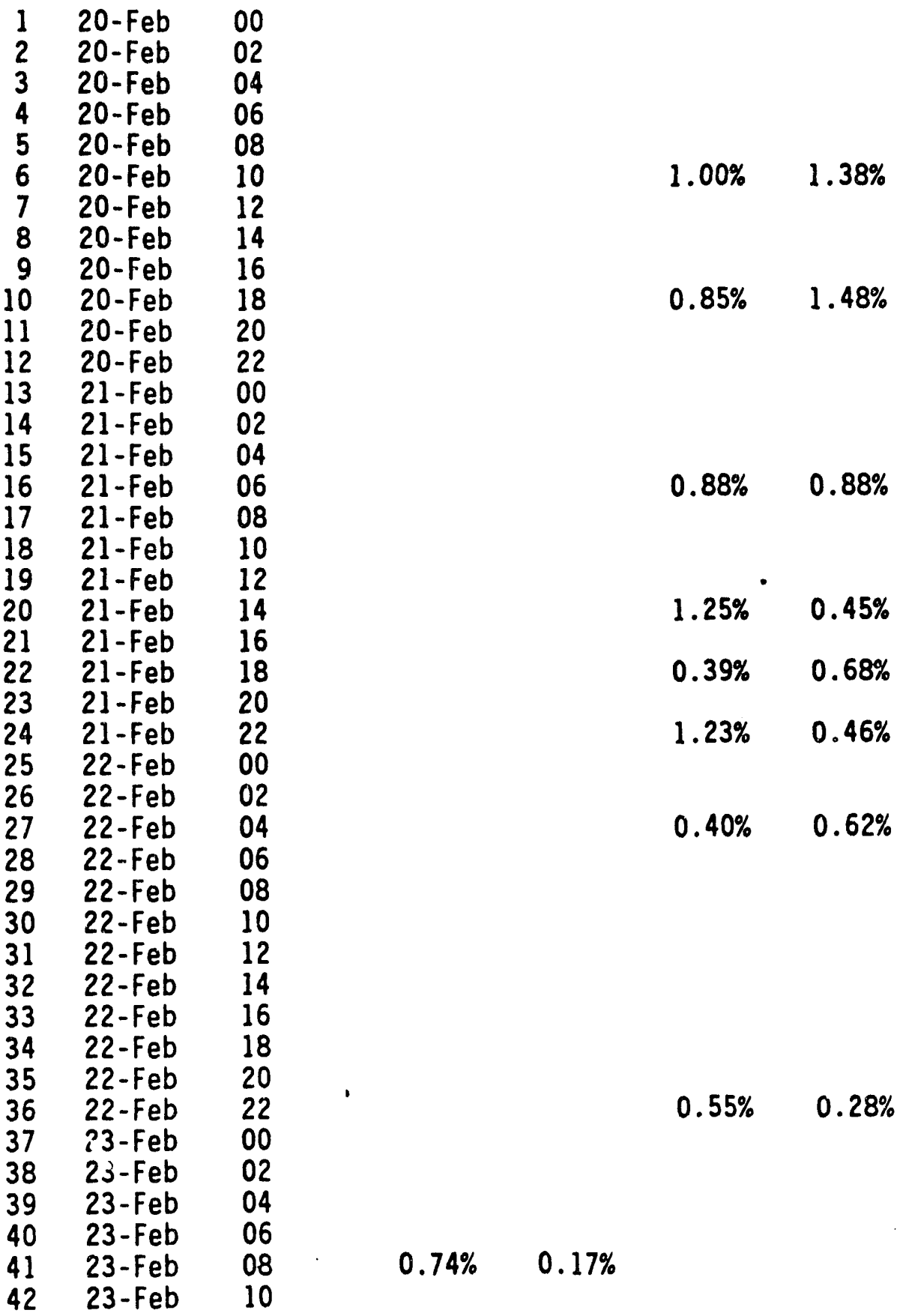

$21.78 \%$ 
COAL PRODUCT DATA TABULATION

RUN NO. $3 ; 2 / 20-2 / 24 / 89$

RUN NO, 3

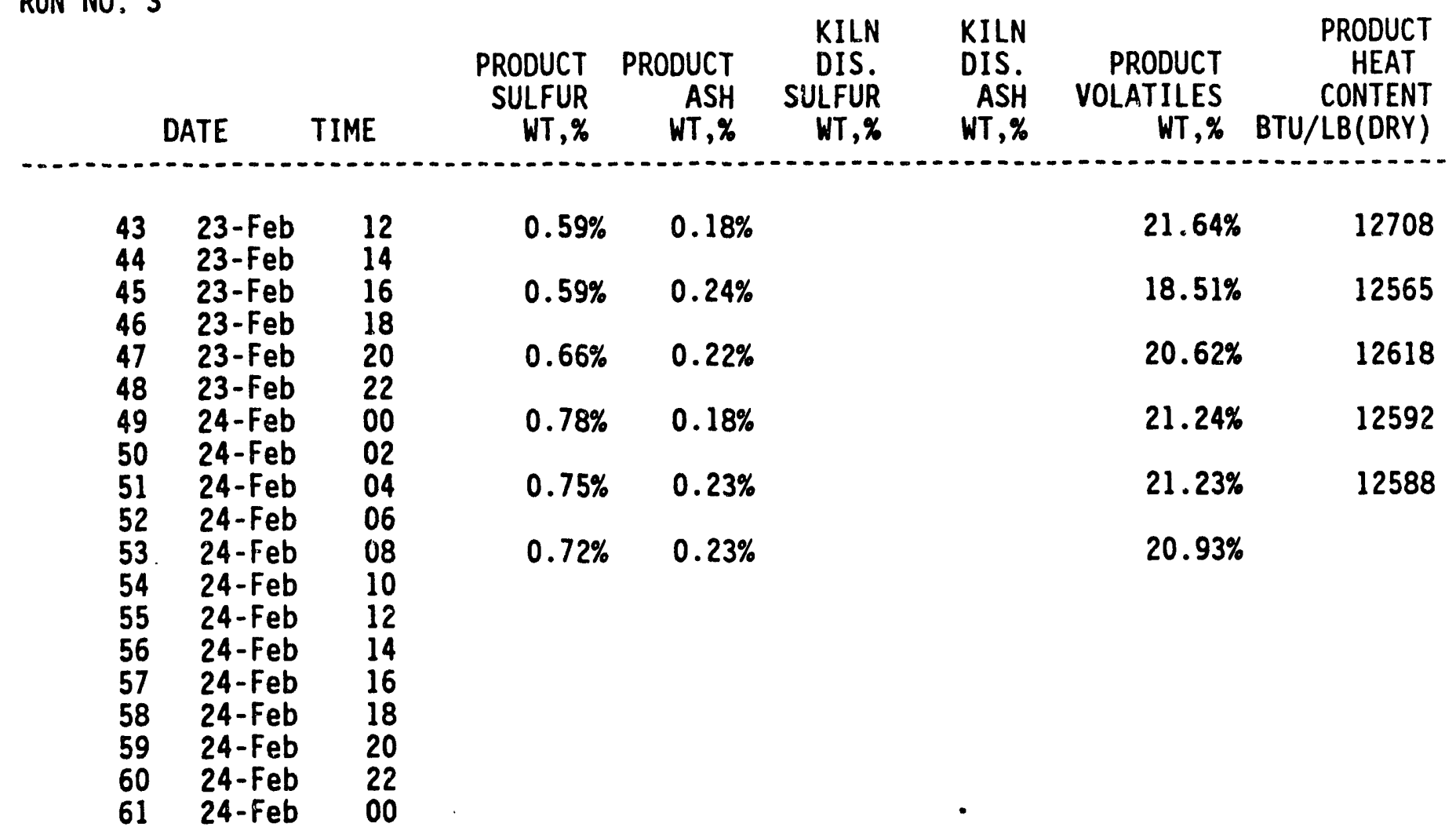


COAL PRODUCT DATA TABULATION

RUN NO. $4 ; 3 / 6-3 / 10 / 89$

RUN NO. 4

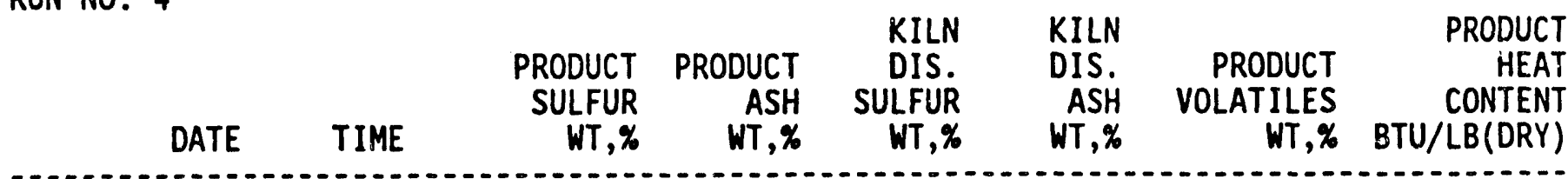

$106-\operatorname{Mar} 00$

2 06-Mar 02

3 06-Mar 04

4 06-Mar 06

5 06-Mar 08

6 06-Mar 10

7 06-Mar 12

8 06-Mar 14

9 06-Mar 16

10 06-Mar 18

11 06-Mar 20

$1206-$ Mar 22

$1307-$ Mar 00

14 07-Mar 02

15 07-Mar 04

16 07-Mar 06

$1707-$ Mar 08

$1807-$ Mar 10

$1907-$ Mar 12

20 07-Mar 14

21 07-Mar 16

22 07-Mar 18

23 07-Mar 20

07-Mar 22

08-Mar 00

08-Mar 02

08-Mar 04

08-Mar 06

08-Mar 08

08-Mar 10

08-Mar 12

08-Mar 14

08-Mar 16

08-Mar 18

08-Mar 20

08-Mar 22

09-Mar 00

09-Mar 02

09-Mar 04

09-Mar 06

09-Mar 08

41 09-Mar 10
$1.74 \%$

$0.79 \%$

$0.76 \%$

$0.82 \%$

$1.11 \%$

$1.30 \%$

$1.29 \%$

$1.63 \%$

$1.60 \%$

$1.37 \%$

$1.40 \%$

$1.34 \%$

$1.23 \%$

$1.12 \%$

$1.13 \%$

$1.17 \%$

$1.31 \%$

$1.27 \%$

$1.25 \%$

$1.21 \%$

$1.20 \%$

$0.43 \%$

$0.51 \% \quad 1.19 \%$

$22.72 \%$

$23.95 \%$

$24.53 \%$

$25.51 \%$

$25.99 \%$

$23.25 \%$

$24.89 \%$

$26.37 \%$

$25.62 \%$

$25.15 \%$

$0.69 \%$

$0.63 \%$

$0.84 \%$

$22.96 \%$

$23.71 \%$

$24.46 \%$

$0.46 \%$

$0.46 \%$

$0.51 \%$

$0.57 \%$

$1.41 \%$

$0.54 \%$

$24.42 \%$

$22.75 \%$

$24.48 \%$

$0.54 \%$

$0.49 \%$

$0.54 \%$

$0.53 \%$

$1.45 \%$

$0.80 \%$

$21.49 \%$

$22.00 \%$

$22.44 \%$

$24.64 \%$

$1.02 \%$

$0.59 \%$

14116

14306

14302

14217

14191

14213

14224

$1.14 \% \quad 0.41 \%$

$24.24 \%$

14201 
COAL PRODUCT DATA TABULATION

RUN NO. $4 ; 3 / 6-3 / 10 / 89$

RUN NO. 4

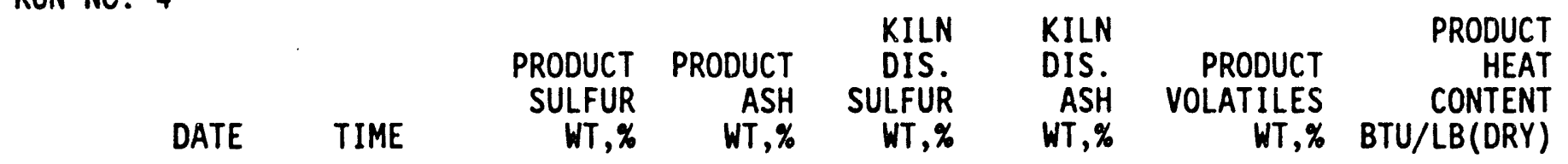

\begin{tabular}{|c|c|c|c|c|c|c|}
\hline $\begin{array}{ll}43 & 09-M a r \\
44 & 09-M a r \\
45 & 09-M a r \\
46 & 09-M a r \\
47 & 09-M a r \\
48 & 09-M a r \\
49 & 10-M a r \\
50 & 10-M a r \\
51 & 10-M a r \\
52 & 10-M a r \\
53 & 10-M a r \\
54 & 10-M a r \\
55 & 10-M a r \\
56 & 10-M a r \\
57 & 10-M a r \\
58 & 10-M a r \\
59 & 10-M a r \\
60 & 10-M a r \\
61 & 10-M a r\end{array}$ & $\begin{array}{l}12 \\
14 \\
16 \\
18 \\
20 \\
22 \\
00 \\
02 \\
04 \\
06 \\
08 \\
10 \\
12 \\
14 \\
16 \\
18 \\
20 \\
22 \\
00\end{array}$ & $\begin{array}{l}1.19 \% \\
1.32 \% \\
1.39 \% \\
1.34 \% \\
1.32 \% \\
1.37 \% \\
1.42 \% \\
1.44 \% \\
1.43 \% \\
1.37 \% \\
1.32 \% \\
1.19 \% \\
1.14 \% \\
1.07 \%\end{array}$ & $\begin{array}{l}0.50 \% \\
0.53 \% \\
0.74 \% \\
0.63 \% \\
0.84 \% \\
0.66 \% \\
0.70 \% \\
0.77 \% \\
0.73 \% \\
0.69 \% \\
0.74 \% \\
0.59 \% \\
0.54 \% \\
0.65 \%\end{array}$ & $\begin{array}{l}1.28 \% \\
1.11 \% \\
1.34 \% \\
1.40 \%\end{array}$ & $\begin{array}{l}24.93 \% \\
26.44 \% \\
26.28 \% \\
26.64 \% \\
28.12 \% \\
28.62 \% \\
28.26 \% \\
28.25 \% \\
25.48 \% \\
25.99 \% \\
26.39 \% \\
27.08 \% \\
26.92 \% \\
23.86 \%\end{array}$ & 14268 \\
\hline
\end{tabular}


COAL PRODUCT DATA TABULATION

RUN NO. $5 ; 3 / 20-3 / 24 / 89$

RUN NO. 5

\begin{tabular}{|c|c|c|c|c|c|c|c|c|}
\hline & ATE & TIME & $\begin{array}{r}\text { PRODUCT } \\
\text { SULFUR } \\
\text { WT, } \%\end{array}$ & $\begin{array}{r}\text { PRODUCT } \\
\text { ASH } \\
\text { WT, } \%\end{array}$ & $\begin{array}{l}\text { KILN } \\
\text { DIS. } \\
\text { SULFUR } \\
\text { WT, \% }\end{array}$ & $\begin{array}{l}\text { KILN } \\
\text { DIS. } \\
\text { ASH } \\
\text { WT, \% }\end{array}$ & $\begin{array}{r}\text { PRODUCT } \\
\text { VOLATILES } \\
\text { WT,\% }\end{array}$ & $\begin{array}{r}\text { PRODUCT } \\
\text { HEAT } \\
\text { CONTENT } \\
\text { BTU/LB(DRY) }\end{array}$ \\
\hline $\begin{array}{r}1 \\
2 \\
3 \\
4 \\
5 \\
6 \\
7 \\
8 \\
9 \\
10 \\
11 \\
12 \\
13 \\
14 \\
15 \\
16 \\
17 \\
18 \\
19 \\
20 \\
21 \\
22 \\
23 \\
24 \\
25 \\
26 \\
27 \\
28 \\
29 \\
30 \\
31 \\
32 \\
33 \\
34 \\
35 \\
36 \\
37 \\
38 \\
39 \\
40 \\
41 \\
42\end{array}$ & $\begin{array}{l}\text { 20-Mar } \\
20-M a r \\
20-M a r \\
20-M a r \\
20-M a r \\
20-M a r \\
20-M a r \\
20-M a r \\
20-M a r \\
20-M a r \\
20-M a r \\
20-M a r \\
21-M a r \\
21-M a r \\
21-M a r \\
21-M a r \\
21-M a r \\
21-M a r \\
21-M a r \\
21-M a r \\
21-M a r \\
21-M a r \\
21-M a r \\
21-M a r \\
22-M a r \\
22-M a r \\
22-M a r \\
22-M a r \\
22-M a r \\
22-M a r \\
22-M a r \\
22-M a r \\
22-M a r \\
22-M a r \\
22-M a r \\
22-M a r \\
23-M a r \\
23-M a r \\
23-M a r \\
23-M a r \\
23-M a r \\
23-M a r\end{array}$ & $\begin{array}{l}00 \\
02 \\
04 \\
06 \\
08 \\
10 \\
12 \\
14 \\
16 \\
18 \\
20 \\
22 \\
00 \\
02 \\
04 \\
06 \\
08 \\
10 \\
12 \\
14 \\
16 \\
18 \\
20 \\
22 \\
00 \\
02 \\
07 \\
06 \\
08 \\
10 \\
12 \\
14 \\
16 \\
18 \\
20 \\
22 \\
00 \\
02 \\
04 \\
06 \\
08 \\
10\end{array}$ & $\begin{array}{l}1.27 \% \\
1.31 \% \\
1.28 \% \\
1.50 \% \\
1.56 \% \\
1.41 \% \\
1.36 \% \\
1.30 \% \\
1.25 \% \\
1.22 \% \\
1.14 \% \\
1.17 \% \\
1.10 \% \\
1.33 \% \\
1.44 \% \\
1.42 \% \\
1.37 \% \\
1.36 \% \\
1.31 \% \\
1.31 \% \\
1.22 \% \\
1.13 \% \\
1.20 \% \\
1.21 \% \\
1.33 \% \\
1.41 \% \\
1.42 \% \\
1.38 \% \\
1.53 \% \\
1.67 \% \\
1.53 \% \\
1.26 \% \\
1.21 \% \\
1.15 \% \\
1.17 \% \\
1.20 \% \\
1.15 \%\end{array}$ & $\begin{array}{l}1.28 \% \\
1.31 \% \\
1.28 \% \\
1.41 \% \\
1.43 \% \\
1.26 \% \\
1.19 \% \\
1.35 \% \\
1.10 \% \\
1.15 \% \\
1.09 \% \\
0.91 \% \\
0.73 \% \\
0.61 \% \\
0.67 \% \\
0.71 \% \\
0.69 \% \\
0.70 \% \\
0.62 \% \\
0.61 \% \\
0.66 \% \\
0.65 \% \\
0.50 \% \\
0.58 \% \\
0.66 \% \\
0.57 \% \\
0.60 \% \\
0.58 \% \\
0.73 \% \\
.1 .14 \% \\
0.75 \% \\
0.57 \% \\
0.43 \% \\
0.45 \% \\
0.45 \% \\
0.40 \% \\
0.39 \%\end{array}$ & $\begin{array}{l}1.96 \% \\
1.38 \%\end{array}$ & $\begin{array}{l}0.75 \% \\
0.90 \% \\
0.71 \% \\
0.41 \%\end{array}$ & $\begin{array}{l}24.47 \% \\
24.89 \% \\
25.09 \% \\
25.43 \% \\
27.00 \% \\
23.62 \% \\
24.27 \% \\
24.25 \% \\
24.50 \% \\
25.23 \% \\
22.37 \% \\
23.18 \% \\
23.60 \% \\
24.96 \% \\
25.51 \% \\
25.43 \% \\
24.86 \% \\
22.99 \% \\
23.73 \% \\
24.41 \% \\
24.71 \% \\
24.66 \% \\
23.52 \% \\
24.99 \% \\
27.08 \% \\
26.22 \% \\
23.11 \% \\
23.84 \% \\
24.61 \% \\
26.98 \% \\
25.79 \% \\
23.14 \% \\
23.85 \% \\
19.34 \% \\
19.96 \% \\
20.64 \% \\
22.01 \%\end{array}$ & $\begin{array}{l}14052 \\
14059\end{array}$ \\
\hline
\end{tabular}


COAL PRODUCT DATA TABULATION

RUN NO. $5 ; 3 / 20$ - 3/24/89

RUN NO. 5

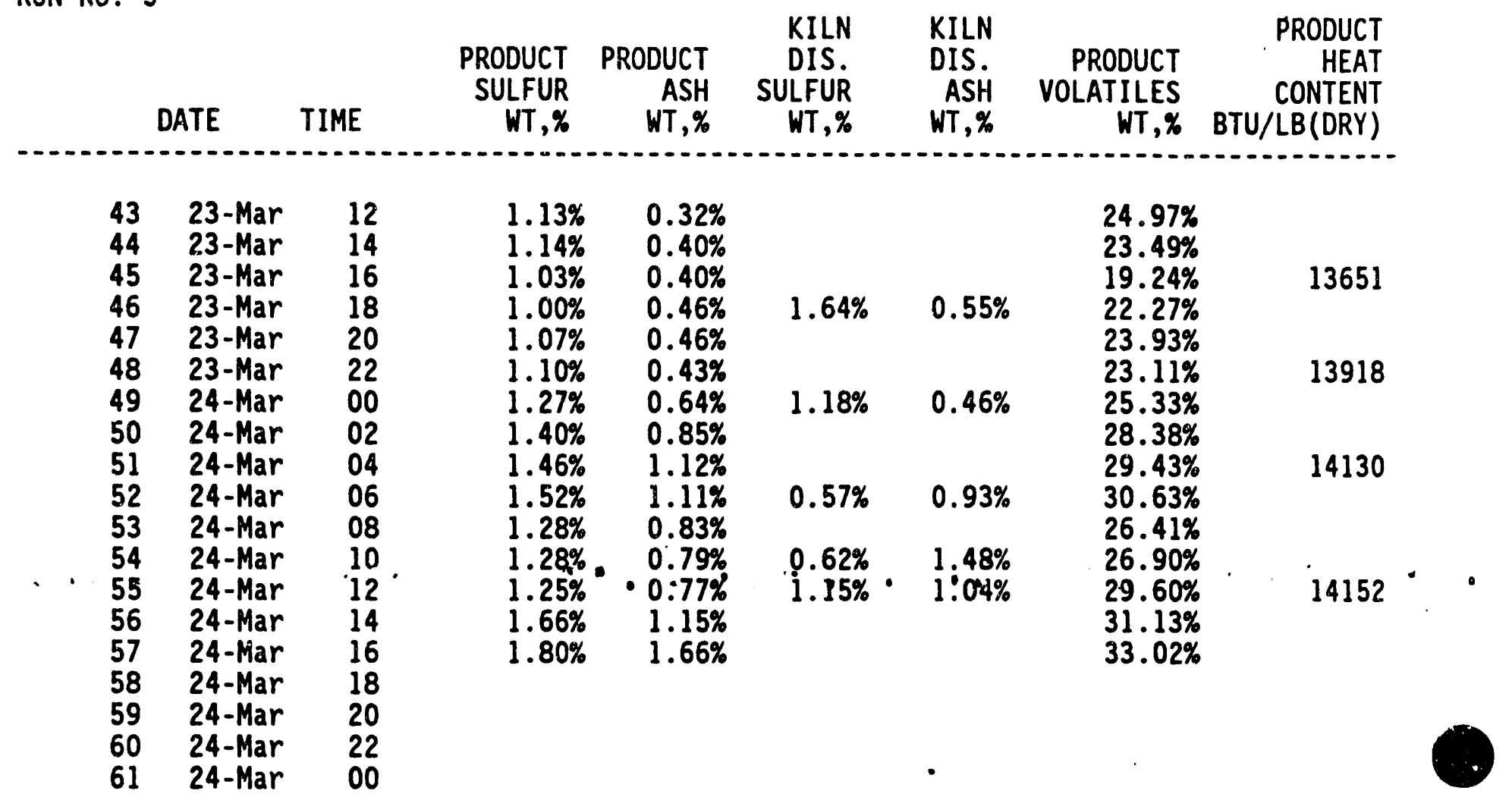


COAL PRODUCT DATA TABULATION

RUN NO. $6 ; 4 / 3$ - 4/7/89

RUN NO. 6

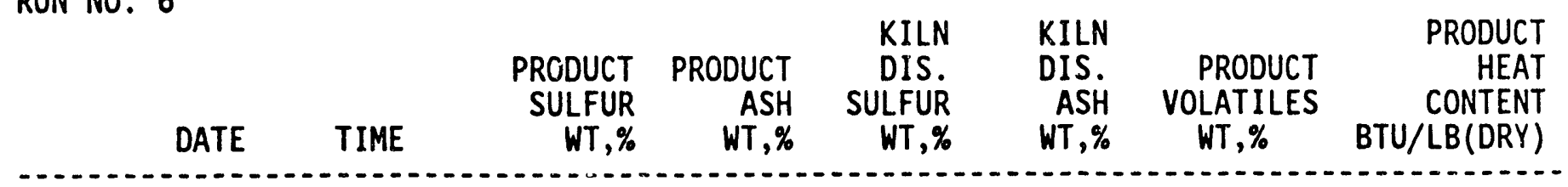

1 03-Apr 00

2 03-Apr 02

3 03-Apr 04

4 03-Apr 06

5 03-Apr 08

6 03-Apr 10

7 03-Apr 12

8 03-Apr 14

9 03-Apr 16

10 03-Apr 18

$1.50 \% \quad 1.22 \%$

$25.99 \%$

$1.52 \% \quad 1.02 \%$

$27.02 \%$

$1.69 \% \quad 1.14 \%$

$27.80 \%$

11 03-Apr 20

$1.70 \% \quad 1.18 \%$

$29.78 \%$

13 04-Apr 00

14 04-Apr 02

15 04-Apr 04

16 04-Apr 06

17 04-Apr 08

18 04-Apr 10

19 04-Apr 12

20 04-Apr 14

$1.03 \%$

$1.44 \%$

$1.43 \%$

$1.48 \%$

$1.34 \%$

$1.68 \%$

$1.81 \%$

$0.55 \%$

$0.62 \%$

$0.61 \%$

$0.37 \%$

$0.52 \%$

$0.75 \%$

$1.03 \%$

05-Apr 00

05-Apr 02

05-Apr 04

05-Apr 06

05-Apr 08

05-Apr 10

05-Apr 12

05-Apr 14

05-Apr 16

05-Apr 18

05-Apr 20

05-Apr 22

06-Apr 00

06-Apr 02

06-Apr 04

06-Apr 06

06-Apr 08

06-Apr 10
$1.45 \%$
$1.74 \%$
$1.78 \%$
$1.76 \%$
$1.62 \%$
$1.41 \%$
$1.79 \%$
$1.86 \%$
$1.78 \%$
$1.75 \%$
$1.71 \%$
$1.78 \%$
$1.67 \%$

$0.85 \%$

$0.89 \%$

$0.87 \%$

$0.75 \%$

$0.65 \%$

$0.63 \%$

$0.99 \%$

$0.98 \%$

$0.94 \%$

$0.91 \%$

$0.76 \%$

$0.83 \%$

$0.77 \%$
13948

$25.64 \%$

$23.47 \%$

$27.34 \%$

$25.44 \%$
$28.94 \%$

$32.06 \%$

$32.79 \%$

$39.46 \%$

$33.16 \%$

$27.57 \%$

$31.63 \%$

$31.87 \%$

$37.11 \%$

$31.53 \%$

$32.75 \%$

$29.53 \%$

$35.91 \%$ 
COAL PRODUCT DATA TABULATION

RUN NO. $6 ; 4 / 3-4 / 7 / 89$

RUN NO. 6

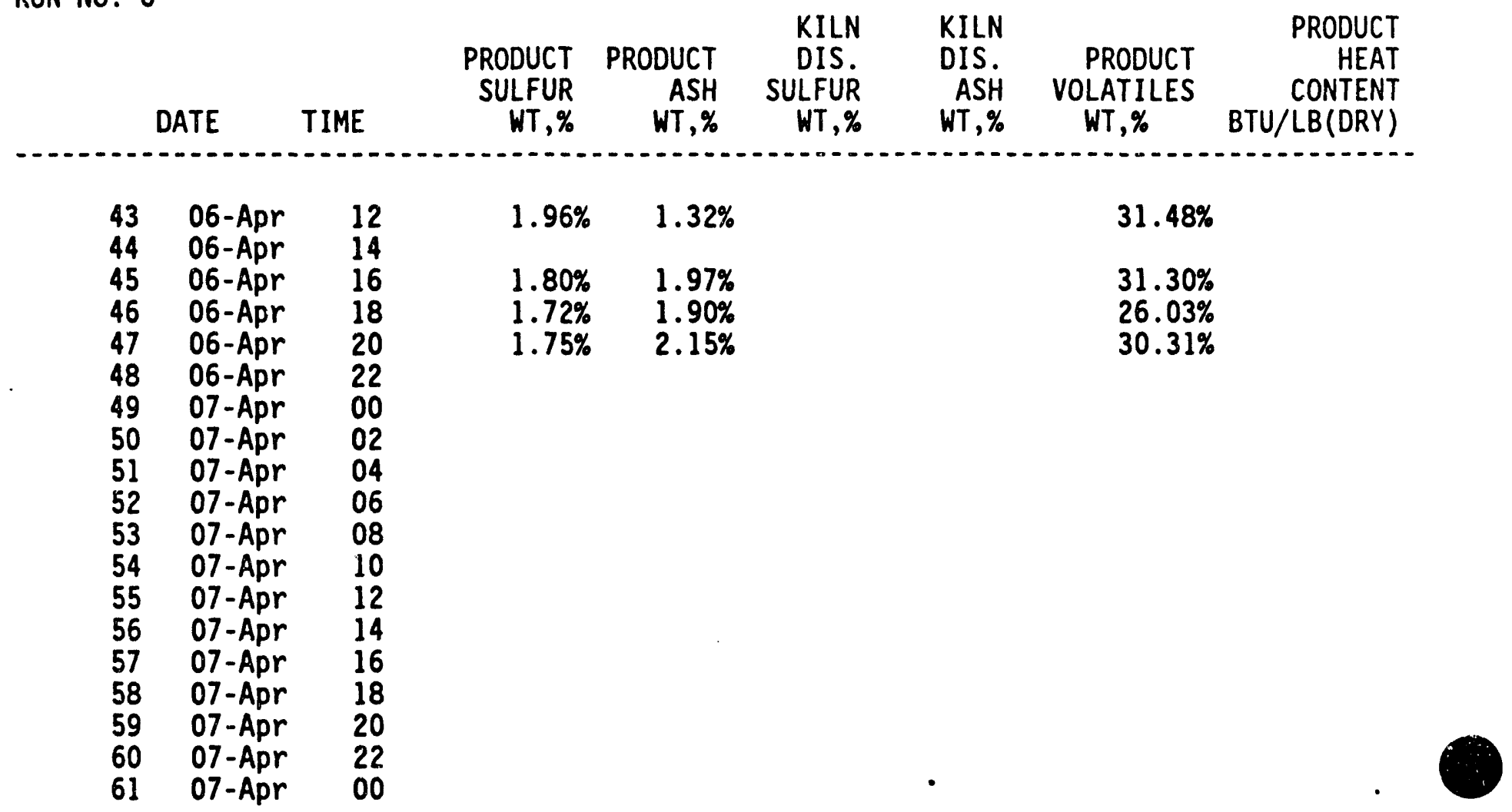


COAL PRODUCT DATA TABULATION

RUN NO. 7; 5/1 - 5/5/89

RUN NO. 7

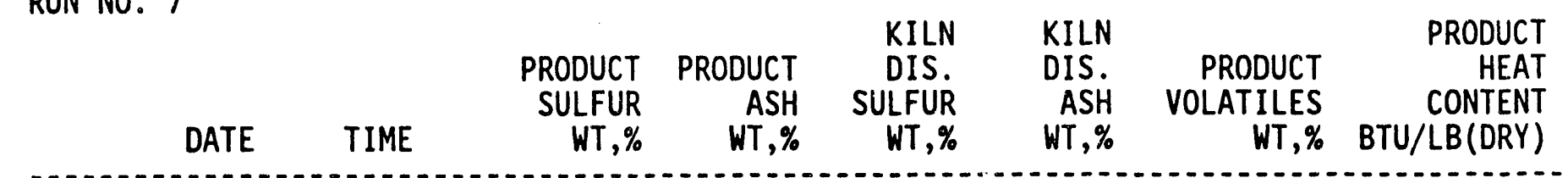

$\begin{array}{rll}1 & 01-\text { May } & 00 \\ 2 & 01-\text { May } & 02 \\ 3 & 01-\text { May } & 04 \\ 4 & 01-\text { May } & 06 \\ 5 & 01-\text { May } & 08 \\ 6 & 01-\text { May } & 10 \\ 7 & 01-\text { May } & 12 \\ 8 & 01-\text { May } & 14 \\ 9 & 01-\text { May } & 16 \\ 10 & 01-\text { May } & 18\end{array}$

$\begin{array}{lll}10 & 01-\text { May } & 18 \\ 11 & 01-\text { May } & 20\end{array}$

12 01-May 22

13 02-May 00

14 02-May 02

15 02-May 04

16 02-May 06

17 02-May 08

18 02-May 10

19 02-May 12

$20 \quad 02-$ May 14

$21 \quad 02-$ May 16

$22 \quad 02-$ May 18

23 02-May 20

24 02-May 22

25 03-May 00

26 03-May 02

27 03-May 04

28 03-May 06

29 03-May 08

30 03-May 10

31 03-May 12

32 03-May 14

33 03-May 16

34 03-May 18

35 03-May 20

36 03-May 22

37 04-May 00

38 04-May 02

39 04-May 04

40 04-May 06

41 04-May 08

42 04-May 10

$\begin{array}{ll}1.08 \% & 0.49 \% \\ 1.12 \% & 0.54 \% \\ 0.46 \% & 1.10 \% \\ 0.51 \% & 0.63 \% \\ 0.45 \% & 0.49 \% \\ 0.84 \% & 0.52 \%\end{array}$

$0.85 \%$

$0.88 \%$

$0.61 \%$

$0.66 \%$

$0.76 \%$

$0.59 \%$

$0.51 \%$

$0.72 \%$

$0.46 \%$

$0.71 \%$

$0.40 \%$

$0.59 \%$

$0.46 \%$

$0.29 \%$

$0.57 \%$

$0.58 \%$

$0.72 \%$

$0.39 \%$

$0.45 \%$

$0.70 \%$

$0.53 \%$

$0.66 \%$

$0.45 \%$

$0.67 \%$

$0.51 \%$

$0.72 \%$

$0.57 \%$

$0.75 \%$

$0.49 \%$

$0.74 \%$

$0.37 \%$

$0.70 \%$

$0.50 \%$

$0.69 \%$

$0.26 \%$

$0.68 \%$

$0.24 \%$

$0.62 \%$

$0.27 \%$

$0.70 \%$

$0.34 \%$

$0.77 \%$

$0.52 \%$

$0.82 \%$

$0.93 \%$

$0.85 \%$

$0.86 \%$

$0.86 \%$

$0.82 \%$

$0.90 \%$

$1.19 \%$

$0.84 \%$

$1.16 \%$

$0.73 \%$

$0.97 \%$

$0.64 \%$

$0.33 \%$

$0.40 \%$

$0.57 \%$

$0.24 \%$

$0.53 \%$

$0.21 \%$

$0.61 \%$

$0.25 \%$

$0.33 \%$

$0.63 \%$

$0.19 \%$

$0.64 \%$

$24.43 \%$

$25.13 \%$

$23.82 \%$

$27.31 \%$

$28.26 \%$

$25.49 \%$

$26.30 \%$

$24.63 \%$

$25.54 \%$

$24.15 \%$

$25.62 \%$

$26.83 \%$

$28.60 \%$

$26.63 \%$

$27.58 \%$

$24.82 \%$

$24.76 \%$

$25.92 \%$

$22.77 \%$

$25.90 \%$

$24.90 \%$

$27.31 \%$

$28.76 \%$

$30.19 \%$

$26.49 \%$

$29.77 \%$

$30.52 \%$

$23.60 \%$

$27.05 \%$

$25.86 \%$

$24.83 \%$

$27.32 \%$
13350

13247

13291

13246

13230

13208

13243 
COAL PRODUCT DATA TABULATION

RUN NO. $7 ; 5 / 1$ - 5/5/89

RUN NO. 7

\begin{tabular}{|c|c|c|c|c|c|c|c|c|}
\hline & ATE & TIME & $\begin{array}{r}\text { PRODUCT } \\
\text { SULFUR } \\
\text { WT, } \%\end{array}$ & $\begin{array}{r}\text { PRODUCT } \\
\text { ASH } \\
W T, \%\end{array}$ & $\begin{array}{l}\text { KILN } \\
\text { DIS. } \\
\text { SULFUR } \\
\text { WT,\% }\end{array}$ & $\begin{array}{l}\text { KILN } \\
\text { DIS. } \\
\text { ASH } \\
\text { WT,\% }\end{array}$ & $\begin{array}{r}\text { PRODUCT } \\
\text { VOLATILES } \\
\text { WT, } \%\end{array}$ & $\begin{array}{r}\text { PRODUCT } \\
\text { HEAT } \\
\text { CONTENT } \\
\text { BTU/LB(DRY) }\end{array}$ \\
\hline $\begin{array}{l}43 \\
44 \\
45 \\
46 \\
47 \\
48 \\
49 \\
50 \\
51 \\
52 \\
53 \\
54 \\
55 \\
56 \\
57 \\
58 \\
59 \\
60 \\
61\end{array}$ & 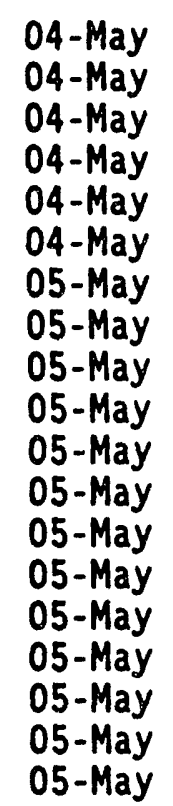 & $\begin{array}{l}12 \\
14 \\
16 \\
18 \\
20 \\
22 \\
00 \\
02 \\
04 \\
06 \\
08 \\
10 \\
12 \\
14 \\
16 \\
18 \\
20 \\
22 \\
00\end{array}$ & $\begin{array}{l}0.62 \% \\
0.54 \% \\
0.52 \% \\
0.57 \% \\
0.61 \% \\
0.65 \% \\
0.62 \% \\
0.68 \% \\
0.70 \% \\
0.68 \% \\
0.52 \% \\
0.50 \% \\
0.40 \% \\
0.82 \% \\
1.32 \%\end{array}$ & $\begin{array}{l}0.25 \% \\
0.32 \% \\
0.29 \% \\
0.38 \% \\
0.43 \% \\
0.56 \% \\
0.48 \% \\
0.73 \% \\
0.92 \% \\
1.27 \% \\
0.56 \% \\
0.55 \% \\
0.32 \% \\
0.90 \% \\
1.42 \%\end{array}$ & $\begin{array}{l}0.66 \% \\
1.50 \%\end{array}$ & $\begin{array}{l}0.34 \% \\
1.09 \%\end{array}$ & $\begin{array}{l}29.53 \% \\
31.74 \% \\
31.30 \% \\
24.87 \% \\
28.79 \% \\
30.16 \% \\
27.28 \% \\
27.71 \% \\
29.59 \% \\
28.45 \% \\
28.28 \% \\
27.19 \% \\
30.07 \% \\
30.21 \% \\
29.05 \%\end{array}$ & $\begin{array}{l}13353 \\
13268 \\
13065 \\
12976\end{array}$ \\
\hline
\end{tabular}


COAL PRODUCT DATA TUBULATION

RUN NO. 8; 5/15 - 5/19/89

RUN NO. 8

\begin{tabular}{|c|c|c|c|c|c|c|c|}
\hline & & $\begin{array}{r}\text { PRODUCT } \\
\text { SULFUR } \\
\text { WT, \% }\end{array}$ & $\begin{array}{r}\text { PRODUCT } \\
\text { ASH } \\
\text { WT,\% }\end{array}$ & $\begin{array}{l}\text { KILN. } \\
\text { DIS. } \\
\text { SULFUR } \\
\text { WT, \% }\end{array}$ & $\begin{array}{l}\text { KILN } \\
\text { DIS. } \\
\text { ASH } \\
\text { WT, \% }\end{array}$ & $\begin{array}{r}\text { PRODUCT } \\
\text { VOLATILES } \\
\text { WT, } \%\end{array}$ & $\begin{array}{c}\text { PRODUCT } \\
\text { HEAT } \\
\text { CONTENT } \\
\text { BTU/LB(DRY) }\end{array}$ \\
\hline
\end{tabular}

1 15-May 00

2 15-May 02

3 15-May 04

4 15-May 06

5 15-May 08

6 15-May 10

7 15-May 12

8 15-May 14

9 15-May 16

10 15-May 18

11 15-May 20

12 15-May 22

13 16-May 00

14 16-May 02

15 16-May 04

16 16-May 06

17 16-May 08

18 16-May 10

$19 \quad 16-$ May 12

2016 -May 14

21 16-May 16

22 16-May 18

23 16-May 20

24 16-May 22

25 17-May 00

$26 \quad 17$-May 02

27 17-May 04

28 17-May 06

29 17-May 08

30 17-May 10

31 17-May 12

32 17-May 14

33 17-May 16

$34 \quad 17-$ May 18

35 17-May 20

36 17-May 22

37 18-May 00

38 18-May 02

39 18-May 04

40 18-May 06

41 18-May 08

42 18-May 10

$\begin{array}{ll}0.96 \% & 1.39 \% \\ 0.66 \% & 1.10 \% \\ 0.53 \% & \\ 1.07 \% & \end{array}$

$1.12 \% \quad 0.92 \%$

$1.34 \% \quad 1.14 \%$

$1.38 \% \quad 1.31 \%$

$1.39 \% \quad 0.91 \%$

$1.38 \% \quad 0.91 \%$

$1.20 \% \quad 0.91 \%$

$1.21 \% \quad 0.92 \%$

$0.86 \% \quad 0.76 \%$

$1.07 \% \quad 0.99 \%$

$1.24 \% \quad 1.32 \%$

$1.44 \% \quad 1.68 \%$

$1.52 \%$

$1.52 \%$

$2.14 \%$

$2.02 \%$

$1.52 \% \quad 2.64 \%$

$2.27 \%$.

$1.42 \%$

$1.16 \%$

$1.08 \%$

$1.02 \%$

$0.76 \% \quad 1.29 \% \quad 1.46 \%$

$0.71 \% \quad 1.25 \%$

$0.91 \% \quad 1.33 \%$

$0.87 \% \quad 0.95 \%$

$0.99 \% \quad 0.88 \%$

$1.31 \% \quad 0.94 \%$

$1.52 \% \quad 1.47 \%$

$1.63 \% \quad 1.35 \%$

$1.44 \% \quad 1.37 \%$

$1.33 \% \quad 1.28 \%$

$1.01 \% \quad 1.07 \%$

$0.98 \% \quad 1.01 \%$

$1.03 \% \quad 1.22 \%$

$0.94 \% \quad .1 .07 \%$

$0.91 \% \quad 1.04 \%$

$0.87 \% \quad 1.02 \%$
$25.32 \%$

$25.63 \%$

$28.38 \%$

$26.25 \%$

$27.71 \%$

$24.78 \%$

$26.01 \%$

$25.72 \%$

$29.37 \%$

$26.24 \%$

$24.59 \%$

$25.22 \%$

$25.32 \%$

$29.13 \%$

$26.33 \%$

$22.96 \%$

$23.49 \%$

$24.09 \%$

$27.15 \%$

$22.14 \%$

$22.86 \%$

$24.08 \%$

$24.45 \%$

$23.99 \%$

$22.99 \%$

$24.35 \%$

$22.39 \%$

$30.00 \%$

$26.08 \%$

$20.98 \%$
13359

13616

13278

13694 
COAL PRODUCT DATA TUBULATION

RUN NO. 8; 5/15 - 5/19/89

RUN NO. 8

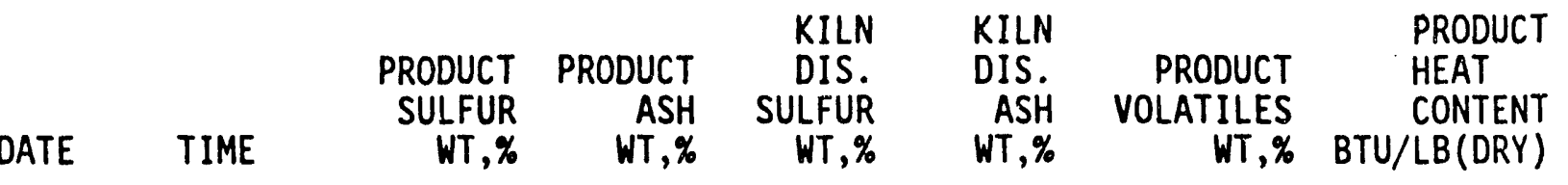

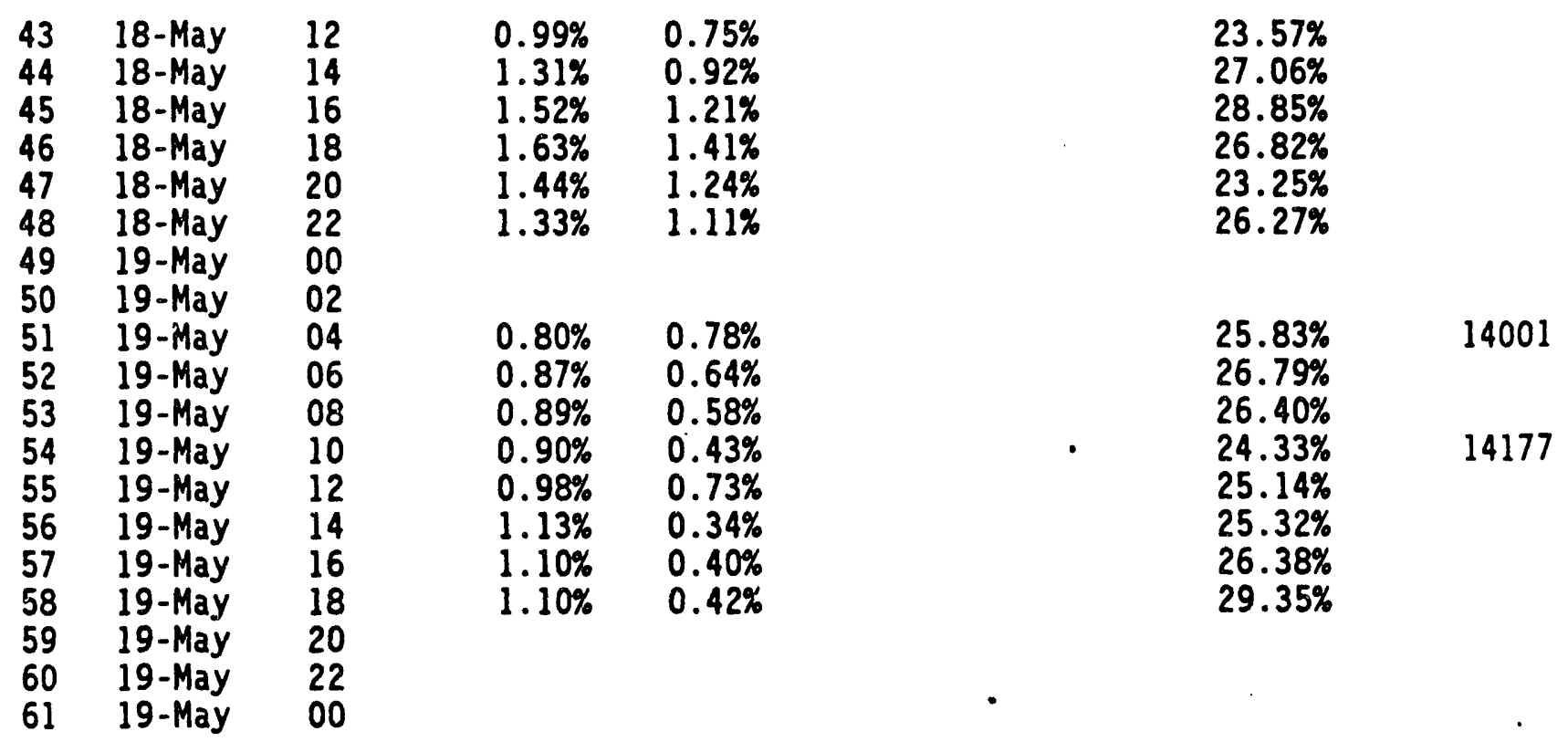


COAL PRODUCT DATA TABULATION

RUN NO. $9 ; 5 / 29-6 / 2 / 89$

RUN NO. 9

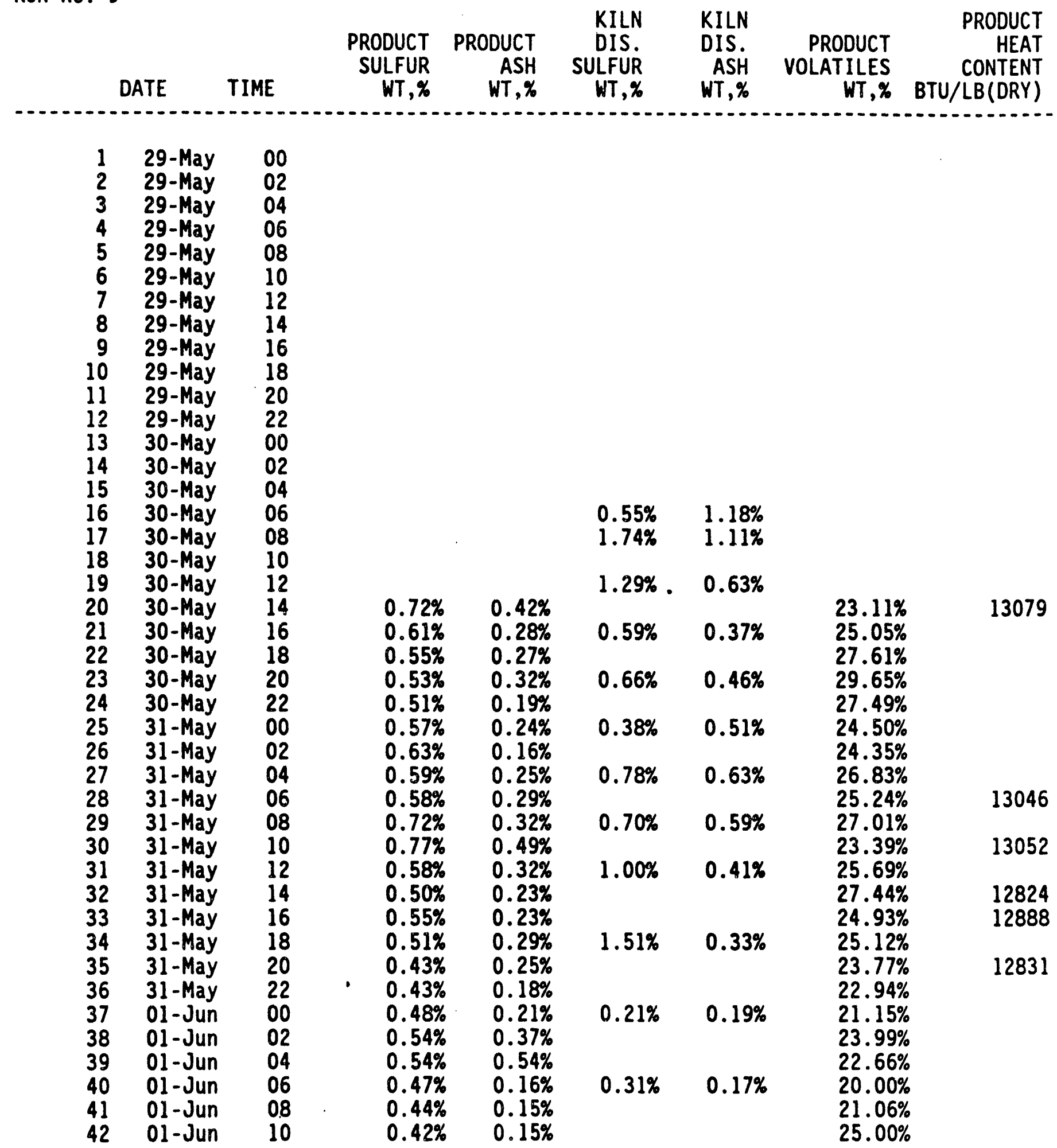


COAL PRODUCT DATA TABULATION

RUN NO. 9; 5/29 - 6/2/89

RUN NO. 9

\begin{tabular}{|c|c|c|c|c|c|c|c|c|}
\hline & IATE & TIME & $\begin{array}{r}\text { PRODUCT } \\
\text { SULFUR } \\
\text { WT,\% }\end{array}$ & $\begin{array}{r}\text { PRODUCT } \\
\text { ASH } \\
W T, \%\end{array}$ & $\begin{array}{l}\text { KILN } \\
\text { DIS. } \\
\text { SULFUR } \\
\text { WT, \% }\end{array}$ & $\begin{array}{c}\text { KILN } \\
\text { DIS. } \\
\text { ASH } \\
\text { WT, \% }\end{array}$ & $\begin{array}{r}\text { PRODUCT } \\
\text { VOLATILES } \\
\text { WT,\% }\end{array}$ & $\begin{array}{r}\text { PRODUCT } \\
\text { HEAT } \\
\text { CONTENT } \\
\text { BTU/LB(DRY) }\end{array}$ \\
\hline $\begin{array}{l}43 \\
44 \\
45 \\
46 \\
47 \\
48 \\
49 \\
50 \\
51 \\
52 \\
53 \\
54 \\
55 \\
56 \\
57 \\
58 \\
59 \\
60 \\
61\end{array}$ & $\begin{array}{l}01 \text {-Jun } \\
01 \text {-Jun } \\
01 \text {-Jun } \\
01 \text {-Jun } \\
01 \text {-Jun } \\
01 \text {-Jun } \\
02 \text {-Jun } \\
02 \text {-Jun } \\
02 \text {-Jun } \\
02 \text {-Jun } \\
02 \text {-Jun } \\
02 \text {-Jun } \\
02 \text {-Jun } \\
02 \text {-Jun } \\
02 \text {-Jun } \\
02 \text {-Jun } \\
02 \text {-Jun } \\
02 \text {-Jun } \\
02 \text {-Jun }\end{array}$ & $\begin{array}{l}12 \\
14 \\
16 \\
18 \\
20 \\
22 \\
00 \\
02 \\
04 \\
06 \\
08 \\
10 \\
12 \\
14 \\
16 \\
18 \\
20 \\
22 \\
00\end{array}$ & $\begin{array}{l}0.33 \% \\
0.29 \% \\
0.31 \% \\
0.32 \% \\
0.34 \% \\
0.37 \% \\
0.39 \% \\
0.39 \% \\
0.43 \% \\
0.41 \% \\
0.39 \% \\
0.37 \% \\
0.38 \% \\
0.37 \% \\
0.38 \% \\
0.39 \%\end{array}$ & $\begin{array}{l}0.10 \% \\
0.09 \% \\
0.17 \% \\
0.12 \% \\
0.05 \% \\
0.04 \% \\
0.10 \% \\
0.20 \% \\
0.08 \% \\
0.02 \% \\
0.06 \% \\
0.16 \% \\
0.13 \% \\
0.14 \% \\
0.14 \% \\
0.11 \%\end{array}$ & $\begin{array}{l}0.18 \% \\
0.20 \% \\
0.24 \% \\
0.15 \% \\
0.31 \%\end{array}$ & $\begin{array}{l}0.07 \% \\
0.06 \% \\
0.08 \% \\
0.08 \% \\
\\
0.10 \%\end{array}$ & $\begin{array}{l}21.81 \% \\
23.27 \% \\
21.92 \% \\
22.24 \% \\
21.85 \% \\
25.75 \% \\
26.64 \% \\
24.27 \% \\
21.20 \% \\
22.91 \% \\
24.70 \% \\
22.26 \% \\
22.03 \% \\
25.98 \% \\
30.09 \% \\
27.78 \%\end{array}$ & $\begin{array}{l}13340 \\
13269 \\
13459 \\
13465\end{array}$ \\
\hline
\end{tabular}


APPENDIX C

PRODUCT COAL DRYING

C-1 
MCL PRODUCT COAL DRYING

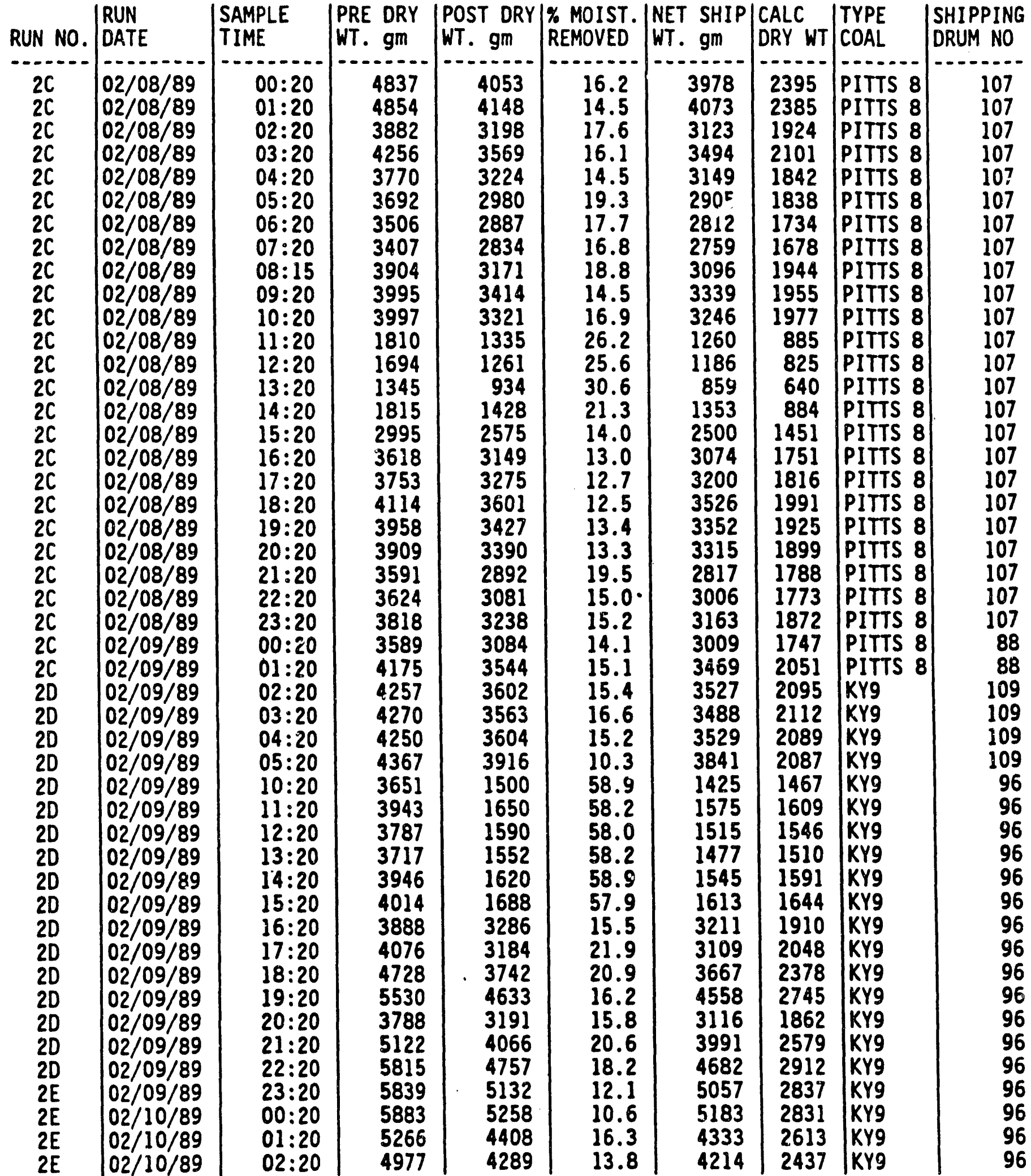


MCL PRODUCT COAL DRYING

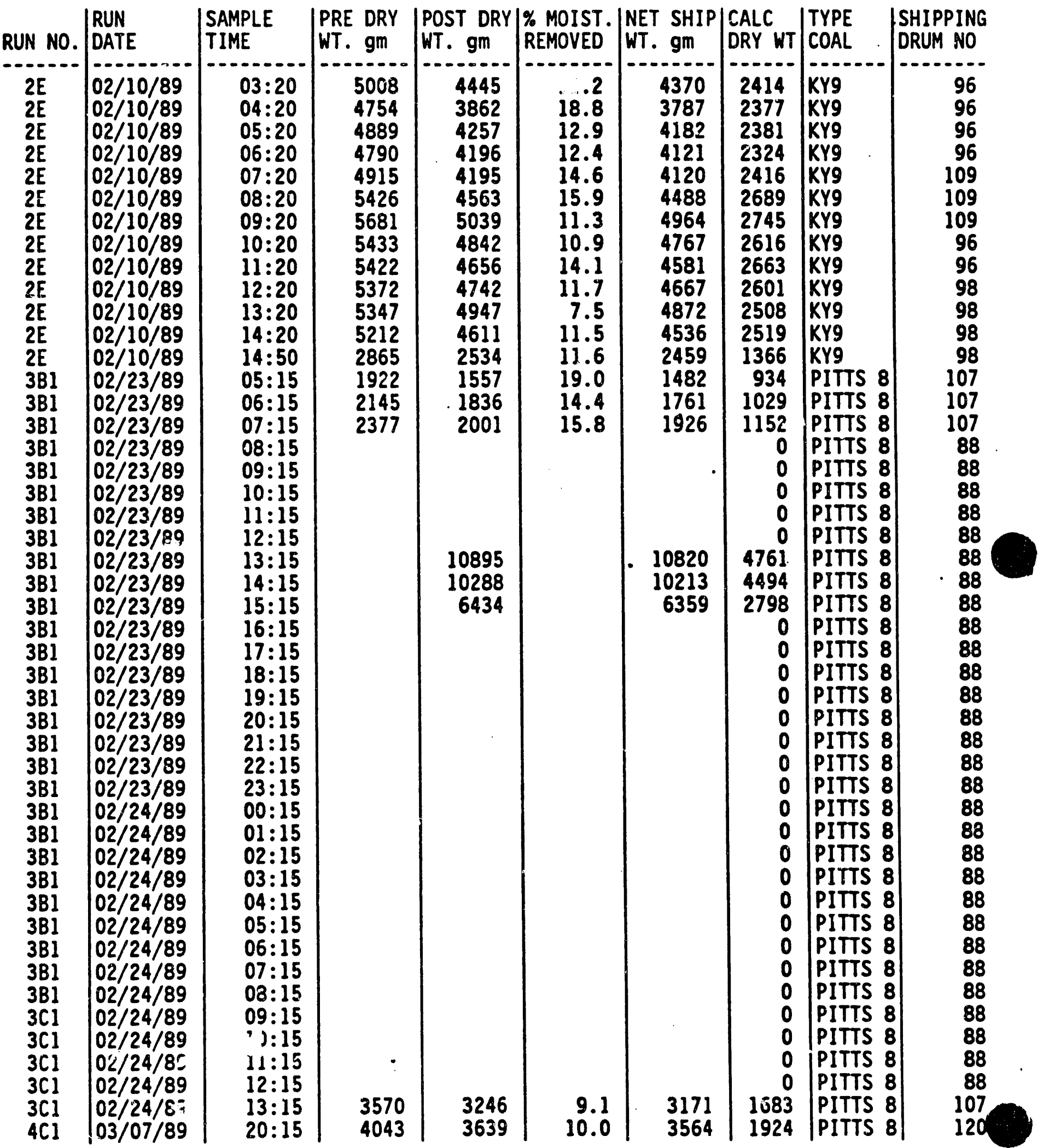


MCL PRODUCT COAL DRYING

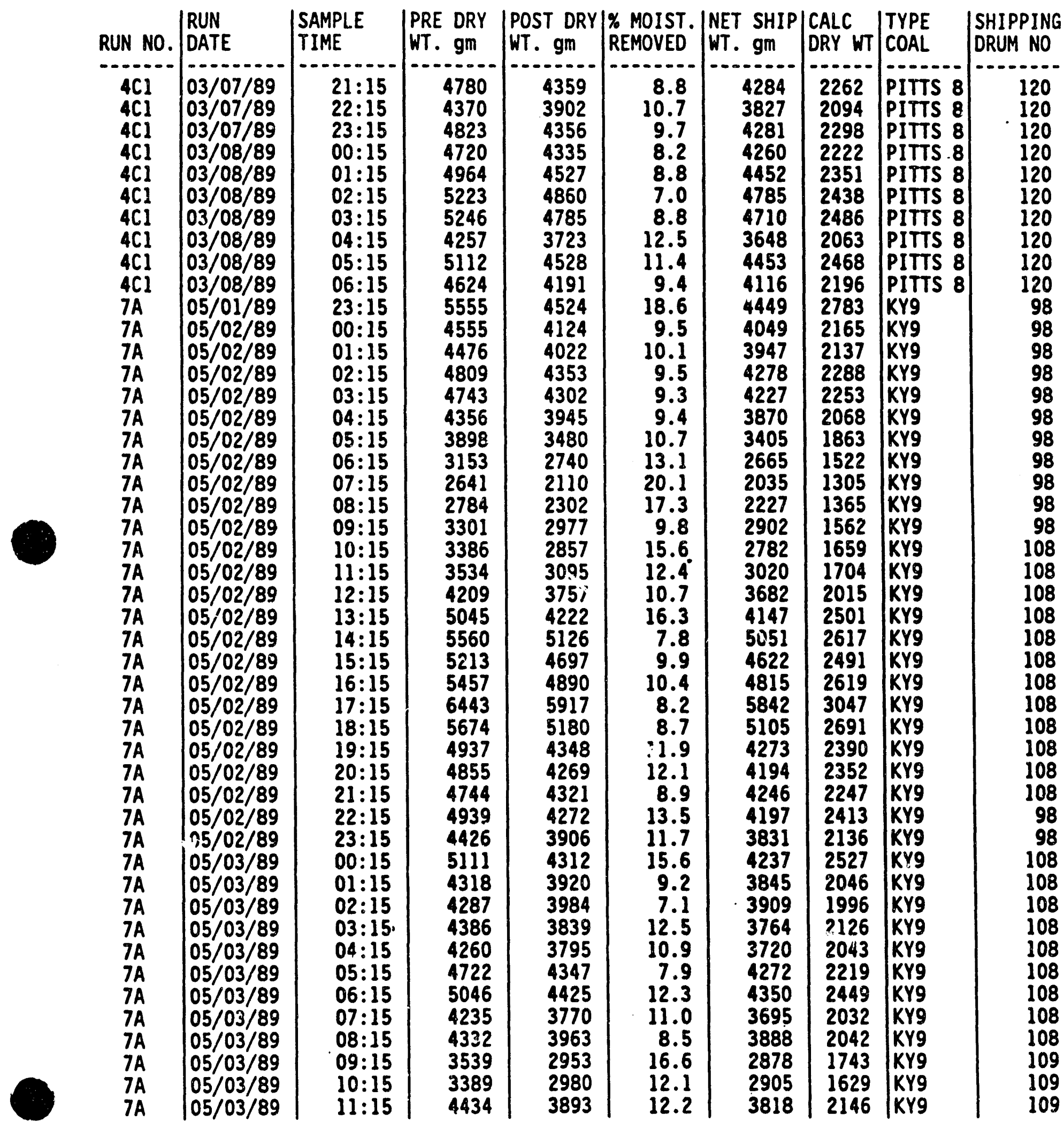


MCL PRODUCT COAL DRYING

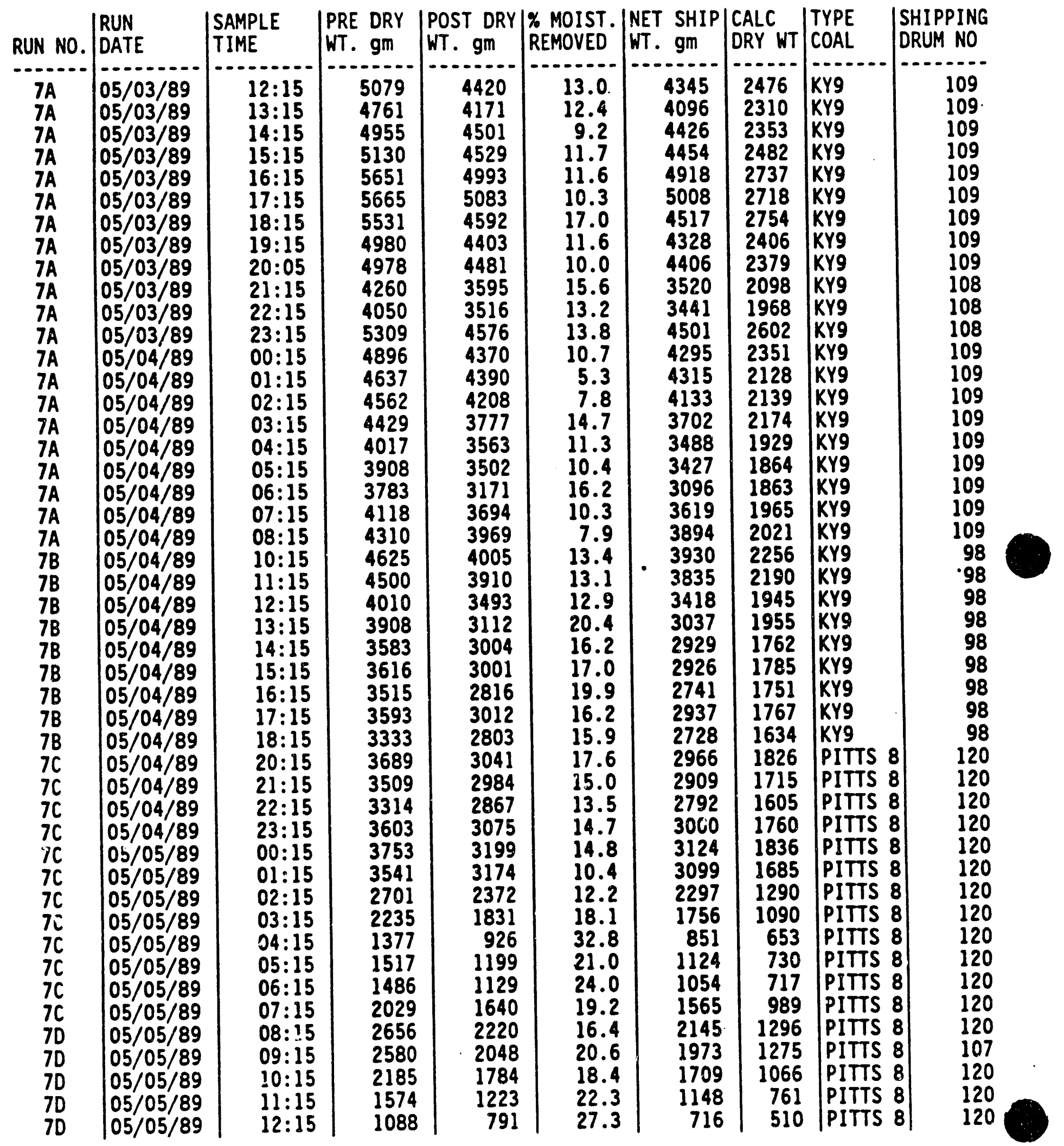


MCL PRODUCT COAL DRYING

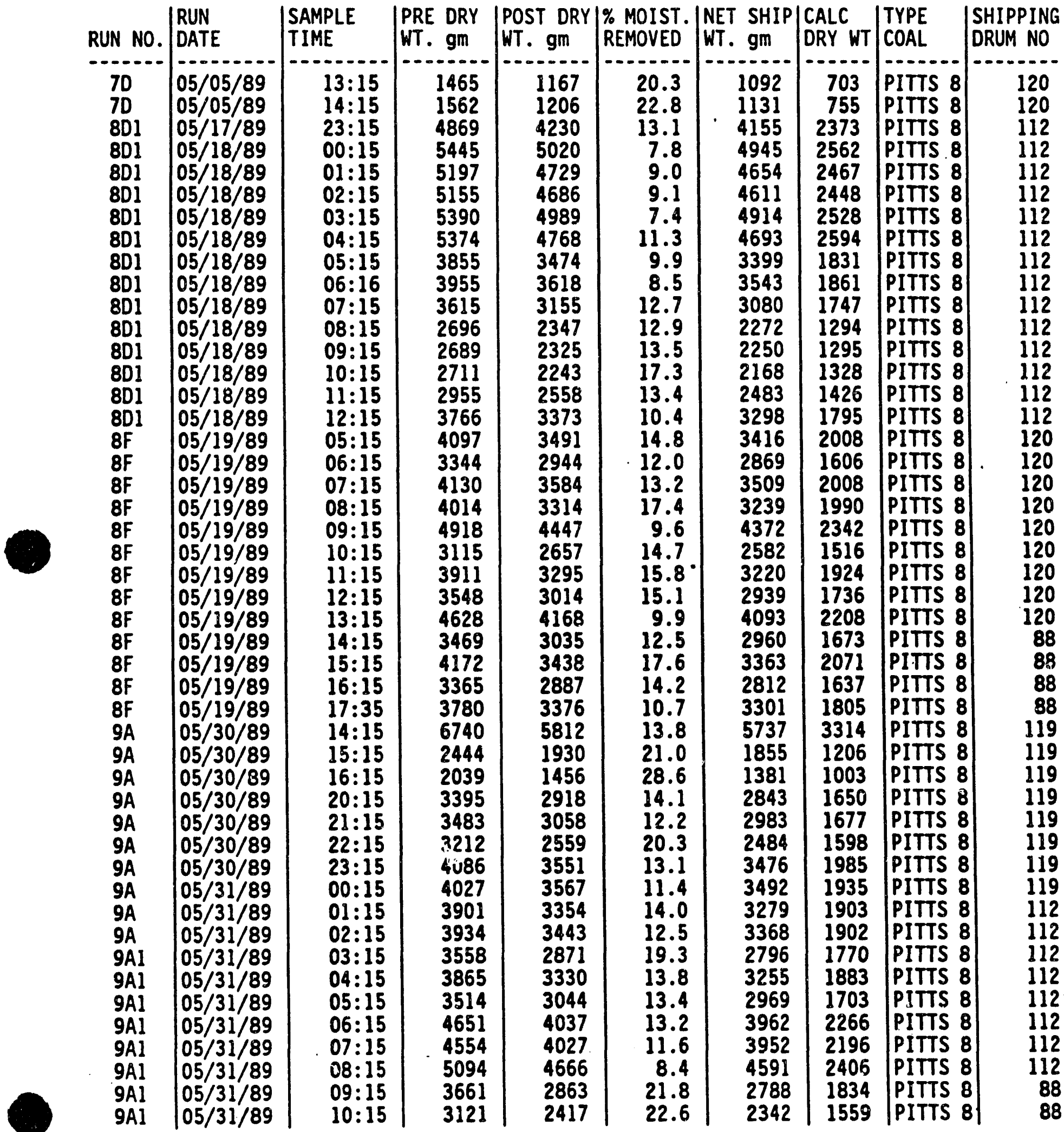


MCL PRODUCT COAL DRYING

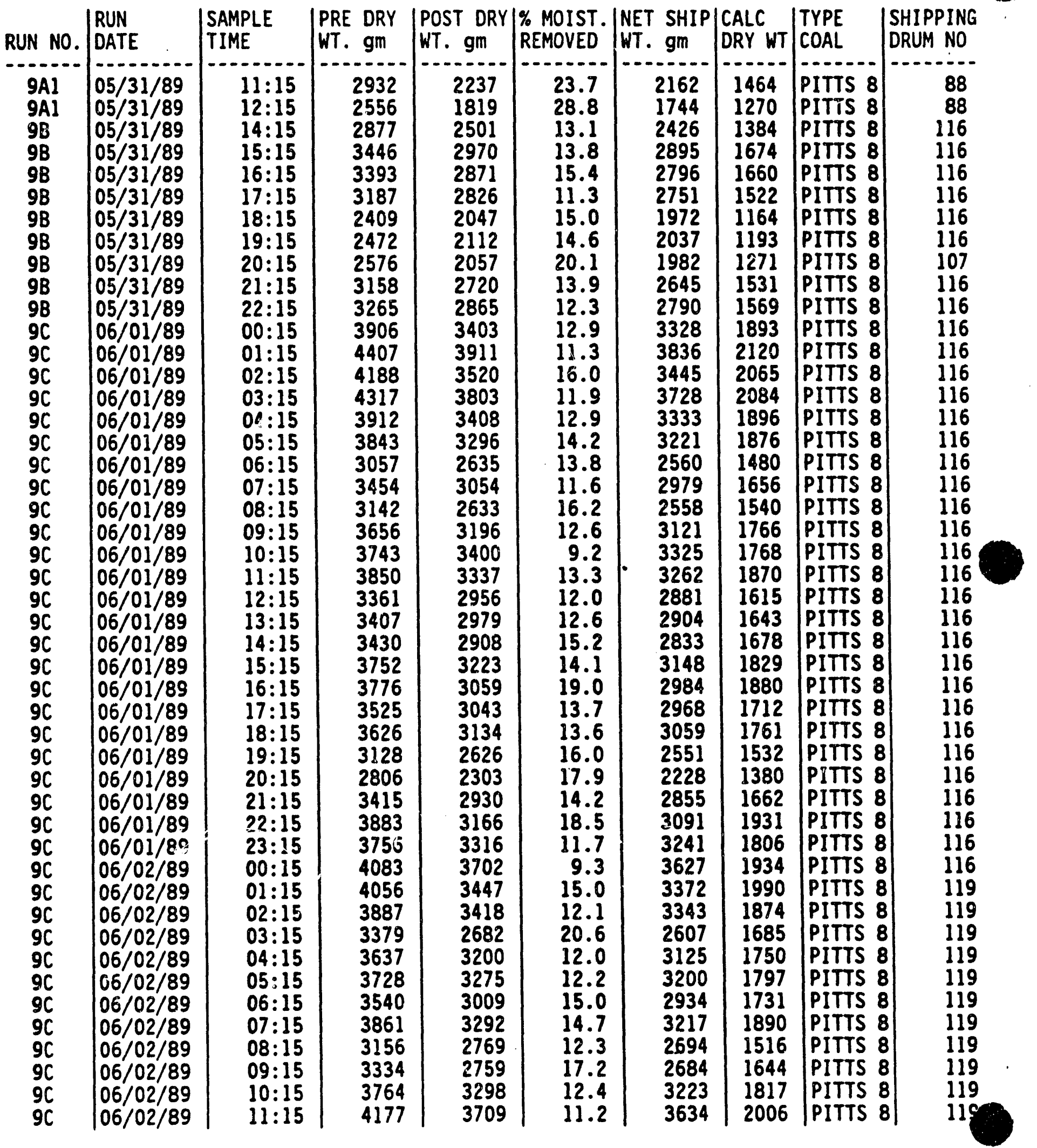


MCL PRODUCT COAL DRYING

\begin{tabular}{|c|c|c|c|c|c|c|c|c|c|}
\hline . & $\begin{array}{l}\text { RUN } \\
\text { DATE }\end{array}$ & $\begin{array}{l}\text { SAMPLE } \\
\text { TIME }\end{array}$ & $\mid \begin{array}{ll}\text { PRE } & \text { DRY } \\
\text { WT. } & \text { gm }\end{array}$ & $\begin{array}{l}\text { POST DRY } \\
\text { WT. gm }\end{array}$ & $\begin{array}{l}\% \text { MOIST. } \\
\text { REMOVED }\end{array}$ & $\begin{array}{l}\text { NET SHIP } \\
\text { WT. gm }\end{array}$ & $\mid \begin{array}{l}\text { CALC } \\
\text { DRY WT }\end{array}$ & TYPE & DRUM NO \\
\hline $9 C$ & $\begin{array}{l}06 / 02 / 89 \\
06 / 02 / 89 \\
06 / 02 / 89 \\
06 / 02 / 89 \\
06 / 02 / 89 \\
06 / 02 / 89\end{array}$ & $\begin{array}{l}12 \\
13 \\
14 \\
15 \\
16\end{array}$ & $\begin{array}{l}4083 \\
3787 \\
3813 \\
3213 \\
3462\end{array}$ & $\begin{array}{l}3741 \\
3357 \\
3211 \\
2845 \\
3074 \\
2666\end{array}$ & $\begin{array}{r}8.4 \\
11.4 \\
15.8 \\
11.5 \\
11.2 \\
15.5 \\
15.3\end{array}$ & $\begin{array}{l}3 \\
3 \\
3 \\
2 \\
2 \\
2\end{array}$ & & $\begin{array}{l}P \\
P \\
P \\
P \\
P\end{array}$ & \\
\hline
\end{tabular}



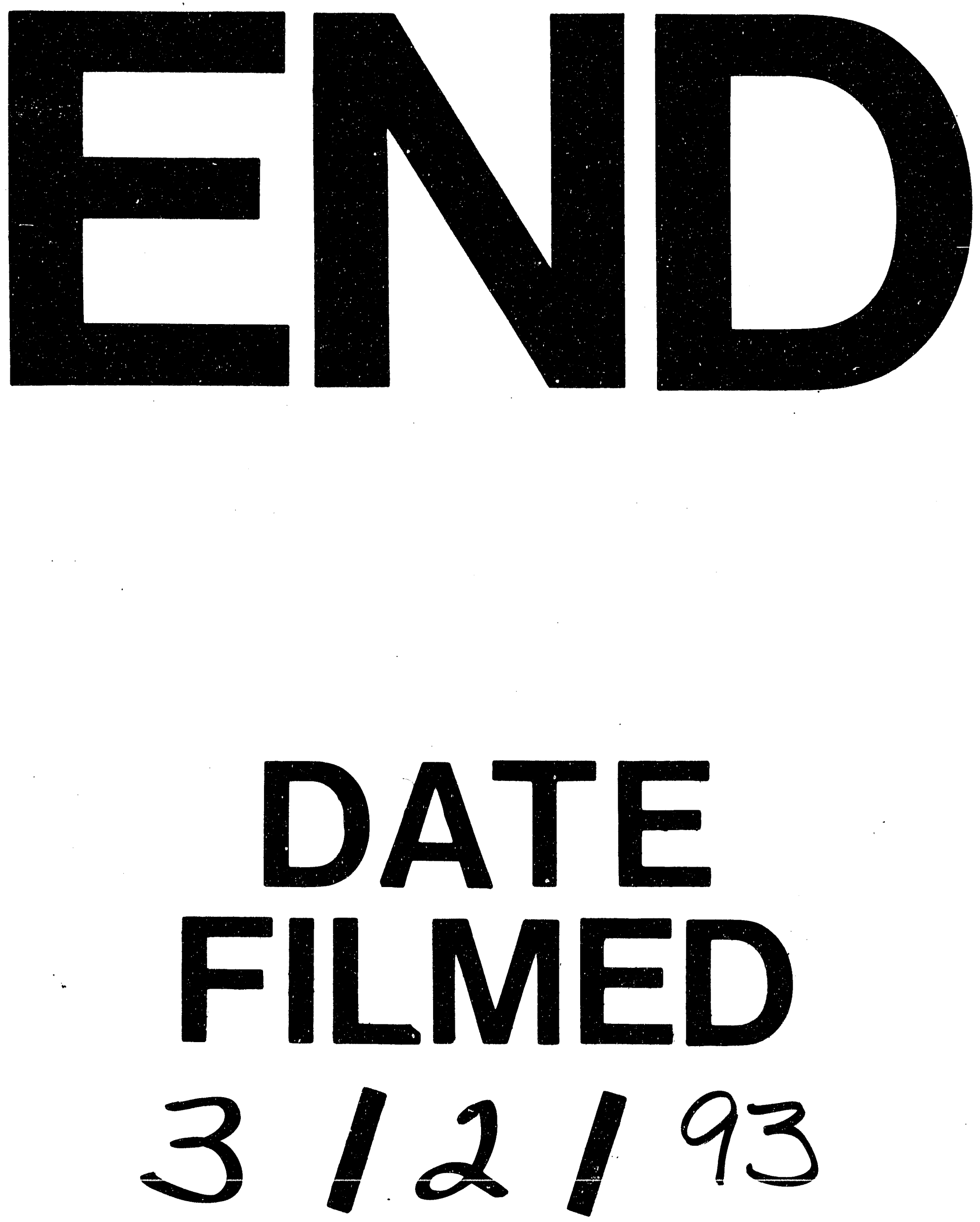
